FACULDADE DE ENGENHARIA DA UNIVERSIDADE DO PORTO

\title{
Development of a Split Hopkinson Pressure Bar machine for high strain rate testing of bonded joints
}

\author{
Alexandre José Boland \\ U.PORTO \\ FEUP FACULDADE DE ENGENHARIA \\ UNIVERSIDADE DO PORTO \\ Mestrado Integrado em Engenharia Mecânica \\ Supervisor: Prof. António Mendes Lopes \\ Co-Supervisors: Inv. Carlos Moreira da Silva \\ Prof. Lucas FM da Silva
}





\section{Resumo}

As juntas adesivas estão a tornar-se num campo de pesquisa muito importante, pois têm muitas aplicações nas indústrias automóvel e aeroespacial, devido às suas características muito diferentes de outros processos de união. Portanto, o estudo do comportamento de juntas adesivas sob cargas de impacto é muito importante e deve ser apoiado por estudos que possam caracterizá-las corretamente.

Os membros do grupo de investigação de adesivos da FEUP, Advanced Joining Processes Unit (AJPU), estão a contribuir neste campo de pesquisa, estudando o comportamento mecânico das juntas adesivas sob diferentes tipos de solicitações, as propriedades dos adesivos e das juntas adesivas, e a influência de certos fatores, como condições ambientais, ou envelhecimento na junta adesiva. Apesar de possuir várias máquinas de teste, a FEUP precisava de um equipamento para realizar testes de impacto em alta velocidade.

Sendo assim, o principal objetivo desta dissertação é dar continuidade ao trabalho realizado por Tenreiro, que consistiu no desenvolvimento de um atuador pneumático para ser implementado numa Split Hopkinson Pressure Bar machine (SHPB). Isso inclui revisão dos desenhos mecânicos já realizados, fabricação e construção do atuador e implementação de um sistema de travagem para parar o atuador pneumático. Finalmente, é efetuado o projeto das barras que transmitirão o impacto proveniente do atuador aos provetes, tanto para o ensaio de tração como para o de compressão, bem como o projeto da estrutura de suporte da máquina. 



\section{Abstract}

Adhesive joints became a very important field of research, with ample applications in the automotive and aerospace industries, due to their characteristics that are very different from other joining processes. So, studying the behavior of the adhesive joints under impact loads is very important and must be supported by studies that can correctly characterize them.

The members of the Advanced Joining Processes Unit (AJPU) at FEUP are contributing to this field of research, by studying the mechanical behavior of the adhesive joints under different types of loads, the properties of the adhesives and the adhesive joints, and the influence of certain factors, such as environmental conditions, or aging of the adhesive joint. Despite having several testing machines, the AJPU needs an apparatus to perform impact tests at high velocities.

As such, the main objective of this dissertation is to continue the work done by Tenreiro, which resumes as the design of a pneumatic actuator to be implemented in a Split Hopkinson Pressure Bar (SHPB) machine. This includes the rectification of the mechanical design, the manufacture and assembly of the pneumatic actuator, and the implementation of a braking system to stop the actuator. Finally, the design of the bars that will transmit the impact from the actuator to the specimen, for both tensile and compression tests, as well as the design of the structure to hold the machine is carried out. 
Development of a Split Hopkinson Pressure Bar machine for high strain rate testing of bonded joints 


\section{Acknowledgments}

Firstly, I would like to thank the Faculdade de Engenharia da Universidade do Porto for the year I spent here and for the opportunity to accomplish this dissertation, without a doubt that this made me grow up a lot in terms of knowledge and as a human being.

To all my supervisors, Prof. António Mendes Lopes, Inv. Carlos Moreira da Silva and Prof. Lucas da Silva, for all the support and data they gave me during this time.

To all AJPU's members for the positive energy they provided, a special thanks to Dr. Eduardo Marques, Dr. Ricardo Carbas, Eng. Diogo Antunes, Eng. Paulo Nunes and Eng. António Tenreiro for their help, knowledge, and availability.

Finally, I want to thank my parents, as they are the ones who allowed me to study and supported me during this phase of my life, and also to my friends, who never left me alone during this journey. 
Development of a Split Hopkinson Pressure Bar machine for high strain rate testing of bonded joints 


\section{Contents}

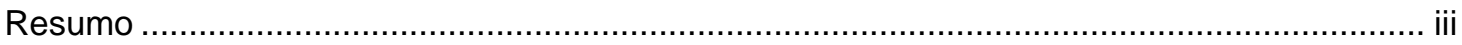

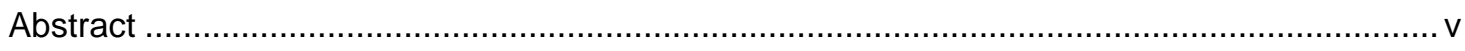

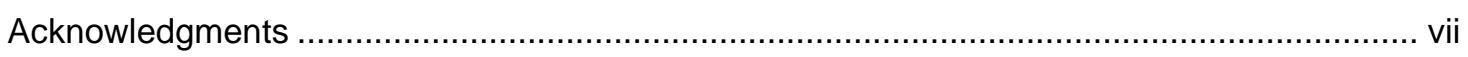

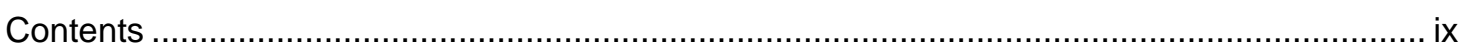

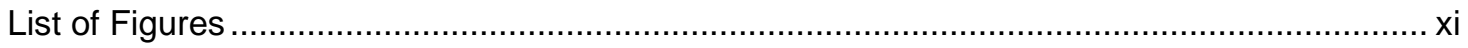

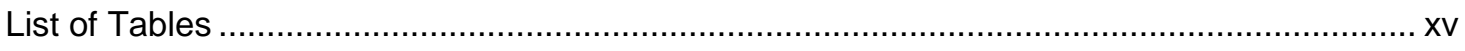

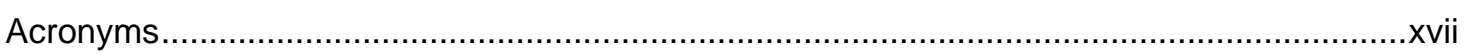

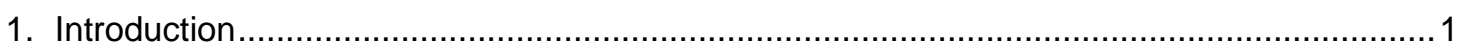

1.1. Context and Motivation............................................................................................. 1

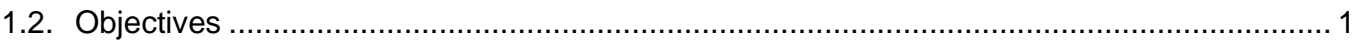

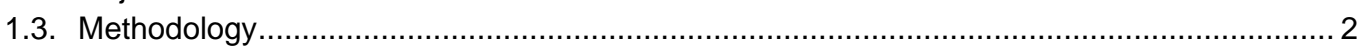

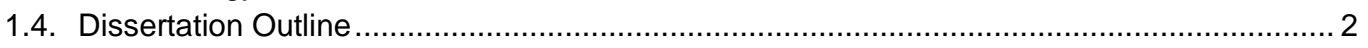

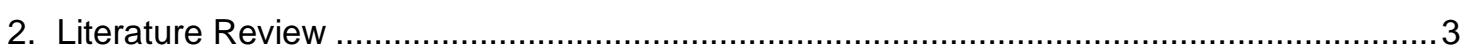

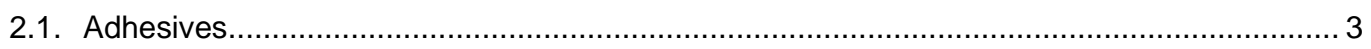

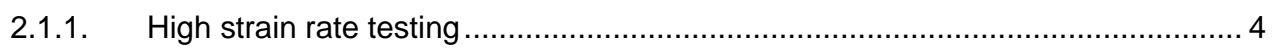

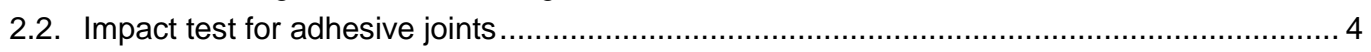

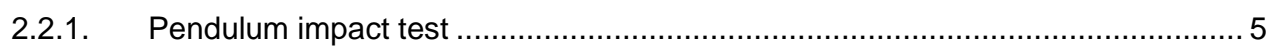

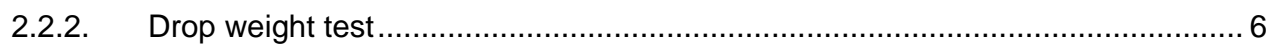

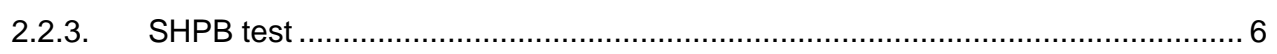

2.3. Commercial SHPB machines ...................................................................................

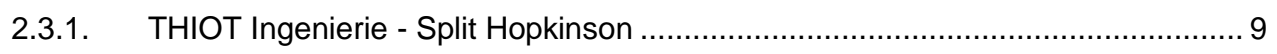

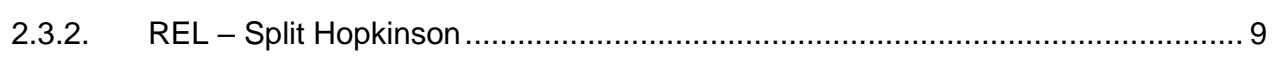

2.3.3. Natural Impacts Ltd - Split Hopkinson ..................................................... 10

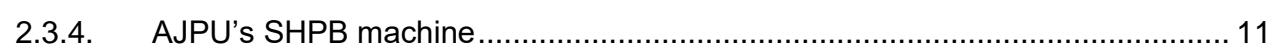

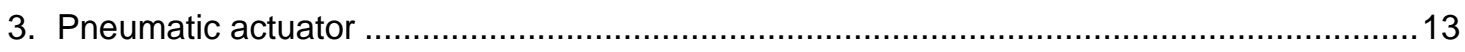

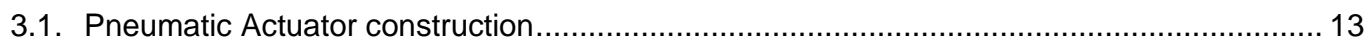

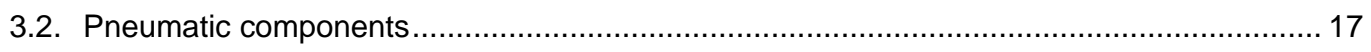

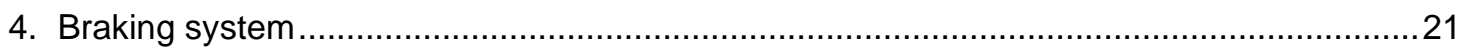

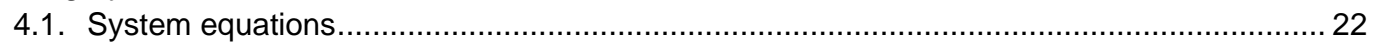

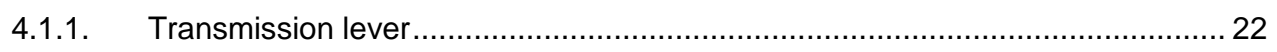

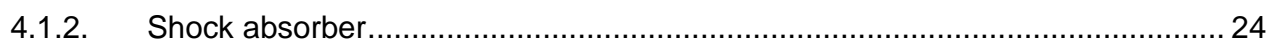

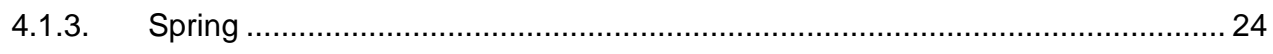

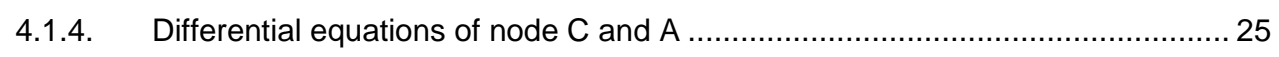

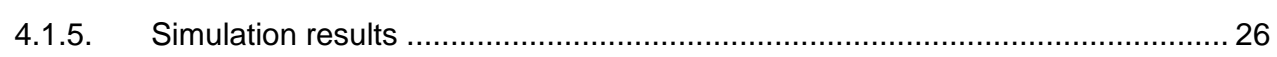

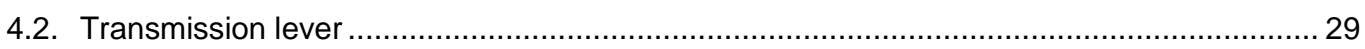

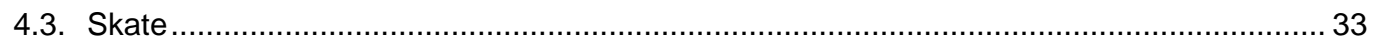

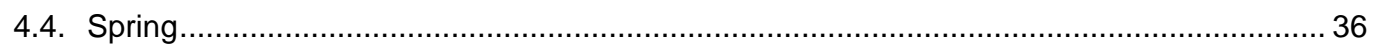

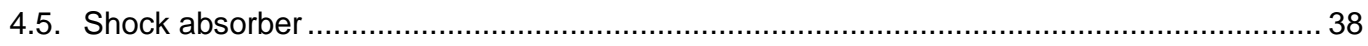

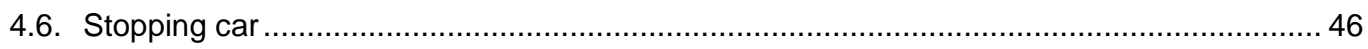

4.7. Support frame to hold the braking system and actuator ............................................... 51

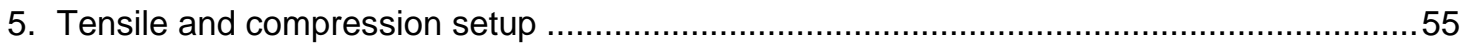

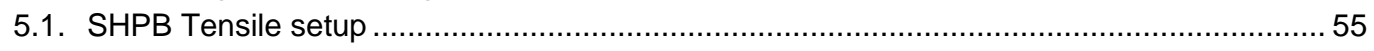

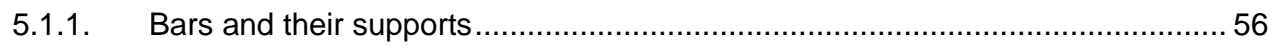

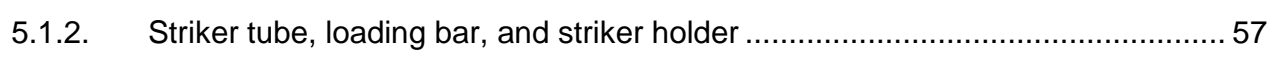

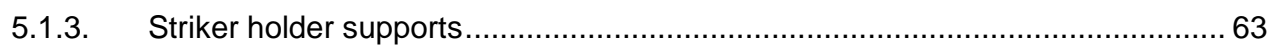

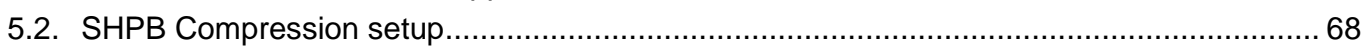

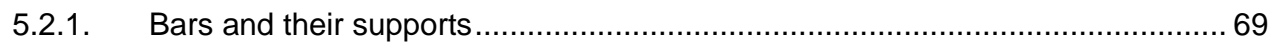

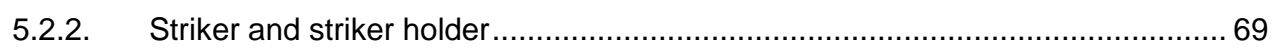




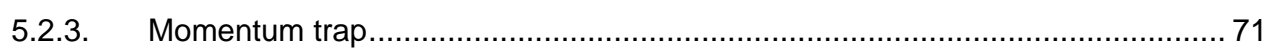

5.3. Support frame to hold both tensile and compression setup.......................................... 73

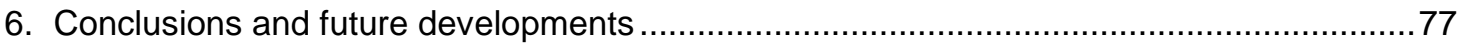

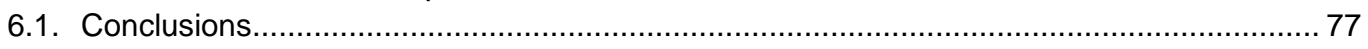

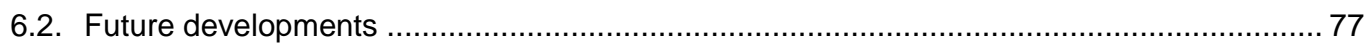

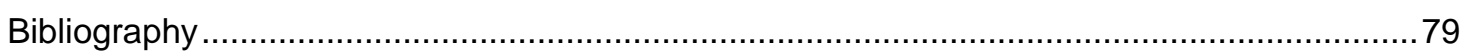

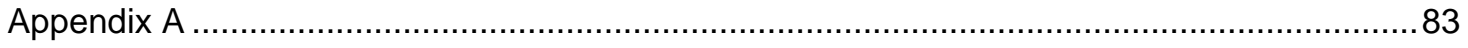

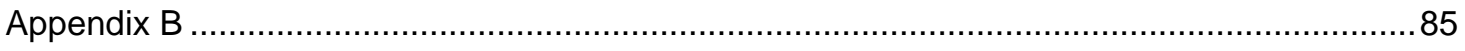

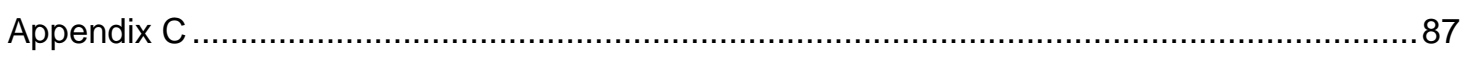

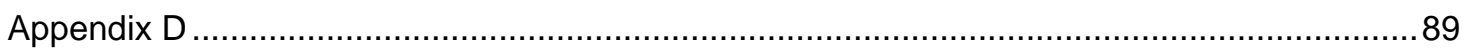

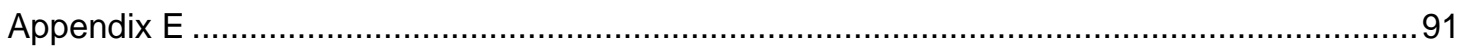

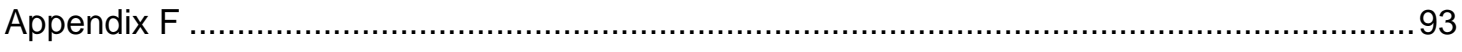

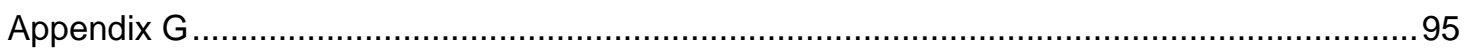

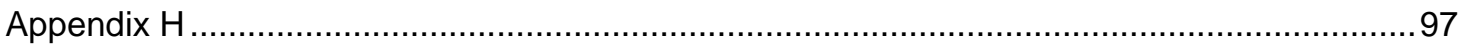




\section{List of Figures}

Figure 2.1 - Stress distribution comparison between bonded surfaces using standard fasteners

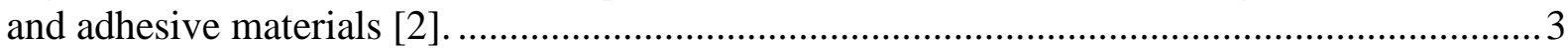

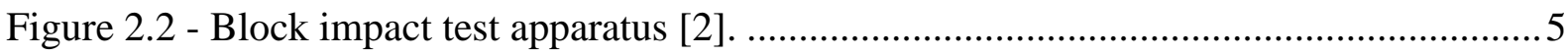

Figure 2.3 - Possible cases of impact between the hammer and the upper block [8]............... 6

Figure 2.4 - Bertram Hopkinson experiment to measure the pressure waves [10] .................. 7

Figure 2.5 - General Kolsky compression bar apparatus [10] ............................................. 7

Figure 2.6 - Lagrangian diagram for SHPB compression setup [11] ..................................... 8

Figure 2.7 - The two most common types of loading devices of the SHPB machine [10] .......8

Figure 2.8 - REL's series commercialized SHPB machine [13] .......................................... 10

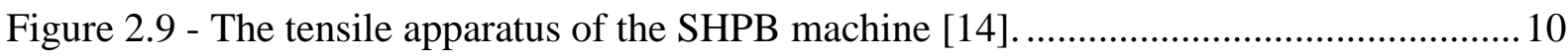

Figure 2.10 - Final SHPB machine, compression test setup. ............................................. 11

Figure 3.1 - Cut view of the Pneumatic actuator assembly made on SolidWorks 2019 .......... 13

Figure 3.2 - Halfway cut of the actuator's head.................................................................. 14

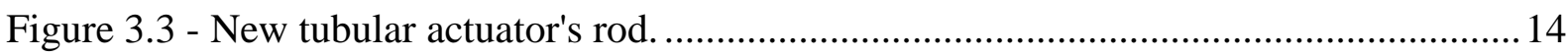

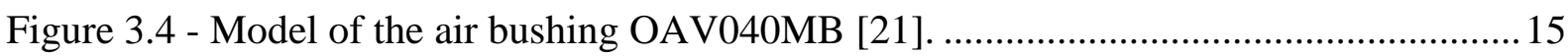

Figure 3.5 - Visualization of the rod and piston assembled on the left; on the right the assembly

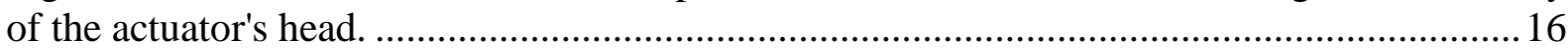

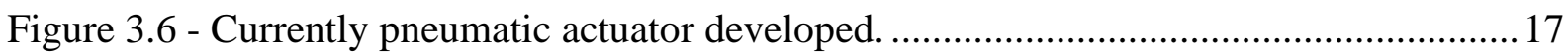

Figure 3.7 - Pneumatic circuit for the actuator proposed by Tenreiro [4].............................. 18

Figure 3.8 - 3D representation of the model ACG40B-F04CG1 [27].................................... 19

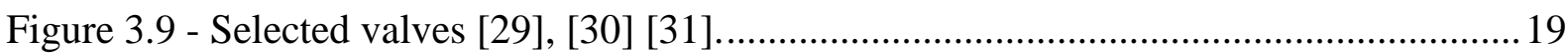

Figure 4.1 - Final model of the braking system designed on Solidworks 2019 ......................21

Figure 4.2 - Free body diagram for the dynamic study of the interaction between the actuator

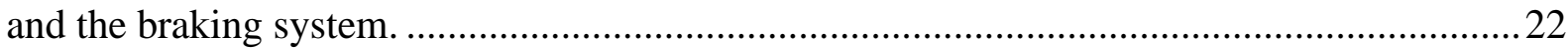

Figure 4.3 - Matlab-Simulink model of the transmission lever. ...........................................23

Figure 4.4 - Stopping force along industrial shock-absorber's stroke [32] ............................24

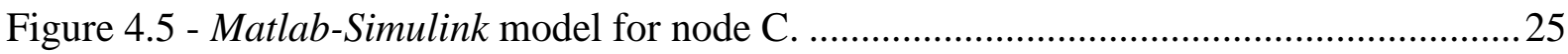

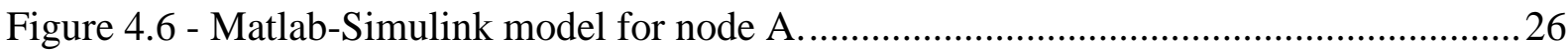

Figure 4.7 - Displacement of node A obtained in the developed Matlab Simulink model. .... 27

Figure 4.8 - Velocity of node A obtained in the developed Matlab Simulink model. .............27

Figure 4.9 - Angle produced by the transmission lever during its movement.........................28

Figure 4.10 - Displacement of node C obtained in the developed Matlab Simulink model. ...28

Figure 4.11 - Velocity of node C obtained in the developed Matlab Simulink model.............29

Figure 4.12 - Final model of the Transmission lever............................................................... 30 
Figure 4.13 - Von Mises stress distribution obtained when a $210 \mathrm{kN}$ force is applied to the transmission lever structure, recurring SolidWorks 2019.

Figure 4.14 - Factor of safety obtained when a $210 \mathrm{kN}$ force is applied to the transmission lever, recurring to SolidWorks 2019.

Figure 4.15 - Total life (cycle) obtained when a $210 \mathrm{kN}$ force is applied to the transmission

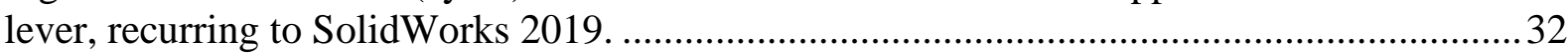

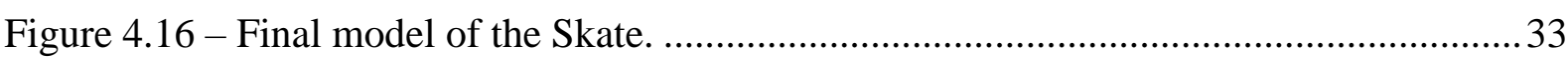

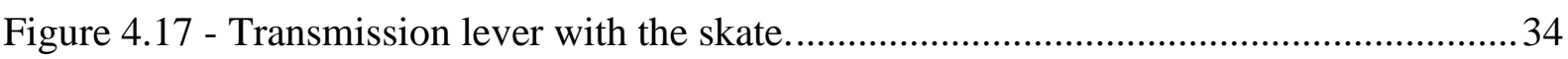

Figure 4.18 - Contact pressure obtained when a $210 \mathrm{kN}$ force is applied to the Skate, recurring to SolidWorks 2019.

Figure 4.19 - Von Mises stress distribution obtained when a $210 \mathrm{kN}$ force is applied to the Skate structure, recurring SolidWorks 2019.

Figure 4.20 - Factor of safety distribution obtained when a $210 \mathrm{kN}$ force is applied to the Skate

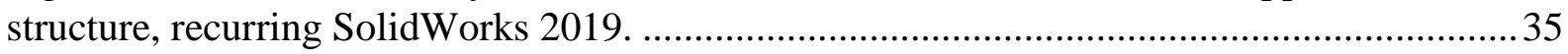

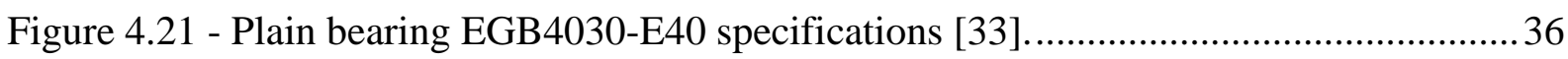

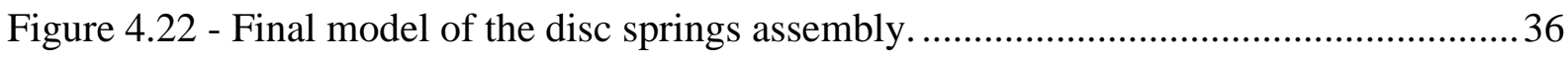

Figure 4.23 - Explanation of the disc spring's combinations................................................ 37

Figure 4.24 - Various types of spring characteristics [35] .................................................. 37

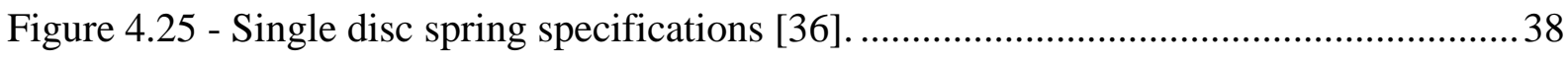

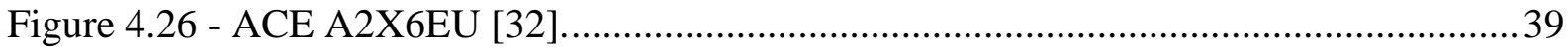

Figure 4.27 - Heavy industrial shock absorber, ACE A2X6EU, specifications [32].............. 39

Figure 4.28 - Final structure to hold the transmission lever, the skate, disc springs combination

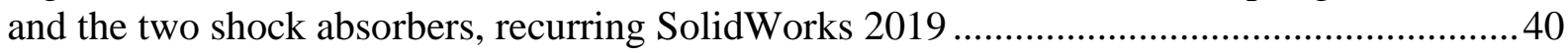

Figure 4.29 - Structures to hold the transmission lever and the disc springs with shock absorbers.

Figure 4.30 - Von Mises stress distribution obtained when a $210 \mathrm{kN}$ force is applied to the central plate, recurring SolidWorks 2019.

Figure 4.31 - URES displacement distribution obtained when a $210 \mathrm{kN}$ force is applied to the

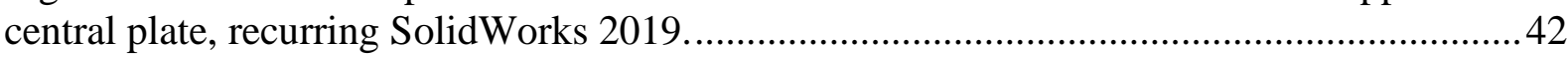

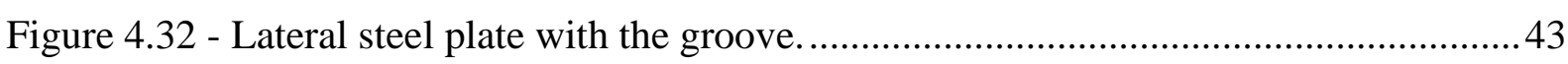

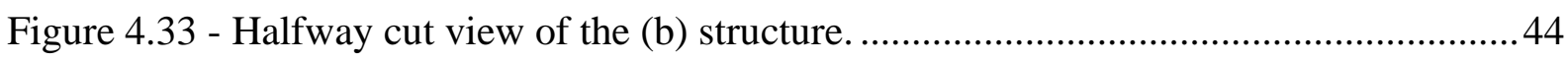

Figure 4.34 - Bearing to support the transmission lever. ..................................................... 44

Figure 4.35 - Final model of the structure that holds the transmission lever, the skate, the disc springs combination and the industrial shock absorbers. ................................................. 45

Figure 4.36 - Final model of the Stopping car assembly................................................... 47

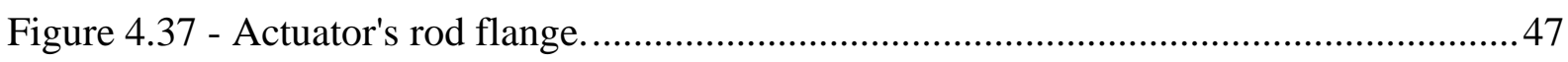

Figure 4.38 - Stopping car position in tensile test and compression test............................... 48

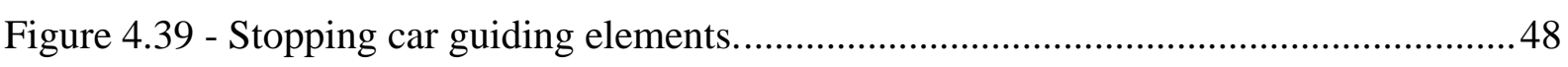

Figure 4.40 - Von Mises stress distribution obtained when a $70 \mathrm{kN}$ force is applied to the

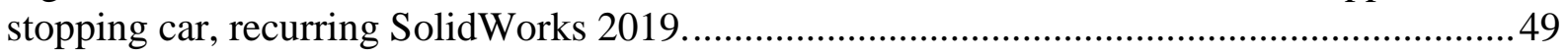


Figure 4.41 - Displacement distribution obtained when a $70 \mathrm{kN}$ force is applied to the stopping car, recurring SolidWorks 2019.

Figure 4.42 - Factor of safety distribution obtained when a $70 \mathrm{kN}$ force is applied to the

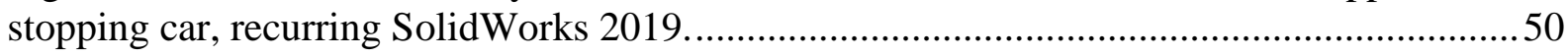

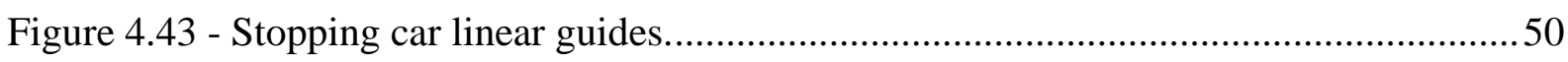

Figure 4.44 - Final model of the support frame for the braking system and pneumatic actuator.

Figure 4.45 - Cross section of the 90x90H series aluminium profiles [38].

Figure 4.46 - Reinforcements used on the support frame for the braking system and pneumatic actuator.

Figure 4.47 - Final braking system setup for both tensile and compression tests. .................53

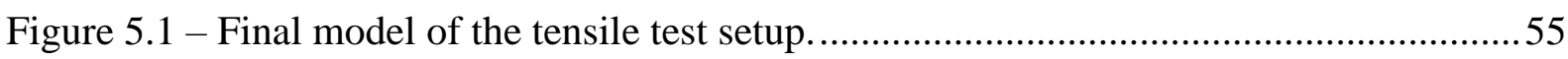

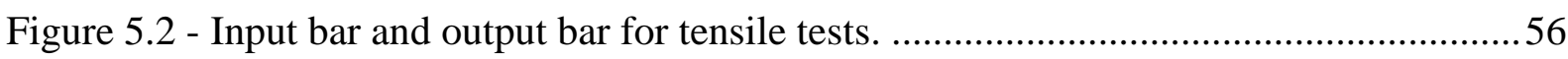

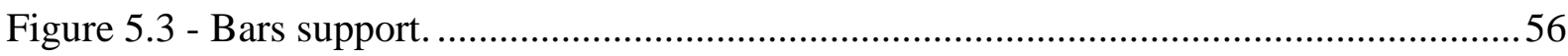

Figure 5.4 - Striker holder, striker tube, and loading bar assembly. ......................................58

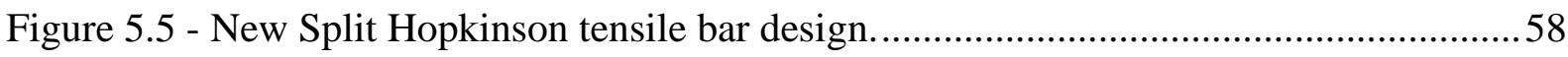

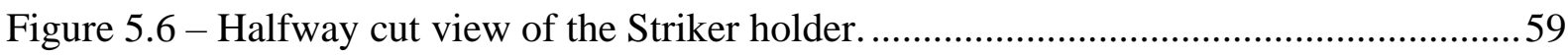

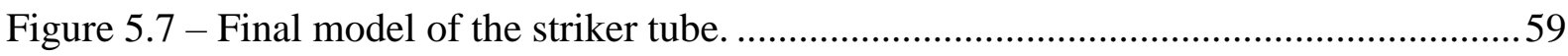

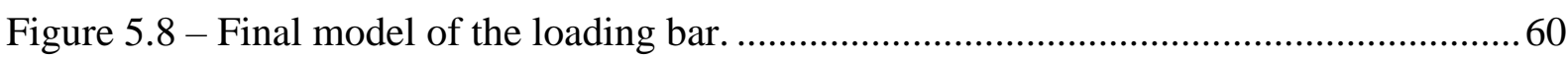

Figure 5.9 - Amplified views of both ends of the loading bar.............................................. 60

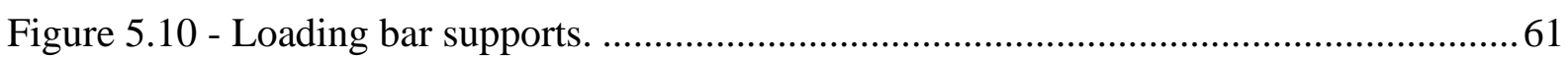

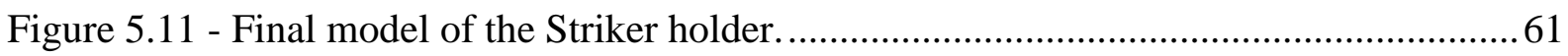

Figure 5.12 - Final model of the ball bearing assembly. .................................................. 62

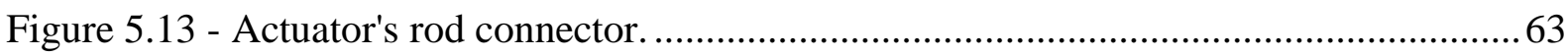

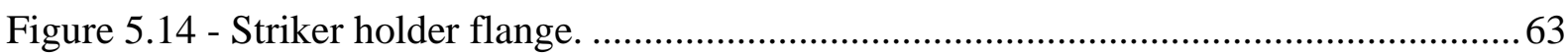

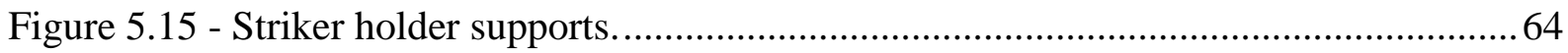

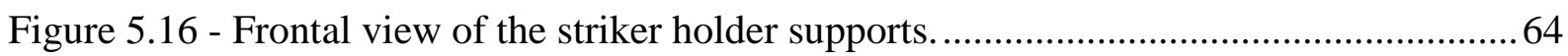

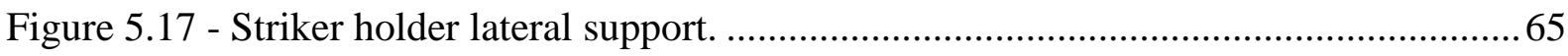

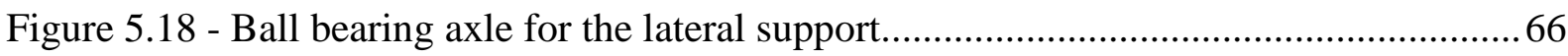

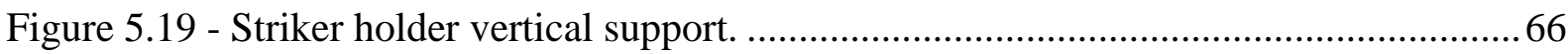

Figure 5.20 - Cross section of the $45 \times 45 \mathrm{H}$ series aluminium profiles. ................................... 67

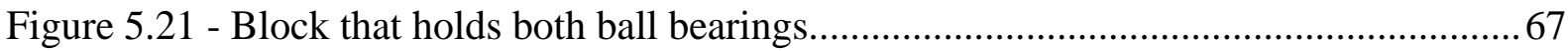

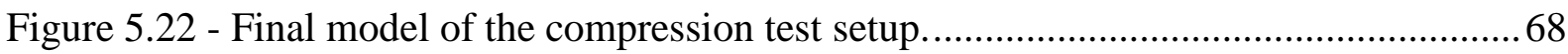

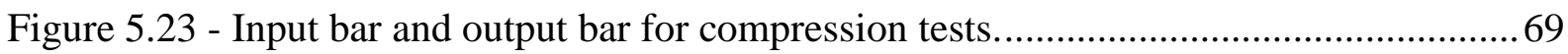

Figure 5.24 - Striker holder and striker bar assembly. .......................................................... 70

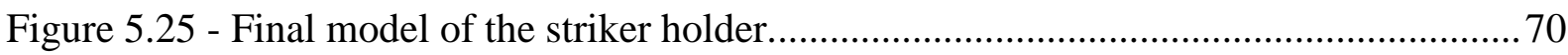

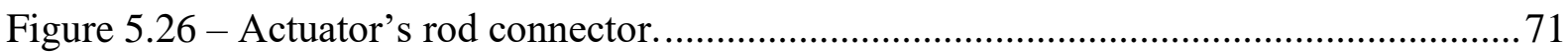

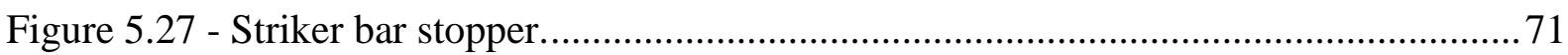




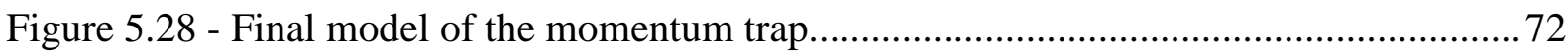

Figure 5.29 - Frontal view of the momentum trap without the brass pin.............................. 72

Figure 5.30 - Final model of the support frame for tensile and compression setup. ...............73

Figure 5.31 - Cross section of the aluminium profiles that compose the support frame for tensile

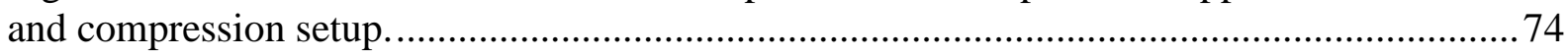

Figure 5.32 - Stopper used to give alignment to the tensile and compression setup............... 74

Figure 5.33 - Final model of the tensile and compression setup............................................ 75 


\section{List of Tables}

Table 2.1 - Mechanical properties and respective impact tests used [3]. .4

Table 2.2 - Impact test classification according to impact testing velocity [3]........................5

Table 3.1 - OAV040MB air bushing specifications [21]................................................. 15

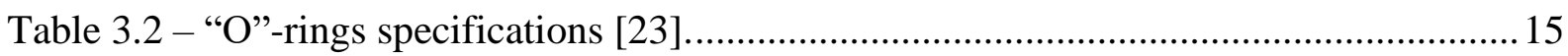

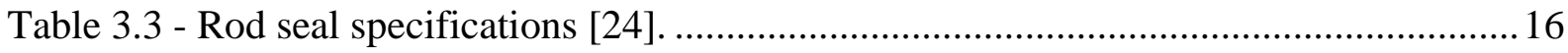

Table 3.4 - Fasteners used to assemble the pneumatic actuator. ............................................. 16

Table 3.5 - Pressurized gas reservoir characteristics [26] .................................................... 18

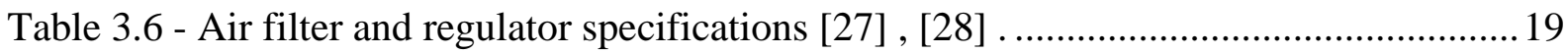

Table 3.7 - SMC VP742K-5YOD1-04 Valve specifications [29] ...........................................20

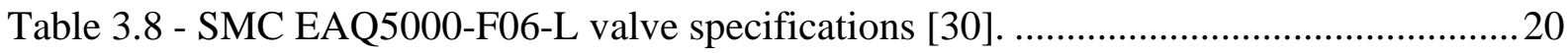

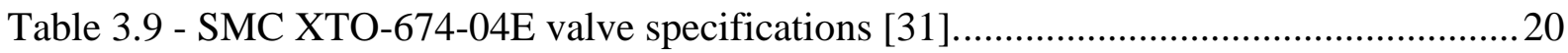

Table 4.1 - Parameters values inserted in the developed Matlab Simulink model, considering a

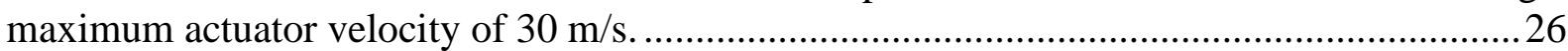

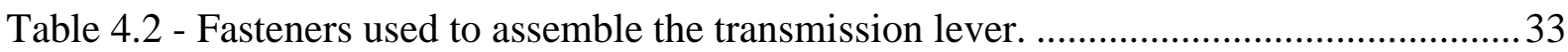

Table 4.3 - Fasteners used to connect all parts and assemble the skate to the transmission lever.

Table 4.4 - Plain bearing specifications, PCM 606560 M [37] ............................................. 45

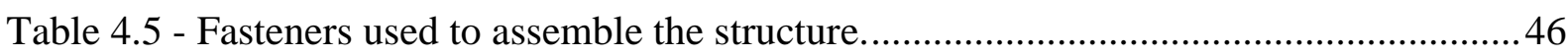

Table 4.6 - Fasteners used to assemble the stopping car..................................................... 51

Table 4.7 - Fasteners used to assemble the support frame. ...................................................53

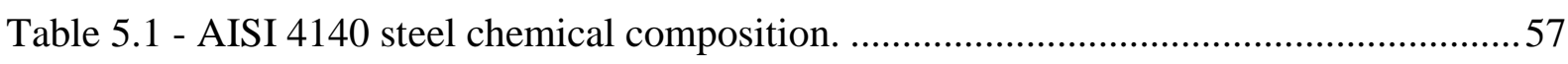

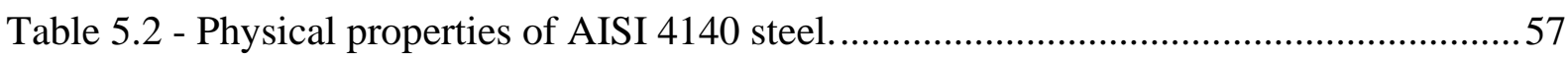

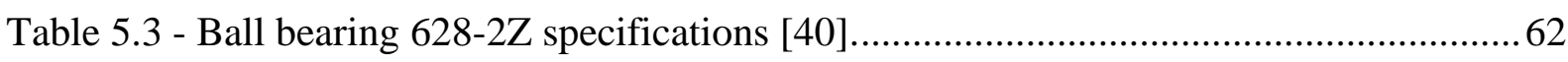

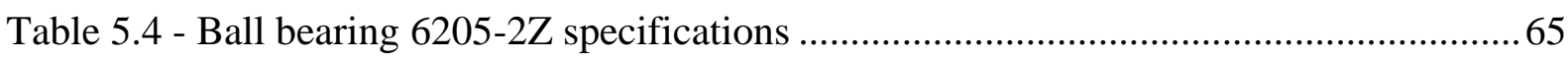

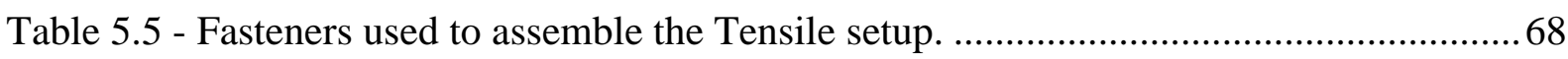

Table 5.6 - Fasteners used to assemble the Compression setup.............................................. 73

Table 5.7 - Fasteners used to assemble the support frame. .................................................. 74 
Development of a Split Hopkinson Pressure Bar machine for high strain rate testing of bonded joints 


\section{Acronyms}

SHPB Split Hopkinson Pressure Bar

AJPU Advanced Joining Processes Unit

TAST Thick Adherent Shear Test

DCB Double Cantilever Beam test

ATDCB Asymmetric Tapered Double-Cantilever Beam

SENB Single-Edge Notched Beam test

CT Compact Tension test

ENF End-Notched Flexure test 
Development of a Split Hopkinson Pressure Bar machine for high strain rate testing of bonded joints 


\section{Introduction}

\subsection{Context and Motivation}

The utilization of adhesive bonding has become very important in the last century, even though this method was already known in ancient times. An adhesive is an organic or inorganic substance capable of bonding two dissimilar surfaces, creating a strong mechanical connection [1].

Adhesive joints are now generally adopted in several industries, such as automotive, aerospace, electronics, and naval, where lightweight structures are needed because of the different properties adhesives have, when compared to other types of joining processes, as welding, riveting, or screwing [2]. Adhesives have the ability to join dissimilar materials, such as composites, that cannot be joined efficiently using other conventional methods.

Since this is a relatively new field and many products that use these bonds are required to perform under sustained impact loads, it is of great importance to understand the behavior of adhesives joints under high strain rate loads. This is not straightforward, as the mechanical behavior of the adhesive structures vary significantly with the strain rate. The mechanical behavior of the joint materials can only be fully characterized as a function of the strain rate $[3]$.

To contribute to this new field of research, the Advanced Joining Processes Unit (AJPU) at FEUP, needs the adequate equipment to correctly characterize adhesives under specific impact loads, thus, a high impact test machine is needed.

\subsection{Objectives}

The dissertation focus is to continue the work done by Tenreiro [4], in a previous master dissertation, into further developing a high impact test machine: a Split Hopkinson Pressure Bar machine (SHPB).

The work done by Tenreiro [4] addressed the design of a pneumatic actuator, capable of reaching high velocities, of the order of $30 \mathrm{~m} / \mathrm{s}$.

In addition to this specification, the machine should also have a variety of subsystems that help in the execution of the machine's action. So, it is required to manufacture the pneumatic actuator, design and build a braking system to stop the pneumatic actuator, develop a structure that holds the machine, and design the assembly of the bars that will transmit the impact from the actuator to the specimen, for both tensile and compression tests. 


\subsection{Methodology}

Initially, an evaluation of the drawings of the pneumatic actuator was made. For that purpose, the master dissertation of Tenreiro [4] was analyzed and the requirements to start the project were identified.

Although the design of the pneumatic actuator was already done, some drawings still needed adjustments for their manufacture. So, the first task was to finish all the actuator's mechanical drawings and order the materials for their fabrication. All the pneumatic components to build the pneumatic actuator were also ordered.

After that starting stage, the design of a braking system was needed to stop the actuator, and after that, the design of the bar's assembly that transmit the impact to the specimen for tensile and compression tests.

Lastly, the design of the support frame that holds the machine was developed.

\subsection{Dissertation Outline}

This dissertation is organized into six chapters, each one covering a different topic that is considered relevant to better understand the work done.

A brief introduction to the project is presented in this first chapter.

The second chapter addresses the literature review about adhesives, impact tests for adhesive joints, and commercial SHPB machines.

The third chapter describes the development of the pneumatic actuator, which includes the final design and its assembly, as well as the acquisition of the pneumatic components.

In chapter four, it is described the development and design of the braking system to stop the pneumatic actuator, as well as the support frame for both.

Chapter five describes the design of the bars that transmit the impact from the actuator to the specimen, for both tensile and compression tests, as well as the support frame.

Finally, in chapter six, this dissertation will be concluded and some proposals for future works on AJPU's SHPB machine are presented. 


\section{Literature Review}

In this chapter, a literature review on adhesives, different types of impact tests on adhesive joints, and commercial SHPB machines are presented.

\subsection{Adhesives}

Adhesives are capable of creating a strong mechanical connection between two bodies with different surface characteristics, known as substrates. There are many advantages in favour of adhesive bonding when compared to other structural joining methods, such as riveting, welding, or fastening. They allow a very smooth stress distribution along the bonded area, enabling higher fatigue resistance, since there are no concentration zones of stress caused by the holes in the surface of the substrates, as it happens with rivets or screws, Figure 2.1. Bonded structures also offer the ability of flexible joint design and they contribute to weight reduction, since dissimilar materials, such as composites, can be effectively joined $[2,5]$.
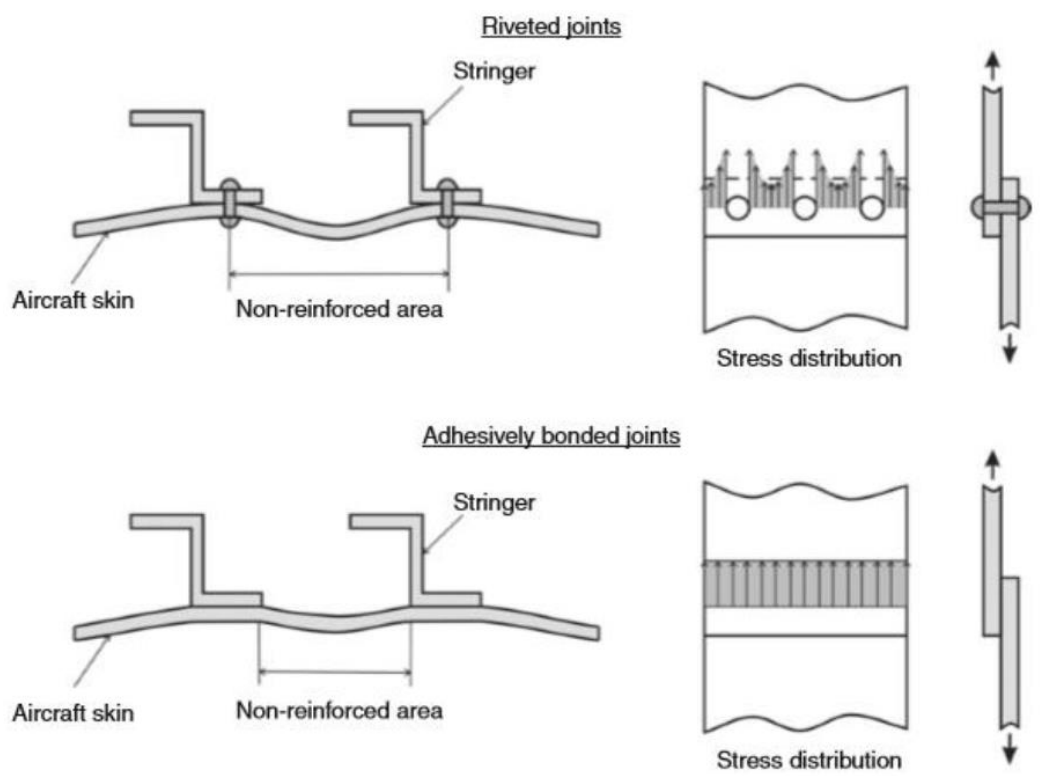

Figure 2.1 - Stress distribution comparison between bonded surfaces using standard fasteners and adhesive materials [2].

There are some disadvantages as well, such as low stability in humidity or extreme temperatures conditions. Moreover, adhesives require surface preparation, long curing times, and have a low resistance to perpendicular forces [2].

Although all these disadvantages were enumerated, the use of adhesives is increasing in many industries, such as aerospace, automotive, naval, and electronics [6]. Many industries manufacture components that are expected to sustain and perform adequately under impact loads. Therefore, studying the behavior of adhesive joints under high strain rate loads is important to understand and optimize the adhesives. 


\subsubsection{High strain rate testing}

Studying the mechanical behavior of adhesives under high strain rates varies significantly. Therefore, to fully characterize the behavior of the adhesive joints as a function of the strain rate to understand the mechanical behavior of the joint under the impact load is needed [3].

Most adhesives are known for being strain rate dependent, which is caused by the inherent viscoelastic behavior of the polymeric structures, which causes the mechanical behavior to be highly sensitive to the loading rate.

Many experiments were made in previous years, by several authors, concluding that the mechanical properties of adhesives change at higher strain rates. Different tests, like tension tests, ARCAN tests, tension-torsion and tensile-compression tests on SHPB machines, showed a tendency of adhesives to change from ductile to brittle behavior as the strain rate increases. In terms of the fracture toughness, it tends to reduce as the strain rate increases [3]. All tests confirmed that the strain rate has a very significant effect on the mechanical properties of the adhesives.

\subsection{Impact test for adhesive joints}

Studying the behavior of adhesives under high impact loads is very complex, as it is very difficult to replicate high strain rate conditions experimentally, therefore bringing high costs to the testing, where it is required many sensors and data acquisition systems.

It is often needed to know how the adhesives will perform under different high strain rate loads and impact tests performed on bulk adhesives, to check the properties of an adhesive [2]. These types of tests are capable of determining the type of failure obtained in the joint, validate the effectiveness of the surface treatment and the energy absorption, as well as many other aspects. Therefore, many different testing devices have been developed and they can be divided into two different groups: impact tests, to determinate the properties of the adhesive; and impact tests, that can test the behavior of a complete adhesive joint [3].

As mentioned before, knowing the mechanical properties of adhesives is fundamental to design an adhesive joint under high impact loads. The most important properties, and the main tests that allow the determination of these properties, are presented in Table 2.1.

Table 2.1 - Mechanical properties and respective impact tests used [3].

\begin{tabular}{|c|c|}
\hline Measured properties & Tests \\
\hline Tensile stiffness and strength & Tensile test \\
\hline Shear stiffness and strength & TAST, Torsion, ARCAN \\
\hline Fracture toughness (Mode I) & DCB, ATDCB, SENB, CT \\
\hline Fracture toughness (Mode II) & ENF \\
\hline Fracture toughness (Mixed-mode) & Custom specimen designs \\
\hline
\end{tabular}


Using these types of tests that are capable to study the properties of adhesives, isolated from other factors, are important, but assessing the impact behavior on the adhesive joint is also extremely important. This is particularly true, when surface preparation, joint geometry, and adherent properties are considered. Therefore, the tests that are used to determine the adhesive joint behavior under high impact loads can be categorized in terms of impact velocity as it is shown in Table 2.2 [3].

Table 2.2 - Impact test classification according to impact testing velocity [3].

\begin{tabular}{|c|c|c|}
\hline Test classification & Testing speed & Suitable test equipment \\
\hline Low velocity & Up to $5 \mathrm{~m} / \mathrm{s}$ & Pendulum impact machine \\
\hline Medium Velocity & Between 5 and $10 \mathrm{~m} / \mathrm{s}$ & Drop weight machine \\
\hline High velocity & Between 10 and $100 \mathrm{~m} / \mathrm{s}$ & SHPB machine \\
\hline
\end{tabular}

\subsubsection{Pendulum impact test}

The block impact test consists of an upper block that is bonded with an adhesive with a larger block, which is attached to a base, then the pendulum will strike the upper block in a parallel direction to the bonded surface. The energy lost by the hammer allows obtaining the energy required to fracture the specimen. This type of test is shown in Figure 2.1, and has the same principle as other impact tests, like the Charpy Impact test and the Izod impact test [2].

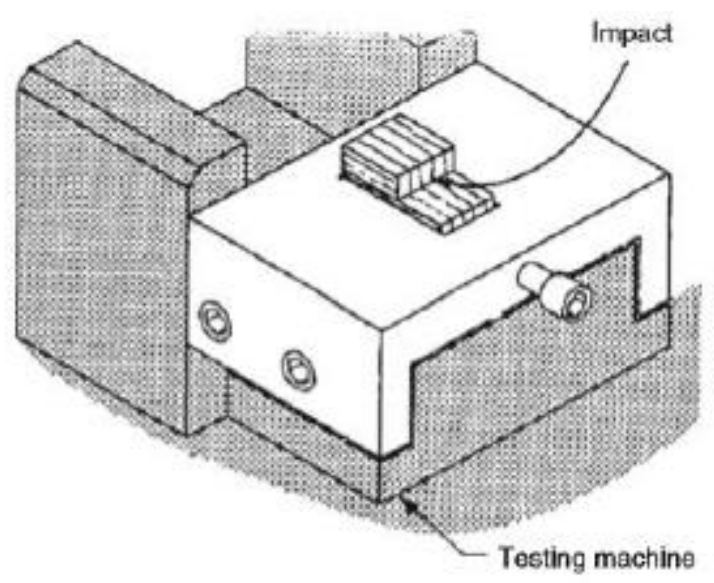

Figure 2.2 - Block impact test apparatus [2].

There are three different possible cases of contact between the hammer and the specimen, found by Adams and Harris [7], which can be seen in Figure 2.3. In cases, II and III where the hammer and the upper block aren't completely aligned, peeling occurs, which means that the results obtained don't correspond with a pure shear loading. In case I, when the hammer hits perfectly the upper block, the stress along the bond is still not constant. From that, Adams and Harris [7] concluded that, even though this type of testing is still very useful to compare the behavior of different types of adhesives, the results shouldn't be interpreted as absolute information about the energy absorption of the bond [2]. 

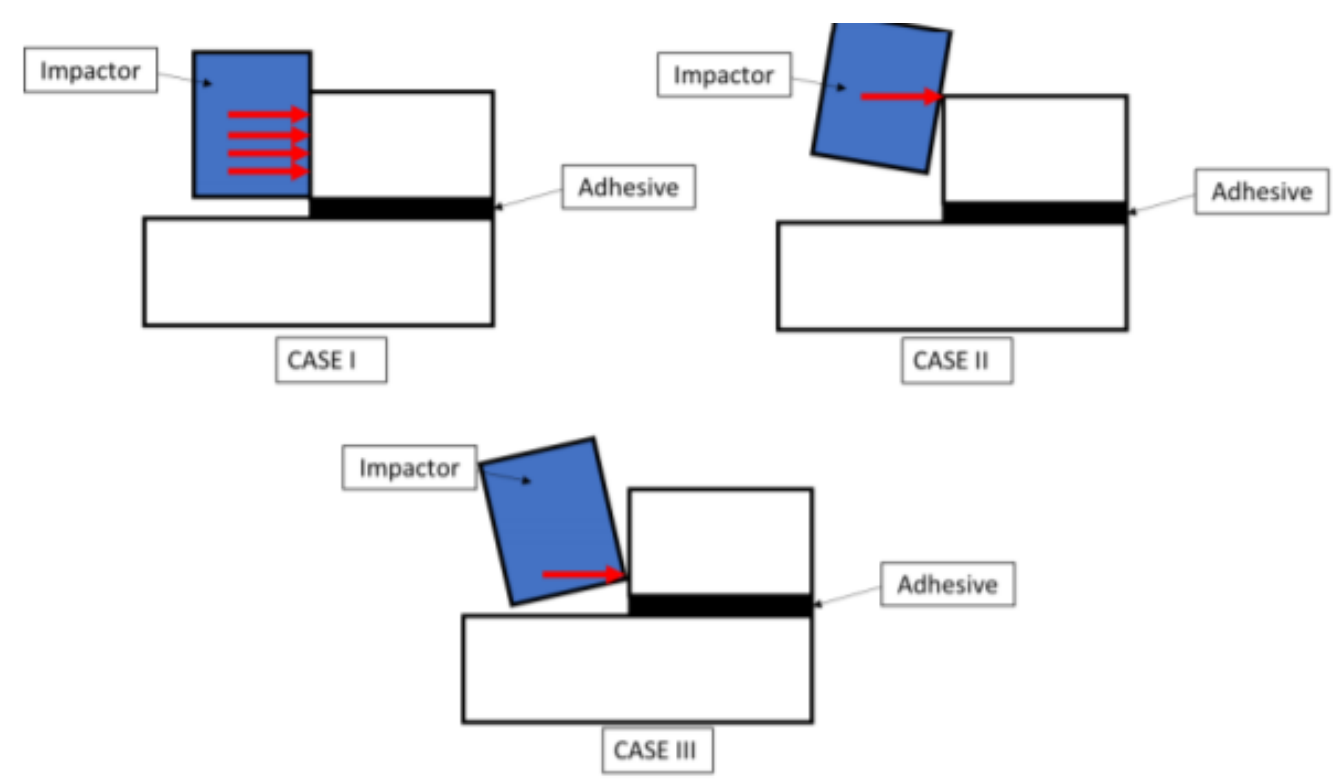

Figure 2.3 - Possible cases of impact between the hammer and the upper block [8].

\subsubsection{Drop weight test}

Drop weight tests are another example of an impact test, which consists of the release of a drop mass, from a previously defined height to the adhesive joint, and depending on how it is fixed in the structure, the specimens can be tested with tensile or compression loads. The kinetic energy from the impactor, that will hit the specimen, is the same as the potential energy before the impactor is released. If the drop weight machine has an acceleration unit sub-system, it will increase the impact of energy, because of the elastic mechanism. To prevent posterior impacts from the impactor, an anti-rebound system is implemented in the drop weight machines [9].

The use of piezoelectric sensors is required to measure the impact loads on these tests. Usually, a load cell or an accelerometer creates an electric charge that is directly proportional to the mechanical load applied to a piezoelectric material. Normally they are made of ceramic or crystal quartz [9].

\subsubsection{SHPB test}

Another type of impact test and the most important one for this dissertation is the Split Hopkinson Pressure Bar machine, which is a test machine dedicated to study the dynamic behavior of materials under medium and high strain rates $\left(0,5-5 \times 10^{3} \mathrm{~s}^{-1}\right)$. The original concept developed by B. Hopkinson, shown in Figure 2.4, consisted of striking one of the ends of a long and thin bar, placed horizontally, with a projectile. This would generate a pressure pulse that would propagate to the other end of the bar, which would be attached to a cylinder that would later be projected against a ballistic pendulum capable of measuring the contained momentum [2]. 


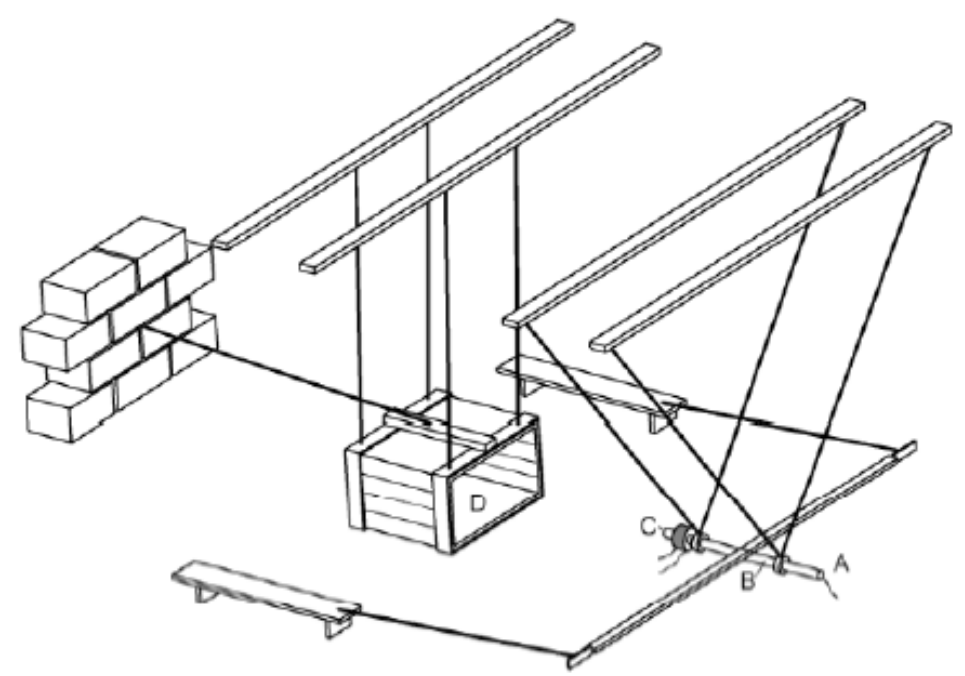

Figure 2.4 - Bertram Hopkinson experiment to measure the pressure waves [10].

Later, Kolsky (1949) developed a new variant of the technique used by Hopkinson, which is the most common nowadays. Kolsky added a second bar to the Hopkinson pressure bar apparatus, placing the specimen between the two bars. This new mechanism consists of three major components, represented in Figure 2.5, which are the loading device, the bar components, composed of the incident bar, the transmission bar, and the momentum trap, and the data acquisition and recording system [10].

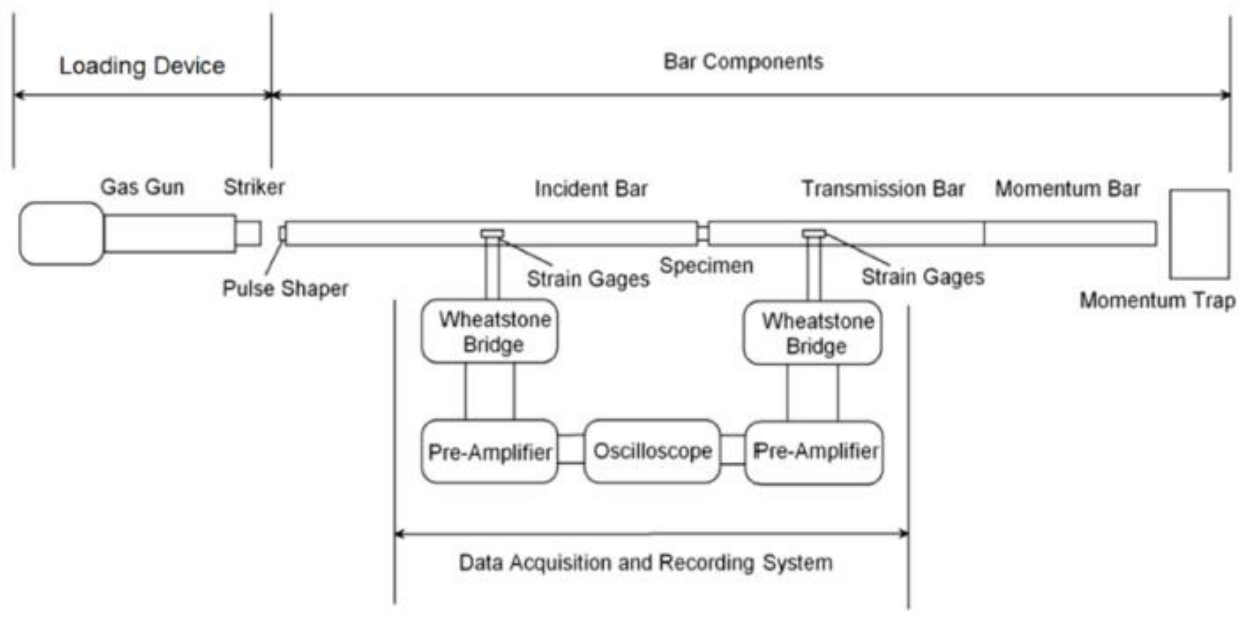

Figure 2.5 - General Kolsky compression bar apparatus [10].

The striker is fired from the gas gun and will hit the incident bar, also called the input bar, generating a pressure pulse that is transmitted to the specimen, where some energy originated by the impact will be reflected. The energy that is propagated to the specimen will then be transmitted to the transmission bar, also known as the output bar. Figure 2.6 shows the basic setup of a SHPB for the compression test and it is possible to visualize the propagation of the pulses through time [11]. 


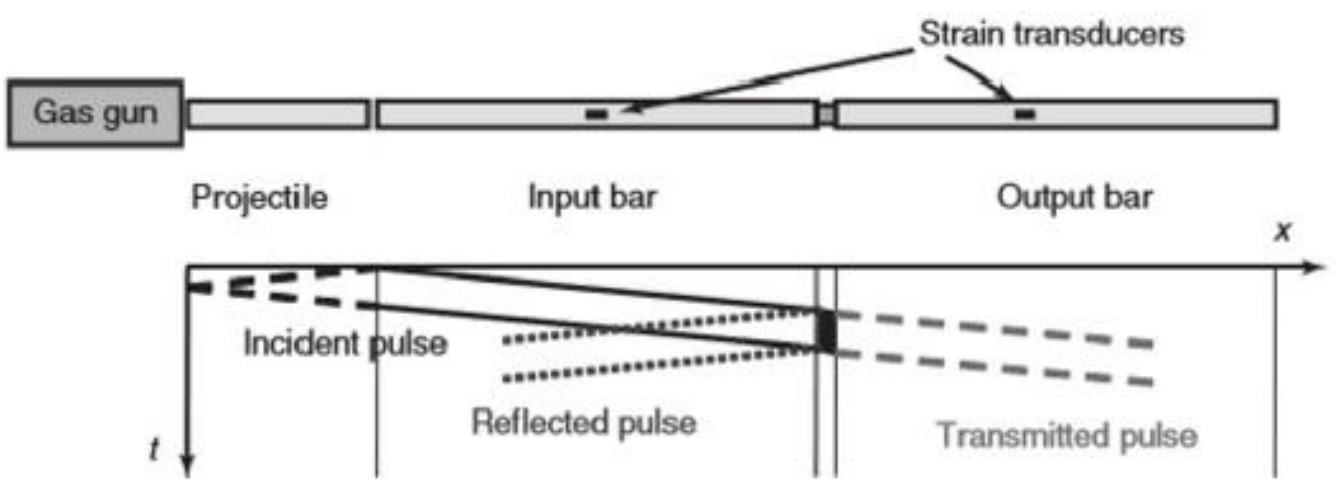

Figure 2.6 - Lagrangian diagram for SHPB compression setup [11].

The loading device should be stable, controllable, and repeatable. Two different methods are commonly used, the static loading and dynamic loading, both represented in Figure 2.7. In the static loading method, the incident bar is statically loaded in pre-compression, and the energy stored is released into the incident bar. Therefore, the compression wave propagates towards the specimen. The dynamic loading method, which is the most common method, is to launch a striker that will impact the incident bar, generating the same compression wave towards the specimen. Gas guns and pneumatic actuation systems are mostly used because of their efficiency, they are safe and controllable, but other systems are used, such as electromechanical linear actuators and hydraulic systems [10].

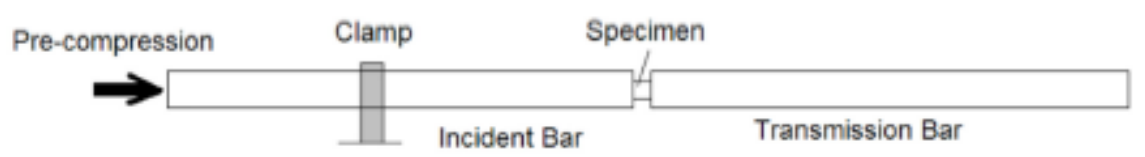

(a) Static Loading

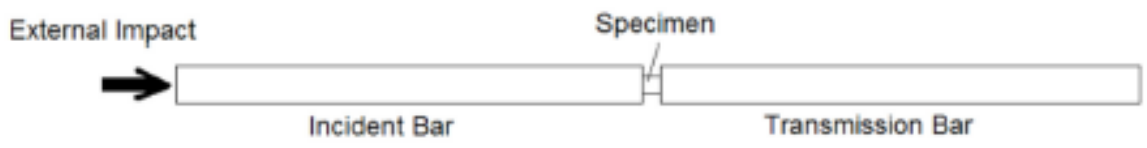

(b) Dynamic Loading

Figure 2.7 - The two most common types of loading devices of the SHPB machine [10].

The bar components are all typical fabricated in the same material and have the same diameter, to ensure one-dimensional wave propagation. The bars must be perfectly aligned and free to move on their supports, with minimized friction. The incident bar should be, at least, twice as long as the striker bar, to avoid overlapping incident and reflected pulses [10].

In terms of data acquisition and recording system, the standard solution found is the use of strain gages to measure the strain in the bars, where two strain gauges are attached symmetrically on the surface of the bars close to where the specimen is being held. With the use of a Wheatstone bridge, the signals are conditioned. Since the voltage from the Wheatstone bridge has low amplitude, there is the need to use an amplifier. Later, the amplified signals are recorded with an oscilloscope or a high-speed data acquisition system. Digital Image Correlation (DIC) has recently been implemented in experimental SHPB setups, which is a noncontact measurement method that allows measuring the specimen's deformations. In this 
method, a pattern with high contrast is applied and with a high speed camera, it is possible to obtain images of the changes in the deformation of the specimen [10].

\subsection{Commercial SHPB machines}

There're many models of SHPB machines available in the market. Even if they are not designed to test adhesive joints, they can still be used for that purpose. The main differences between the machines are their specifications, like the maximum impact velocity obtained with a gas gun, the dimension of the bars, and different equipment for the data acquisition system. Most of the companies sell this type of machine as a complete package with different speed ranges to satisfy the needs of various customers. In this section, some commercial SHPB machines are presented around the same impact speed, of $30 \mathrm{~m} / \mathrm{s}$, which is required for the development of this machine's dissertation, as well as the solution developed in this dissertation.

\subsubsection{THIOT Ingenierie - Split Hopkinson}

The SHPB machines developed by THIOT Ingenierie [12], have a great variety of different testing conditions for the materials to be tested.

Their testing machines are specially designed for characterizing the dynamic behavior of materials subjected to high strain rates, using either tensile or compression testing, and are equipped with sophisticated measurement systems for high quality signal acquisition. In compression testing, they can reach strain rates from 500 to $10000 \mathrm{~s}^{-1}$, and in tensile testing, up to $3000 \mathrm{~s}^{-1}$ in less than $25 \mu \mathrm{s}$.

As mentioned before, the specifications of the SHPB machine are determined by the customer's need. The model manufactured by THIOT, which corresponded to AJPU's requirements to test adhesive joints at $30 \mathrm{~m} / \mathrm{s}$, was a turnkey gas launcher with $26 \mathrm{~mm}$ of diameter capable to operate up to $30 \mathrm{~m} / \mathrm{s}$ and project a striker bar of $20 \mathrm{~mm}$ diameter. the estimated cost is of $37000 €$. The gas launcher was fully-automated with a control panel, which allowed to adjust all the settings in just a few minutes and is capable of working for tensile tests and compression tests. There was as well as a velocity measurement system with optical barriers and mechanical supports for $17000 €$.

\subsubsection{REL - Split Hopkinson}

REL [13], is another company that also sells equipment for impact testing at high strain rates, from 100 to $10000 \mathrm{~s}^{-1}$ at compression tests. Figure 2.8, shows the REL's series SHPB machine for compression testing.

When asked for a gas gun capable of testing specimens with impact velocities of $30 \mathrm{~m} / \mathrm{s}$ the solution given had a price tag of $27000 €$ and consisted of a bar accelerator automation package, two bar accelerator adapters, each one for compression and tensile testing, and a barrel. 


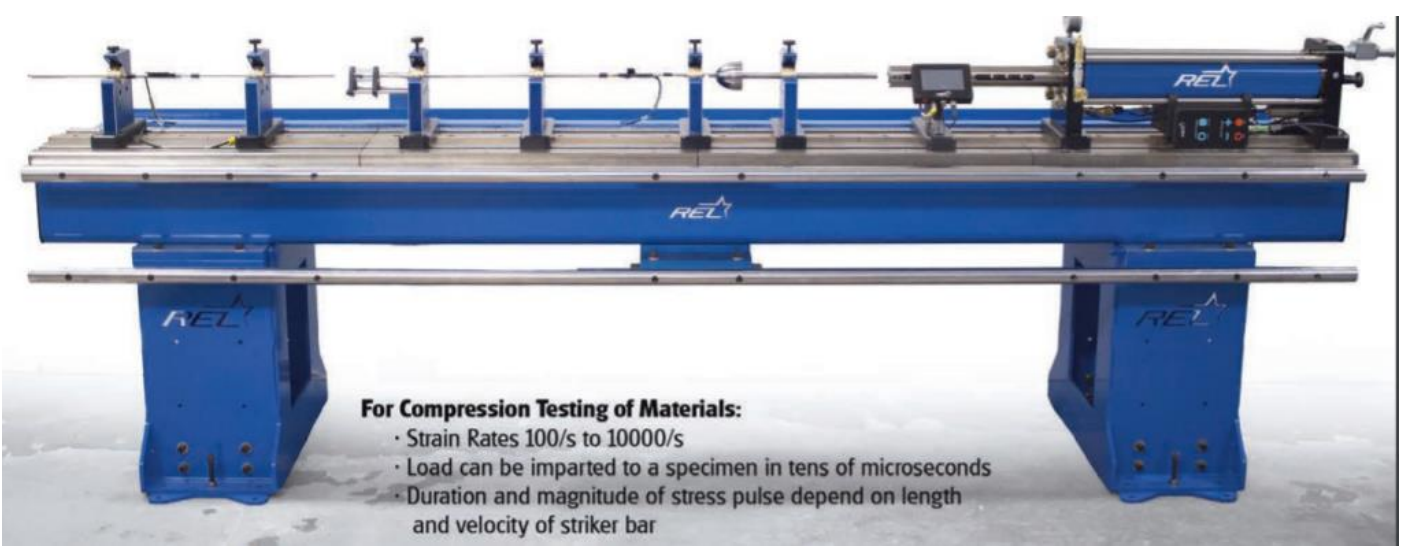

Figure 2.8 - REL's series commercialized SHPB machine [13].

\subsubsection{Natural Impacts Ltd - Split Hopkinson}

Natural Impacts had an SHPB apparatus that wanted to sell, presented in Figure 2.9.

The price of the apparatus for tensile and compression testing was of $55200 €$. The compression apparatus consisted of input and output bars of $16 \mathrm{~mm}$ diameter by $1200 \mathrm{~mm}$ long, with a $500 \mathrm{~mm}$ long striker bar, all made of silver steel. The launcher is powered by compressed air capable to reach $30 \mathrm{~m} / \mathrm{s}$ and a velocity meter. The data acquisition system with amplifiers and the control system was fired from a remote control panel, which would fill and maintain the required pressure. The tensile apparatus had an input and output bar with $16 \mathrm{~mm}$ of diameter made of titanium 64, where the input bar is $3000 \mathrm{~mm}$ long, and the output bar $1200 \mathrm{~mm}$ long. The striker, made of titanium 64 as well, has a length of $700 \mathrm{~mm}$. The launcher was a twincylinder launcher, powered by compressed air capable of only $20 \mathrm{~m} / \mathrm{s}$. The data acquisition was the same as the one used for tensile testing.

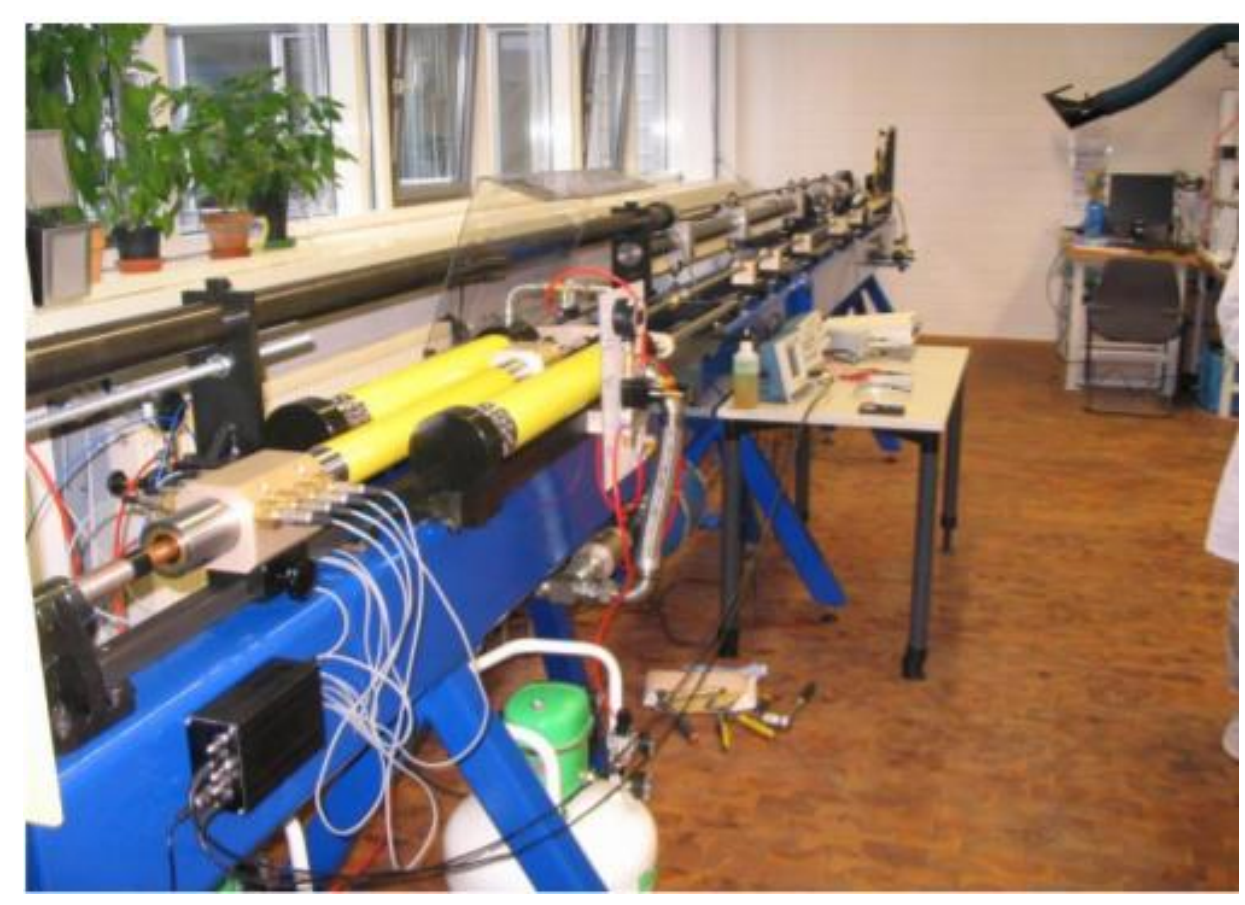

Figure 2.9 - The tensile apparatus of the SHPB machine [14]. 


\subsubsection{AJPU's SHPB machine}

The development of the SHPB machine was firstly initiated by Tenreiro [4], with the development of a pneumatic actuator to be the loading device of the machine. This one is capable to operate at up to $30 \mathrm{~m} / \mathrm{s}$, for both tensile and compression tests. The need to design a SHPB machine grew, not only for the necessity of means to experiment with adhesive joints but also for enabling students to consolidate the gathered knowledge during their master's degree.

The initial point was to validate and correct the mechanical drawings to manufacture the pneumatic actuator. After this verification process, it was required to develop a braking system to stop the actuator's rod movement under $300 \mathrm{~mm}$ of available length and work as well for tensile and compression tests. Finally, to build a support frame to hold the pneumatic actuator and his braking system.

The bar components for compression and tensile tests had to be designed and a second support frame, to hold the bar components, had to be developed, to avoid transmission of vibrations from the actuator to the bar's testbed.

All the developments on the SHPB machine are fully described in the next chapters, and the final product is presented in Figure 2.10, which shows the compression test setup with the tensile bar's setup on the side, fixed to the support frame.

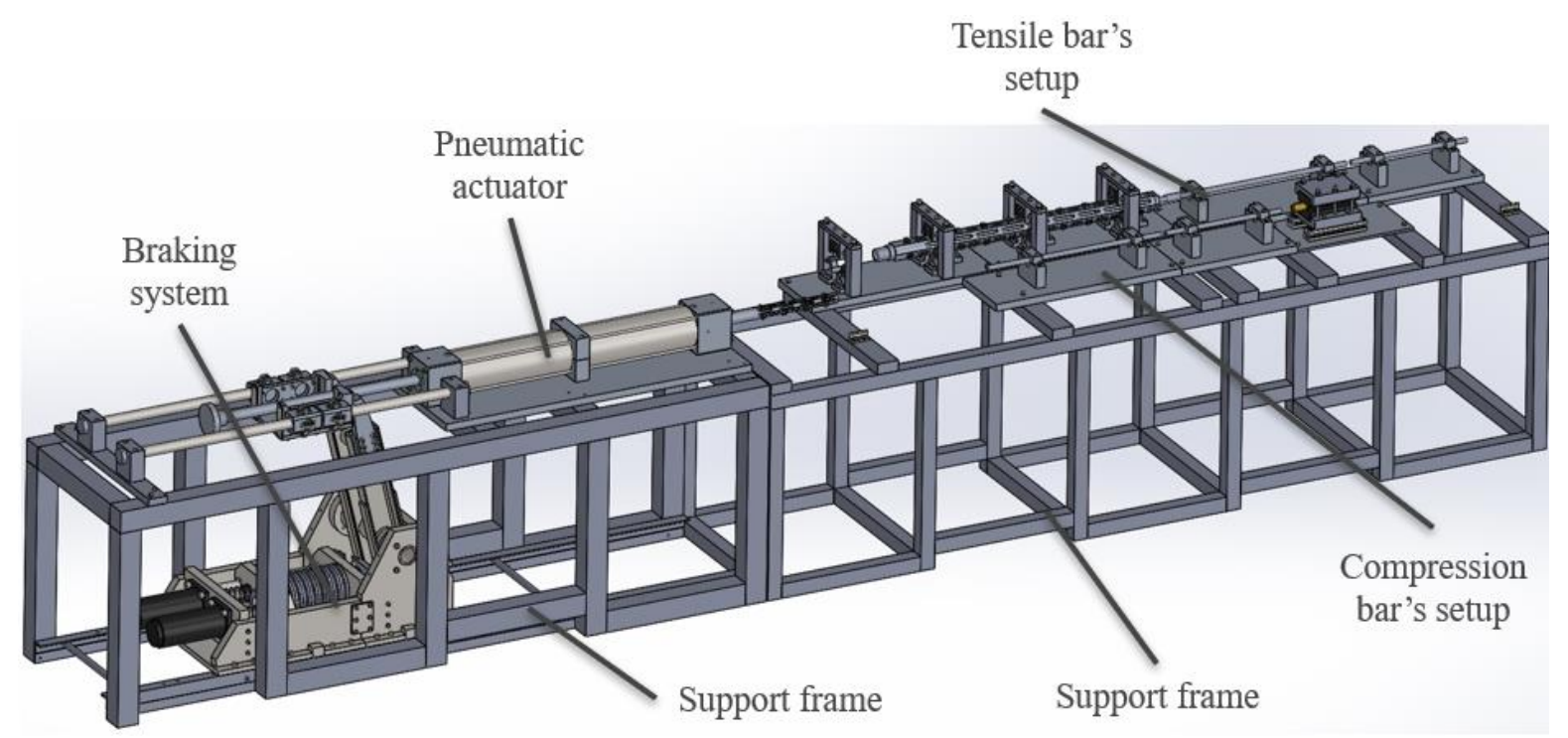

Figure 2.10 - Final SHPB machine, compression test setup. 



\section{Pneumatic actuator}

This chapter describes the design and the validation process for the building of the pneumatic actuator as well as the selection and acquisition of the pneumatic components for its construction.

\subsection{Pneumatic Actuator construction}

As it was previously said, Tenreiro [4] made the initial design of a pneumatic actuator that would be used on a SHPB machine. However, that design had some flaws that needed to be corrected. As such, the initial tasks for this dissertation were to carefully analyze his work, to correct the mechanical drawings previously made, that can be seen in Appendix B, and finally to choose materials for their fabrication. All these initial tasks were done with the help of SolidWorks 2019 and the final design of the pneumatic actuator can be seen in Figure 3.1.

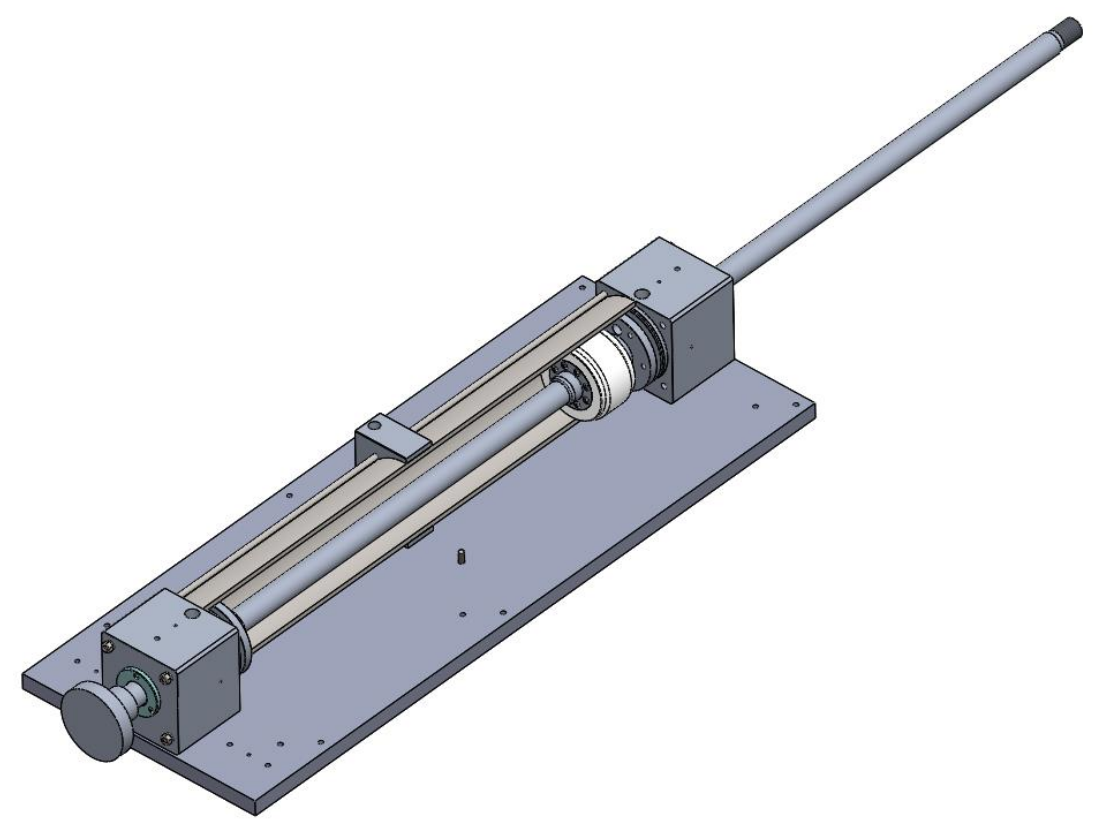

Figure 3.1 - Cut view of the Pneumatic actuator assembly made on SolidWorks 2019

This actuator consists of a rod that is supported by air bushings to prevent any physical contact between components. The cylinder wall should also have no contact as well with the piston. In both stroke ends, there is a sealed damping chamber that allows the start of the rod's motion without air flowing out of the chamber.

The major changes done were to correct the mechanical drawings of the actuator's head, namely the inner diameters where the air bushings would be inserted and the channels for outflow and inflow for the air bushings, as they can be seen in Figure 3.2. 


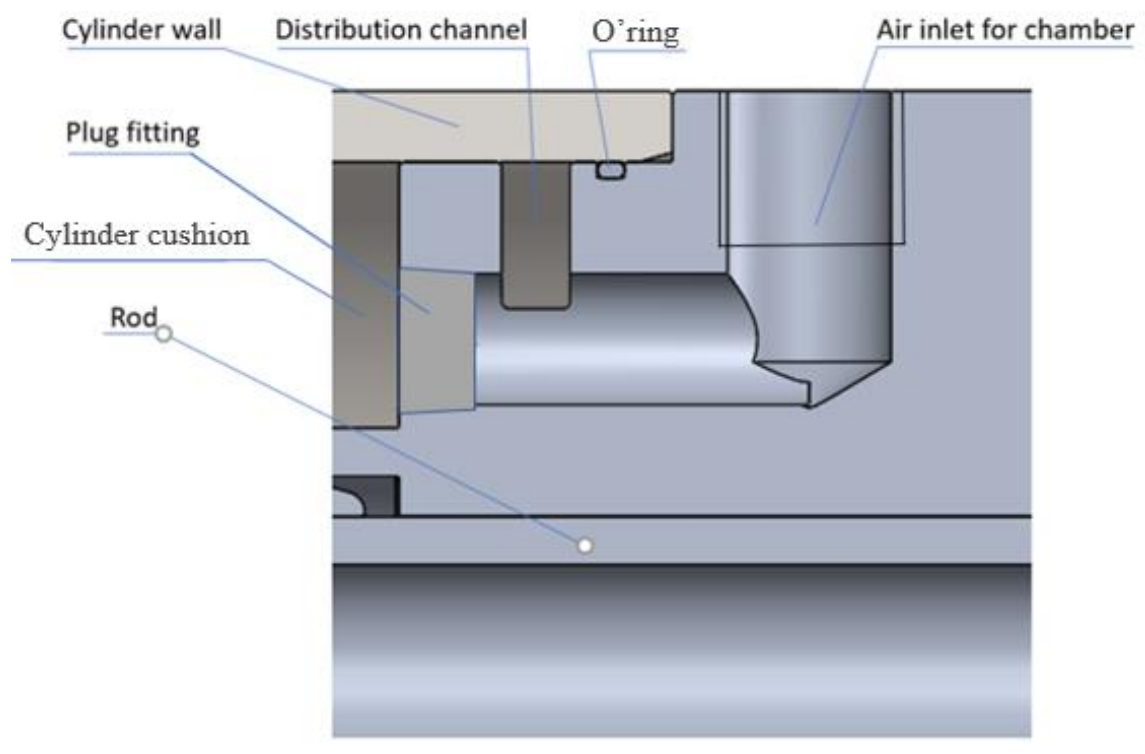

Figure 3.2 - Halfway cut of the actuator's head.

Previously the rod's actuator was defined to be built in aluminium Alloy 6063-T6 to maintain rigidity and minimize the weight, but the problem was that it wasn't possible to guarantee these characteristics and respect the tolerances along the full length of the rod. The solution found was to change the $40 \mathrm{~mm}$ diameter aluminium shaft to a heat-treated $\mathrm{H} 6$ tubular shaft steel from Bosch Rexroth [15] with an inside diameter of $26.5 \mathrm{~mm}$ while maintaining the $40 \mathrm{~mm}$ of outside diameter to continue to be compatible with the air bushings previously chosen, Figure 3.3. The rod has also threaded ends to allow the connection with the assembly that will launch the striker bar and in the other end where it will provide the contact with the braking system. The rod's weight is around $14 \mathrm{~kg}$.

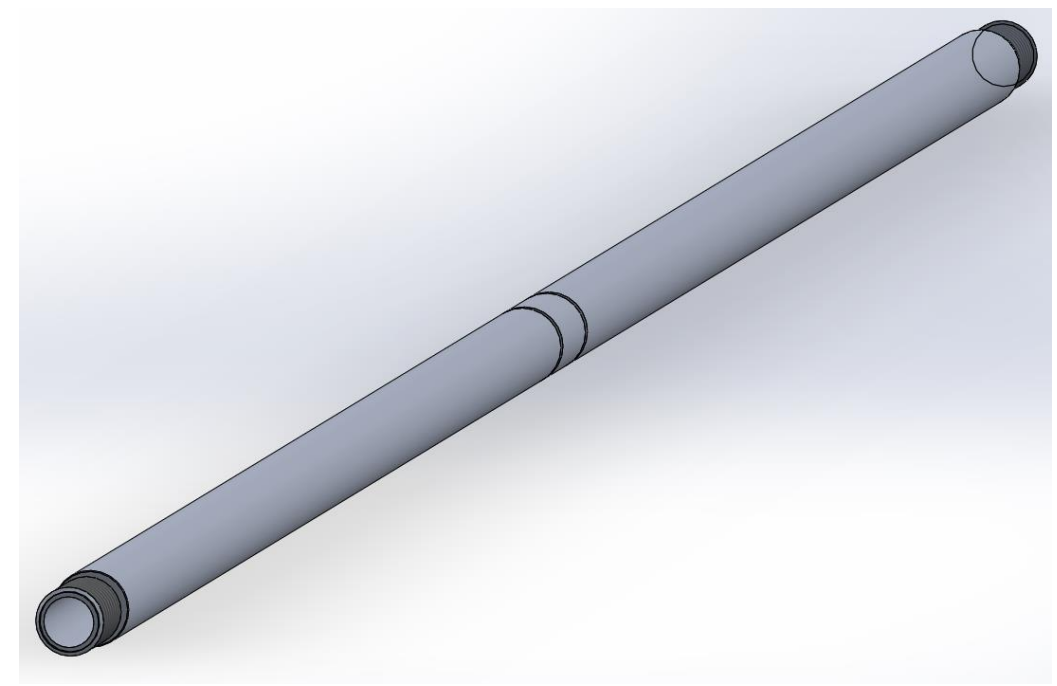

Figure 3.3 - New tubular actuator's rod.

To build the pneumatic actuator, after all of the mechanical drawings were reviewed, the order of all the materials was needed. So, all the Aluminium components and the Nylatron GSM for the piston were bought from Polylanema [16], and the steel components from Ramada Aços [17]. The cylinder wall was bought from Teclena [18], and the actuator's rod was bought from Equinotec [19]. Some parts were able to be manufactured by FEUP mechanical 
engineering department workshop and the rest was sent to Tecnogial [20], like the cylinder wall and the two actuator's heads. The air bushings were bought from OAV bearings [21]. This bearing has a core made of graphite, where a rod passes through it, Figure 3.4, and their specifications are shown in Table 3.1.

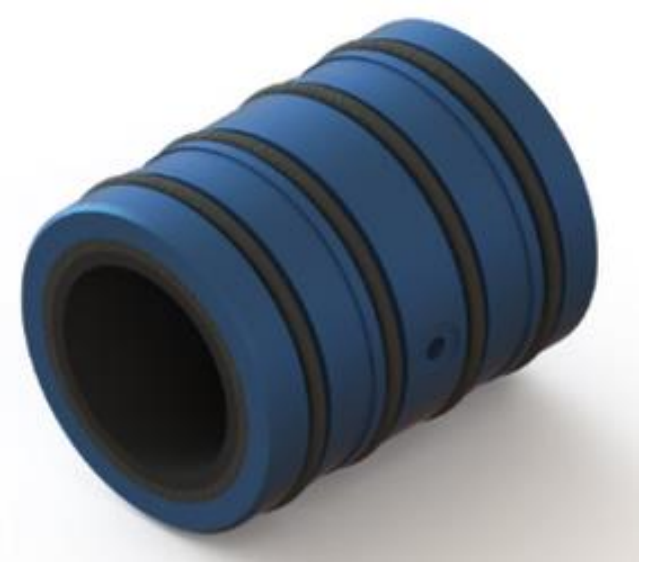

Figure 3.4 - Model of the air bushing OAV040MB [21].

Table 3.1 - OAV040MB air bushing specifications [21].

\begin{tabular}{|l|c|}
\hline Input pressure [bar] & 2.8 to 6.8 \\
Radial Load [N] & 866.3 \\
Radial stiffness [N m ${ }^{-1}$ ] & $72 \cdot 10^{6}$ \\
Maximum Pitch Moment [N m] & 3.1 \\
Flow Rate [slpm] & $11.10 \cdot 10^{-3}$ \\
Mass [g] & 249.1 \\
\hline \hline Inside Diameter [mm] & $40.018_{0}^{+0.005}$ \\
Outside Diameter [mm] & $59.59_{0}^{+0.13}$ \\
Length [mm] & 76.2 \\
Recommended shaft outside diameter [mm] & $40 \mathrm{~g} 6$ \\
Pressure Port Thread & $\mathrm{M} 5 \times 0.8$ \\
\hline
\end{tabular}

The static "O"-rings used in each actuator's head to remove the possibility of air leaking through gaps between the cylinder wall and the head have their specifications shown in Table 3.2. From the rod, seal specifications can be consulted as well. All these components were bought from Rovandi [22]. A 72 Shore A material hardness was enough, as the pressure is quite low and the gaps between the cylinder body and heads are small.

Table 3.2 - “O”-rings specifications [23].

\begin{tabular}{|c|c|c|}
\hline Reference & 445642 & 14452149 \\
\hline $\mathrm{d} 1[\mathrm{~mm}]$ & 40 & 136 \\
\hline $\mathrm{d} 2[\mathrm{~mm}]$ & 1.50 & 3 \\
\hline Material & 72 NBR 872 72 NB & 72 NBR 87272 NB \\
\hline
\end{tabular}

The rod seal was selected to prevent the leakage from the pneumatic damping chamber during the star of the piston's motion and its specifications can be consulted in Table 3.3. 
Table 3.3 - Rod seal specifications [24].

\begin{tabular}{|l|c|}
\hline Reference & 425523 \\
\hline \hline$\varnothing \mathrm{d}_{\mathrm{N}}[\mathrm{mm}]$ & 50 \\
$\varnothing \mathrm{D}_{\mathrm{N}}[\mathrm{mm}]$ & 60 \\
$\mathrm{H}_{1}[\mathrm{~mm}]$ & 6.2 \\
$\mathrm{H}_{2}[\mathrm{~mm}]$ & 8 \\
\hline \hline Material & High performance polyurethane \\
Material Code & $94 \mathrm{AU} 925$ \\
Hardness (Shore A) & 94 \\
Operating Pressure [bar] & $\leq 25$ \\
Running Speed [m s$\left.{ }^{-1}\right]$ & $\leq 1$ \\
\hline
\end{tabular}

All the fasteners used to connect the parts were bought from Fabory [25], and the list is represented by Table 3.4

Table 3.4 - Fasteners used to assemble the pneumatic actuator.

\begin{tabular}{|c|c|c|}
\hline Element & Norm & Qt. \\
\hline \multirow{3}{*}{ Screws } & ISO 4762 M4x10-8.8 & 6 \\
\cline { 2 - 3 } & ISO 4762 M6x20-8.8 & 16 \\
\cline { 2 - 3 } & ISO 4762 M10x60 - 8.8 & 2 \\
\hline Nuts & ISO 4032 - M10-8 & 8 \\
\hline Washer & W10 NF 25-515 & 8 \\
\hline
\end{tabular}

After the parts were manufactured it was possible to mount the pneumatic actuator. The following Figure 3.5 shows the actuator's rod mounted with the piston as well as the actuator's head.
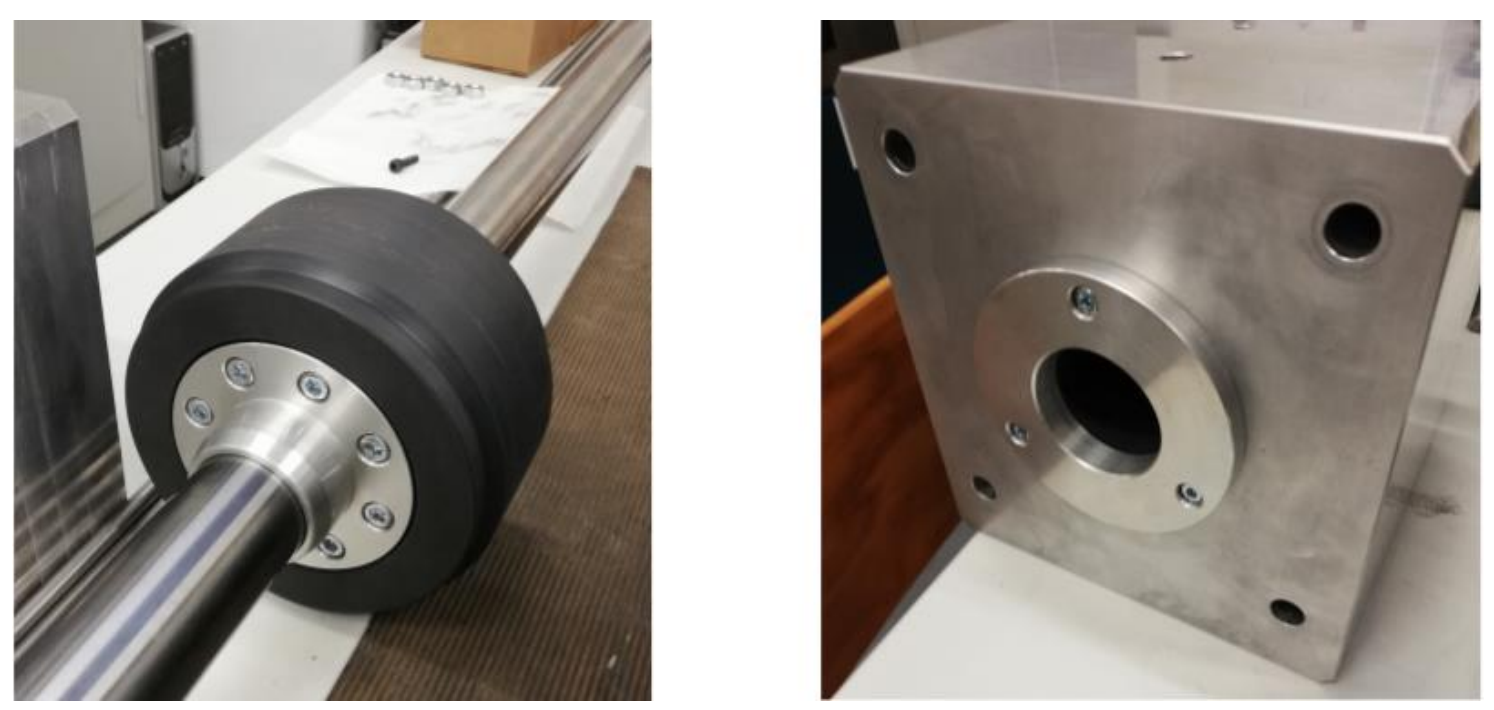

Figure 3.5 - Visualization of the rod and piston assembled on the left; on the right the assembly of the actuator's head.

However, it is only possible to visualize the pneumatic actuator without its sitting table because at the time of writing that table was still being designed to complement the rest of the assembly of the SHPB machine. The pneumatic actuator can be seen in Figure 3.6 


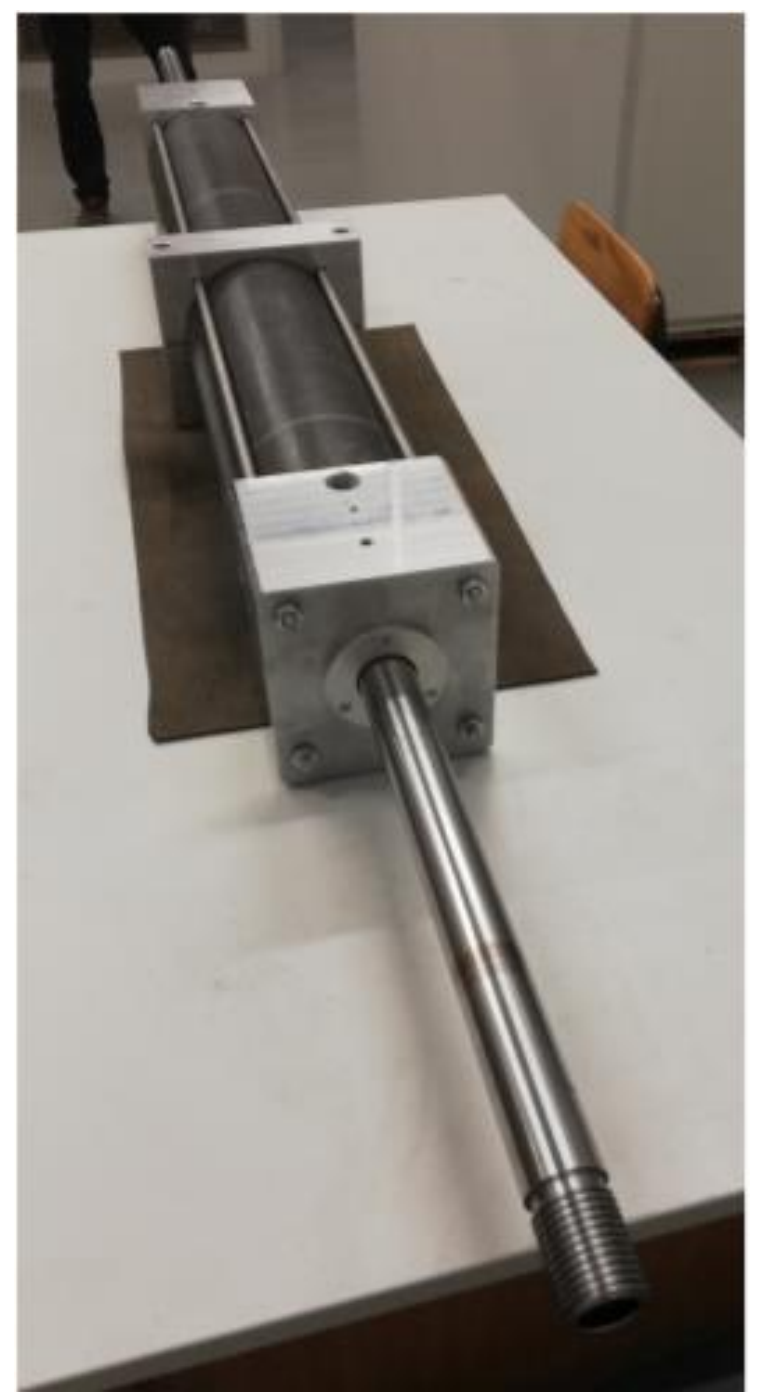

Figure 3.6 - Currently pneumatic actuator developed.

\subsection{Pneumatic components}

At the same time that the actuator was being built, the pneumatic components had to be ordered. Most of the components were already selected by Tenreiro [4] but some changes had to be made to fit properly with the construction of the actuator itself.

The pneumatic circuit proposed by Tenreiro [4], is presented in Figure 3.7, and the cost of acquisition of all the pneumatic components was around $800 €$. 


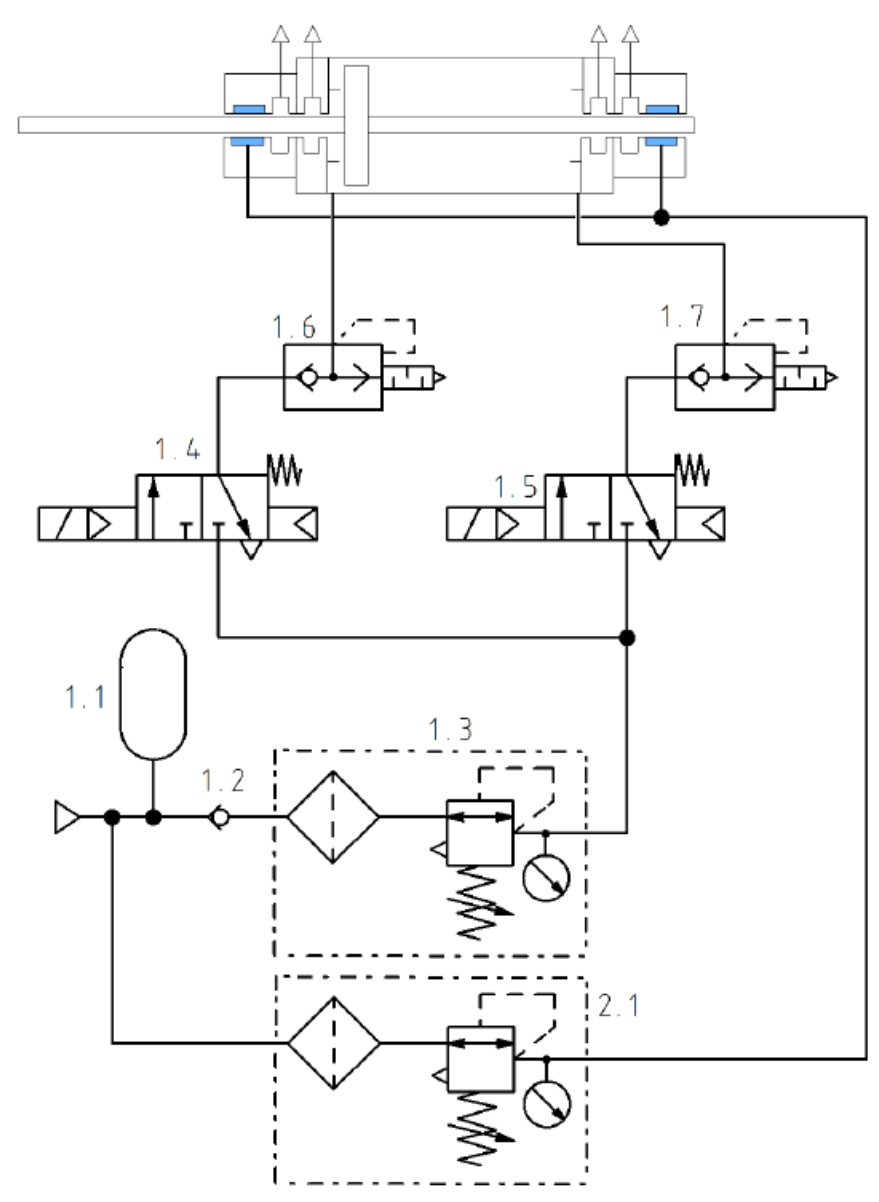

Figure 3.7 - Pneumatic circuit for the actuator proposed by Tenreiro [4].

The actuator had to have a stable supply of air without pressure variations. Therefore, the supply line was unable to deliver a flow of air steady enough for all the actuator travel. A dedicated reservoir was selected with a computed capacity of 60 liters, component 1.1 from the pneumatic circuit. It was chosen a gas reservoir from Amtrol-Alfa [26], its characteristics are summarized in Table 3.5.

Table 3.5 - Pressurized gas reservoir characteristics [26].

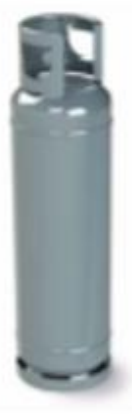

\begin{tabular}{|c|c|}
\hline Height $[\mathrm{mm}]$ & 1150 \\
Diameter $[\mathrm{mm}]$ & 300 \\
Volume $\left[\mathrm{dm}^{3}\right]$ & 61.0 \\
Tare Weight $[\mathrm{kg}]$ & 27.4 \\
\hline
\end{tabular}

Air filter and pressure regulator were needed to regulate and maintain a clean air mass flow to work in normal conditions and to ensure stable functioning conditions. Therefore, an air filter pressure regulator is selected for the main pneumatic circuit and another air supply unit to regulate the airflow for the air bushings, that operate at a different pressure. 
The air filter and regulator combination, 1.3 and 2.1 from the pneumatic circuit, to be implemented in the main pneumatic circuit is the model ACG40B-F04CG1 manufactured by SMC. Figure 3.8 shows a 3D representation of this unit.

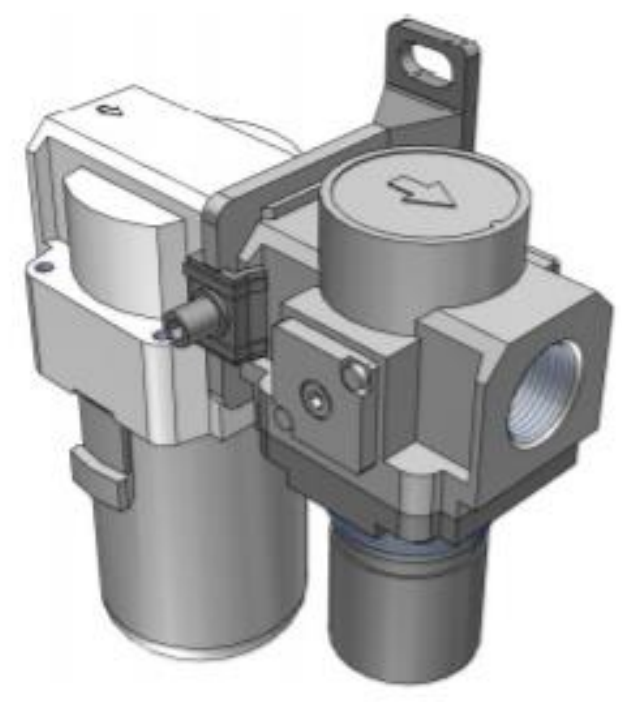

Figure 3.8 - 3D representation of the model ACG40B-F04CG1 [27].

For the air bushing pneumatic supply, the selected model is ACG20B-F02CG1 manufactured by SMC as well [28]. The Table 3.6 presents the most important specifications of these two units.

Table 3.6 - Air filter and regulator specifications [27], [28] .

\begin{tabular}{|l|c|c|}
\hline Model & ACG40B-F04CG1 & ACG20B-F02DG1 \\
\hline \hline Port size & G3/4 & G1/4 \\
Set pressure range [bar] & 0.5 to 8.5 & 0.5 to 8.5 \\
Maximum operating pressure $[\mathrm{bar}]$ & 10 & 10 \\
Nominal filtration rating $[\mu \mathrm{m}]$ & 5 & 5 \\
\hline
\end{tabular}

To command the actuator, it was required two directional valves, represented as 1.4 and 1.5 from the pneumatic circuit, and two quick exhaust valves, 1.6 and 1.7, where each one controls the mass flow that enters the chamber to which they will be connected. The quick exhaust valves will allow the air to flow from the chamber to the atmosphere as quickly as possible giving the actuator's rod the ability to reach high accelerations. The selected valves are shown in Figure 3.9, and all their specifications can be consulted in Table 3.7, Table 3.8, and Table 3.9.

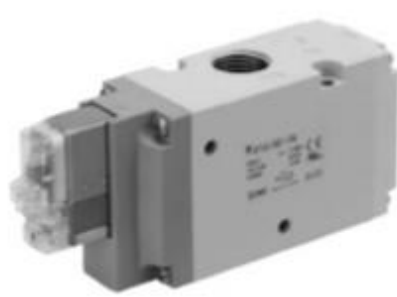

(a) SMC Directional Valve VP742K-5YOD1-04

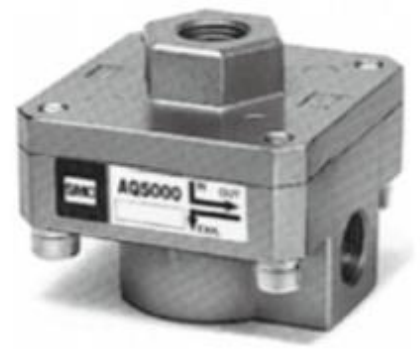

(b) SMC Quick Exhaust Valve EAQ5000-F06-L

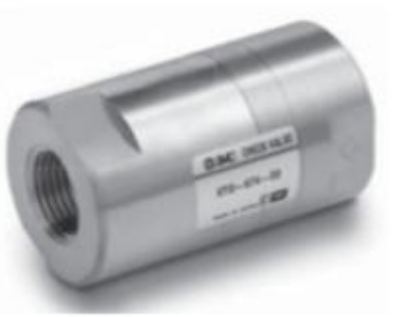

(c) SMC Check Valve XTO-674-04E

Figure 3.9 - Selected valves [29], [30] [31]. 
Table 3.7 - SMC VP742K-5YOD1-04 Valve specifications [29].

\begin{tabular}{|l|l|}
\hline Internal pilot operating pressure range [bar] & 2 to 10 \\
Response time at 5 bar $[\mathrm{ms}]$ & 22 or less \\
Coil rated voltage [V] & $24 \pm 10 \%$ \\
Power consumption [W] & 1.5 \\
Dimensions $[\mathrm{mm} \times \mathrm{mm} \times \mathrm{mm}]$ & $162.1 \times 135.5 \times 66$ \\
Manual override & Push-turn locking slotted type \\
\hline
\end{tabular}

Table 3.8 - SMC EAQ5000-F06-L valve specifications [30].

\begin{tabular}{|l|l|}
\hline Operating pressure range [bar] & 0.5 to 10 \\
Port Size & G $3 / 4$ \\
Dimensions $[\mathrm{mm} \times \mathrm{mm} \times \mathrm{mm}]$ & $85 \times 75 \times 85$ \\
Effective Area $(1 \leftrightarrow 2$ or IN $\leftrightarrow$ OUT $)\left[\mathrm{mm}^{2}\right]$ & 1.5 \\
Effective Area $\left(2 \leftrightarrow 3\right.$ or OUT $\leftrightarrow$ EXH) $\left[\mathrm{mm}^{2}\right]$ & Push-turn locking slotted type \\
\hline
\end{tabular}

Table 3.9 - SMC XTO-674-04E valve specifications [31].

\begin{tabular}{|l|c|}
\hline Port Size & Rc $1 / 4$ \\
Operating Pressure Range $[\mathrm{bar}]$ & 0.1 to 10 \\
Sonic Conductance, $C\left[\mathrm{~m}^{3}(\mathrm{~Pa} \mathrm{~s})\right]^{-1}$ & $10.5 \cdot 10^{-8}$ \\
Critical Pressure Ratio, $b^{*}$ & 0.45 \\
Dimensions $[\mathrm{mm} \times \mathrm{mm}]$ & $\varnothing 32 \times 55$ \\
\hline
\end{tabular}




\section{Braking system}

As the name suggests, the braking system is needed to stop the pneumatic actuator. The pneumatic actuator can operate at $30 \mathrm{~m} / \mathrm{s}$, so there must be some kind of a braking system to stop it and to decrease $30 \mathrm{~m} / \mathrm{s}$ to a maximum of $5 \mathrm{~m} / \mathrm{s}$, which is the maximum velocity that an industrial shock absorber can support. This braking system also has to be able to stop the actuator movement within $300 \mathrm{~mm}$ of travel, because it was the length available to drive the actuator to stop. The idea was to build a lever system, which is one of the six simple machines identified by Renaissance scientists, that could reduce the velocity.

In this case, a ratio of 1:6 would reduce the velocity from those $30 \mathrm{~m} / \mathrm{s}$ to $5 \mathrm{~m} / \mathrm{s}$, but the forces on the shock absorber were very high since they would be 6 times higher, so the ratio had to decrease. By doing that the velocity on the contact point with the shock absorber would increase, so to help the stoppage and still reaching the $5 \mathrm{~m} / \mathrm{s}$, the use of a spring connected to the shock absorber is also needed.

To know the length of the transmission lever, the spring stiffness, and the shock absorber force, a dynamic study of the interaction between the actuator and the braking system was needed. This study leads to a $4^{\text {th }}$ order differential equation system, so it is impossible to evaluate without a simulation, that is why this system was simulated in Matlab Simulink.

This chapter describes the design of the braking system and all the tasks were done with the help of Matlab Simulink and SolidWorks 2019. The final design of the braking system can be seen in Figure 4.1 and all the mechanical drawings can be consulted in Appendix C, D, and E.

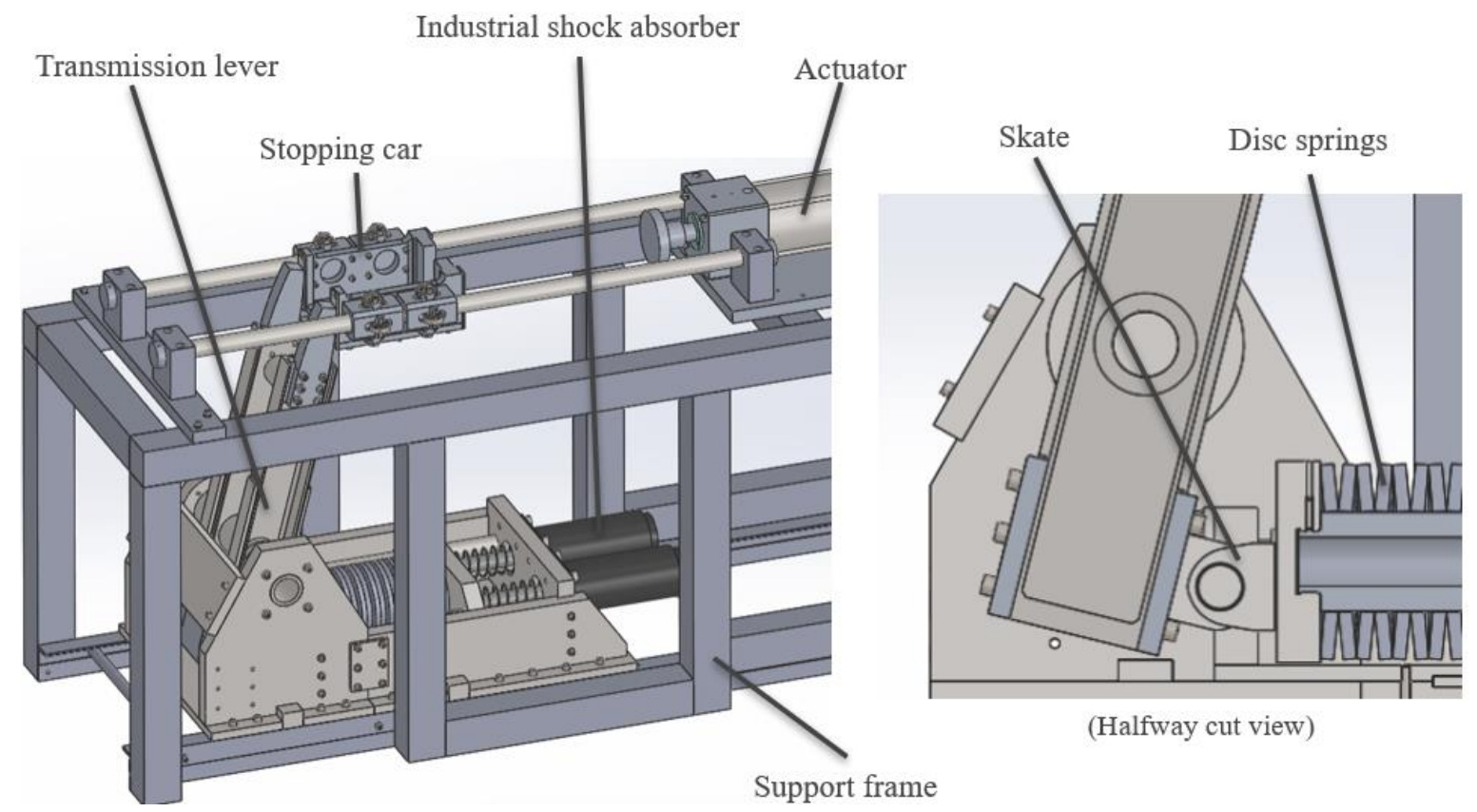

Figure 4.1 - Final model of the braking system designed on Solidworks 2019 


\subsection{System equations}

To initiate the dynamic study, a free body diagram, Figure 4.2, was defined to identify all the interacting forces.

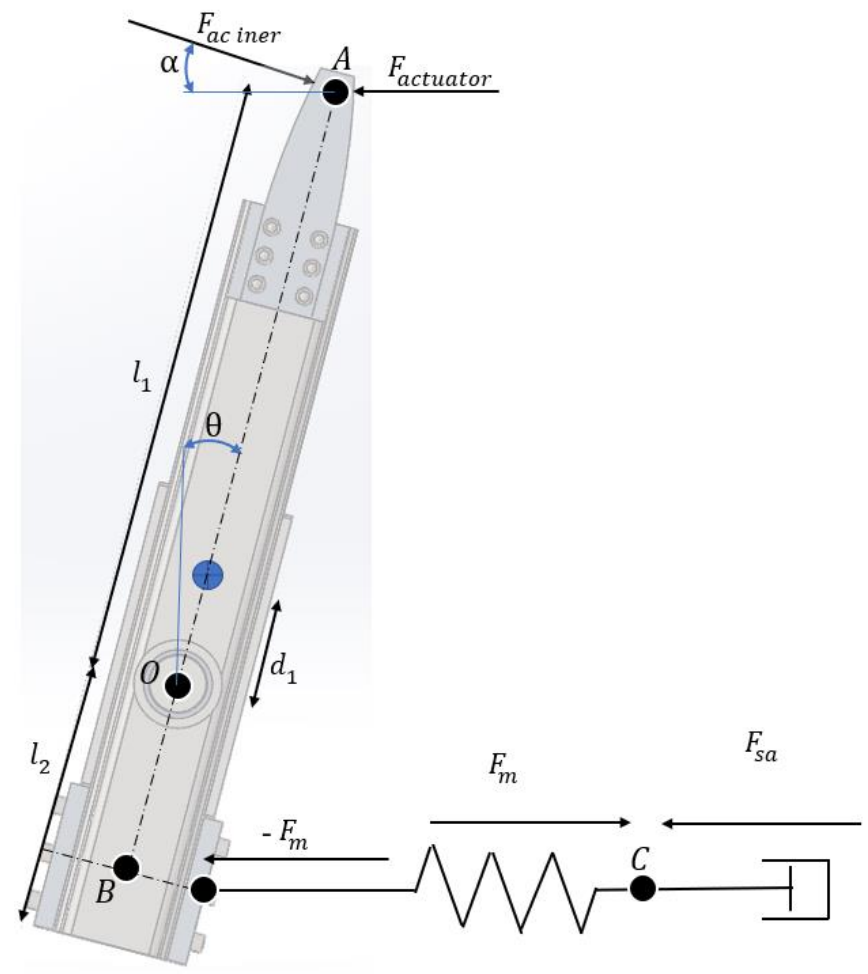

Figure 4.2 - Free body diagram for the dynamic study of the interaction between the actuator and the braking system.

\subsubsection{Transmission lever}

In one end of the transmission lever would be the contact point with the actuator, node A, on the other end would be the point of contact with the spring, node B. Node C represents the contact point between the spring and the shock absorber. The distance from the center of rotation of the transmission bar to the contact with the actuator is represented by $l_{1}$, the distance to the contact point with the spring represented by $\mathrm{l}_{2}$, and $\mathrm{d}$, represents the distance from the center of the mass of the transmission lever to the center of rotation. The length of the transmission lever is represented by $l_{b}$, and can be defined as:

$$
l_{b}=l_{1}+l_{2}
$$

The transmission ratio is represented by $i$, and can be defined as:

$$
\mathrm{i}=\frac{\mathrm{l}_{1}}{\mathrm{l}_{2}}
$$

Where $l_{1}$ and $l_{2}$ can be defined by:

$$
\mathrm{l}_{2}=\frac{\mathrm{l}_{b}}{\mathrm{i}+1} \quad ; \quad \mathrm{l}_{1}=\mathrm{l}_{b}-\frac{\mathrm{l}_{b}}{\mathrm{i}+1}
$$


The distance from the center of the mass of the transmission lever to the center of rotation can be determined by the combination of previous equations:

$$
\mathrm{d}=\frac{\mathrm{l}_{b}}{2}-\frac{\mathrm{l}_{1}}{\mathrm{i}}
$$

The momentum of inertia of the transmission lever was approximated to a moment of inertia from a circular bar, where $m_{b}$ represents the mass of the bar. Combined with the Steiner theorem, the following expression is defined by:

$$
\mathrm{I}=\mathrm{m}_{\mathrm{b}}\left(\frac{\mathrm{l}^{2}}{12}+d^{2}\right)
$$

The actuator was designed to be stopped under $300 \mathrm{~mm}$, so the node A can only travel at maximum, $300 \mathrm{~mm}$. $\theta$ represents the angle produced by the transmission lever during its movement. Knowing this, it can be achieved by the following expression:

$$
\theta=\sin ^{-1}\left(\frac{x_{A}}{l_{1}}\right)
$$

To represent the acceleration force of inertia produced from the transmission lever, it can be defined by:

$$
\mathrm{F}_{\mathrm{aciner}}=\cos \theta * \frac{\mathrm{I} \alpha}{\mathrm{l}_{1}}
$$

Where $\alpha$ stands for the angular acceleration of the transmission lever:

$$
\alpha=\frac{\ddot{x}_{\mathrm{A}}}{\mathrm{l}_{1}}
$$

All previous expressions were introduced into the Matlab Simulink software as it can be seen in Figure 4.3. In Appendix A is depicted the implemented dynamic model, in Matlab Simulink, to its full extent, as well as the results.

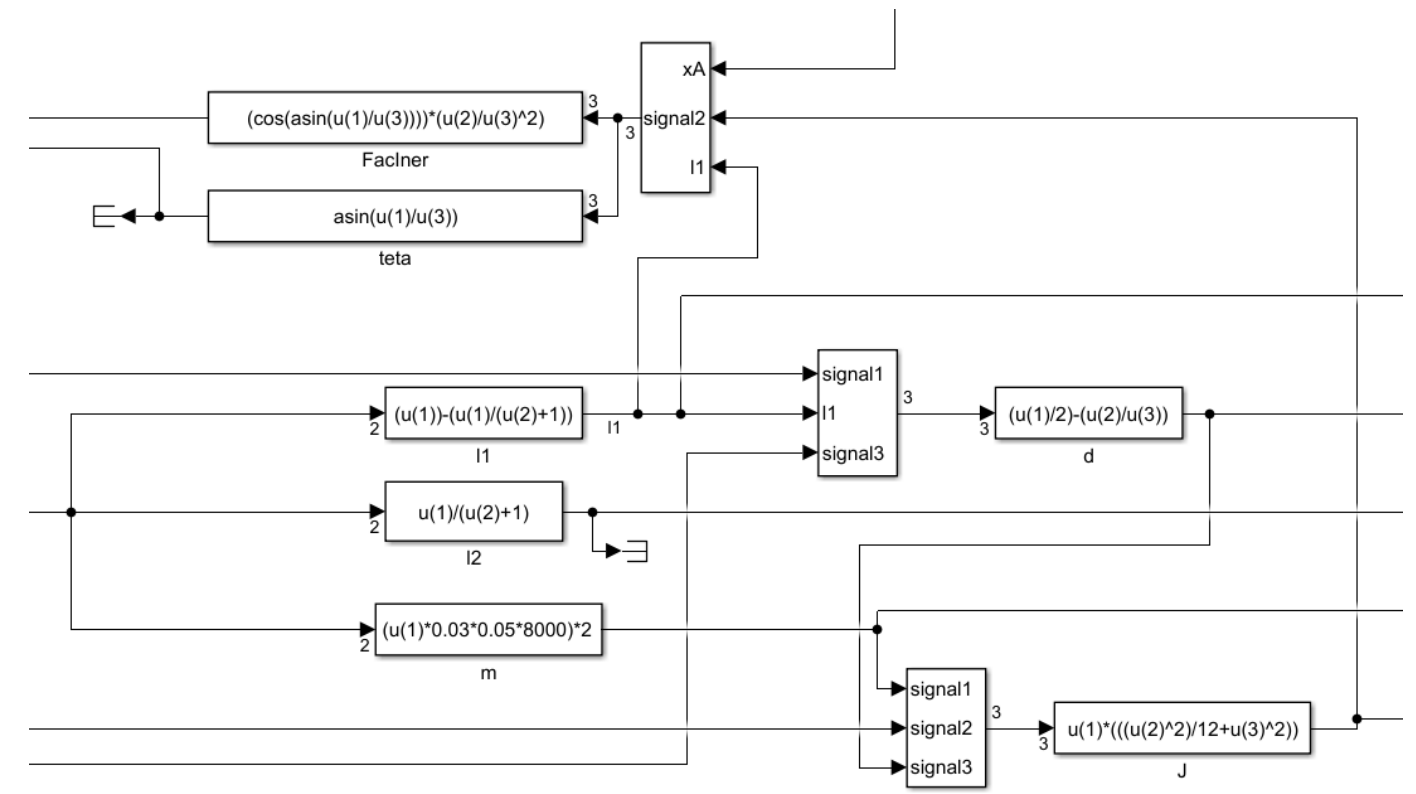

Figure 4.3 - Matlab-Simulink model of the transmission lever. 


\subsubsection{Shock absorber}

Since all the parameters of the transmission lever were defined, it was time to define the parameters from the shock absorber and the spring.

In the case of the shock absorber, the industrial shock absorbers from ACE manufacturer show that the force of this component is constant along the whole stroke, as it can be seen in Figure 4.4. This is just a generical graph from ACE manufacturer to illustrate the behavior of their industrial shock absorbers [32].

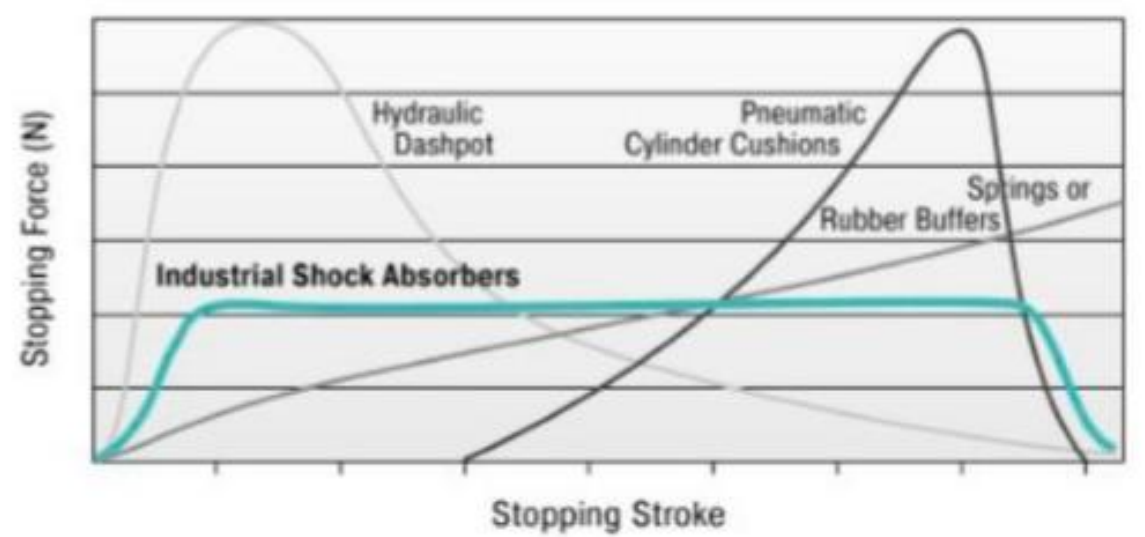

Figure 4.4 - Stopping force along industrial shock-absorber's stroke [32].

Where $U_{\text {máx, }}$ is the dissipated energy by the shock-absorbers per cycle, $\mathrm{s}$ is the shockabsorbers stroke, $x_{s a}$ the maximum speed that the shock absorber operates at, and $\dot{x}_{C}$ the velocity of the point of contact between the springs and the shock absorber. All these characteristics can be correlated, and the force of the shock absorber can be defined as:

$$
\mathrm{F}_{\mathrm{sa}}=\frac{U_{m a ́ x}}{s * x_{s a}} \dot{x}_{c}
$$

In the Matlab-Simulink was introduced a small detail, where the $\mathrm{F}_{\mathrm{sa}}$ would be calculated if the displacement of the node $\mathrm{C}, \mathrm{x}_{\mathrm{C}}$ was positive or null. If the displacement was negative, the value of the $\mathrm{F}_{\mathrm{sa}}$ would be 0 .

\subsubsection{Spring}

The calculation of the force of the spring, $F_{m}$, needed the rigidity of the spring, $k_{m}$, the displacement of the node $\mathrm{B}$, the contact point between the transmission lever and the spring, and the displacement of node $\mathrm{C}$ :

$$
\mathrm{F}_{\mathrm{m}}=\mathrm{k}_{\mathrm{m}}\left(\mathrm{x}_{\mathrm{b}}-\mathrm{X}_{\mathrm{c}}\right)
$$

Where $\mathrm{x}_{\mathrm{b}}$ :

$$
\mathrm{X}_{\mathrm{B}}=\frac{x_{A}}{i}
$$




\subsubsection{Differential equations of node $C$ and $A$}

To determinate the acceleration of node $\mathrm{C}$, an equilibrium of forces had to be made and the following equation was defined:

$$
\mathrm{a}_{\mathrm{C}}=\frac{F_{m}-F_{s a}}{m_{\text {spring }}}
$$

All previous expressions were introduced into the Matlab Simulink software and can be seen in Figure 4.5.

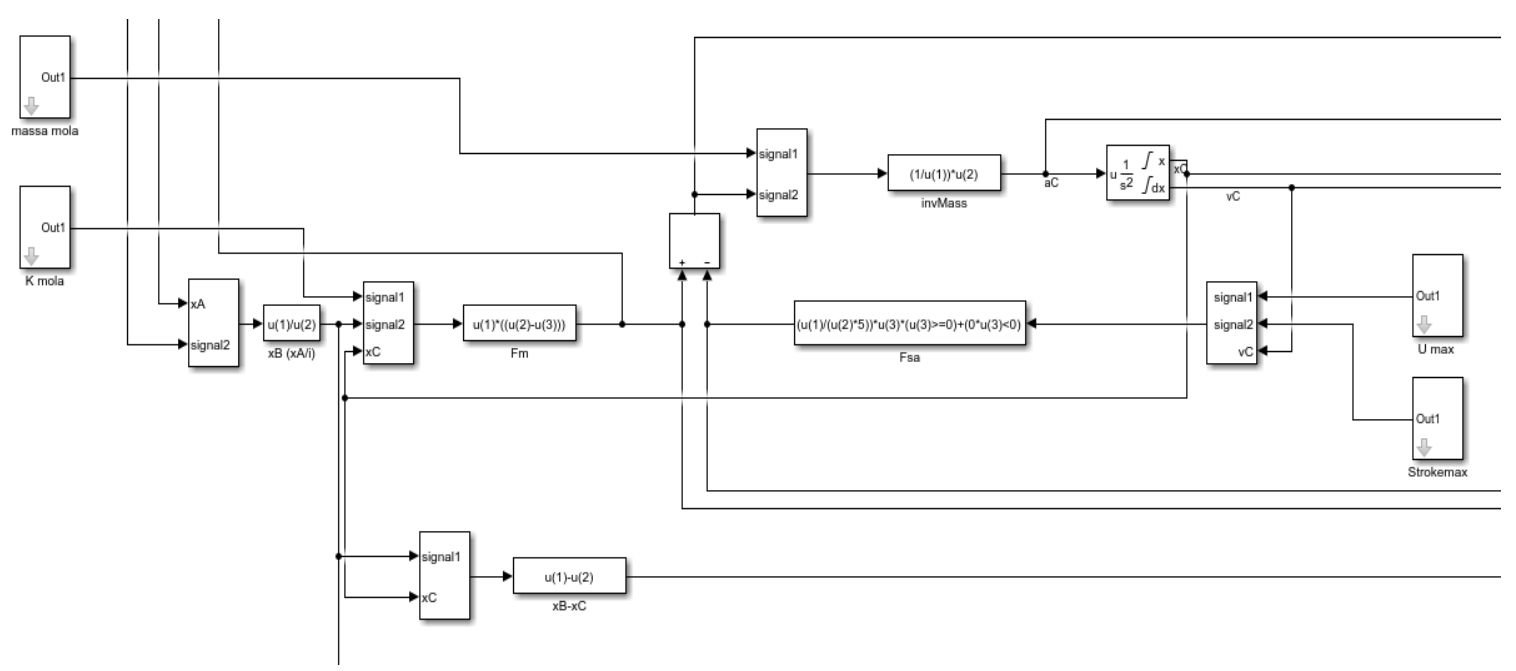

Figure 4.5 - Matlab-Simulink model for node C.

The force of the shock absorber, the force of spring, and the acceleration force of inertia produced from the transmission lever were correlated with an equilibrium of forces as well, where $m_{1}$ and $m_{2}$ represent the masses of the actuator rod and the stopping car used to make the contact between the actuator and the transmission lever:

$$
\begin{gathered}
\left(\mathrm{m}_{1}+\mathrm{m}_{2}\right) \mathrm{a}_{\mathrm{A}}+\mathrm{F}_{\mathrm{mA}}+\mathrm{F}_{\mathrm{aciner}}=0 \\
\mathrm{a}_{\mathrm{A}}=\frac{-F_{m A}-F_{\text {aciner }}}{\mathrm{m} 1+\mathrm{m} 2}
\end{gathered}
$$

Where $F_{m A}$ is the force of spring, $F_{m}$ divided by $i$. From this previous equation, the value of $\mathrm{a}_{\mathrm{A}}$ could be determined, and $\mathrm{a}_{\mathrm{A}}$ and $\mathrm{a}_{\mathrm{C}}$ were defined, just by using a second-order integrator. This integrator is limited in velocity and position to eliminate numerical problems during the stoppage of the system. Those accelerations obtained could give the values for the velocities and displacements for nodes A, B, and C. That correlation is represented in Figure 4.6. 


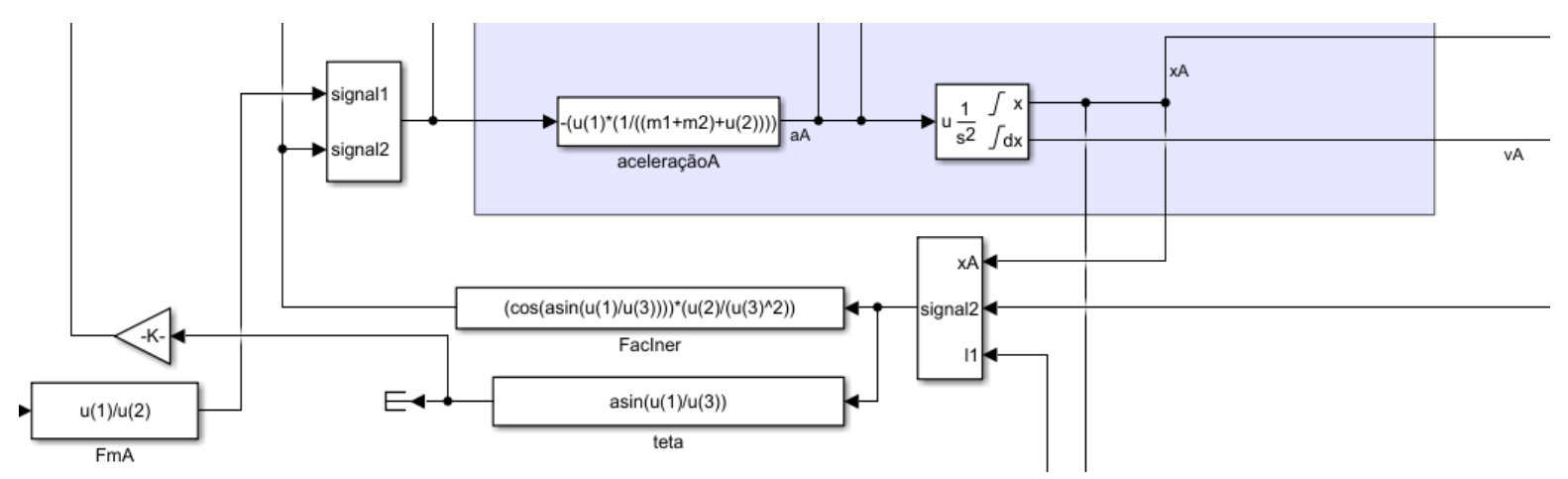

Figure 4.6 - Matlab-Simulink model for node A.

\subsubsection{Simulation results}

Since all the system equations were defined, the parametrization of the system must be accomplished, followed by experimenting with different spring rigidities, different shock absorber forces, and different lengths for the transmission lever. All this process was iterative and, in the end, to have a proper correlation from parts dimensioning and simulation values, a search of specific springs characteristics and shock absorber had to be made. This meant to introduce values from catalogs found during this search for the spring and shock absorber. To better characterize the transmission lever on the Matlab Simulink software, it was used Solidworks to design the transmission lever. With this, the value of the momentum of inertia and mass of the bar were manually introduced in the Matlab Simulink software.

All the values for all parameters were inserted in the Matlab Simulink model to be able to define the system and find a solution for the dimensioning of the shock absorber, the spring, and transmission lever, as shown in Table 4.1.

Table 4.1 - Parameters values inserted in the developed Matlab Simulink model, considering a maximum actuator velocity of $30 \mathrm{~m} / \mathrm{s}$.

\begin{tabular}{|c|c|}
\hline Parameters & Values \\
\hline $\mathrm{m}_{1}$ (actuator rod mass) $[\mathrm{kg}]$ & 14 \\
\hline $\mathrm{m}_{1}$ (stopping car mass) $[\mathrm{kg}]$ & 4 \\
\hline$l_{b}$ (length of transmission lever) [m] & 0.8 \\
\hline i (transmission ratio) $[-]$ & $3: 1$ \\
\hline $\mathrm{m}_{\mathrm{b}}$ (transmission lever mass) $[\mathrm{kg}]$ & 46.1 \\
\hline I (momentum of inertia of the transmission lever) $\left[\mathrm{kg}^{*} \mathrm{~m}^{2}\right]$ & 3.043 \\
\hline $\begin{array}{l}\mathrm{d}_{1} \text { (distance from the center of the mass of the transmission bar } \\
\text { to the center of rotation) [m] }\end{array}$ & 0.12555 \\
\hline $\mathrm{k}_{\mathrm{m}}$ (rigidity of the spring) $[\mathrm{N} / \mathrm{m}]$ & 5000000 \\
\hline $\mathrm{m}_{\mathrm{m}}$ (spring mass) $[\mathrm{kg}]$ & 25 \\
\hline $\begin{array}{l}U_{\text {máx }}(\text { dissipated energy by the shock-absorbers per cycle) } \\
\text { [Nm/cycle] }\end{array}$ & 27000 \\
\hline s (shock-absorber stroke) $[\mathrm{m}]$ & 0.152 \\
\hline
\end{tabular}


By running the model, the results for the displacement of node $\mathrm{A}, \mathrm{x}_{\mathrm{A}}$, can be consulted in Figure 4.7. Where the maximum displacement was $0.285 \mathrm{~m}$ at $0.02 \mathrm{~s}$, showing that the system was able to stop before reaching the maximum length available of $0.3 \mathrm{~m}$. After that peak, the figure shows that the actuator rod starts to come back to his initial position where it is reached at $0.09 \mathrm{~s}$.

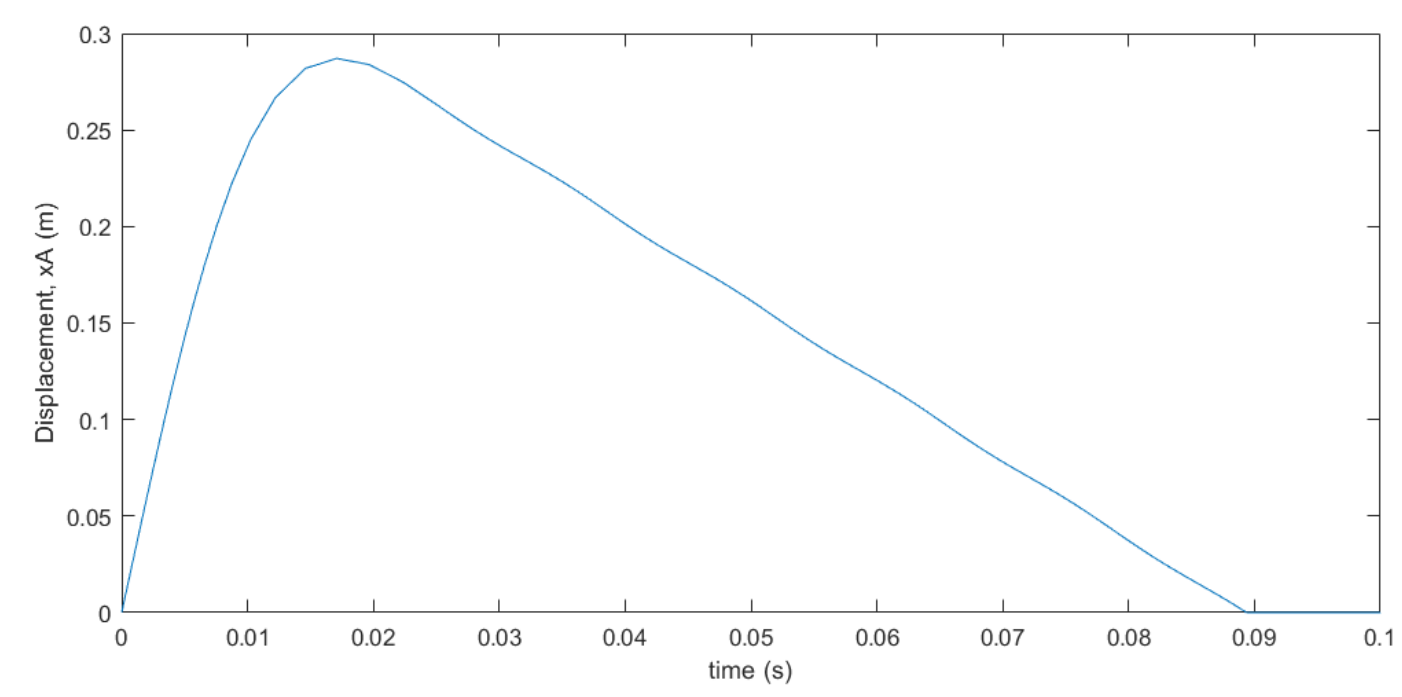

Figure 4.7 - Displacement of node A obtained in the developed Matlab Simulink model.

From Figure 4.8, the velocity of node A, vA, shows that the actuator rod starts at $30 \mathrm{~m} / \mathrm{s}$ and slows down till $0 \mathrm{~m} / \mathrm{s}$ in $0.02 \mathrm{~s}$, where it represents the maximum displacement reached shown in the previous figure. The negative values from the graph represent the velocity during the opposite movement until the initial position under $0.09 \mathrm{~s}$ where that maximum velocity was always under $4.6 \mathrm{~m} / \mathrm{s}$.

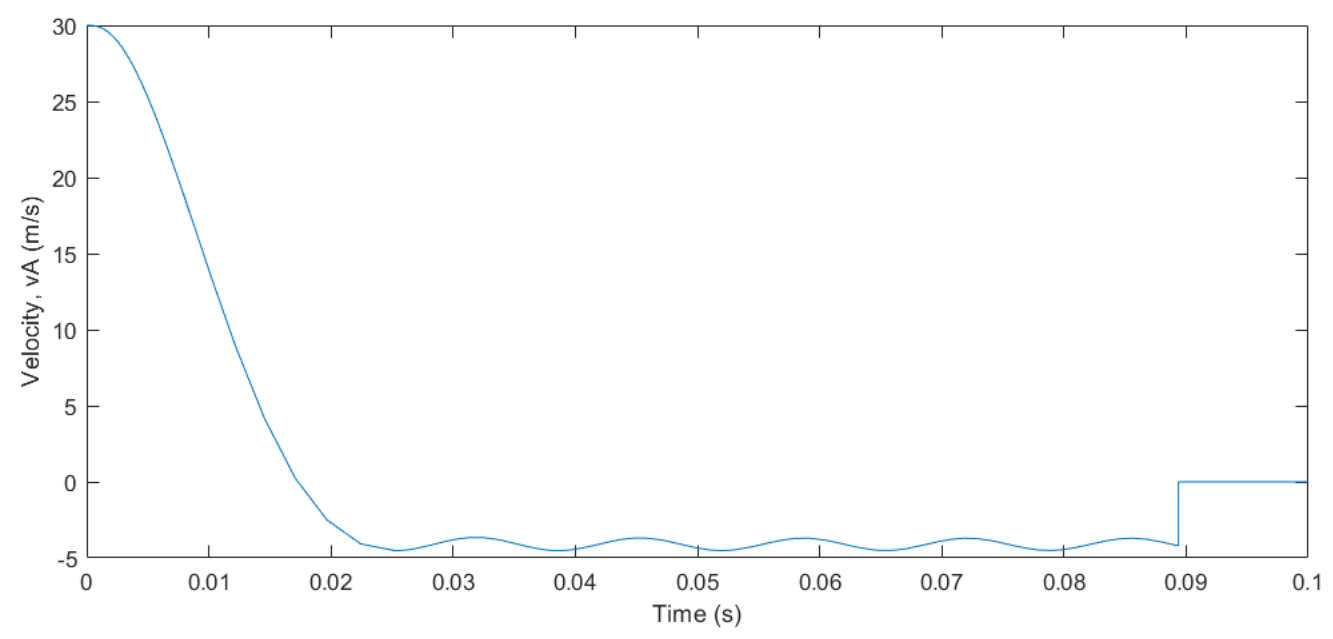

Figure 4.8 - Velocity of node A obtained in the developed Matlab Simulink model.

The angle produced by the transmission lever can be seen in Figure 4.9, at the maximum displacement of the transmission lever it made a rotation of $28^{\circ}$. To have a more stable system and reduce the overall inclination of the lever the idea was to put the transmission lever at $76^{\circ}$ 
and then the system would make the $28^{\circ}$ of movement so the transmission lever would be at $90^{\circ}$ at the intermediate position. This means the lever system would move between $76^{\circ}$ up to $104^{\circ}$.

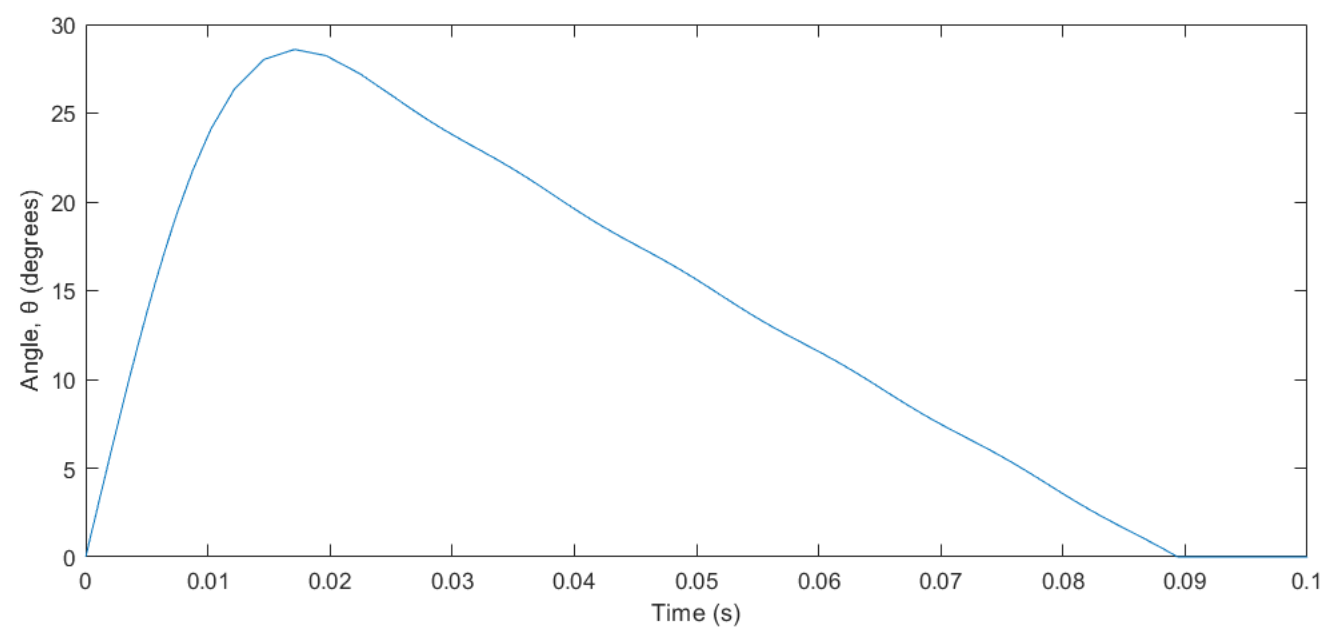

Figure 4.9 - Angle produced by the transmission lever during its movement.

At the other end of the transmission lever would be connected to the springs and shock absorbers assembly. Figure 4.10 shows the displacement of node $\mathrm{C}$, the contact point between the springs and shock absorbers assembly. The maximum displacement obtained was at $0.02 \mathrm{~s}$ meaning that it is the position where the lever system reaches the maximum angle produced, and the value is $0.085 \mathrm{~m}$. After that, there is a "stairs" effect on the variation of the position of node $\mathrm{C}$ where it can be explained by the tension being released from the springs that after the compression they suffer and finally gets to the initial position under $0.15 \mathrm{~s}$.

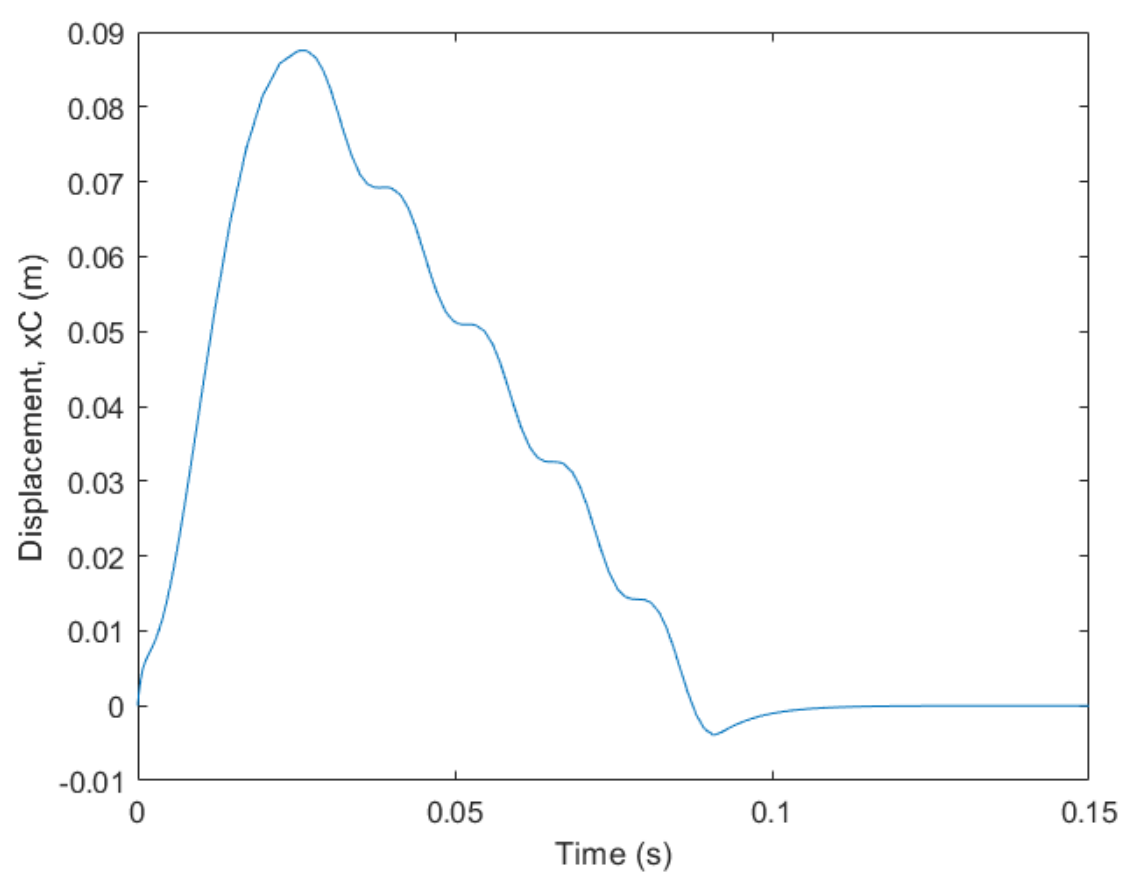

Figure 4.10 - Displacement of node C obtained in the developed Matlab Simulink model. 
In Figure 4.11, the velocity of node $C, v_{C}$, reaches a maximum velocity of $5.5 \mathrm{~m} / \mathrm{s}$ at $0.01 \mathrm{~s}$ and quickly drops again to $0 \mathrm{~m} / \mathrm{s}$. At the start of the graph, there is an oscillation till it reaches the maximum velocity provoked by a transitory adaptation. After that, the velocity oscillates between $0 \mathrm{~m} / \mathrm{s}$ and $2.8 \mathrm{~m} / \mathrm{s}$ negative because it shows that the shock absorbers are going back to their initial position and that wave behavior is explained by the springs releasing tension. It was important to have a maximum velocity of around $5 \mathrm{~m} / \mathrm{s}$, since it is the maximum velocity that the shock absorbers were able to operate. The time of being over those $5 \mathrm{~m} / \mathrm{s}$ was so short, less than $0.01 \mathrm{~s}$, so it was considered that the system respected the limits of the shock absorbers.

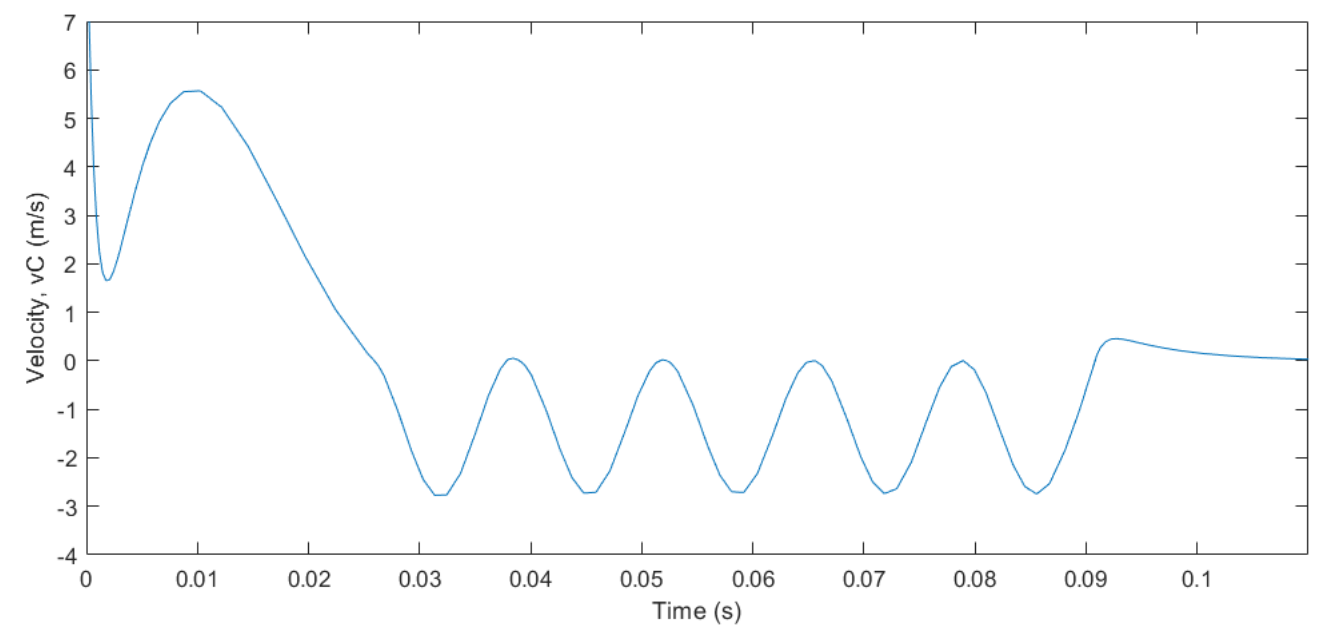

Figure 4.11 - Velocity of node C obtained in the developed Matlab Simulink model.

\subsection{Transmission lever}

As it was previously said in the last chapter, to stop the actuator's rod movement it was required a lever system to reduce the $30 \mathrm{~m} / \mathrm{s}$ of velocity from the actuator's rod to $5 \mathrm{~m} / \mathrm{s}$, were the industrial shock absorber and the spring could act and finally stop the movement of the rod. As such the initial task was to simulate with help of SolidWorks 2019 the forces that this lever system would have to operate to dimension the bars. Therefore, the designed transmission lever structure needs to be strong enough to withstand the impact load of the rod.

The final concept was to use two UPN120 standard profiles and reinforce them with C60 steel plates on the beams, that would be welded to the UPN profiles, as well as two tubular C45 steel, that would also be welded to the UPN profiles and connected together. The tubular steel on the bottom is used as well for the axle of this lever system, where the ratio of 3:1 is respected. On the bottom part of this transmission lever, there are two aluminium 7075-T6 plates, one on each side of the profiles, to allow the implementation of the skate, which will be presented in the next chapter. Therefore, the contact between the transmission lever and the spring could happen. These aluminium plates would be screwed to the UPN profiles. On the top part of the transmission lever there are two blocks of aluminium 7075-T6, one on each of the UPN profiles, also screwed, to receive the impact from the actuator. The final transmission lever assembly is represented in Figure 4.12, and all the mechanical drawings can be seen in Appendix C. 


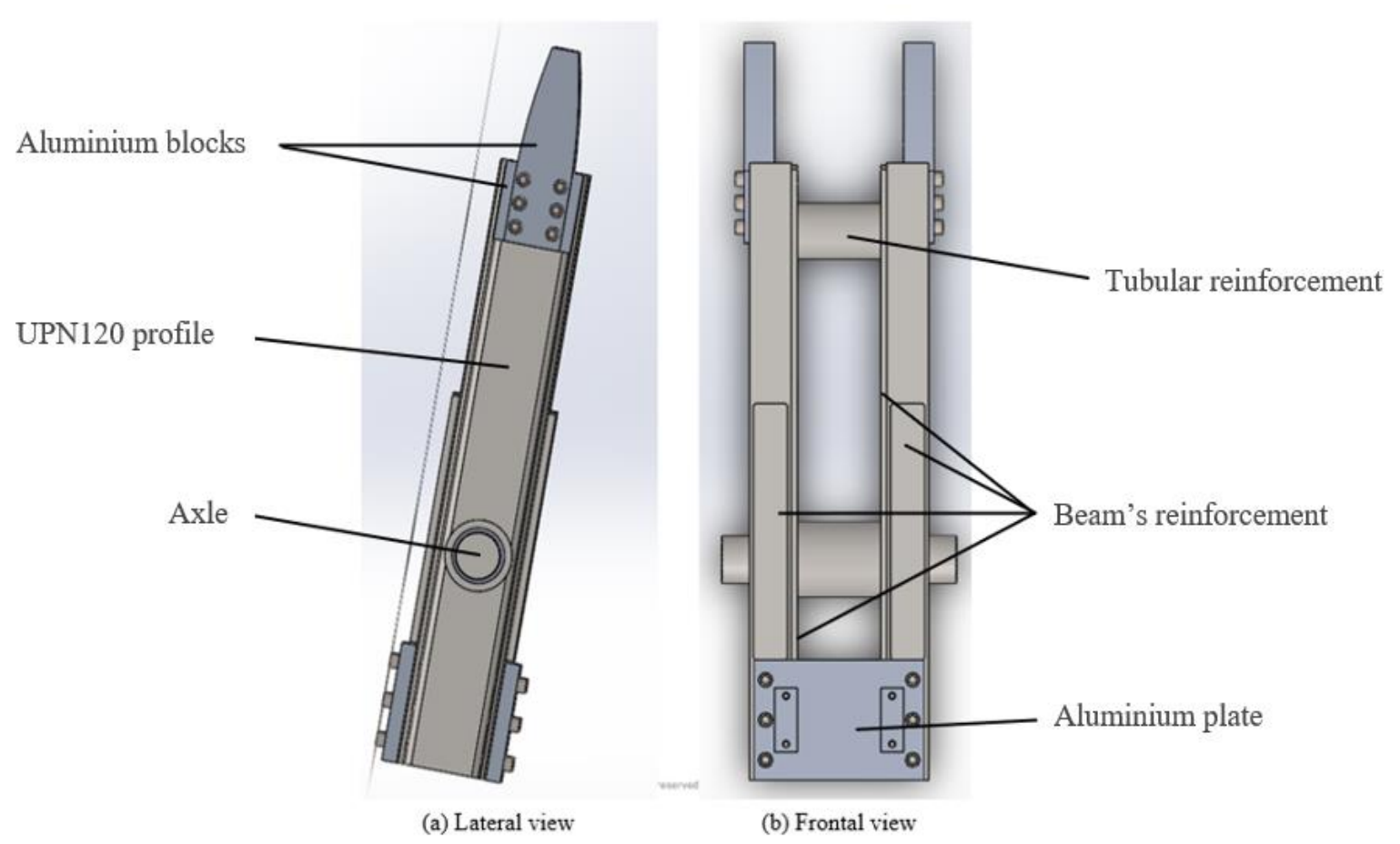

Figure 4.12 - Final model of the Transmission lever.

To start the simulation, it was required to determine the forces that this transmission lever would have to withstand. From the simulations run in Matlab Simulink, it was determined that on the bottom of the lever. The force was around $198 \mathrm{kN}$, the resultant force produced by the spring on node $\mathrm{B}, \mathrm{F}_{\mathrm{m}}$, where the aluminium plate is allocated. This value can be consulted in Appendix A, but at the time this study was being made the force used in SolidWorks simulation was calculated numerically.

From the kinetic energy produced by the actuator, it was possible to determine the energy of the rod's motion and to verify that the energy is constant throughout the length of the transmission lever. It was made a rough estimate, so it was considered more mass than the actual mass used in Matlab Simulink simulation, $20 \mathrm{~kg}$, and the velocity of $30 \mathrm{~m} / \mathrm{s}$.

$$
\begin{gathered}
E=\frac{1}{2} m * v^{2} \\
\mathrm{E}=\frac{1}{2} 20 * 30^{2}=9000 \mathrm{~J}
\end{gathered}
$$

Now, the energy provided from the actuator's rod movement can be considered as equal to the elastic potential energy of the spring and since it is known the distanced stretched, $\mathrm{x}$, from the Matlab Simulink simulation, the value of the spring constant k can be determined:

$$
\begin{gathered}
E P=\frac{1}{2} k * x^{2} \\
9000=\frac{1}{2} k * 0.08737^{2} \Leftrightarrow \mathrm{k}=2.35^{*} 10^{6} \mathrm{~N} / \mathrm{m}
\end{gathered}
$$


After obtaining the value of the spring constant, the force of the spring can be determined by:

$$
\begin{gathered}
F=k * x \\
\mathrm{~F}=2.35 * 10^{6} * 0.08737=206 \mathrm{kN}
\end{gathered}
$$

The value of the force obtained by the equations was $206 \mathrm{kN}$ so in the SolidWorks simulation, the force was approximated to $210 \mathrm{kN}$. That force was applied in the aluminium plate on the bottom of the transmission lever on the area where the skate would be screwed to the plate. This skate is a contact component between the transmission lever to the spring assembly, that will be explained in the next chapter. The structure would rotate on the axle of the transmission lever with a diameter of $60 \mathrm{~mm}$. To simulate the slip contact between the stopping car and the transmission lever on the top it was used a cylindrical shaft in AISI 4340 steel. The diameter of this shaft is smaller than the area of contact between the aluminium blocks and the actuator, in this case, more critical results can occur. The mesh utilized in this simulation was a high mesh quality, the maximum allowed in SolidWorks2019's software.

Inserting these values in SolidWorks 2019's simulation parameters, it is possible to obtain the Von Mises stress distribution, shown in Figure 4.13. The maximum value found for the stress distribution was 273.1 MPa located in the small red area on the top of the beam's reinforcements. No matter the length of the beam's reinforcements, this behavior will always occur because of the indent between the parts since they have a clean edge. All the rest of the structure is way far from the yield strength of each of the materials utilized in the simulation.

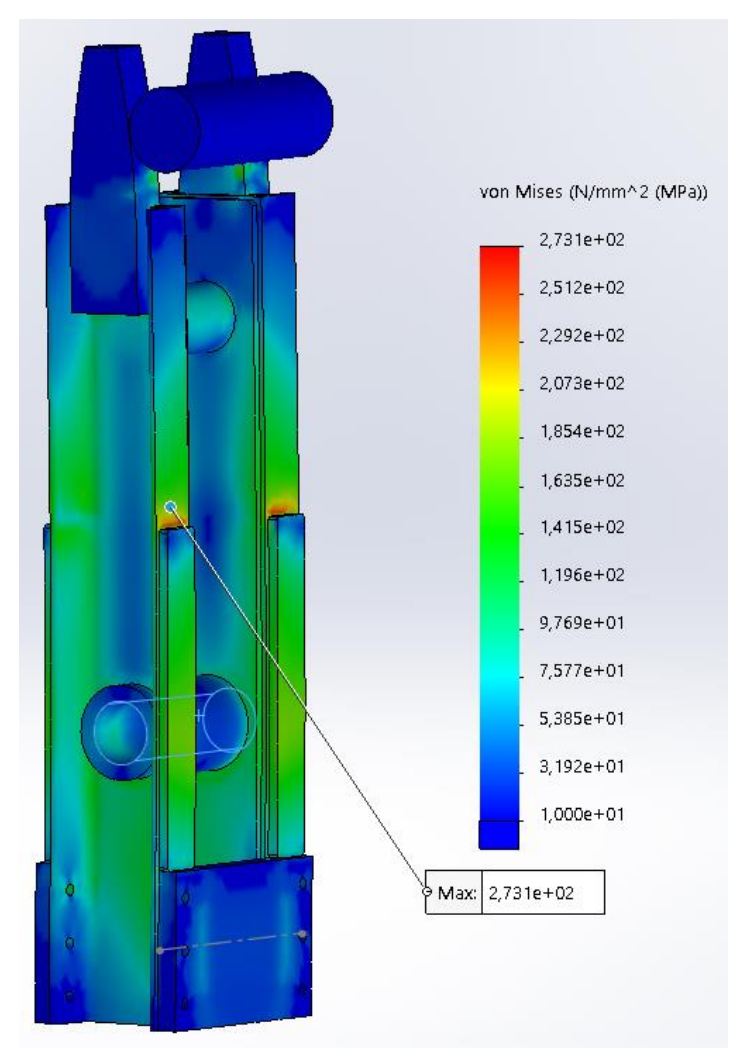

Figure 4.13 - Von Mises stress distribution obtained when a $210 \mathrm{kN}$ force is applied to the transmission lever structure, recurring SolidWorks 2019. 
It was also possible to obtain the results for the factor of safety, shown in Figure 4.14. The minimum value found was 1 , once again happening in the same where the Von Mises stress values were higher, but all the red areas represent all the values found under a factor of safety of 2 .

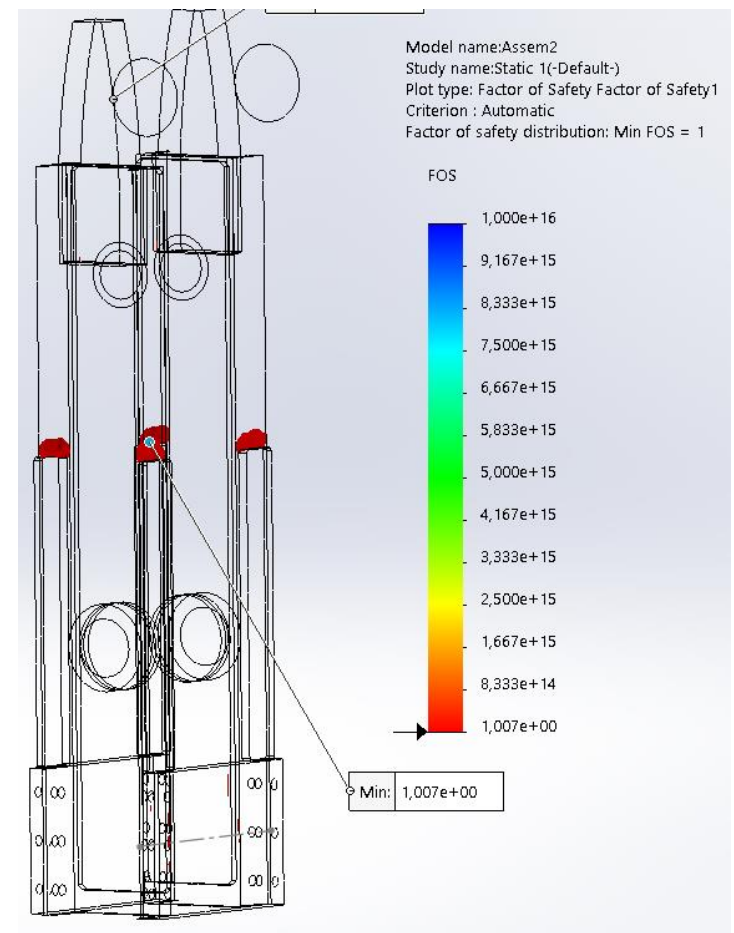

Figure 4.14 - Factor of safety obtained when a $210 \mathrm{kN}$ force is applied to the transmission lever, recurring to SolidWorks 2019.

To make sure the structure was holding its integrity it was also made a fatigue test, shown in Figure 4.15, to determine the total life cycle. The minimum value obtained was 706400 cycles.

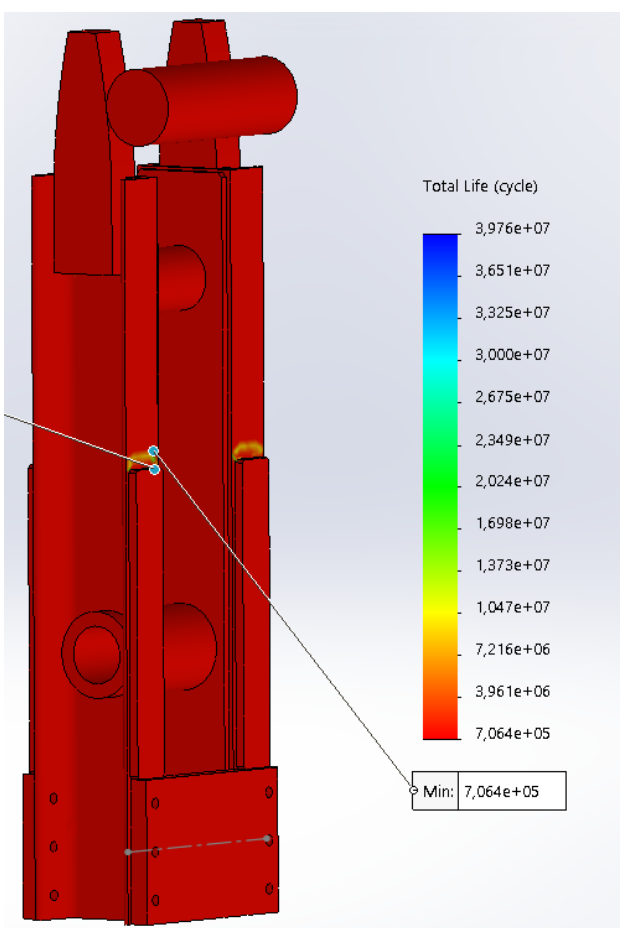

Figure 4.15 - Total life (cycle) obtained when a $210 \mathrm{kN}$ force is applied to the transmission lever, recurring to SolidWorks 2019. 
To connect all the parts that assemble the transmission lever, the fasteners are presented in Table 4.2.

Table 4.2 - Fasteners used to assemble the transmission lever.

\begin{tabular}{|c|c|c|}
\hline Element & Norm & Qt. \\
\hline \multirow{2}{*}{ Screws } & ISO 4762 M12x30-8.8 & 12 \\
\cline { 2 - 3 } & ISO 4762 M12x70-8.8 & 12 \\
\hline
\end{tabular}

\subsection{Skate}

A mechanism to promote the contact between the transmission lever to the spring and shock absorber assembly was developed. The solution found was to build a skate, Figure 4.16, that would be supported by two plain bearings with a cylindrical shaft inside, where this shaft would be held by two bearings that would be screwed to the Aluminium plate of the transmission lever. This would give the ability of free rotation of the skate to enter in perfect contact to the spring during the rotation of the transmission lever and take the very high $210 \mathrm{kN}$ force, with low contact pressures both on the skate surface and the plain bearings. All the mechanical parts drawings can be seen in Appendix C.
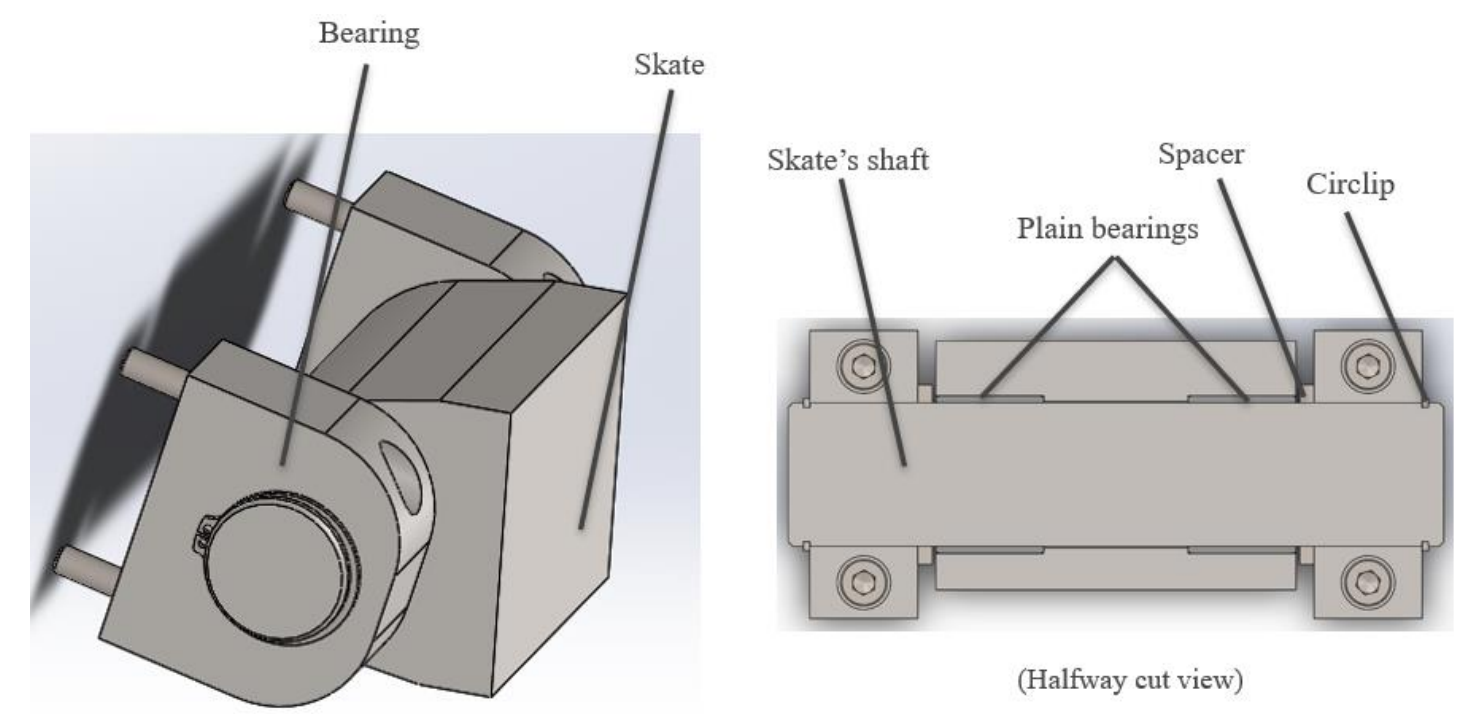

Figure 4.16 - Final model of the Skate.

The mounting of the skate to the transmission lever can be seen in Figure 4.17. 


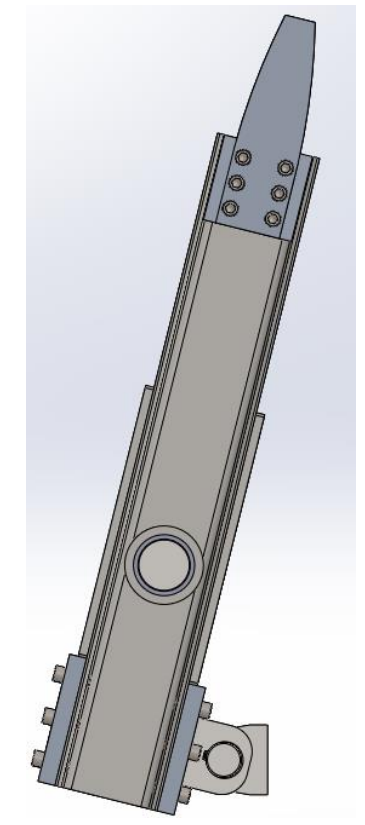

Figure 4.17 - Transmission lever with the skate.

To start dimensioning this assembly, a simulation in SolidWorks 2019 was made, where it was applied the force of $210 \mathrm{kN}$, mentioned before, in the plate that would hold the springs assembly. It was possible to obtain the results of contact pressure in the skate's surface, shown in Figure 4.18, to dimension the surface area of the skate. The goal was to get a surface tension under $70 \mathrm{MPa}$. The maximum value found was $444.9 \mathrm{MPa}$, but it was just a single node, so it was selected different nodes and all the values were under the $70 \mathrm{MPa}$ of surface tension. All the materials used were C45 steel.

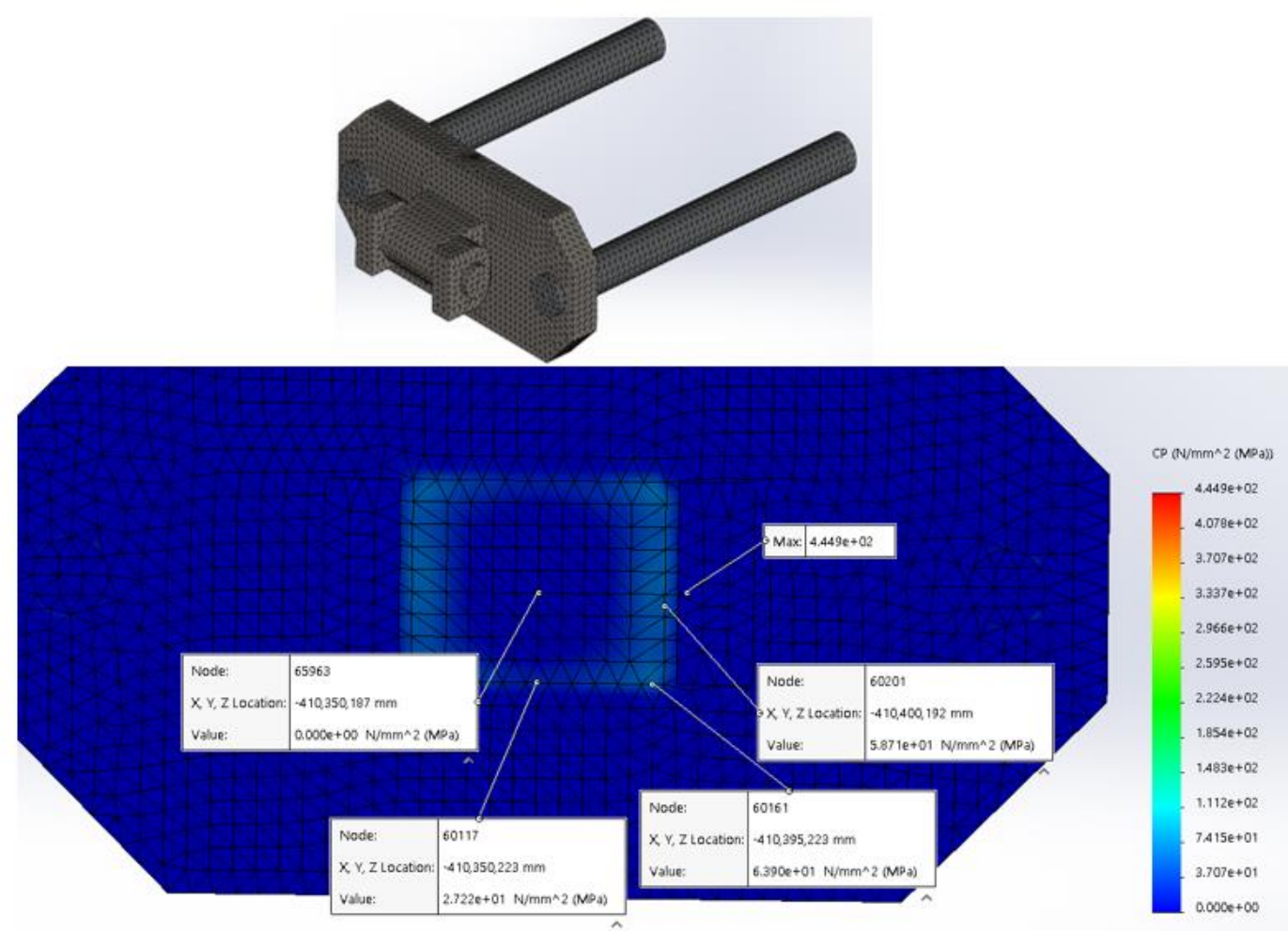

Figure 4.18 - Contact pressure obtained when a $210 \mathrm{kN}$ force is applied to the Skate, recurring to SolidWorks 2019. 
It was also made a Von Mises stress simulation, shown in Figure 4.19. This figure only shows the bearing, since it was the most critical part of the assembly, and the maximum value found was $529.8 \mathrm{MPa}$ in a single node due to the mesh size. But it was impossible to refine more the mesh since it was the highest mesh quality possible in the software. To check the integrity of the components various nodes were selected around that critical value found and the results were much lower, around $380 \mathrm{MPa}$, and lower close to $126 \mathrm{MPa}$. Since the material selected, C45 steel has a yield strength of $580 \mathrm{MPa}$, it was considered that the component would keep its integrity with the impacts.

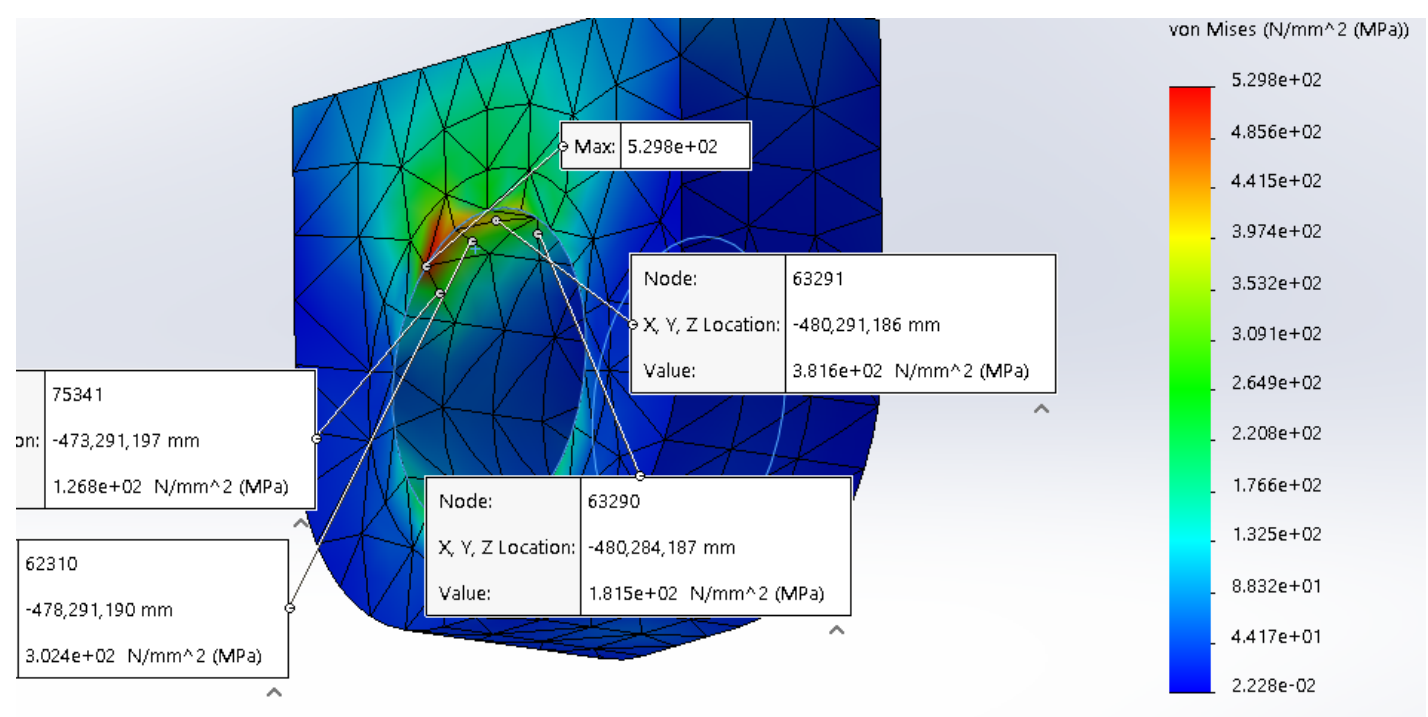

Figure 4.19 - Von Mises stress distribution obtained when a $210 \mathrm{kN}$ force is applied to the Skate structure, recurring SolidWorks 2019.

To check the deflection of the cylindrical shaft it was also made a factor of safety test, where the minimum value found was 1.1 and the red areas represent the values under a factor of safety of 2 .

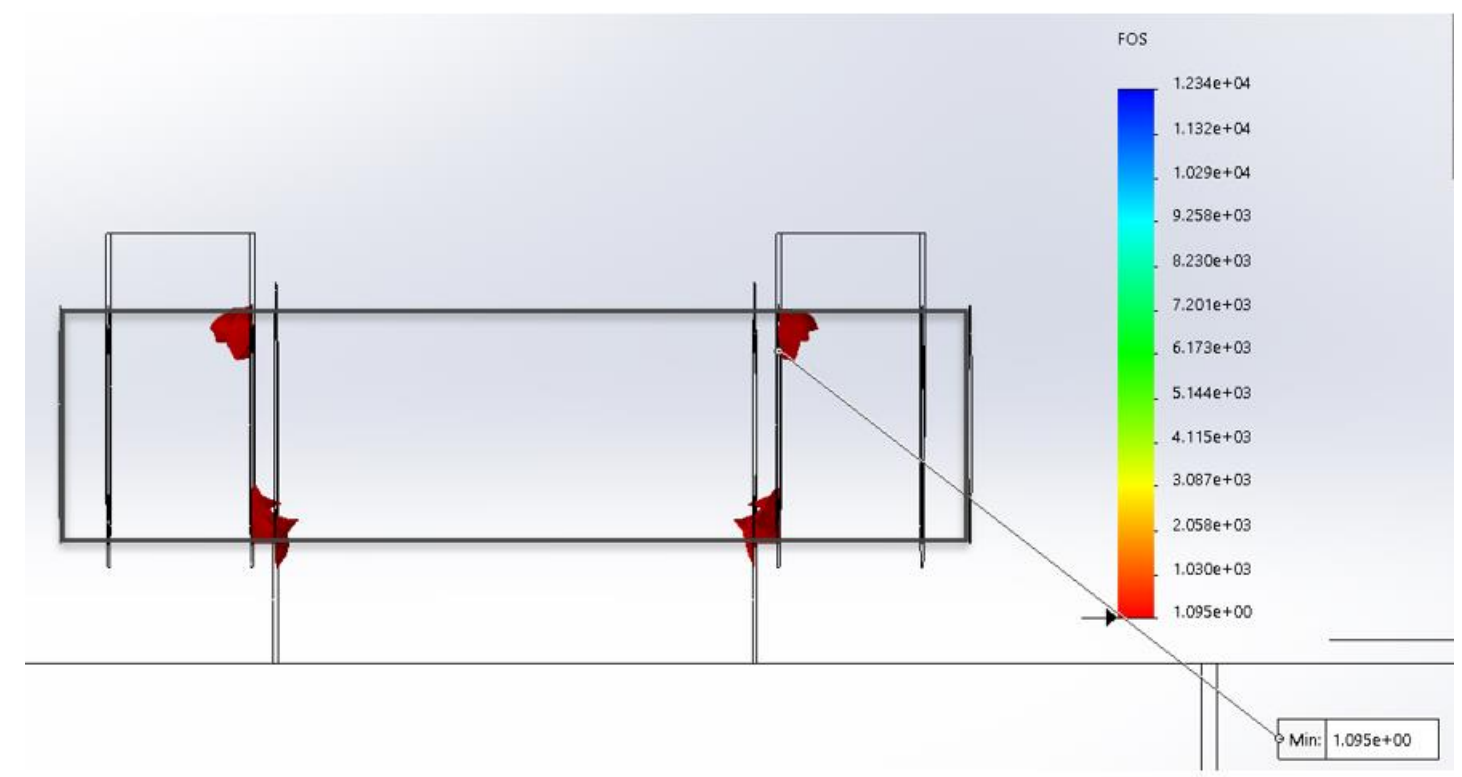

Figure 4.20 - Factor of safety distribution obtained when a $210 \mathrm{kN}$ force is applied to the Skate structure, recurring SolidWorks 2019. 
The two plain bearings used in this assembly are EGB4030-E40 from Schaeffler [33] and the most important specifications are shown in. The use of two was required since each one could only withstand $168 \mathrm{kN}$.
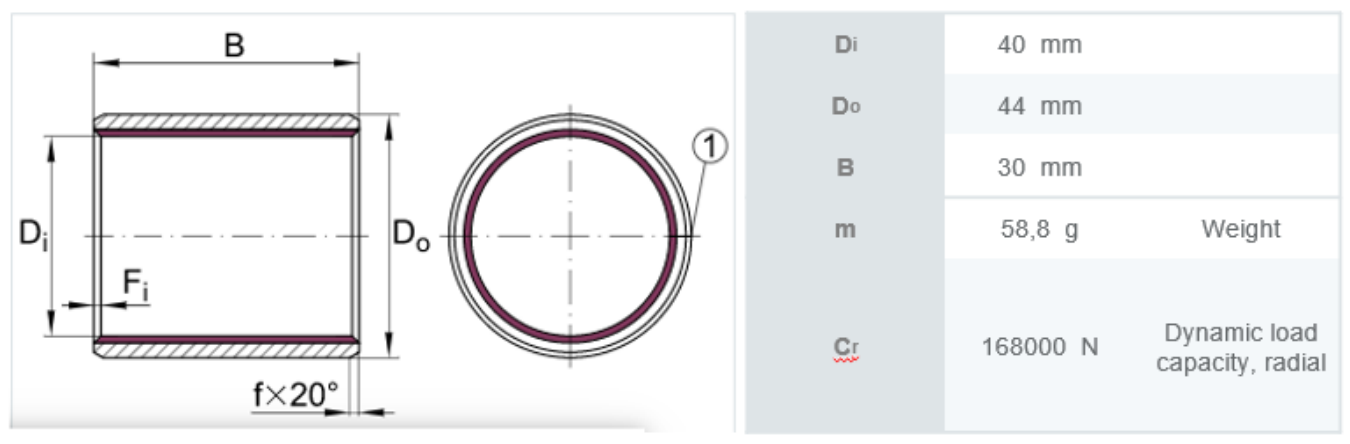

Figure 4.21 - Plain bearing EGB4030-E40 specifications [33].

To connect all the parts and assemble the skate to the transmission lever, the materials are presented in

Table 4.3.

Table 4.3 - Fasteners used to connect all parts and assemble the skate to the transmission lever.

\begin{tabular}{|c|c|c|}
\hline Element & Norm & Qt. \\
\hline Screws & ISO 4762 M8*50-8.8 & 4 \\
\cline { 2 - 3 } Circlip & DIN 471 - 38 x1.75 & 2 \\
\hline
\end{tabular}

\subsection{Spring}

There were a lot of studies to find a solution for the spring to be used. Since this system would have to withstand big load forces, around $210 \mathrm{kN}$, a very strong spring would have to be found. The solution found was to use a stack of disc springs. The final model for this assembly is shown in Figure 4.22. The assembly is composed of two S890QL (1.8983) steel plates that will hold the disc springs combination. Those will be guided by two $40 \mathrm{~mm}$ diameter heattreated H6 tubular shaft steel from Bosch Rexroth [15] with an inside diameter of $26.5 \mathrm{~mm}$. The disc springs would be aligned with an Aluminium hollow shaft that would be threaded to one of the plates and aligned with the second one by a PTFE gasket.

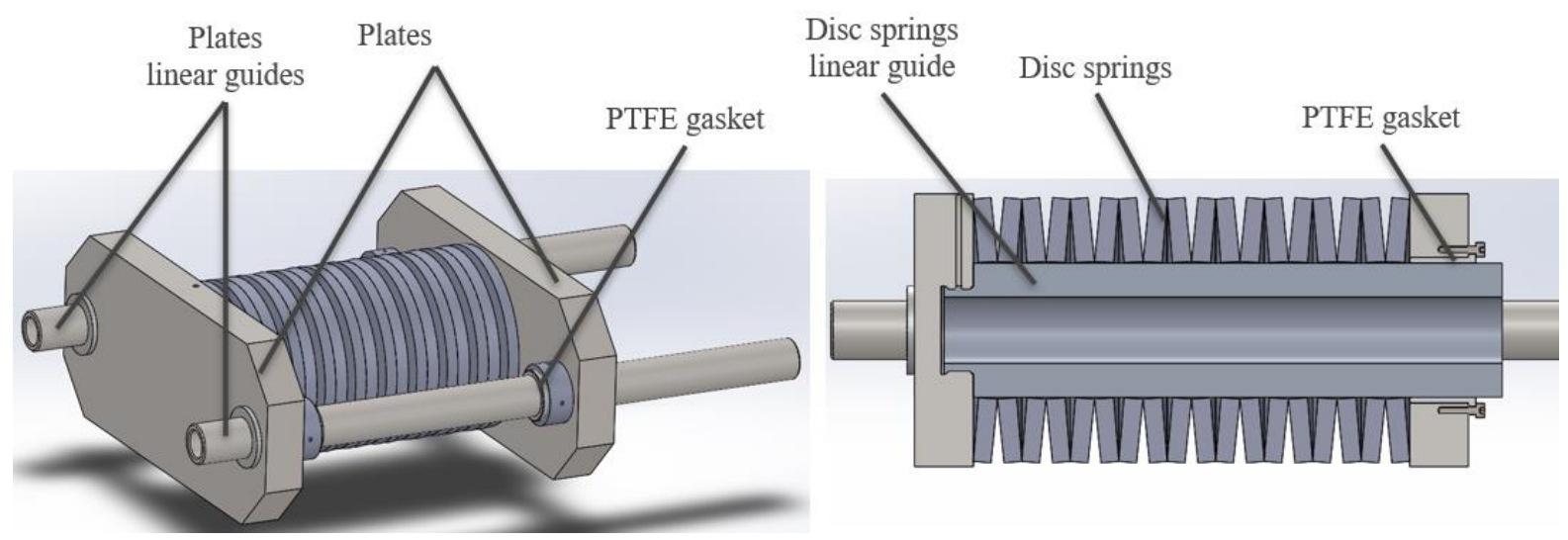

Figure 4.22 - Final model of the disc springs assembly. 
Disc springs, or Belleville springs, are well known for their versatile assemble with a relatively small size, which allows them to have a wide range of applications with the desired load conditions.

When stacked in parallel the total deflection is equal to a deflection of a single disc spring and the total load capacity equals the load capacity for each spring times the number of springs in a stack. When put in series the total deflection equals the deflection of a single disc spring times the number of springs in a stack and the total load capacity is equal to a single disc spring load capacity. When assembled in parallel-series combinations they can be designed to accommodate virtually any load or deflection and to obtain progressive or regressive characteristics [34]. These combinations can also be explained in Figure 4.23.

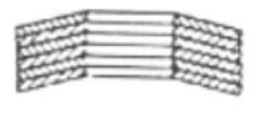

Stacked in parallel

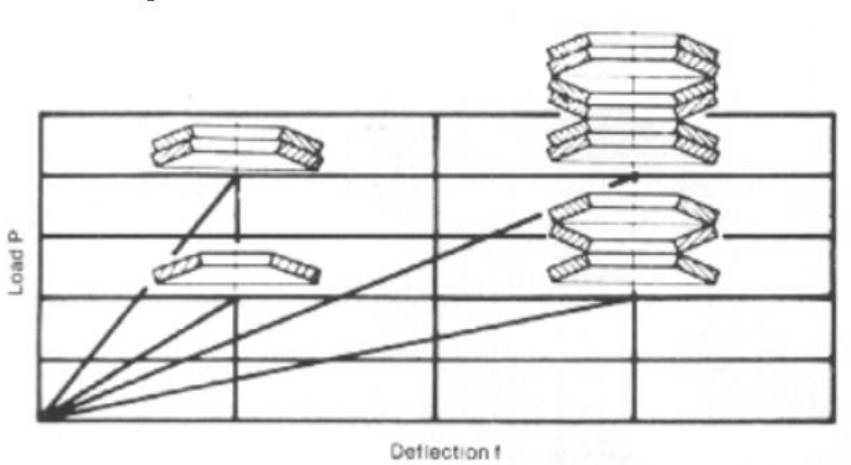

Figure 4.23 - Explanation of the disc spring's combinations.

Since these combinations can obtain progressive, regressive, or linear characteristics with the use of flats or spacers between the stacks of disc springs, the solution found was to have a linear characteristic. This means that spring load increases progressively as the deflection increases. These different characteristics are represented in Figure 4.24.

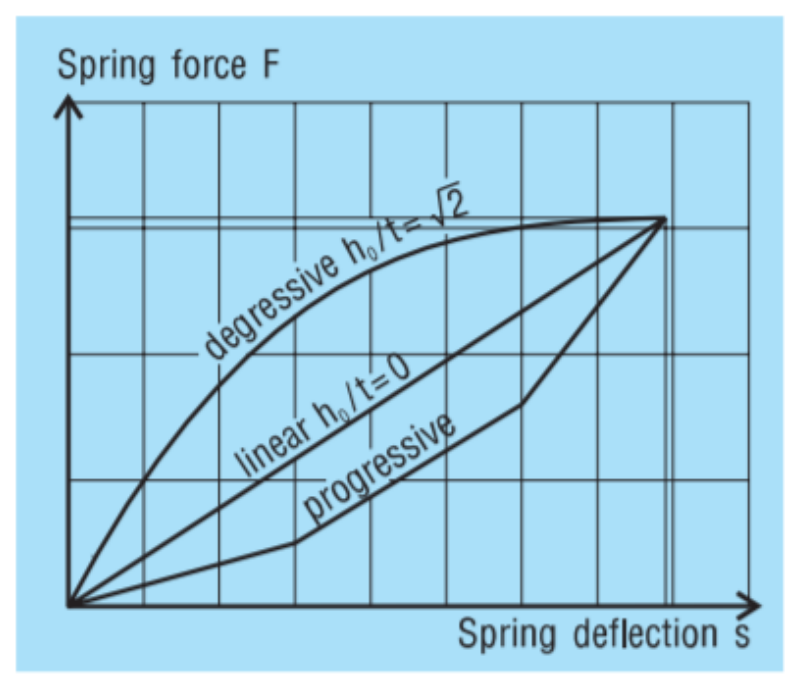

Figure 4.24 - Various types of spring characteristics [35]. 
A study was made to determine the combination of disc springs that respected the initial values obtained in the Matlab Simulink model, meaning a spring rigidity of $5000 \mathrm{kN} / \mathrm{m}$, a possible spring deflection higher than the deflection obtained in the Matlab Simulink simulation, and to withstand a load of $210 \mathrm{kN}$. After making various combinations, the solution found was to use 18 disc springs stacked in series. The disc spring 022050 from the Schnorr catalog [36]. In Figure 4.25 are represented the most important specifications of the disc spring selected.

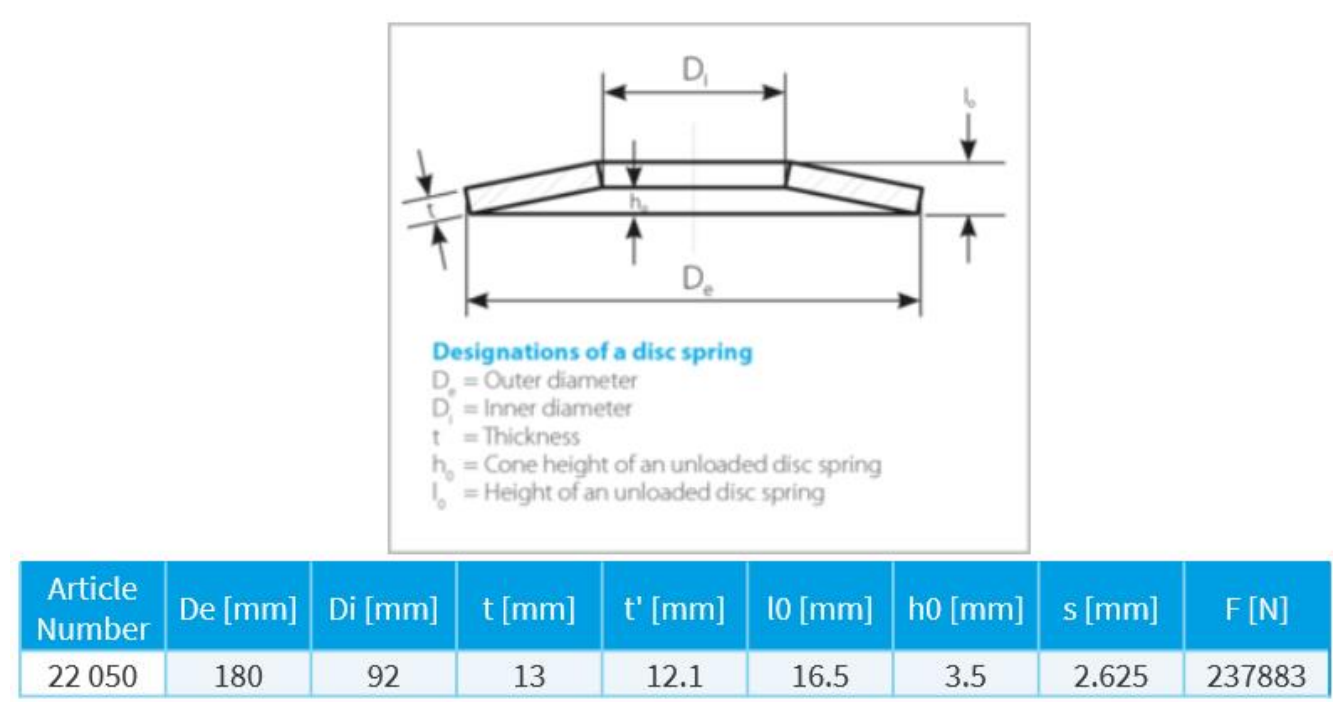

Figure 4.25 - Single disc spring specifications [36].

The dimensioning of the guiding elements of the disc springs was determined by Schnorr specifications [35] where a guide clearance of $1.0 \mathrm{~mm}$ is required since the inside diameter of the disc springs is $92 \mathrm{~mm}$, the guiding element should have a diameter of $91 \mathrm{~mm}$. The inside diameter of the hollow shaft is $50 \mathrm{~mm}$ to be implemented an M60 thread to connect with one of the steel plates that are holding the disc springs combination. The material selected for this component was Aluminium 7075-T6 to save as much weight as possible.

\subsection{Shock absorber}

The values introduced in the Matlab Simulink model for the shock absorber component resulted in a previous selection of an industrial shock absorber from ACE [32]. The manufacturer informs that the force of this component is constant along the whole stroke, as it may be seen in Figure 4.4. The solution consists of the use of two heavy industrial shock absorbers ACE A2X6EU, presented in Figure 4.26, but with a different type of mounting. 


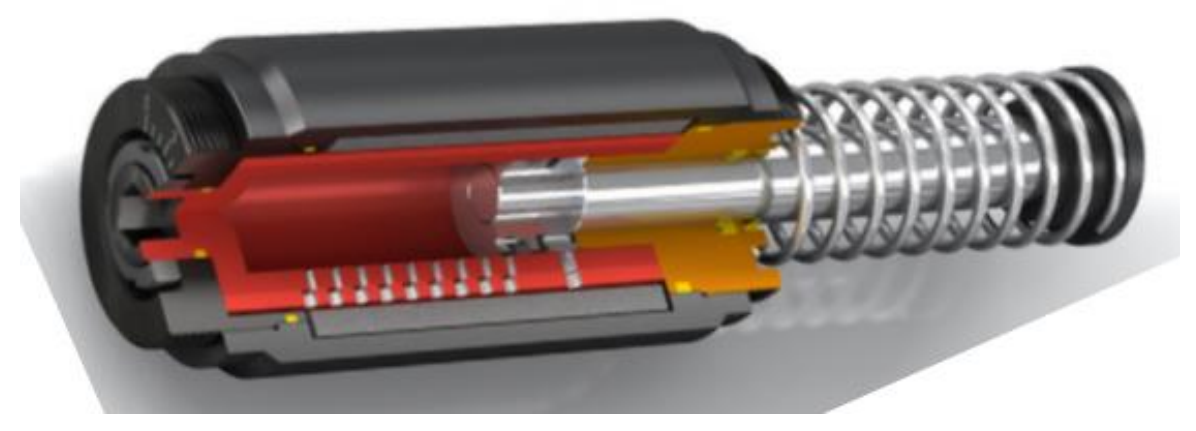

Figure 4.26 - ACE A2X6EU [32].

After selecting the industrial shock absorber, it was decided to use a front flange mounting to implement with the spring's assembly. The most important specifications of the industrial shock absorber are presented in Figure 4.27.

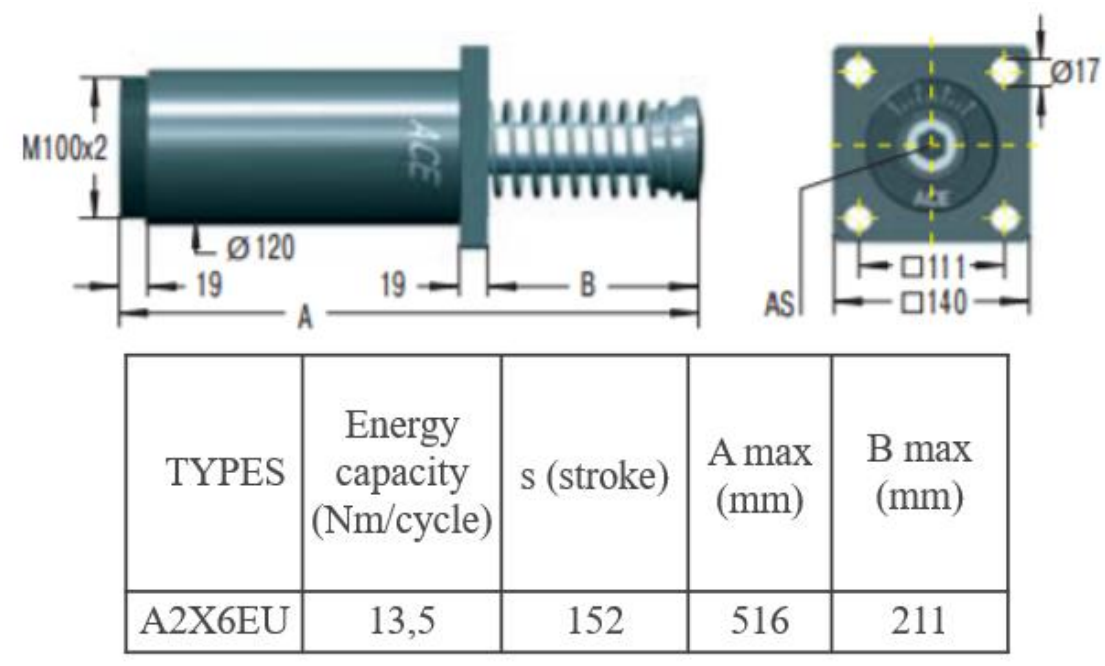

Figure 4.27 - Heavy industrial shock absorber, ACE A2X6EU, specifications [32].

Since the transmission lever, the skate, the disc springs combinations were completely defined, and the two industrial shock absorbers selected, it was required to design a structure that could hold all these components in a single structure. Thus, being able to rotate this structure to work in one way for the tensile tests and then rotate this structure to be able to do the compression testing. The final model of this structure that would hold these mentioned components is shown in Figure 4.28. 


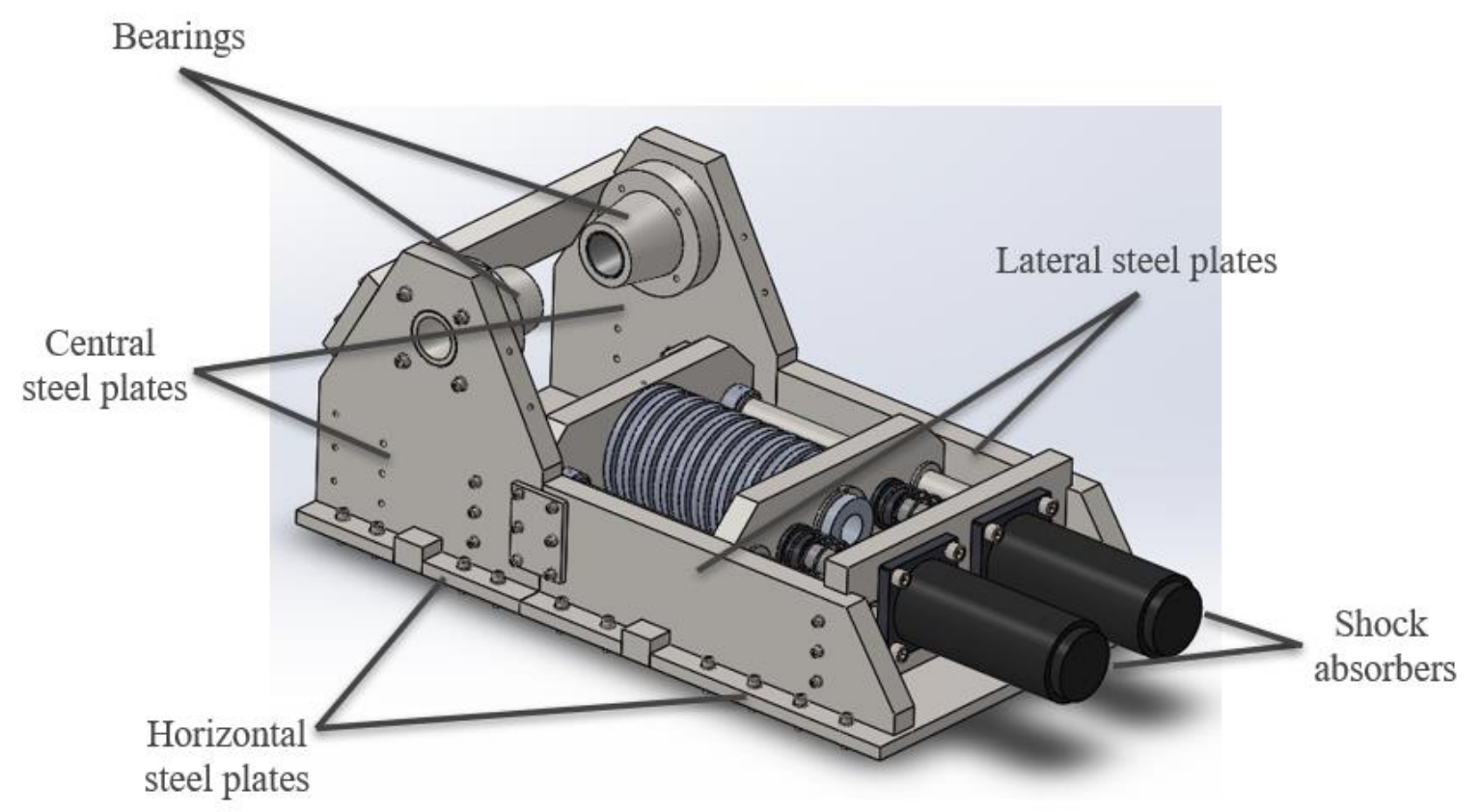

Figure 4.28 - Final structure to hold the transmission lever, the skate, disc springs combination and the two shock absorbers, recurring SolidWorks 2019

To simplify the designing of the steel plates that compose this structure it was decided to have two different structures that would be attached with the help of fasteners and reinforcement plates that would be screwed to hold both structures.

One structure is composed of one horizontal steel plate and two central lateral steel plates, with two bearing supports, made of $18 \mathrm{CrNiMo} 7-6$ steel with a plain bearing inside, that would hold the axle for the transmission lever. The other structure is composed of one horizontal steel plate, two lateral steel plates, two blocks that will support the linear guides from the disc springs assembly, and a steel plate that will support the two front foot mounted industrial shock absorbers.

These two structures will be held together with two lateral steel plates that will be screwed to both of lateral plates from each side and the blocks that hold the linear guides from (b) structure are going to be screwed to the central lateral plates from (a) structure, shown in Figure 4.29. All the steel components from this assembly were designed with S890QL (1.8983) steel. 


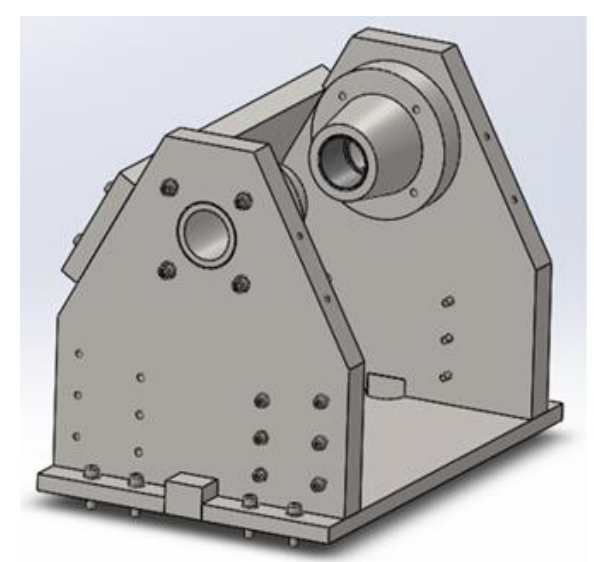

(a) Structure to hold the transmission lever

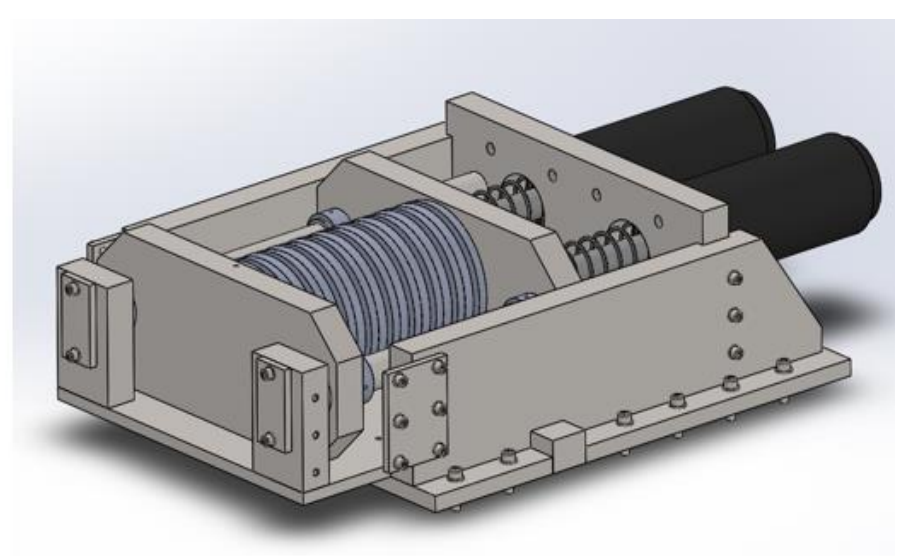

(b) Structure to hold the disc springs and shock absorbers

Figure 4.29 - Structures to hold the transmission lever and the disc springs with shock absorbers.

To dissipate the energy provided by the rod's actuator, the central lateral steel plates would have to transmit the forces to the horizontal plate. The solution found was to use a square key screwed to the central plate from the bottom that would transmit the $210 \mathrm{kN}$ to the horizontal steel plate.

To dimension the square key, it was used SolidWorks 2019, to study the stress distribution on the key to check if the component would keep its integrity during the loads. Figure 4.30 shows the Von Mises stress distribution and the maximum value obtained in the simulation was $471 \mathrm{MPa}$ in the contact point between the horizontal and central lateral plates. All the other values were way under $170 \mathrm{MPa}$. The square key has a surface area of contact of $1520 \mathrm{~mm}^{2}$. The material used for simulation was C60 steel, which has a yield strength of 660 $\mathrm{N} / \mathrm{mm}^{2}$. But in reality, the material selected for the building of this component will be an S890QL (1.8983) steel which has a yield strength higher than C60, because it was only able to find C60 material for plates under $10 \mathrm{~mm}$ of thickness. 


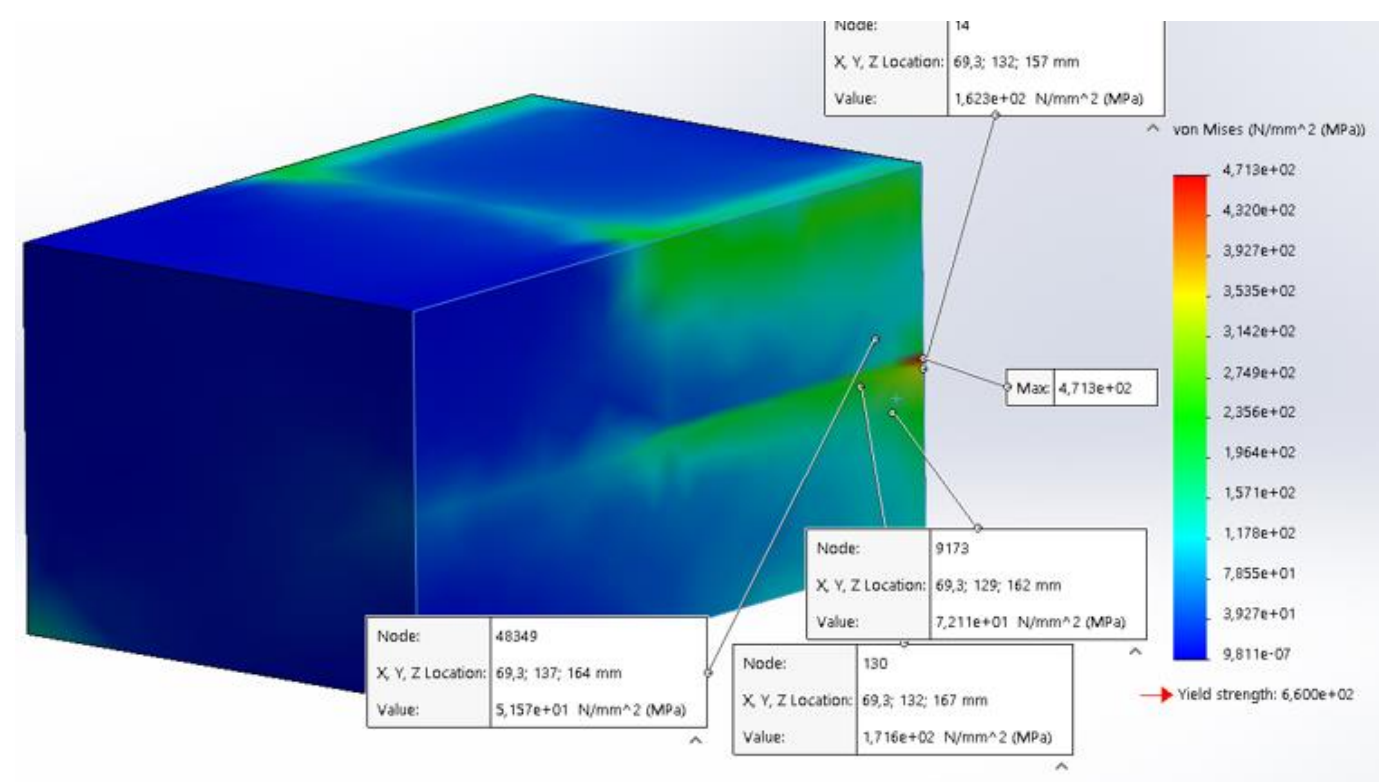

(a) Amplified view of the square key

Figure 4.30 - Von Mises stress distribution obtained when a $210 \mathrm{k} N$ force is applied to the central plate, recurring SolidWorks 2019.

It was also made a displacement distribution analysis to understand the deformation of the key under the loads, as can be seen in Figure 4.31. The maximum value obtained was 0.057 mm which shows that the component will be able to withstand the loads.

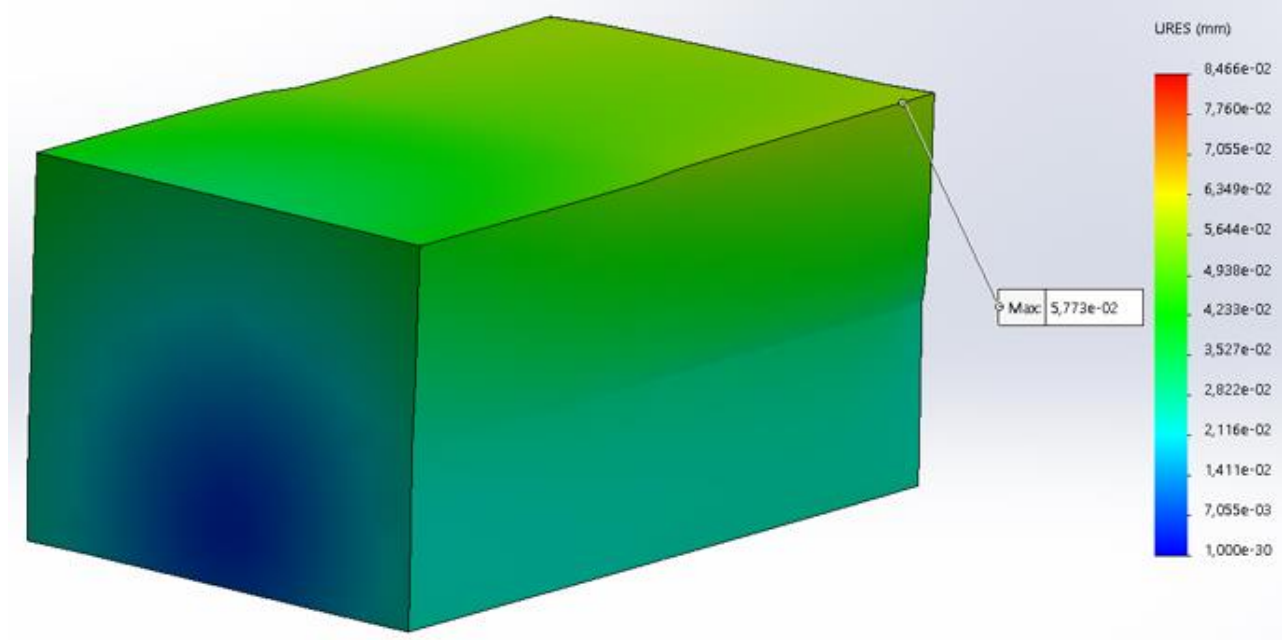

(a) Amplified view of the square key

Figure 4.31 - URES displacement distribution obtained when a $210 \mathrm{kN}$ force is applied to the central plate, recurring SolidWorks 2019.

The same square key was used for the lateral plates that hold the disc springs and the shock absorber, since the loads are the same, the same square key can be used in each one of those lateral plates to transmit the forces to the horizontal steel plate. 
A grove had to be made on the lateral steel plates to fix the steel plate that is holding the two shock absorbers. To determine the groove area, an identical calculation to the one done for the area of the skate was performed. The goal was to have a surface tension under $70 \mathrm{MPa}$. The solution found was to have a groove area with $3200 \mathrm{~mm}^{2}$, granting a surface tension of 65.6 MPa.

$$
\begin{gathered}
\text { Surface tension }(\mathrm{MPa})=\frac{\operatorname{Load}(\mathrm{N})}{\operatorname{Area}\left(\mathrm{mm}^{2}\right)} \\
=\frac{210000}{3200}=65.6 \mathrm{MPa}
\end{gathered}
$$

This means that each lateral plate can have half of the groove area. Each lateral plate was designed with a grove with $1600 \mathrm{~mm}^{2}$ in order the forces produced by the shock absorbers could be transmitted to the lateral steel plates. The groove can be seen in Figure 4.32.

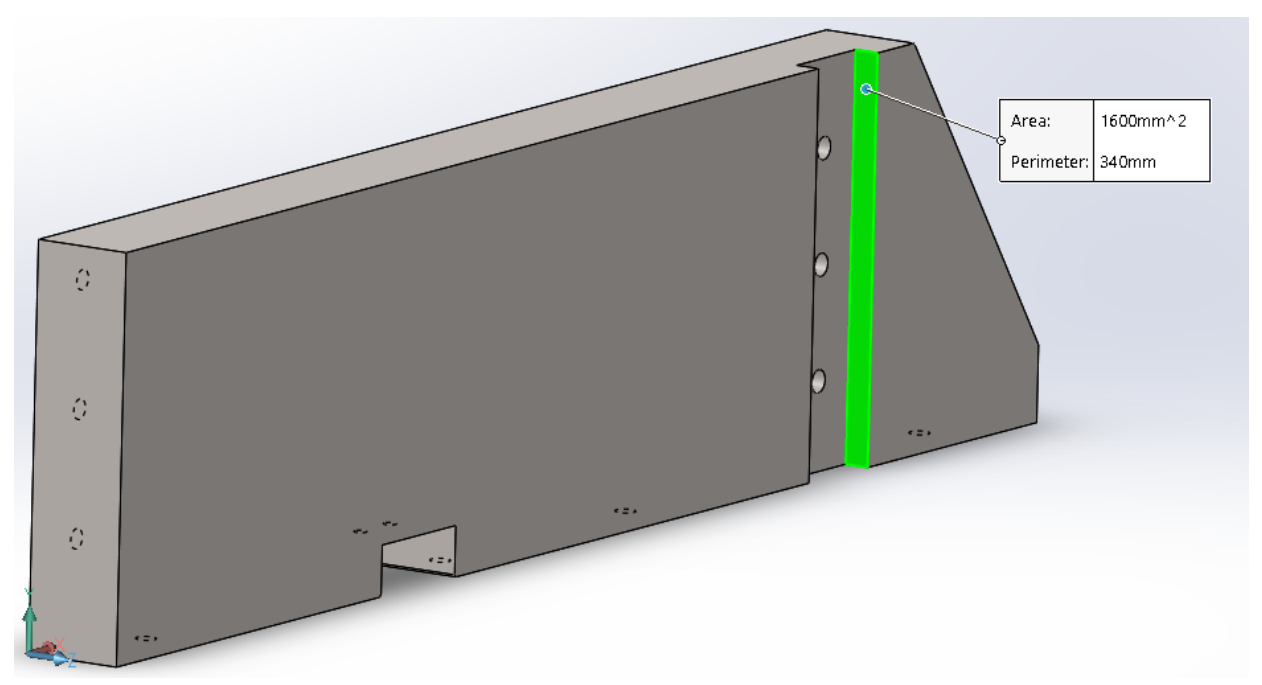

Figure 4.32 - Lateral steel plate with the groove.

The horizontal plate had also a groove made because the (b) structure had another smaller horizontal plate that was screwed to the main one and its function was to support the two blocks that are holding the linear guides of the disc spring assembly, represented in Figure 4.33. The flat key used in this case has a surface area of contact of $4400 \mathrm{~mm}^{2}$ which means that the surface tension is around 47.7 $\mathrm{MPa}$. 


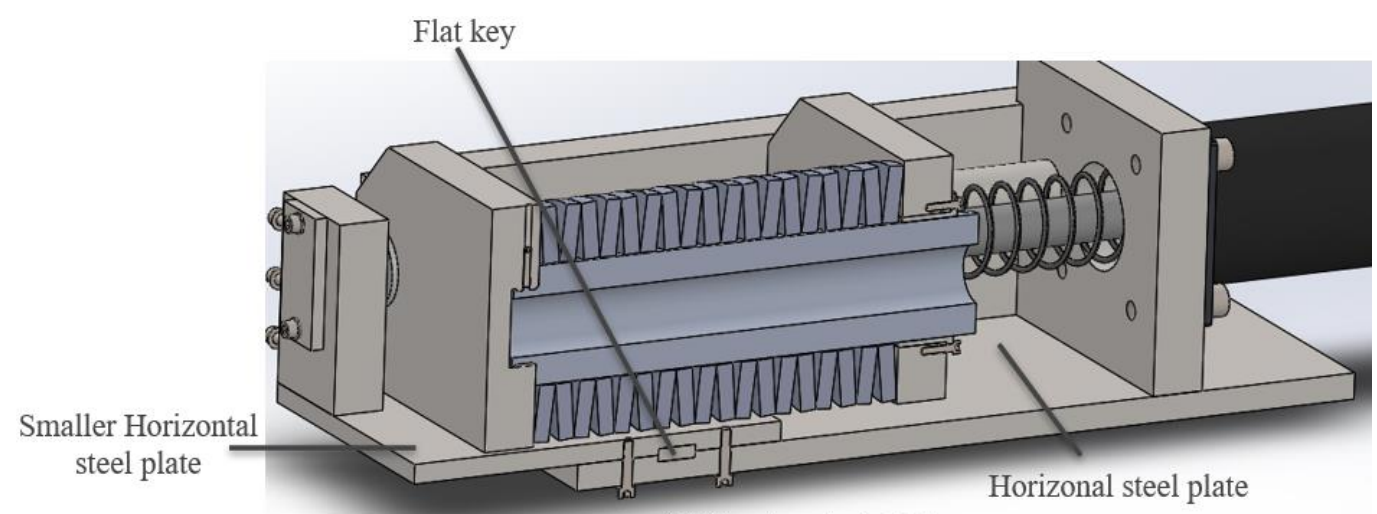

(b) Structure to hold the

disc springs and shock absorbers

Figure 4.33 - Halfway cut view of the (b) structure.

To hold the axle of the transmission lever, the lateral central steel plates had to have a bearing that could withstand the $210 \mathrm{kN}$, and to allow the rotation of it the bearings made of $18 \mathrm{CrNiMo} 7-6$ steel had a plain bearing inside. There is a circlip on each side of the bearings to block the transmission lever's axle to slide out of the bearings. This is shown in Figure 4.34.
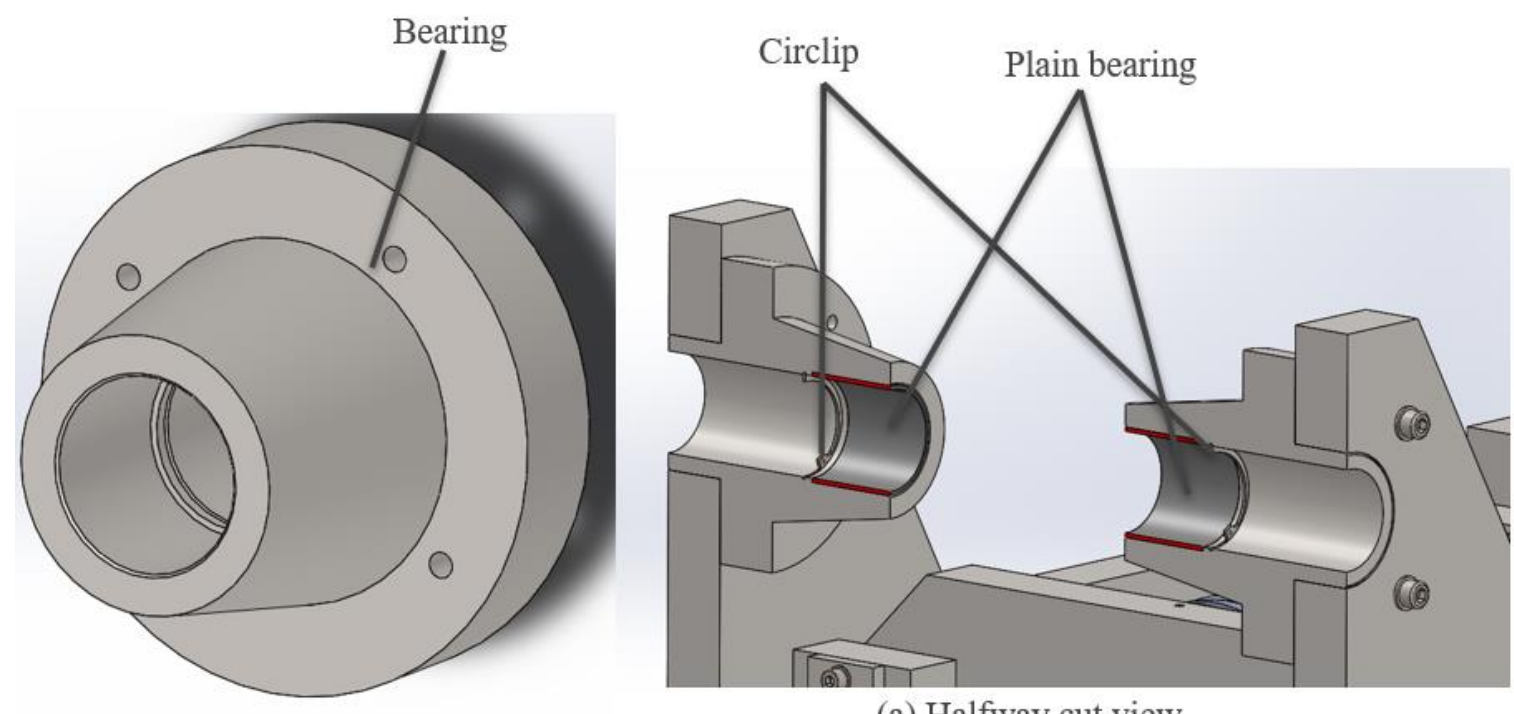

(a) Halfway cut view

Figure 4.34 - Bearing to support the transmission lever.

The two plain bearings utilized in this assemble are from SKF [37] and their most important specifications are shown in Table 4.4 
Table 4.4 - Plain bearing specifications, PCM 606560 M [37].

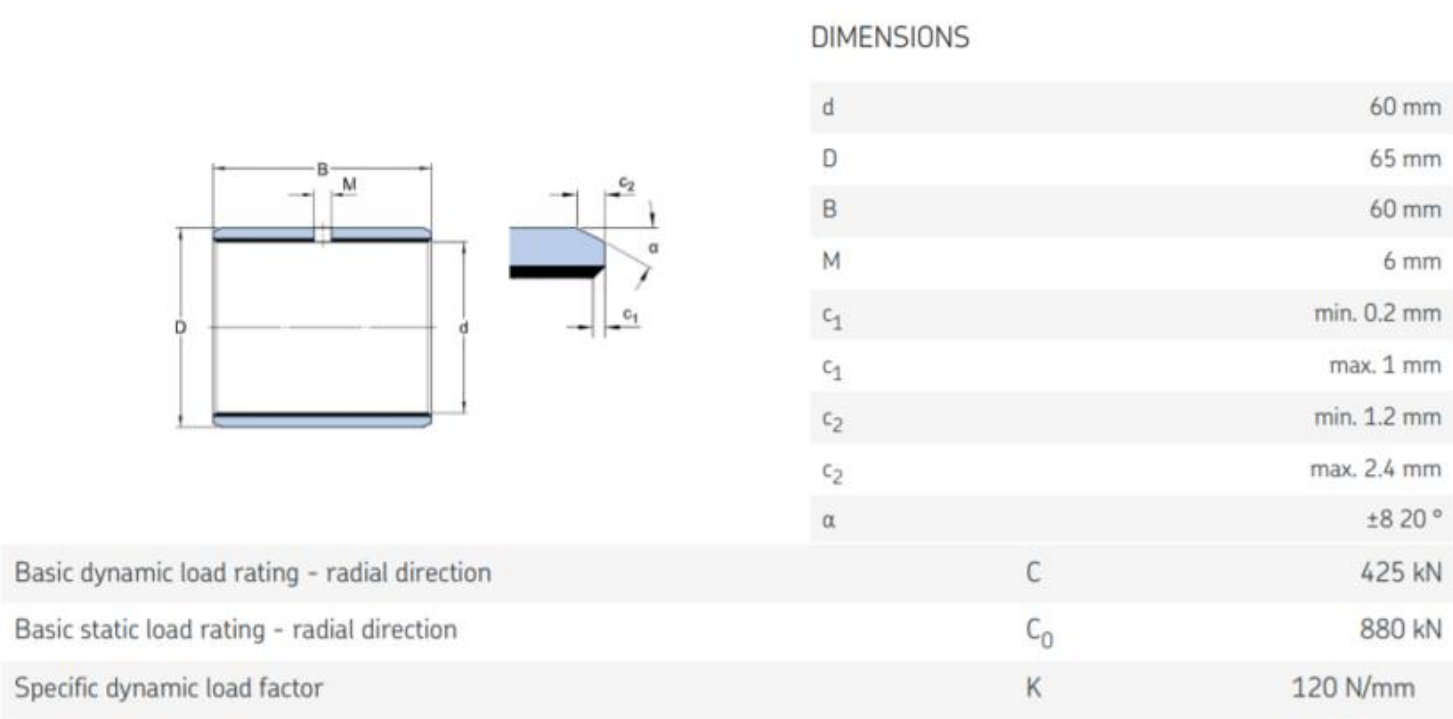

The final look of the model of the structure that holds the transmission lever, the skate, the disc springs combination and the industrial shock absorbers is shown in Figure 4.35. All the mechanical parts drawings can be seen in Appendix C. To connect this structure to the support frame there were used 20 - ISO $4762 \mathrm{M} 10 \times 40$ - 8.8. This structure can be rotated and positioned correctly, to work for tensile and for compression tests, to stop the actuator's rod movement

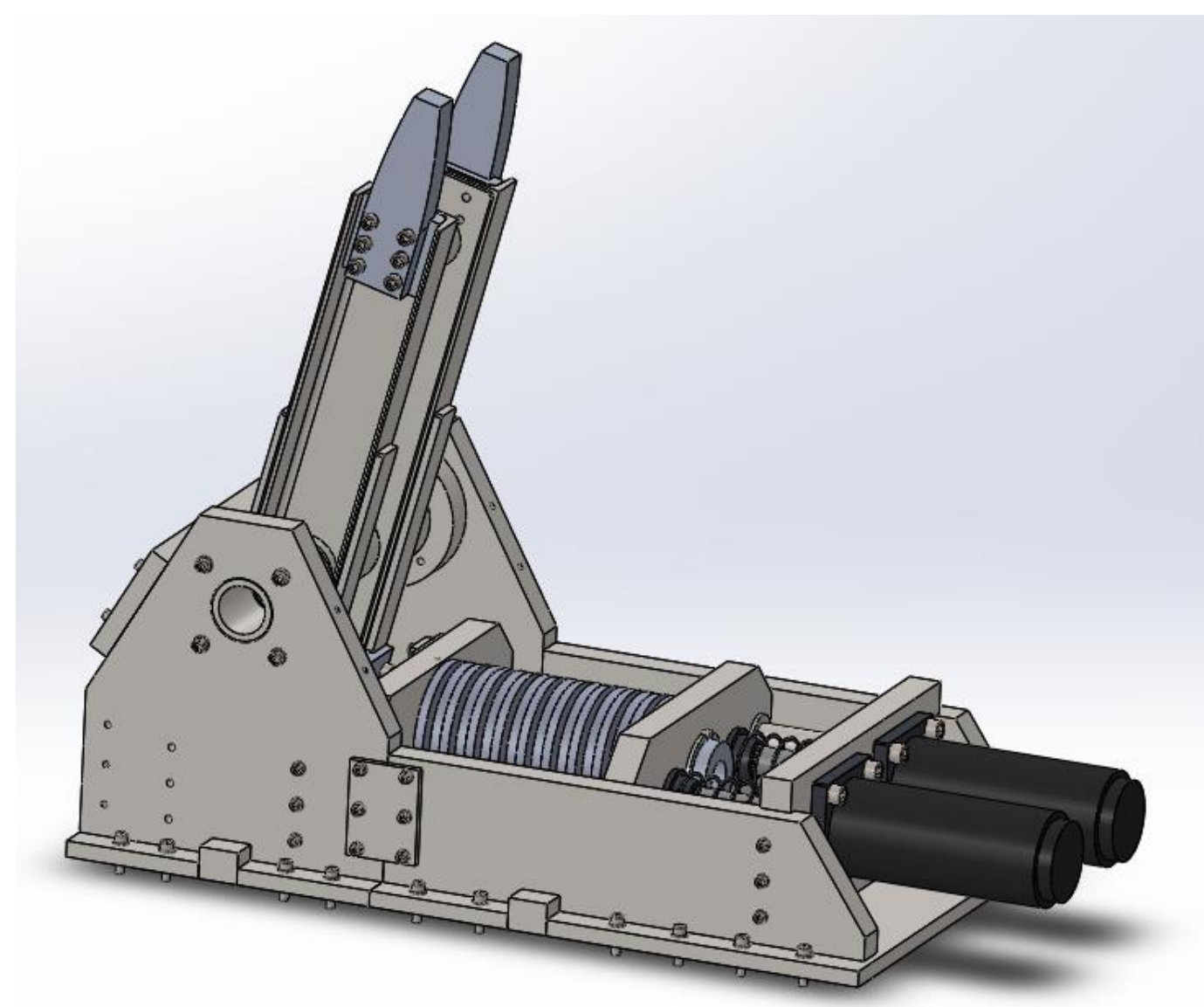

Figure 4.35 - Final model of the structure that holds the transmission lever, the skate, the disc springs combination and the industrial shock absorbers. 
The materials used to connect all the parts of this structure are presented in Table 4.5.

Table 4.5 - Fasteners used to assemble the structure.

\begin{tabular}{|c|c|c|}
\hline Element & Norm & Qt. \\
\hline \multirow{5}{*}{} & ISO 4762 M6x25-8.8 & 2 \\
\cline { 2 - 3 } & ISO 4762 M16x50-8.8 & 8 \\
\cline { 2 - 3 } & DIN 7984 M6x25-8.8 & 4 \\
\cline { 2 - 3 } & DIN 7984 M8x30-8.8 & 16 \\
\cline { 2 - 3 } & ISO 4762 M10x65-8.8 & 8 \\
\cline { 2 - 3 } & ISO 4762 M8x30-8.8 & 4 \\
\cline { 2 - 3 } & ISO 4762 M10x40-8.8 & 20 \\
\cline { 2 - 3 } & ISO 4762 M8x35-8.8 & 6 \\
\cline { 2 - 3 } & ISO 4029 M6x30-8.8 & 1 \\
\cline { 2 - 3 } & ISO 4762 M5x30-8.8 & 8 \\
\cline { 2 - 3 } & ISO 4762 M5x40 - 8.8 & 4 \\
\cline { 2 - 3 } & ISO 4762 M8x45-8.8 & 6 \\
\cline { 2 - 3 } & ISO 4762 M8x25-8.8 & 12 \\
\cline { 2 - 3 } & ISO 4762 M8x55-8.8 & 6 \\
\hline Washers & DIN 125 - A 10.5 300 HV & 28 \\
\hline & DIN 125 - A 8.4 & 38 \\
\hline Circlip & DIN 472 - 60 x2 & 2 \\
\hline
\end{tabular}

\subsection{Stopping car}

The stopping car is the component that will transmit the force produced from the actuator rod's movement to the transmission lever. The solution found can be seen in Figure 4.36, where it is composed of two aluminium 6063-T6 blocks that are held together with a horizontal plate made of aluminium 6063-T6. These blocks are supported by 4 guiding smaller blocks, each one with 3 ball bearings. The ball bearings will provide the alignment and the guidance over the two heat-treated H6 tubular shaft steel from Bosch Rexroth [15] with an inside diameter of $26.5 \mathrm{~mm}$ and $40 \mathrm{~mm}$ of the outside diameter. The linear guides will be supported by blocks made of aluminium 6063-T6 where two of them will be screwed to the plate that is holding the pneumatic actuator and the other two to a single horizontal plate made of the same aluminium.

The blocks that will receive the impact of the actuator's rod have 4 thin rolling plates made of 18CrNiMo7-6 steel to allow a better slippage with the transmission lever. All the mechanical parts drawings are presented in Appendix D. 


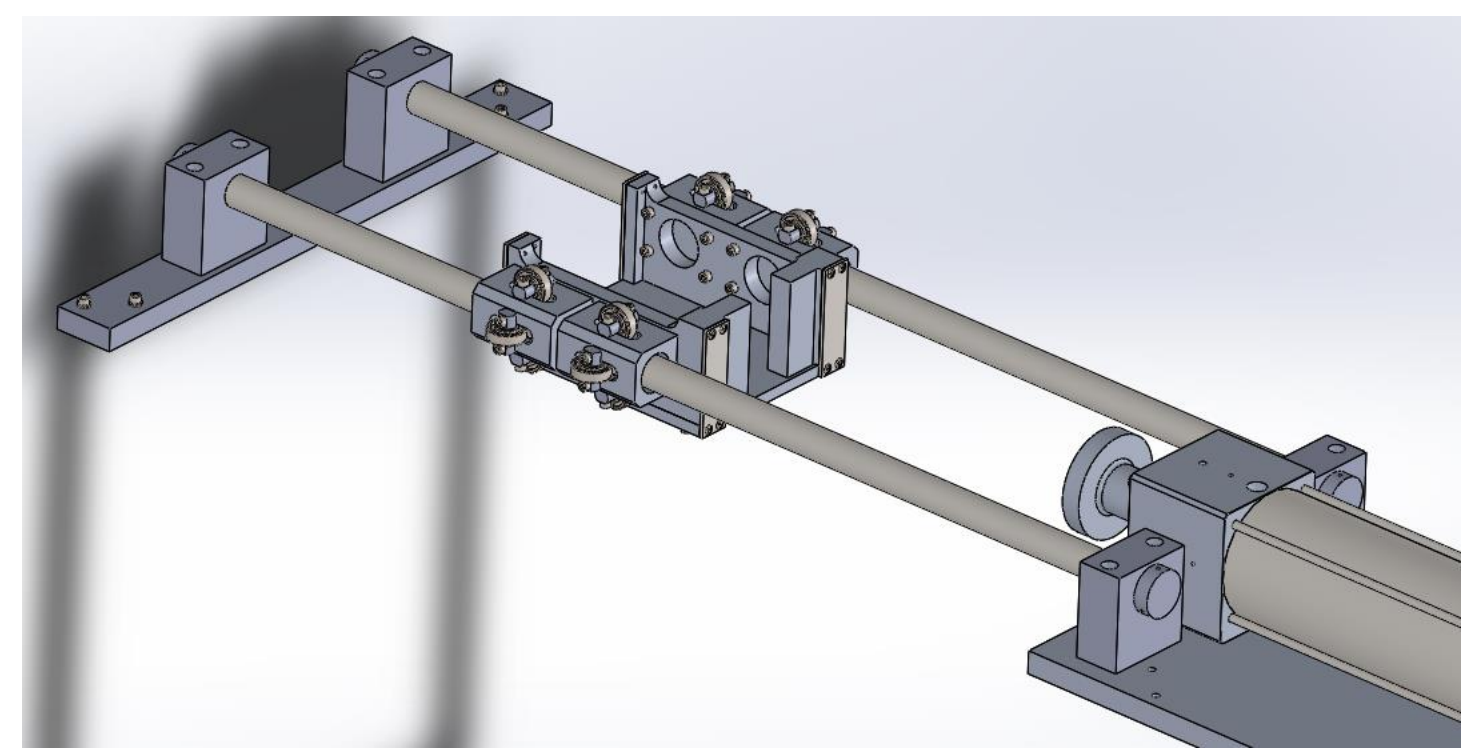

Figure 4.36 - Final model of the Stopping car assembly.

The actuator's rod has a flange that will be screwed with M39 on the end of the rod to that will impact the stopping car. This component can be seen in Figure 4.37 and it is made of aluminium 7075-T6. The flange has an outside diameter of $130 \mathrm{~mm}$, thus having a contact area of $4634 \mathrm{~mm}^{2}$ with the stopping car. Since the force on the bottom part of the transmission lever was around $210 \mathrm{kN}$ has been mentioned before, and the transmission lever has a ratio of 3:1, The force on the top part is 3 times less. Therefore, the force obtained in the transmission lever is around $70 \mathrm{kN}$ and represents the reaction force in the stopping car produced by the actuator's rod. Dividing that force by the contact area gives a surface tension of $15.1 \mathrm{MPa}$.

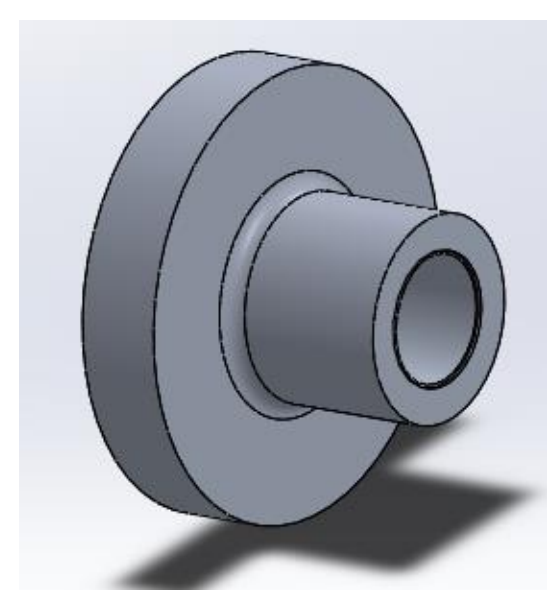

Figure 4.37 - Actuator's rod flange.

The stopping car had to have the ability to receive the impact from the actuator's rod during a tensile test, but also to have construction to allow the rod to travel inside the stopping car and move in the other direction when compression testing would be needed. This way the flange would hit the stopping car from the inside part. The two different relative positions of the stopping car relative to the actuator's rod can be seen in Figure 4.38. 


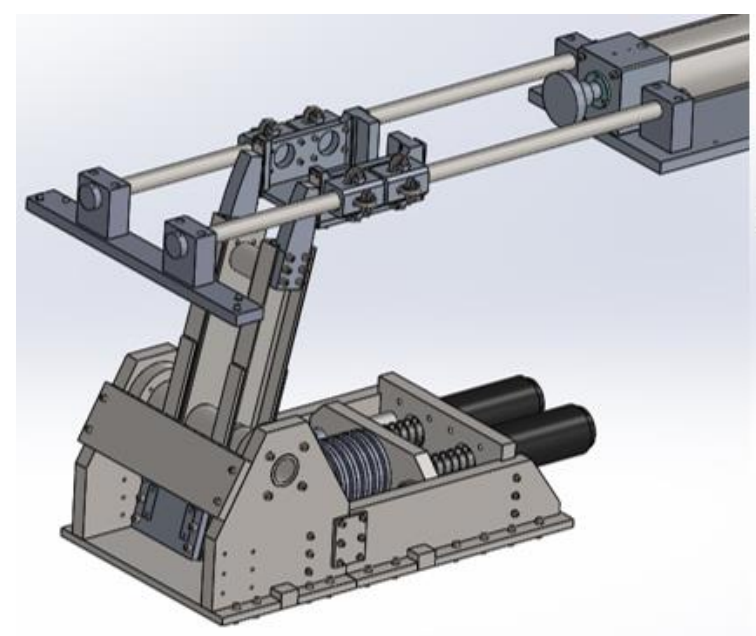

(a) Tensile test.

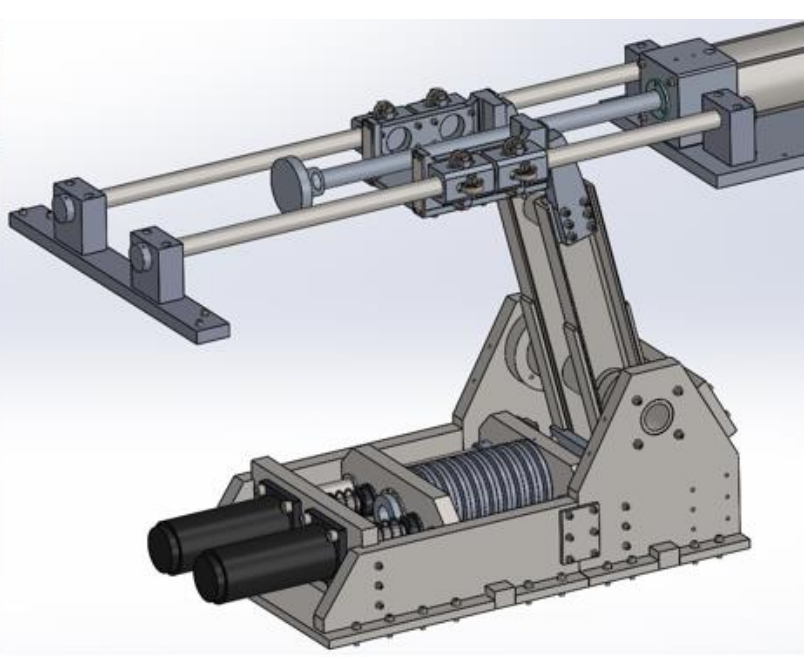

(b) Compression test.

Figure 4.38 - Stopping car position in tensile test and compression test.

As mentioned before the stopping car is being guided by 4 guiding elements where each one contains 3 ball bearings that will roll on the linear guides. These guiding elements are shown in Figure 4.39. The ball bearings are DIN 625 - 6204 with an inside diameter of $20 \mathrm{~mm}$ and $47 \mathrm{~mm}$ of the outside diameter.

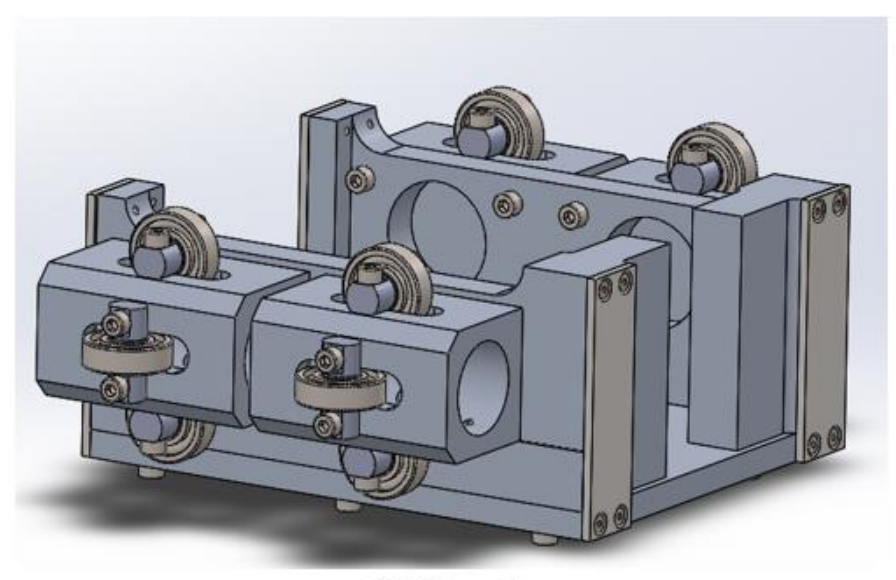

(a) Stopping car.

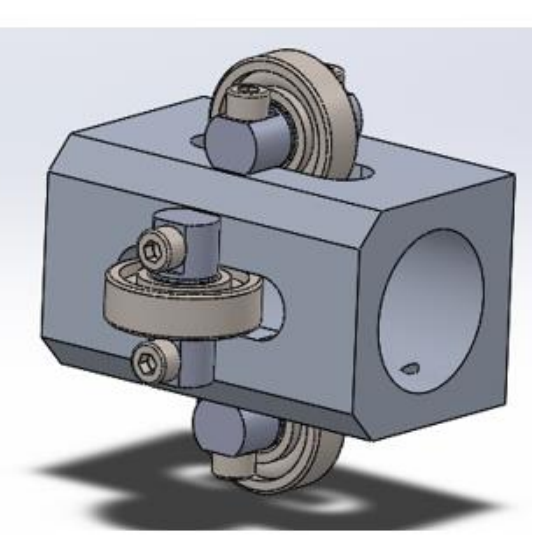

(b) Guiding element.

Figure 4.39 - Stopping car guiding elements.

To dimension the stopping car, a study was made to see how the assembly would behave under the loads. To study this situation it was made a simulation in SolidWorks 2019 applying a $70 \mathrm{kN}$ force in the front face of the stopping car. To obtain the reaction forces it was used the same technique adopted for the simulation of the transmission lever. To simulate the slippage of the stopping car with the transmission lever it was used a cylindrical shaft made of AISI 4340 steel. The results for the Von Mises stress distribution are represented in Figure 4.40. The maximum value obtained was $149.4 \mathrm{MPa}$ and the aluminium selected has a yield strength of $215 \mathrm{MPa}$. 


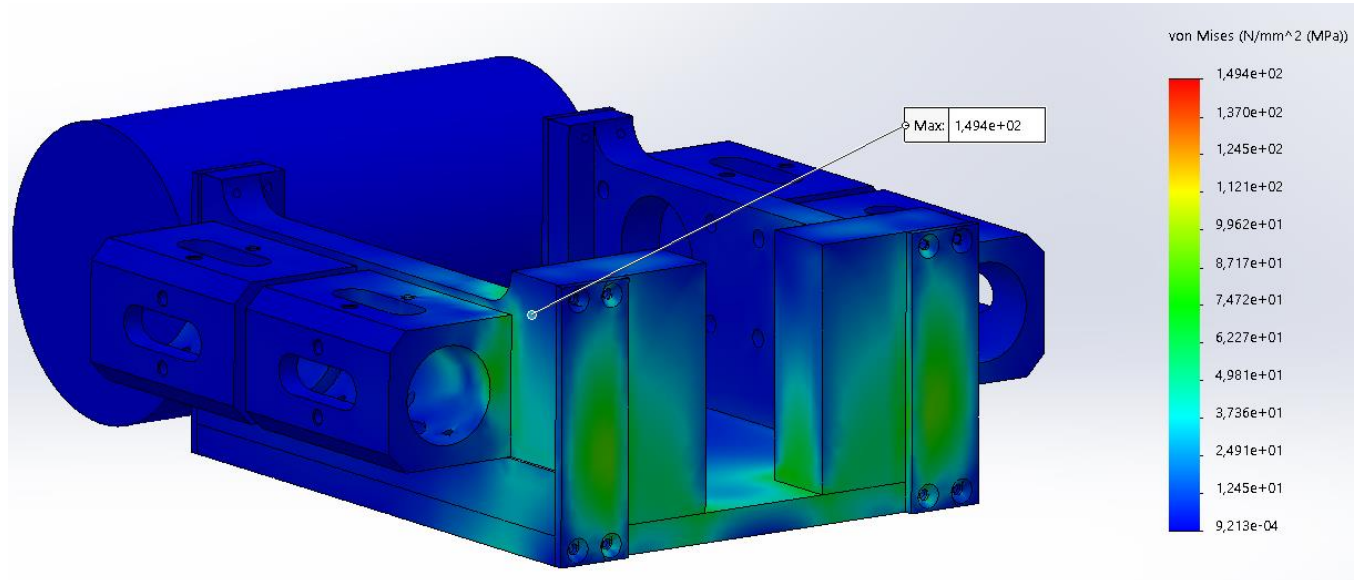

Figure 4.40 - Von Mises stress distribution obtained when a $70 \mathrm{kN}$ force is applied to the stopping car, recurring SolidWorks 2019.

A displacement simulation was also possible to obtain, and the results are shown in Figure 4.41, where the maximum value was $0.35 \mathrm{~mm}$.

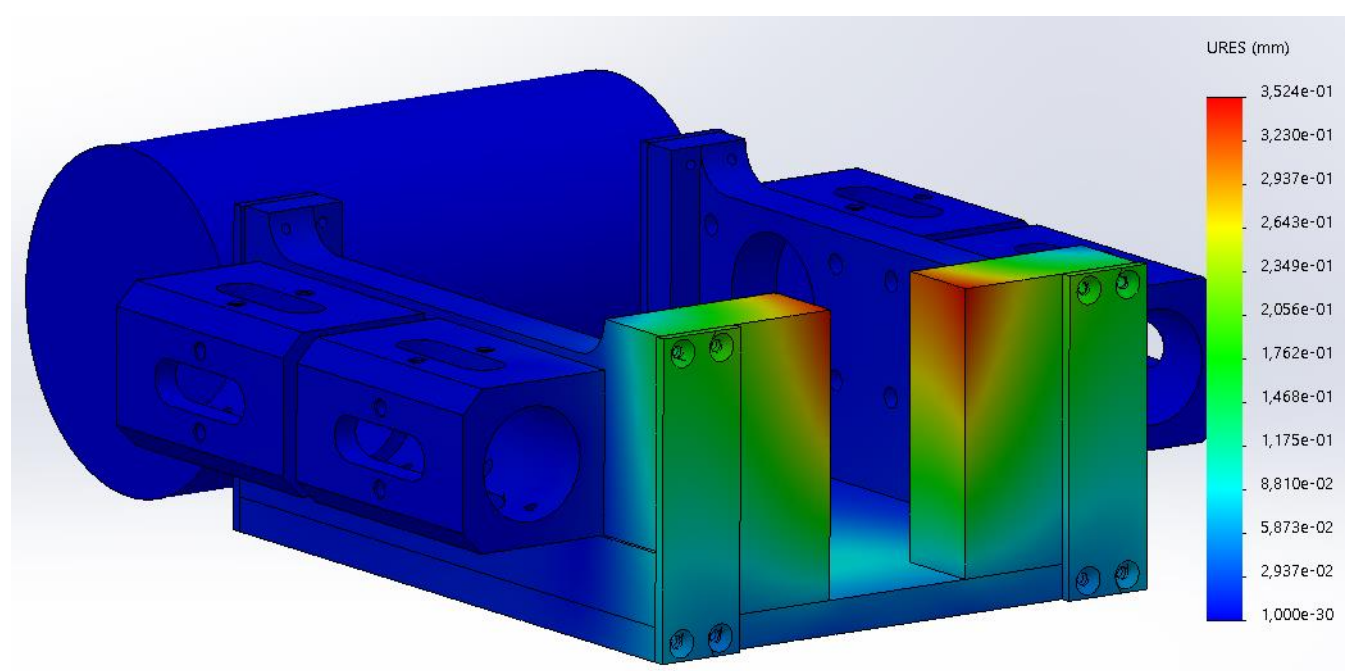

Figure 4.41 - Displacement distribution obtained when a $70 \mathrm{kN}$ force is applied to the stopping car, recurring SolidWorks 2019.

A factor of safety test was also made, where the minimum value found was a factor of 1.44 , ensuring that the materials will keep their integrity with the impacts. 


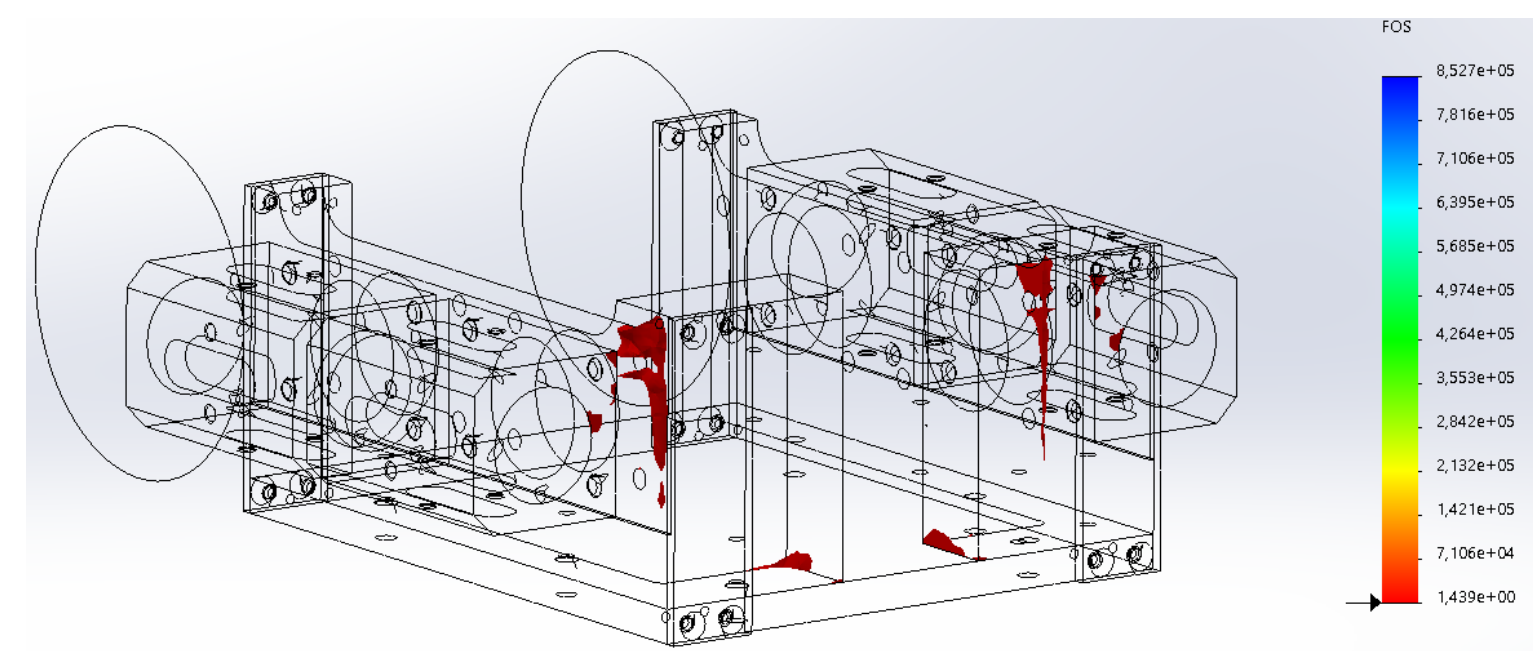

Figure 4.42 - Factor of safety distribution obtained when a $70 \mathrm{kN}$ force is applied to the stopping car, recurring SolidWorks 2019.

The linear guides, as mentioned before, are made of a heat-treated H6 tubular shaft steel from Bosch Rexroth [15] with $40 \mathrm{~mm}$ of outside diameter. They will be held by four blocks made of aluminium 6063-T6, two of them will be screwed to the horizontal plate which supports the pneumatic actuator and the other two will be screwed to a horizontal plate made of Ck45 steel. These blocks also contain a Ck45 component with a flange that will screw to the inside of the linear guides with M33, which will pull the linear guides to the aluminium blocks. This construction can be seen in Figure 4.43.

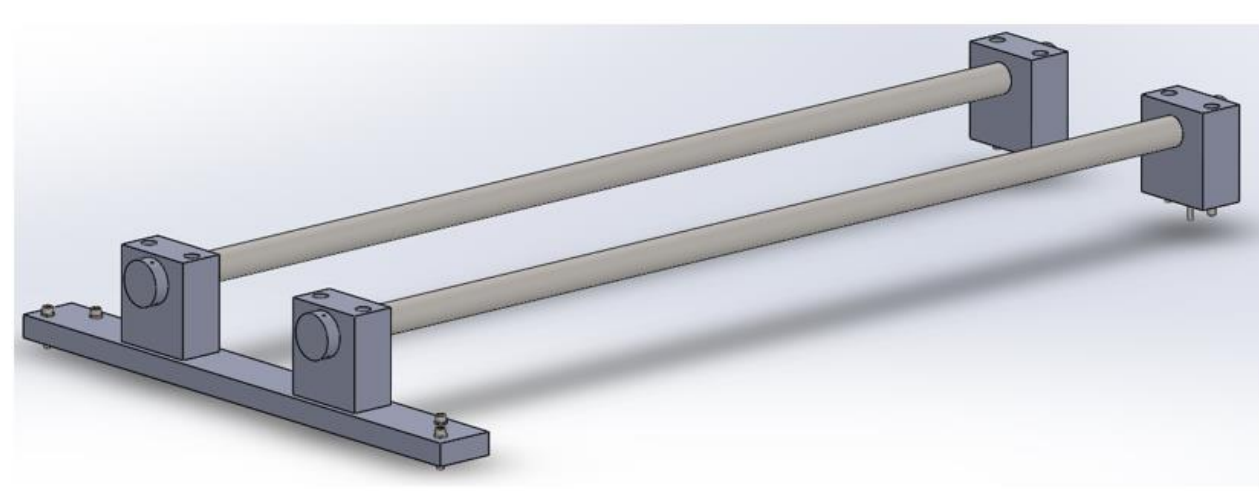

(a) Blocks that will hold the linear guides.

Figure 4.43 - Stopping car linear guides.

The materials used to connect all the parts are presented in Table 4.6. 
Table 4.6 - Fasteners used to assemble the stopping car.

\begin{tabular}{|c|c|c|}
\hline Element & Norm & Qt. \\
\hline Ball-bearing & DIN 625 - 6204 & 12 \\
\hline \multirow{4}{*}{ Screws } & ISO 4762 M8x30-8.8 & 36 \\
\cline { 2 - 3 } & ISO 10642 M5x16-8.8 & 16 \\
\cline { 2 - 3 } & ISO 4762 M8x35-8.8 & 8 \\
\cline { 2 - 3 } & ISO 4762 M8x45-8.8 & 20 \\
\cline { 2 - 3 } & ISO 4762 M10x55-8.8 & 8 \\
\hline Washer & DIN 125 - A 8.4 300 HV & 8 \\
\hline Pin & ISO 8734 M8x45-8.8 & 4 \\
\hline
\end{tabular}

\subsection{Support frame to hold the braking system and actuator}

The support frame, represented in Figure 4.44, is the structure that will hold the pneumatic actuator and the braking system. It is composed of aluminium frames of the 90 series profiles from Bosch Rexroth Group [38], the table that will support the pneumatic actuator, made of aluminium 6063-T6, and reinforcements composed of two L profiles, two steel plates, and four rod steel reinforcements. These reinforcements were required to strengthen the support frame structure and to support the braking system and to dissipate the loads in the structure. The structure has a length of $2.8 \mathrm{~m}$, a height of $0.93 \mathrm{~m}$, and a width of $0.78 \mathrm{~m}$. all the mechanical drawings of the parts that form the support frame can be consulted in Appendix E.

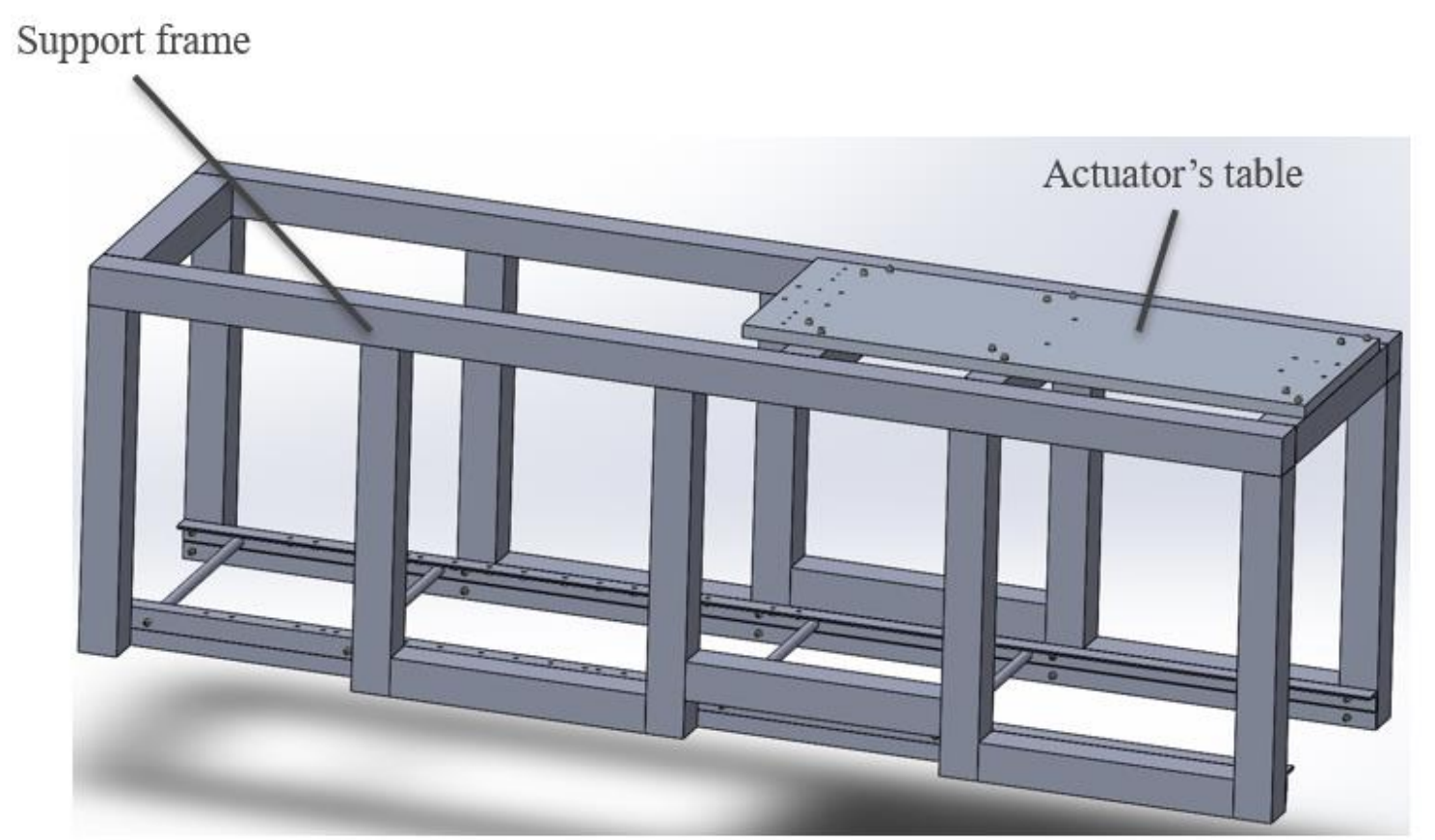

Figure 4.44 - Final model of the support frame for the braking system and pneumatic actuator.

The aluminium frames from Bosch Rexroth Group [38] are the 90x90H series profiles and the cross-section of the profiles is shown in Figure 4.45. These profiles are ideal for heavyduty applications where added strength and T-slots are a must. For this construction all the T- 
slots used to assemble the structure were M8 T-slots. The structure is composed of $290 \times 90 \mathrm{H}$ profiles with $2.8 \mathrm{~m}$ of length, 10 profiles of $0.6 \mathrm{~m}$ of length, and another 10 profiles with a length of $0,81 \mathrm{~m}$.

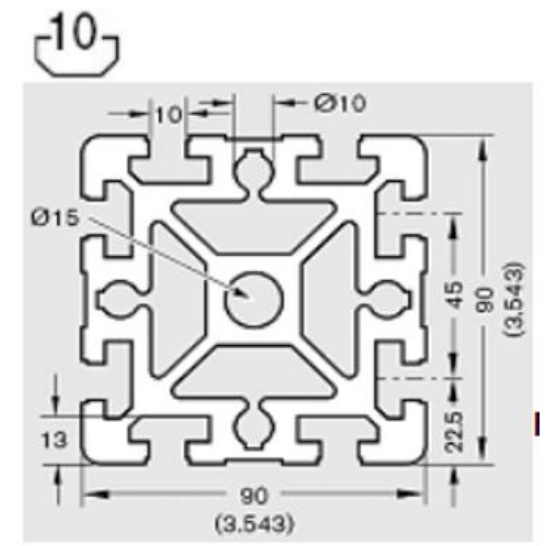

(a) Cross section profile.

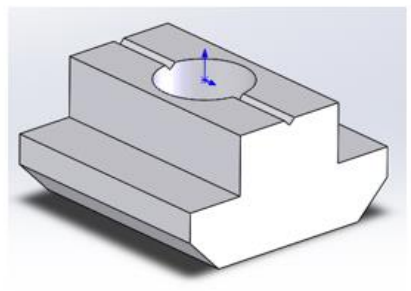

(b) M8 T-slots.

Figure 4.45 - Cross section of the 90x90H series aluminium profiles [38].

To reinforce the support frame, it was used two L profiles $50 \times 50 \times 2800 \mathrm{~mm}$ with a thickness of $7 \mathrm{~mm}$. These L profiles have nuts, ISO $4032 \mathrm{M} 10 \mathrm{D}$, that are welded to allow the braking system to be threaded in those nuts, thus, fixing the braking system to the support frame. These L profiles rest against a steel plate with $5 \mathrm{~mm}$ of thickness along the full length of the support frame. Both these reinforcements are screwed to the $90 \times 90 \mathrm{H}$ profiles from Bosch [38] with screws. Four rod steel reinforcement with an outside diameter of $25 \mathrm{~mm}$ and are used to give more strength to the support frame. They are screwed in the rod's end, connecting both of the L profiles. The reinforcements utilized can be seen in Figure 4.46.

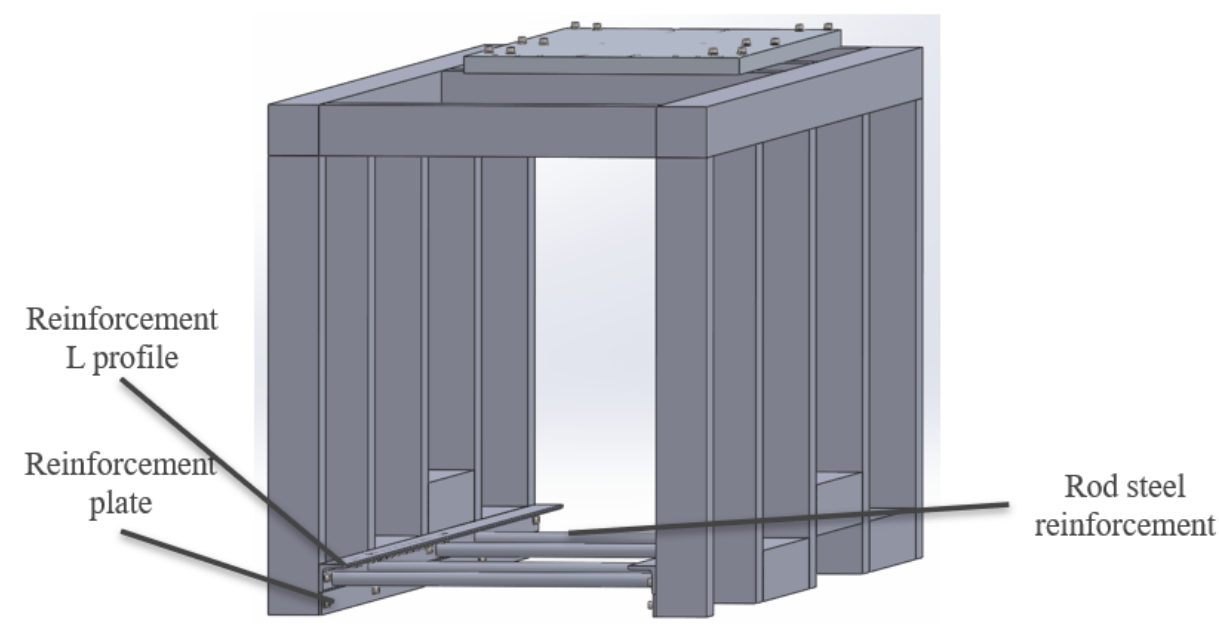

Figure 4.46 - Reinforcements used on the support frame for the braking system and pneumatic actuator.

The materials used to connect all the parts that assemble the support frame are presented in Table 4.7. 
Table 4.7 - Fasteners used to assemble the support frame.

\begin{tabular}{|c|c|c|}
\hline Element & Norm & Qt. \\
\hline \multirow{3}{*}{ Screws } & ISO 4762 M10x25-8.8 & 8 \\
\cline { 2 - 3 } & ISO 4762 M8x45-8.8 & 12 \\
\cline { 2 - 3 } & ISO 4762 M8x20-8.8 & 20 \\
\hline \multirow{2}{*}{ Washer } & DIN 125 - A 8.4 300 HV & 54 \\
\hline Nuts & ISO 4032 M10 D & 32 \\
\hline T- slots & 10 mm M8, T-Block & 32 \\
\hline
\end{tabular}

The final model of the braking system is shown in Figure 4.47, where (a) shows the braking system setup for the tensile test, where (b) represents the setup for compression testing.

(a) Braking system setup for tensile test.

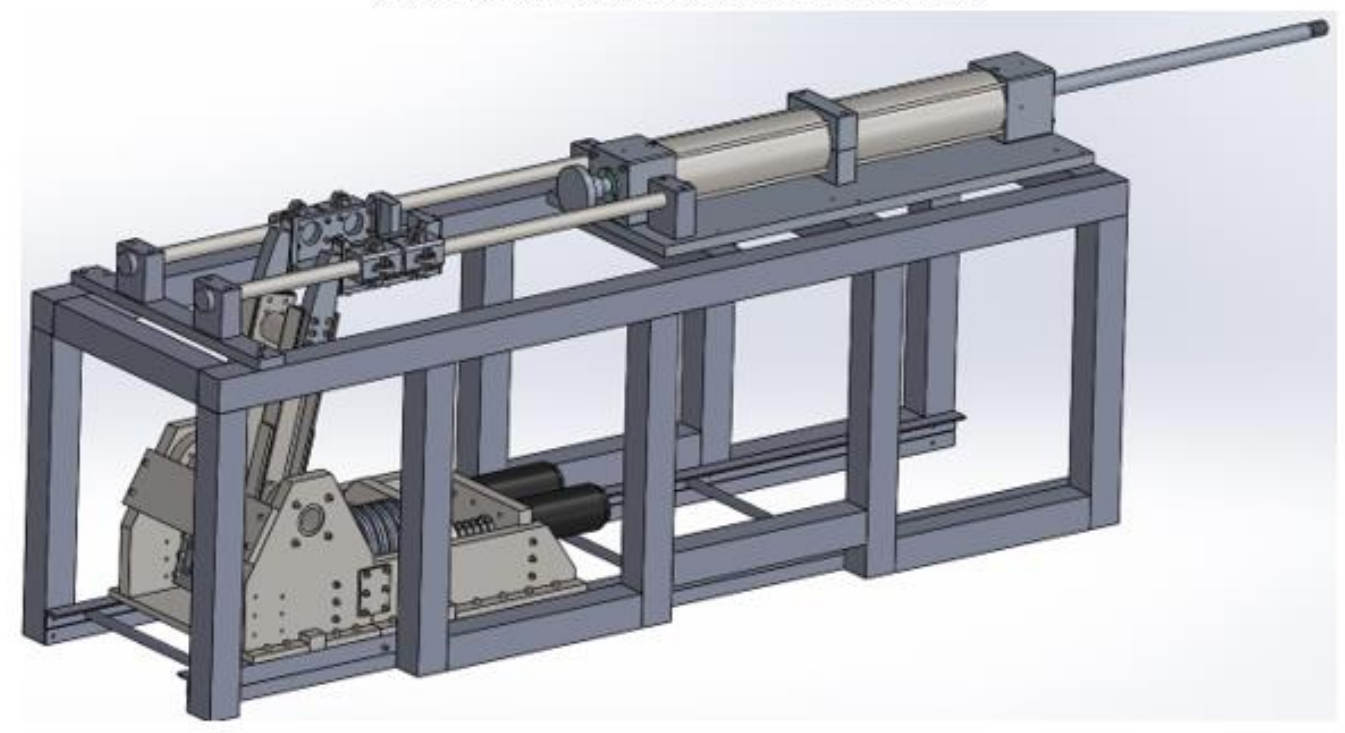

(b) Braking system setup for compression test.

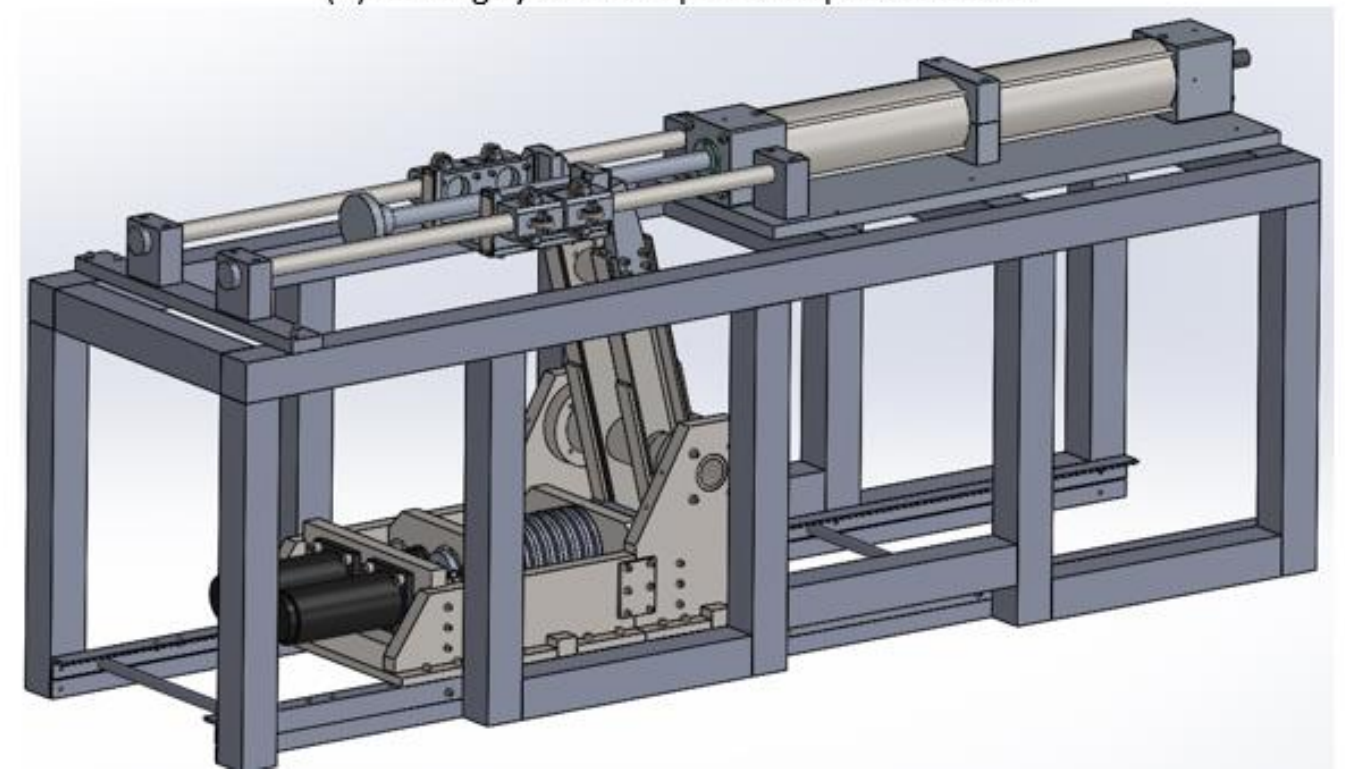

Figure 4.47 - Final braking system setup for both tensile and compression tests. 



\section{Tensile and compression setup}

This chapter describes the designing process for the two different setups for the SHPB machine: tensile and compression tests. The first and second sections present the tensile and compression setups, respectively. The last section presents the support frame for both setups and a final look of the complete SHPB machine.

Tenreiro [4] made a study of the wave propagation dynamics, determining the length of the striker bar to fracture a bonded joint as well the lengths for the output bar and input bar and their diameter.

\subsection{SHPB Tensile setup}

As it was previously said, Tenreiro [4] made an initial study and determined the dimensions for the output and input bars and their diameter. As such, the initial task was to make the mechanical parts for the complete setup for a tensile test, which can be seen in Appendix F. This task was done with the help of SolidWorks 2019, and the final design of the tensile setup of can be seen in Figure 5.1.

This setup is composed of a pneumatic actuator that will project a rod at $30 \mathrm{~m} / \mathrm{s}$. This actuator's rod will be attached to a striker holder that is guided by supports composed of ball bearings. This striker holder will impact with a flange on the striker tube, which is guided in the inside of the striker holder by the ball bearings on it. The striker tube will travel and then hit the loading bar flange. This loading bar is attached to the input bar. Therefore, the input bar will be pulled and the bonded joint that is being held by the input and output bars will break.

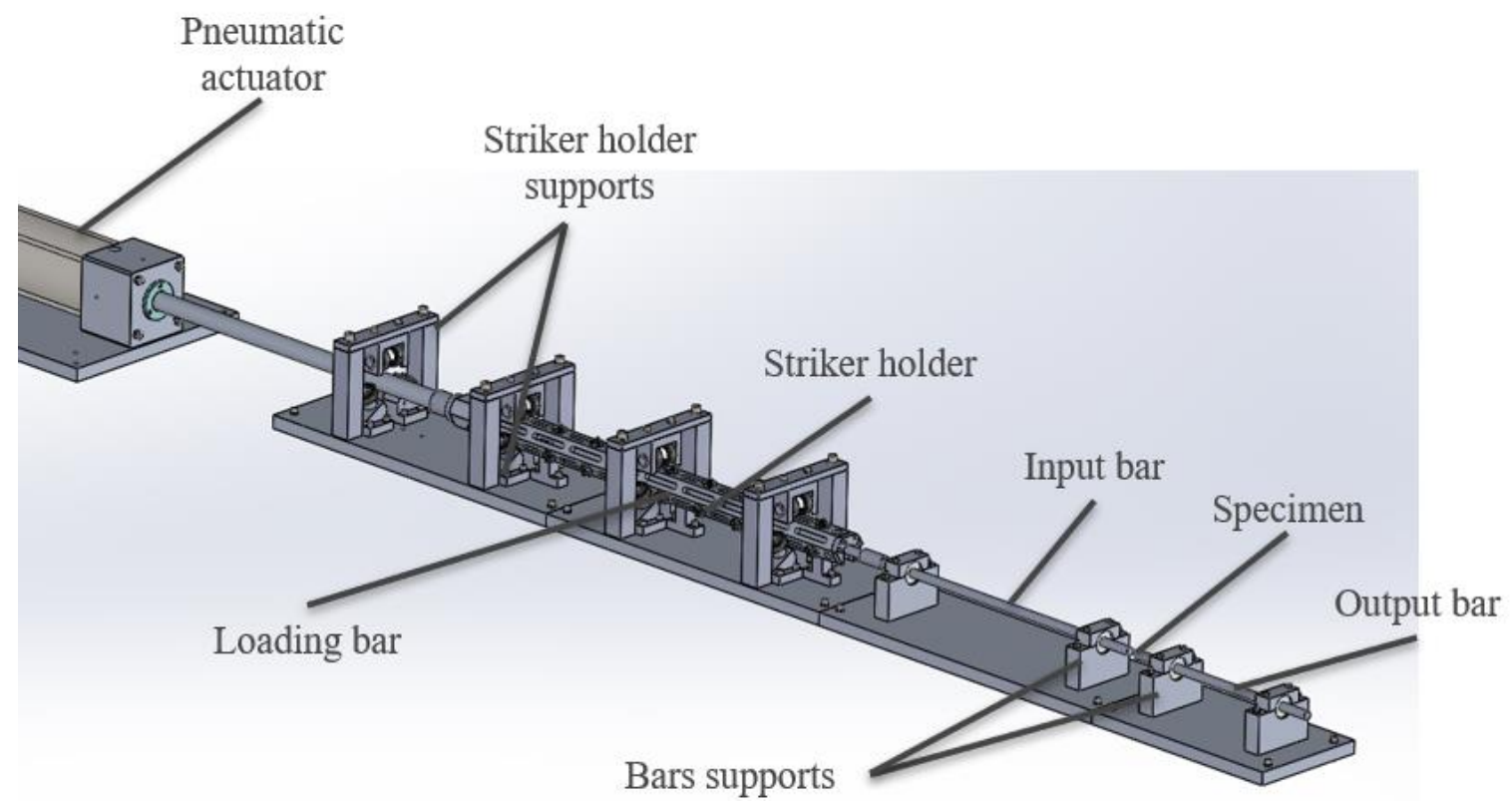

Figure 5.1 - Final model of the tensile test setup. 


\subsubsection{Bars and their supports}

The length of the input bar and output bar was determined by Tenreiro [4]. The input bar should have a length of $750 \mathrm{~mm}$ and the output bar $500 \mathrm{~mm}$. Both bars have $20 \mathrm{~mm}$ in diameter and are made from the same material, stainless steel. These bars are responsible for the holding of the bonded joint specimens which will be screwed to both bars. Figure 5.2 shows the final look of the bars. Both bars are threaded with M18 so the bonded joint specimen can be screwed there and be fixed. At the other end of the input bar, there is an M18 thread where the sleeve connector to the loading bar is fixed.

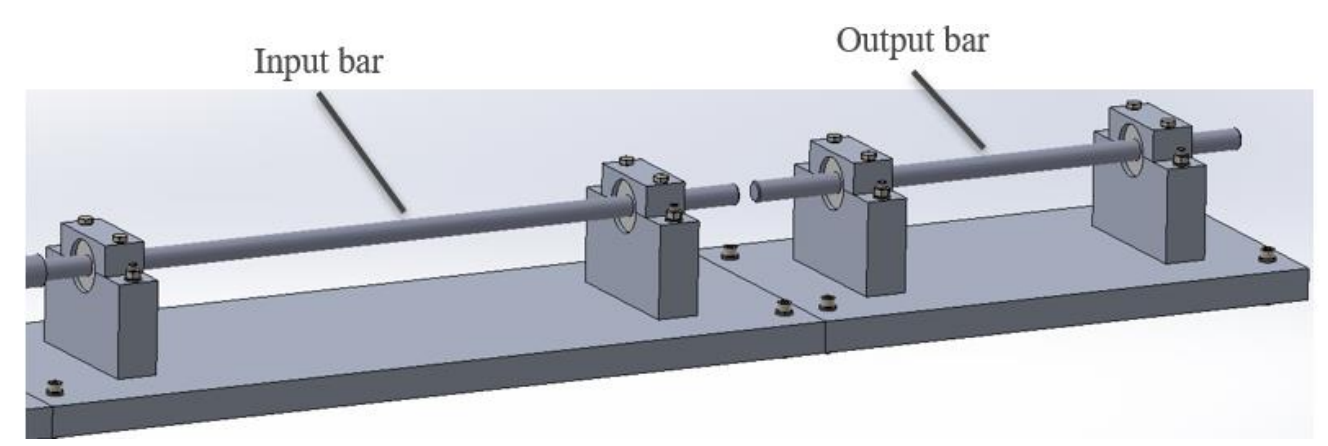

Figure 5.2 - Input bar and output bar for tensile tests.

These bars needed a support frame. The solution found is shown in Figure 5.3. All the support blocks are the same, since the bars have the same diameter. The bars will slide in the sleeve bushings made of PTFE and that bushing is compressed by two aluminium 6061-T4 blocks that will be screwed together. Then, the aluminium block on the bottom will be screwed to the plate that will sit on top of the support frame of the machine. Each bar will be supported by two supports. The plates where these supports will be fixed are made of aluminium 6063T6 with a thickness of $30 \mathrm{~mm}$. In the next figure, it is also possible to see how the PTFE bushing is fixed between the two aluminium blocks.

This construction is very helpful since it will be easy to substitute the PTFE bushings in case they are destroyed. It just requires unscrewing the top block, remove the bushing, and substitute the element. These PTFE bushings are presented in this construction because they give a low friction surface for the bars to move on. They can be a complete bushing, or a bushing cut in half as it is shown in the following figure.

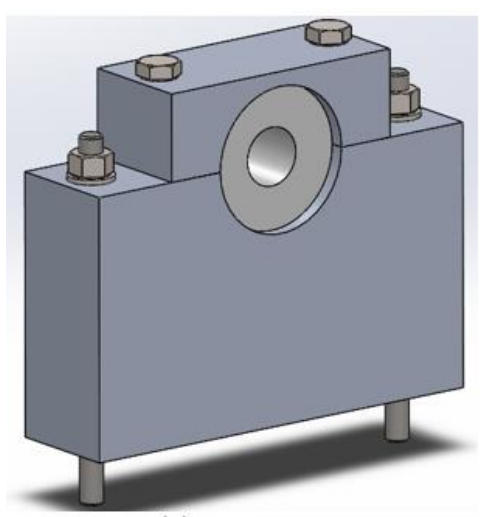

(a) Bars support.

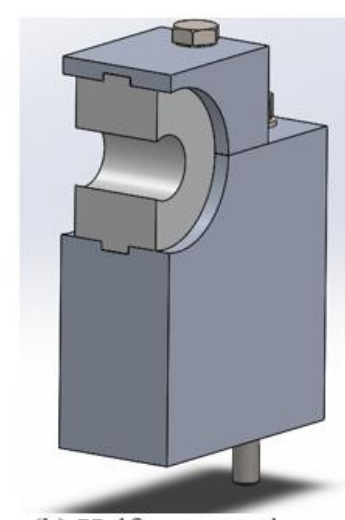

(b) Halfway cut view of the support.

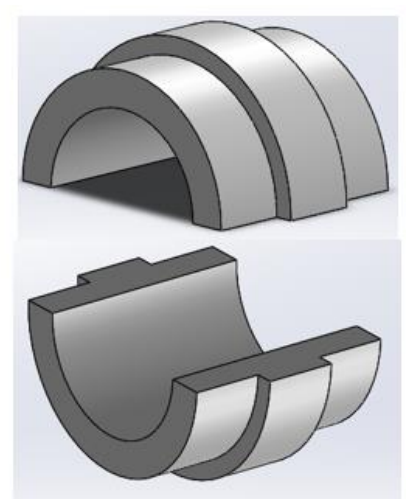

(c) PTFE bushing cut in half.

Figure 5.3 - Bars support. 
The stainless steel selected for the bars is the AISI 4140 steel. This material has good impact resistance, high fatigue strength, abrasion resistance, and toughness. The chemical composition is presented in Table 5.1.

Table 5.1 - AISI 4140 steel chemical composition.

\begin{tabular}{|c|c|c|c|c|c|c|c|}
\hline $\begin{array}{c}\text { Grade } \\
\text { Designation }\end{array}$ & Carbon & Manganese & $\begin{array}{c}\text { Phosphorus } \\
\text { Max }\end{array}$ & $\begin{array}{c}\text { Sulfur } \\
\text { Max }\end{array}$ & Silicon & Chromium & Molybdenum \\
\hline 4140 & $\begin{array}{c}0.38- \\
0.43\end{array}$ & $0.75-1.00$ & 0.035 & 0.040 & $\begin{array}{c}0.15- \\
0.35\end{array}$ & $\begin{array}{c}0.80- \\
1.10\end{array}$ & $0.15-0.25$ \\
\hline
\end{tabular}

The physical properties of AISI 4140 steel are provided in Table 5.2.

Table 5.2 - Physical properties of AISI 4140 steel.

\begin{tabular}{|c|c|c|c|c|c|}
\hline Material & $\begin{array}{c}\text { Density } \\
\left(\mathrm{kg} / \mathrm{m}^{3}\right)\end{array}$ & $\begin{array}{c}\text { Yield strength } \\
0.2 \% \\
(\mathrm{MPa})\end{array}$ & $\begin{array}{c}\text { Ultimate } \\
\text { Tensile } \\
\text { Strength } \\
(\mathrm{MPa})\end{array}$ & $\begin{array}{c}\text { Young's } \\
\text { Modulus } \\
(\mathrm{GPa})\end{array}$ & $\begin{array}{c}\text { Elongation } \\
\text { at Break } \\
(\%)\end{array}$ \\
\hline AISI 4140 & 7850 & $415-1735$ & $655-1965$ & 205 & $11-25.7$ \\
\hline
\end{tabular}

\subsubsection{Striker tube, loading bar, and striker holder}

For the stress wave to propagate with the same velocity through both the input bar and output bar, the striker tube must be made of the same material and keeping the same crosssection area as the input bar, $414.2 \mathrm{~mm}^{2}$.

Since the input bar had to have a specific length of $750 \mathrm{~mm}$, it was required to build another bar to be attached to the input bar to be able to increase the length, called a loading bar, so the actuator could work with the setup. Therefore, the loading bar would be attached to the input bar with the help of a sleeve connector that would be screwed in one side to the input bar and the other side to the loading bar. The loading bar has a flange at the other end where it will receive the impact provoked by the striker tube, which is launched by the striker holder. This striker holder is the component that is screwed to the actuator's rod and has a flange to transmit the movement to the striker tube. The construction can be seen in Figure 5.4. 


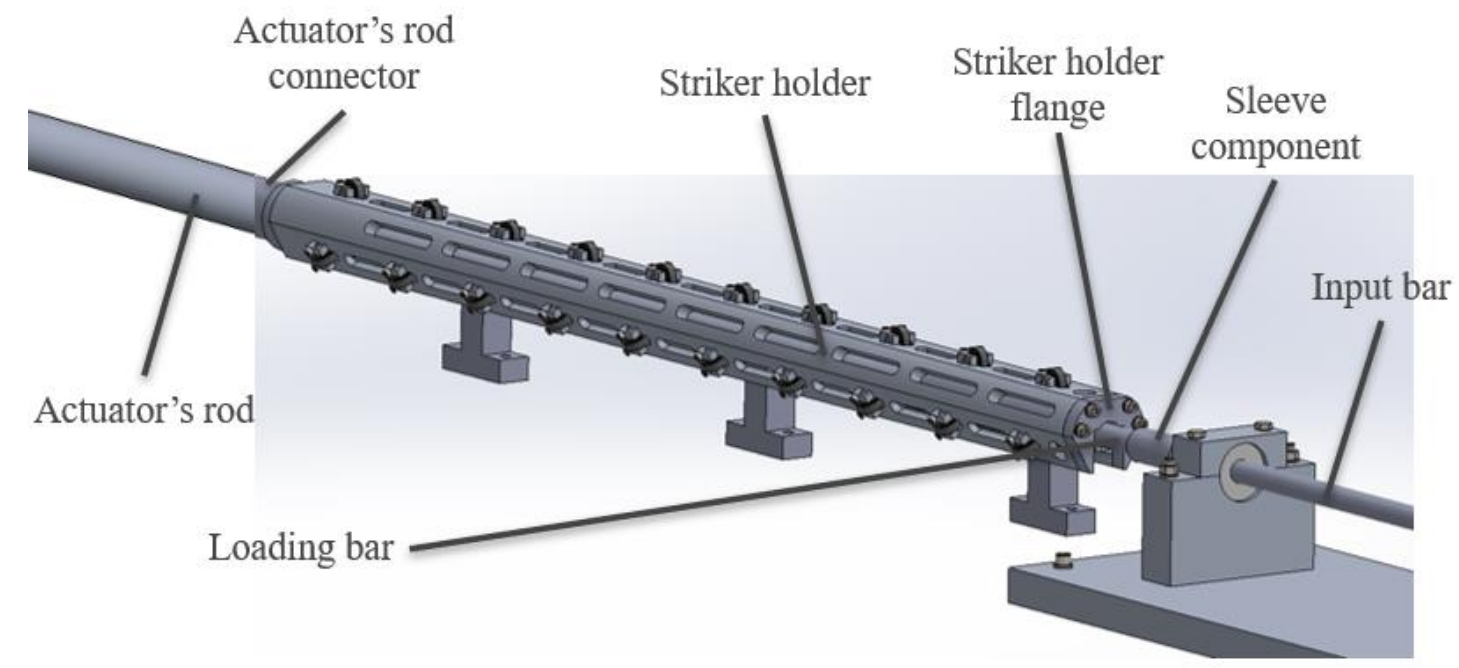

Figure 5.4 - Striker holder, striker tube, and loading bar assembly.

This construction was inspired by the concept developed by Robert Gerlach, Christian Kettenbeil, Nik Petrinic [39], where they used a U shaped projectile cross-section instead of the classic cylindrical projectile cross-section. In Figure 5.5 one can be seen the main differences.

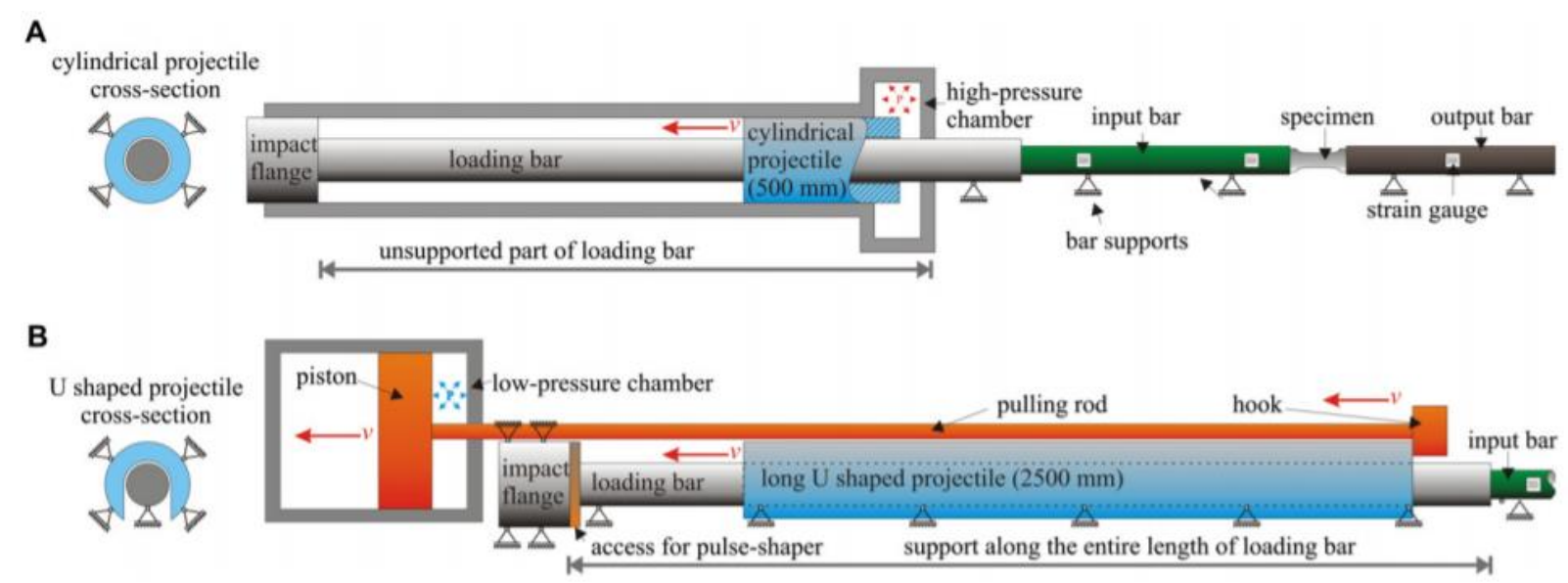

Fig. 1. Classic (A) and new (B) design for the tensile Split Hopkinson Bar apparatus.

Figure 5.5 - New Split Hopkinson tensile bar design.

\section{Striker tube}

The striker tube was not shown in the previous figure since this component is guided from the inside of the striker holder. The Figure 5.6 shows a halfway cut view of the striker holder to show the striker tube on the inside. As mentioned before, the actuator's rod is attached to the striker holder and, when the rod starts its movement, the striker holder will launch the striker tube with a flange that will be screwed into the striker holder. The striker tube will travel $500 \mathrm{~mm}$ until it reaches the $30 \mathrm{~m} / \mathrm{s}$ and then will impact against the loading bar flange that will be screwed to the loading bar. When the loading bar flange will receive the impact, it will pull the input bar and therefore. The bonded joint specimen will then break. 


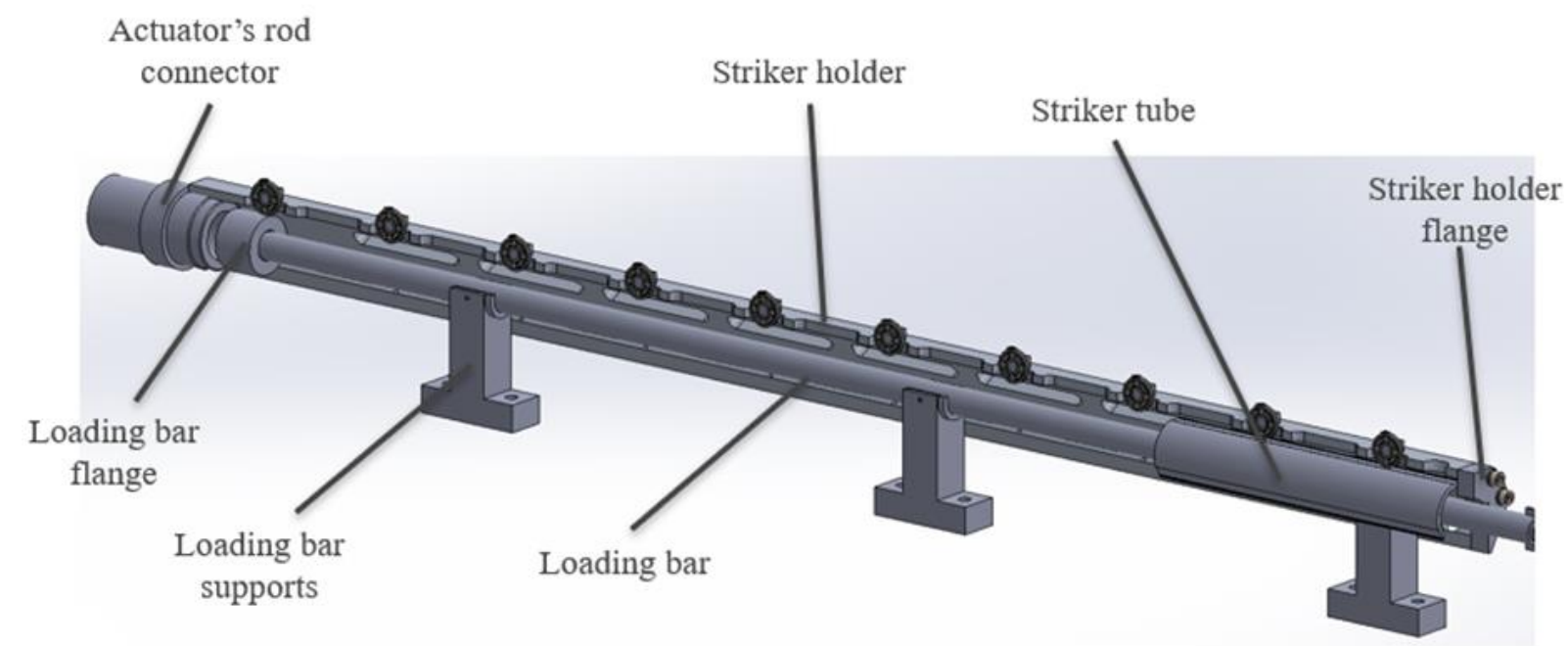

Figure 5.6 - Halfway cut view of the Striker holder.

The cross-section area of the striker tube is around $315 \mathrm{~mm}^{2}$. The striker tube has an outside diameter of $45.2 \mathrm{~mm}$ and an inside diameter of $38.1 \mathrm{~mm}$ with a length of $250 \mathrm{~mm}$ defined by [4]. The striker tube, Figure 5.7, is guided by ball bearings that are assembled to the strike holder along its full length. This can be seen in the figure, where 3 small cuts form the trail for the ball bearings, which will not allow the striker tube to rotate in its axle. On the bottom part of the striker tube, there is a cut intentionally made, so the striker tube will not hit the loading bar supports when it starts the movement. The material is the same AISI 4140 steel selected for the bars.
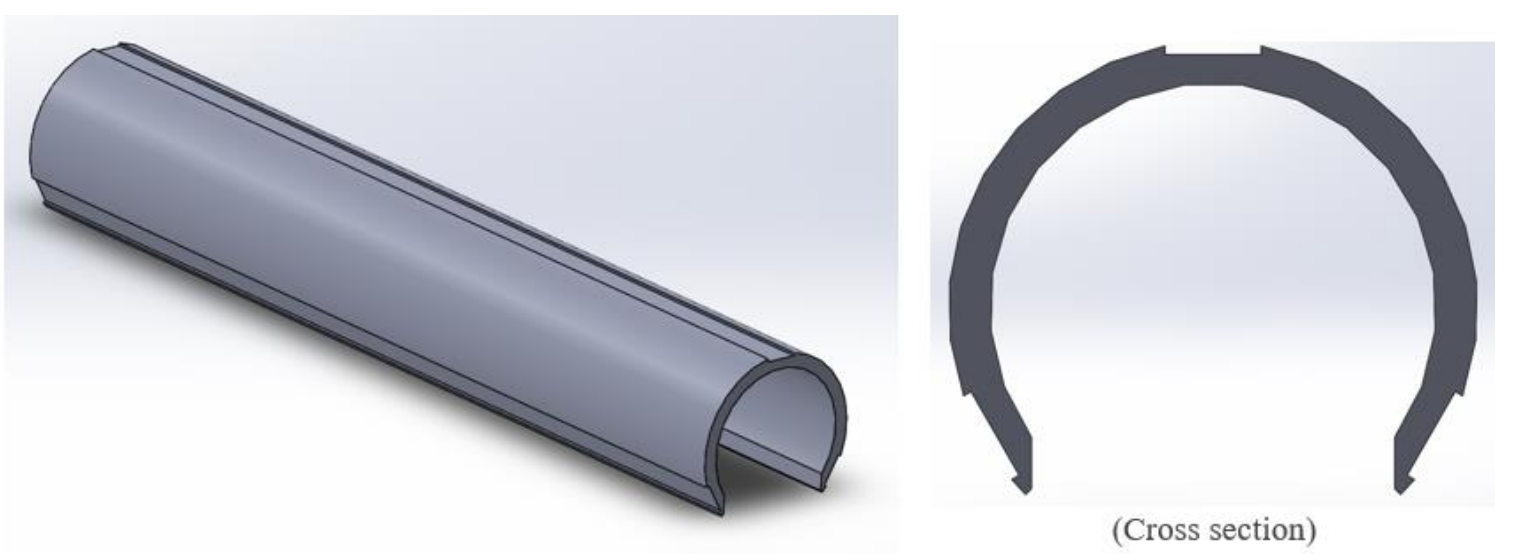

Figure 5.7 - Final model of the striker tube.

\section{Loading bar}

The loading bar is responsible to transmit the impact received from the striker tube to the input bar. The loading bar is made of the same AISI 4140 steel from the bars, has the same outside diameter as the input bar, $20 \mathrm{~mm}$, and a total length of $1170 \mathrm{~mm}$ (Figure 5.8). 


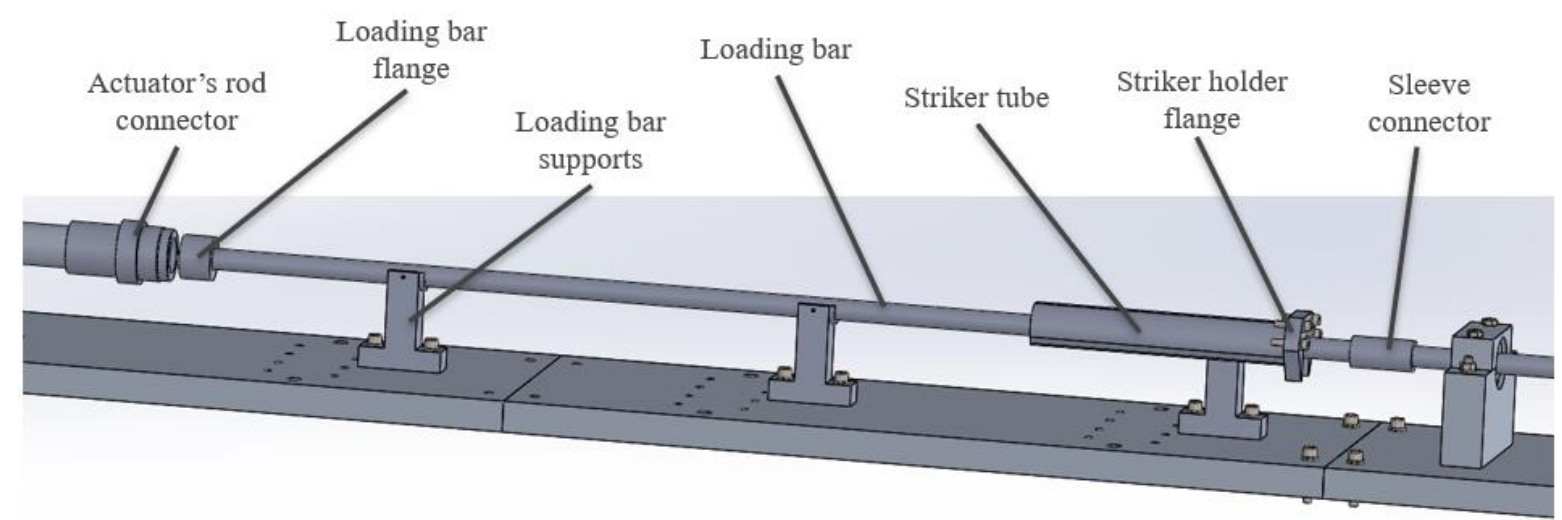

Figure 5.8 - Final model of the loading bar.

At one end of the loading bar, there is a flange that is screwed to the bar, which will receive the impact of the striker tube. The loading bar flange is also made from the same AISI 4140 steel as the rest. On the other end, there is a sleeve connector that is responsible to connect the loading bar to the input bar, also made from the same AISI 4140 steel. Both ends of the loading bar are shown in detail in Figure 5.9.

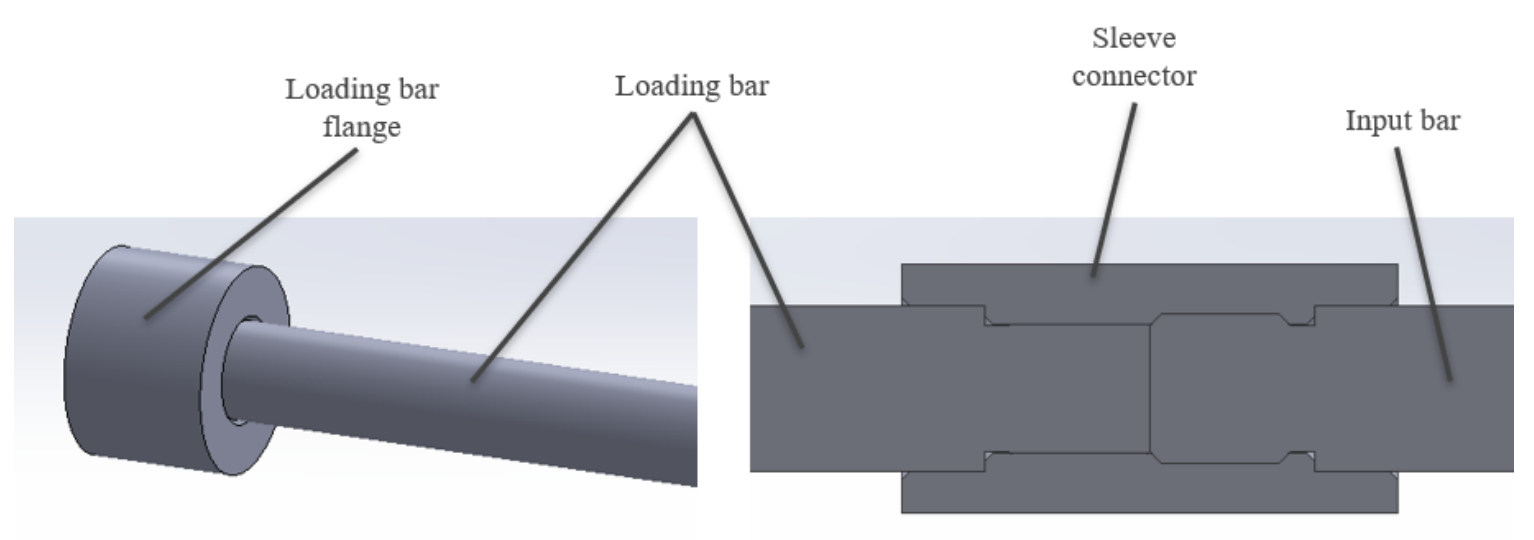

(a) Loading bar with the flange.

(b) Loading bar and input bar connector.

Figure 5.9 - Amplified views of both ends of the loading bar.

The loading bar is supported by three supports along its full length. Those supports are composed of a PTFE bushing and an aluminium 6063-T6 block and are screwed to the aluminium plates of $30 \mathrm{~mm}$ of thickness. Both aluminium supports and the bushing are cut at 5 $\mathrm{mm}$ above the center of the bushing, so the loading bar will be always fixed and will not escape during its movement. The PTFE bushing is fixed to the support by an ISO $4028 \mathrm{M} 3 \times 4$ screw, so the bushing will not rotate on the support. From Figure 5.10 it is possible to see the design of these supports. 


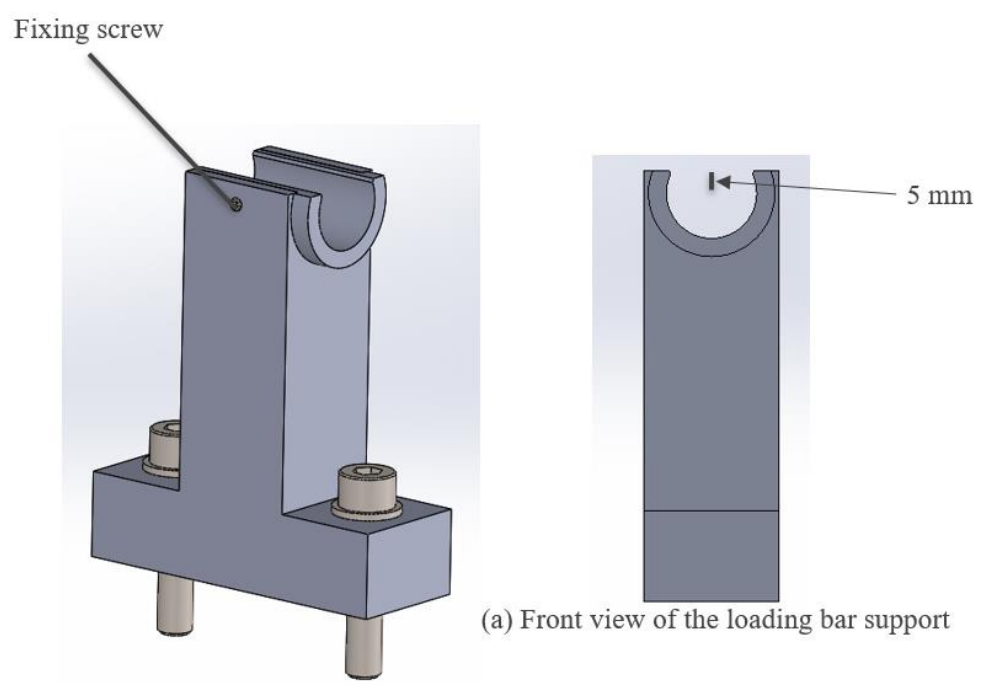

Figure 5.10 - Loading bar supports.

\section{Striker holder}

The striker holder is the component that is fixed to the actuator's rod and will launch the striker tube against the loading bar. It is also responsible for the guidance of the striker tube, where it is achieved with 30 ball bearings fixed to the striker holder. The striker holder consists of a hollow shaft made of aluminium 7075-T6 with an outside diameter of $75 \mathrm{~mm}$ and $50 \mathrm{~mm}$ inside and a length of $1120 \mathrm{~mm}$. Three flat surfaces are cut to the ball bearings assembly to be fixed. As can be seen in Figure 5.11, the striker holder has many slots to save as maximum weight as possible. The figure also shows how the ball bearings are supporting the striker tube inside, and the striker tube will always be in contact with at least 6 ball bearings.
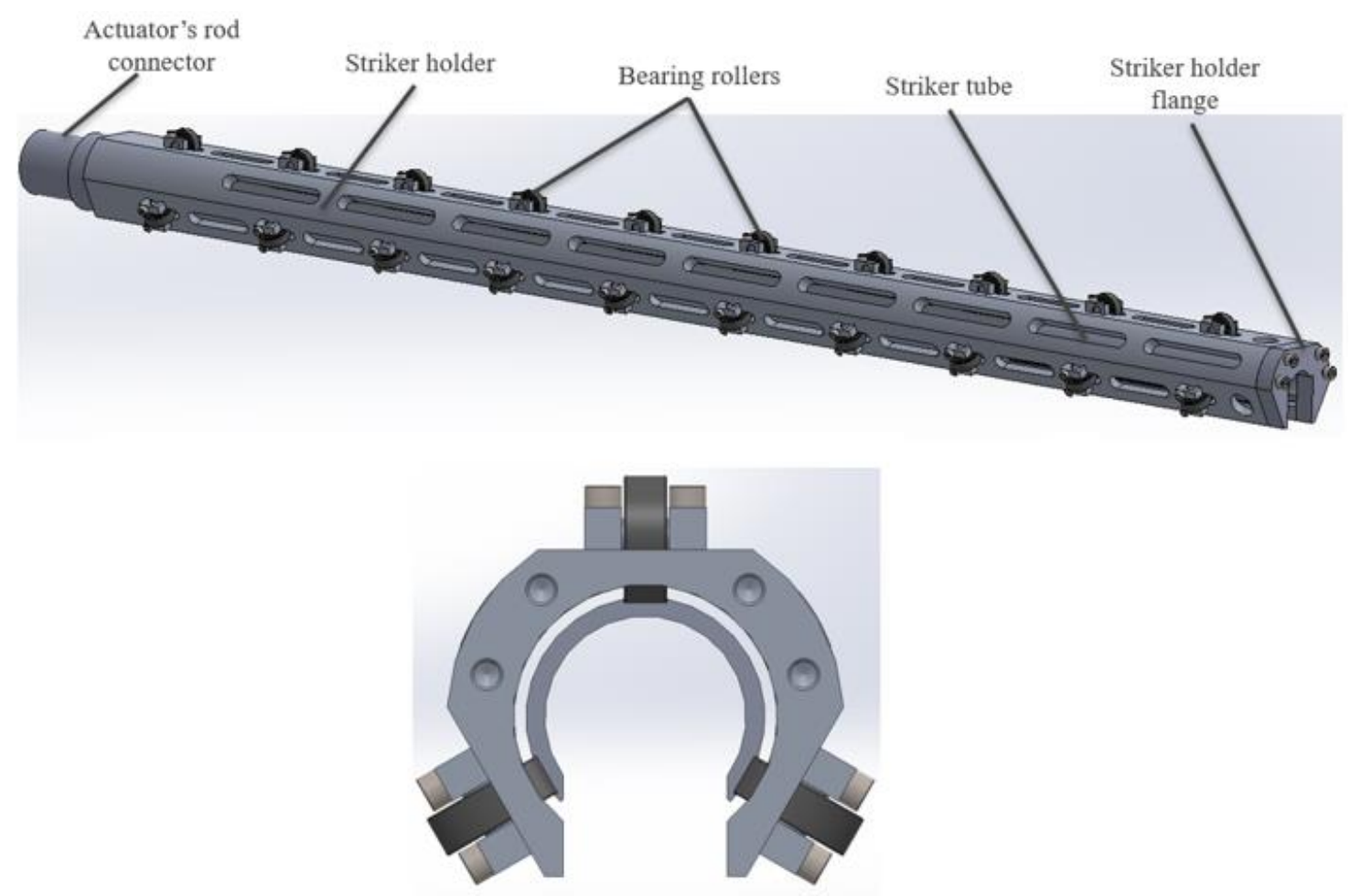

(a) Front view of the striker holder without the flange

Figure 5.11 - Final model of the Striker holder. 
The ball bearings assembly that is attached to the striker holder structure can be seen in Figure 5.12. It is composed of an axle that will support a $628-2 \mathrm{Z}$ ball bearing from SKF [40], with an inside diameter of $8 \mathrm{~mm}$ and $24 \mathrm{~mm}$ of the outside diameter. The axle is fixed with two small aluminium blocks and then screwed to the striker holder. The axle made of aluminium as well has $8 \mathrm{~mm}$ of diameter and in both ends. It is cut for a flat surface to fix to the flat surfaces made on the striker holder, so the axle will not rotate.
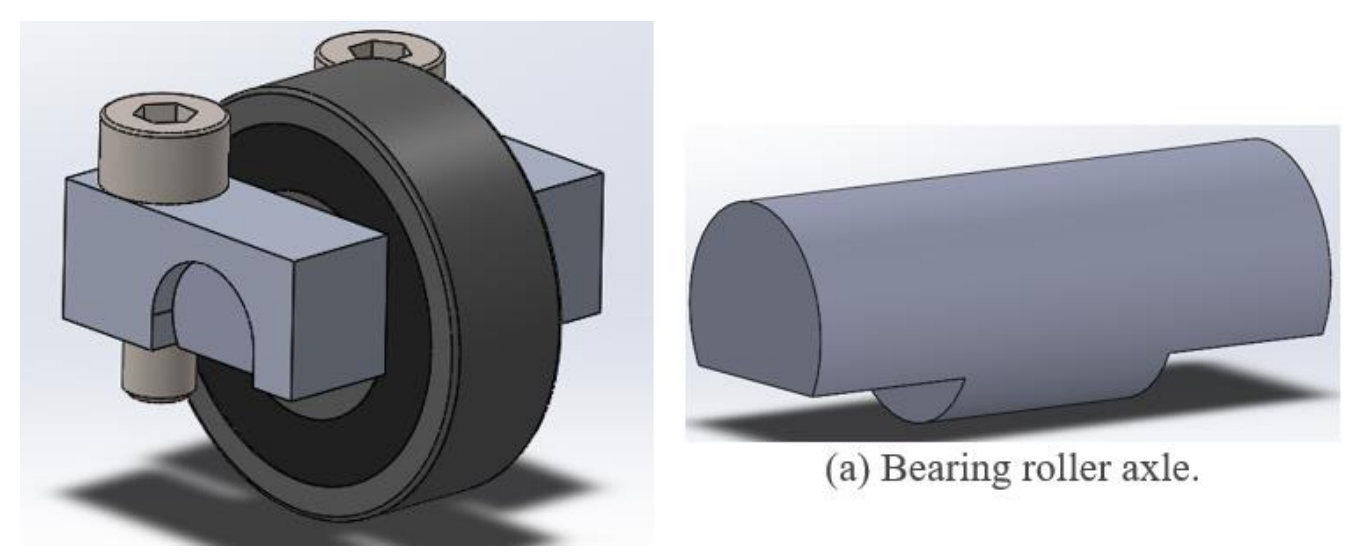

(a) Bearing roller axle.

Figure 5.12 - Final model of the ball bearing assembly.

The ball bearing specifications can be consulted in Table 5.3.

Table 5.3 - Ball bearing 628-2Z specifications [40].
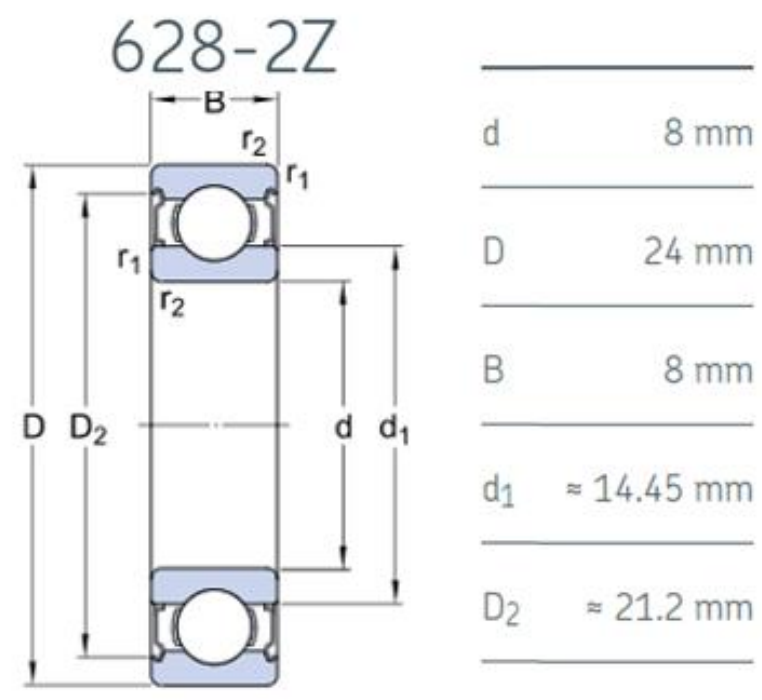

$r_{1,2} \min .0 .3 \mathrm{~mm}$

The component designed to allow the connection between the actuator's rod and the striker holder is shown in Figure 5.13 and it is made of aluminium 7075-T6. This component has $\mathrm{H} 7$ tolerance to give the alignment to the striker holder and the actuator's rod and then it is screwed to the actuator's rod with M39 and with M52 on the inside of the striker holder. 

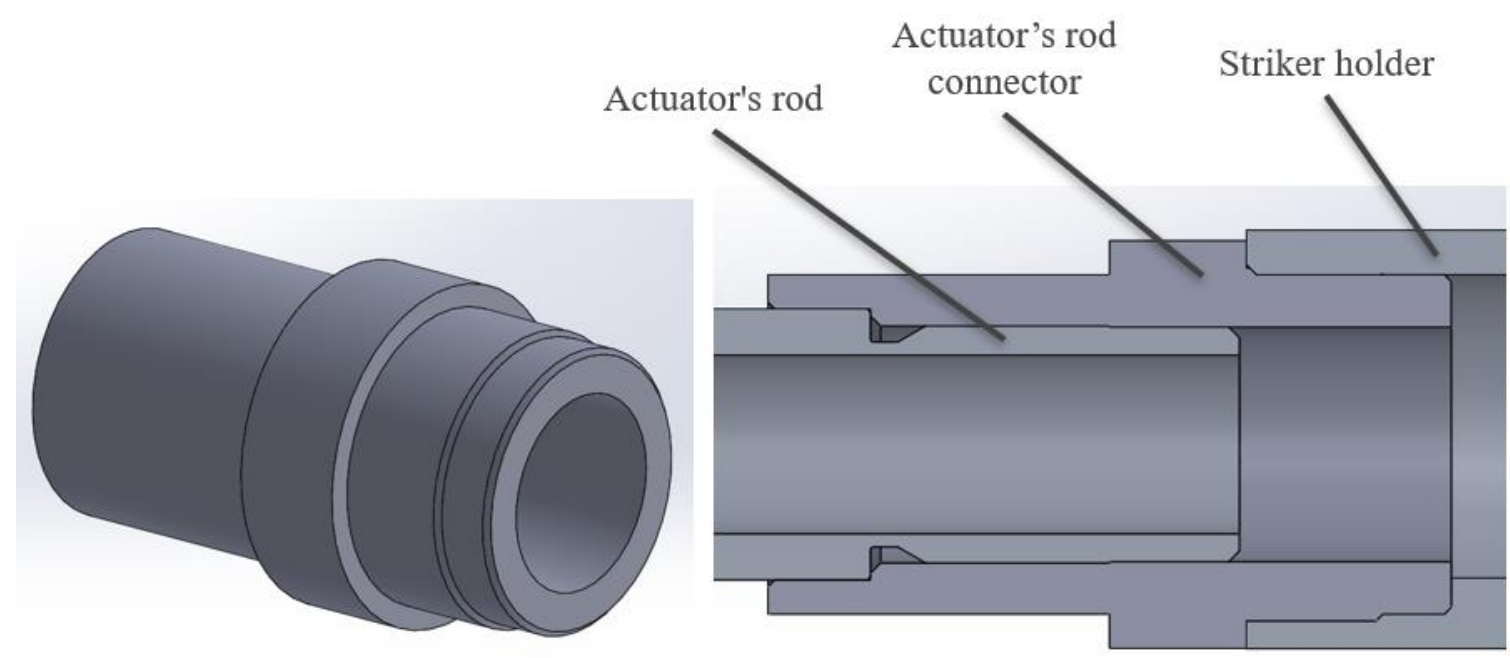

(a) Halfway cut view.

Figure 5.13 - Actuator's rod connector.

The designed striker holder flange can be seen in Figure 5.14 It is made of AISI 4140 steel with $15 \mathrm{~mm}$ of thickness and it is responsible to hit the striker tube and launch it against the loading bar flange. This component is crewed to the striker holder and has the same crosssection as the striker holder.

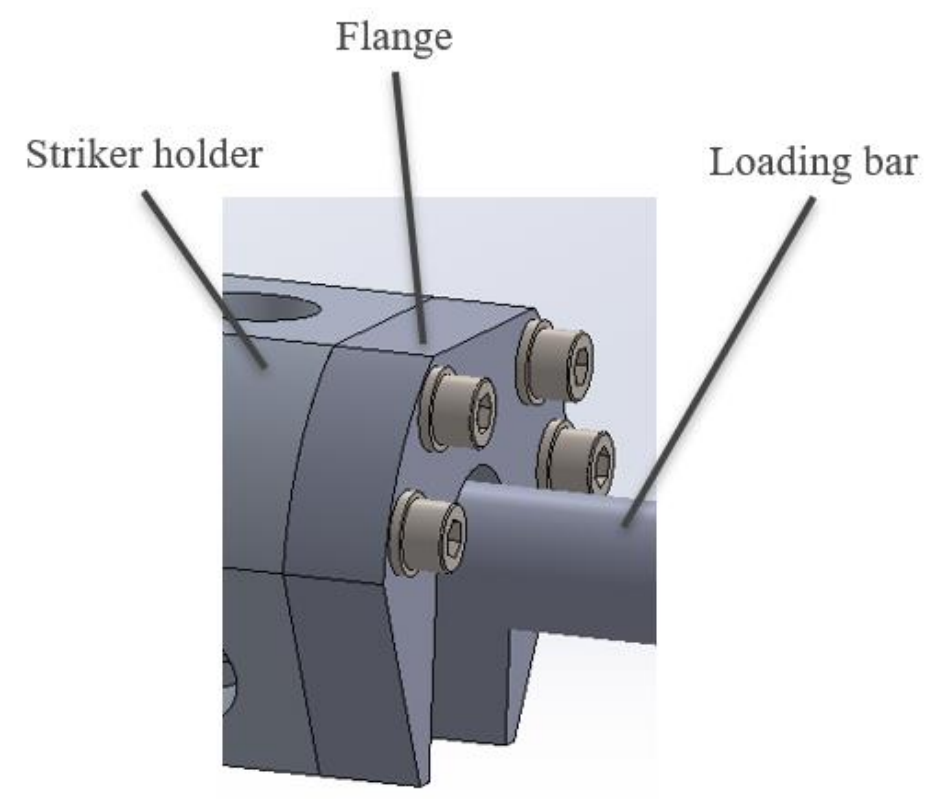

Figure 5.14 - Striker holder flange.

\subsubsection{Striker holder supports}

The solution found to support the striker holder and to guide it during the tensile test movement consists of having an assembly composed of ball bearings to allow the striker holder to roll between the rollers, thus, being fixed and not being able to rotate under its axle. For that, it was used four gates composed of two lateral ball bearings on each side of the striker holder and a vertical support with another two ball bearings. These ball bearings enter in contact with the striker holder on the 3 flat surfaces previously made for the small ball bearings that are 
guiding the striker tube. Its assembly can be seen in Figure 5.15. All supports and the loading bar supports are fixed to the horizontal aluminium plates.

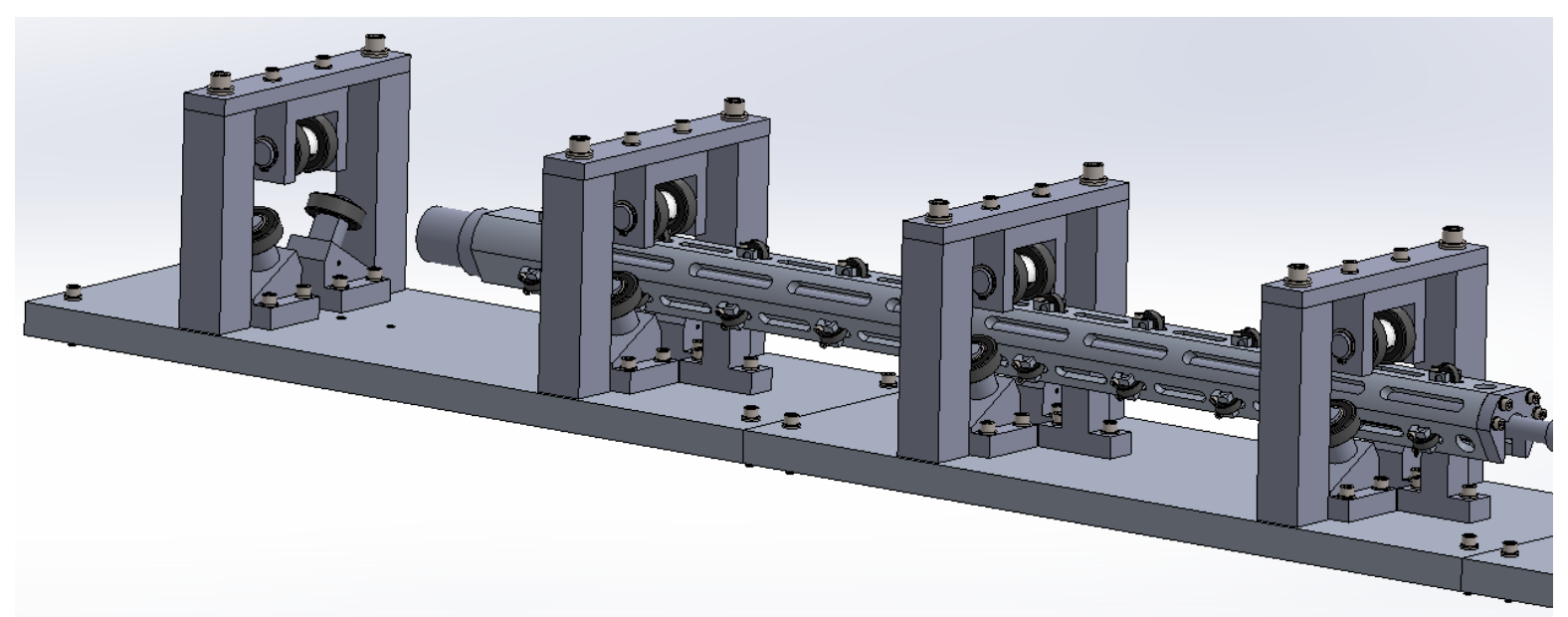

Figure 5.15 - Striker holder supports.

The frontal view of the supports can be seen in Figure 5.16.

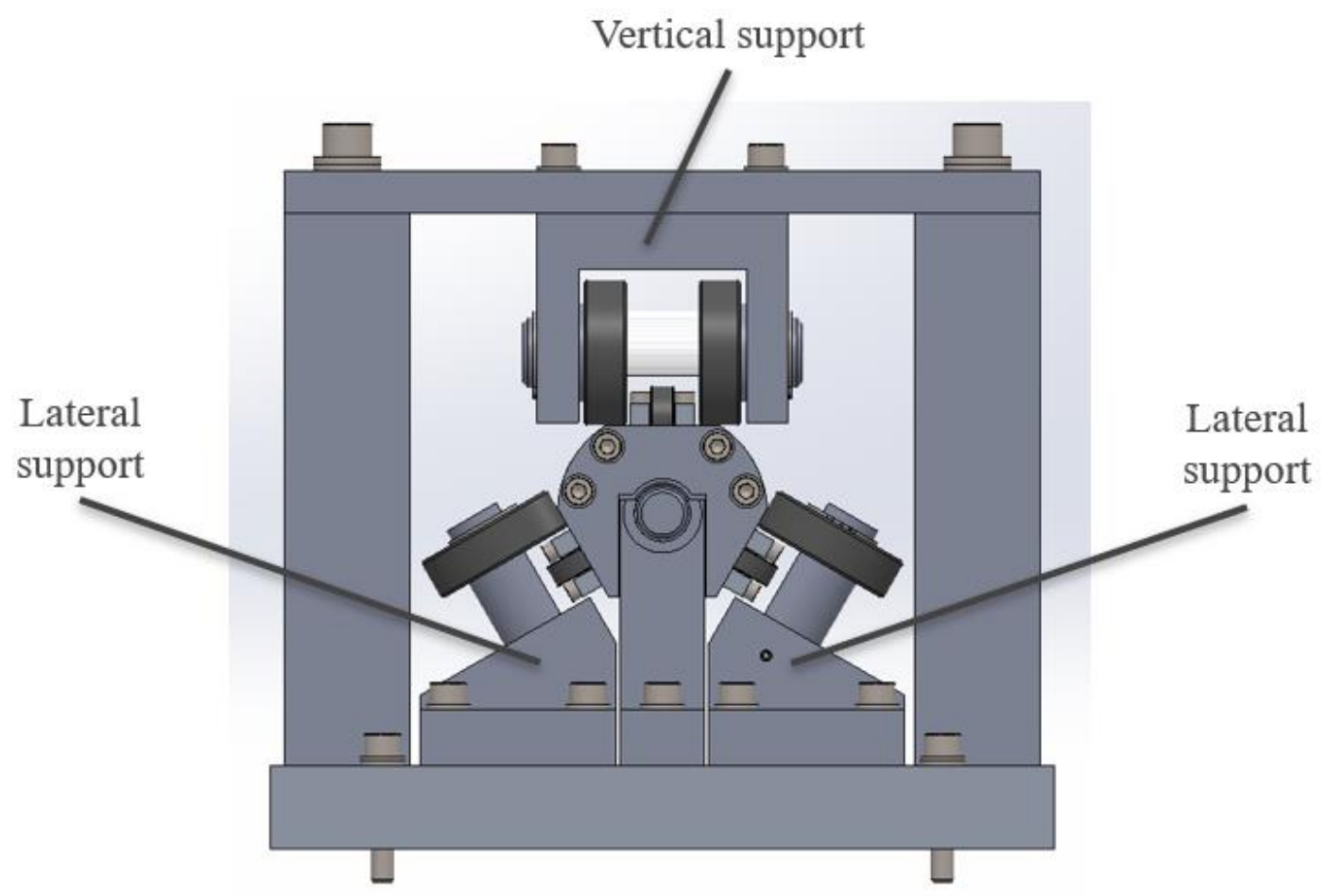

Figure 5.16 - Frontal view of the striker holder supports.

\section{Lateral supports}

The lateral supports consist of a ball bearing 6205-2Z from SKF [40], with an inside diameter of $25 \mathrm{~mm}$ and $52 \mathrm{~mm}$ of outside diameter, which is fixed to an aluminium axle that is screwed to a base made of aluminium as well with a socket head screw dog point, so the axle will not be able to rotate. This aluminium base is then attached to the horizontal plate. 
The fixing of the ball bearing to the axle is made with the help of a circlip, where the axle has a groove for the allocation of the circlip and a bigger diameter at the base, so the ball bearing stays in contact and doesn't fall. This assembly is shown in Figure 5.17, and the ball bearing specification can be consulted in Table 5.4. In total there are 8 lateral supports to hold the striker holder.

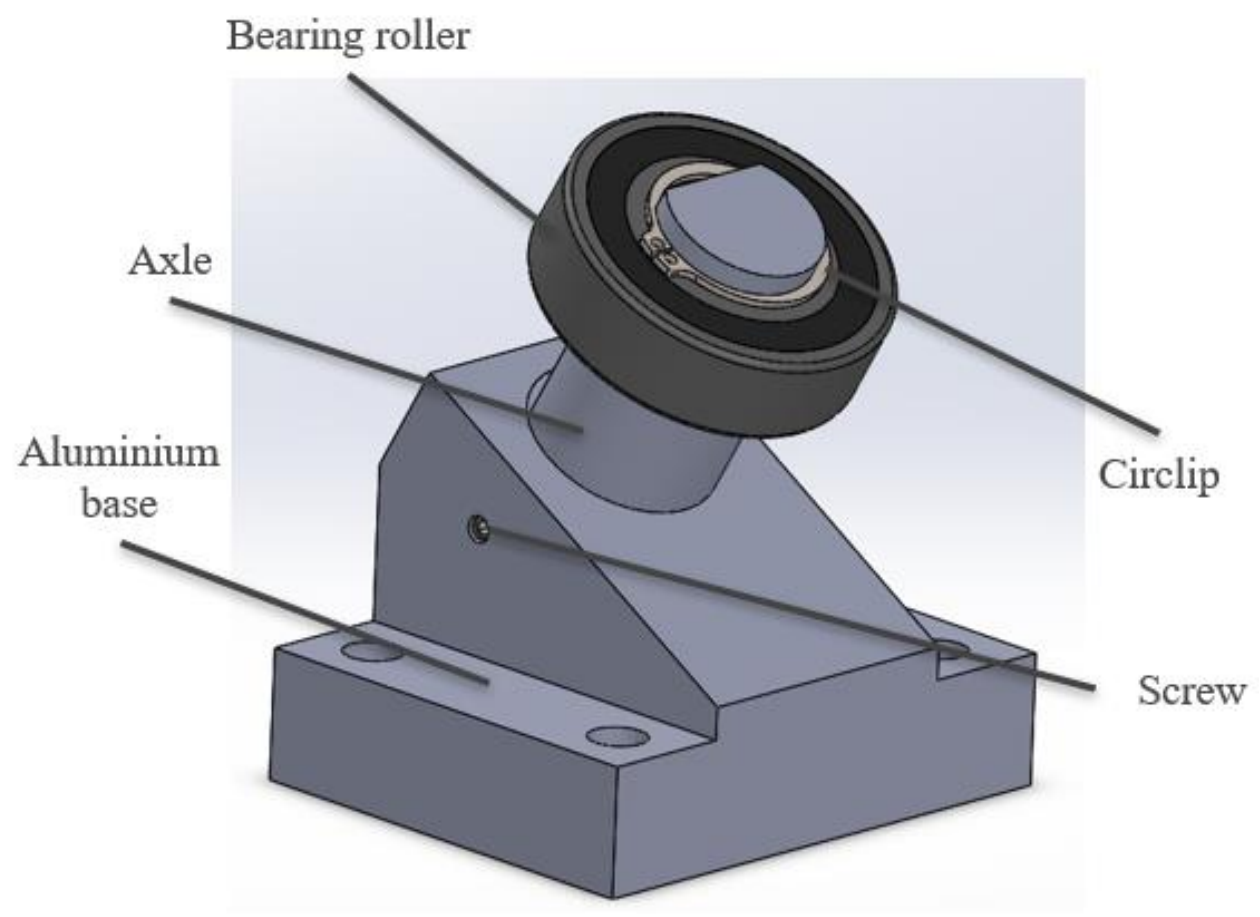

Figure 5.17 - Striker holder lateral support.

Table 5.4 - Ball bearing 6205-2Z specifications
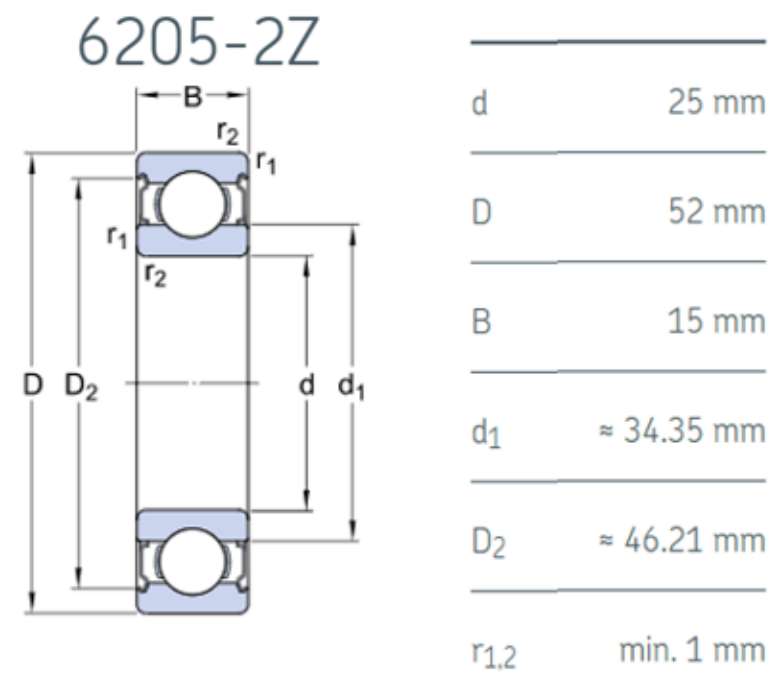

The axle used had to have a flat cut on its side, so the axle wouldn't hit the small ball bearing's assembly that is fixed to the striker holder structure. The detail is shown in Figure 5.18 . 


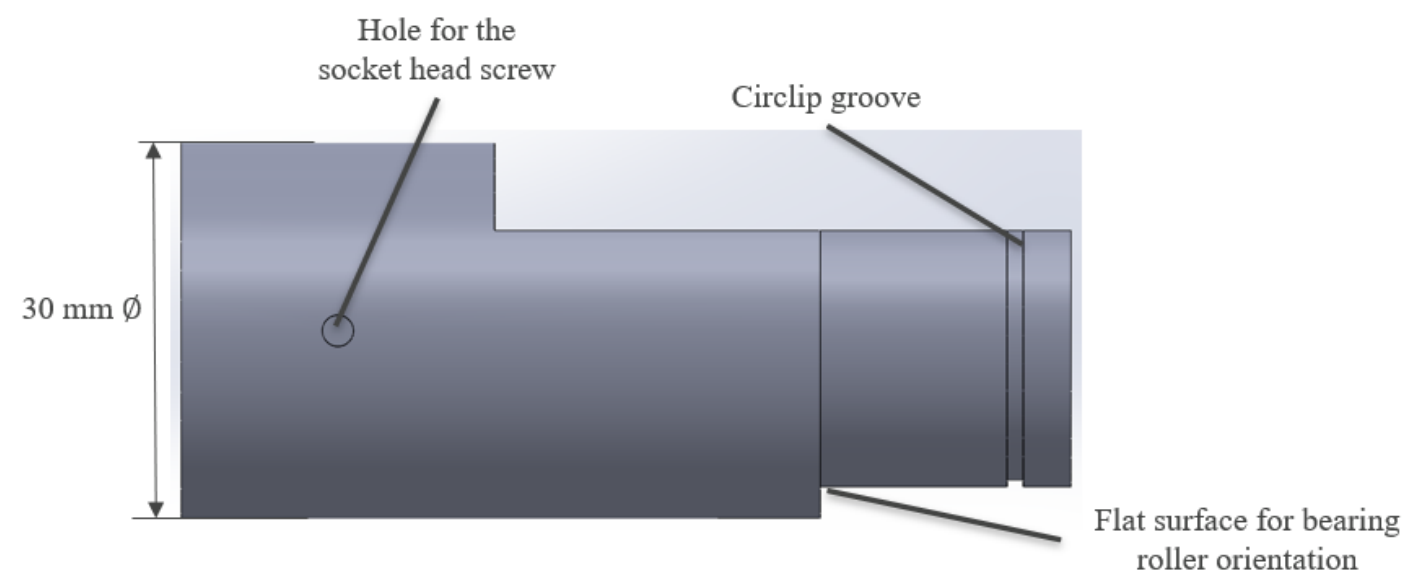

Figure 5.18 - Ball bearing axle for the lateral support.

\section{Vertical supports}

The vertical supports consist of two vertical $45 \mathrm{x} 45 \mathrm{H}$ series profiles from Bosch Rexroth Group [38], with a length of $197.5 \mathrm{~mm}$ that are fixed to the horizontal plate that holds all the supports for the tensile test. On top of these two profiles, there is an aluminium 6063-T6 plate with $15 \mathrm{~mm}$ of thickness, which is holding a block that has an axle made of the same aluminium where the two ball bearings are attached to guide the striker holder. This assembly is shown in Figure 5.19.

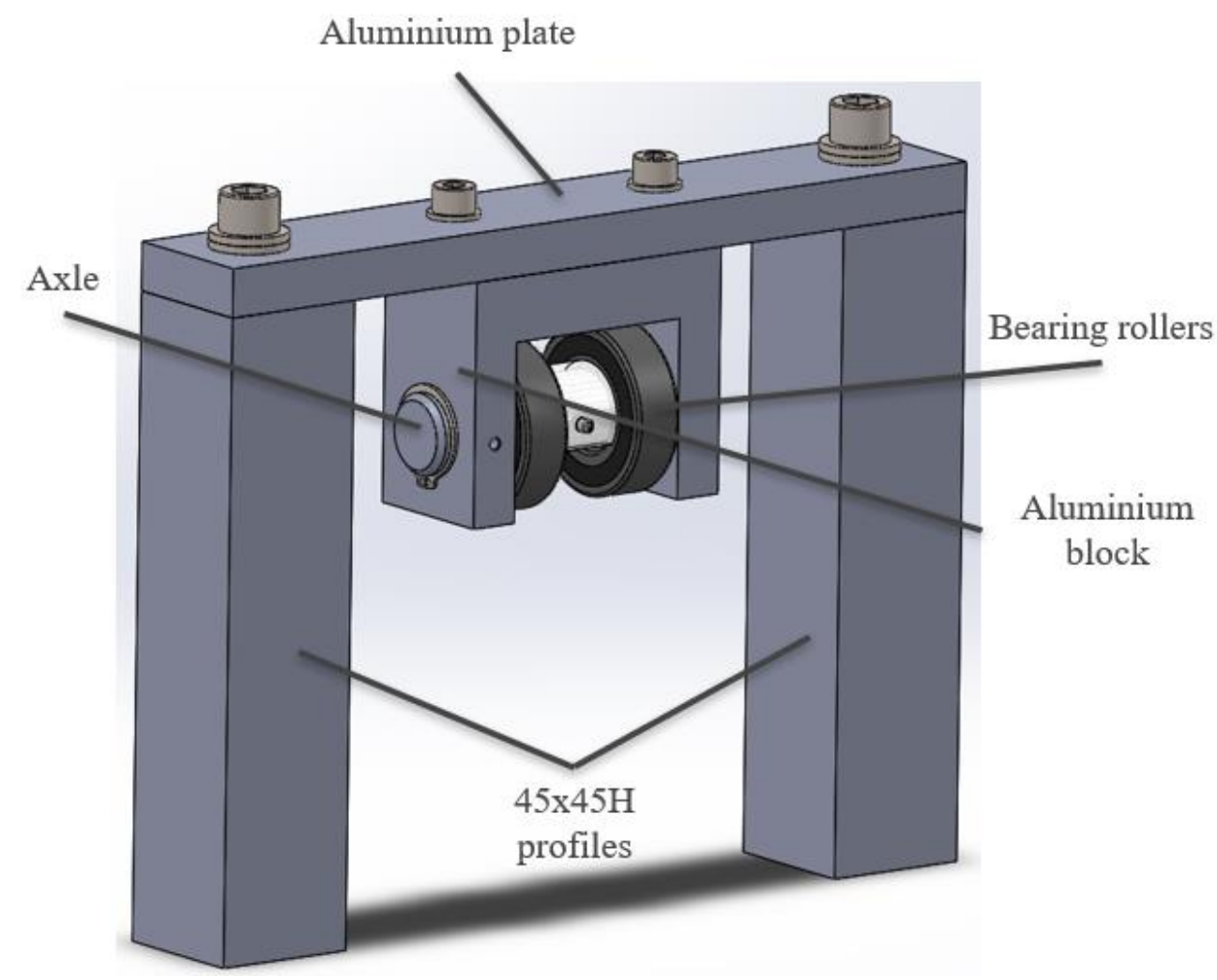

Figure 5.19 - Striker holder vertical support.

The cross-section of the aluminium profiles from Bosch Rexroth Group [38] is shown in Figure 5.20 and in total it was used $845 \times 45 \mathrm{H}$ profiles with a length of $197.5 \mathrm{~mm}$. 


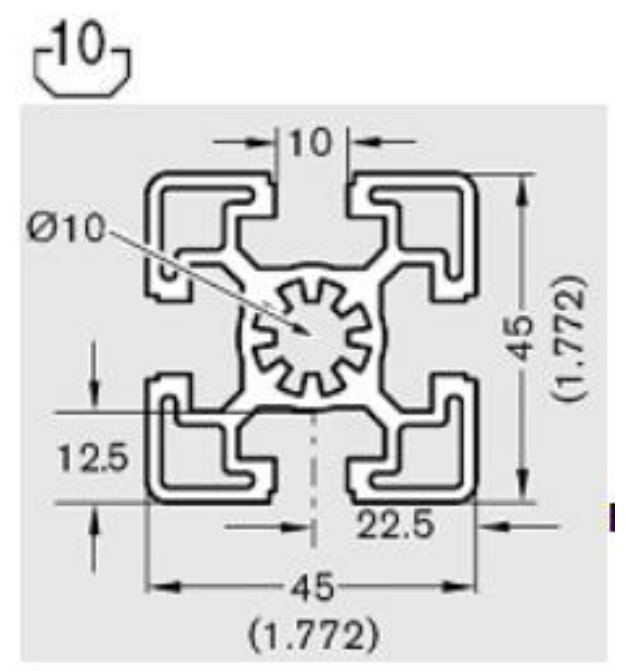

Figure 5.20 - Cross section of the $45 \times 45 \mathrm{H}$ series aluminium profiles.

The aluminium block is fixed to the aluminium plate that is fixed to the top part of the aluminium profiles and it holds both ball bearings as shown in Figure 5.21. This block holds an axle that it is fixed on the ends with the help of a circlip and with the use of a socket head screw dog pin the axle will not be able to rotate. The bearings are fixed with spacers on both sides where they contact the block and are separated by a Nylon bushing that has a socket head screw dog pin to be fixed to the axle. Both axle and nylon bushing have the same flat cut, as mentioned before for the axle in the lateral supports, for the same reason, not hit the small ball bearings that are fixed to the striker holder.

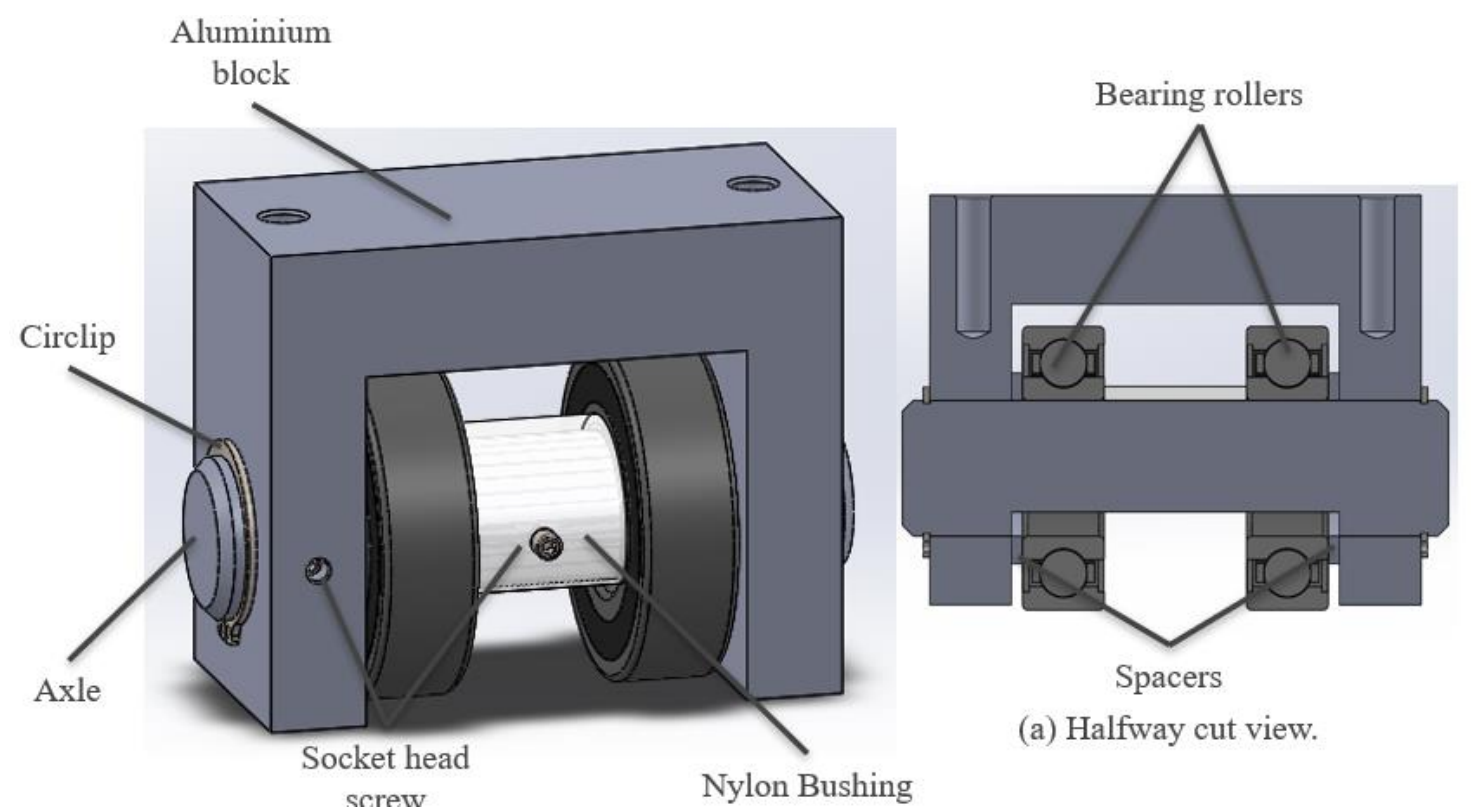

Figure 5.21 - Block that holds both ball bearings.

The ball bearings used for the vertical support are the same ones as used in the lateral supports, the 6205-2Z, and their specifications are presented in Table 5.4.

To connect all the Tensile setup, the materials are presented in Table 5.5. 
Table 5.5 - Fasteners used to assemble the Tensile setup.

\begin{tabular}{|c|c|c|}
\hline Element & Norm & Qt. \\
\hline \multirow{2}{*}{ Ball-bearing } & 628-2Z & 30 \\
\cline { 2 - 3 } & $6205-2 Z$ & 16 \\
\hline Stud & M8x125 mm & 8 \\
\hline Nut & ISO 4033 - M8 - W - N & 8 \\
\hline \multirow{5}{*}{ Screws } & ISO 4017 M8x45 - 8.8 & 24 \\
\cline { 2 - 3 } & ISO 4762 M4x12-8.8 & 60 \\
\cline { 2 - 3 } & ISO 4028 M4x8-8.8 & 16 \\
\cline { 2 - 3 } & ISO 4762 M12x40-8.8 & 16 \\
\cline { 2 - 3 } & ISO 4762 M8x30-8.8 & 8 \\
\cline { 2 - 3 } & ISO 4028 M3x4 - 8.8 & 3 \\
\cline { 2 - 3 } & ISO 4029 M6x30-8.8 & 4 \\
\cline { 2 - 3 } & ISO 4762 M8x40-8.8 & 38 \\
\hline \multirow{5}{*}{ Washer } & DIN 125 - A 6.4 300 HV & 4 \\
\cline { 2 - 3 } & DIN 125 - A 8.4 300 HV & 86 \\
\cline { 2 - 3 } & DIN 125 - A 13 300 HV & 24 \\
\hline Circlip & DIN 471 - 25 x1.2 & 16 \\
\hline
\end{tabular}

\subsection{SHPB Compression setup}

All the mechanical parts that compose this setup can be consulted in Appendix G. This task was done with the help of SolidWorks 2019 and the final design of the compression setup is shown in Figure 5.22. The setup is composed of a pneumatic actuator that will launch a striker bar at $30 \mathrm{~m} / \mathrm{s}$ against the input bar that is holding the bonded joint specimen together with the output bar. To launch the striker bar, this setup requires a striker holder that will be connected to the actuator's rod, which is much smaller when compared to the striker holder used in the tensile setup. The striker holder for the compression test doesn't need any supports, since it is lightweight, around $1 \mathrm{~kg}$, and only requires to be screwed to the rod's end. The striker holder has 12 ball bearings along his full length to guide the striker bar till the impact instant against the input bar. Since it is a compression test, the output bar needs to be stopped after the impact received from the striker bar. The stoppage is done with a momentum trap that will dissipate the energy and stop the output bar.

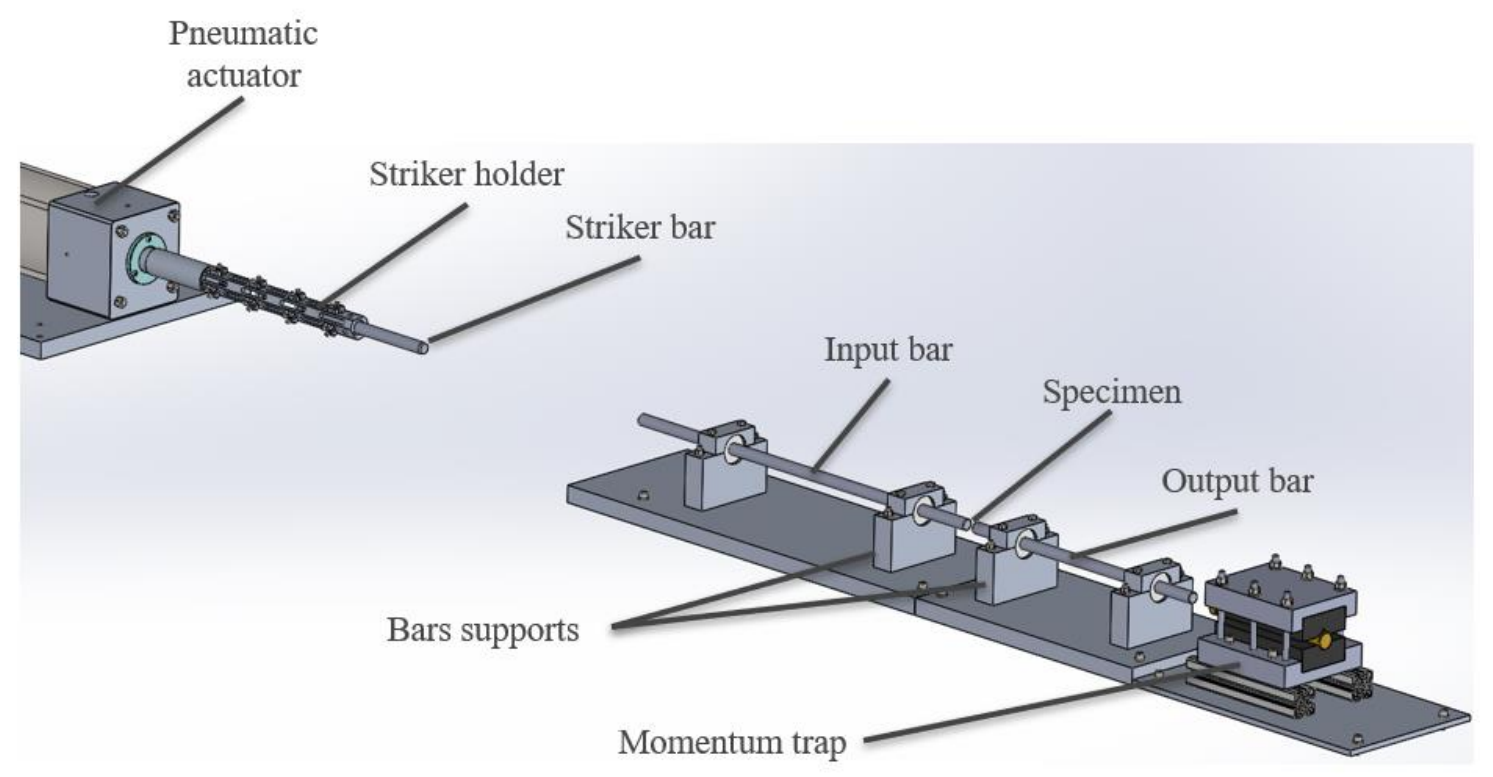

Figure 5.22 - Final model of the compression test setup. 


\subsubsection{Bars and their supports}

The bars and their supports are the same ones used for the tensile test. The bars have the same length, diameter, material, and supports. The only difference is the input bar since there is only a thread with M18 to hold the bonded joint specimen in one end. On the other end, there is no thread because this time there is no loading bar that needs to be attached. This configuration can be viewed in more detail in the previous chapter 5.1.1, and the final look of the bars is shown in Figure 5.23.

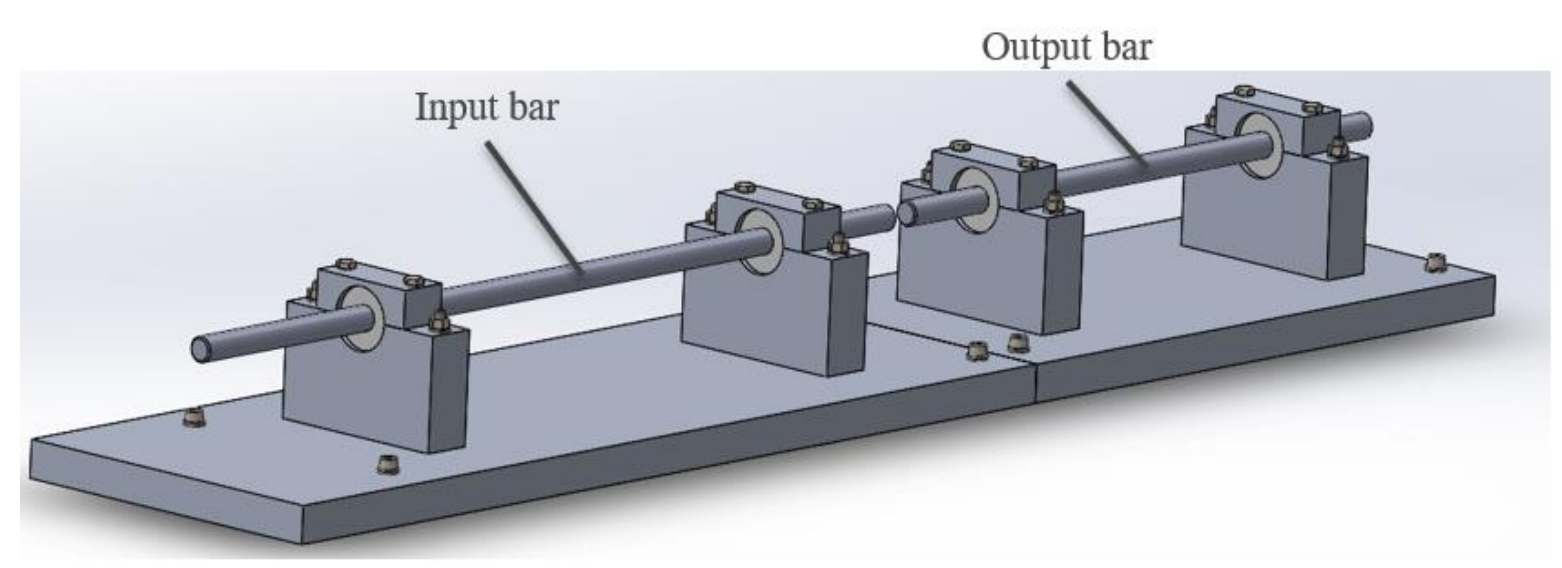

Figure 5.23 - Input bar and output bar for compression tests.

\subsubsection{Striker and striker holder}

For the stress wave propagation to propagate with the same velocity through the input and output bar, the striker bar must be made from the same material as the bars. Therefore, the striker bar is made of AISI 4140 steel, and its mechanical properties can be consulted in Table 5.2 .

The striker bar has a specific length of $250 \mathrm{~mm}$ and an outside diameter of $20 \mathrm{~mm}$, determined by Tenreiro [4]. The striker bar is going to be launched against the input bar by the striker holder which is attached to the pneumatic actuator's rod, and it will be guided by an assembly of ball bearings that are attached to the striker holder.

The striker holder has a connector component to allow fixing it to the pneumatic actuator's rod, made of aluminium 7075-T6. It also has a stopper made of aluminium 6063-T6, which is required to be implemented on the inside of the striker holder, so the striker bar will never go inside of the hollow shaft of the actuator's rod. This assemble is shown in Figure 5.24. 

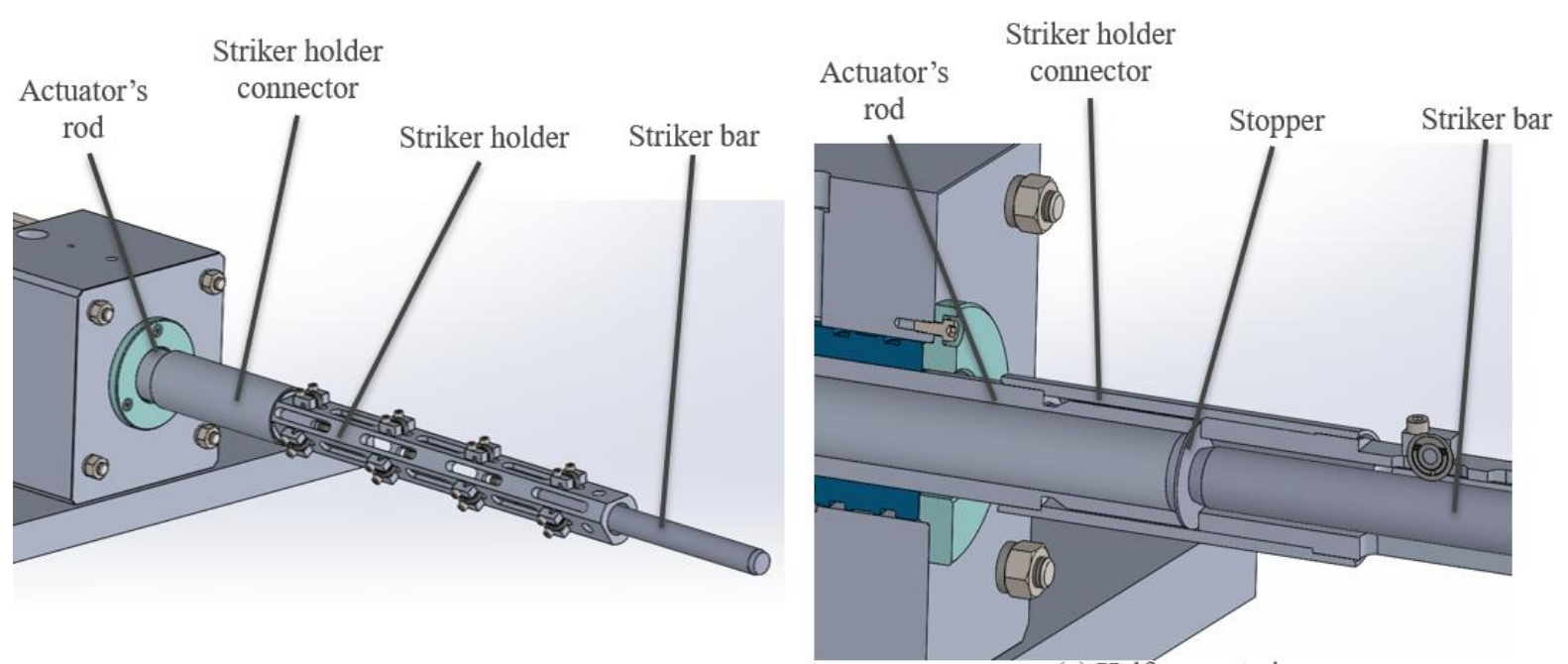

(a) Halfway cut view.

Figure 5.24 - Striker holder and striker bar assembly.

\section{Striker holder}

The striker holder is shown in detail in Figure 5.25. It is made of aluminium 6063-T6 with a length of $400 \mathrm{~mm}$ and $25 \mathrm{~mm}$ of inside diameter and $40 \mathrm{~mm}$ outside diameter. It has 12 ball bearings fixed to the flat surfaces made on the striker holder structure to hold and guide the striker bar and has cuts in form of slots to save as maximum weight as possible while maintaining the integrity of the component. This idea is similar to the one used in the tensile test, but since this structure is much smaller and lighter there are no supports needed, and it will only be fixed to the actuator's rod.
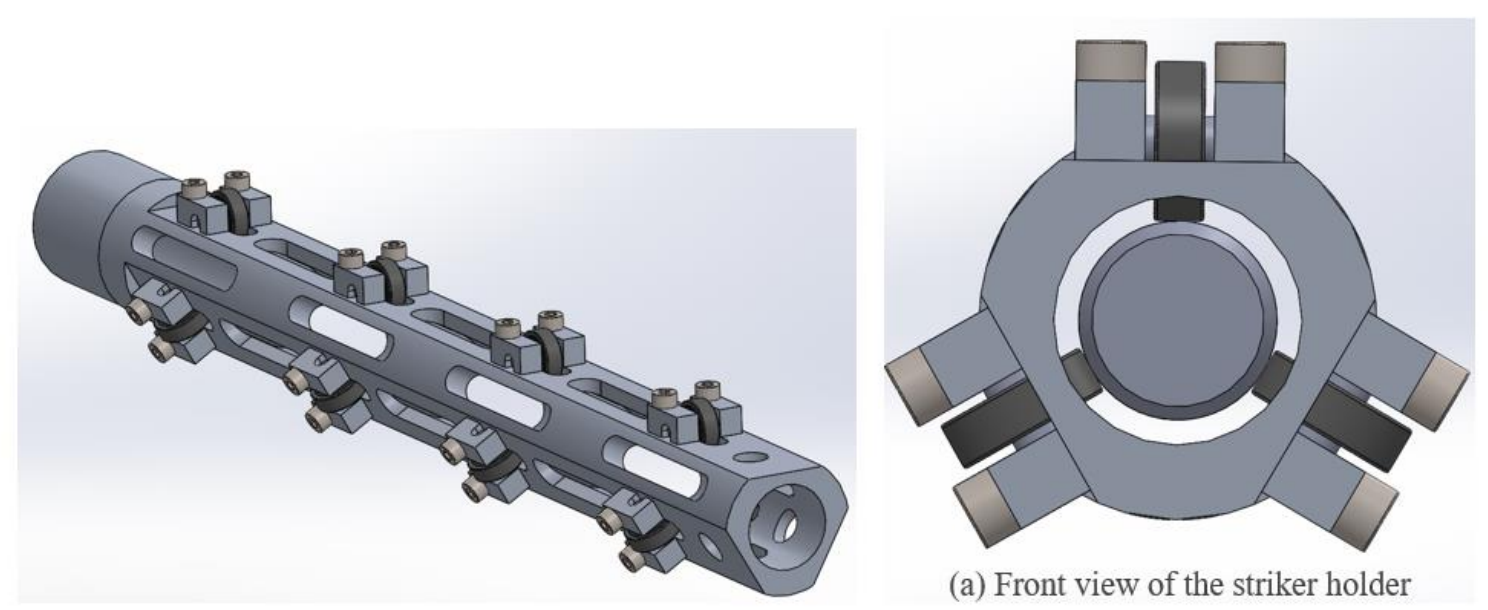

(a) Front view of the striker holder

Figure 5.25 - Final model of the striker holder.

The component designed to allow the connection between the actuator's rod and the striker holder is shown in Figure 5.26. It is made of aluminium 7075-T6 with an outside diameter of $45 \mathrm{~mm}$ and a length of $125 \mathrm{~mm}$. This component has $\mathrm{H} 7$ tolerance in both ends to give the alignment to the striker holder and the actuator's rod and then it screws to both of them with M39. 


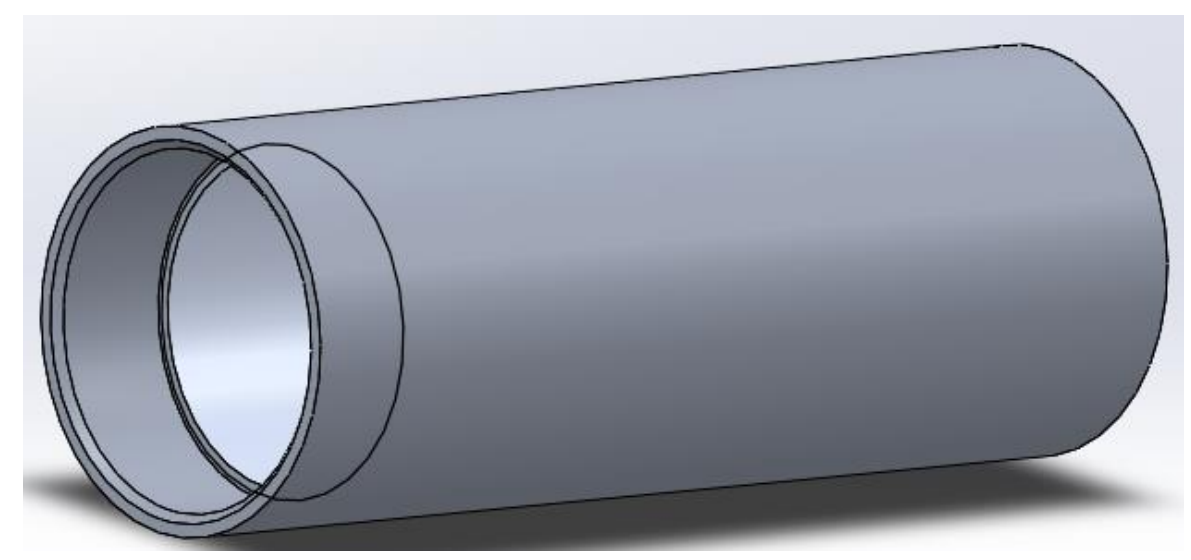

Figure 5.26 - Actuator's rod connector.

The striker bar stopper, made of aluminium 6063-T6, is required since when the striker bar is being loaded on the striker holder it will not travel inside the actuator's rod, as the rod has a higher inside diameter than the striker bar. Therefore, the component is shown in Figure 5.27, where the smaller diameter will slide inside the actuator's rod and will be inserted until the actuator's rod end will hit the flange on the stopper. Then, it will be fixed on the other side because the striker holder is screwed and the space available on the connector is the space where the stopper's flange is allocated.

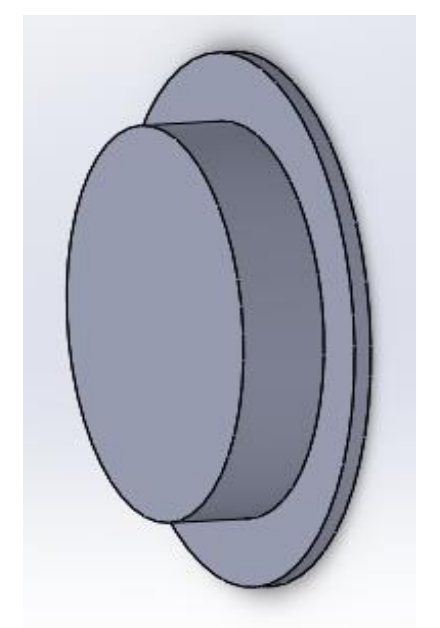

Figure 5.27 - Striker bar stopper.

\subsubsection{Momentum trap}

The purpose of the momentum trap is to arrest the forward motion of the output bar, by dissipating its kinetic energy in a controlled manner. For the specimen to be subject to the compression loading only, the gap between the momentum trap and the output bar must be set precisely before the test. The momentum trap, shown in Figure 5.28, is composed of an aluminium 6063-T6 base and top cap block made from the same aluminium that will compress two blocks with a V groove that extends their length made of Polyurethane with the help of 6 M6 studs and nuts. The aluminium base is screwed to $45 \mathrm{x} 45 \mathrm{H}$ Bosch profiles [38], with the help of T-slots from Bosch Rexroth Group [38], which then is screwed to an aluminium 6063T6 plate with $10 \mathrm{~mm}$ of thickness that will be attached to the support frame. 


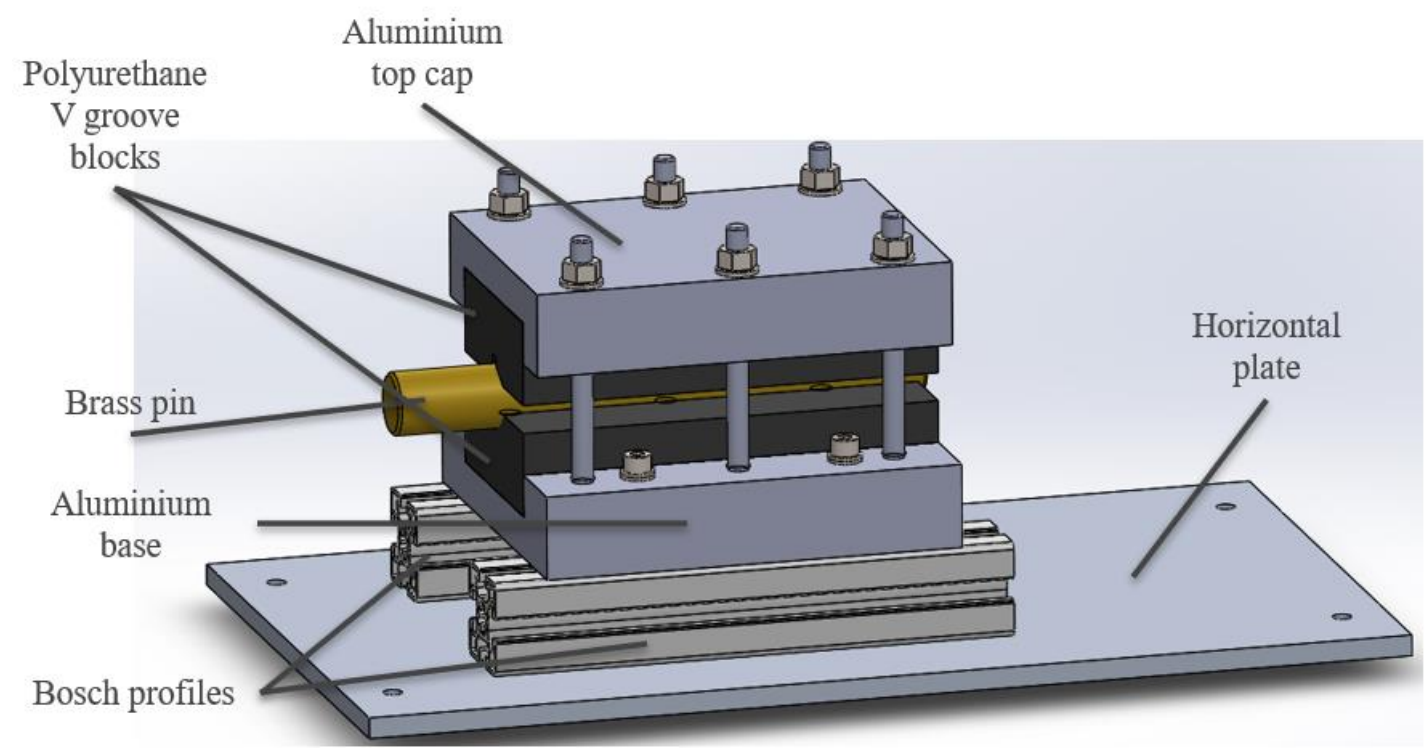

Figure 5.28 - Final model of the momentum trap.

A brass pin is sandwiched between the two polyurethane $\mathrm{V}$ groove blocks to transfer the kinetic energy into heat from the output bar to the polyurethane blocks, the brass pin, and the aluminium base. The V groove in the polyurethane blocks, shown in Figure 5.29, extends the whole length of the blocks. If the pin is hit with too much kinetic energy it can be used a stopper at the end of the momentum trap to provide a safety stop.

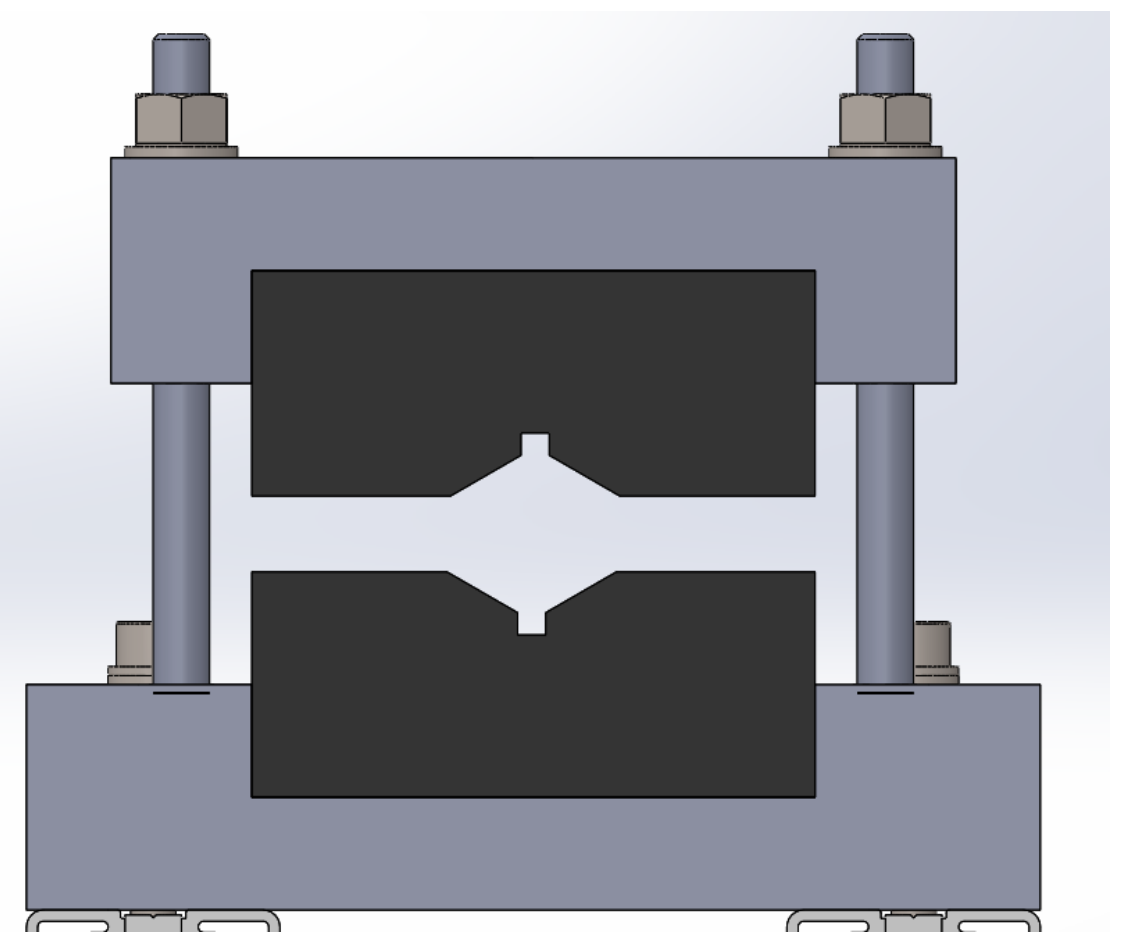

Figure 5.29 - Frontal view of the momentum trap without the brass pin. 
To connect all the Compression setup, the materials are presented in Table 5.6.

Table 5.6 - Fasteners used to assemble the Compression setup.

\begin{tabular}{|c|c|c|}
\hline Element & Norm & Qt. \\
\hline $\begin{array}{c}\text { Ball- } \\
\text { bearing }\end{array}$ & $625-2 Z$ & 12 \\
\hline \multirow{2}{*}{ Stud } & M8x125 mm & 8 \\
\cline { 2 - 3 } & M10x140 mm & 6 \\
\hline Nut & ISO 4033 - M10 - W - N & 6 \\
\hline \multirow{4}{*}{ Screws } & ISO 4017 M8x45-8.8 & 16 \\
\cline { 2 - 3 } & ISO 4762 M4x12-8.8 & 24 \\
\cline { 2 - 3 } & ISO 4762 M8x55-8.8 & 4 \\
\cline { 2 - 3 } & ISO 4762 M8x25-8.8 & 8 \\
\cline { 2 - 3 } & DIN 125 - A 8.4 & 48 \\
\cline { 2 - 3 } & DIN 125 - A 10.5 & 6 \\
\hline T- slots & 10 mm M8, T-Block & 20 \\
\hline
\end{tabular}

\subsection{Support frame to hold both tensile and compression setup}

The support frame, represented in Figure 5.30, is the structure that will hold the tensile and compression setup. It is composed of aluminium frames of the 45 series and 60 series profiles from Bosch Rexroth Group [38], where has two stoppers to give some alignment to the horizontal plates that compose both setups. The idea was to have a structure capable to hold both setups at the same time and when wanted to change from one to another it would just slide the horizontal plates and align the required setup with the actuator's rod. The structure is built with $60 \times 60 \mathrm{H}$ profiles and the profiles used to attach the horizontal plates of the setups are the $45 \times 90 \mathrm{H}$ profiles. It has a height of $900 \mathrm{~mm}$, a width of $780 \mathrm{~mm}$, and a length of $3360 \mathrm{~mm}$. All the mechanical drawings of the parts that compose the support frame can be consulted in Appendix $\mathrm{H}$.

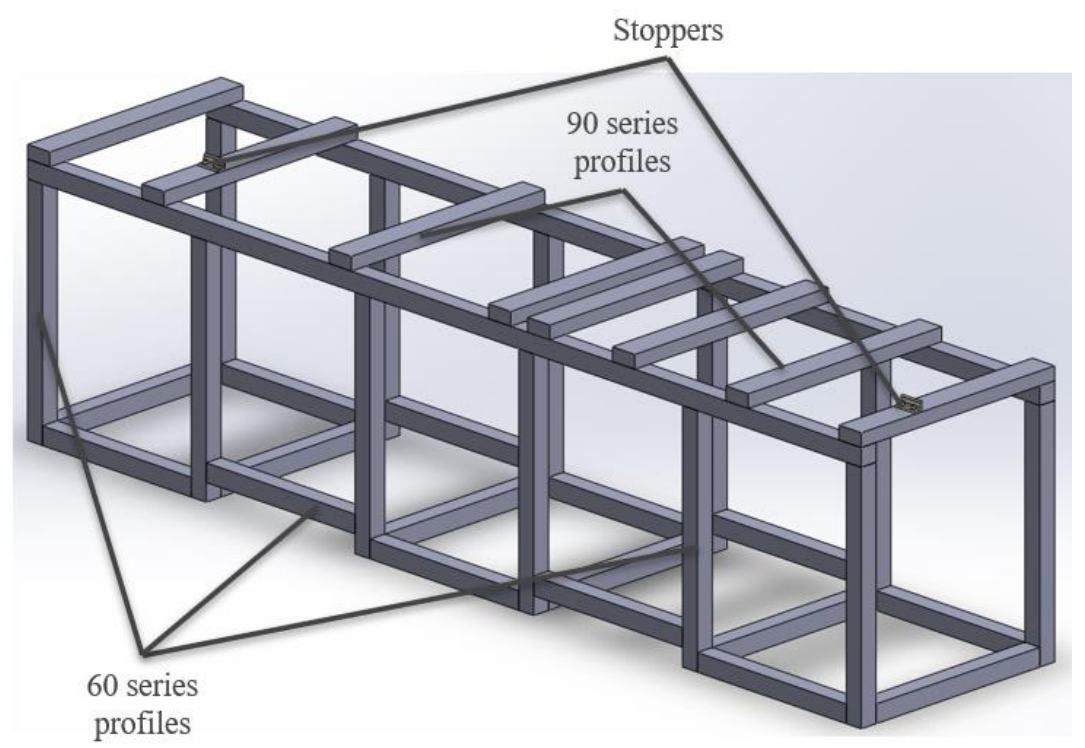

Figure 5.30 - Final model of the support frame for tensile and compression setup. 
The aluminium frames from Bosch Rexroth Group [38], used in this assembly are the $60 \mathrm{x} 60 \mathrm{H}$ profiles that compose the overall structure and on the top of it. The profiles where the horizontal plates will be attached are the $45 \times 90 \mathrm{H}$. Both cross-sections are presented in Figure 5.31 and, as mentioned before, these profiles are ideal for heavy-duty applications. For the connection of the parts, the use of T-slots is a requirement.

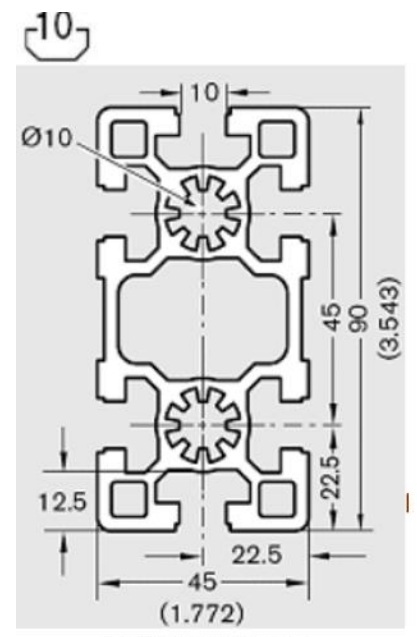

(a) $45 \times 90 \mathrm{H}$ profile.

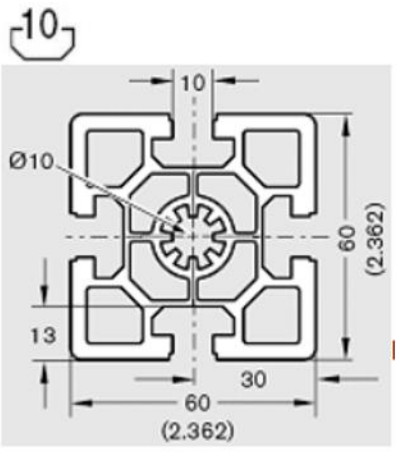

(b) $60 \times 60 \mathrm{H}$ profile .

Figure 5.31 - Cross section of the aluminium profiles that compose the support frame for tensile and compression setup.

The structure is composed of $260 \times 60 \mathrm{H}$ profiles with a length of $3360 \mathrm{~mm}, 845 \times 90 \mathrm{H}$ profiles with $780 \mathrm{~mm}$ of length, $1260 \times 60 \mathrm{H}$ profiles with a length of $795 \mathrm{~mm}, 1060 \times 60 \mathrm{H}$ profiles with $600 \mathrm{~mm}$ of length, and finally with $660 \times 60 \mathrm{H}$ profiles with $660 \mathrm{~mm}$ of length.

The structure also has two stoppers, as mentioned before, to align the horizontal plates of the tensile setup or the compression setup to the actuator's rod, composed of a 30x30x80 mm L profile made of S275 steel and two bolts to be screwed to the structure.

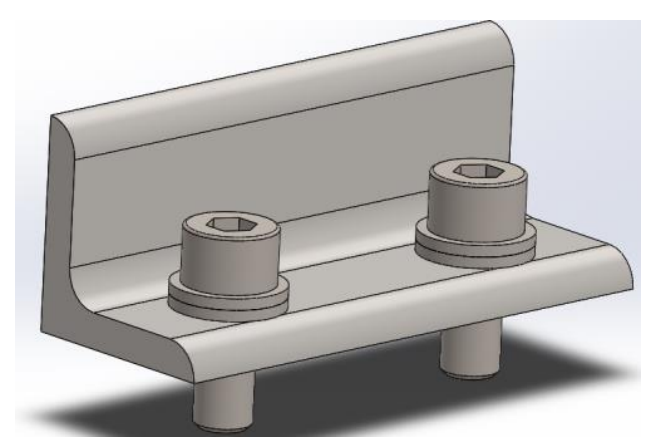

Figure 5.32 - Stopper used to give alignment to the tensile and compression setup.

To connect the stoppers to the support frame, the materials are shown in Table 5.7.

Table 5.7 - Fasteners used to assemble the support frame.

\begin{tabular}{|c|c|c|}
\hline Element & Norm & Qt. \\
\hline Screw & ISO 4762 M8x20-8.8 & 4 \\
\hline Washer & DIN 125 - A 8.4 300 HV & 8 \\
\hline
\end{tabular}


The final model of the tensile setup and compression setup mounted in the support frame is shown in Figure 5.33, where (a) shows the tensile setup aligned with the actuator's rod with compression setup on the side, and (b) the compression setup aligned with the tensile setup on the side.
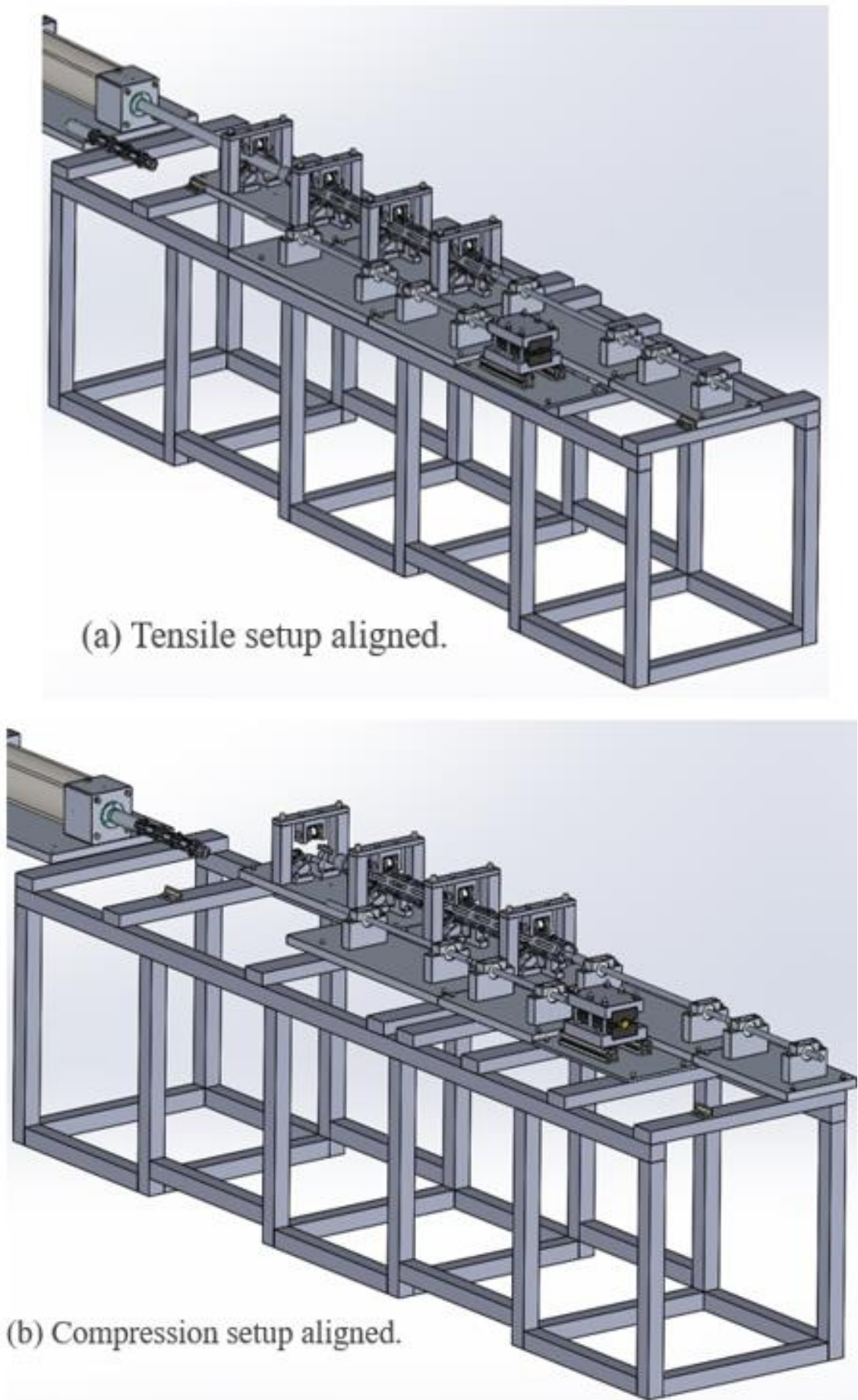

Figure 5.33 - Final model of the tensile and compression setup. 
Development of a Split Hopkinson Pressure Bar machine for high strain rate testing of bonded joints 


\section{Conclusions and future developments}

This chapter concludes this dissertation's report, making considerations about the achieved objectives and presenting some proposals for future developments on the Split Hopkinson Pressure Bar machine.

\subsection{Conclusions}

As stated in section 1.2, the main objective for this dissertation's work was to develop a Split Hopkinson Pressure Bar machine and continue the work started by Tenreiro [4], that respected the requirements such as test adhesive joints at an impact velocity of $30 \mathrm{~m} / \mathrm{s}$ and a braking system to stop the pneumatic actuator within a stroke of $300 \mathrm{~mm}$ of length.

The braking system has been successfully designed and, to validate its construction, a dynamic study was made to understand how the system could stop the actuator's rod movement. The solution found was to develop a braking system inspired by a transmission lever system. This way, the system is capable of reducing the forces, therefore it was possible to develop an assembly composed of disc springs and industrial shock absorbers to stop the actuator. The results of that study showed that the system had to dissipate $210 \mathrm{kN}$ of force. Many simulations were done to determine which materials were needed to make the structure capable to withstand the load forces. The braking system developed is capable of stopping the actuator's rod movement in both tensile and compression testing, by just rotating the braking system structure.

Both tensile and compression bar's setup were completely developed. The bars must be made of the same stainless steel and must have the same cross-section area, so the stress wave propagation can propagate with the same velocity throughout the different bars and specimen.

A support frame to support the pneumatic actuator and braking system was also designed, as well as another support frame to hold both tensile and compression bar's setup. It was built two different support frames to avoid the transmission of vibrations from the actuator and braking system assembly to the bar's components structure that holds the adhesive joints to be tested.

The mechanical drawings of the pneumatic actuator developed by Tenreiro [4] were revised and, after validating them, the actuator was manufactured and completely assembled. All the pneumatic components needed to make the actuator were bought.

Despite all the objectives defined in chapter 1.2 were completed, there is still room for more development and some proposals for future work are presented in the next section.

\subsection{Future developments}

Although the machine is completely designed, there is a need to order the materials to manufacture the parts to complete the machine construction. After the acquisition of all materials, the assembling of the machine is possible, and it will be ready to be tested.

There is also the need to implement the data acquisition system to test the adhesive joints and the development of software to control the machine. 
The support frame structure that holds the pneumatic actuator and the braking system needs to be reinforced to dissipate the $70 \mathrm{kN}$ of force generated when the machine works at its maximum velocity of $30 \mathrm{~m} / \mathrm{s}$. 


\section{Bibliography}

[1] J. Kuczmaszewski, "Fundamentals of metal-metal adhesive joint design," Lublin University of Technology, 2006.

[2] L. F. d. Silva, A. Öchsner and R. D. Adams, "Handbook of adhesion technology," 2011.

[3] J. J. d. M. Machado, "Impact strength optimization with cohesive zone elements of multimaterial bonded structures used in the automotive industry," 2017.

[4] A. F. d. G. Tenreiro, "Development of a Split Hopkinson Bar type machine to measure the impact resistance of bonded joints," September 2018.

[5] M. D. Banea and L. F. M. d. Silva, "Proceedings of the Institution of Mechanical Engineers," in Part L: Journal of Materials Design and Applications, 2009, p. 223.

[6] M. D. Banea, L. F. M. d. Silva and R. D. Campilho, "The Journal of Adhesion," p. 90, 2014.

[7] R. Adams and J. A. Harris, "A critical assessment of the block impact strenght of adhesive bonds," pp. vol. 16, no. 2, pp. 61-71, 1996.

[8] A. Gursel and H. M. Cekirge, "Adhesive Joints Subjected to Impact Loading: A Review," International Journal of Materials Engineering, vol. 9(1), pp. 16-21, 2019.

[9] D. d. P. C. Antunes, "Development of a Drop Weight Machine for Adhesive Joints Testing," February 2019.

[10] W. W. Chen and B. Song, Split Hopkinson (Kolsky) Bar: Design, Testing and Applications, New York, USA: Springer, 1 ed., 2011.

[11] L. F. d. Silva, D. A. Dillard, B. Blackman and R. D. Adams, "Testing adhesive joints: best practices. John Wiley \& Sons,” 2012.

[12] “THIOT Ingenierie," [Online]. Available: https://www.thiot-ingenierie.com/en/. [Accessed 1011 2019].

[13] "REL," [Online]. Available: https://www.relinc.com/split-hopkinson-bar-kolskybars/sure-test-systems/. [Accessed 1011 2019].

[14] "Natural Impacts LTD," [Online]. Available: https://www.naturalimpacts.com/. [Accessed 209 2019].

[15] B. Rexroth, "Bosch Rexroth Linear bushings and shaft," [Online]. Available: https://www.boschrexroth.com/MTeShop/Configuration/?Scenario=portal\&cat=LinearMotion-Technology-Catalog \&p=g255581\&pi=442CC8B5-01E7-9C8F1535DC03769DC180_ICS_87\&Configurator=Wellen\&Modelcode=Wellen\&ConfigSta teChange=NextStep:(0-93*297). [Accessed 2012 2019].

[16] Polylanema, "Polylanema," [Online]. Available: https://www.polylanema.pt/. [Accessed $25112019]$.

[17] R. Aços, "Ramada Aços," [Online]. Available: https://www.ramada.pt/pt/. [Accessed 25 $112019]$. 
[18] Teclena, "Teclena tubos Hidraulicos retificados," [Online]. Available: http://www.teclena.pt/pt/produtos/oleohidraulica/tuboretificadohastecromadaeolhaispar acilindros/\#/pt/. [Accessed 2511 2020].

[19] Equinotec, "Equinotec - Bosch Rexroth,” [Online]. Available: https://www.equinotec.pt/. [Accessed 1012 2019].

[20] Tecnogial, "Tecnogial," [Online]. Available: http://www.tecnogial.pt/. [Accessed 101 2020].

[21] OAV, "OAV Air bearings,” [Online]. Available: https://www.oavco.com/oav040mb.

[22] Rovandi, "Rovandi," [Online]. Available: https://www.rovandi.pt/. [Accessed 146 2020].

[23] Simrit, “O-Rings and Static Seals, 2007.

[24] Simrit, "Seals for Fluid Power, 2007.

[25] Fabory. [Online]. Available: https://www.fabory.com/pt. [Accessed 206 2020].

[26] Amtrol-Alfa, "Refrigerant - Inovation Is Cool".

[27] SMC, "Modular F.R.L. Unit - Series AC".

[28] SMC, "Regulator with Built-in Pressure Gauge - Filter Regulator with Built-in.

[29] SMC, “3 Port Solenoid Valve - Series VP 300/500/700.”.

[30] SMC, “Quick Exhaust Valve - Series AQ.”.

[31] SMC, “Check Valves INA-14 and XTO-674.”.

[32] ACE, ACE Main Catalogue, 2016.

[33] Schaeffler, "schaeffler medias," [Online]. Available: https://medias.schaeffler.com/medias/pt!hp/. [Accessed 2012 2019].

[34] F. DISC, “SERIES SP BELLEVILlE SPRINGS," [Online]. Available: https://www.fandisc.com/disc-springs-series-sp-belleville-spring-index.html\#. [Accessed 101 2020].

[35] Schnorr, Handbook for Disc Springs, Adolf Schnorr GmbH + Co. KG, 2003.

[36] Schnorr, "Schnorr Disc Spring Engineering," [Online]. Available: https://www.schnorrgroup.com/en/products/disc-springs/standard-discsprings/?tx_avschnor__productfilter\%5Breset\%5D=. [Accessed 1012020 ].

[37] SKF, "SKF plain bearing medias," [Online]. Available: https://www.skf.com/au/products/plain-bearings/bushings-thrust-washersstrips/bushings/productid-PCM\%20606560\%20M. [Accessed 102 2020].

[38] B. R. Group, “ Aluminium Framing Resource Center," [Online]. Available: https://www13.boschrexrothus.com/Framing_Shop/Product/View_Product.aspx? category=10108\&subcategory=1. [Accessed 106 2020].

[39] R. Gerlach, C. Kettenbeil and N. Petrinic, "A new split Hopkinson tensile bar design," International Journal of Impact Engineering, pp. 63-67, 2012. 
[40] SKF, "SKF Rolamento rígido de esferas medias," [Online]. Available: https://www.skf.com/pt/products/rolling-bearings/ball-bearings/deep-groove-ballbearings. [Accessed 106 2020].

[41] S. C. Constantino, "Aluminium FSW joints under high strain rate tensile testing," September 2016.

[42] Schnorr, Handbook for Disc Springs. 
Development of a Split Hopkinson Pressure Bar machine for high strain rate testing of bonded joints 


\section{Appendix A}

\section{Matlab Simulink}

\section{Dynamic Behavior Model}


Dynamic model for transmission lever

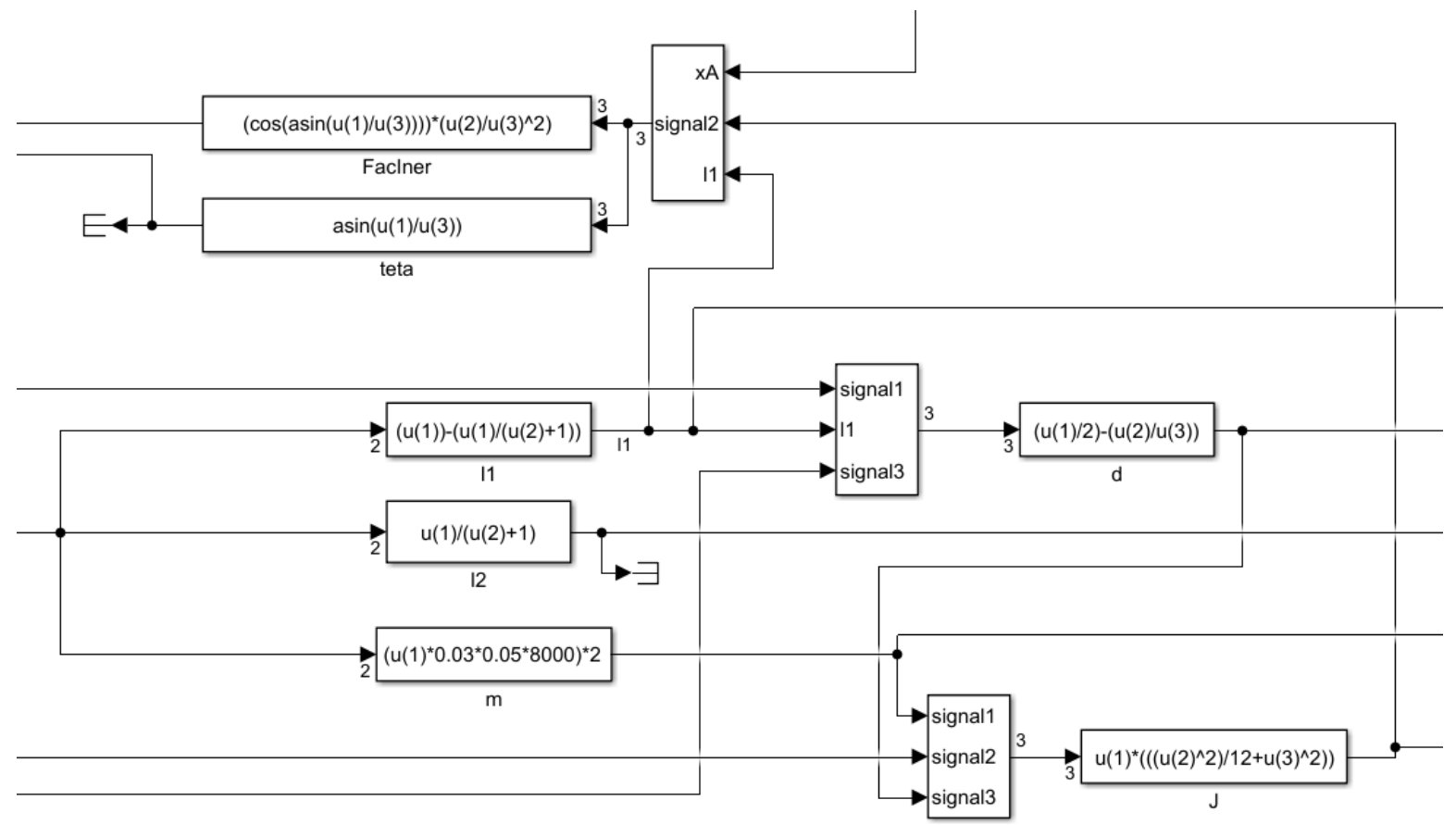

Dynamic model on Node C

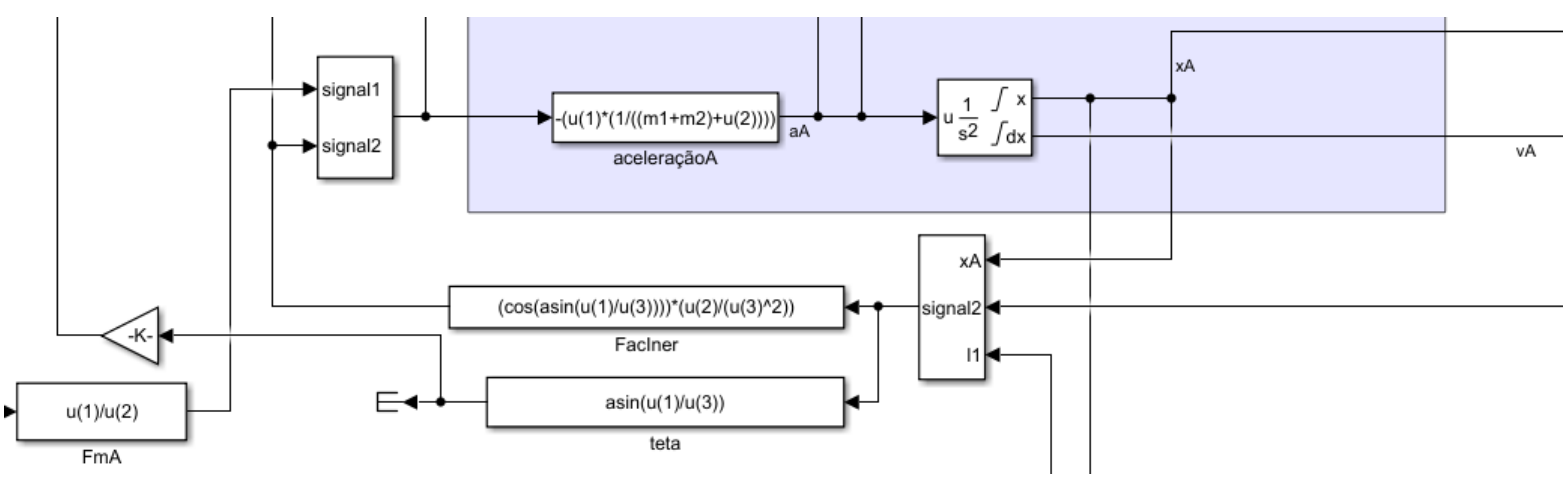

\section{Dynamic model on Node A}

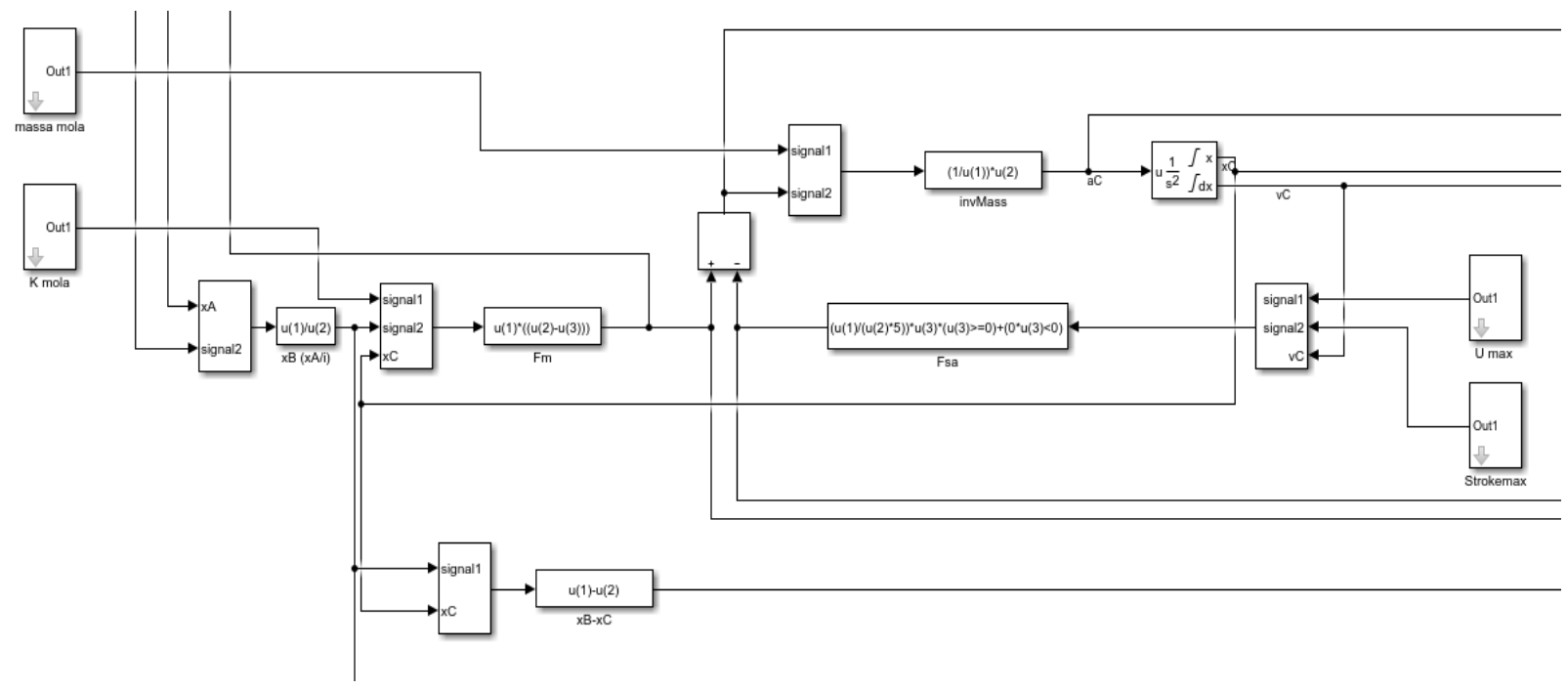




\section{Appendix B}

\section{Mechanical Drawings}

\section{Pneumatic Actuator}




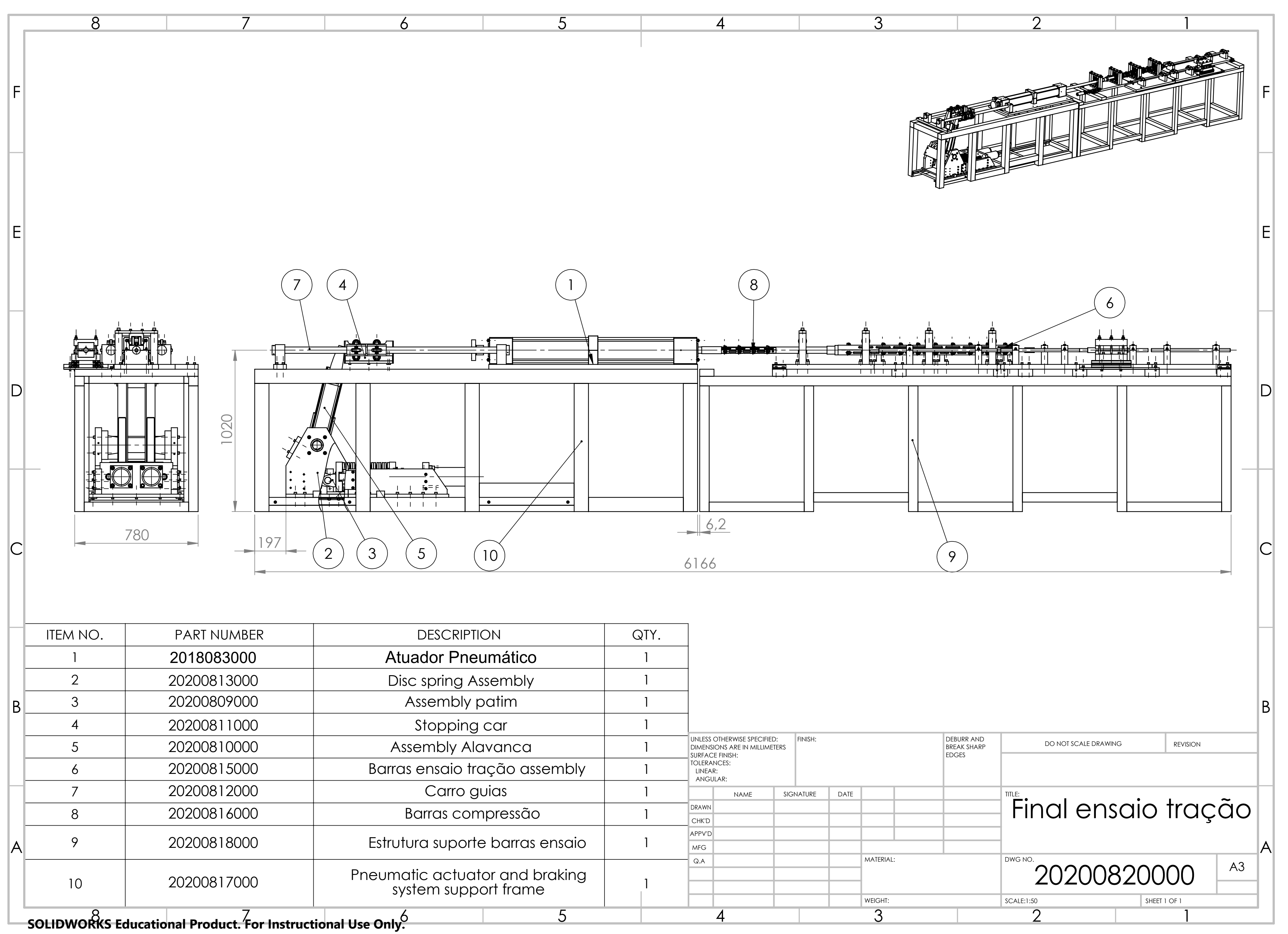




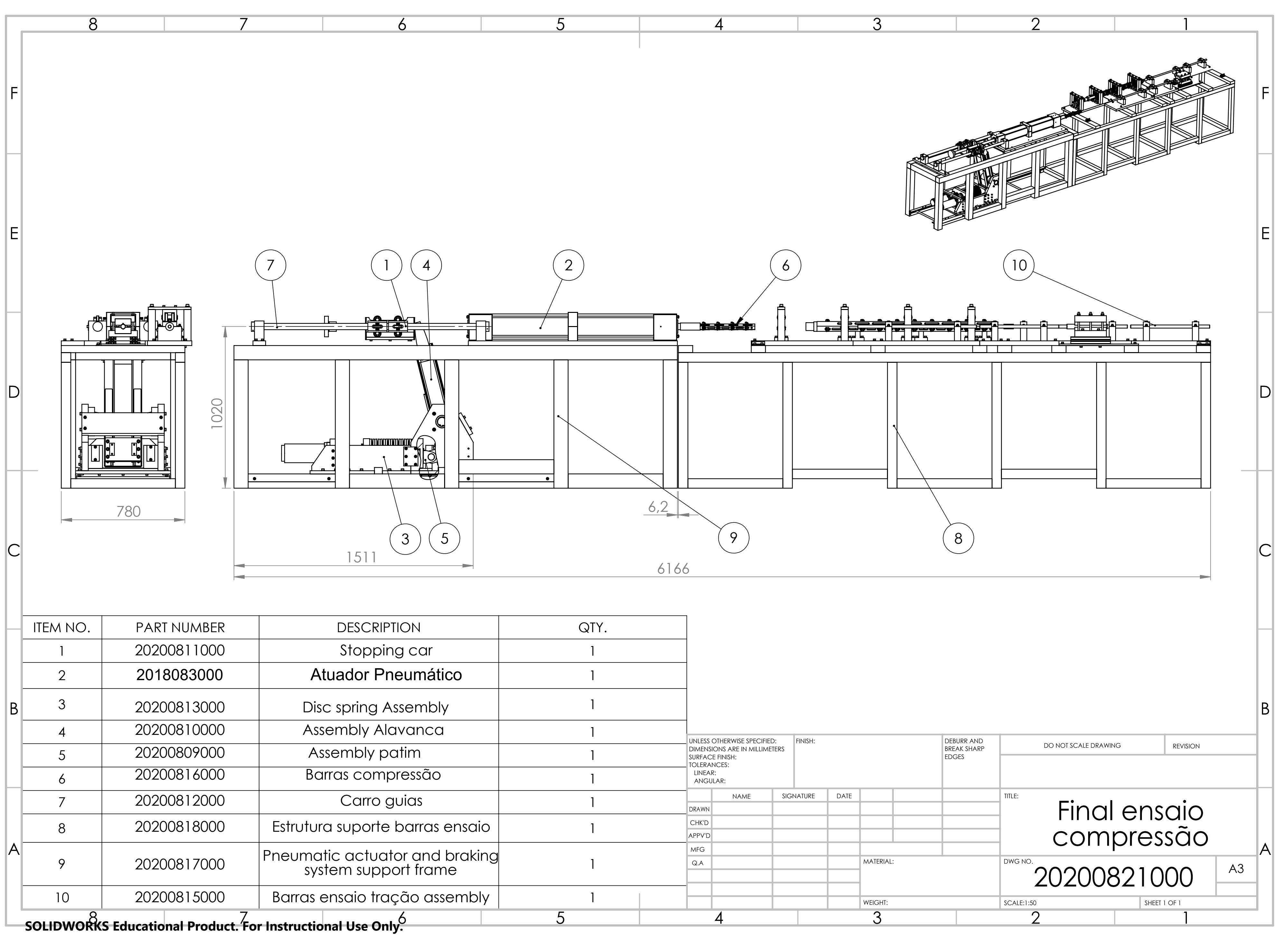



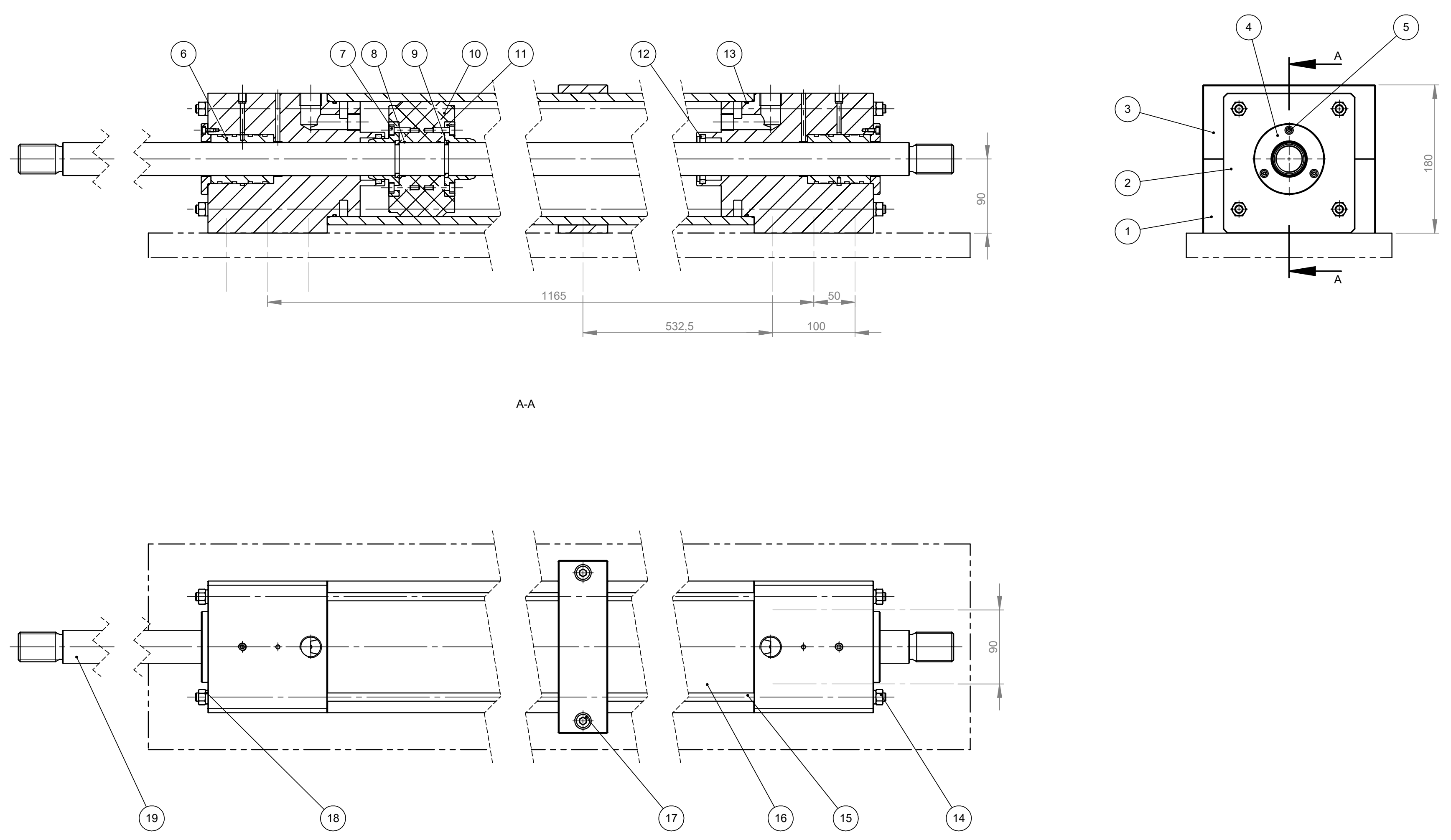

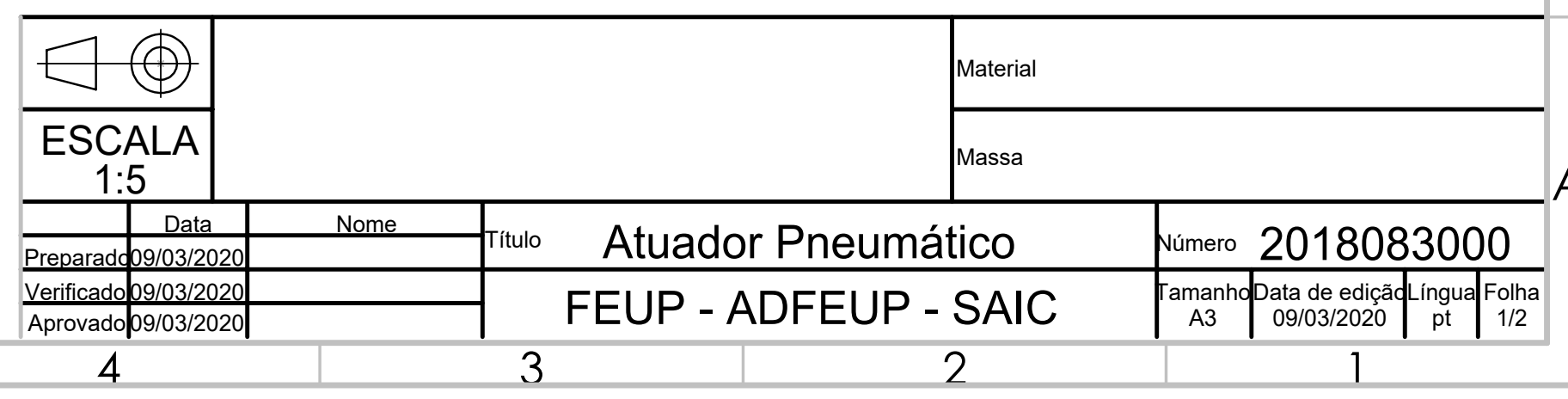




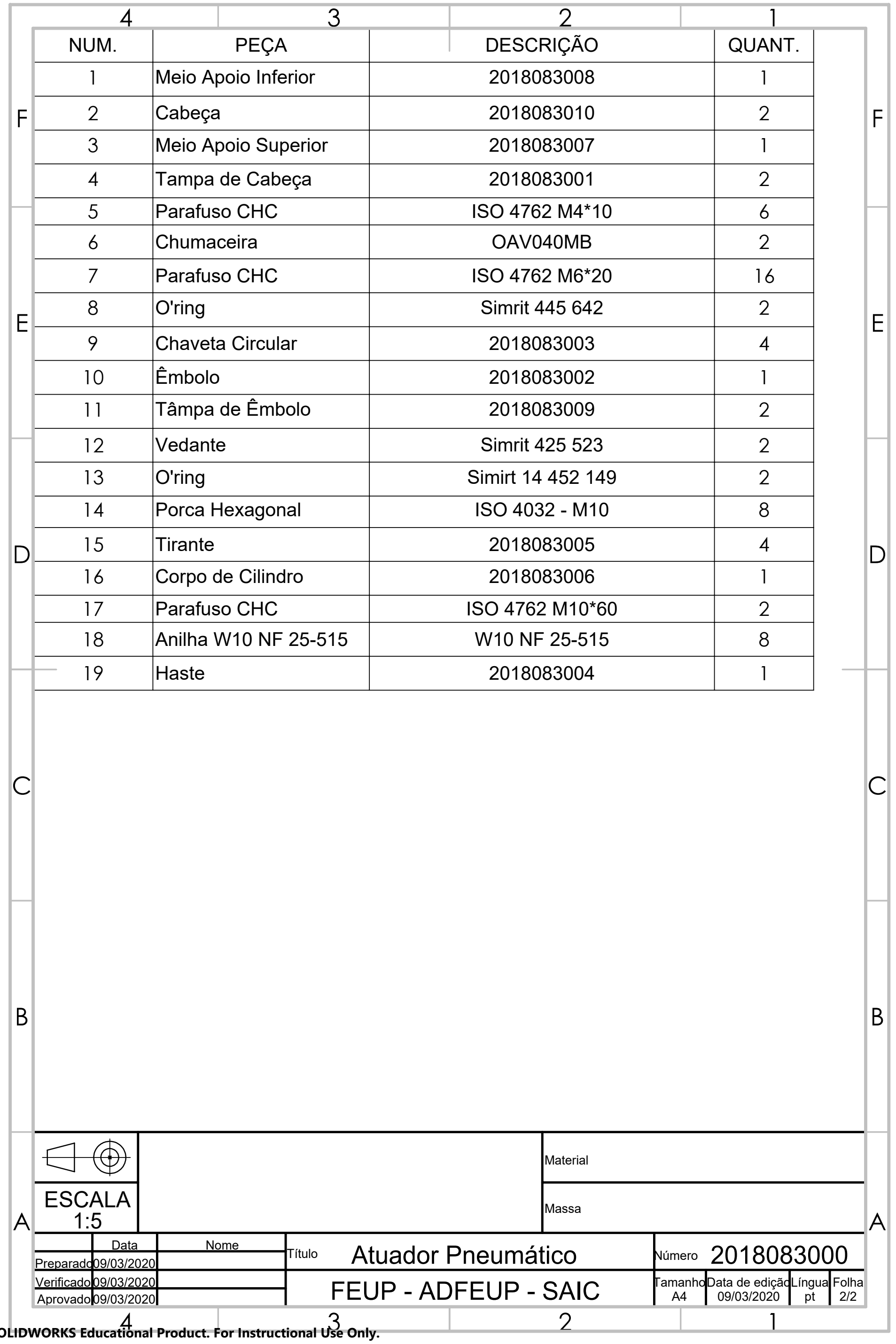




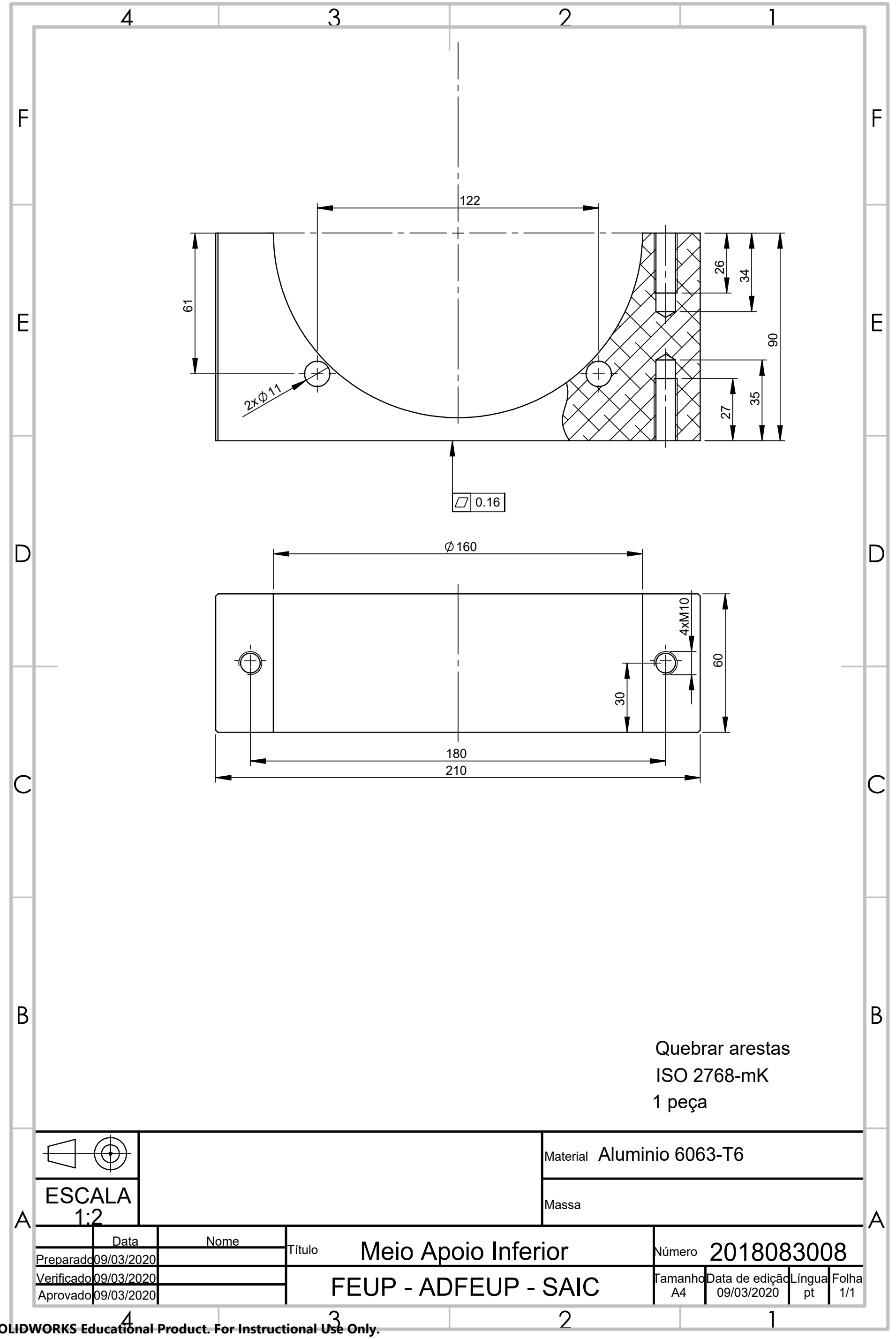




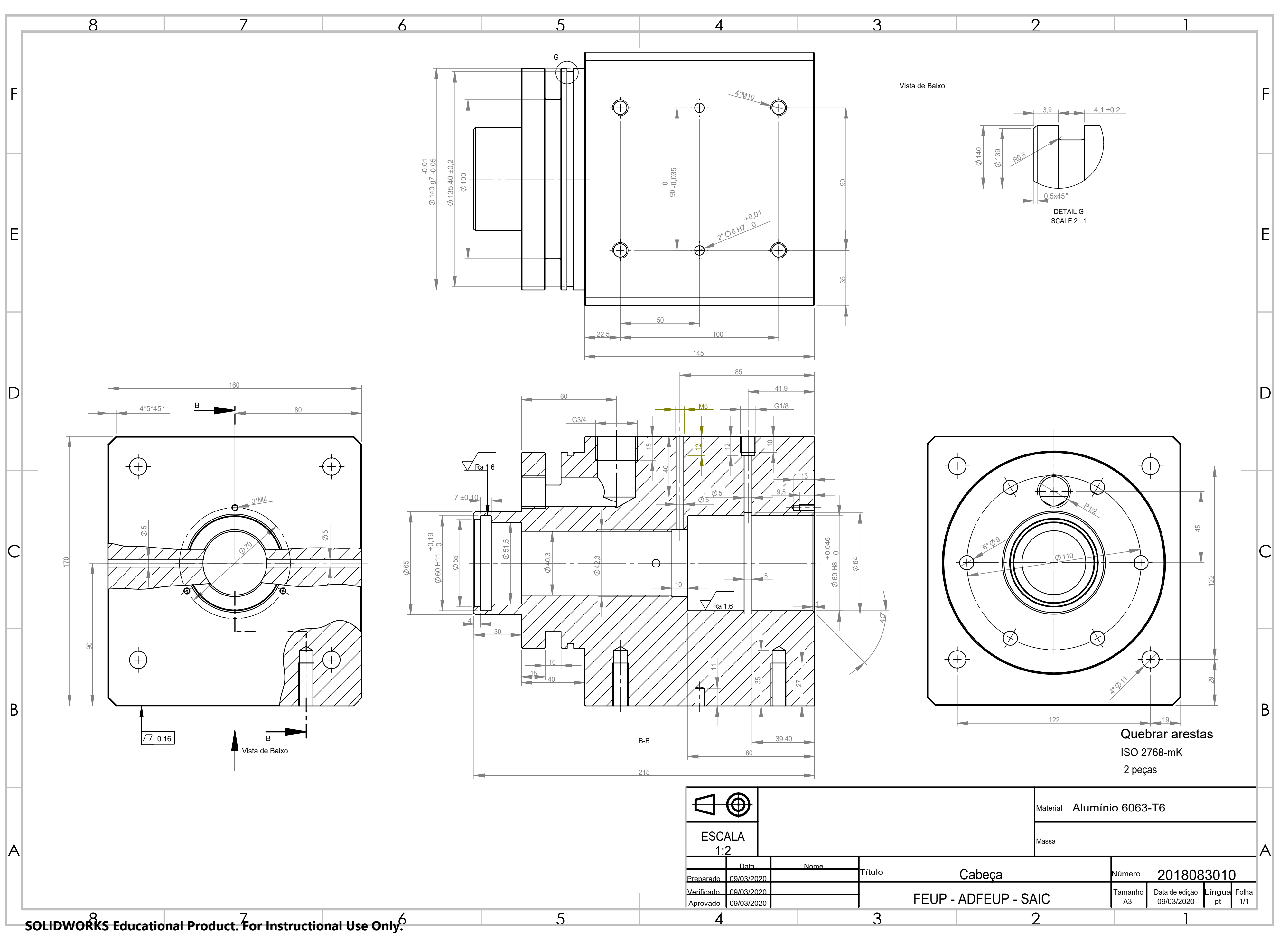




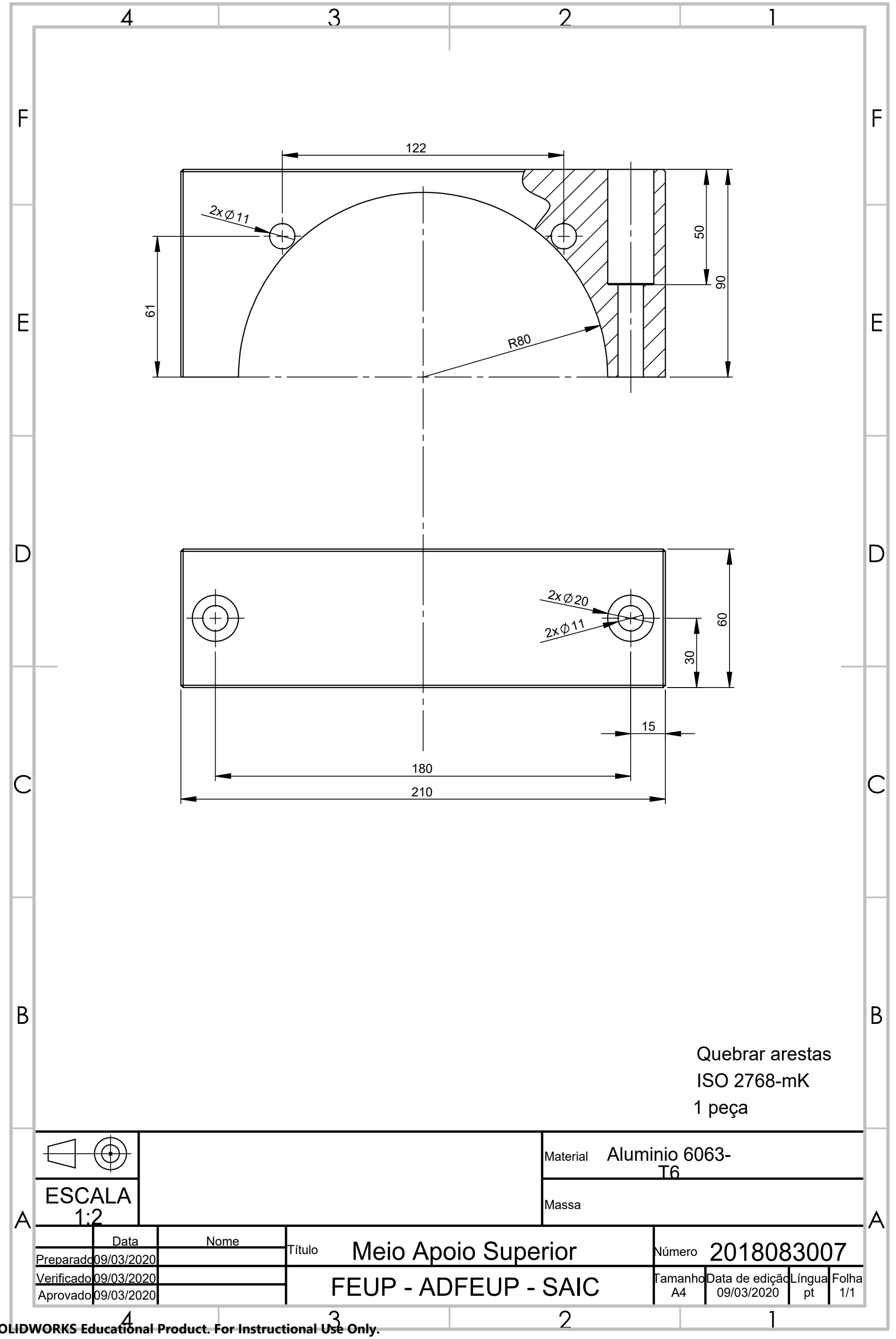




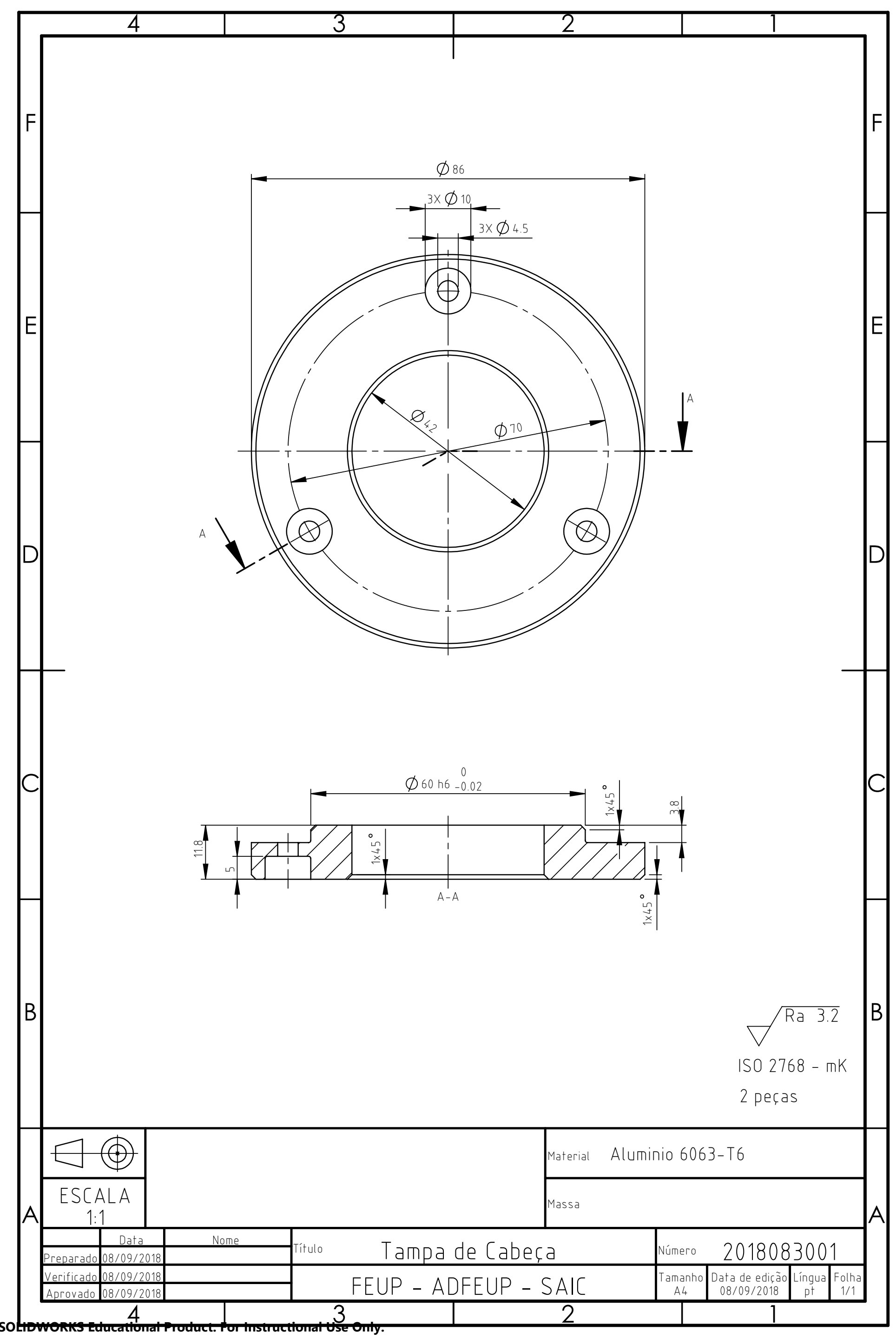




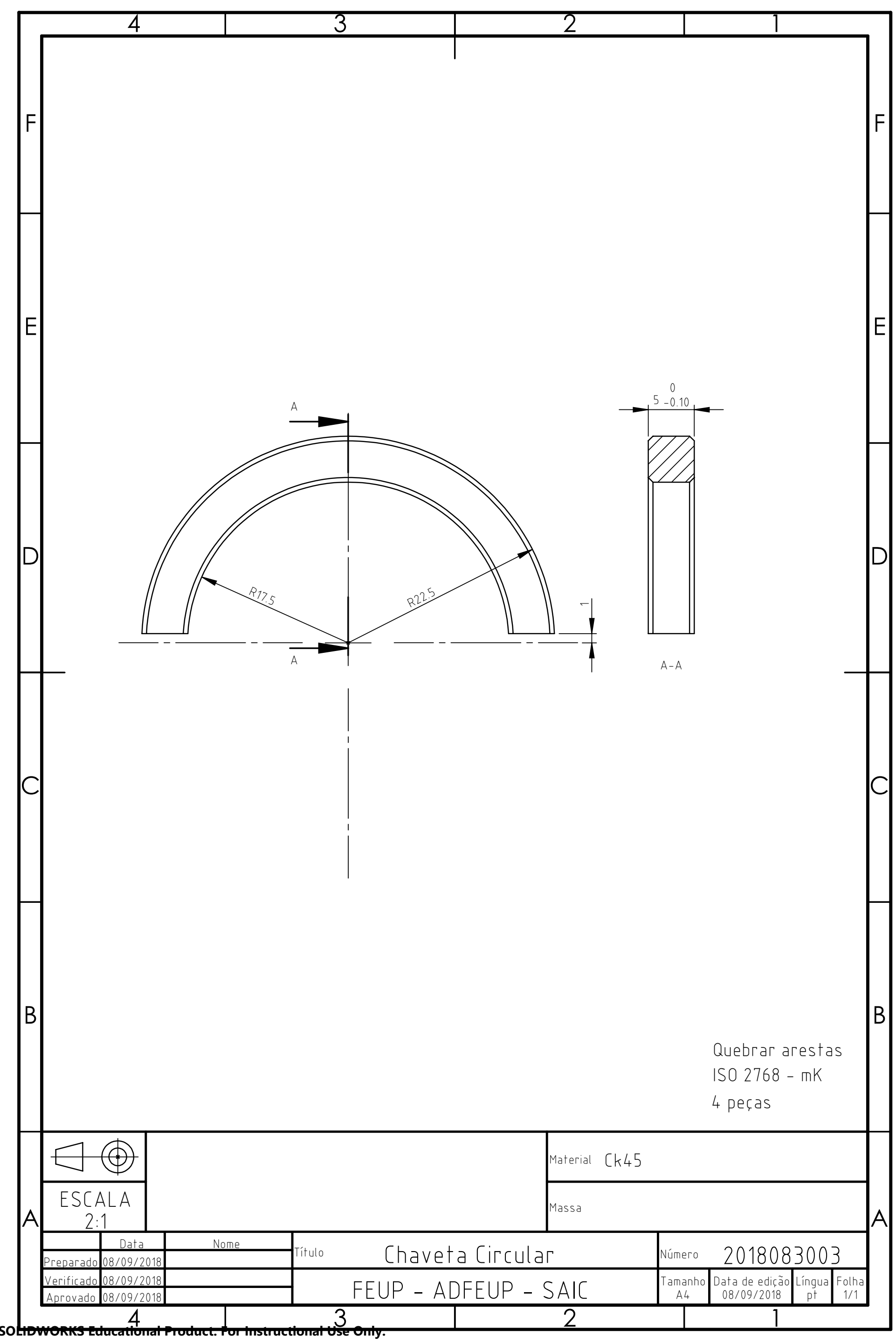




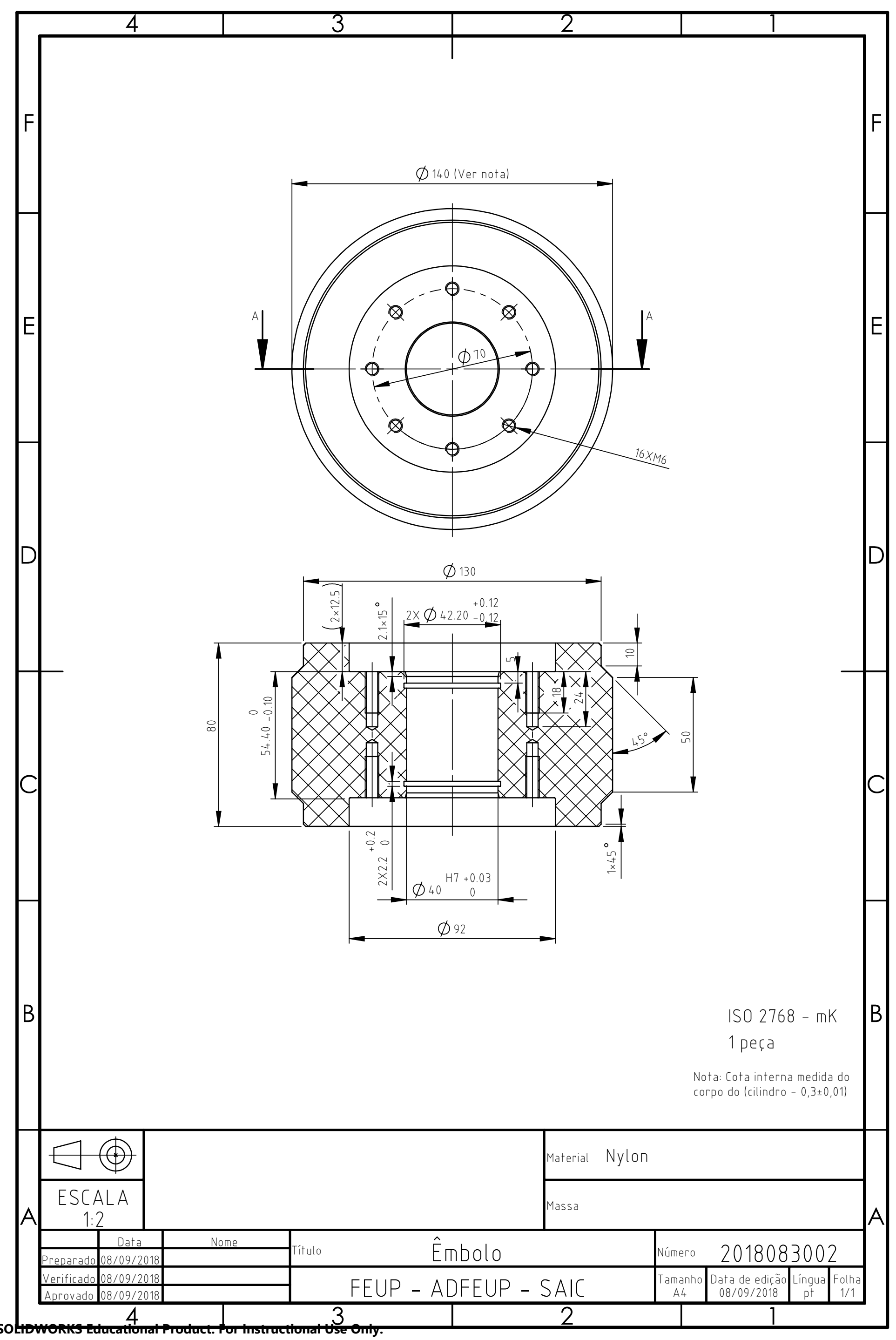




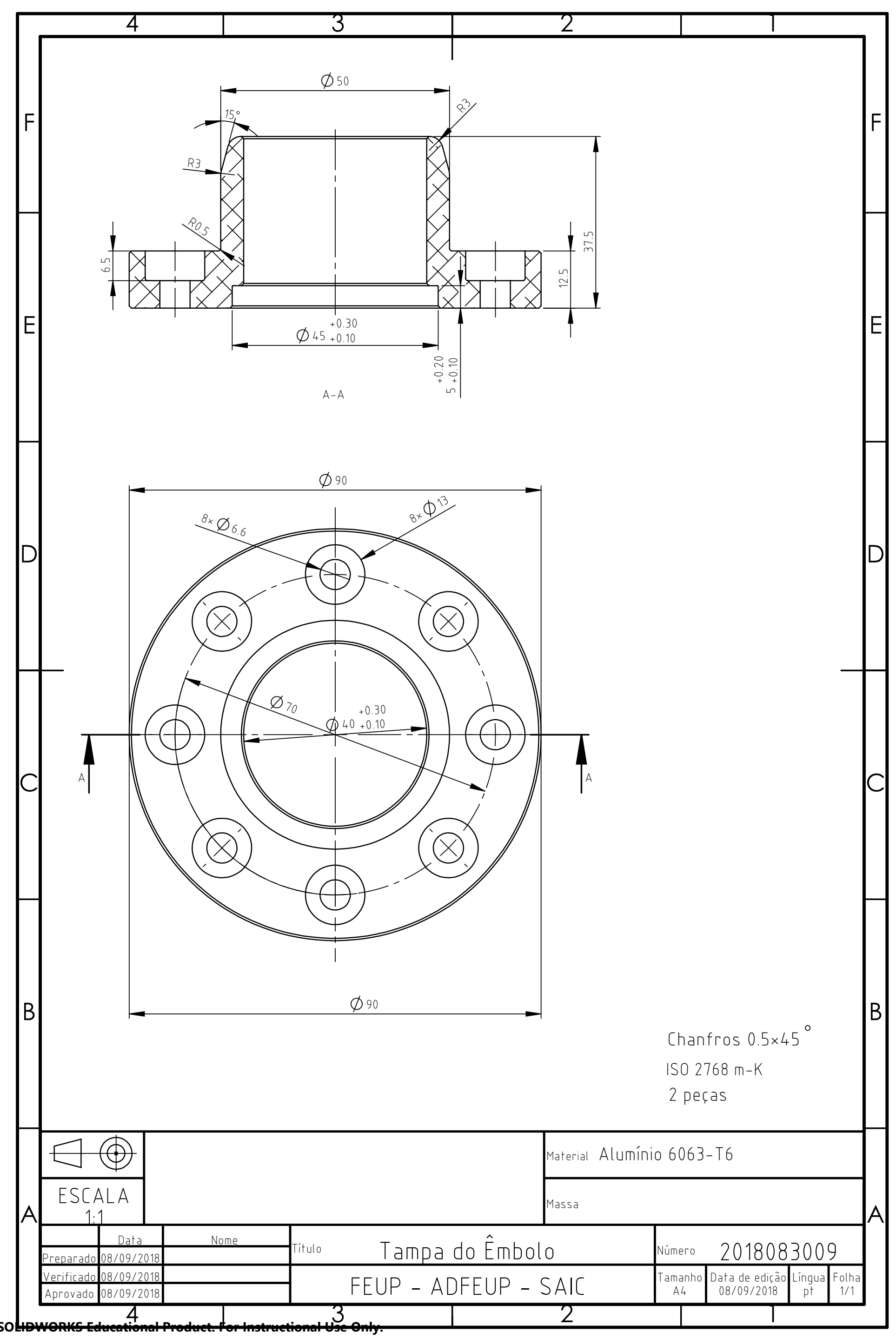




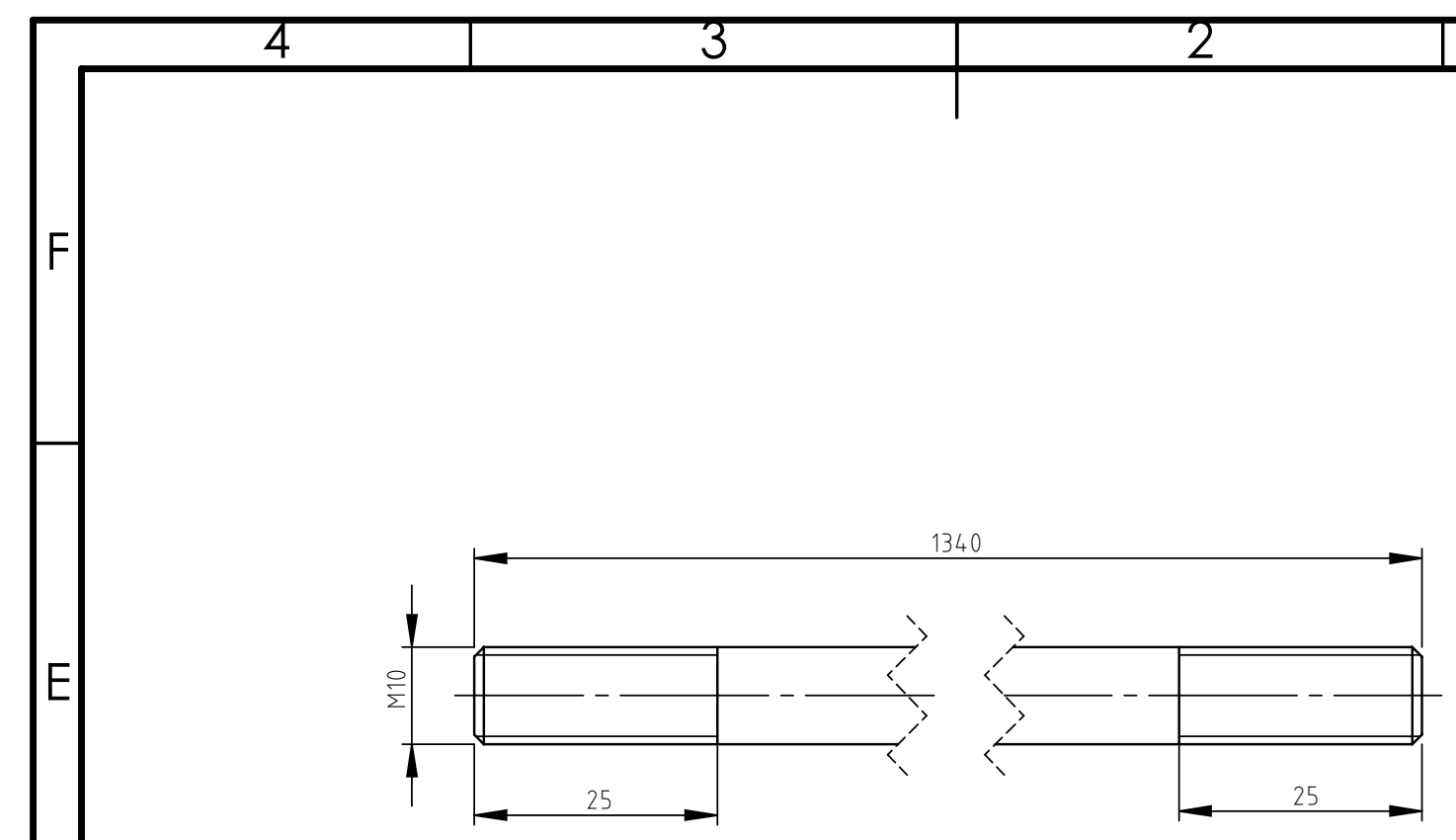

ISO 2768 - mK

4 peças

D

B

D

C

E

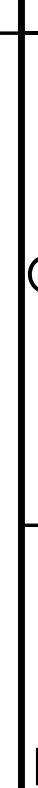

F 


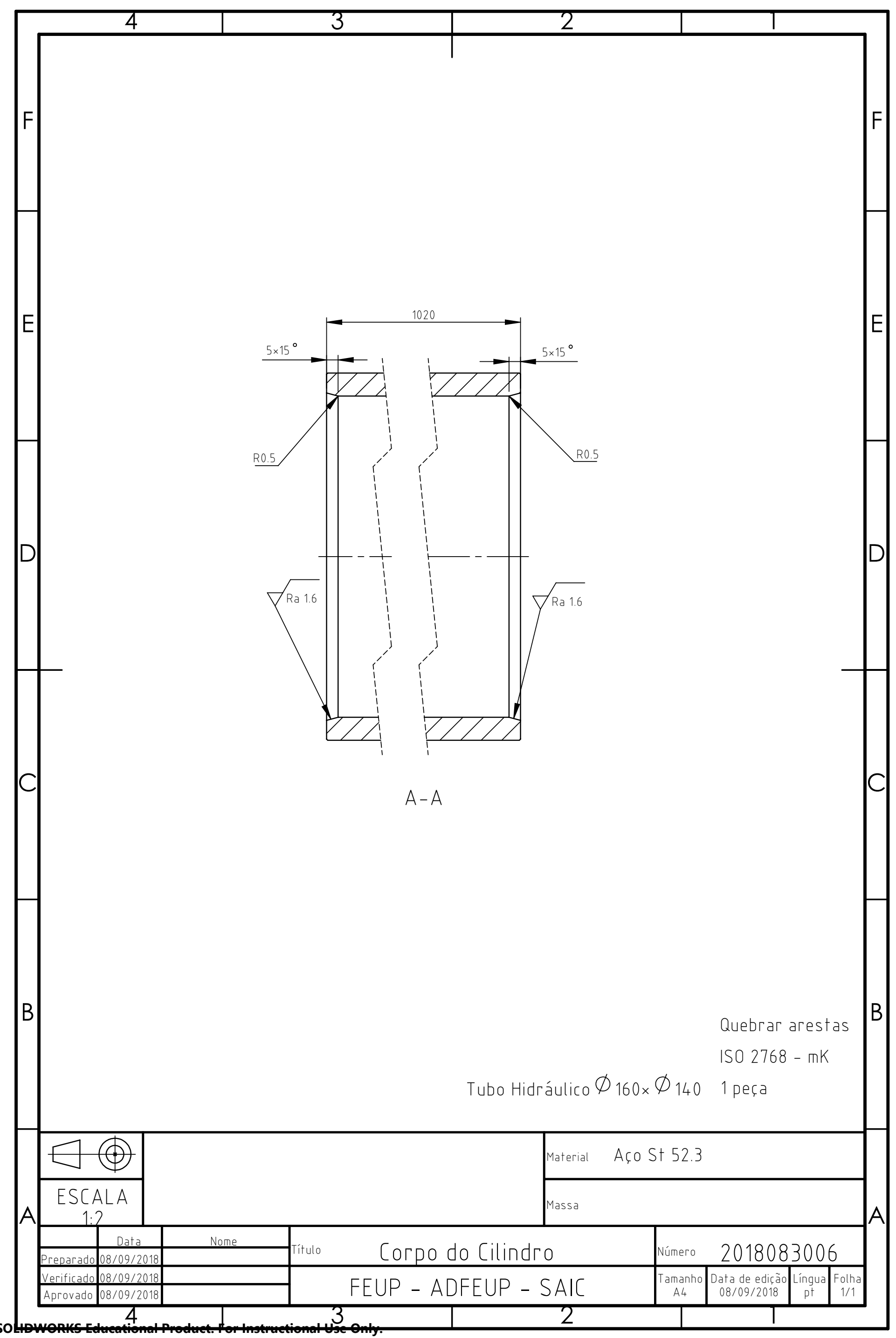


E

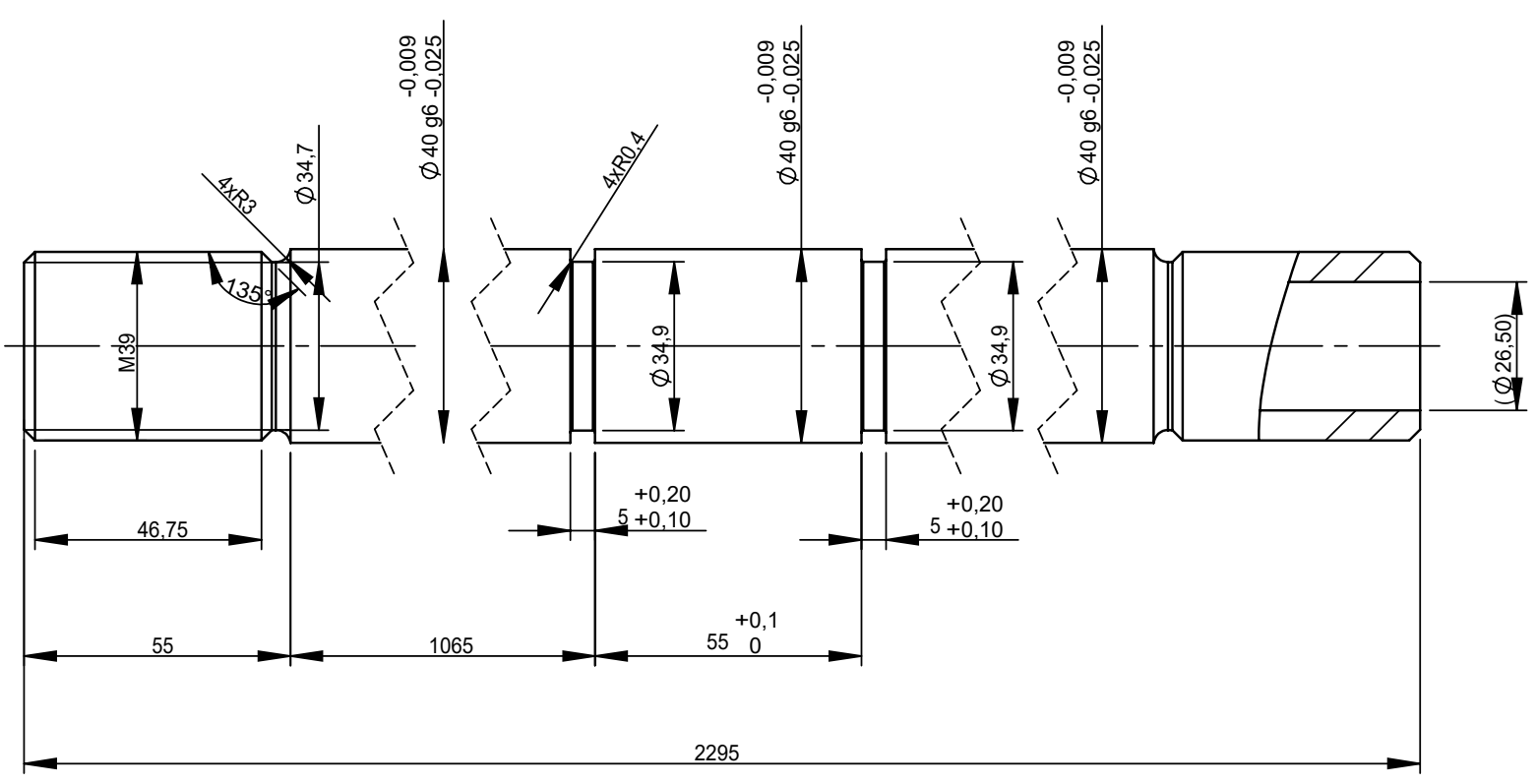

E

D

D

B

Quebrar arestas

ISO 2768 - mK

1 peça

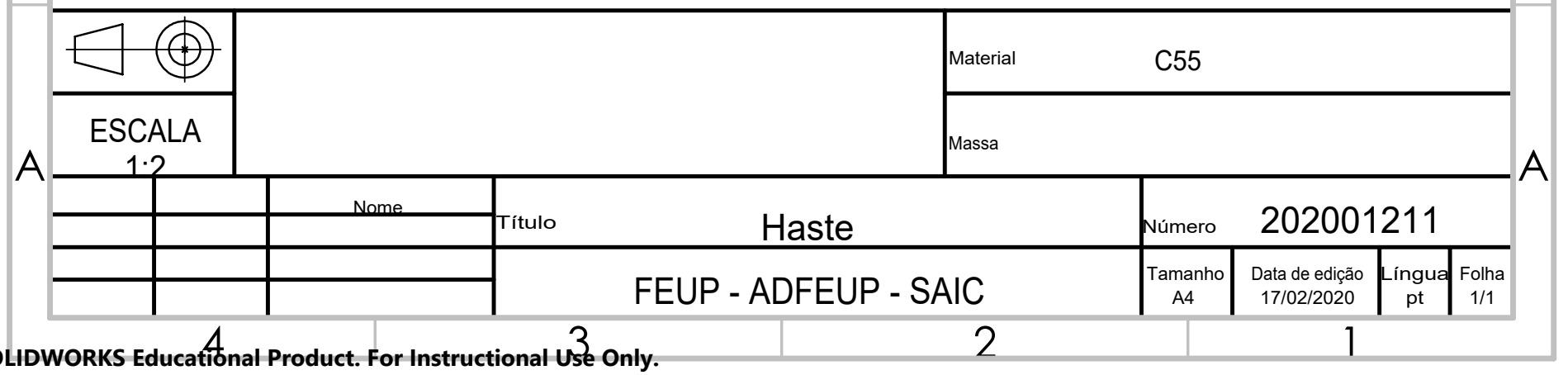




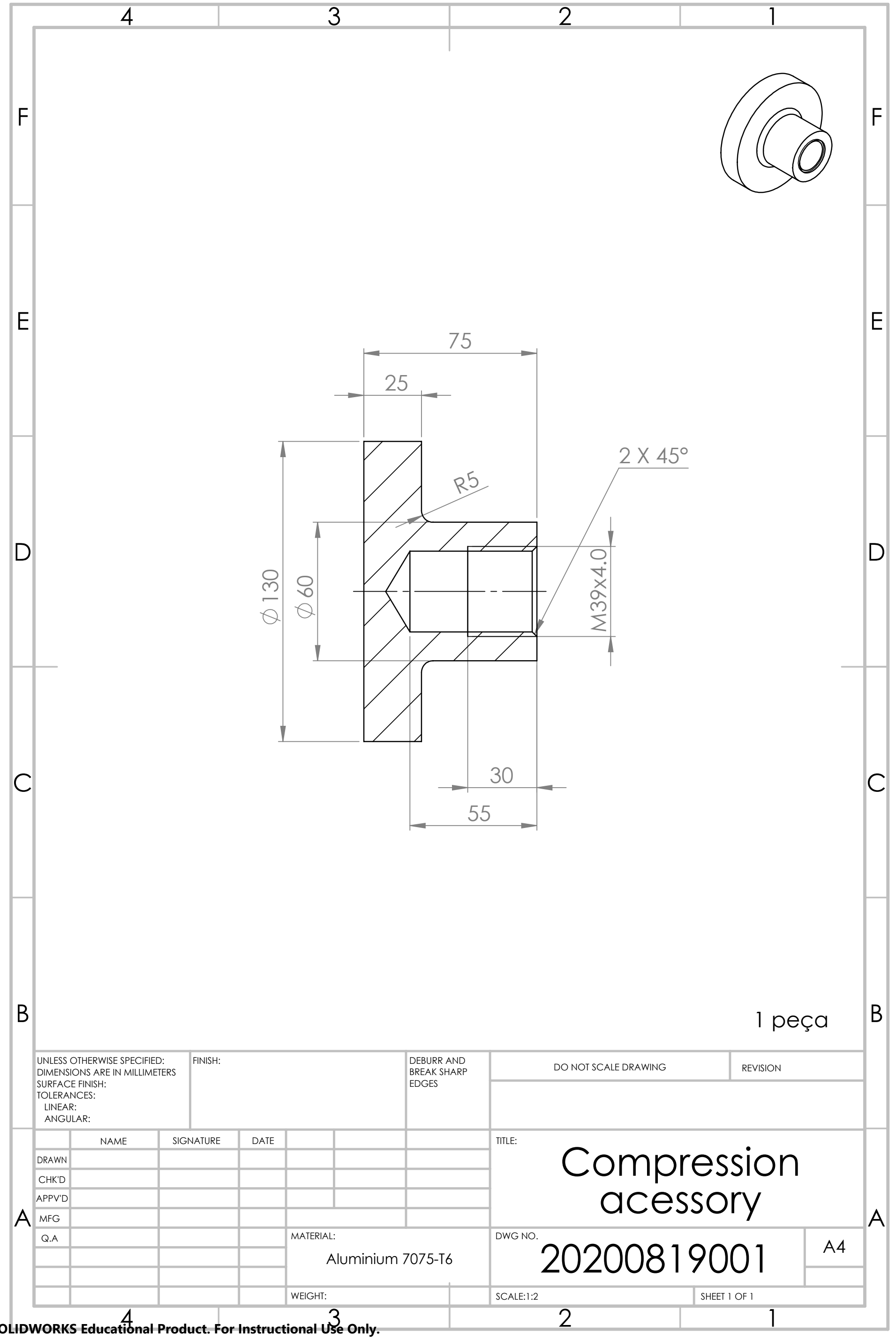





\section{Appendix C}

\section{Mechanical Drawings}

Transmission lever, skate, springs assembly, and shock absorber 


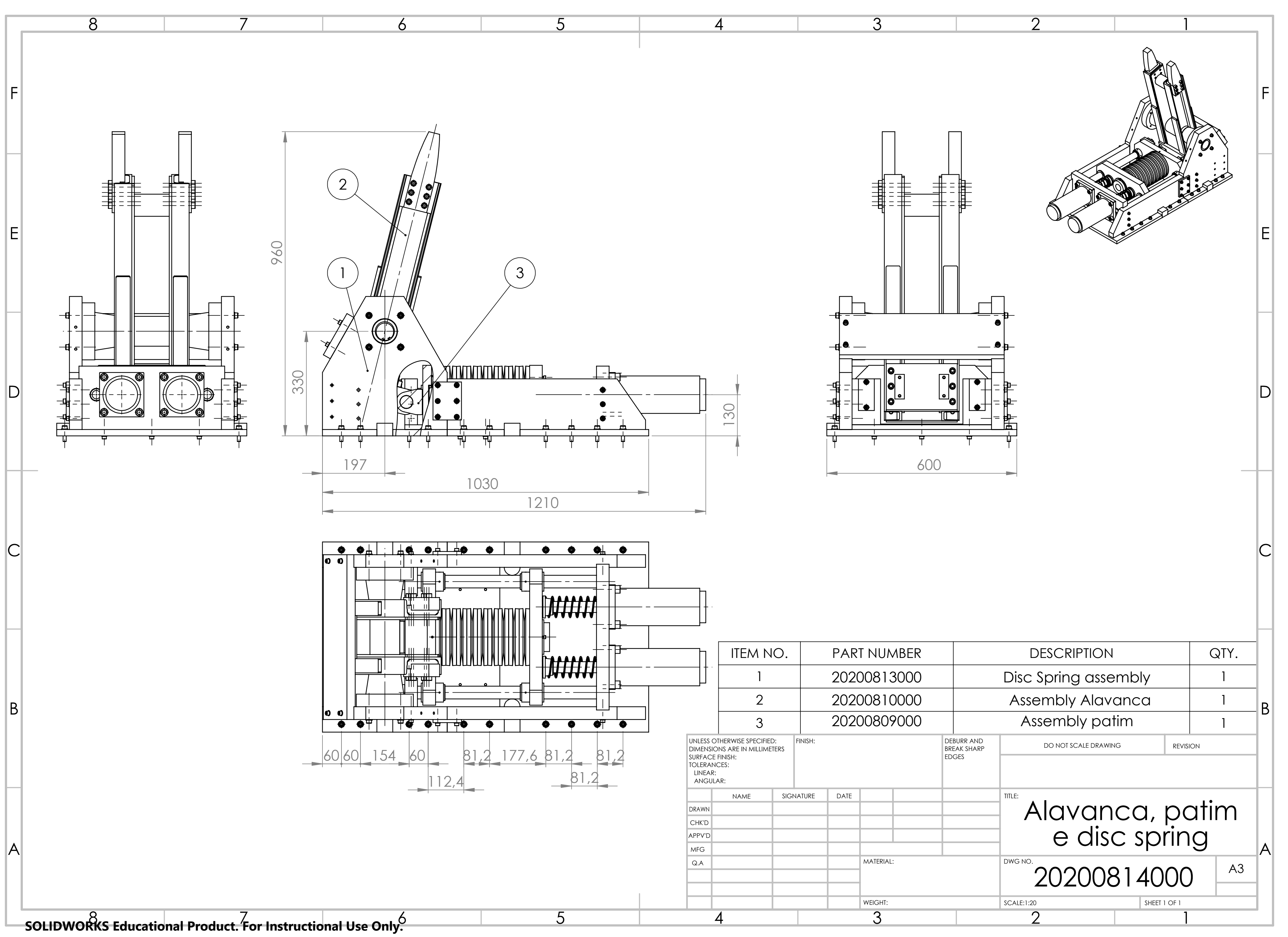




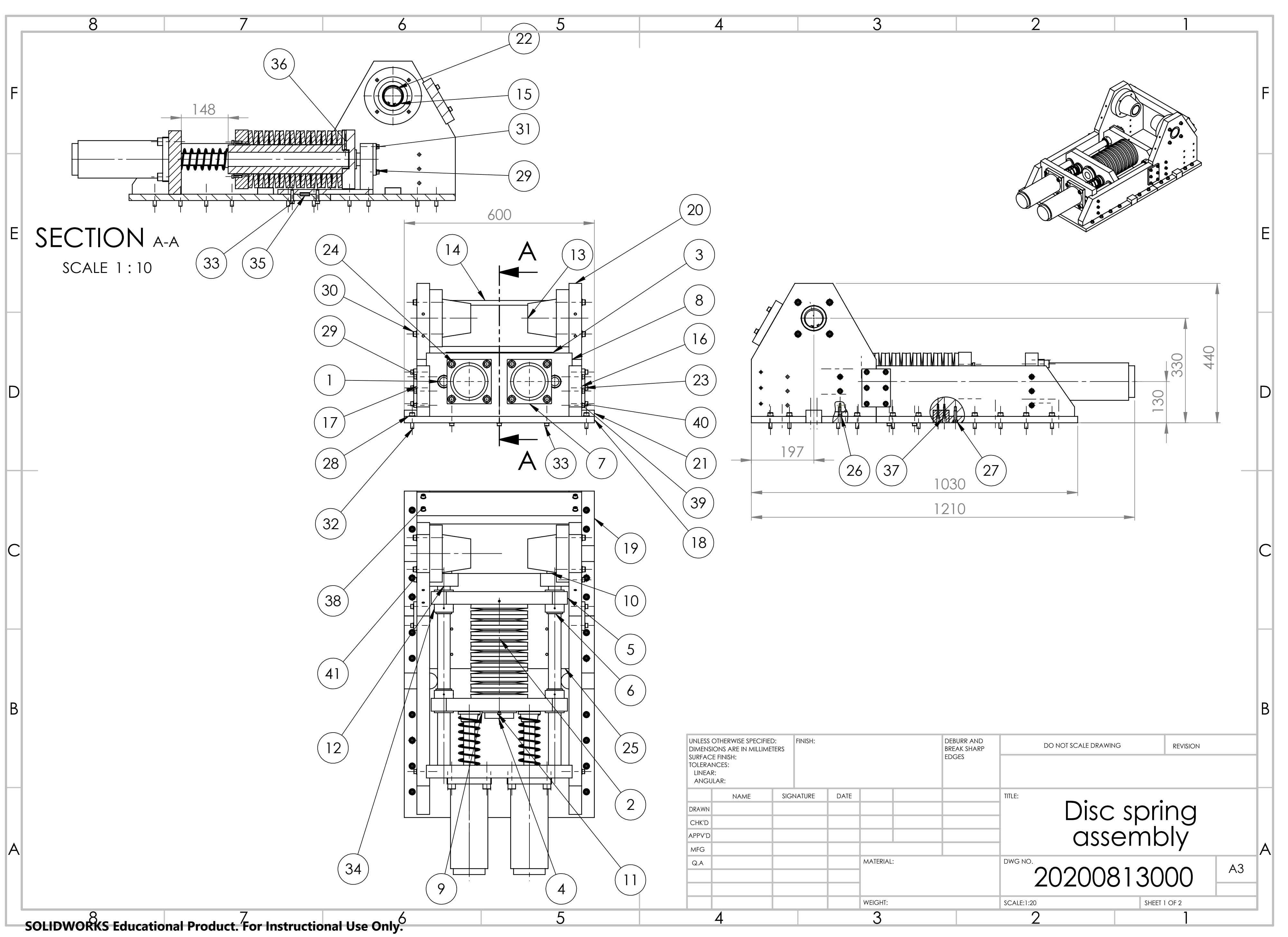




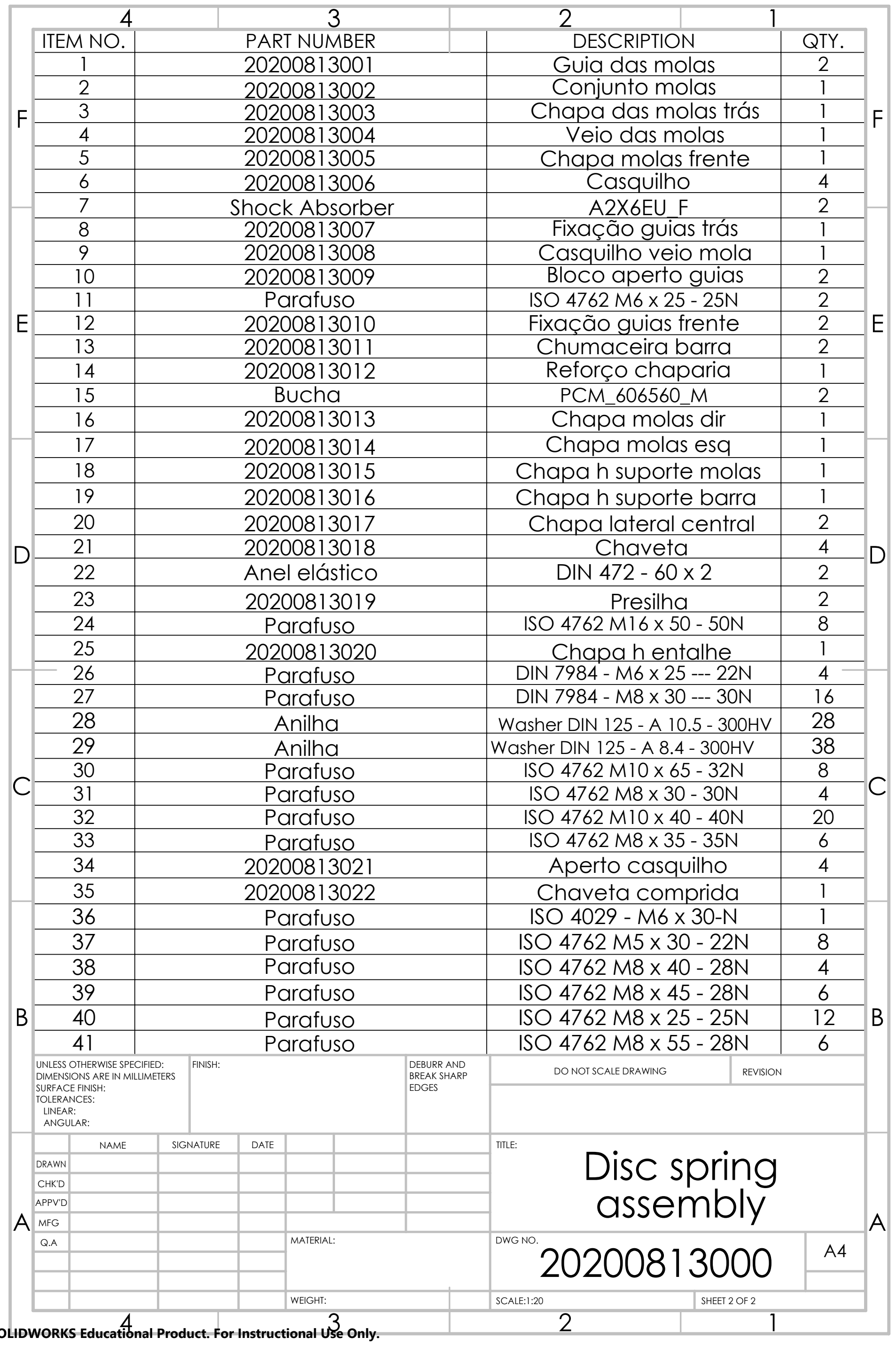




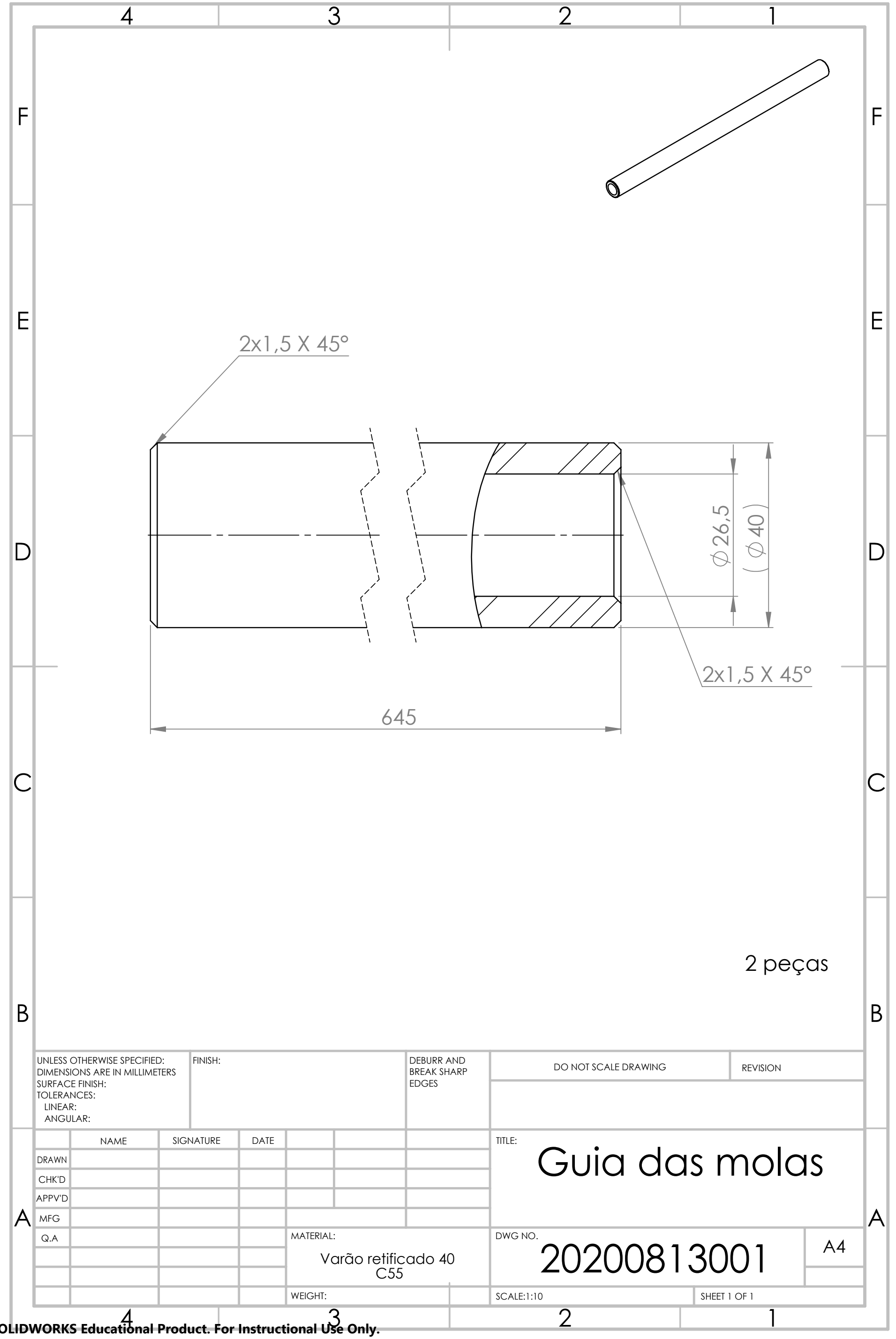




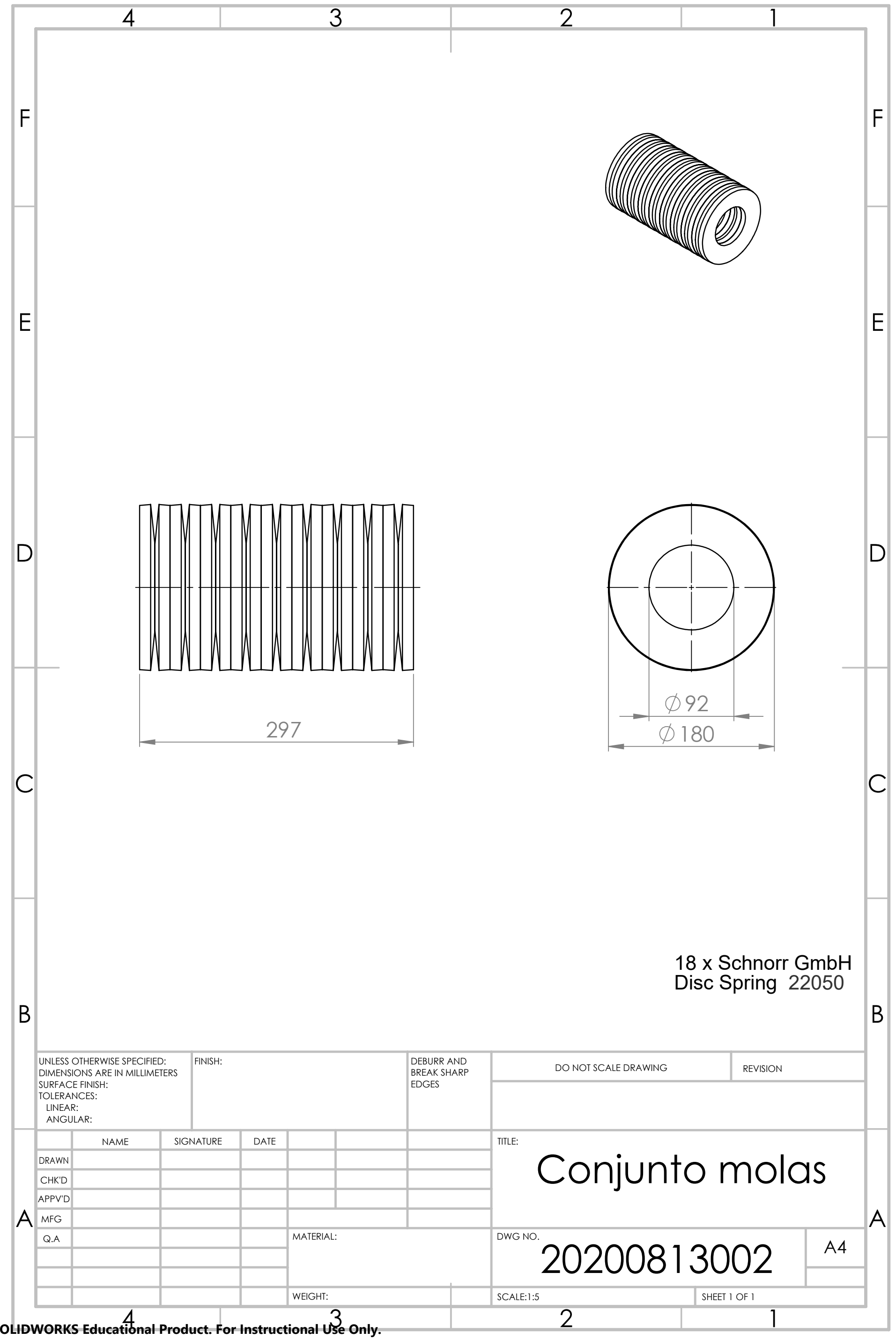




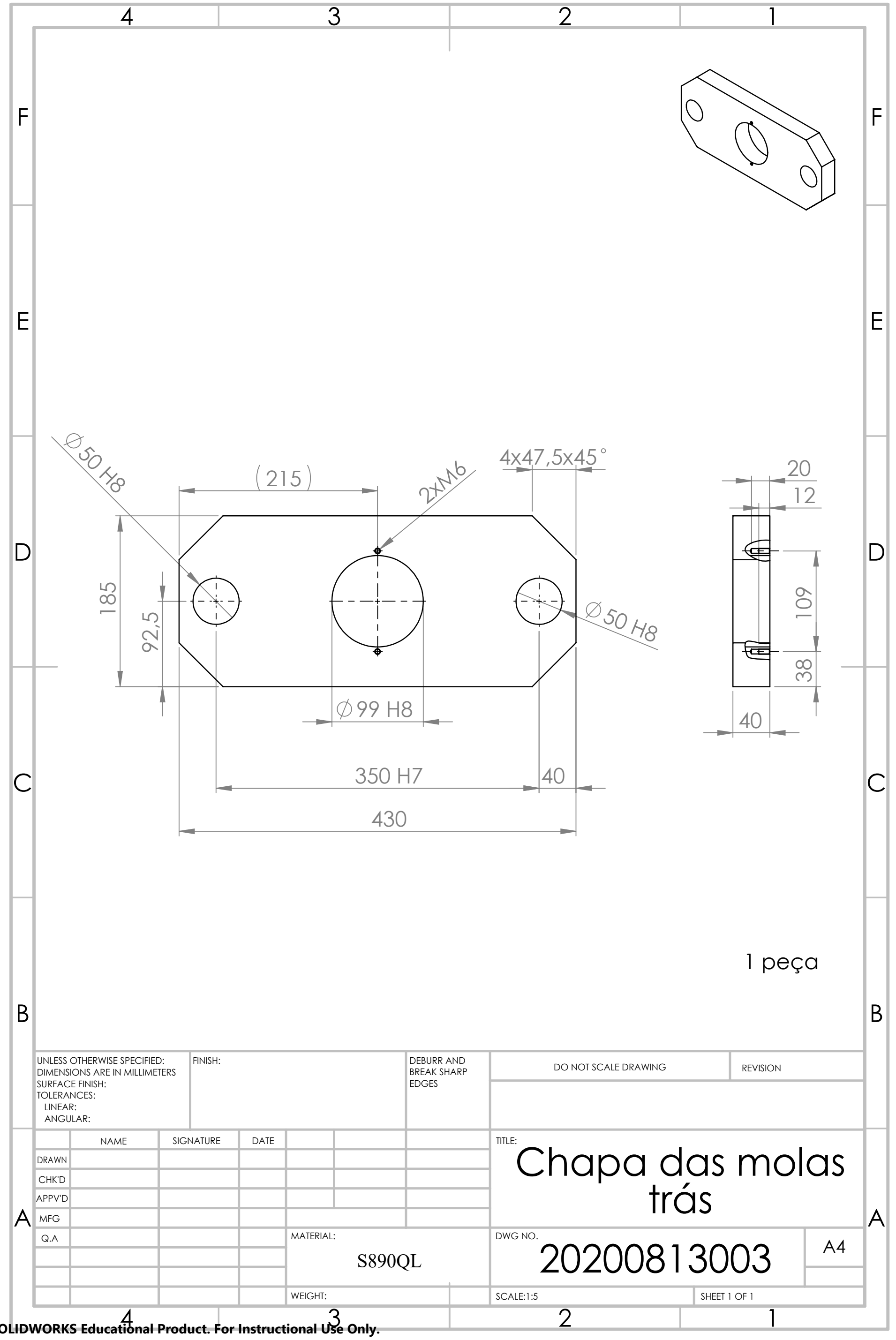




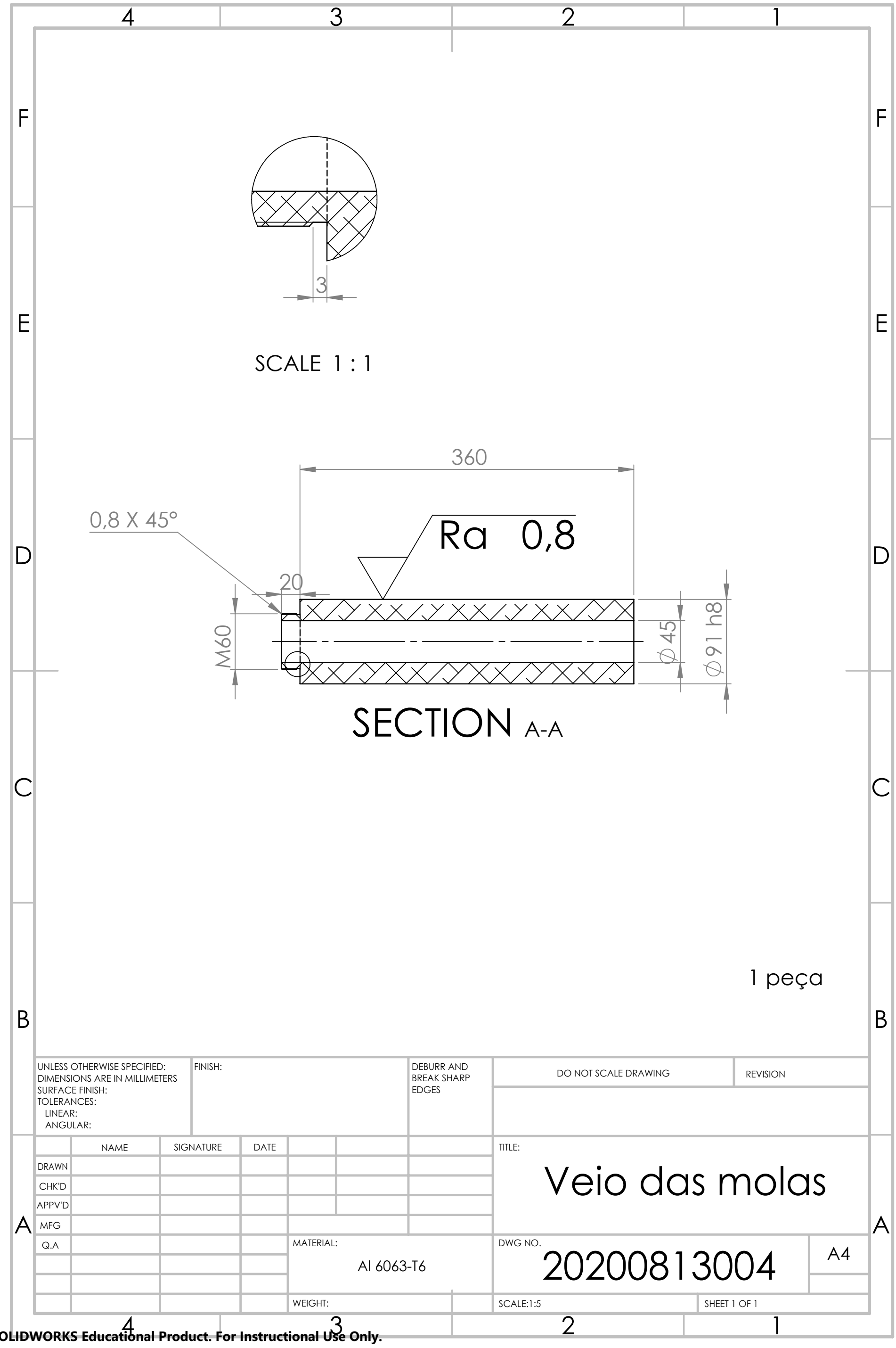




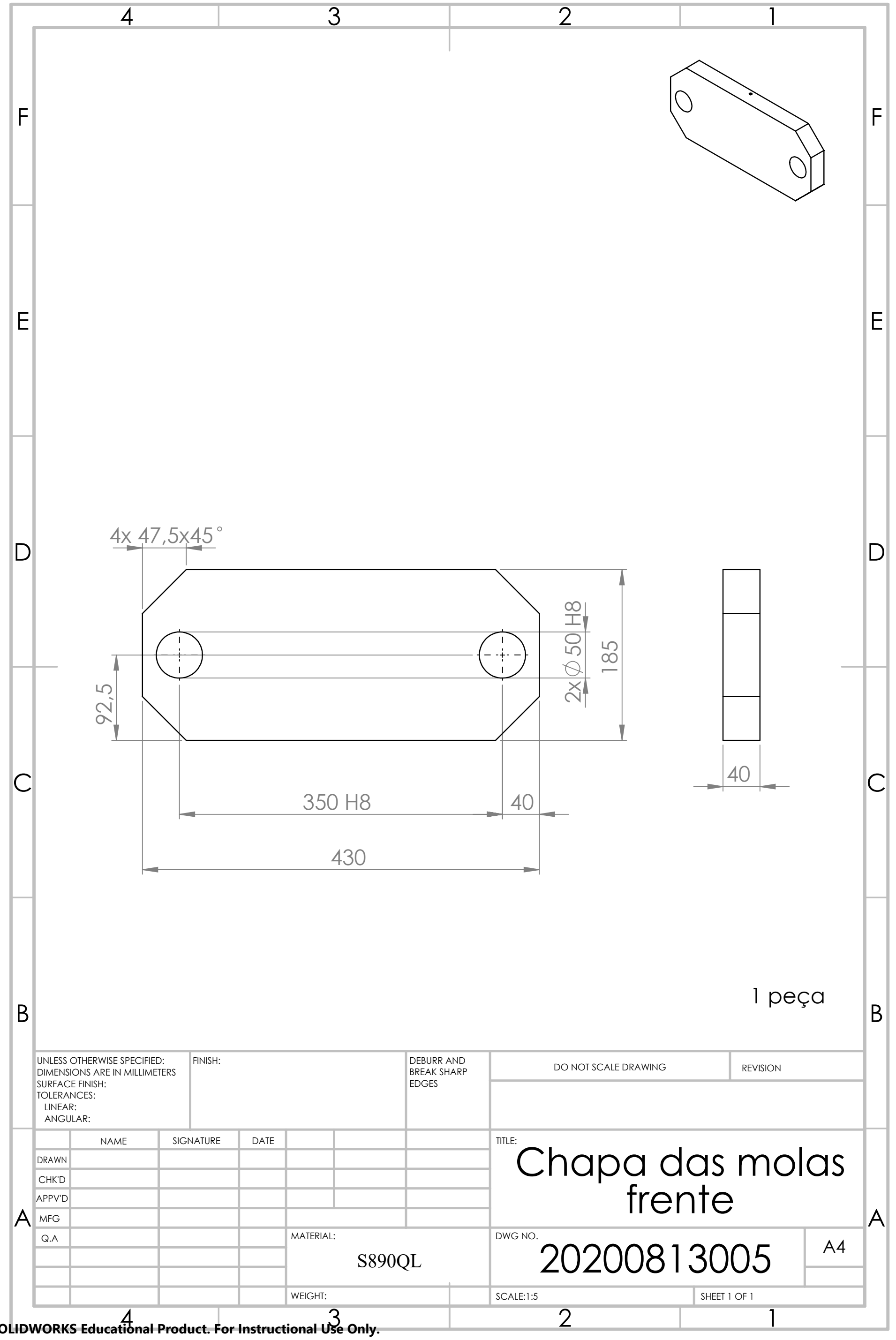




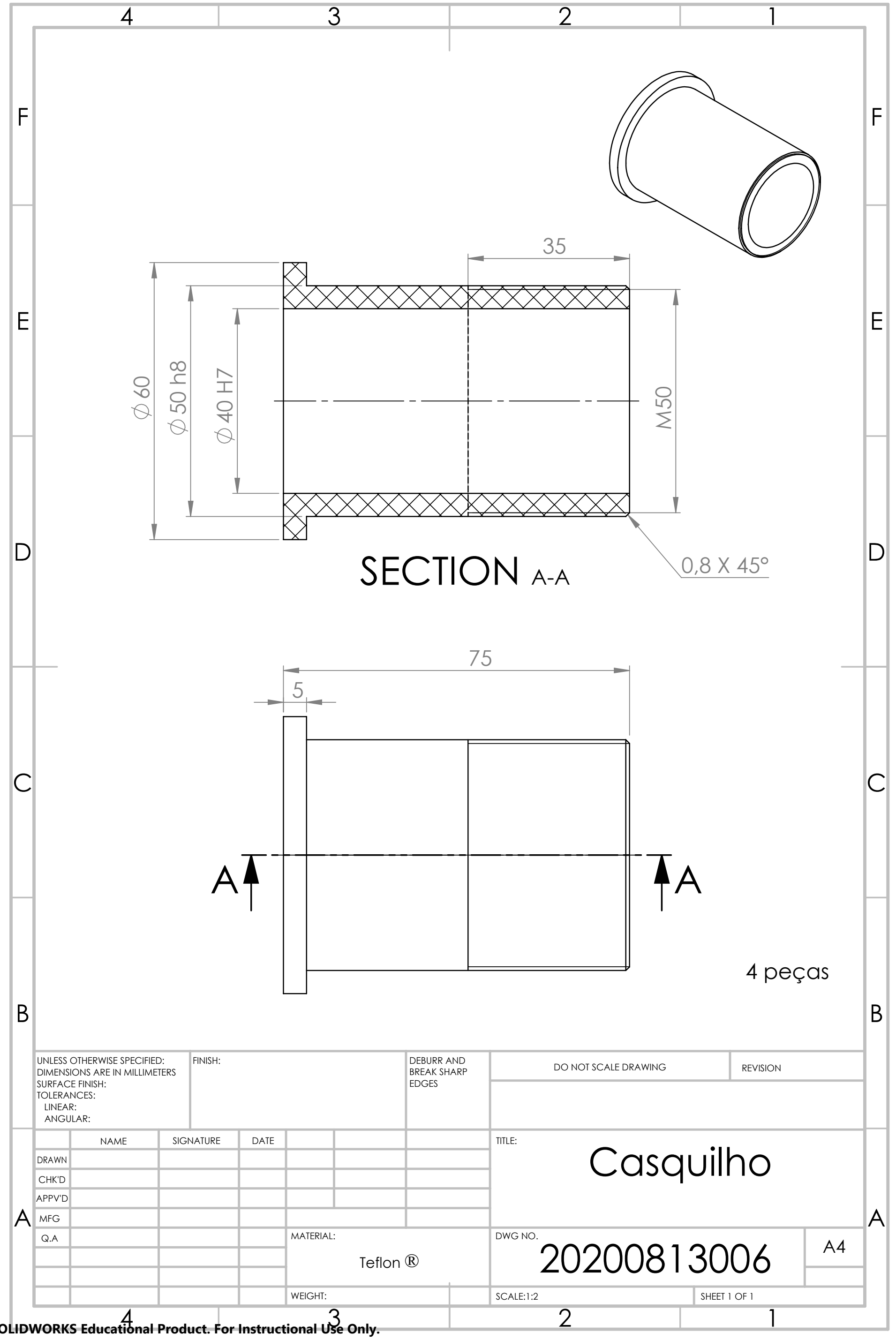




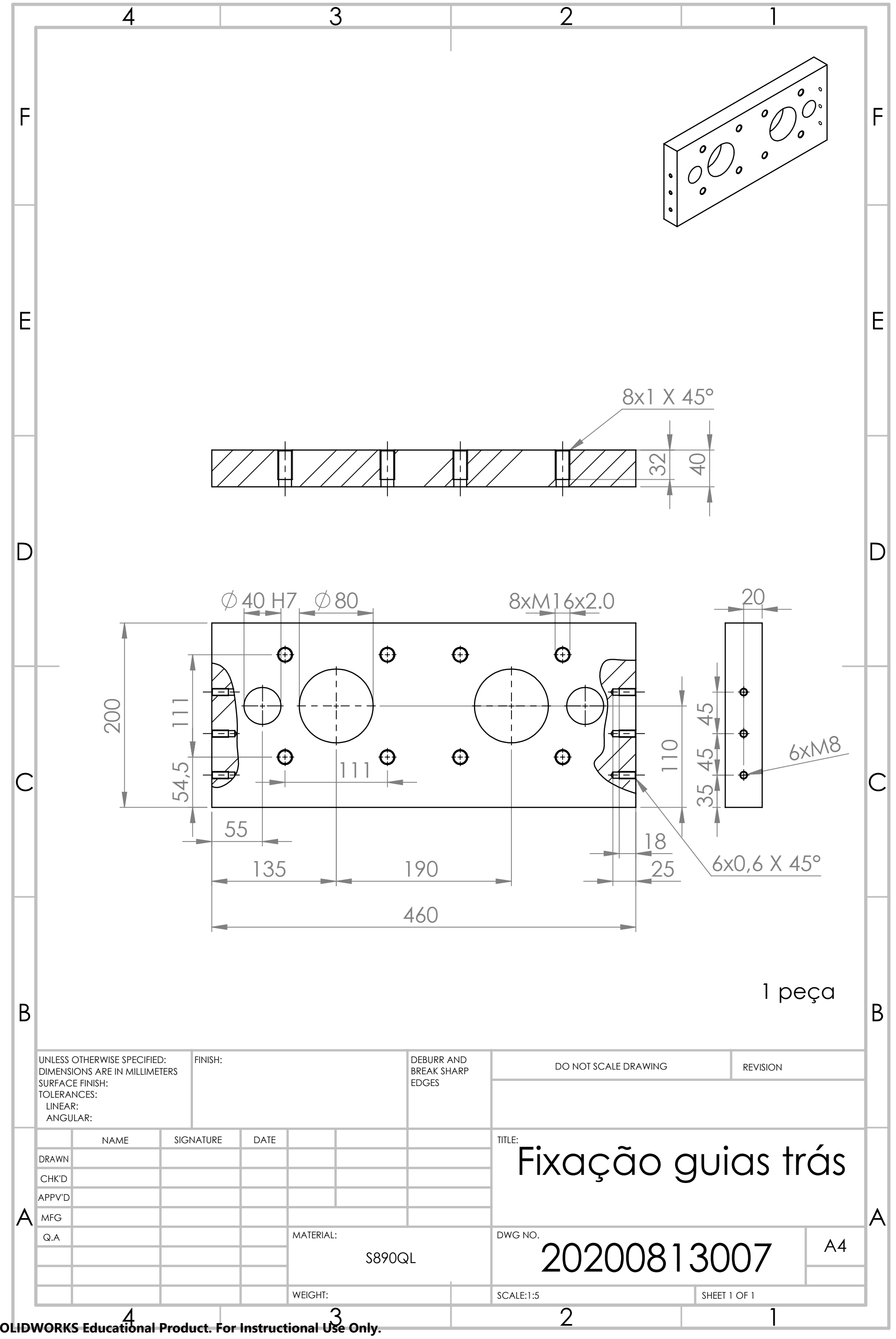



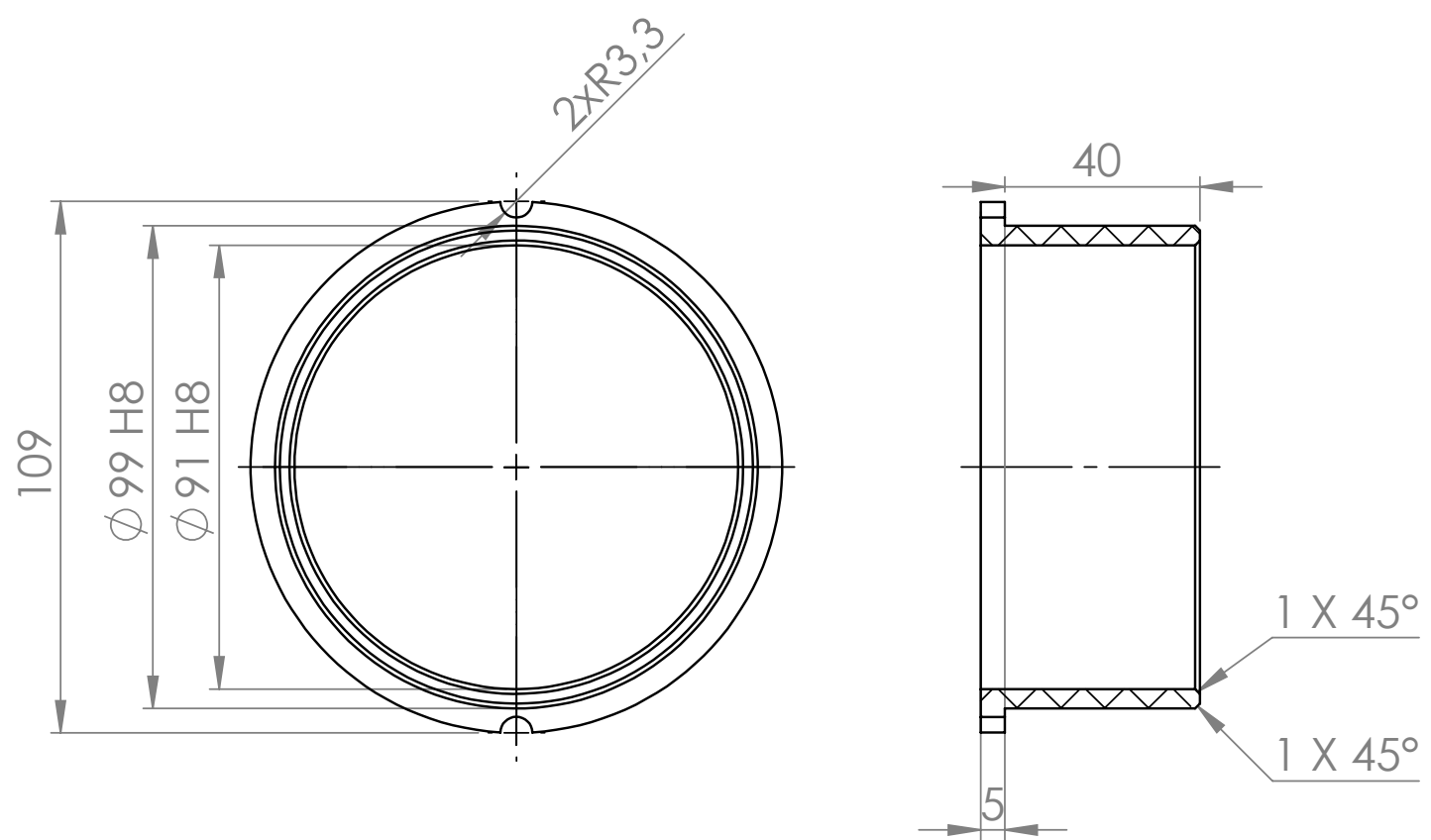

C

B

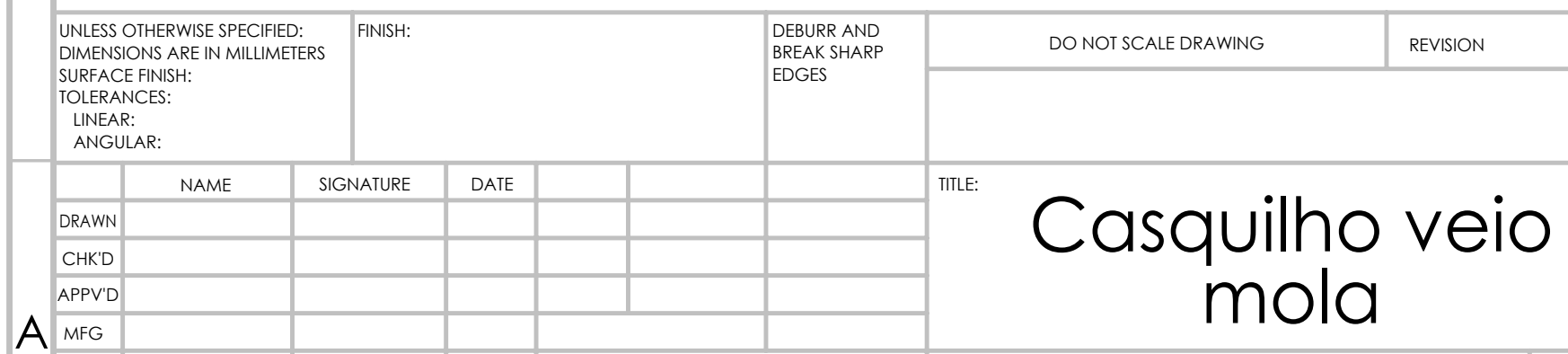

$A$

Q.A MATERIAL: 


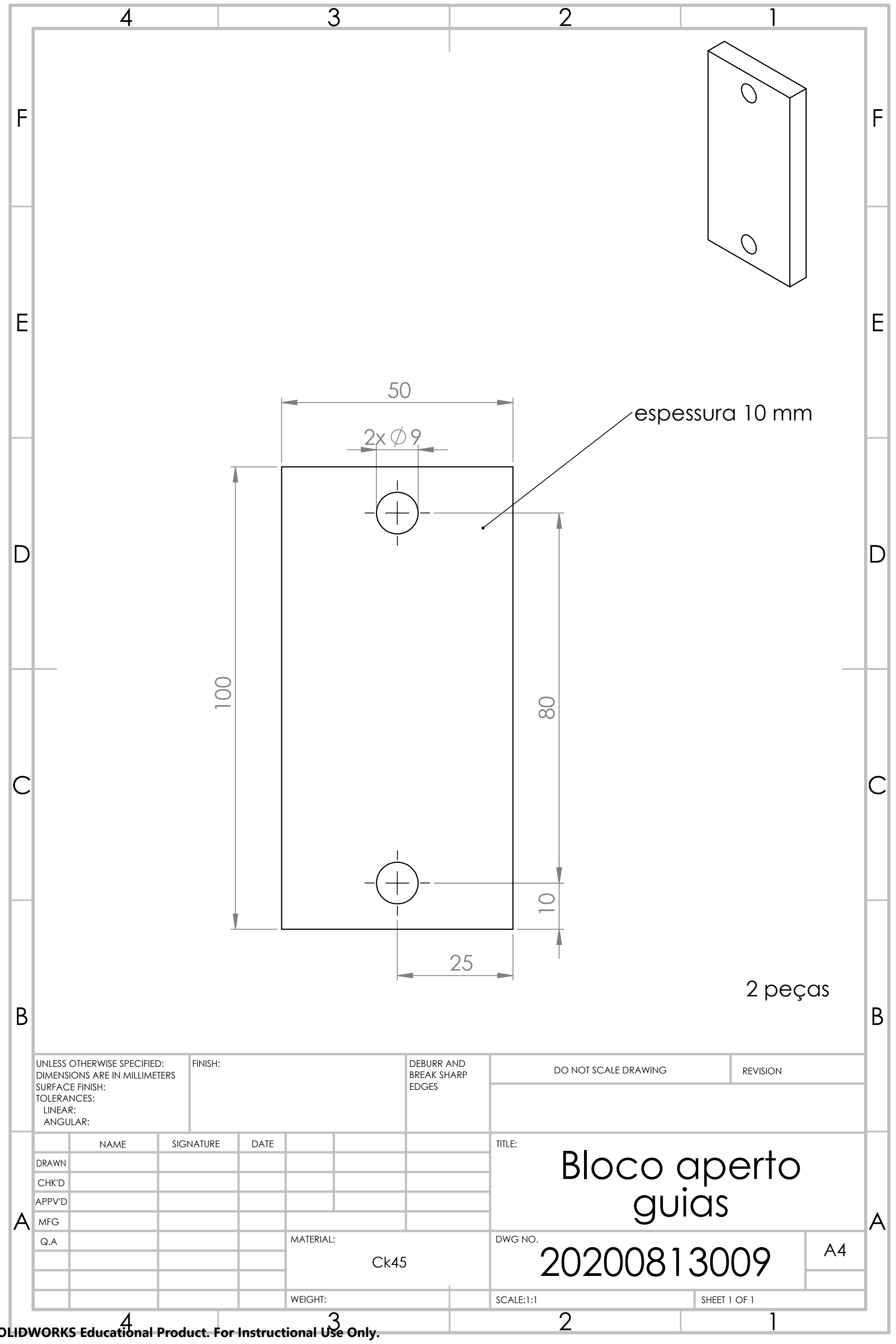




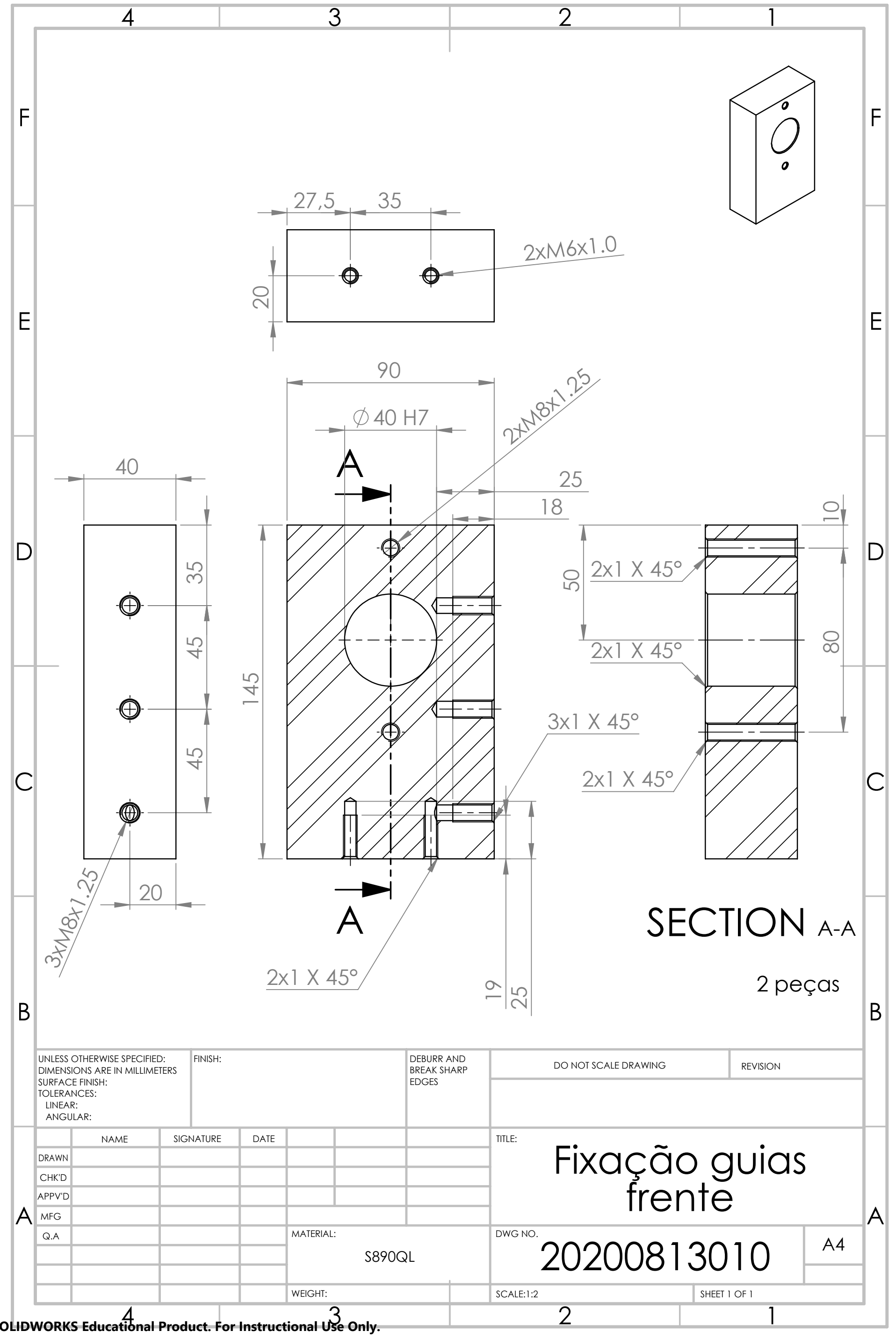




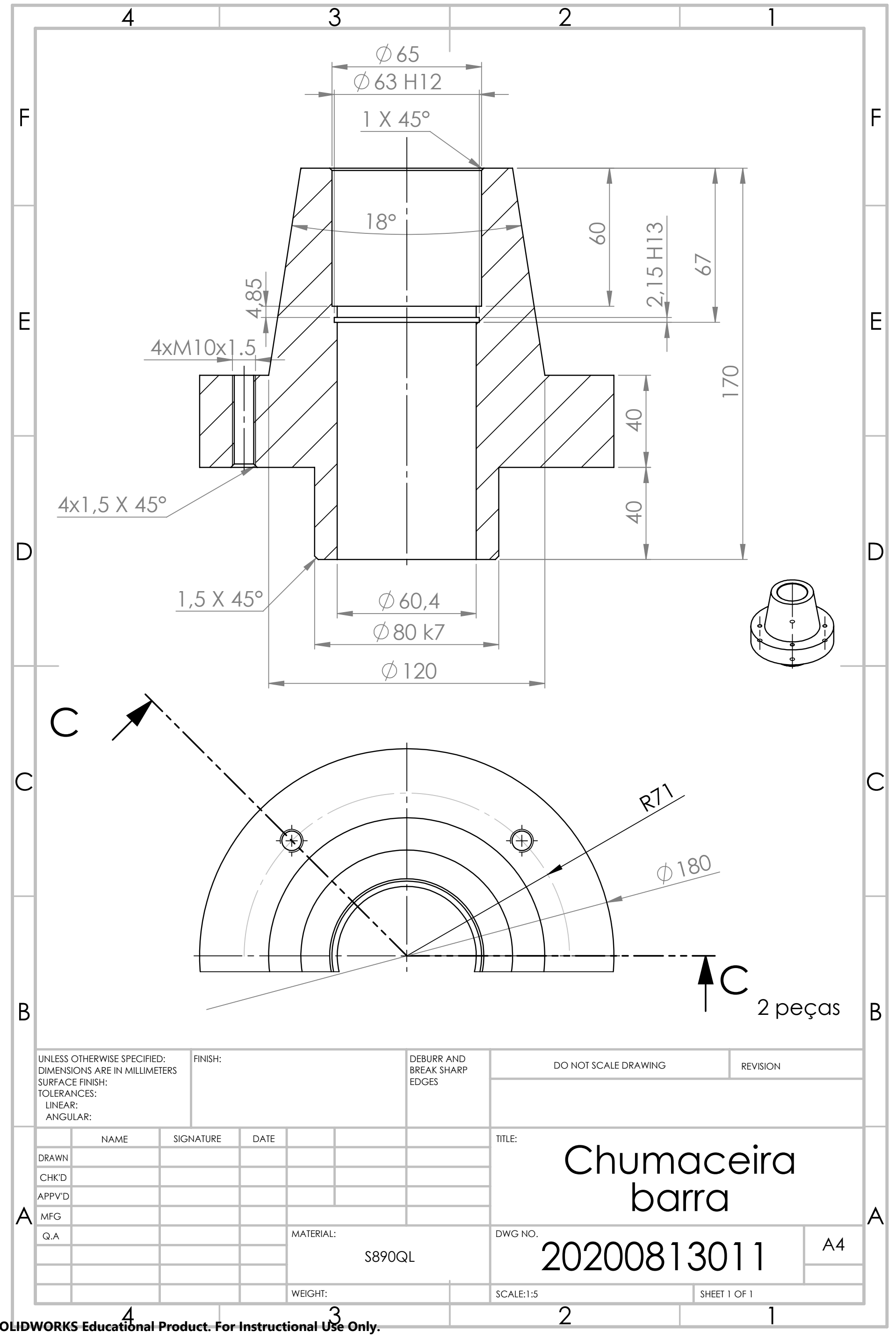




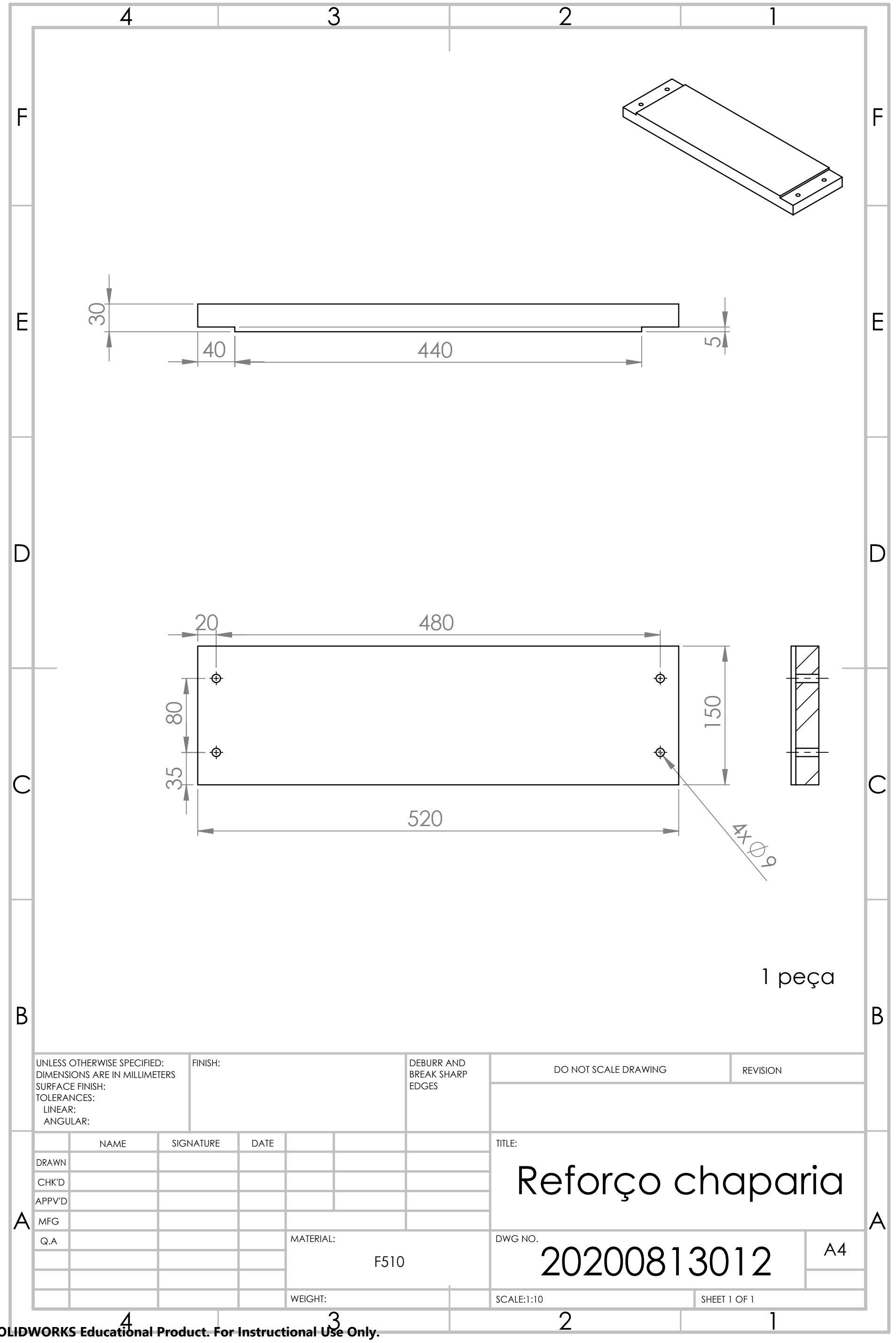




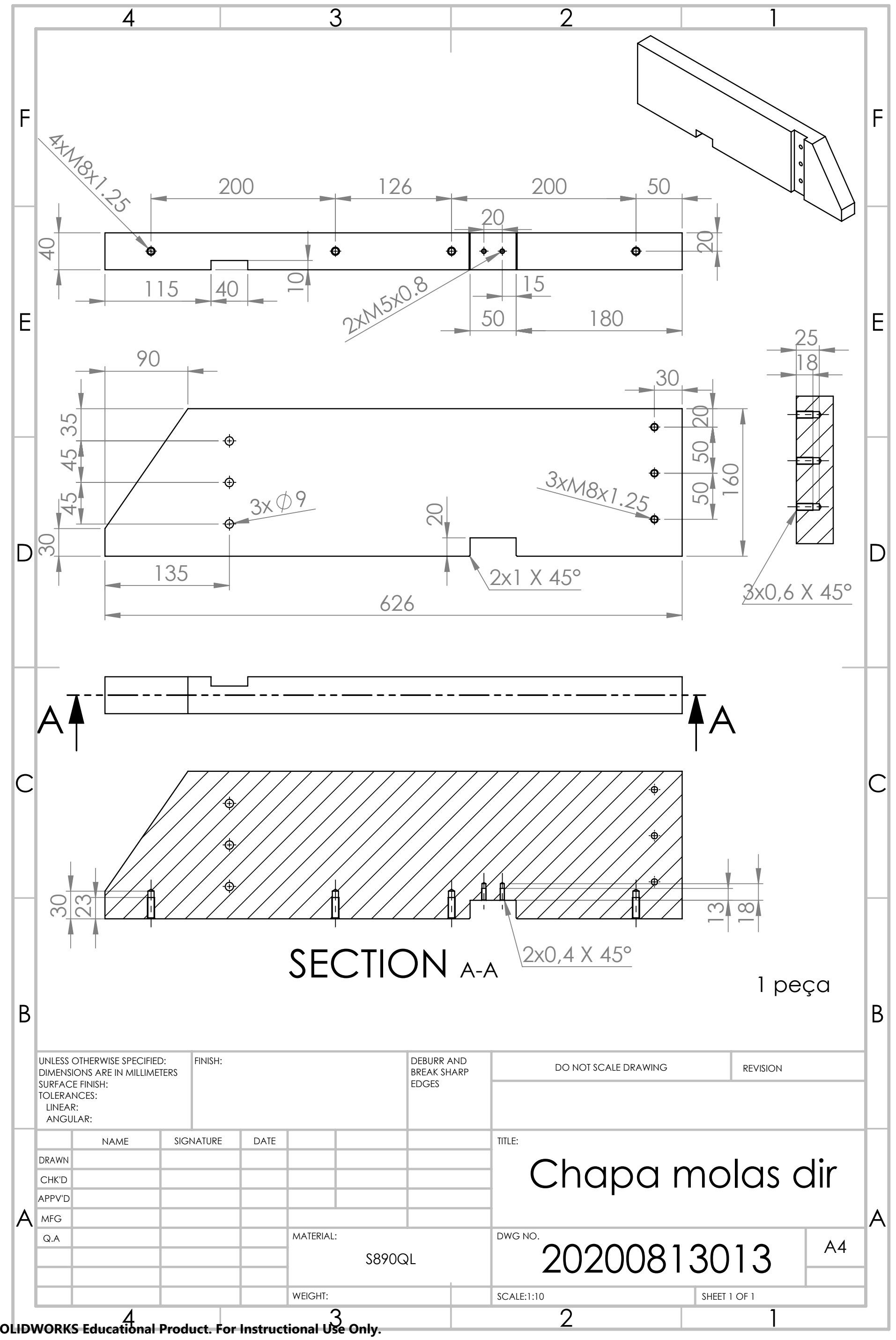




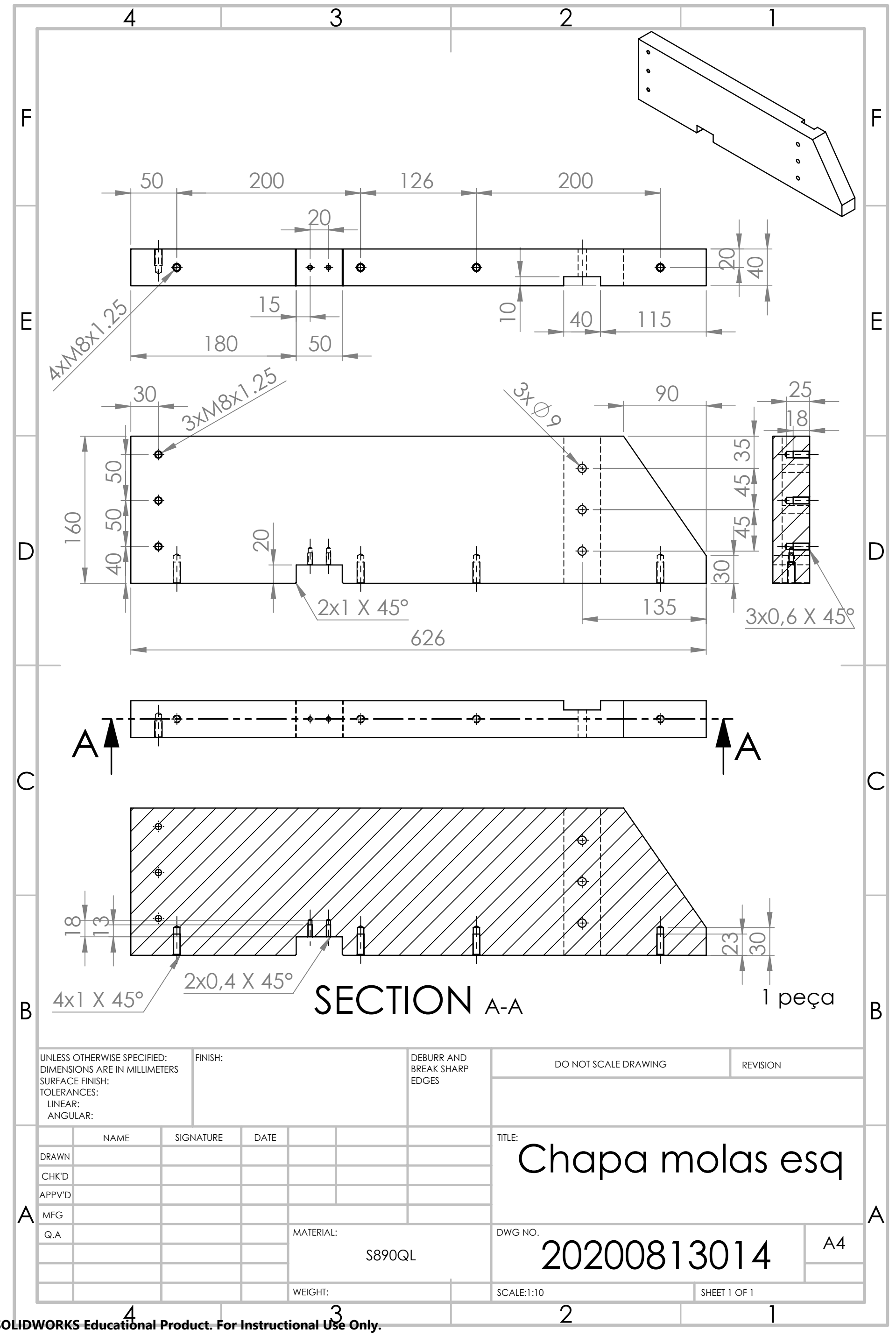




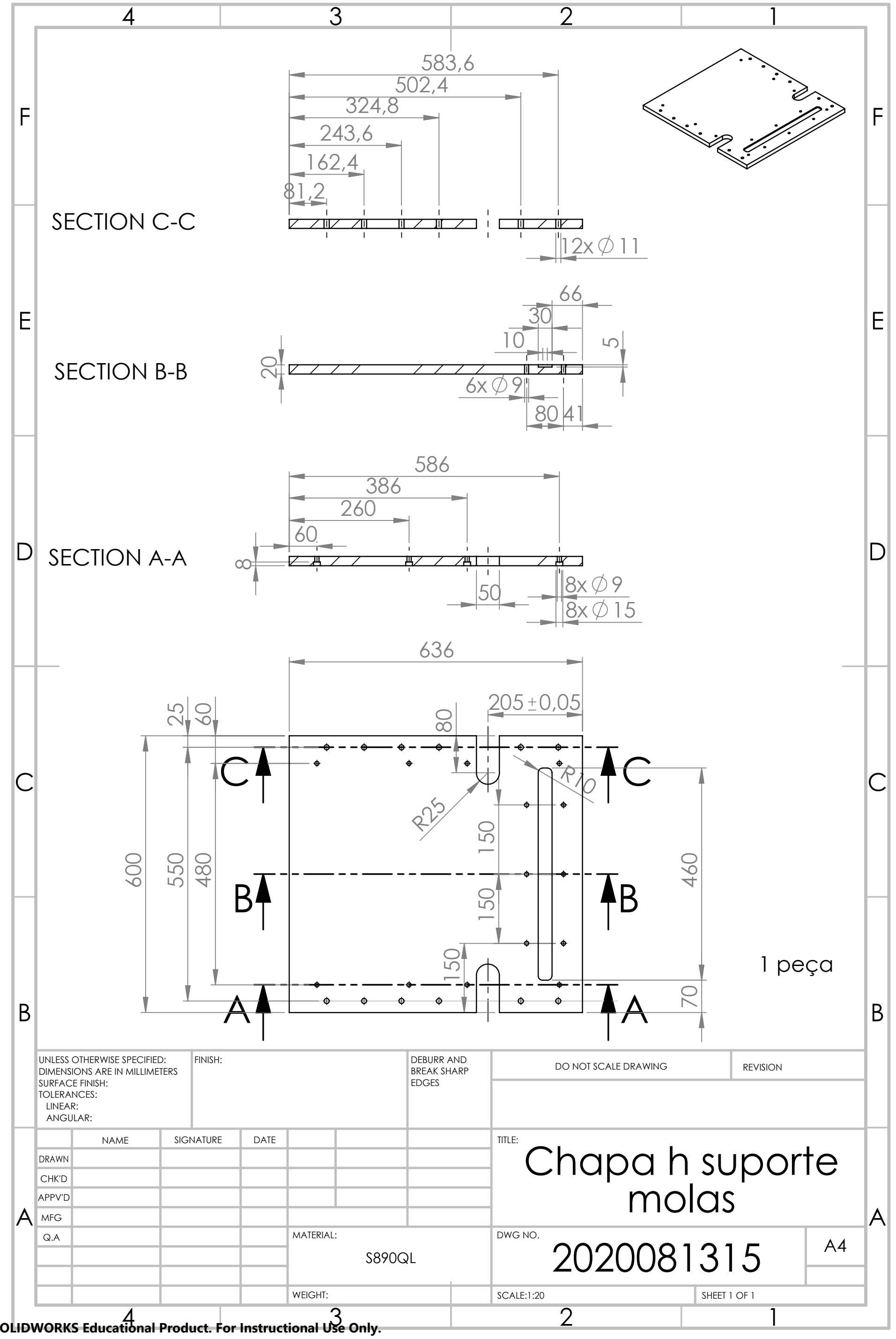




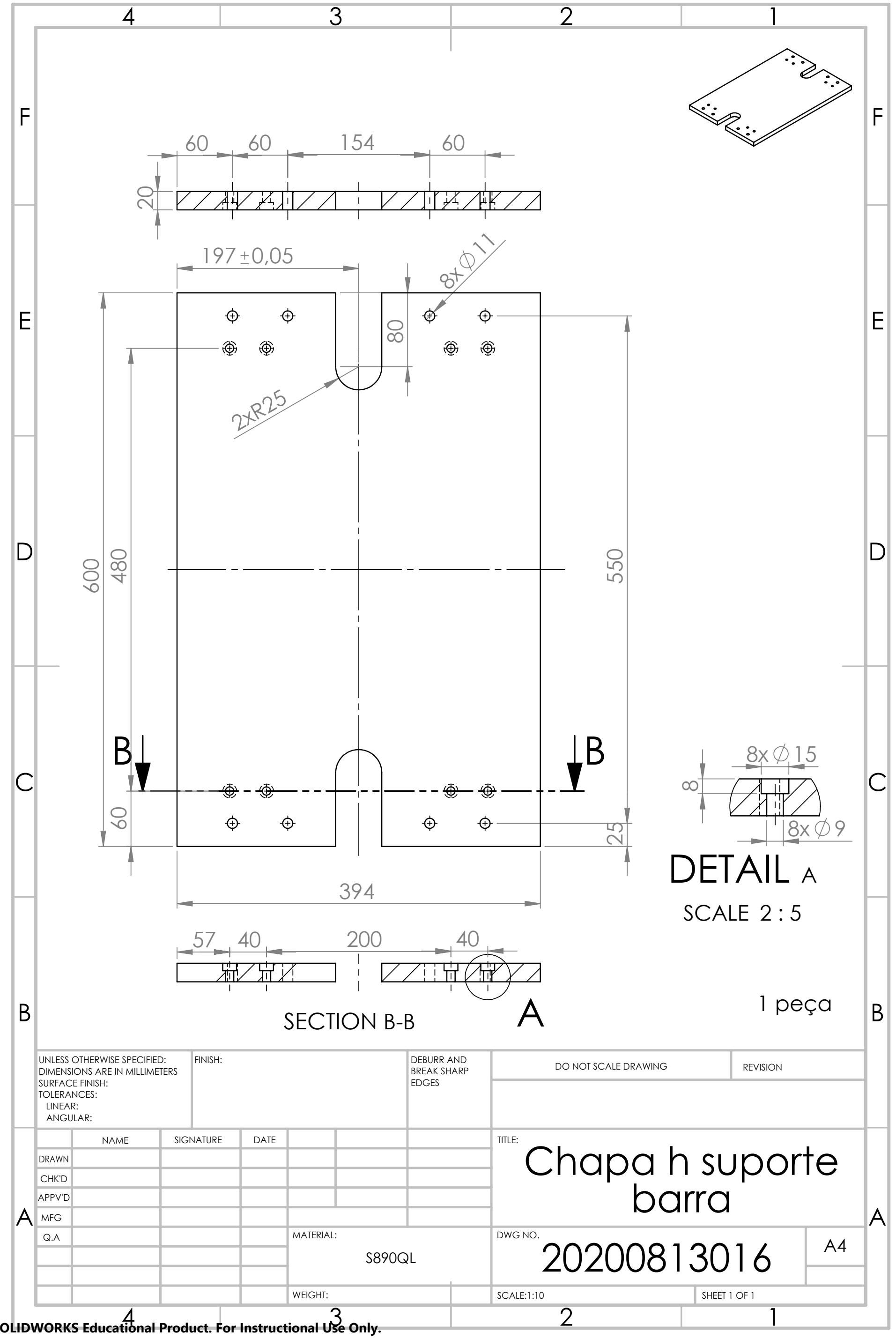




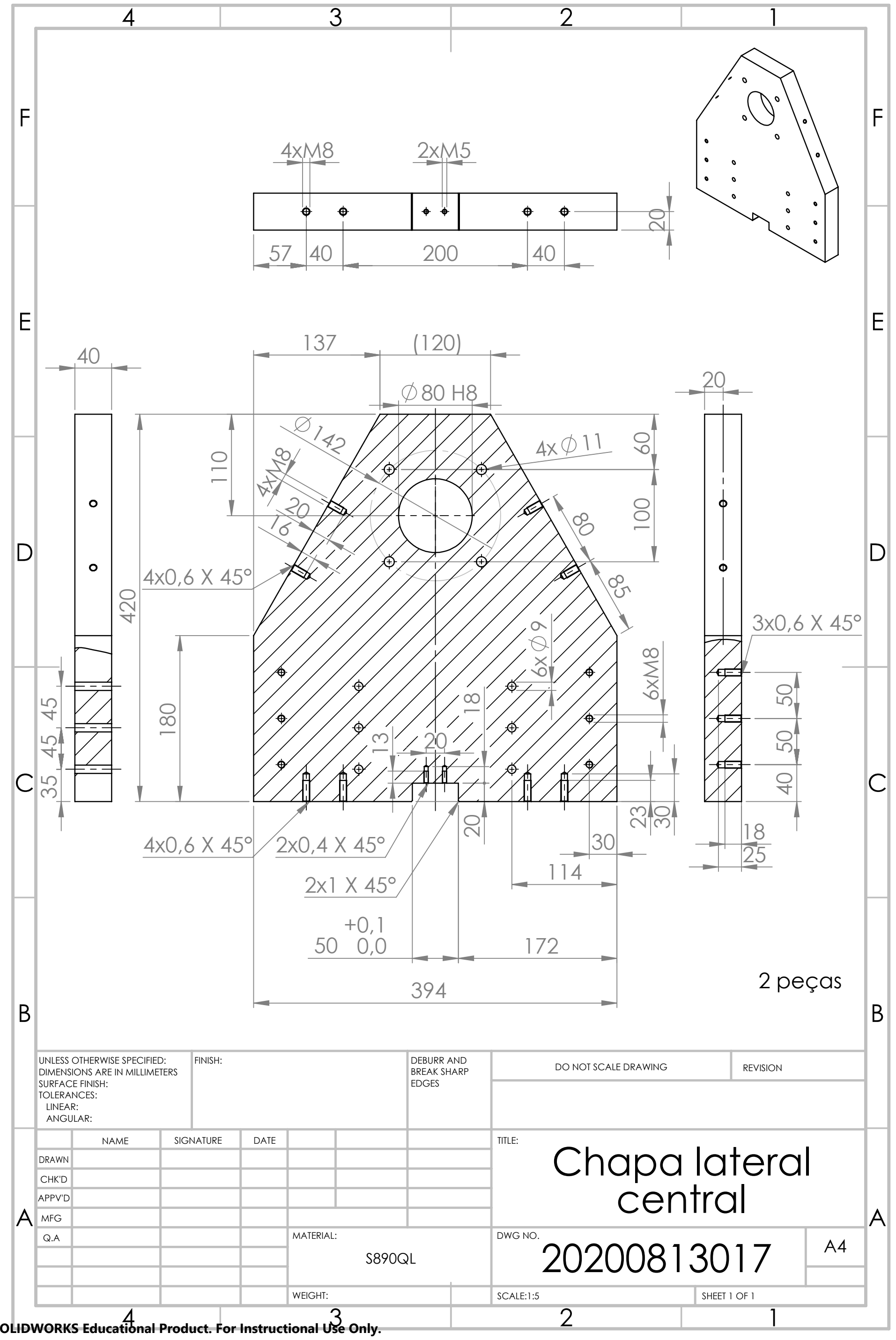




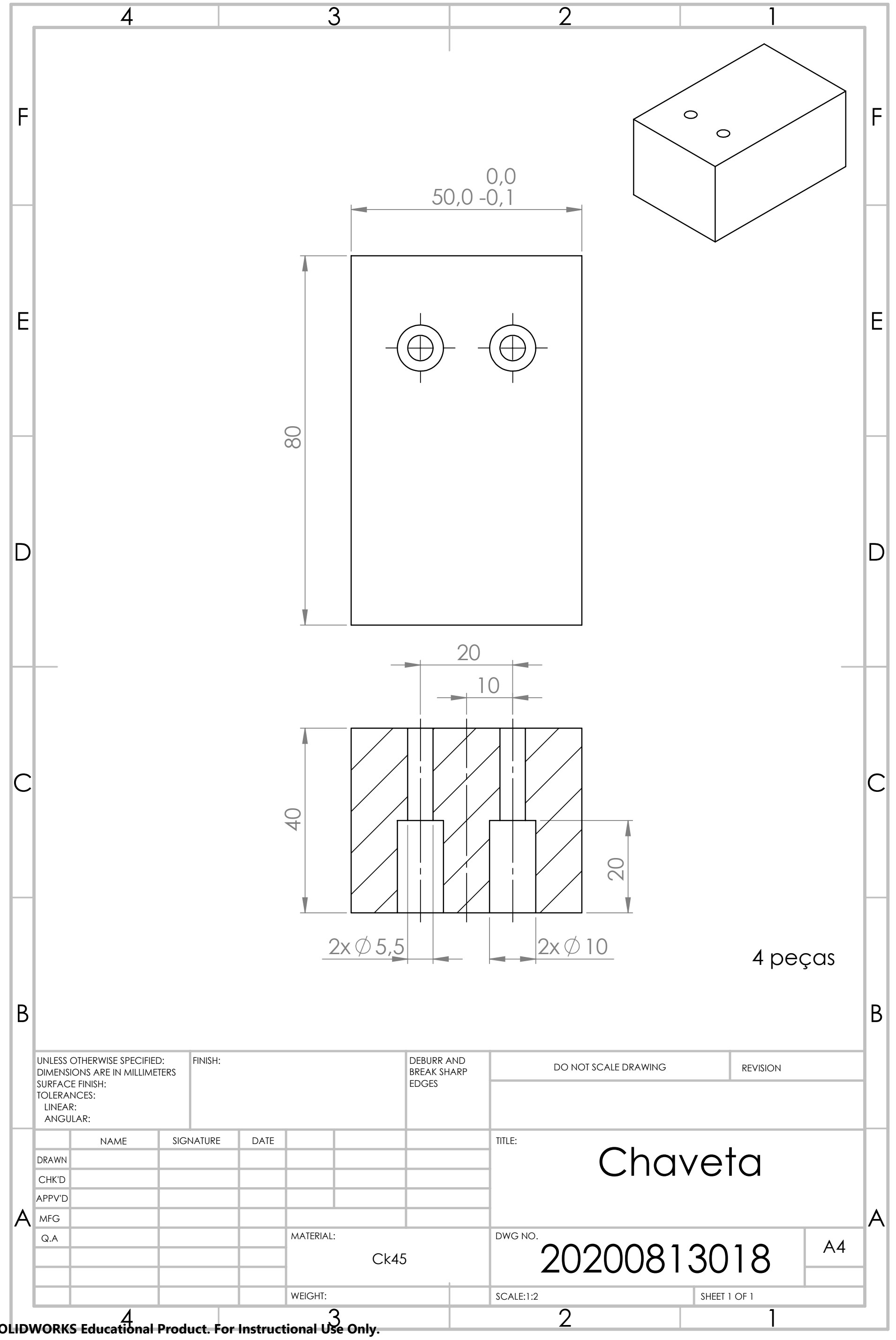




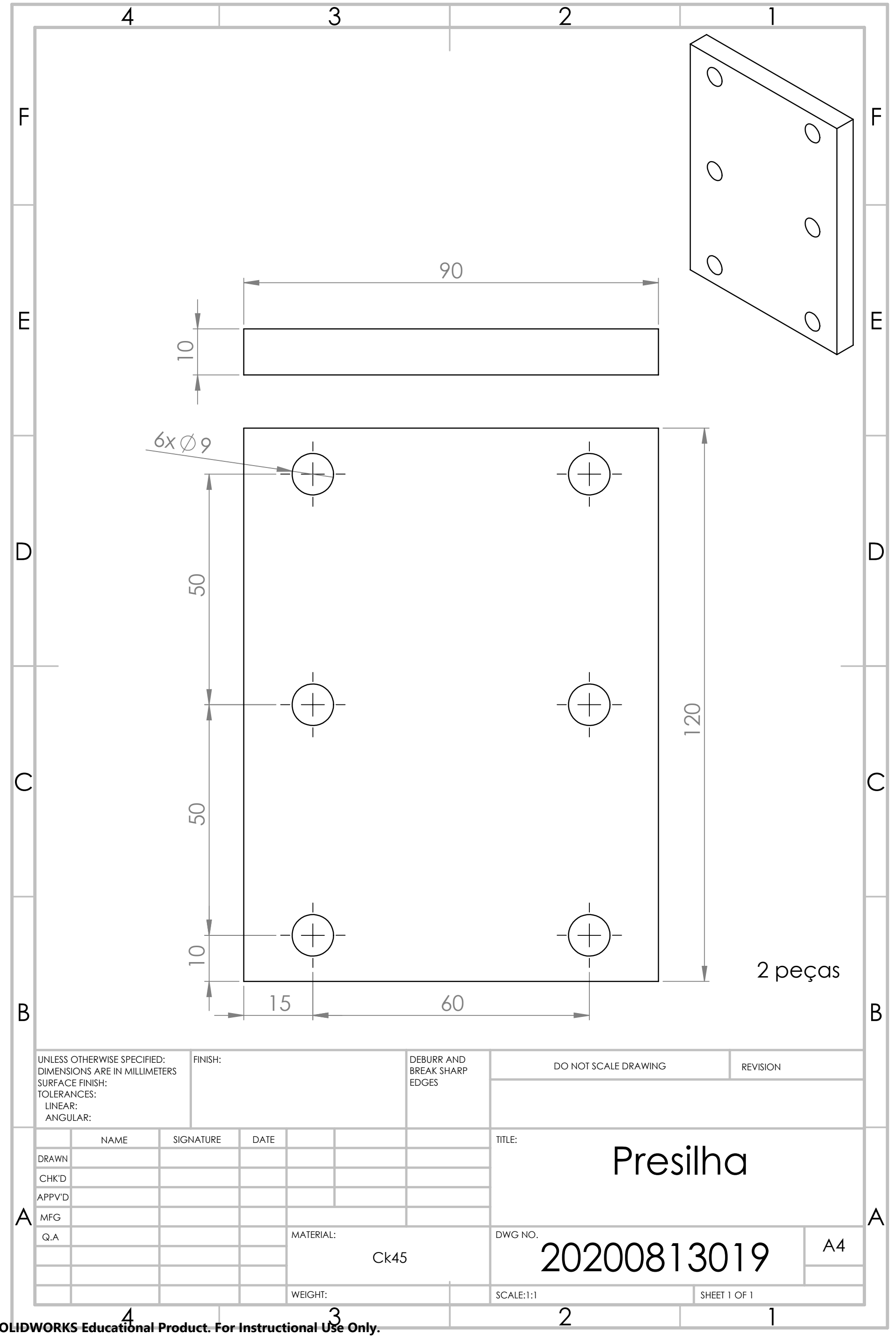




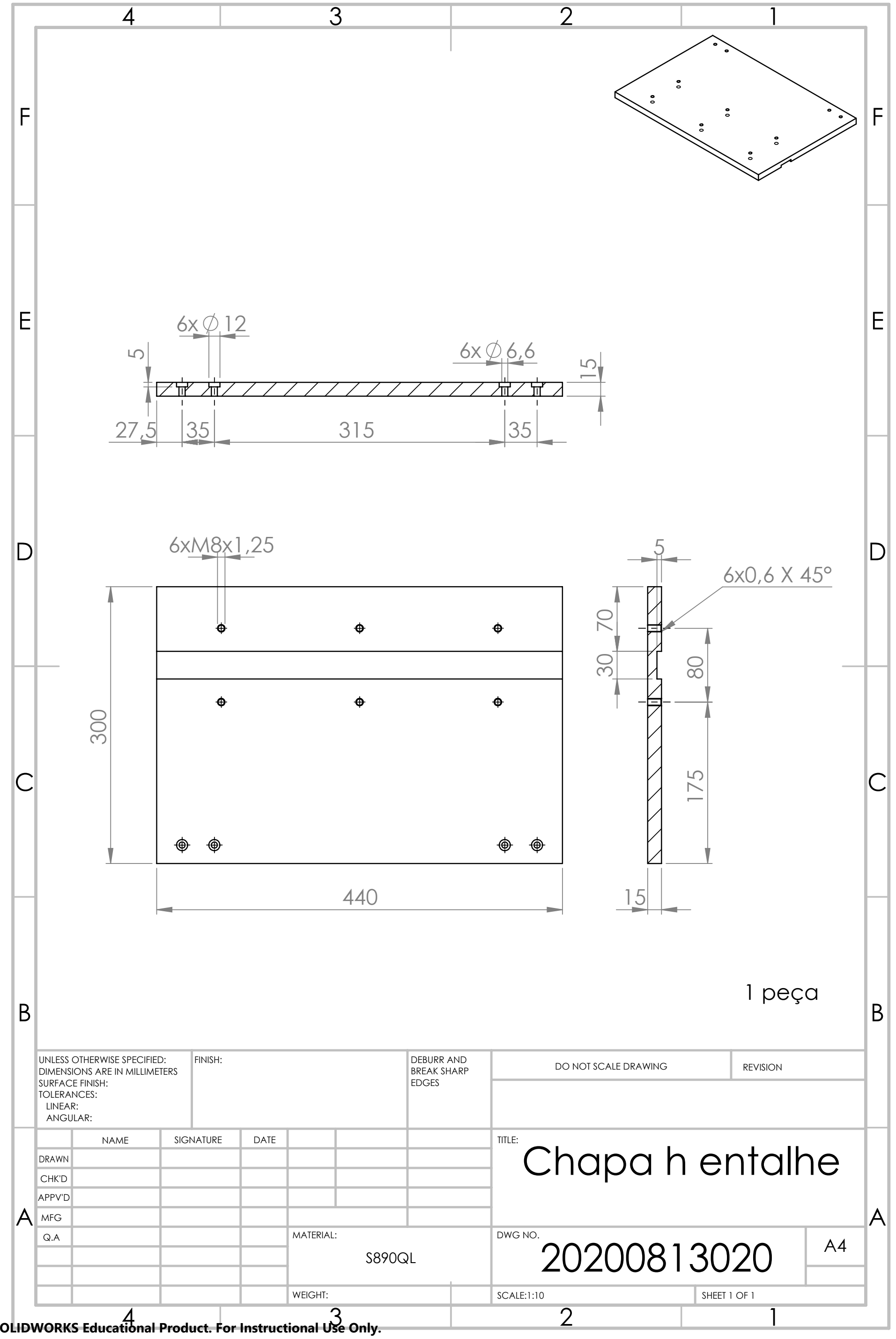




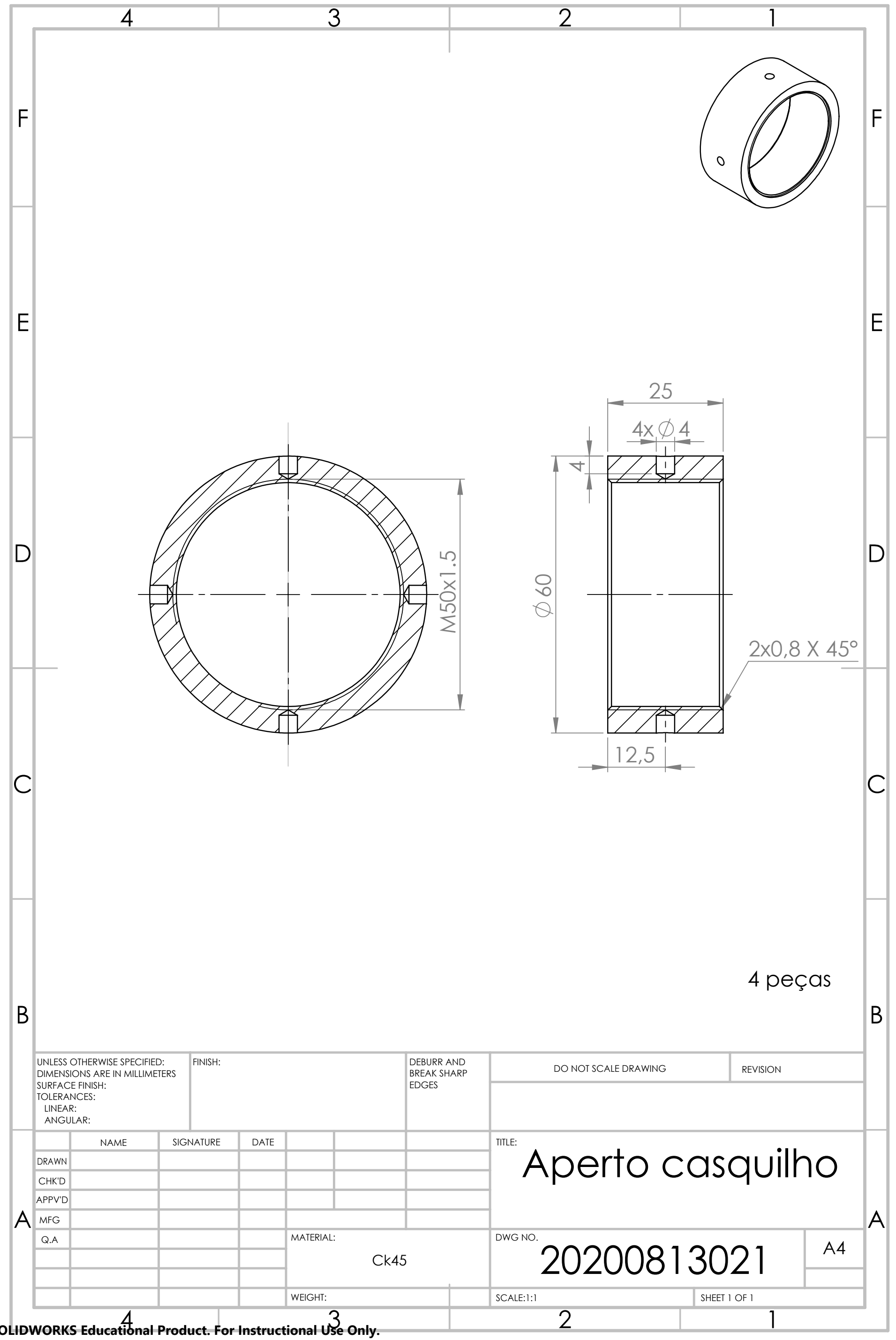




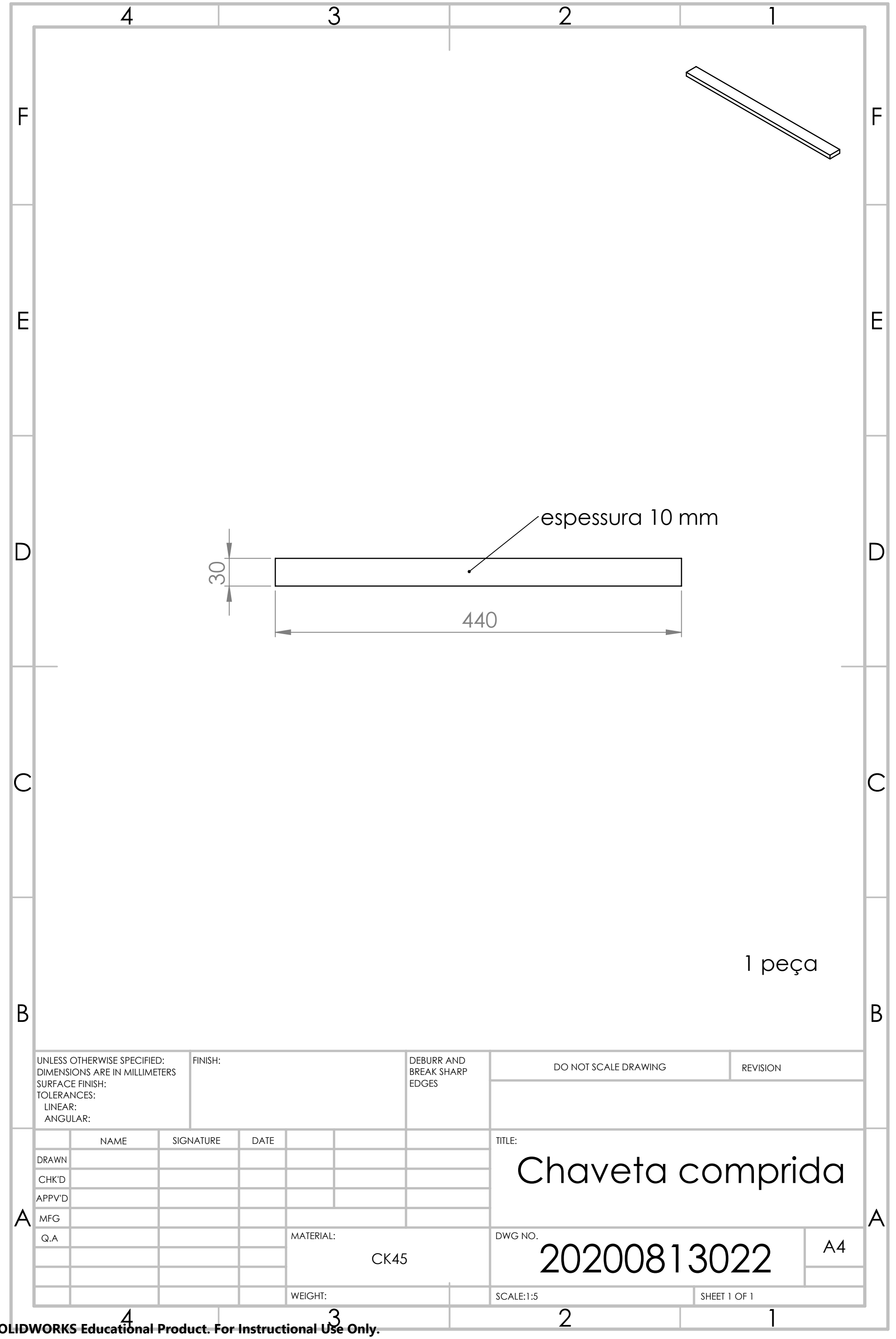




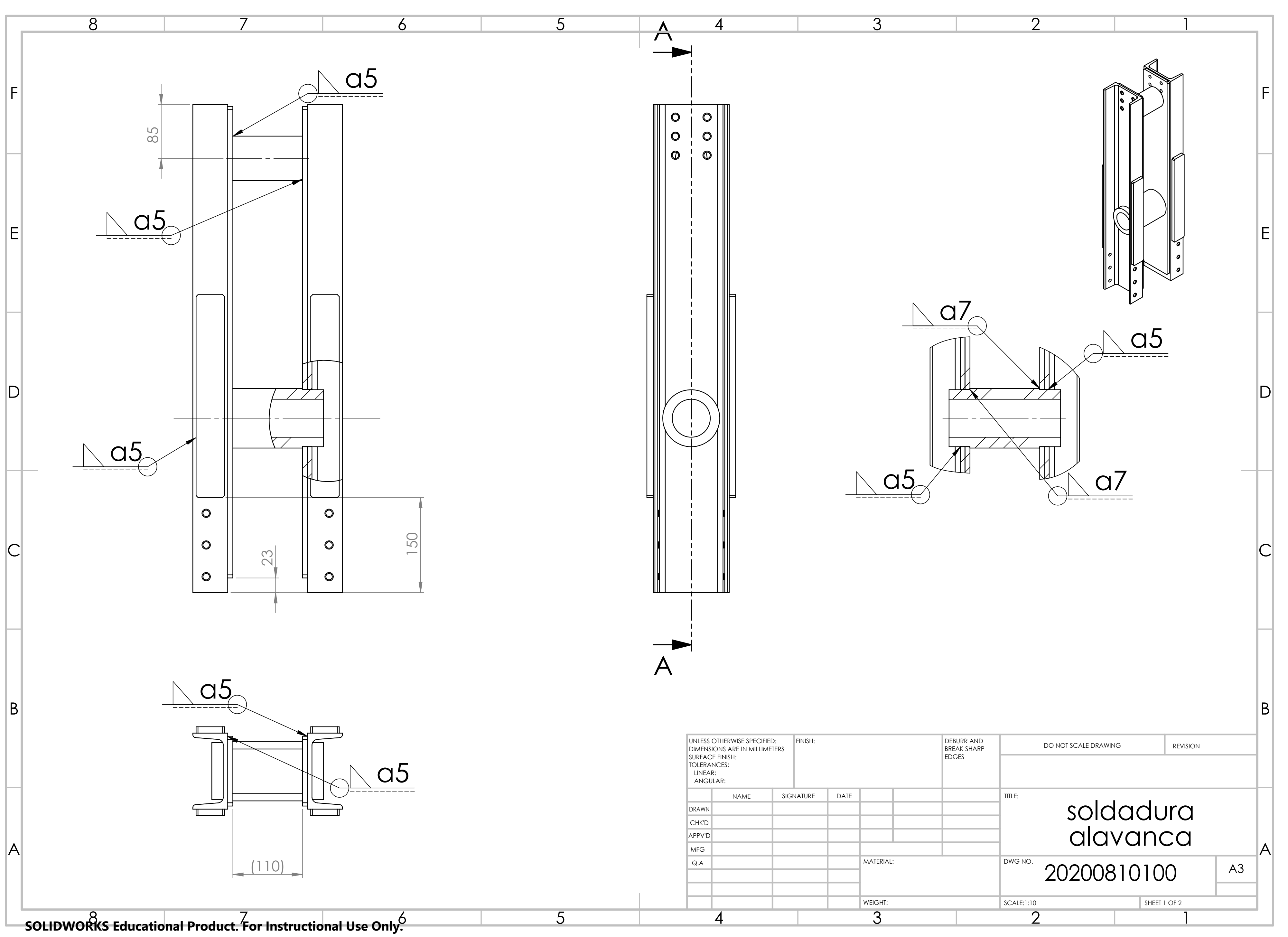




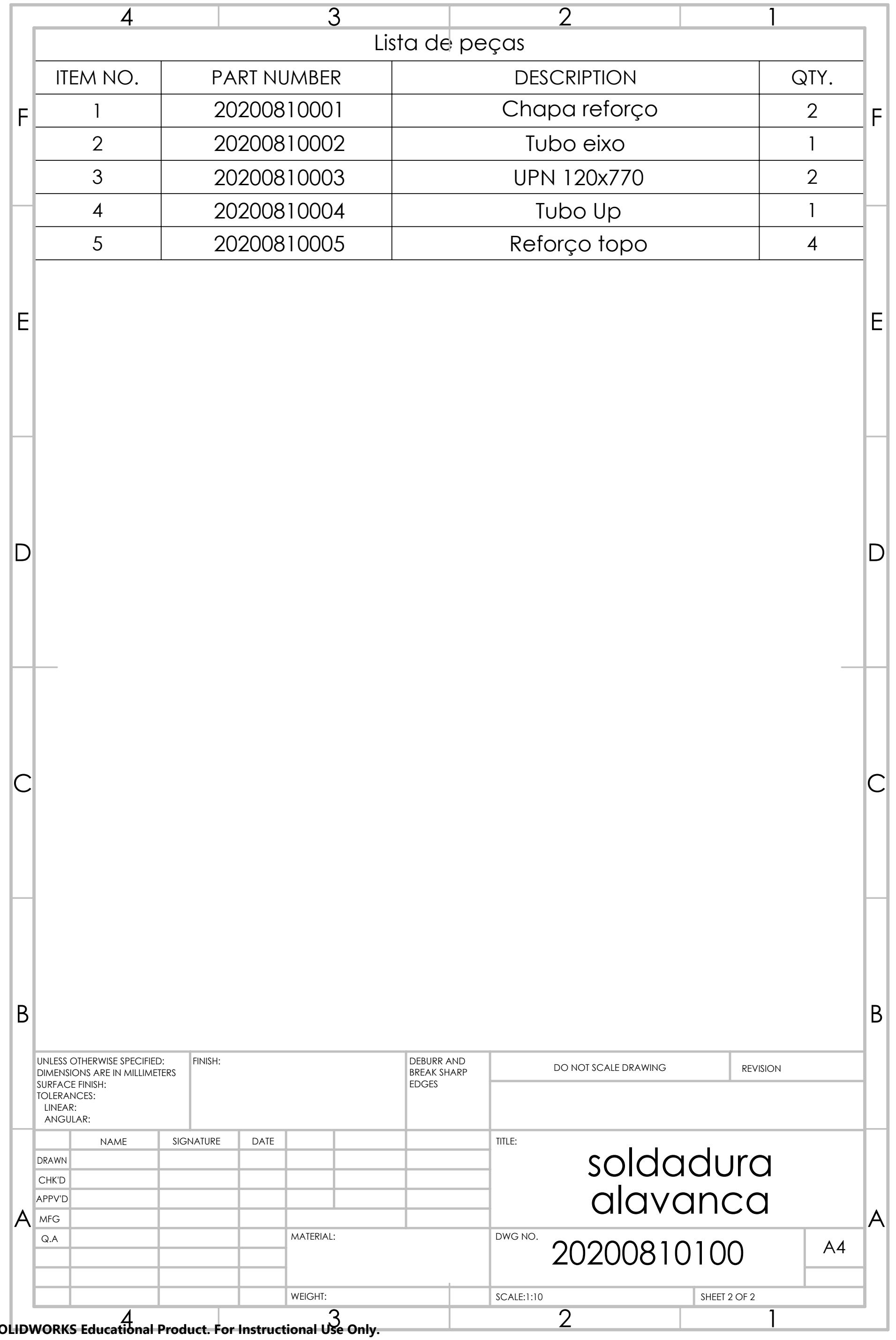




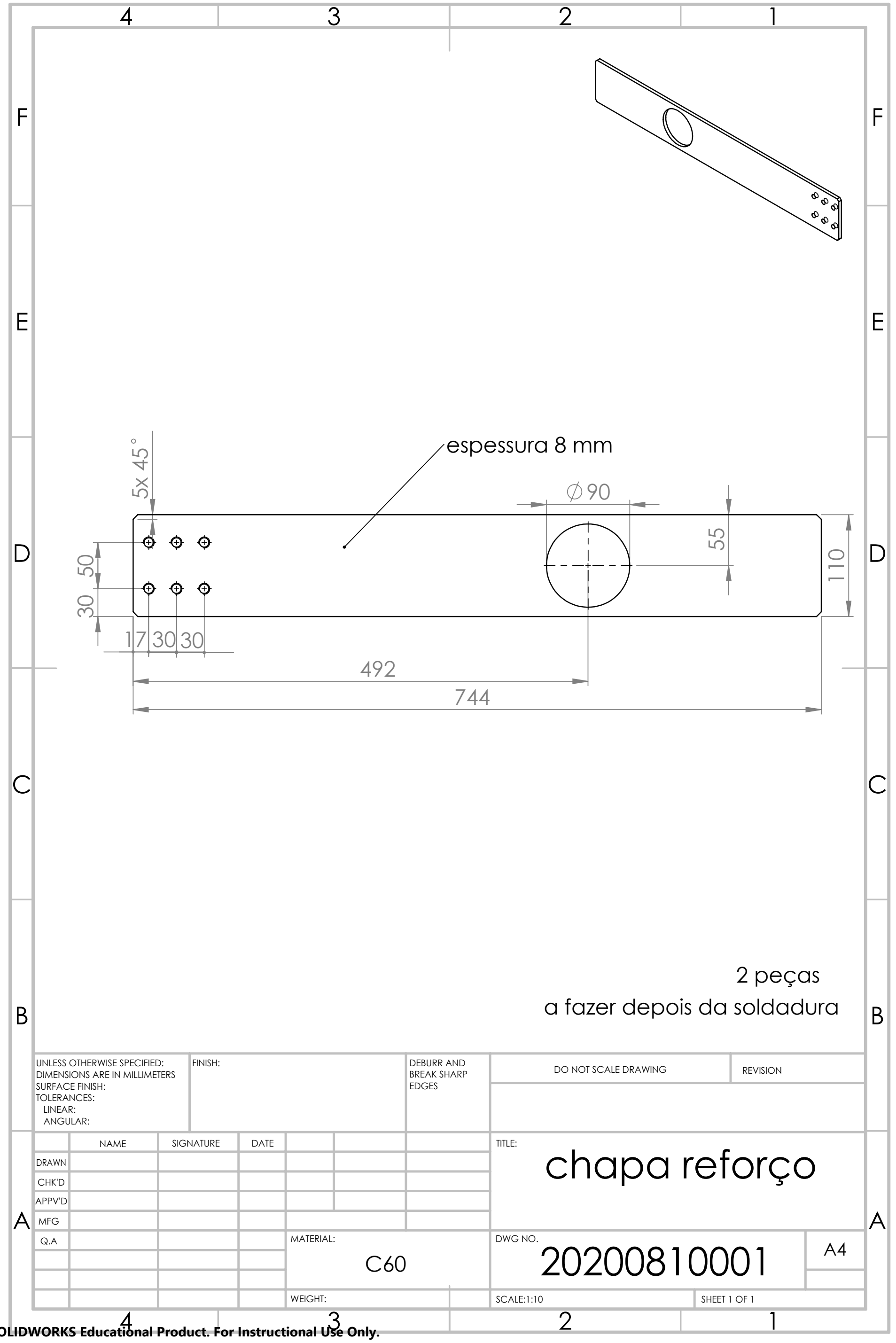




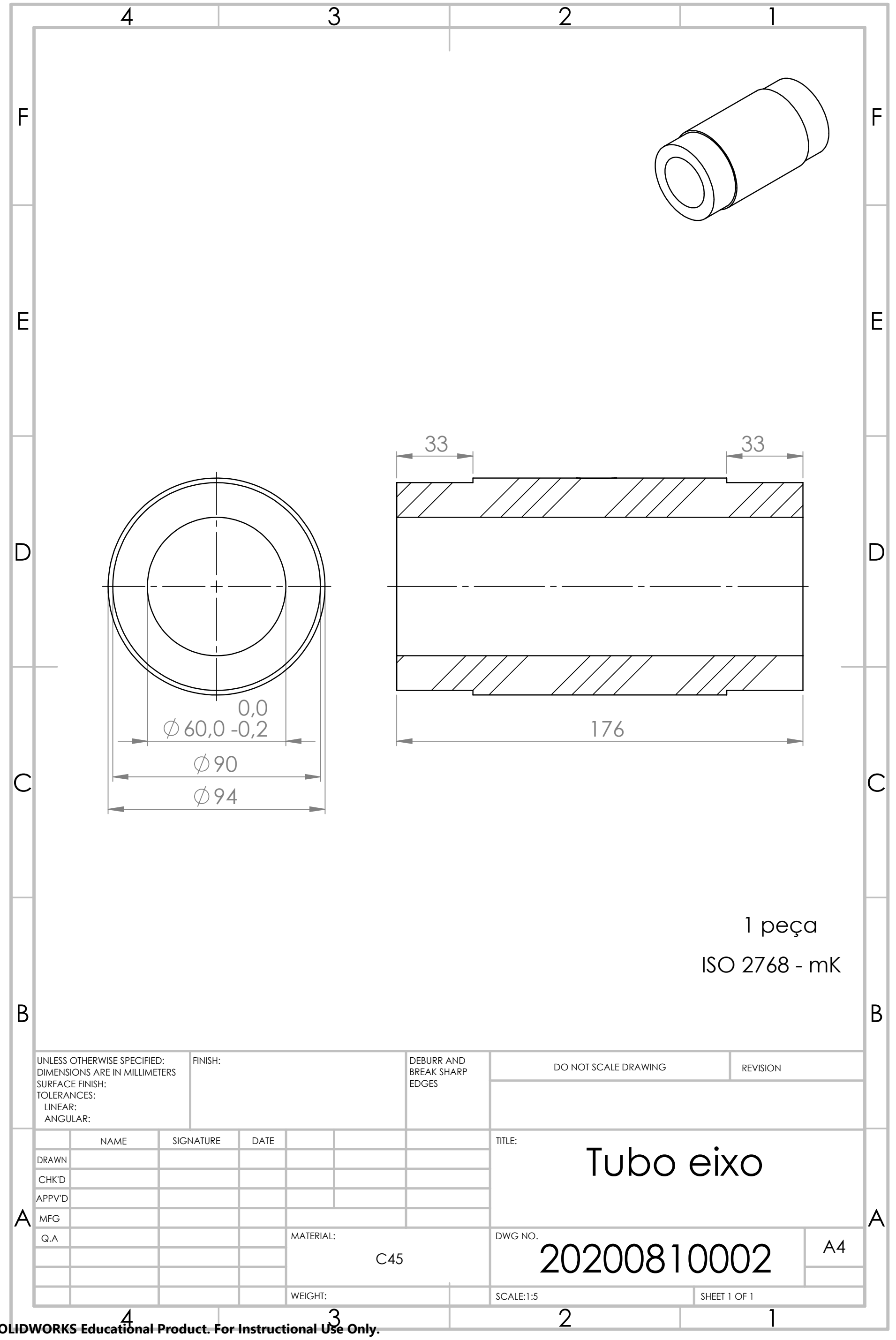




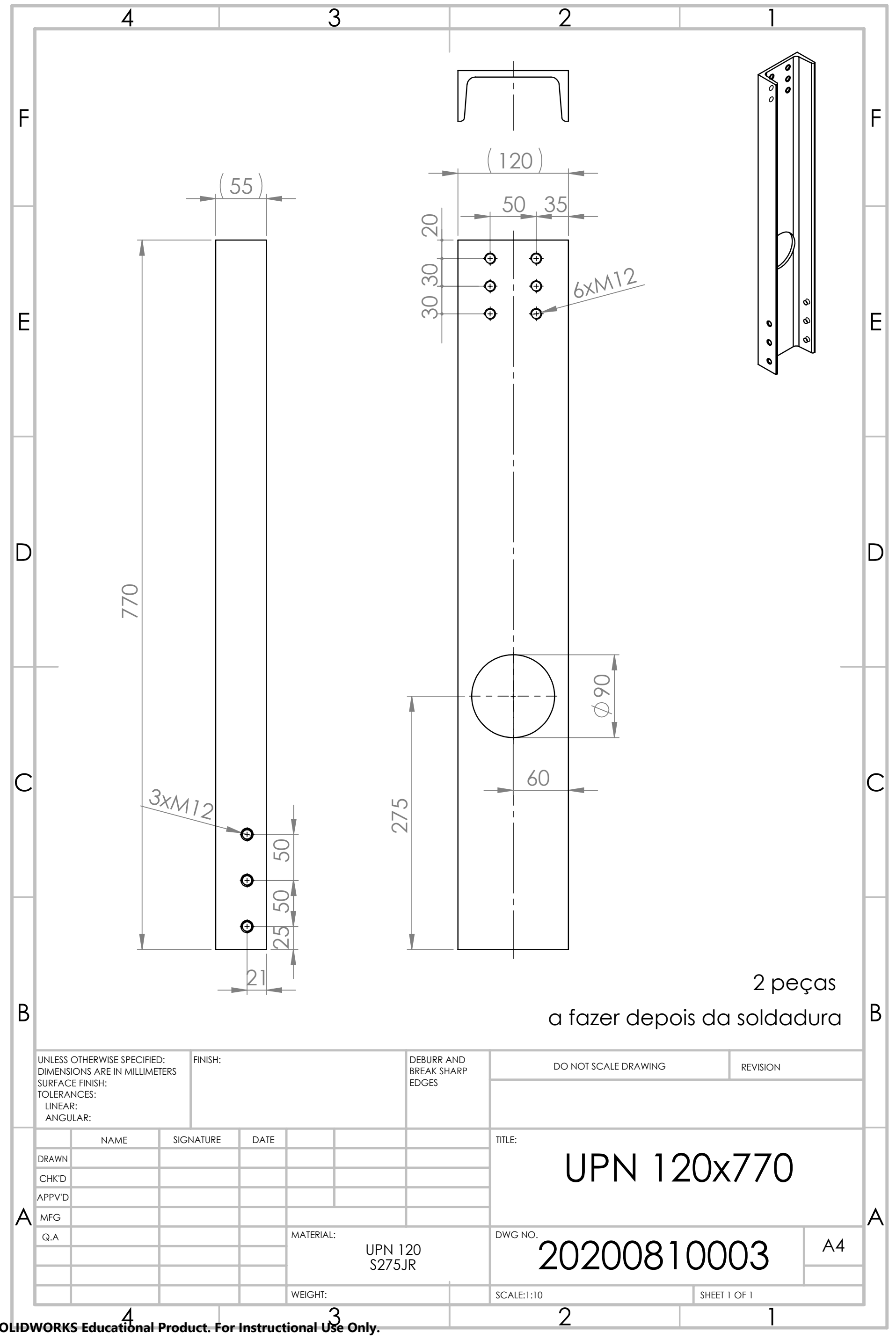




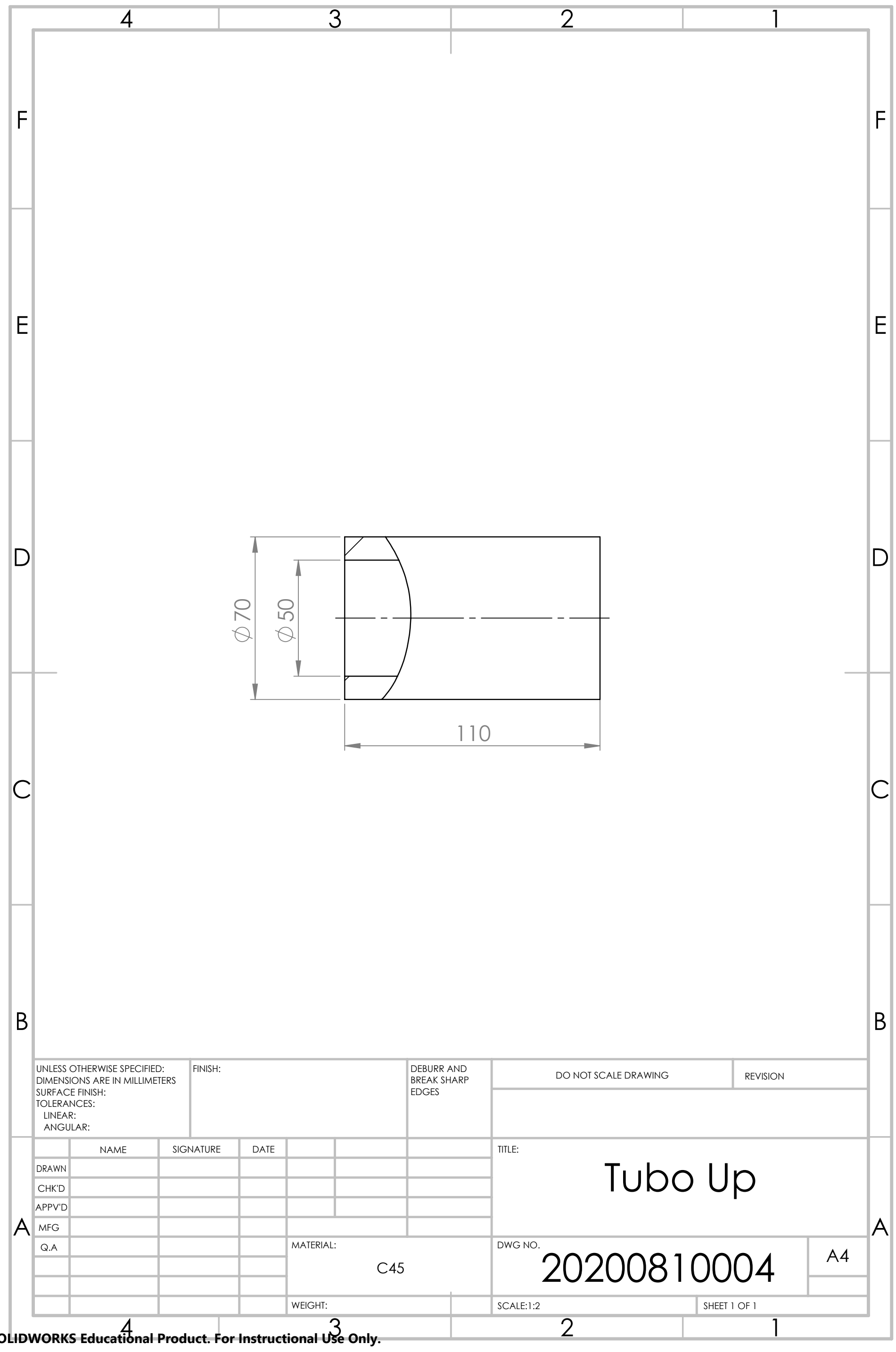




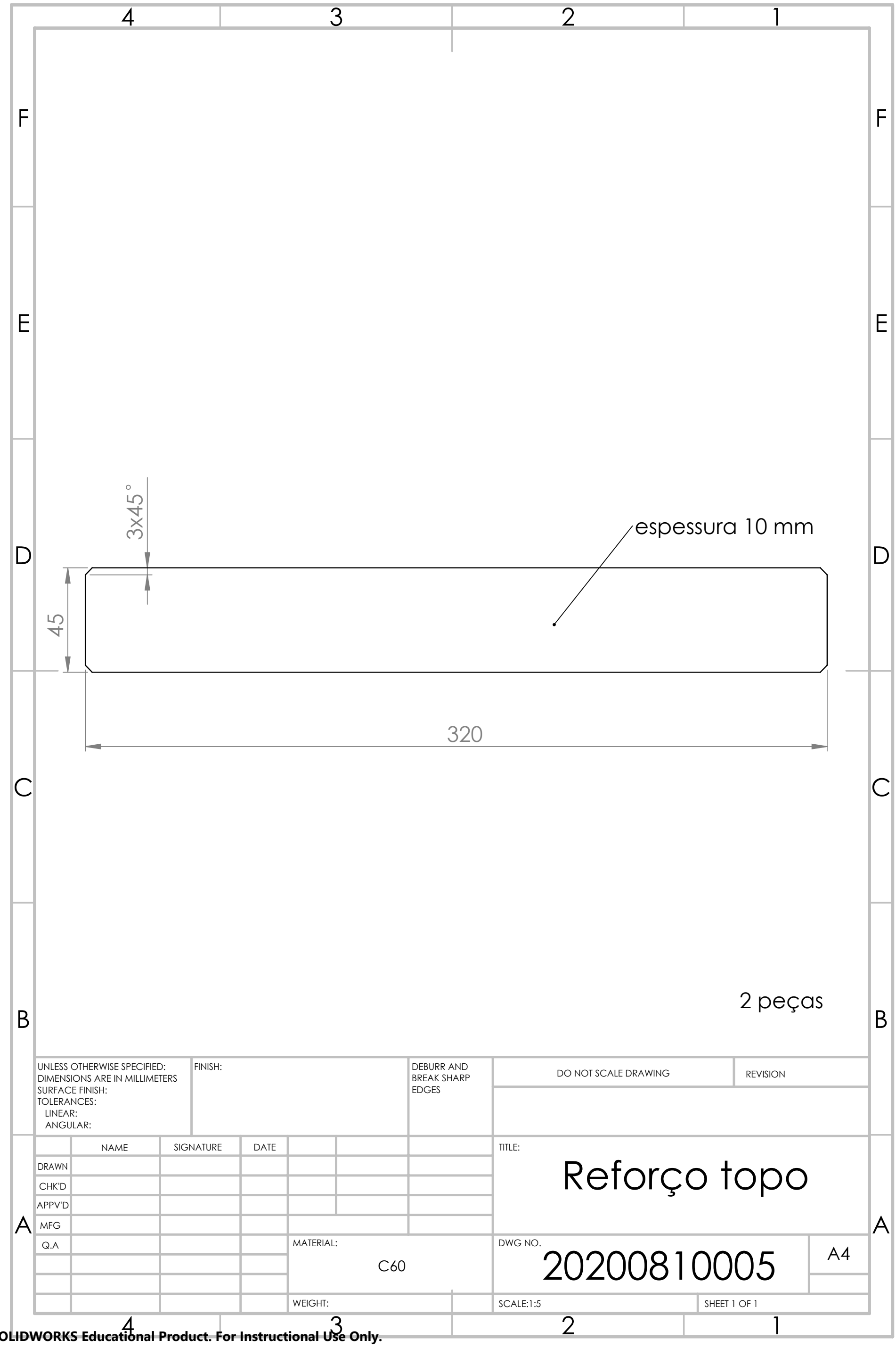




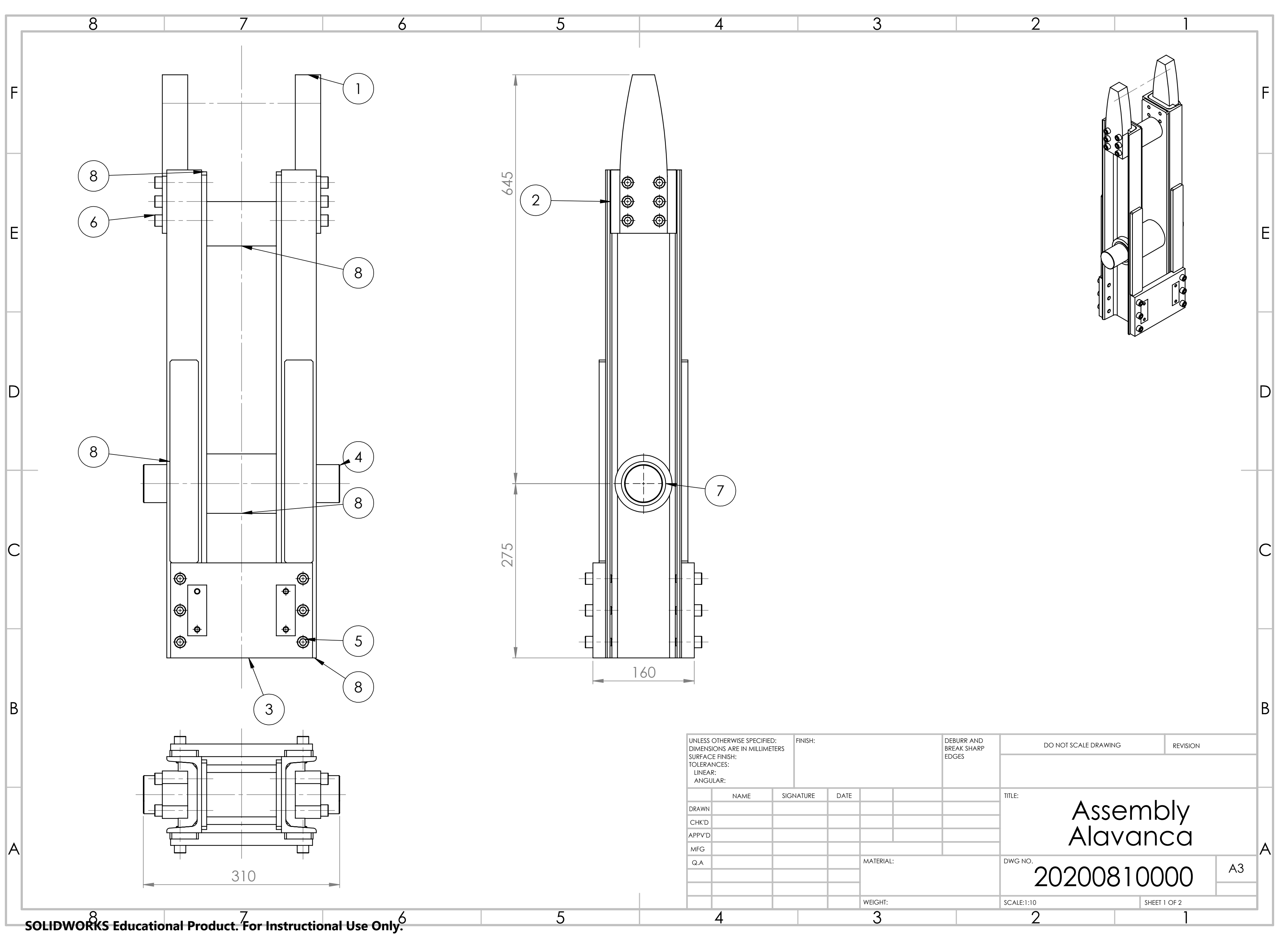




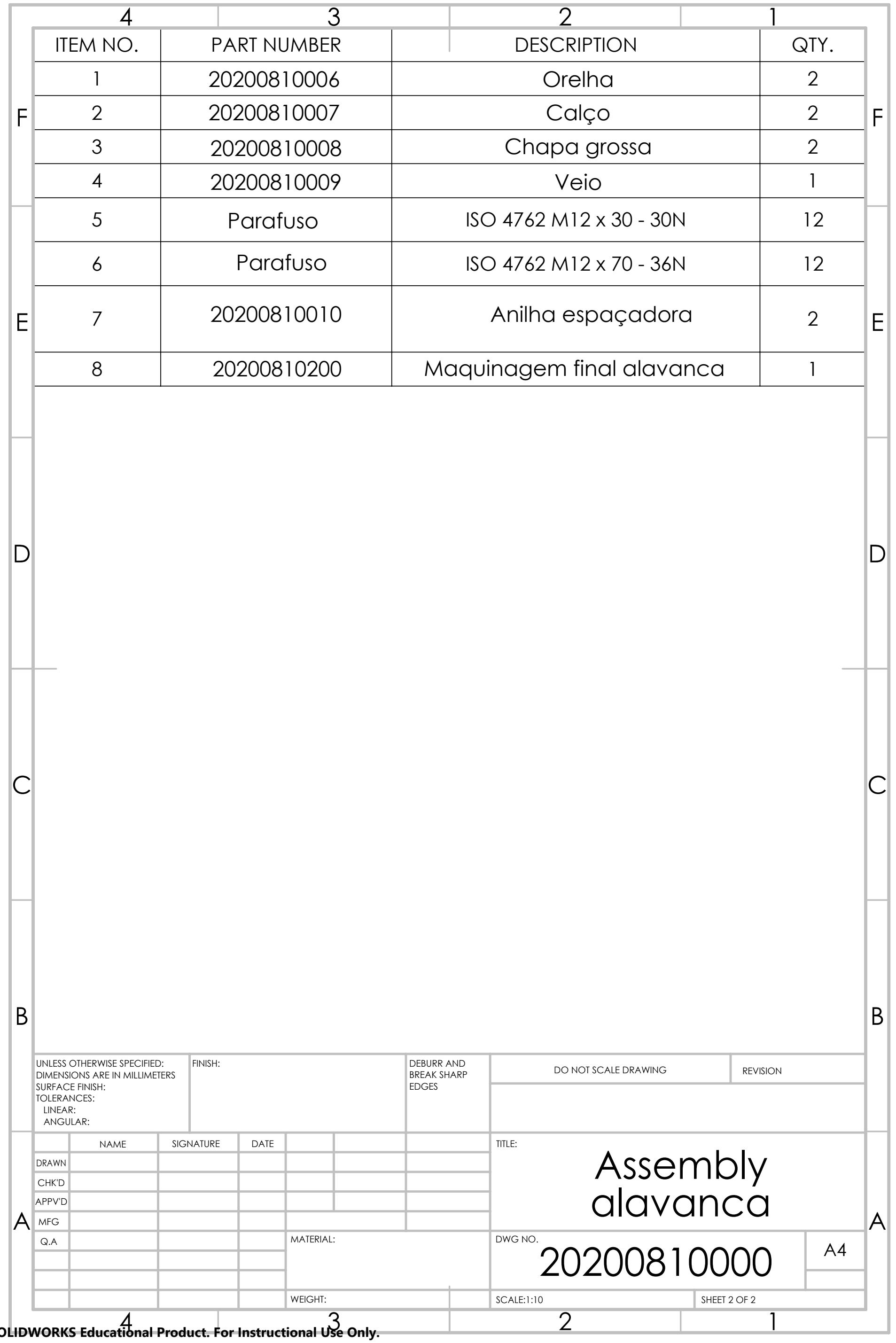


F
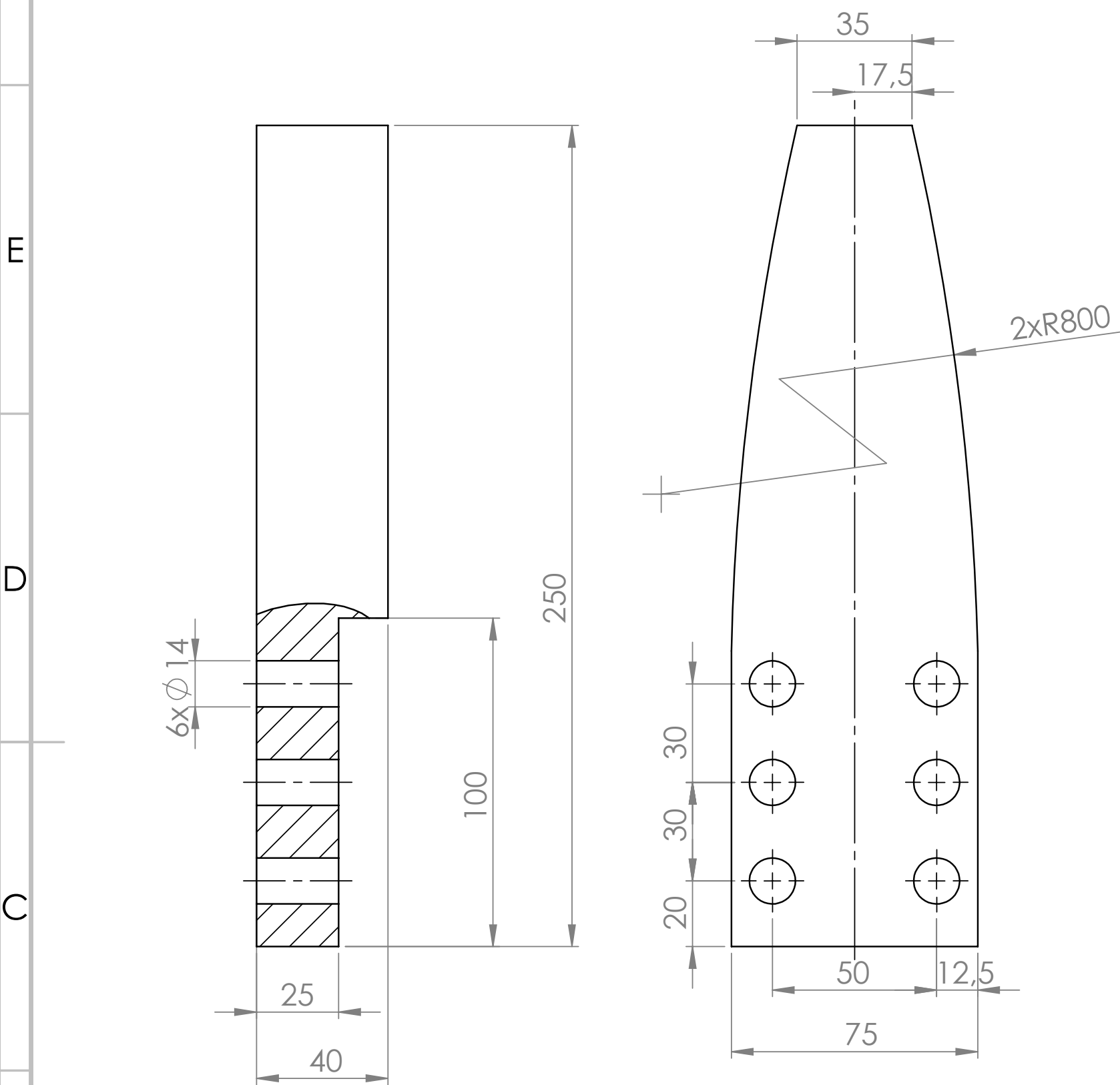

$E$

$\mathrm{D}$

2 peças

ISO $2768-\mathrm{mK}$

B

UNLESS OTHERWISE SPECIFIED:

TOLERANCES:
LINEAR:

LINEAR:
ANGULAR:

\begin{tabular}{|l|l|l|l|l|l|l|}
\hline & NAME & SIGNATURE & DATE & & & TITL: \\
\hline DRAWN & & & & & & \\
\hline CHK'D & & & & & & \\
\hline APPV'D & & & & & & \\
\hline
\end{tabular}

$A$

\begin{tabular}{|l|l|l|l|l|}
\hline APPV'D & & & & \\
\hline MFG & & & \\
\hline
\end{tabular}

DEBURR AND BREAK SHARP EDGES

DO NOT SCALE DRAWING

REVISION

\begin{tabular}{|l|l|l|l|l|l|}
\hline Q.A & & & MATERIAL: & \\
\hline & & & & Al 7075-T6 \\
\hline & & & & \\
\hline
\end{tabular}

\section{Orelha}




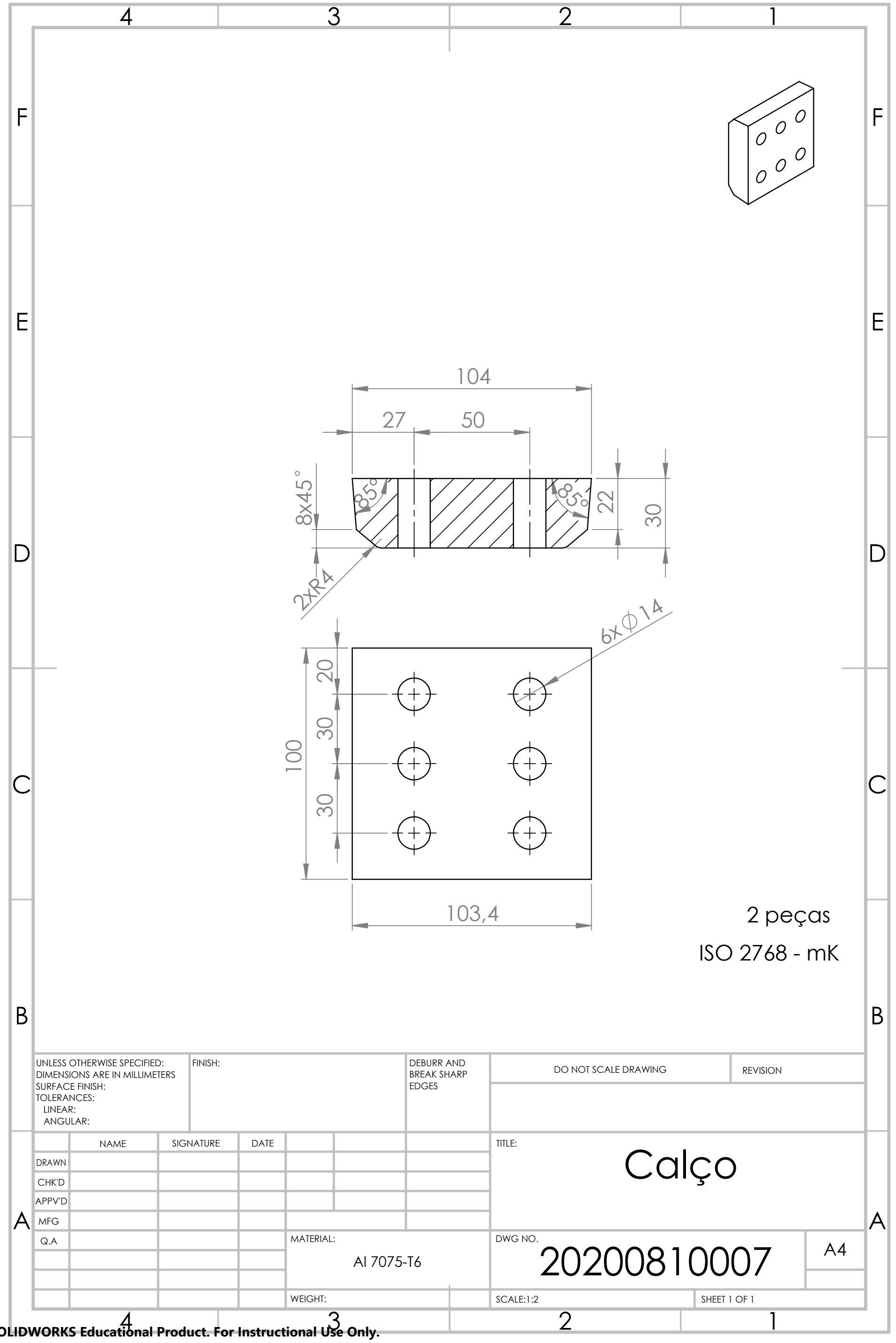




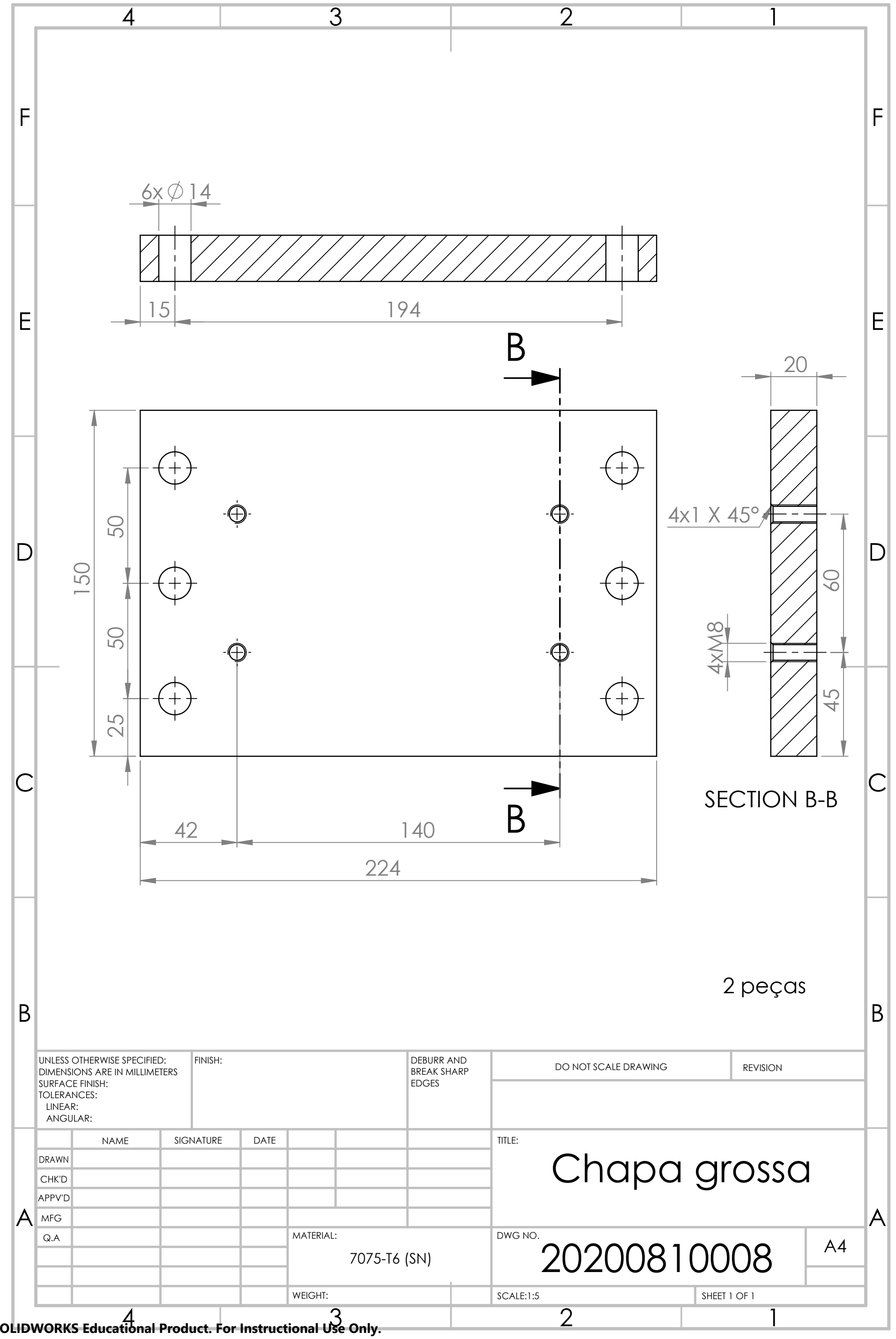




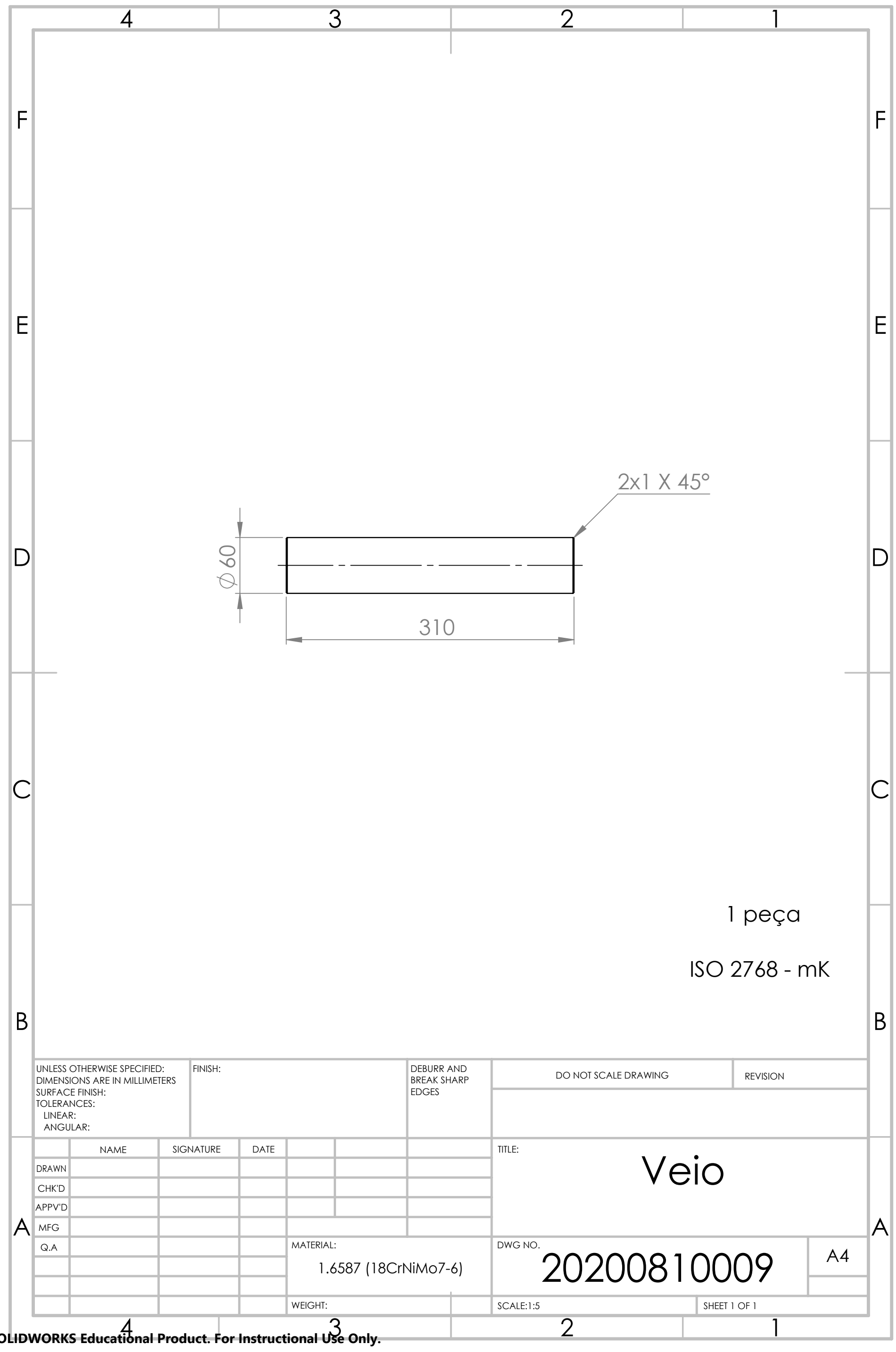




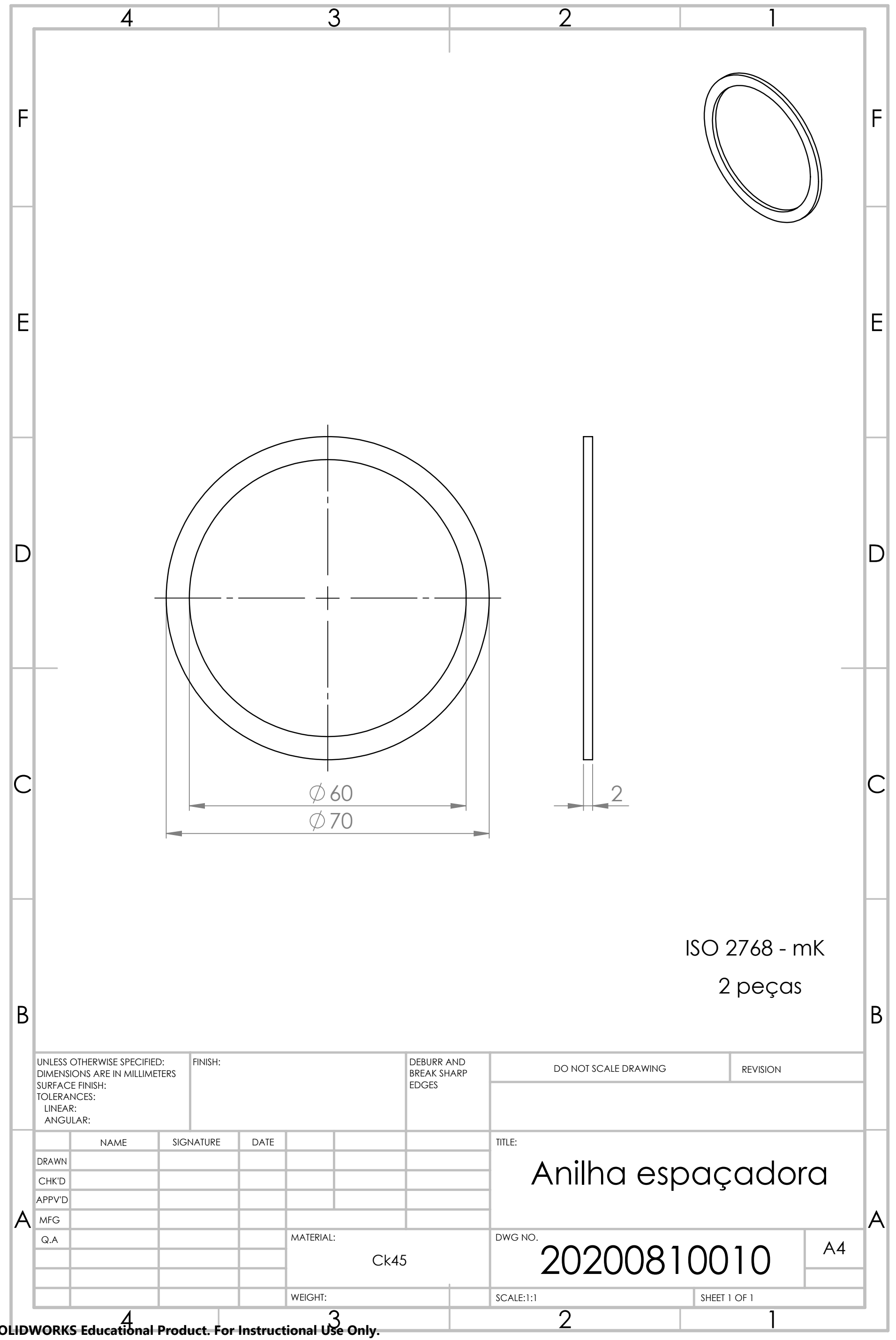




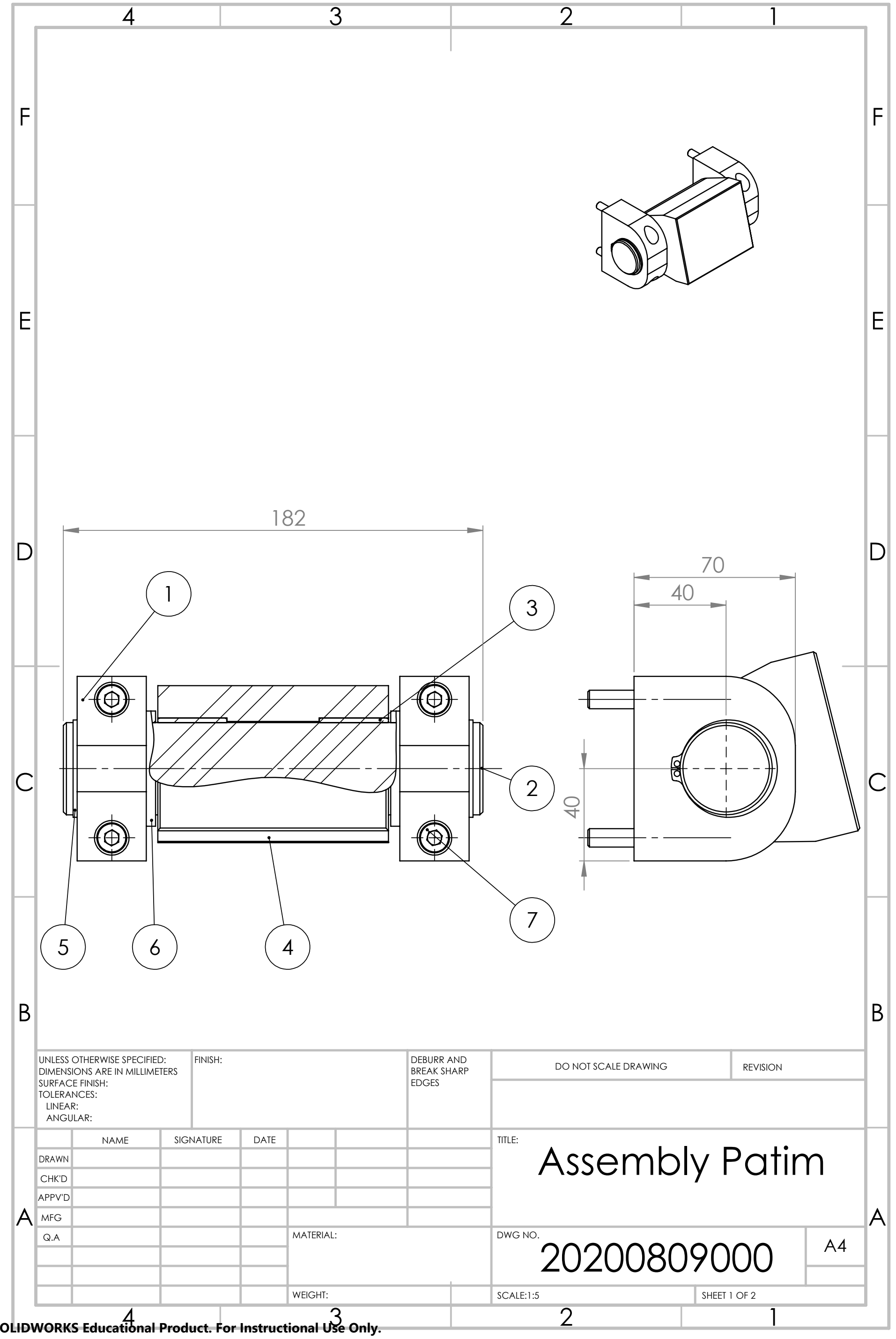




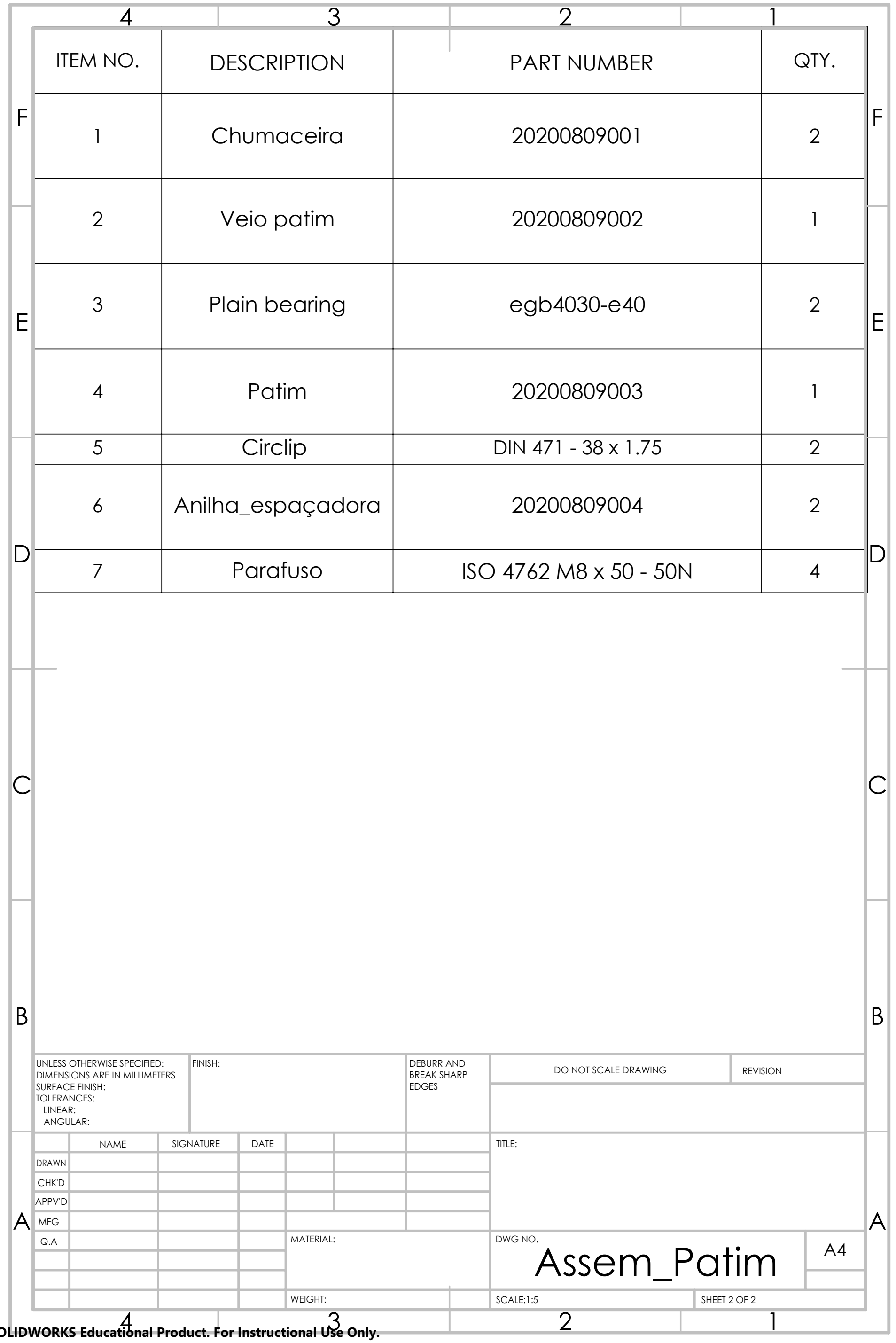




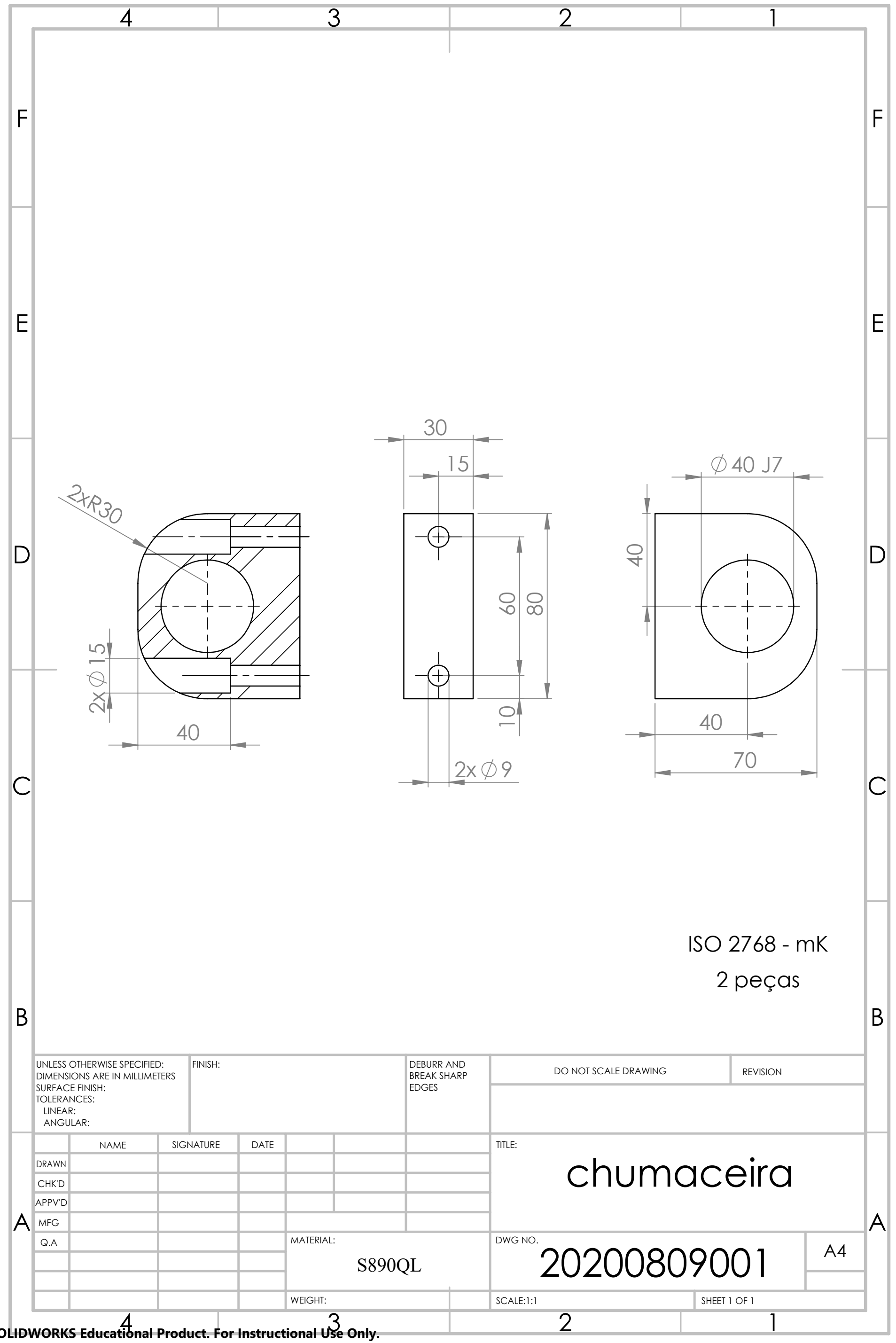




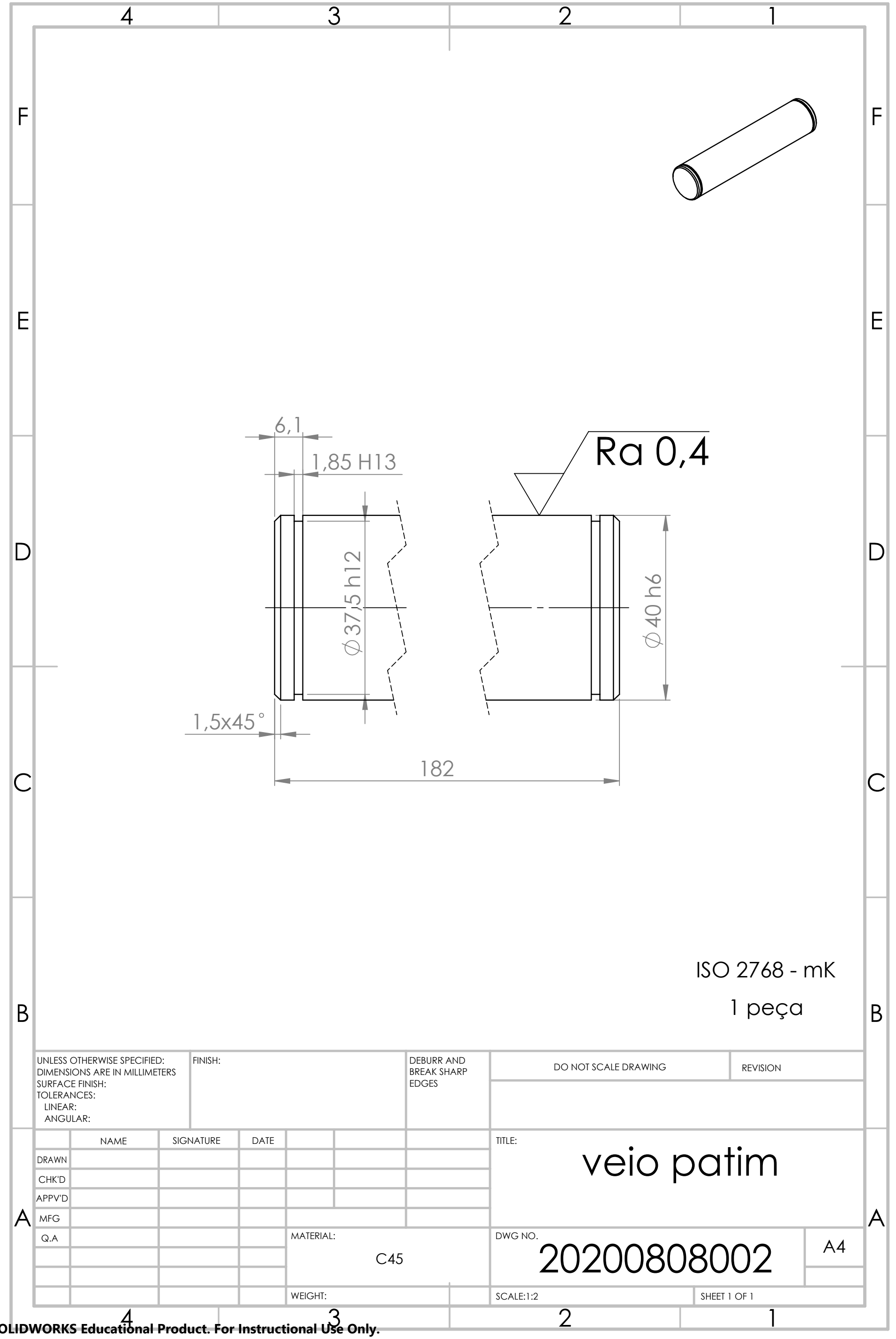




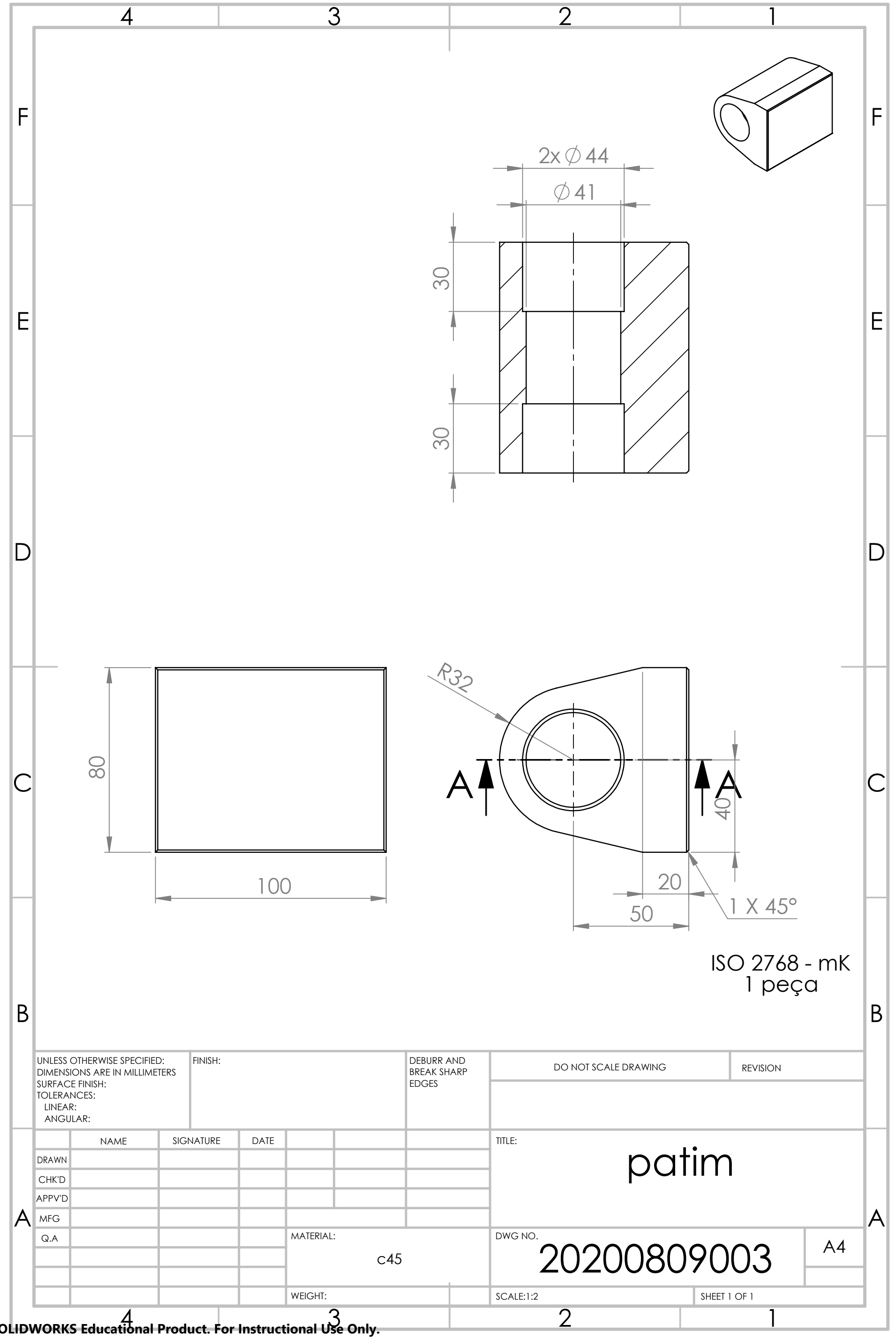




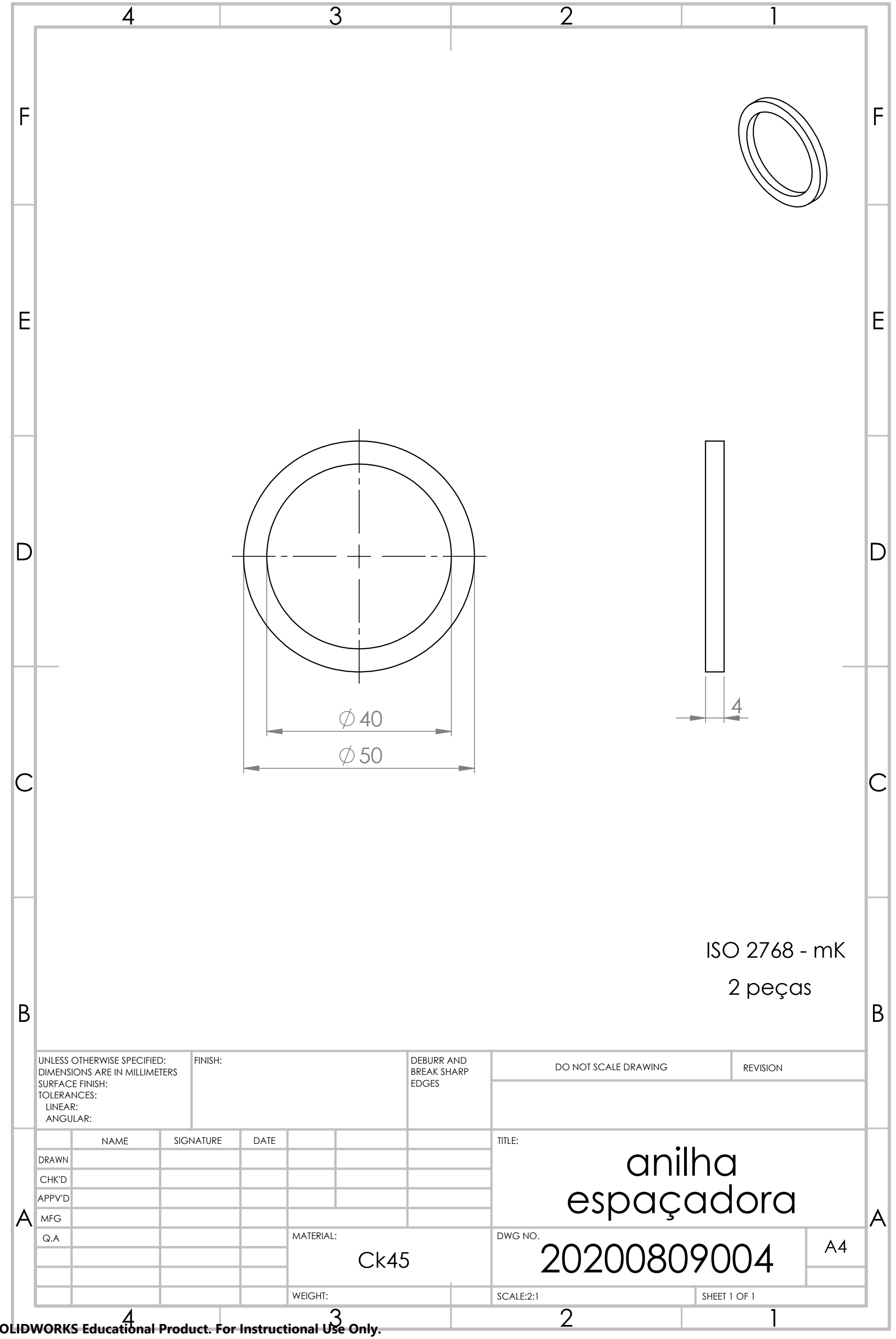





\section{Appendix D}

Mechanical Drawings

Stopping car 


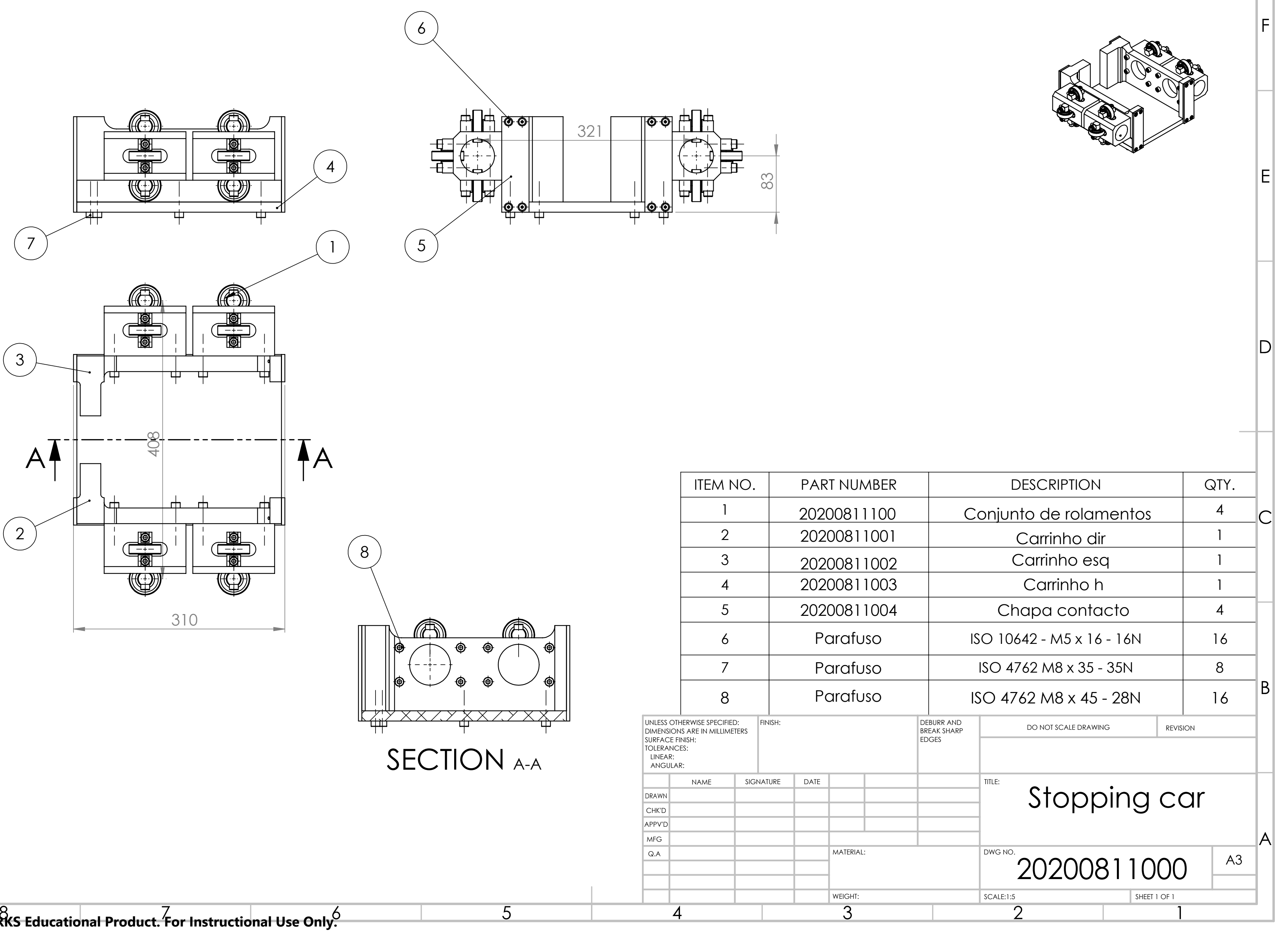

SOLIDWORk Ed Educational Product. For Instructional Use Only.

SECTION A-A

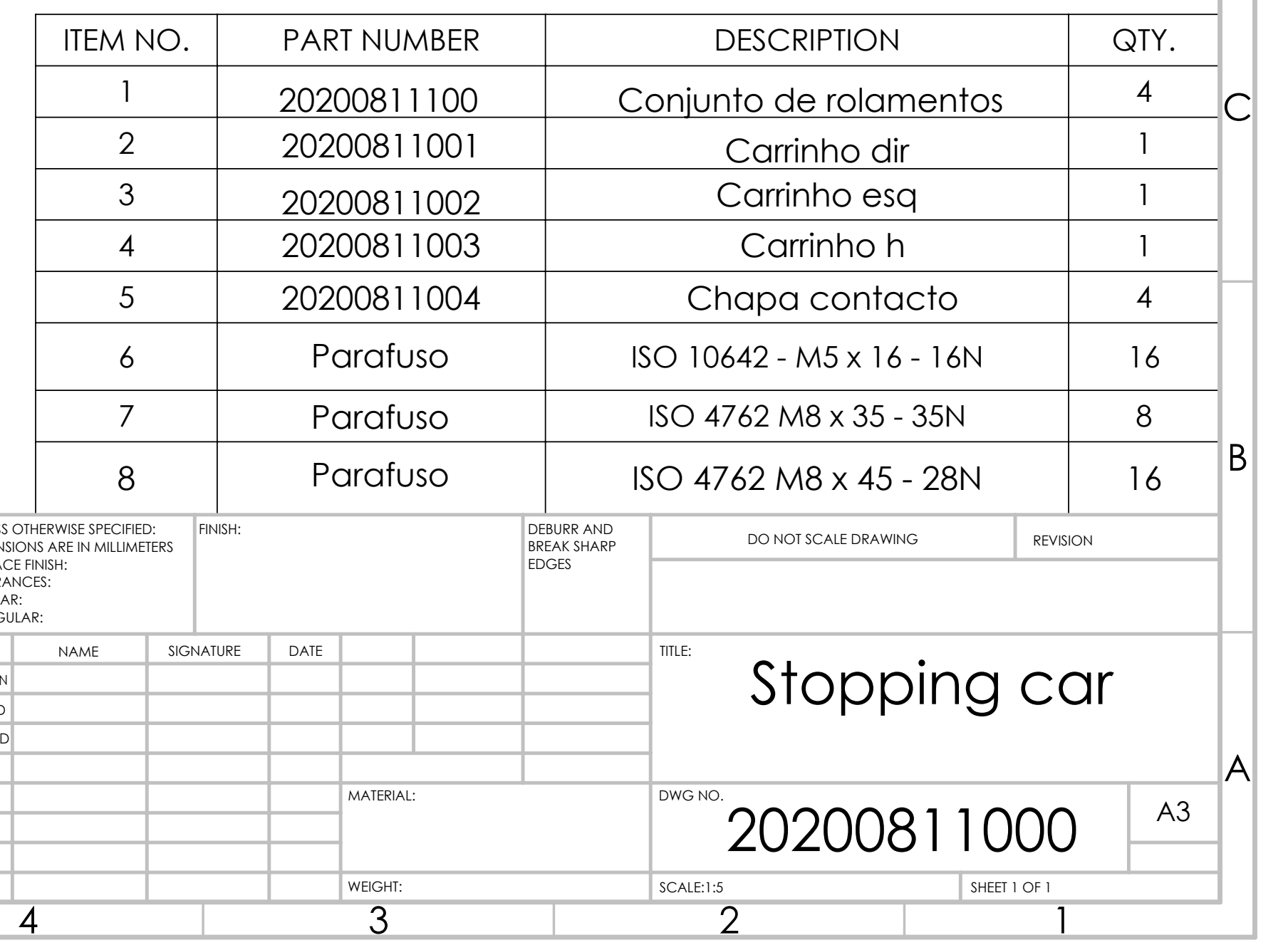




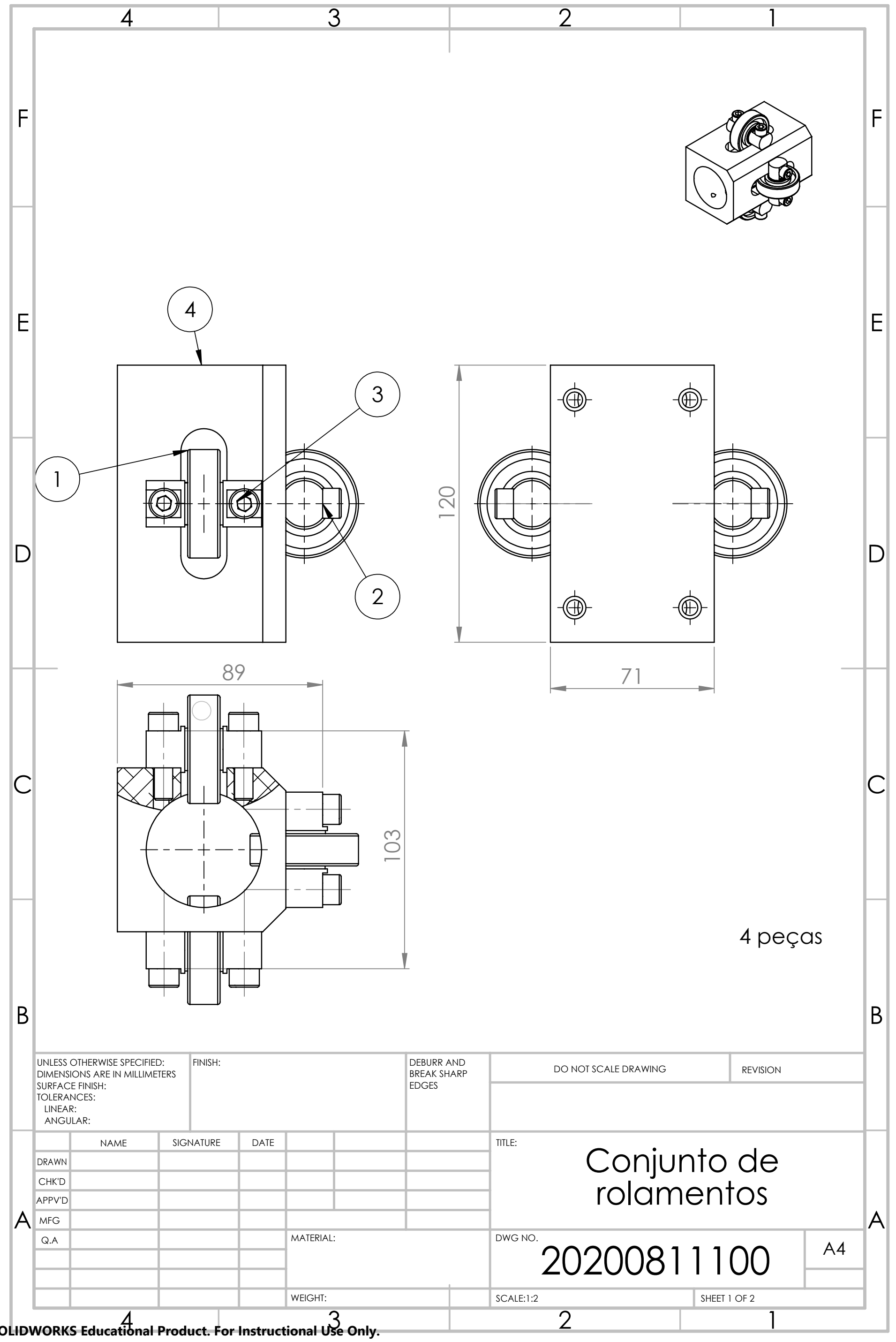




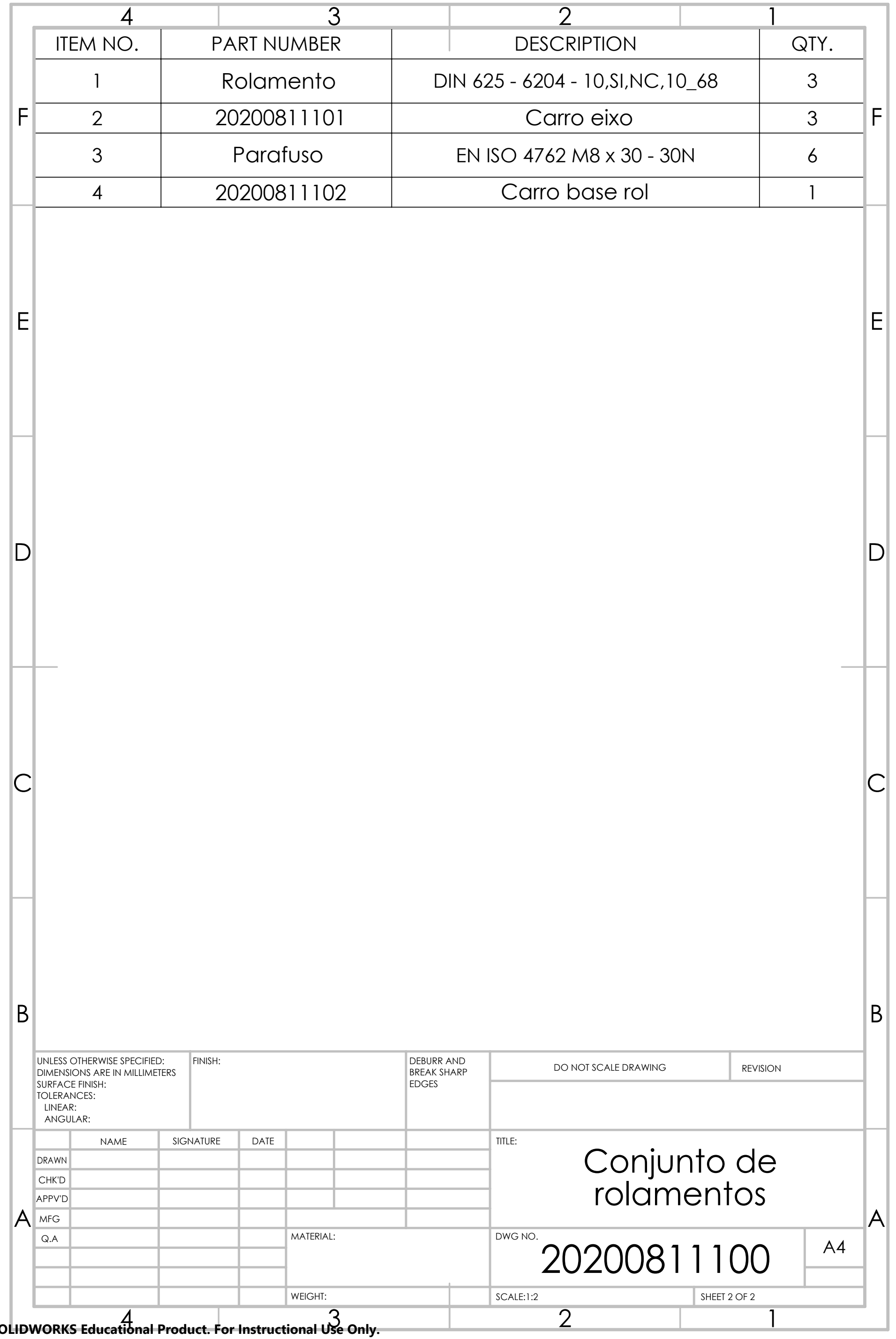




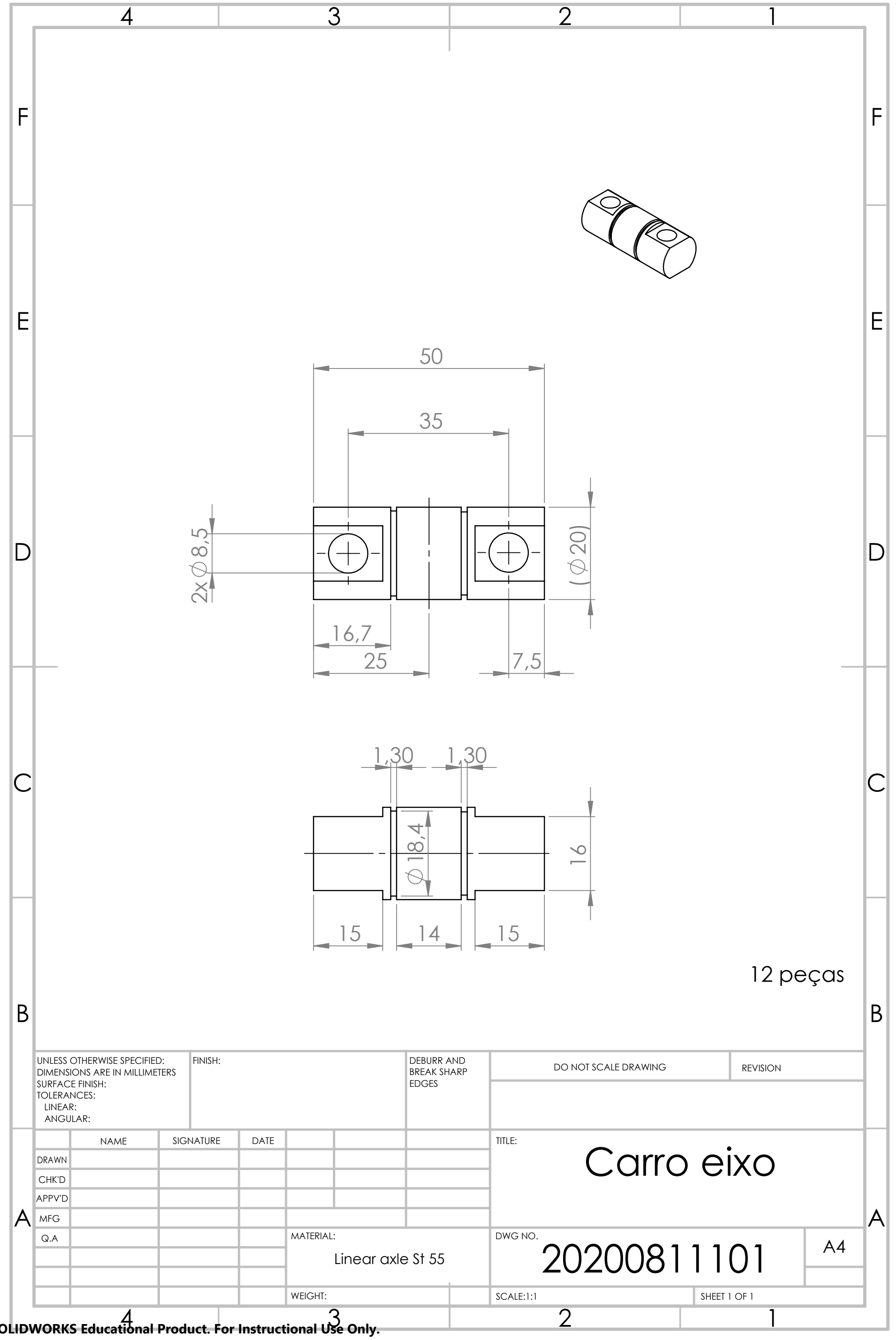




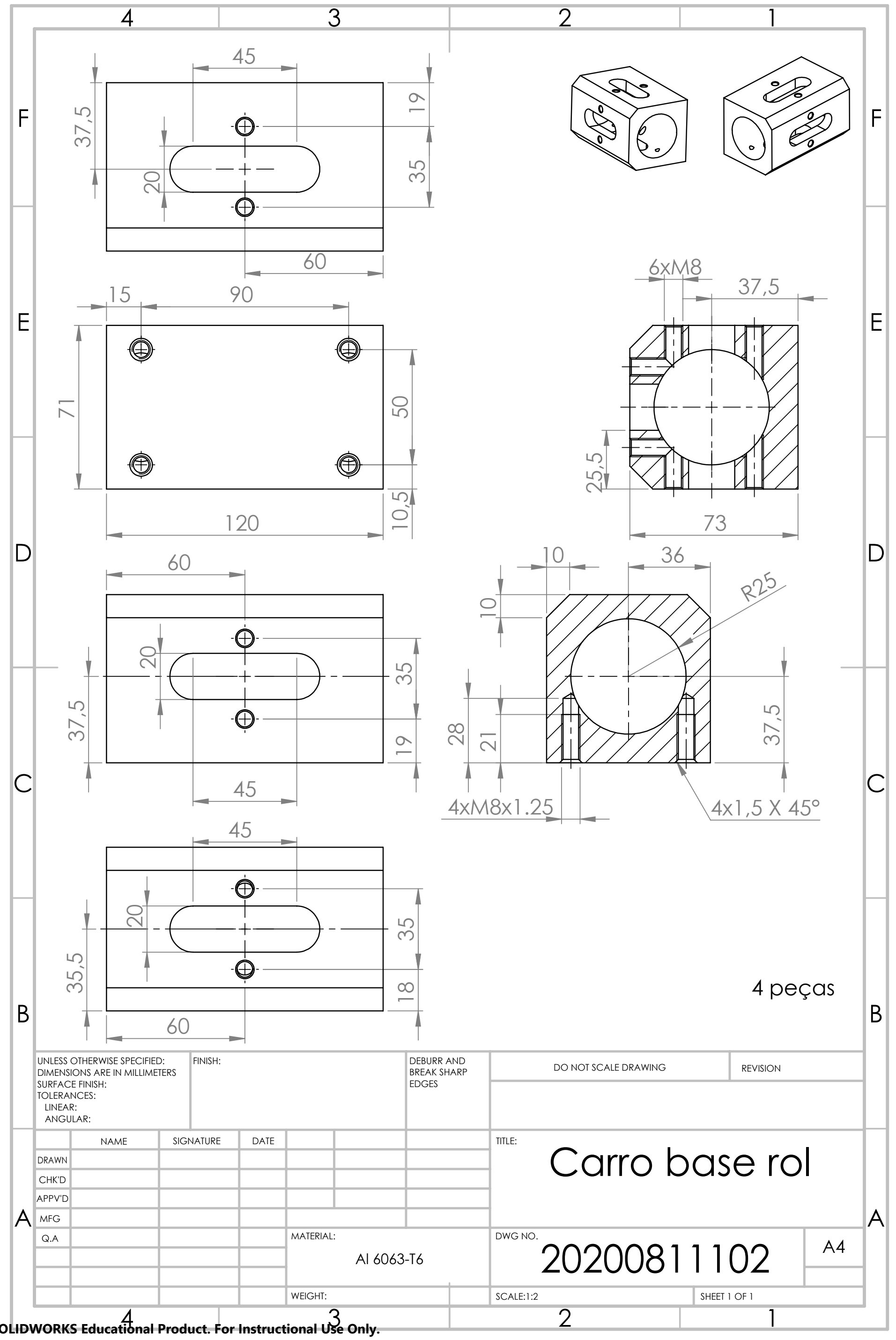



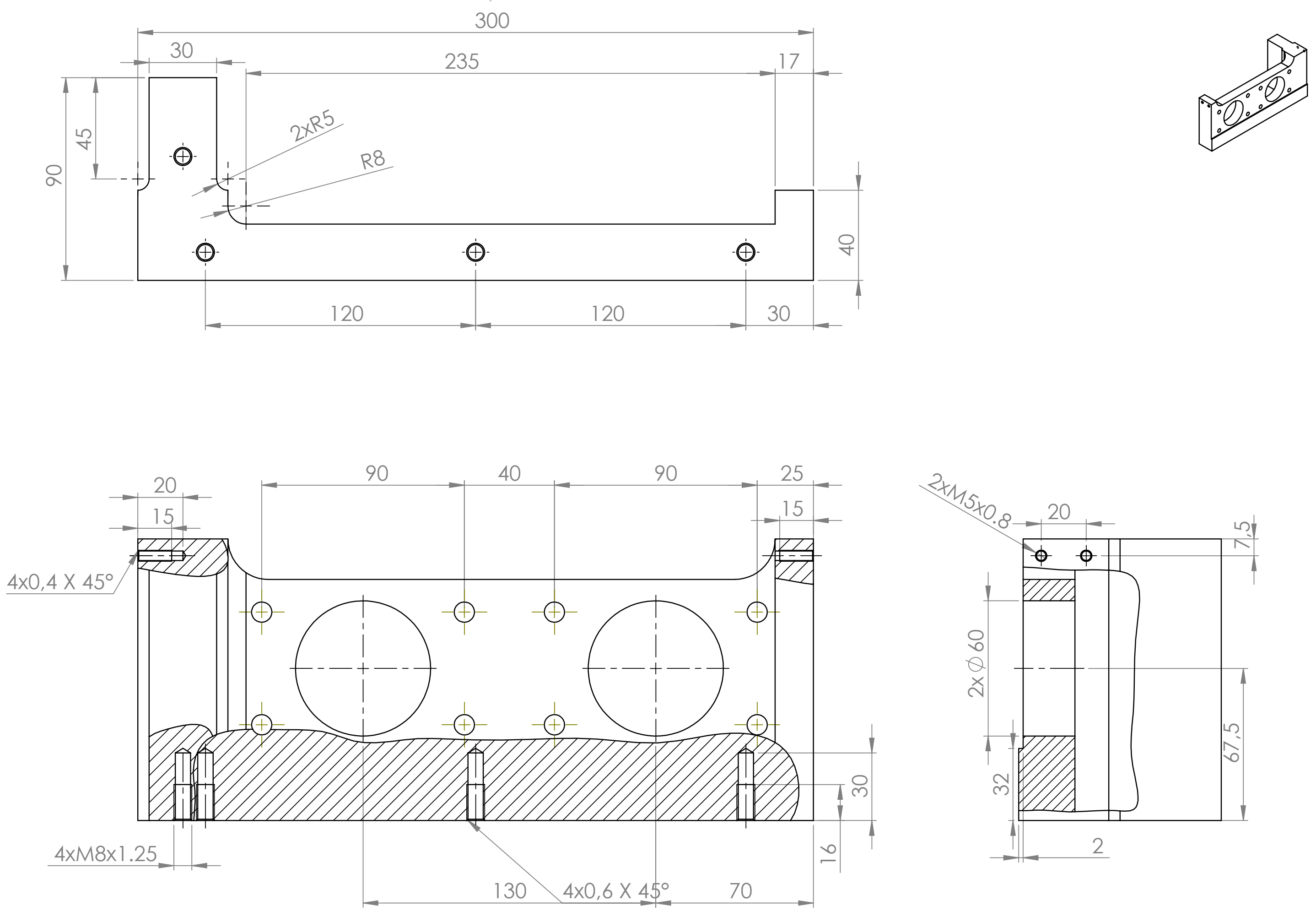

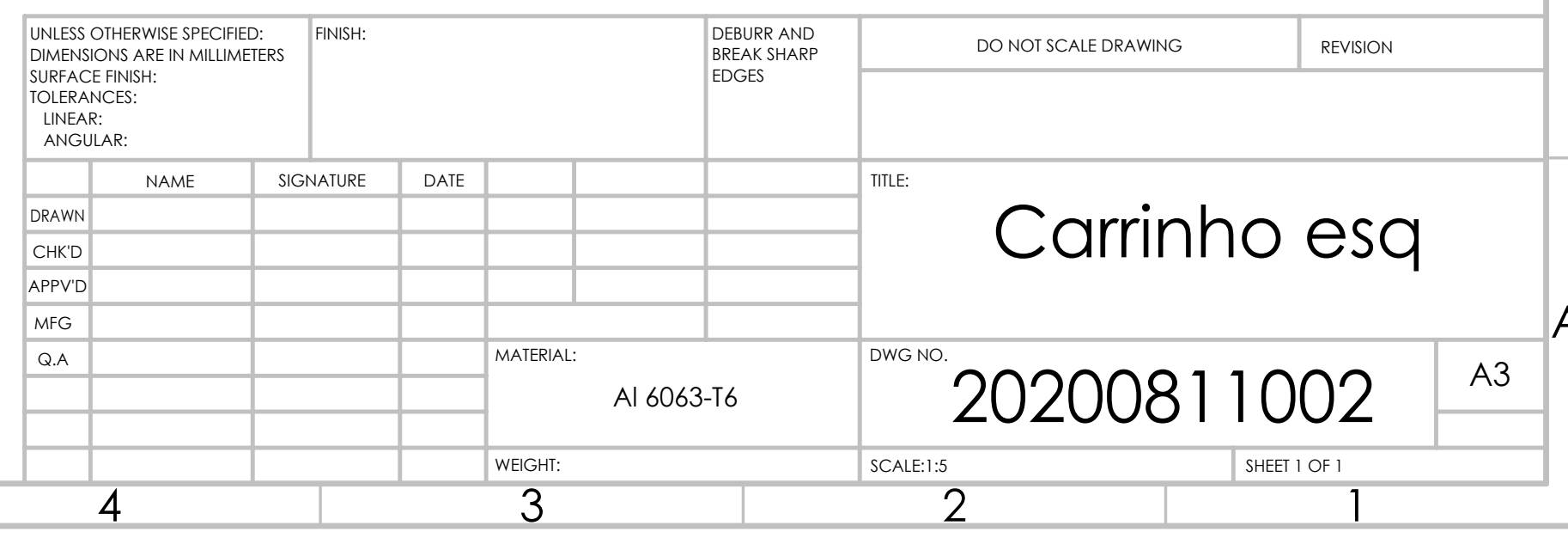



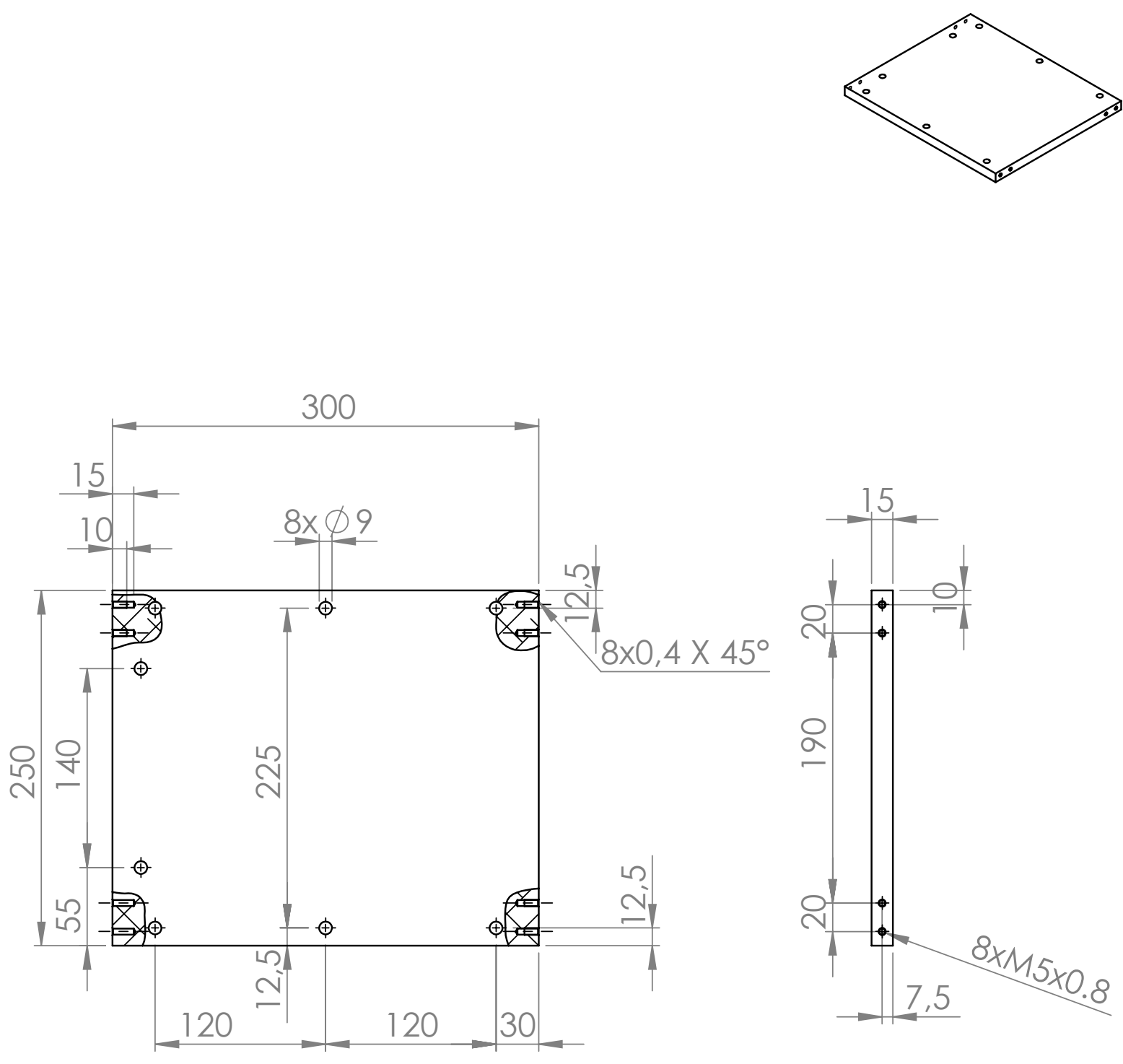

C

D

B

\begin{tabular}{|l|l|l|l|l|l|l|}
\hline & NAME & SIGNATURE & DATE & & & TITLE: \\
\hline DRAWN & & & & & & \\
\hline CHK'D & & & & & & \\
\hline
\end{tabular}

\section{Carrinho h}

A

\begin{tabular}{|l|l|}
\hline APPV \\
\hline M.A \\
\hline Q.A \\
\hline
\end{tabular}

Q.A




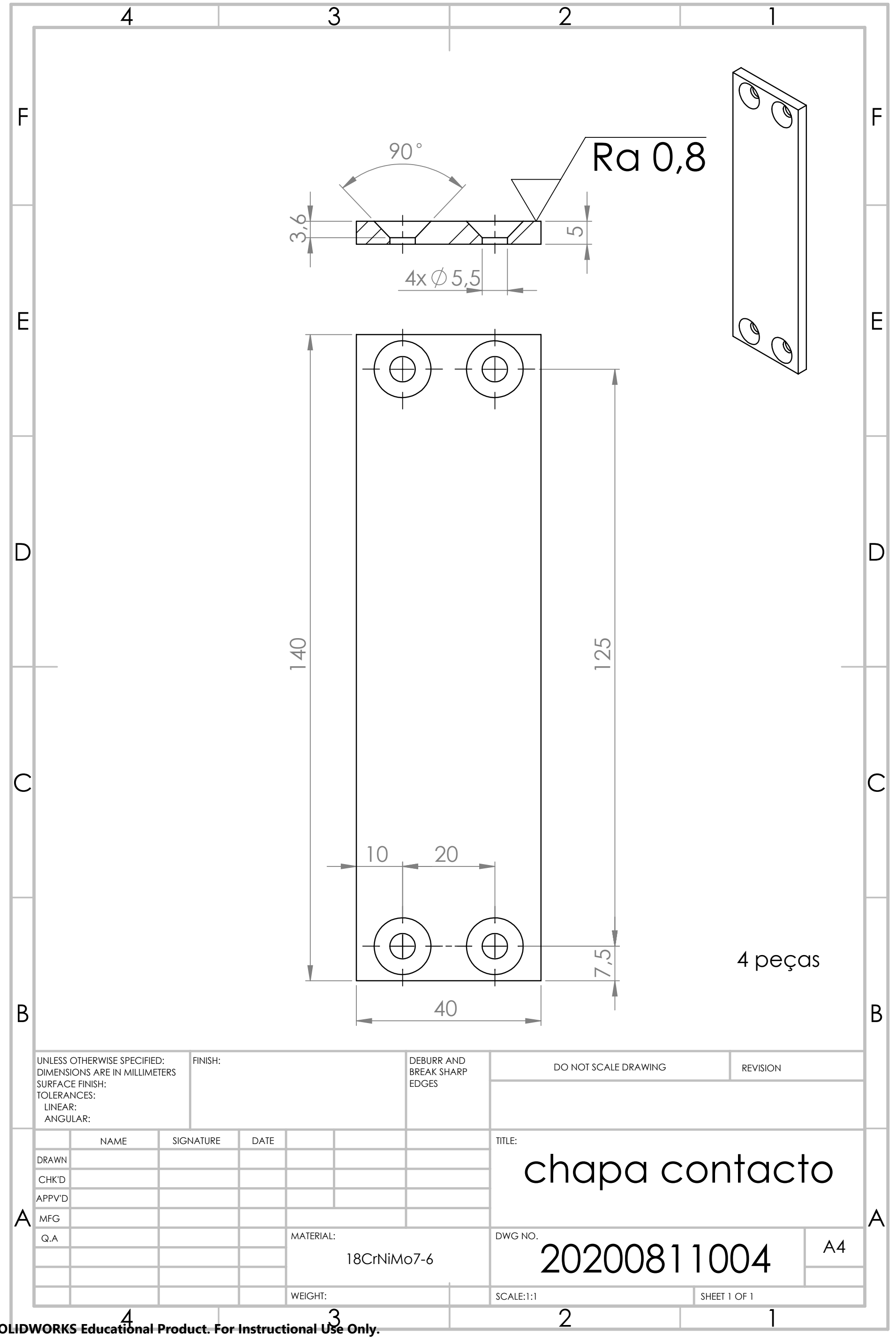



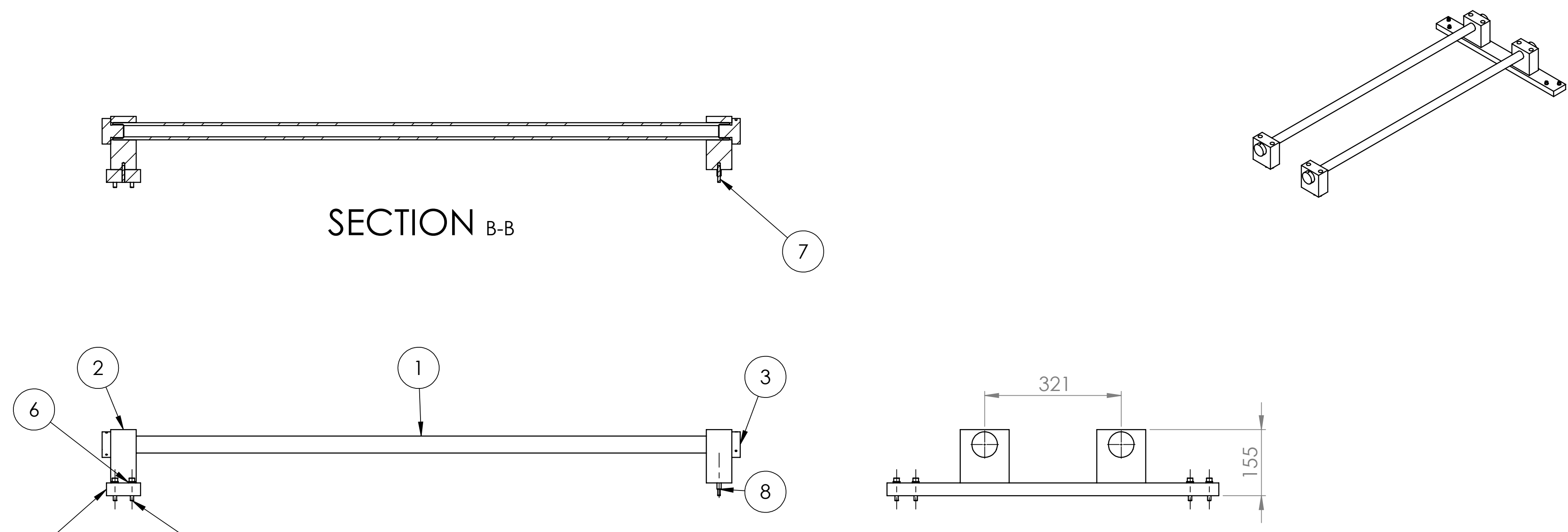

(3)<smiles>[CH]</smiles>

(5)

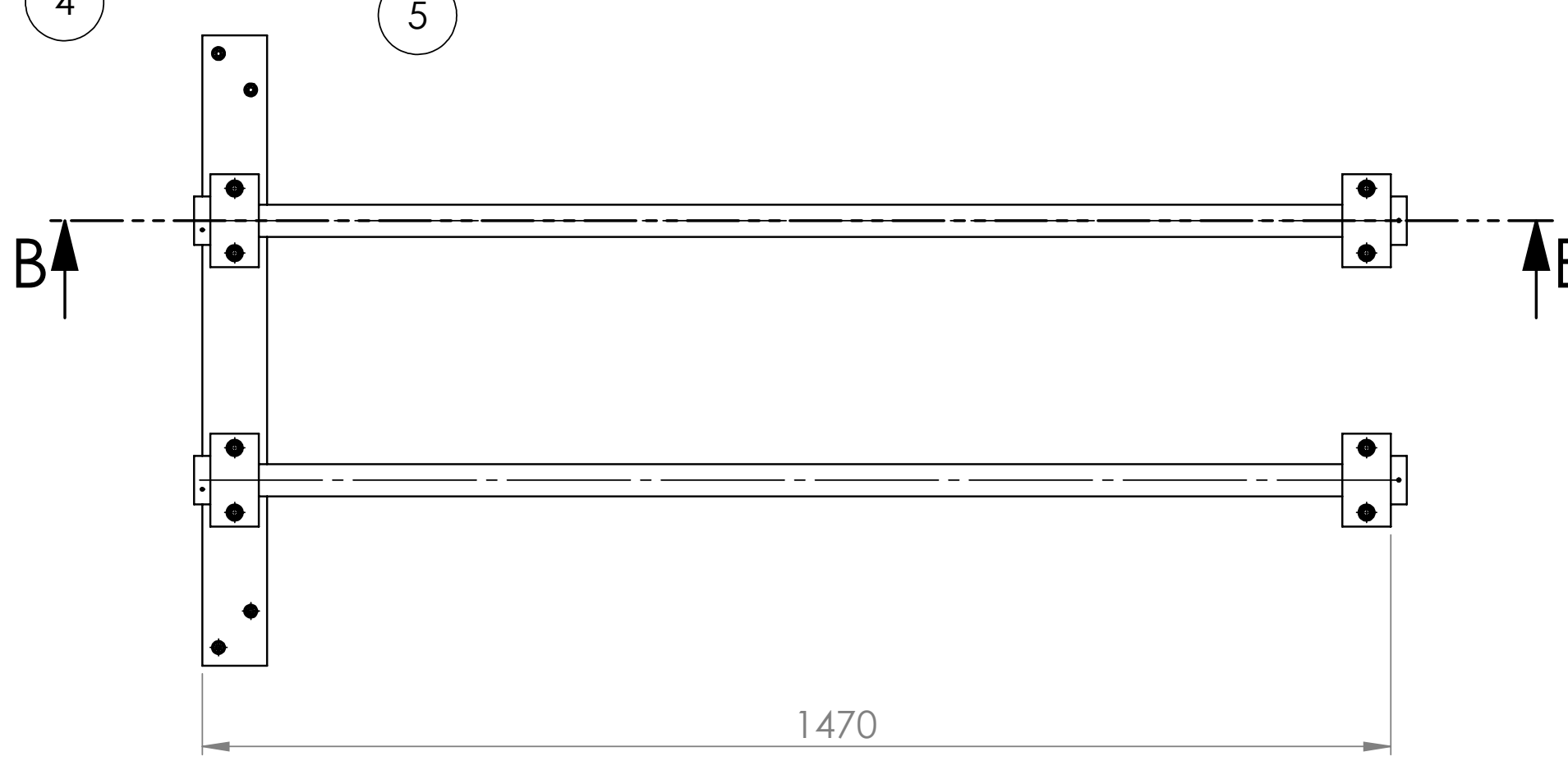

A SOLIDWORKS Educational Product. For Instructional Use Only.

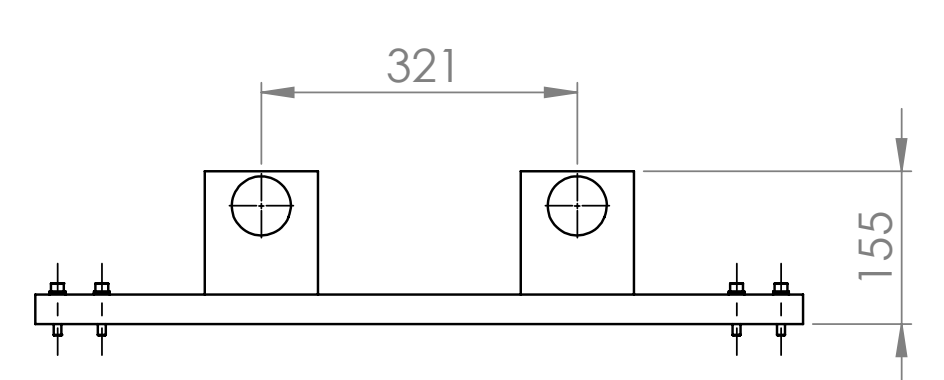

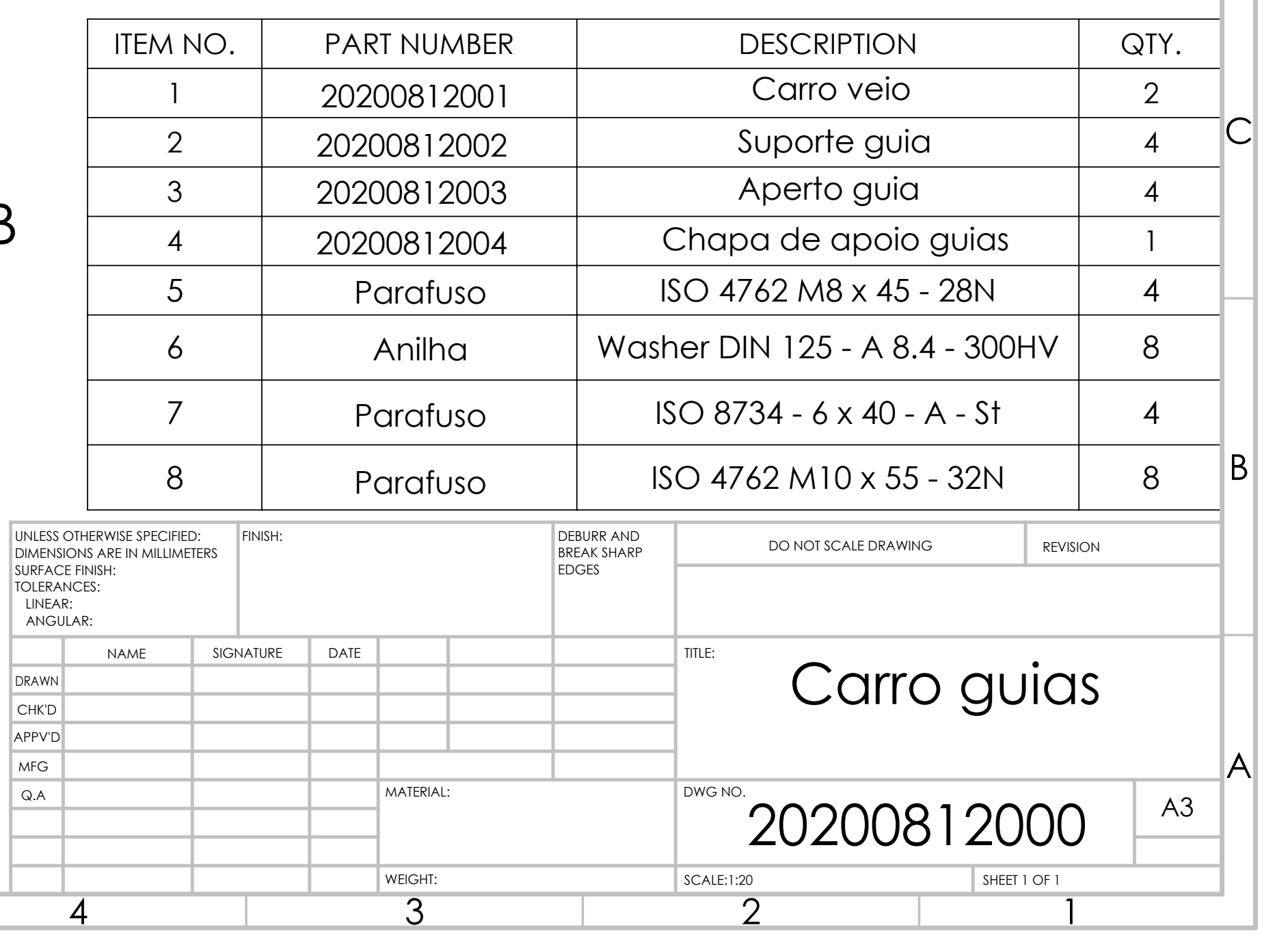




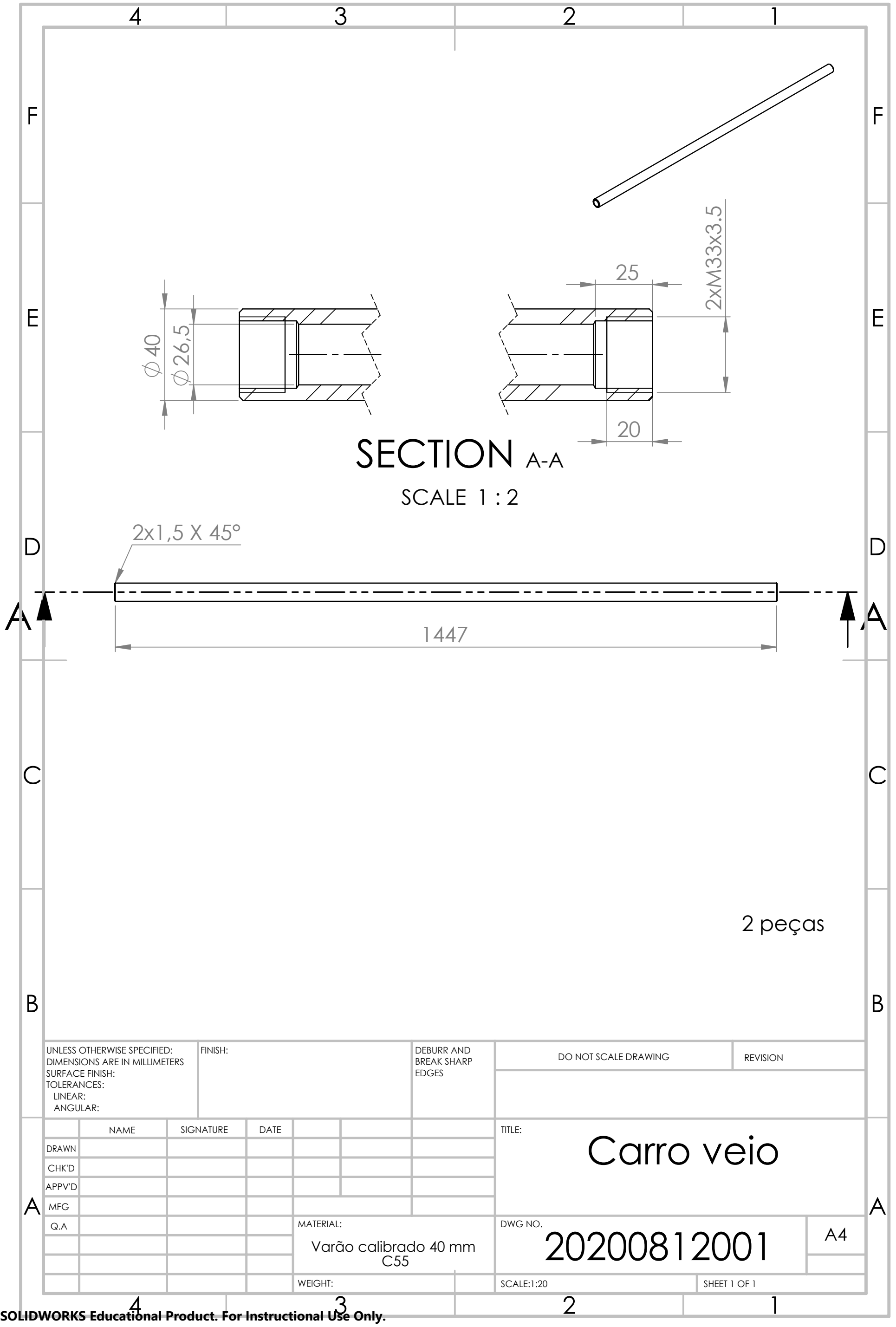




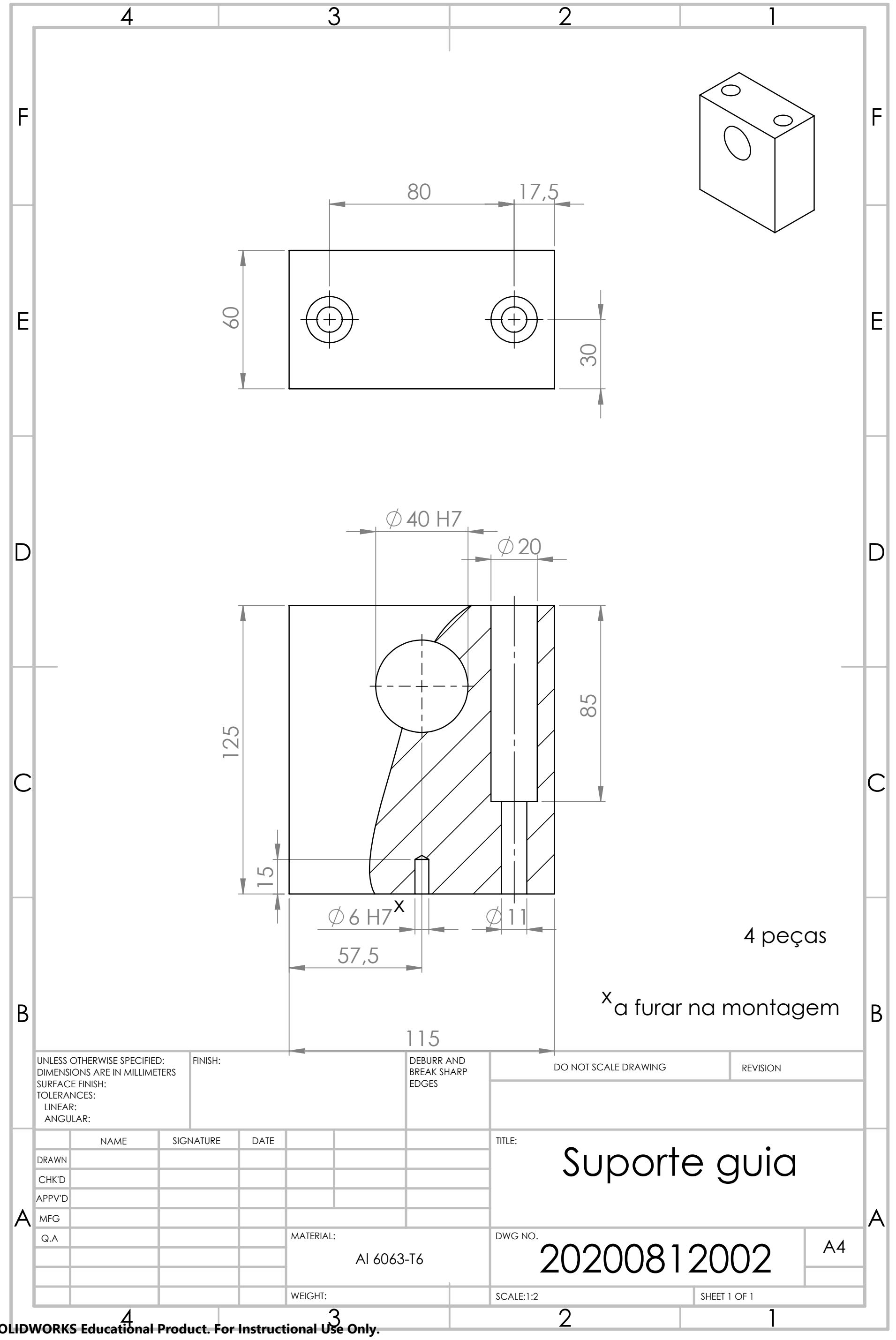




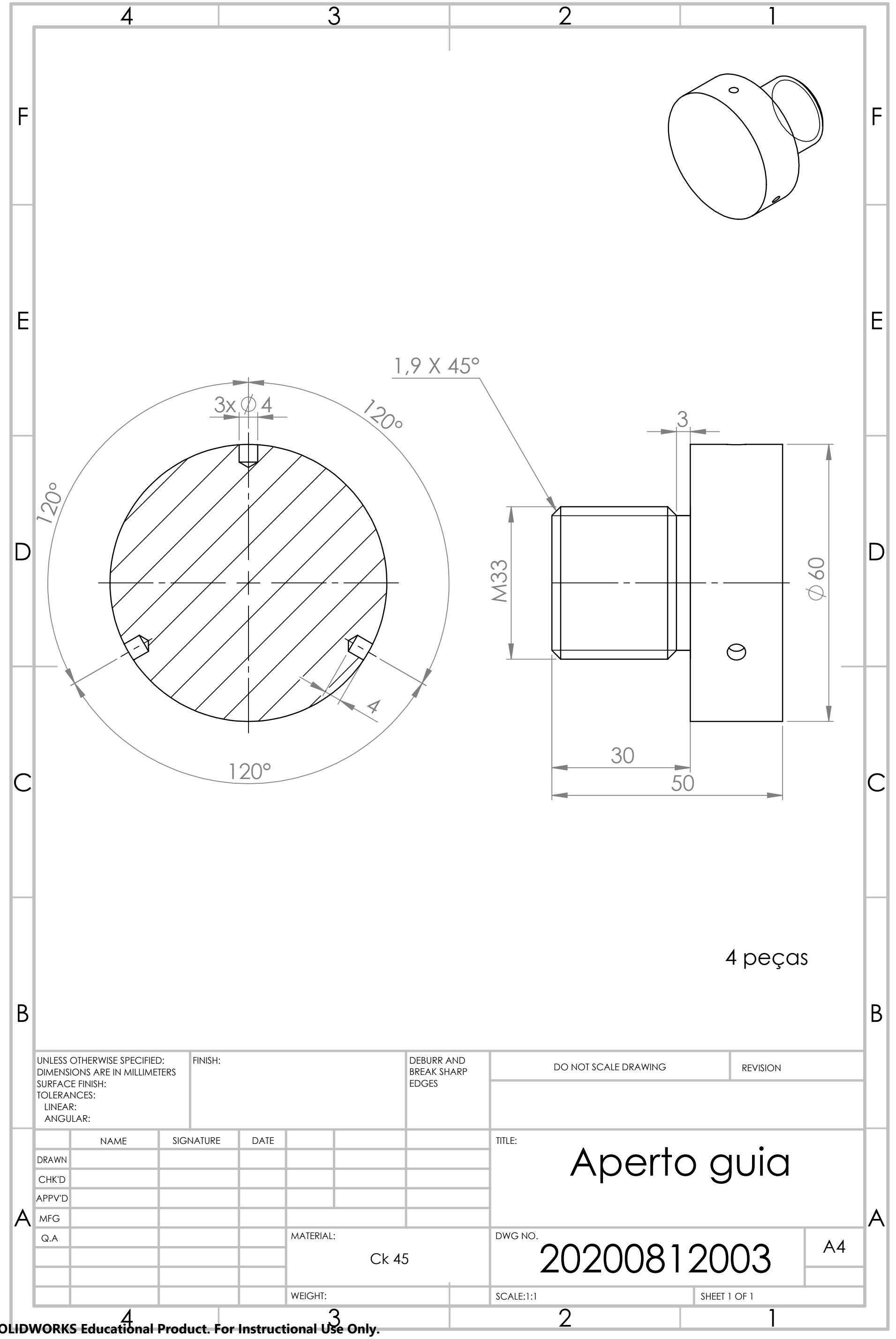




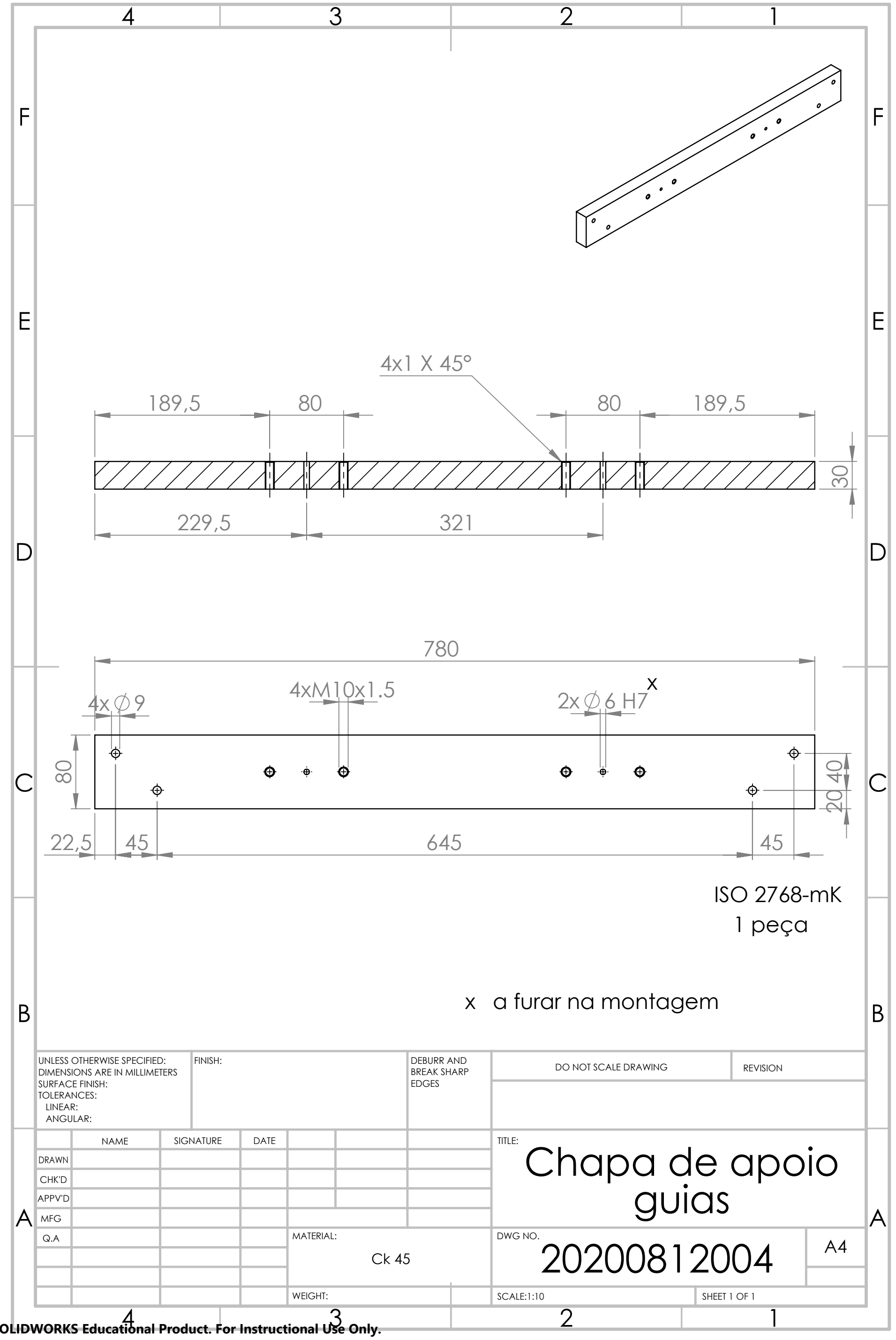



Appendix E

Mechanical Drawings

Support frame for the braking system and pneumatic actuator 


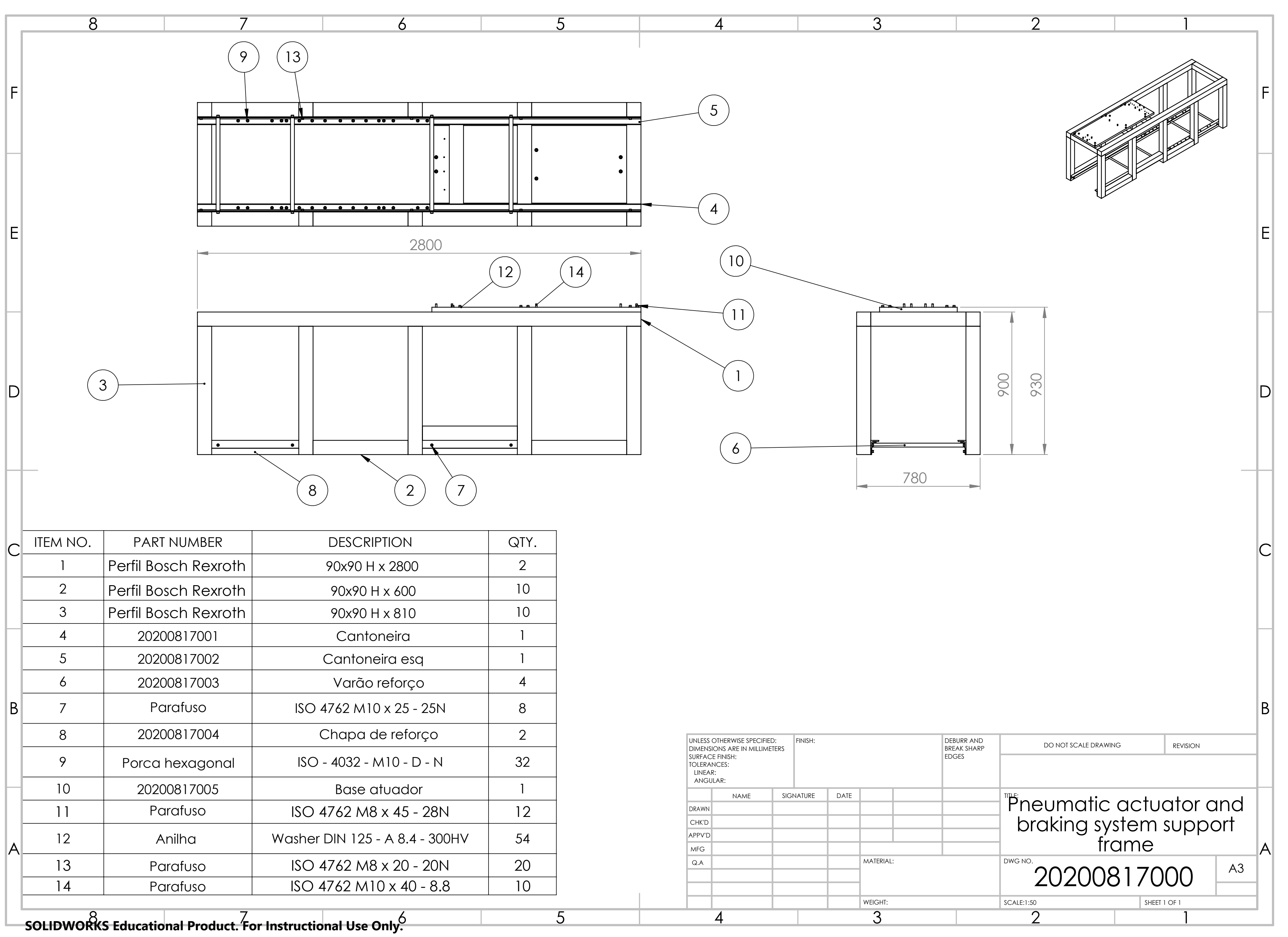




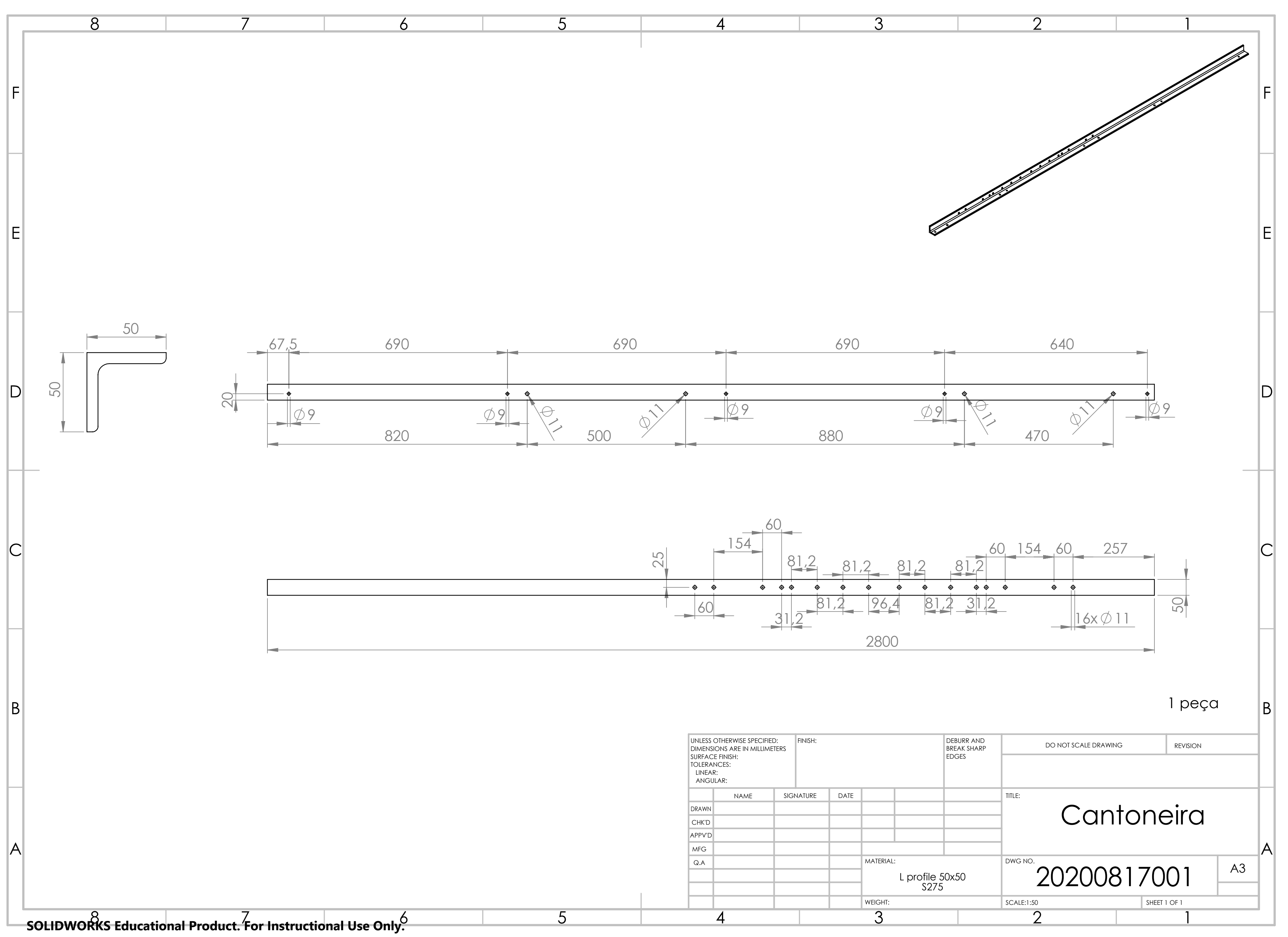




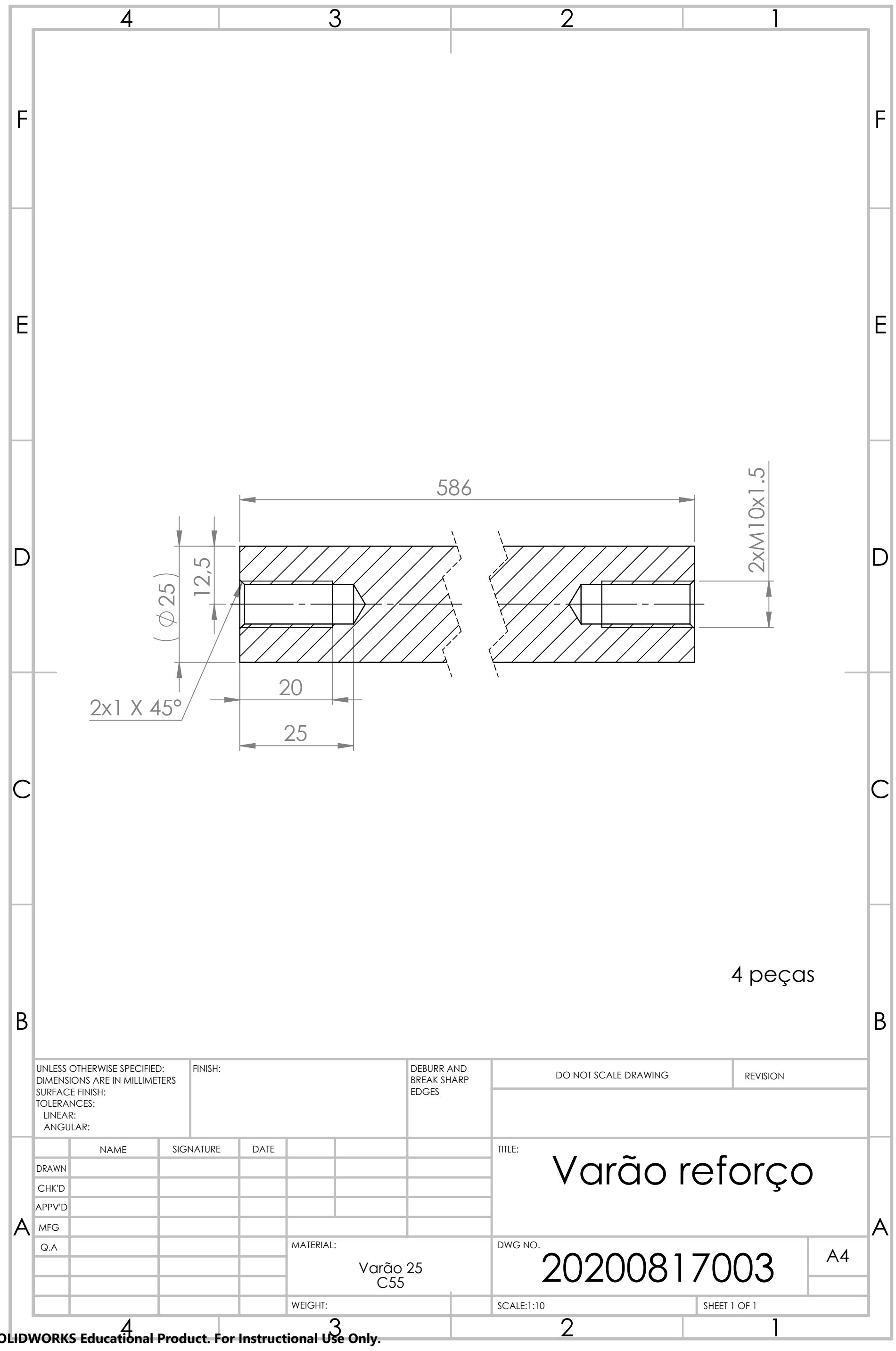




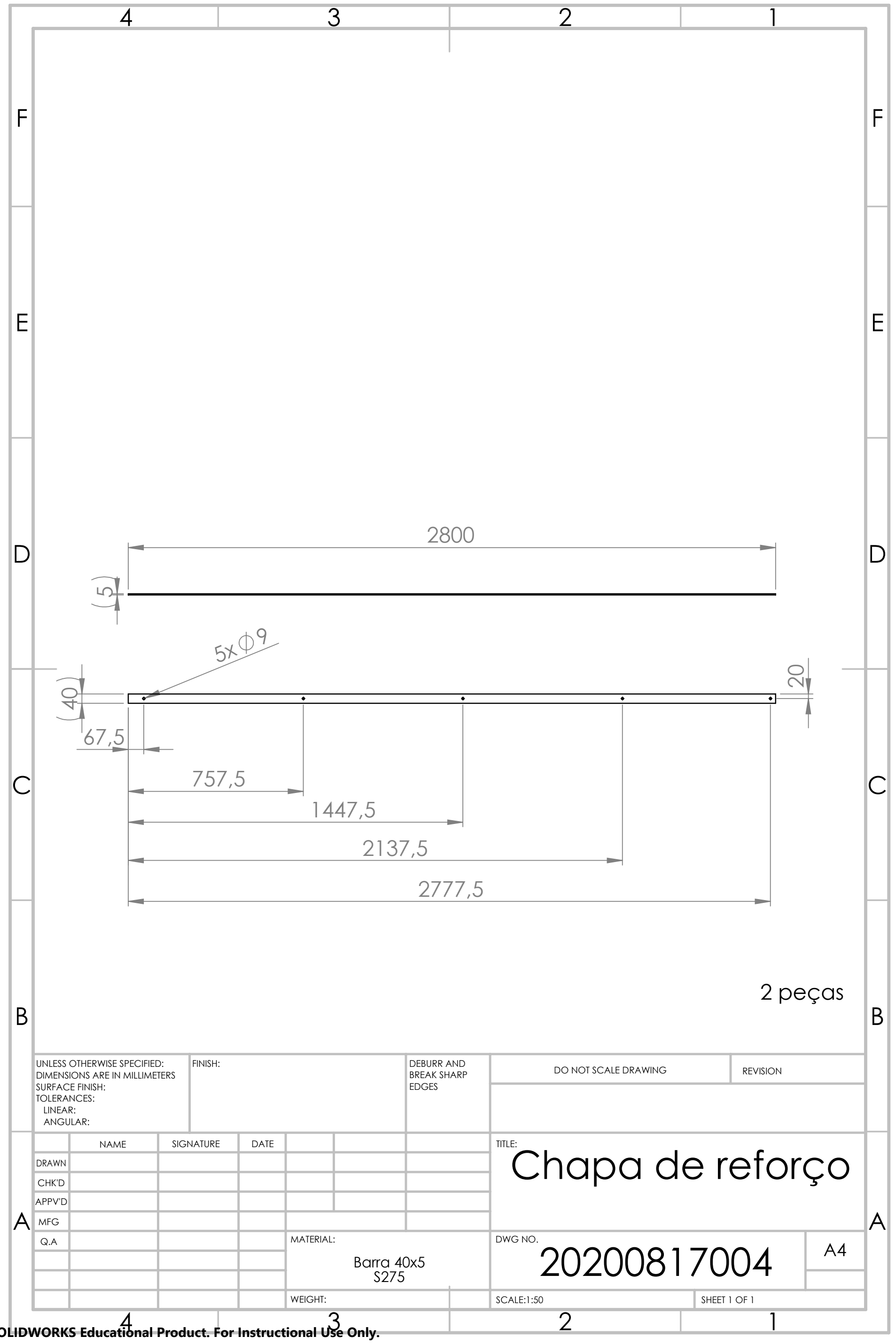




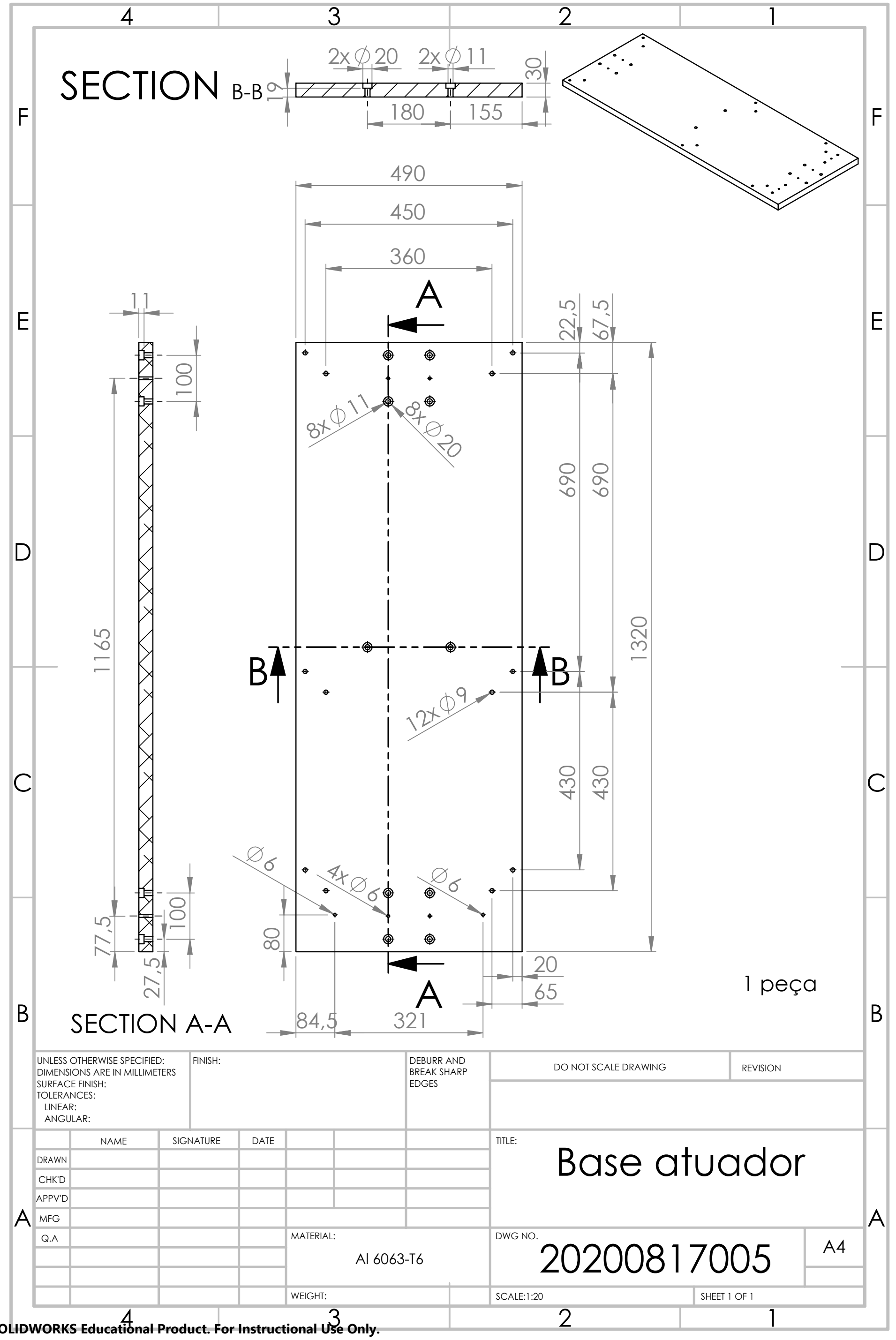





\section{Appendix F}

Mechanical Drawings

Tensile Setup 


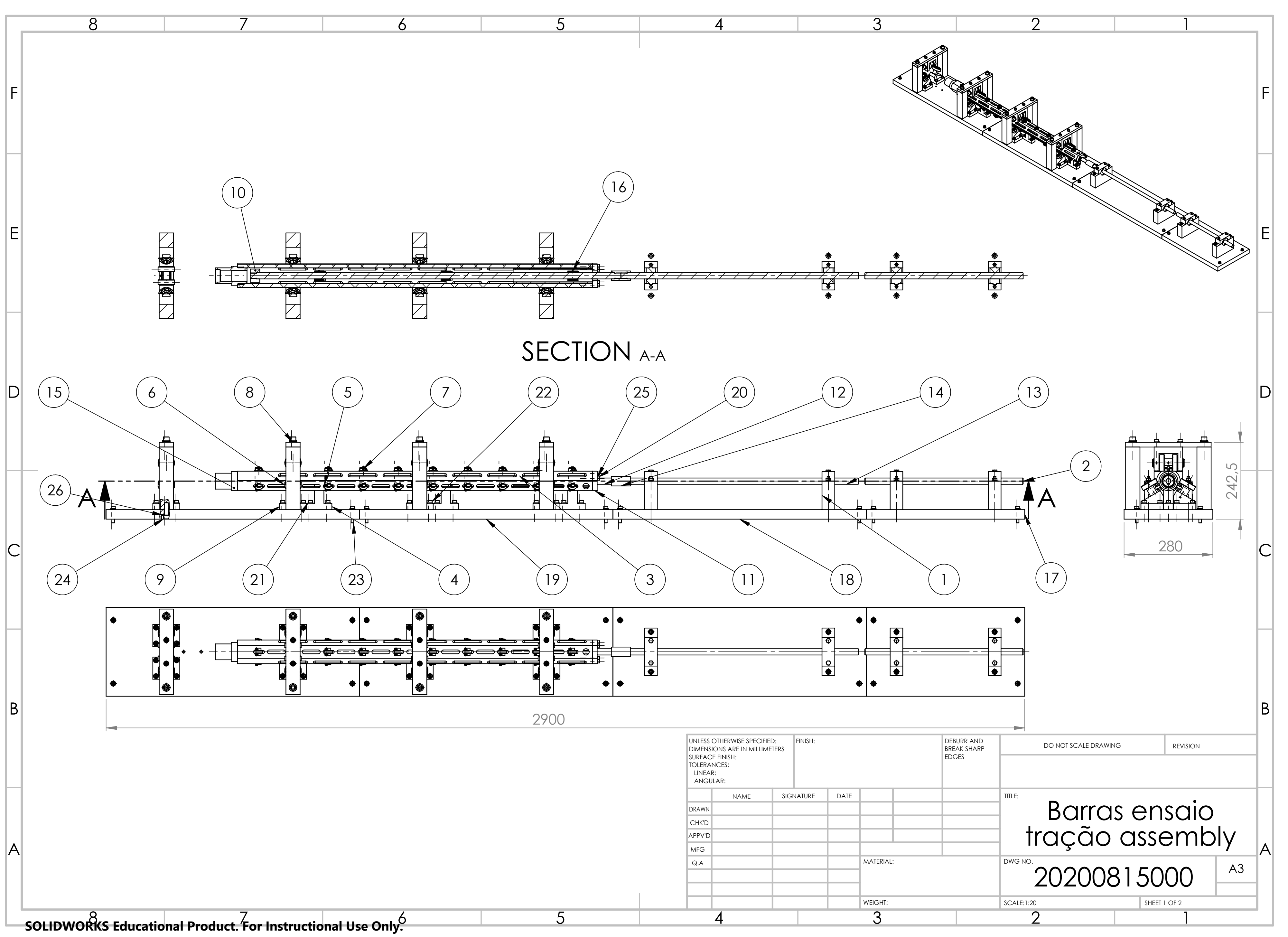




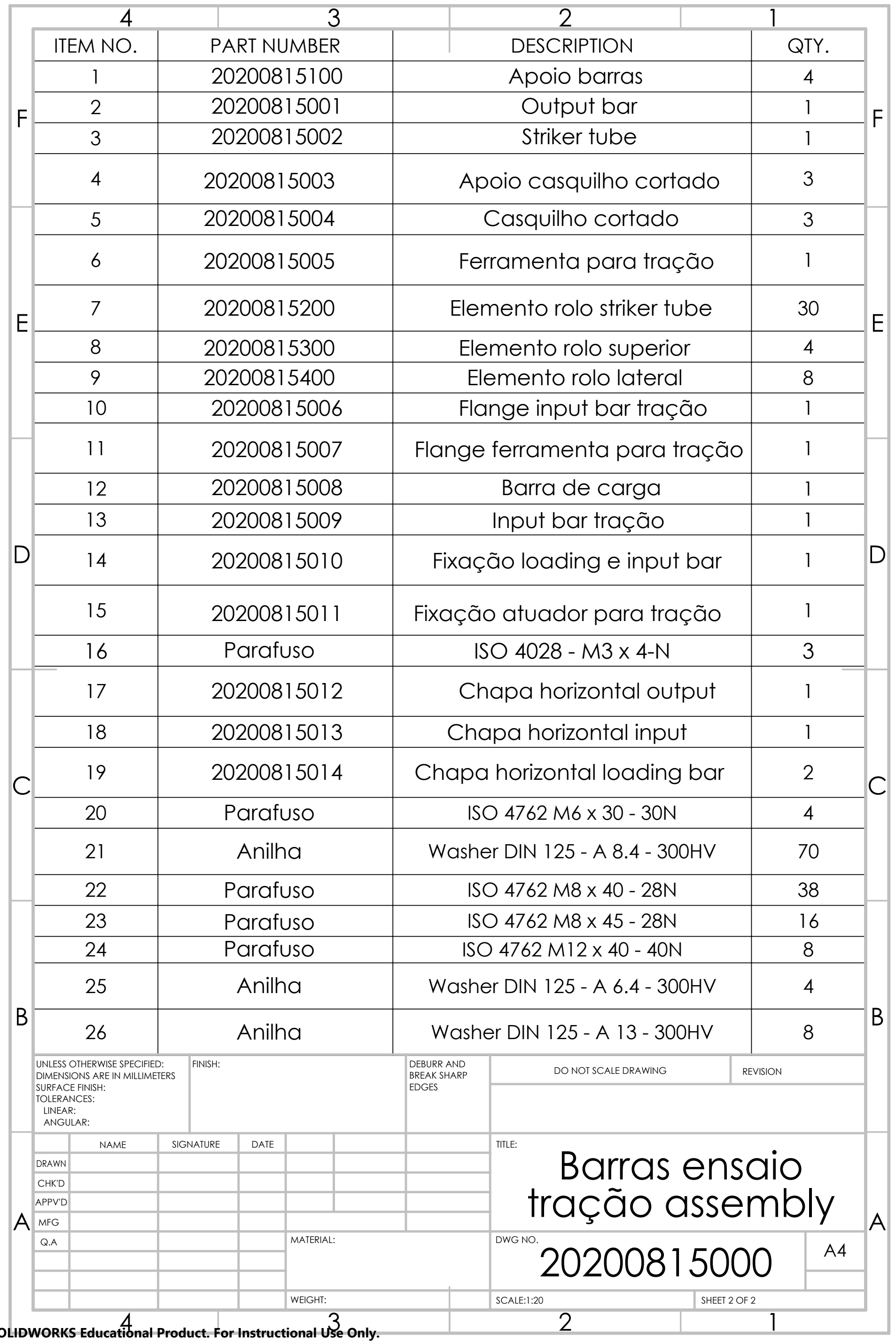




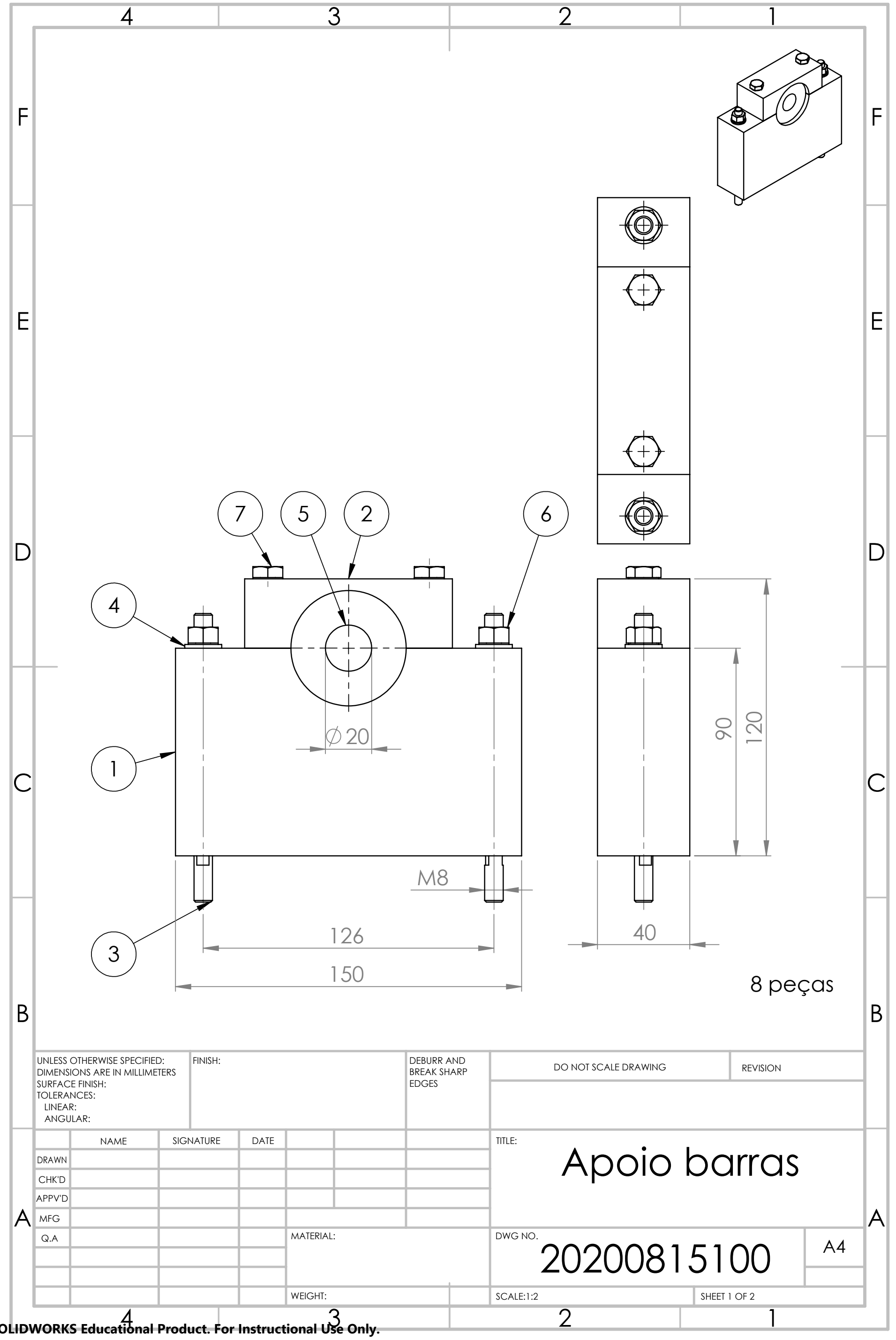




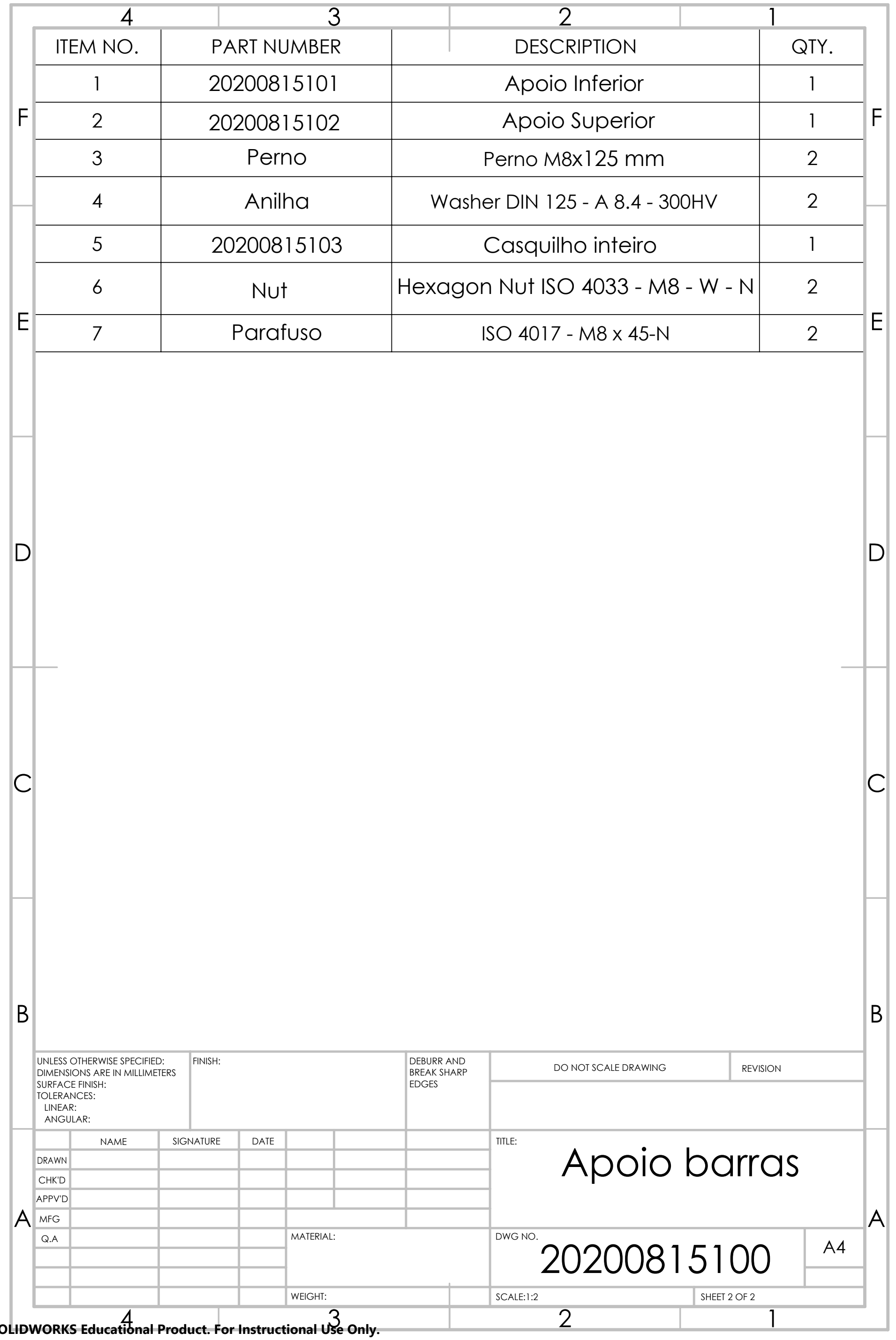




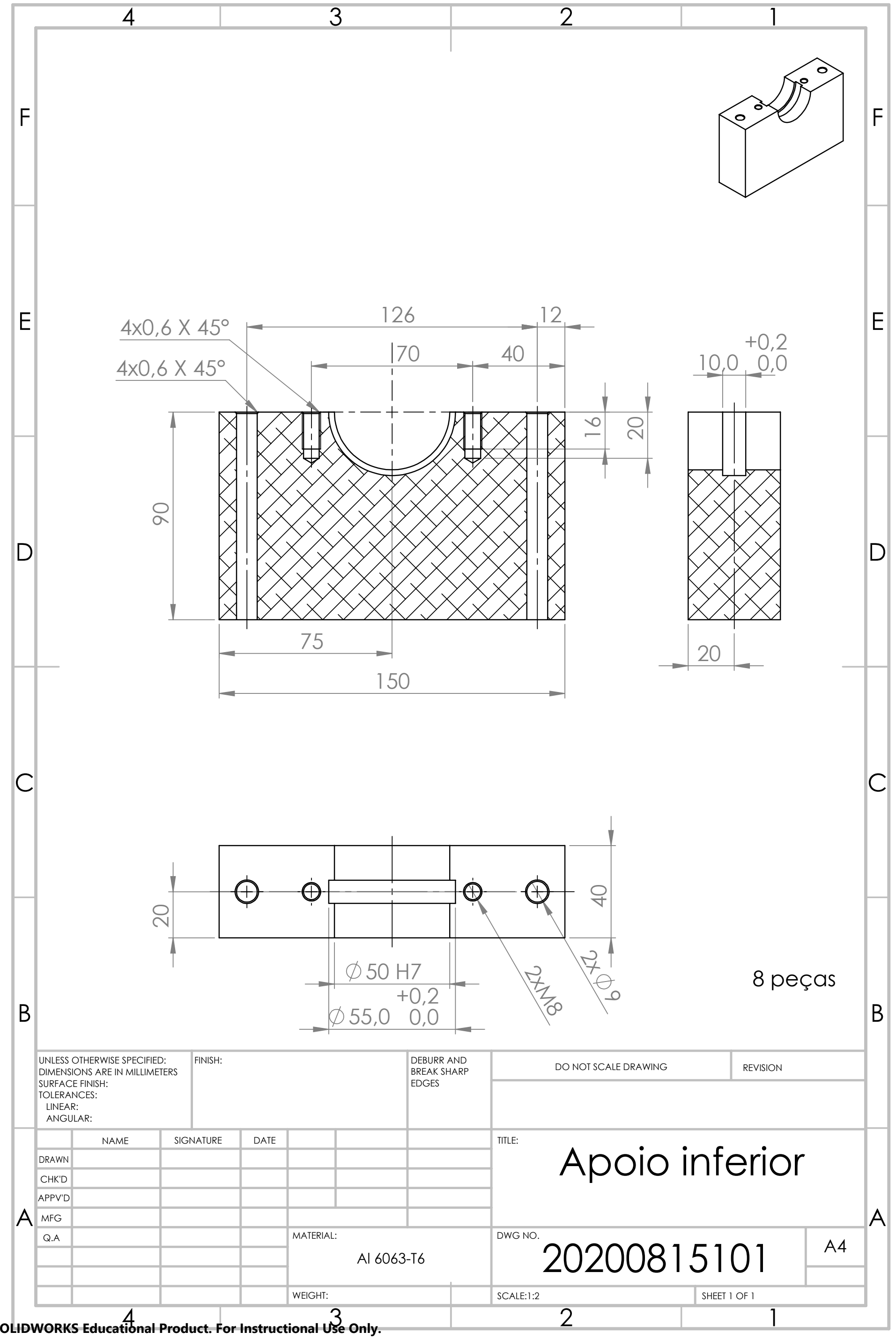




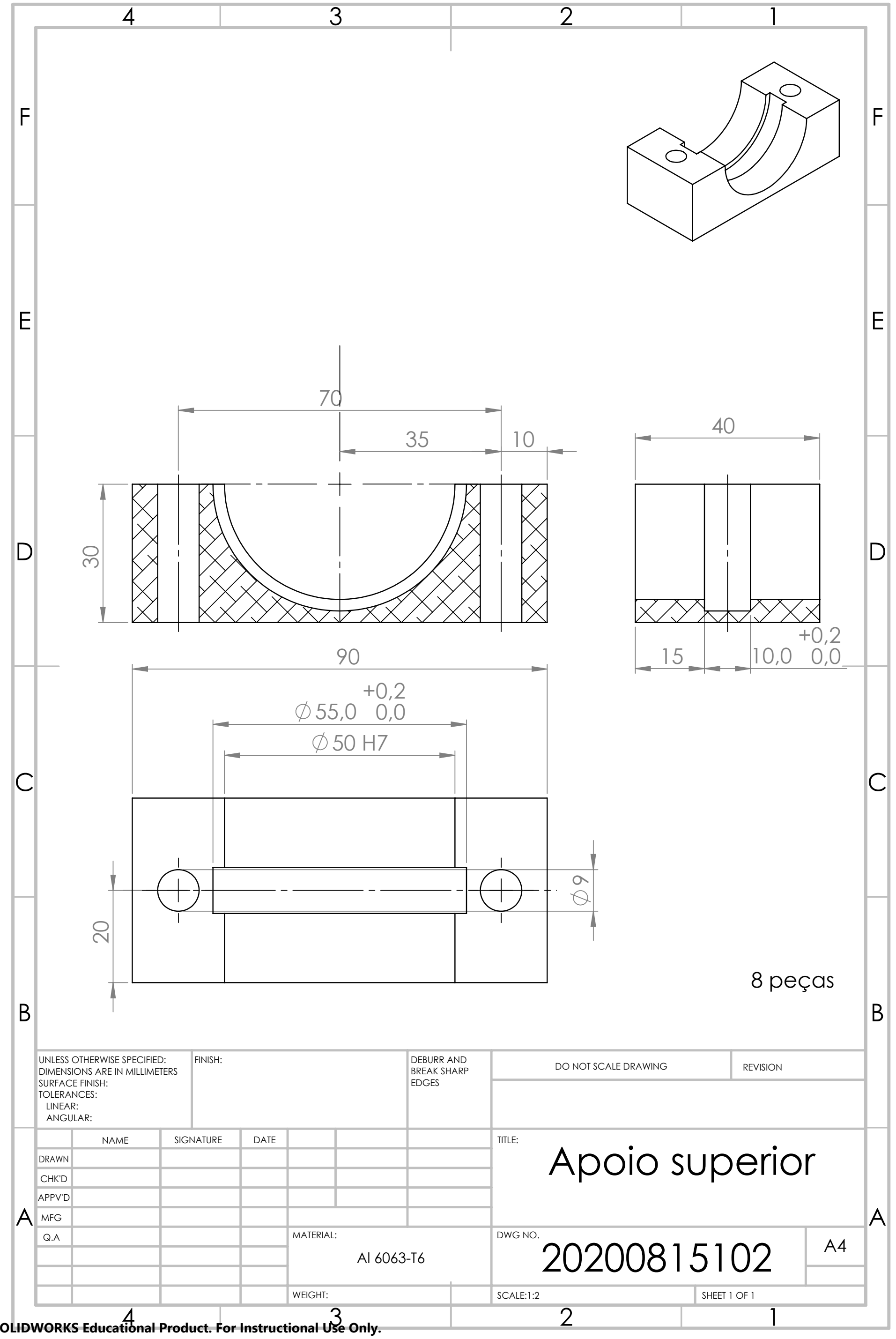




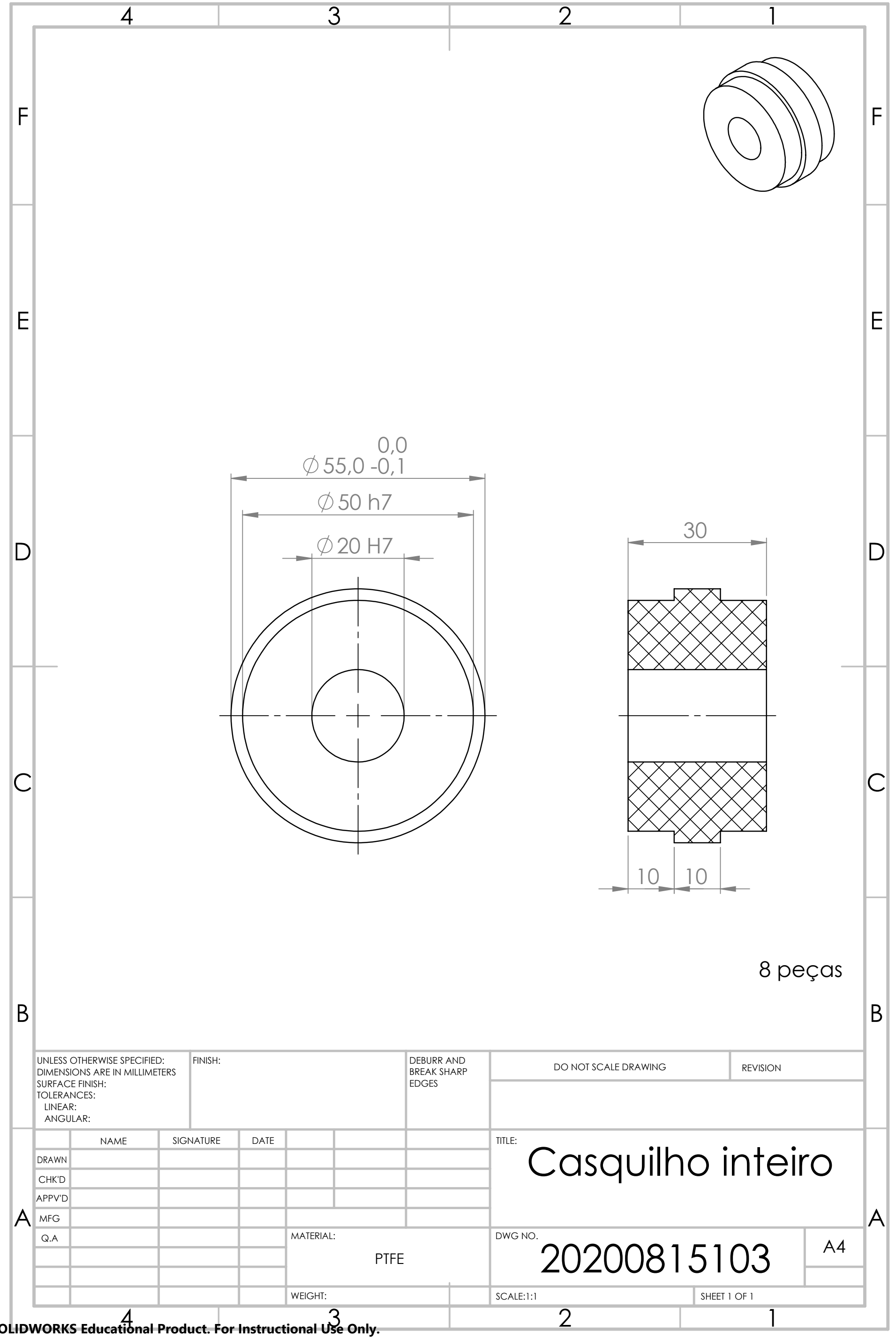




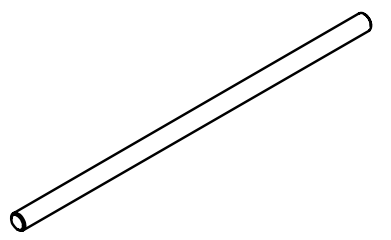

D

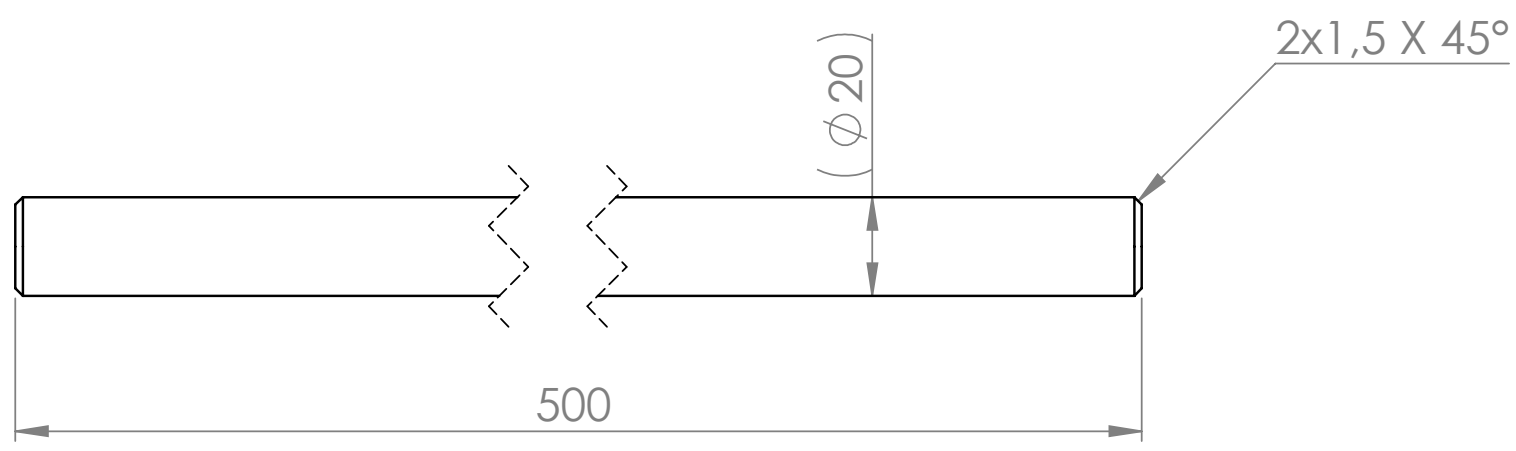

C

1 peça

B

UNLESS OTHERWISE SPECIFIED:

UNLESS OTHERWISE SPECIFIED:
DIMENSIONS ARE IN MILLIMETERS

SURFACE FINISH:

TOLERANCES:

LINEAR:
ANGULAR:

\begin{tabular}{|l|l|l|l|l|l|l|}
\hline & NAME & SIGNATURE & DATE & & & TITLE: \\
\hline DRAWN & & & & & & \\
\hline CHK'D & & & & & & \\
\hline APPV'D & & & & & & \\
\hline
\end{tabular}

TITLE:

DO NOT SCALE DRAWING

REVISION

$A$

\begin{tabular}{|l|l|l|l|l|l|l|l|l|l|l|}
\hline APPV'D & & & \\
\hline MFG & & & \\
\hline
\end{tabular}

Q.A

Q.A




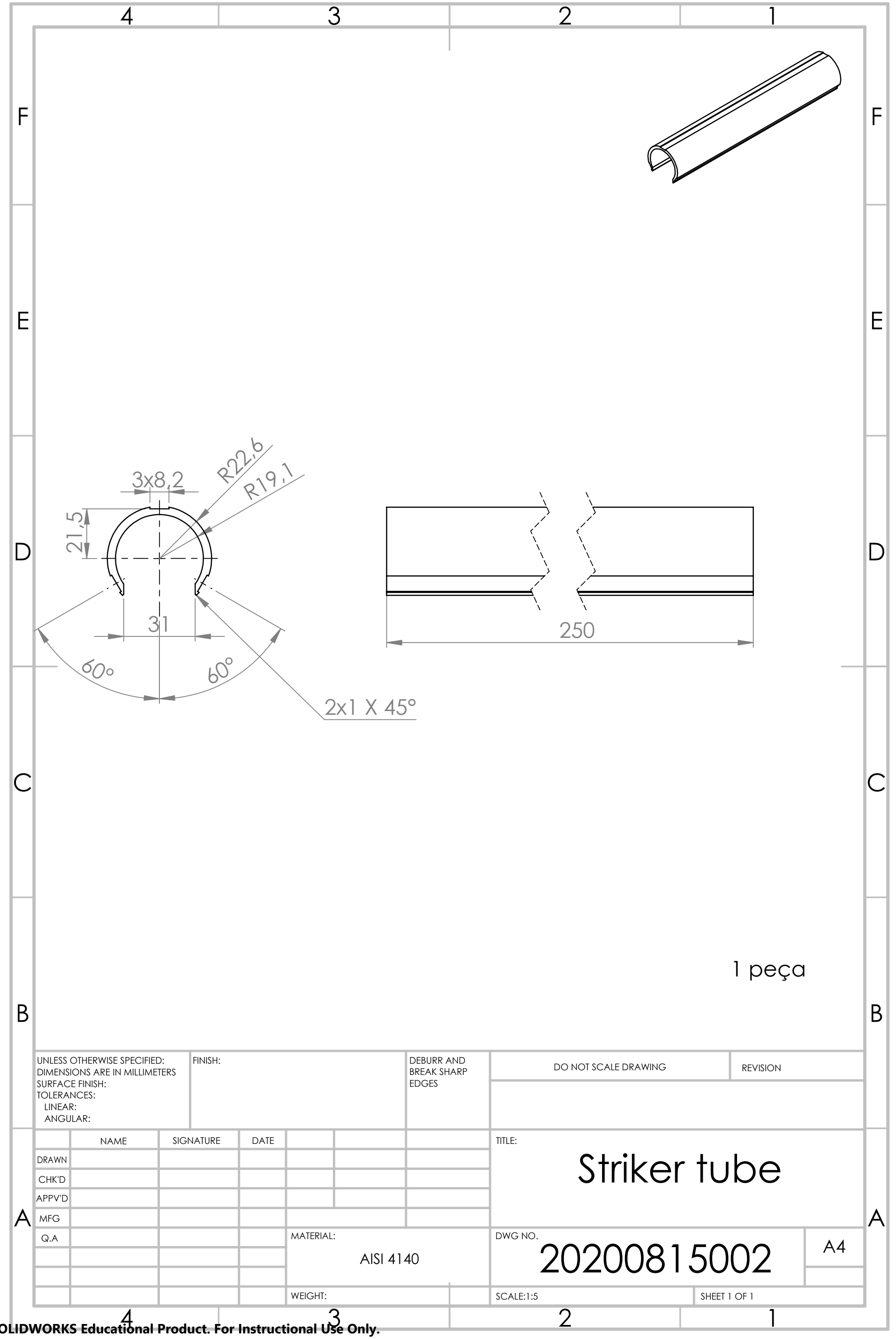




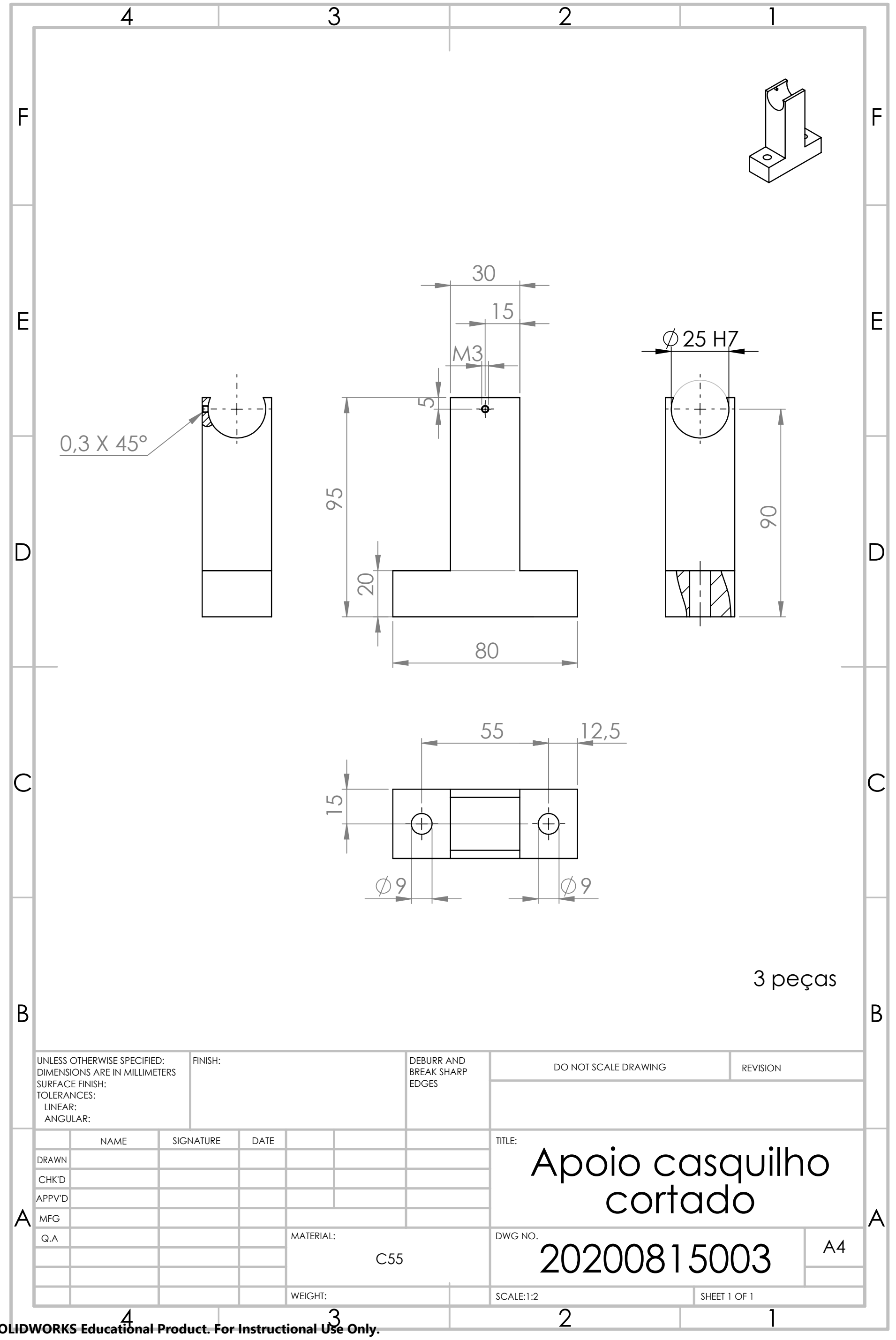



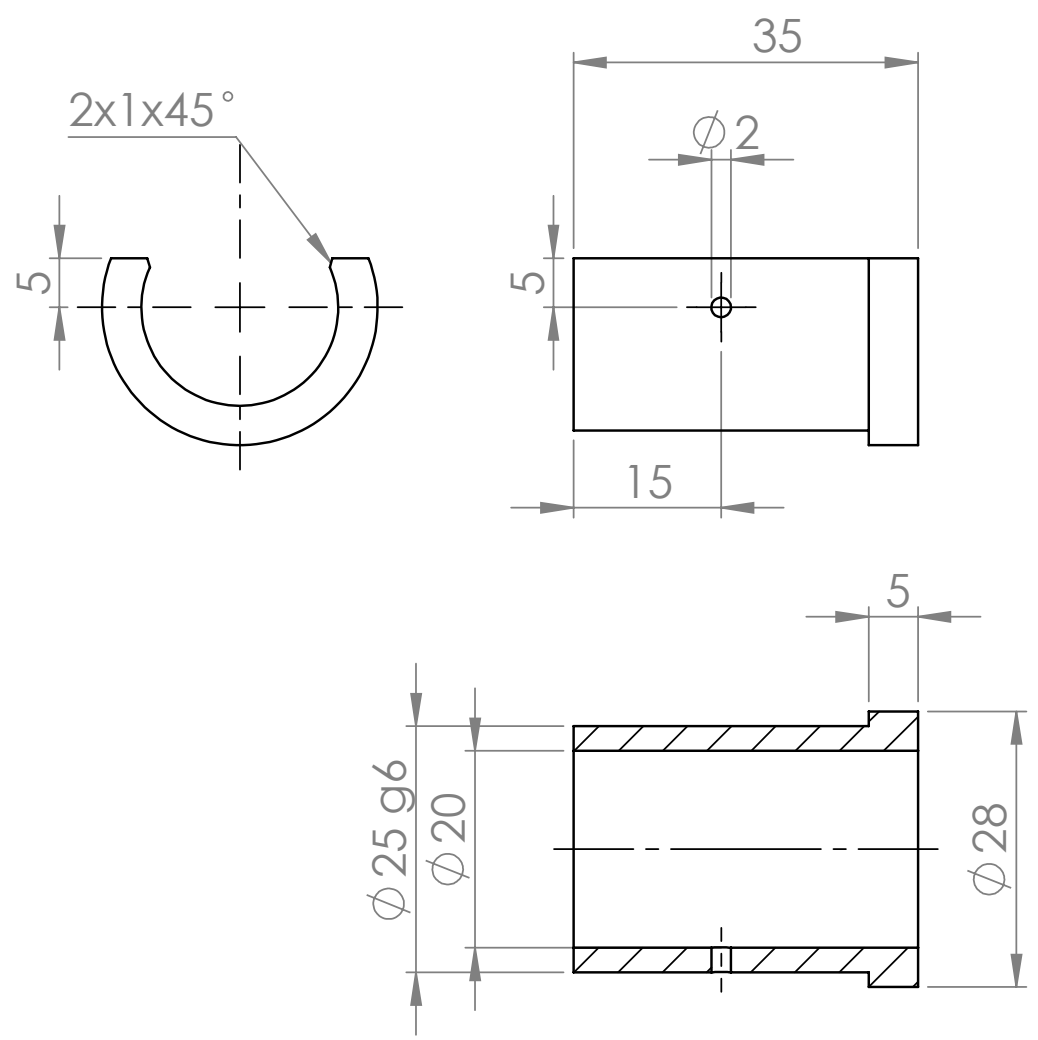

\begin{tabular}{|l|l|l|l|l|l|l|}
\hline & NAME & SIGNATURE & DATE & & & \\
\hline DRAWN & & & & & & \\
\hline CHK'D & & & & & & \\
\hline
\end{tabular}

A

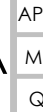

APPVID

Q.A

\begin{tabular}{|l|l|l|}
\hline & MATERIAL:
\end{tabular}

\begin{tabular}{l|l} 
MATERIAL: & DWG NO.
\end{tabular}

PTFE 20200815004 


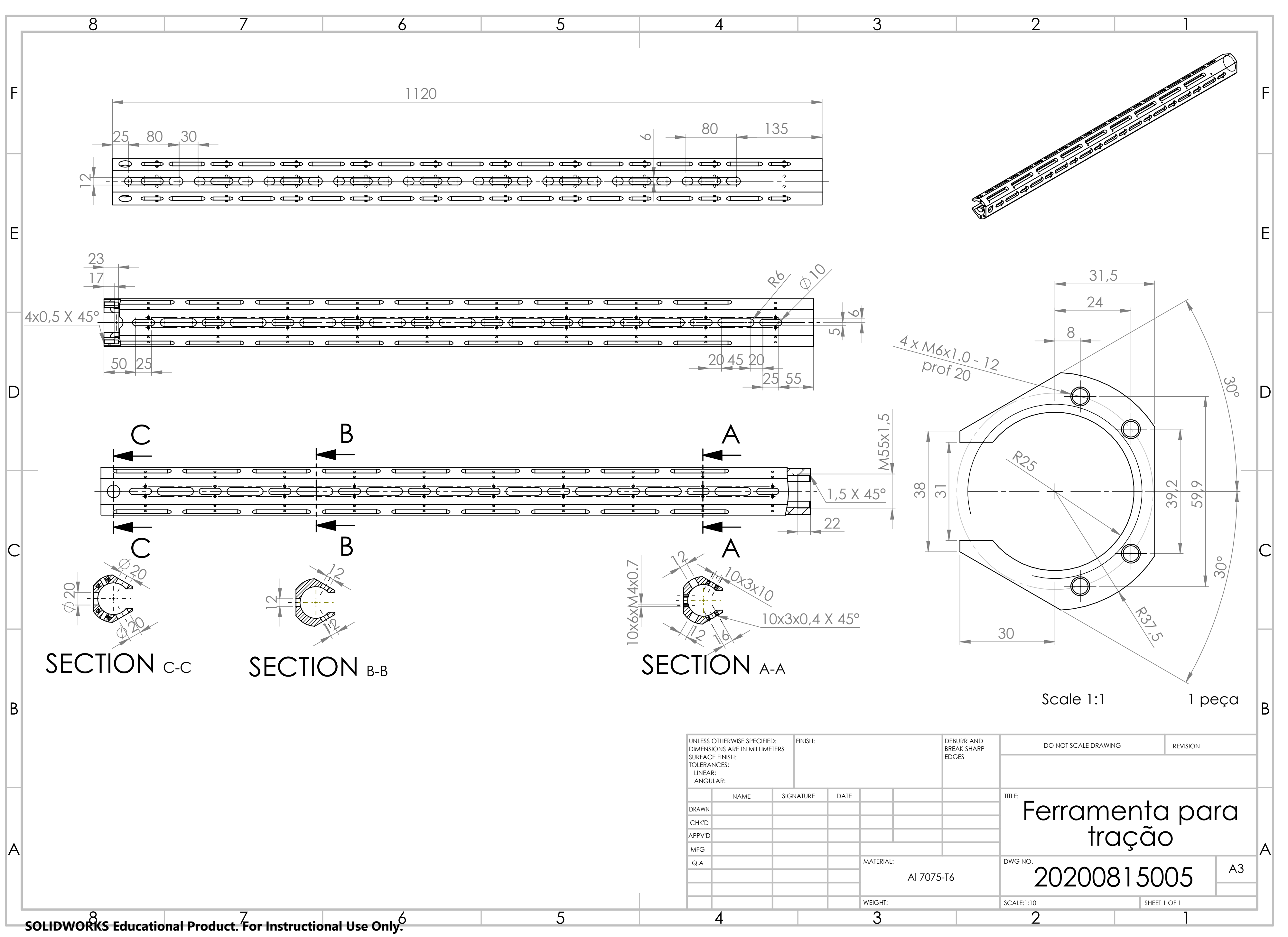




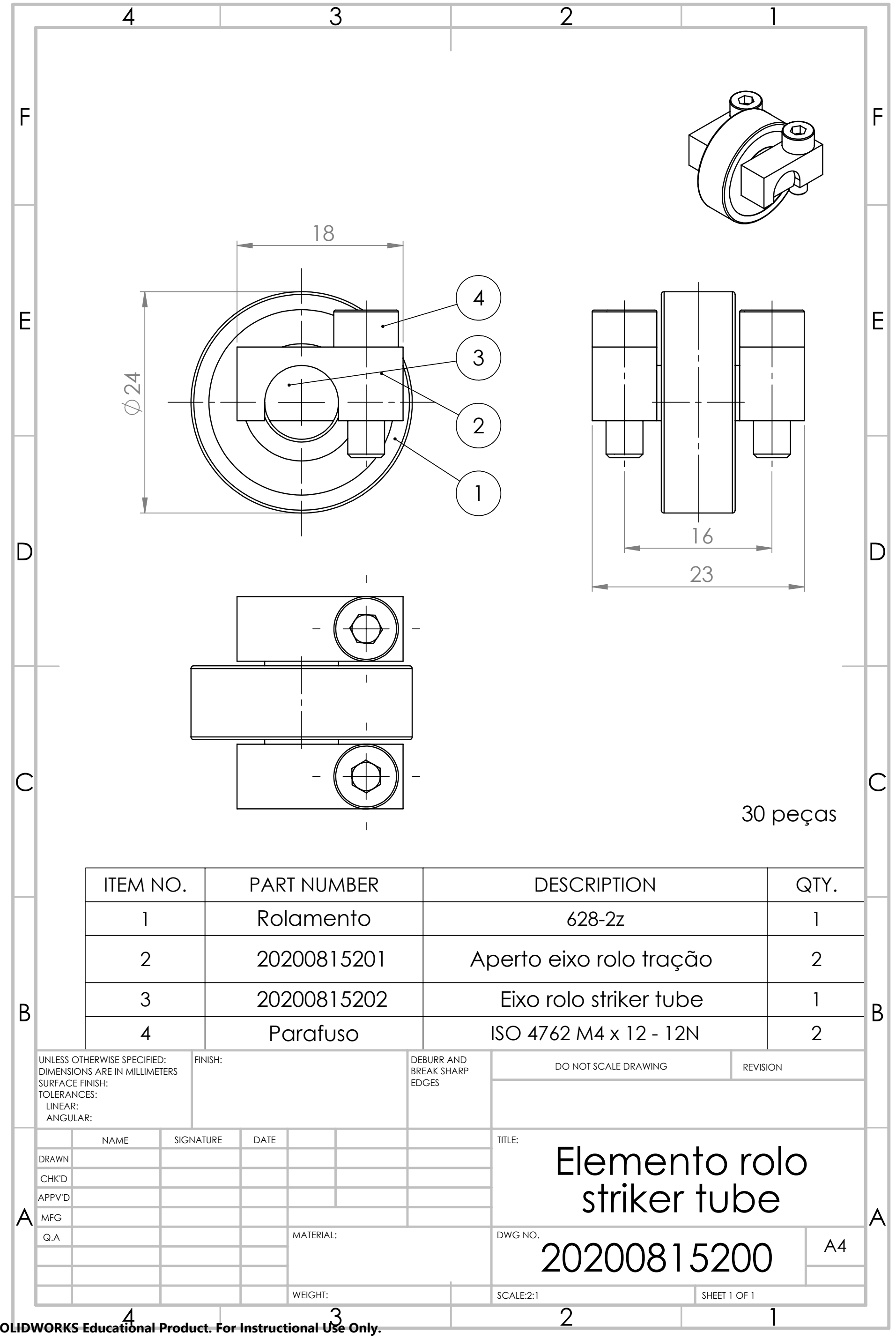




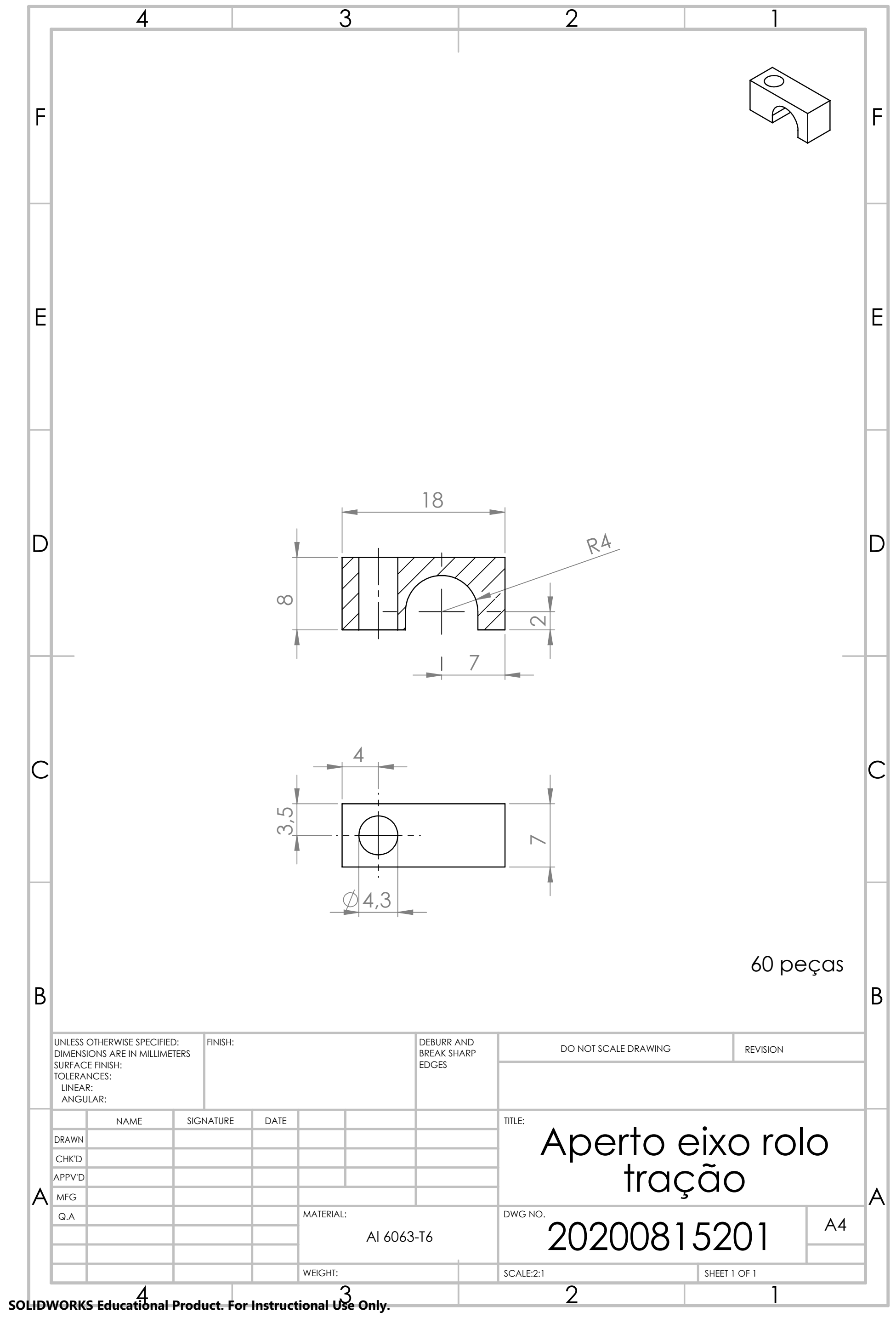




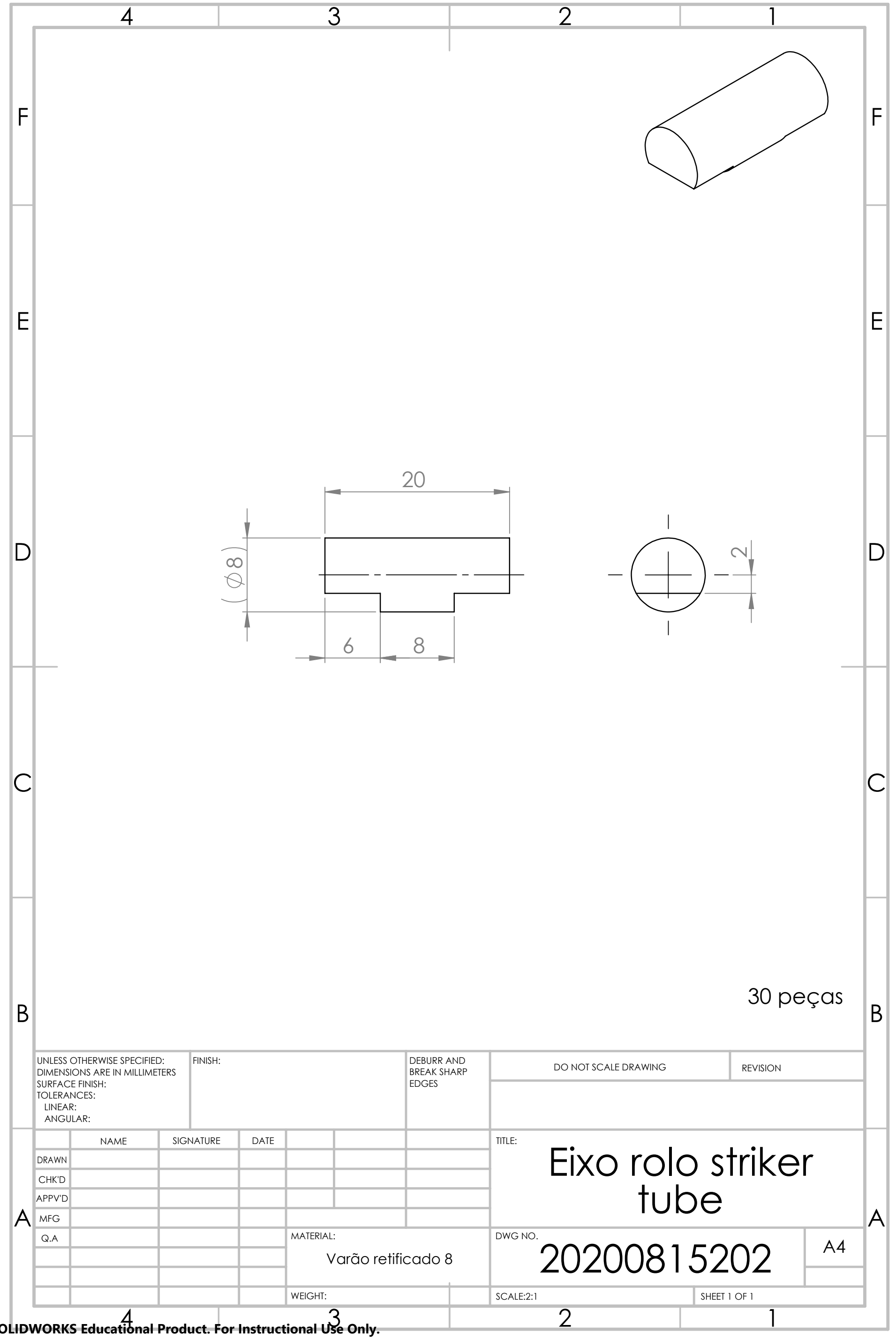




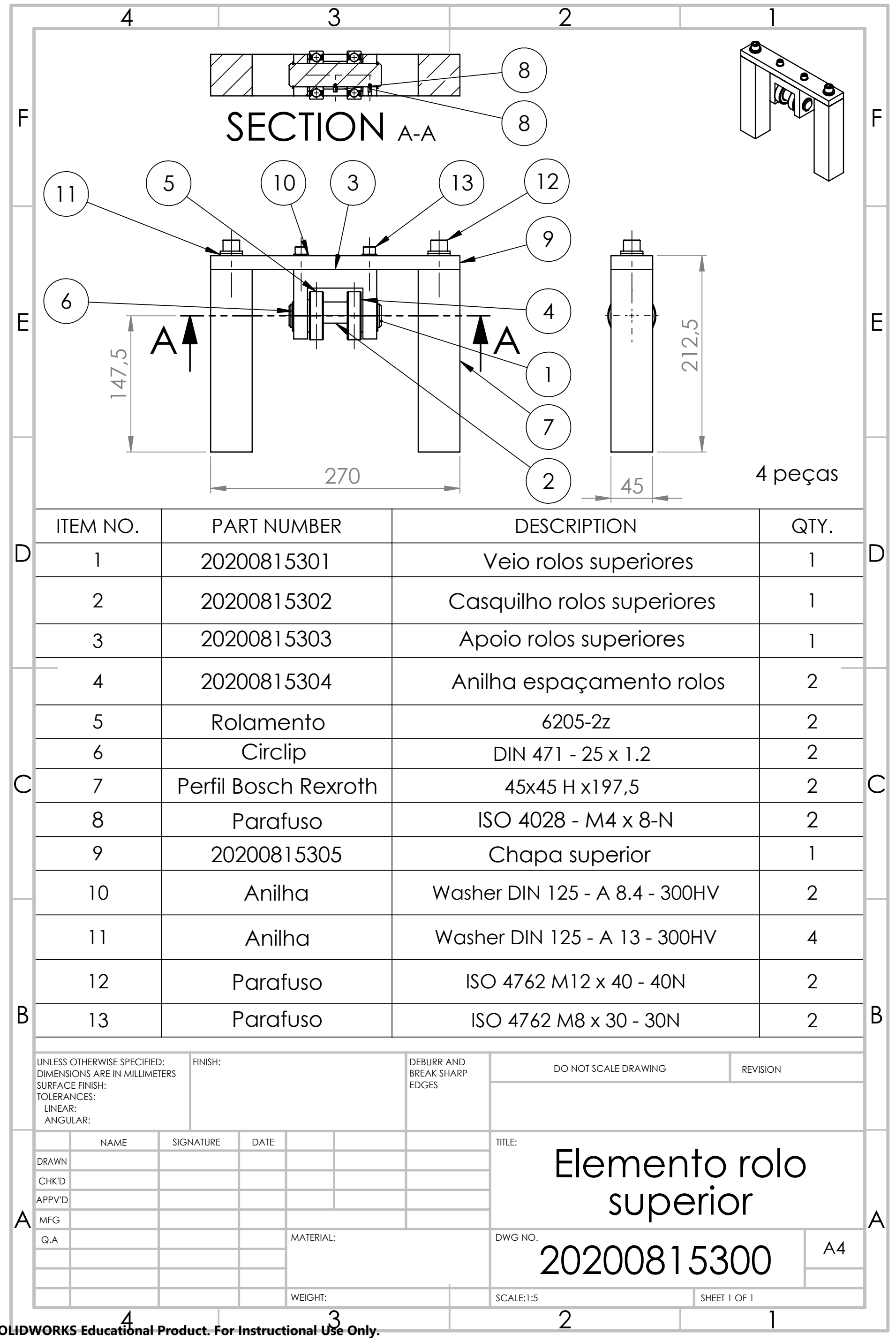




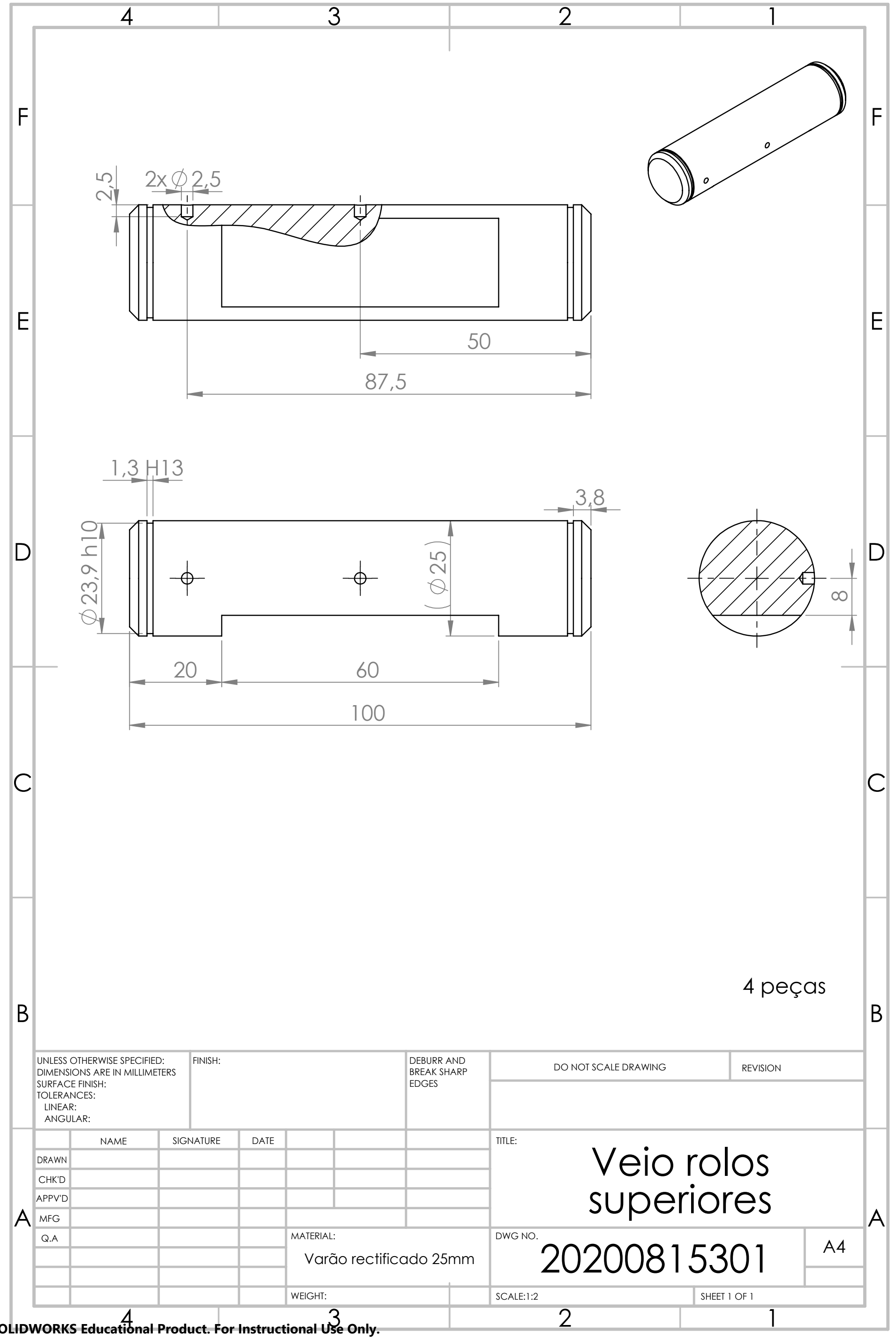




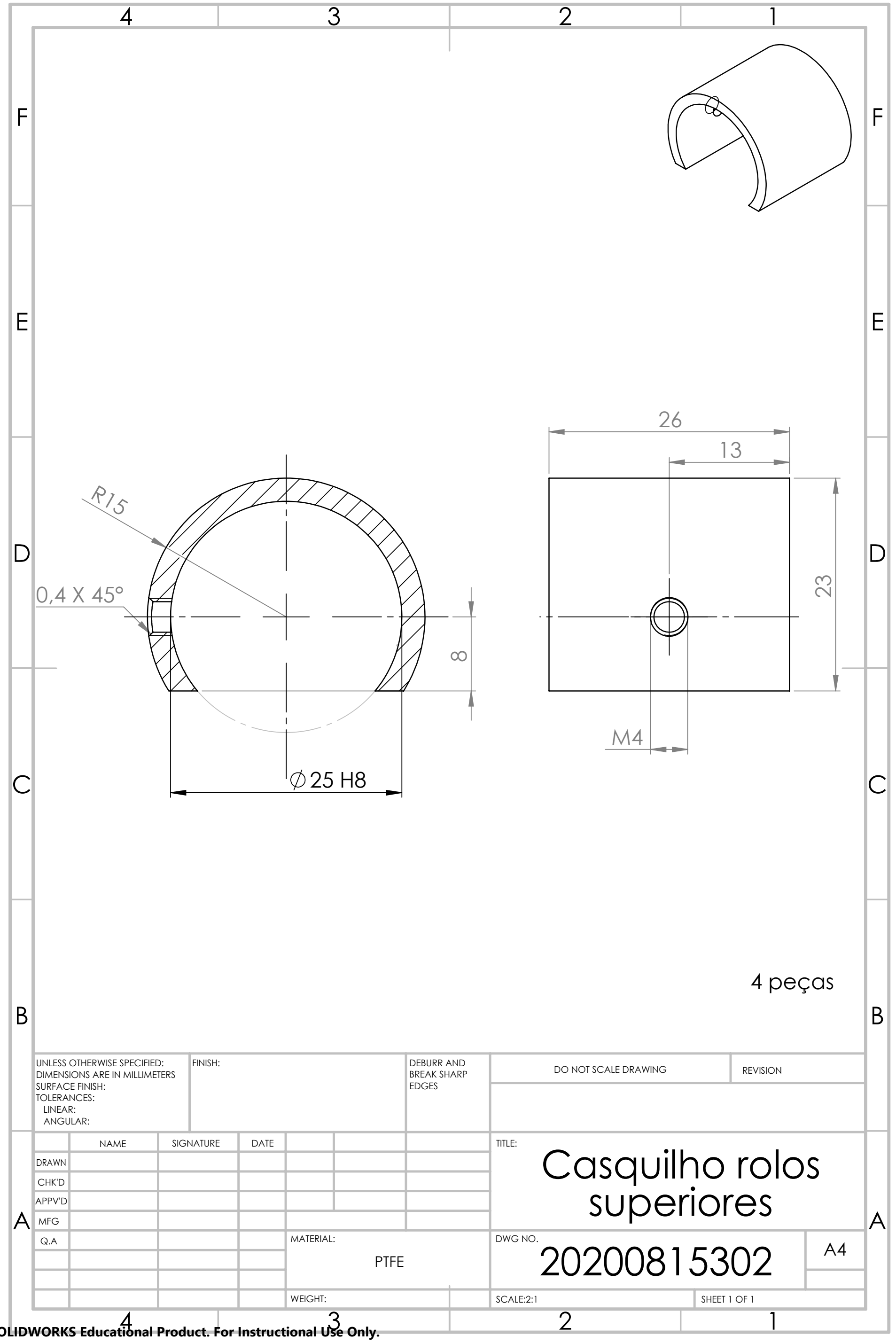




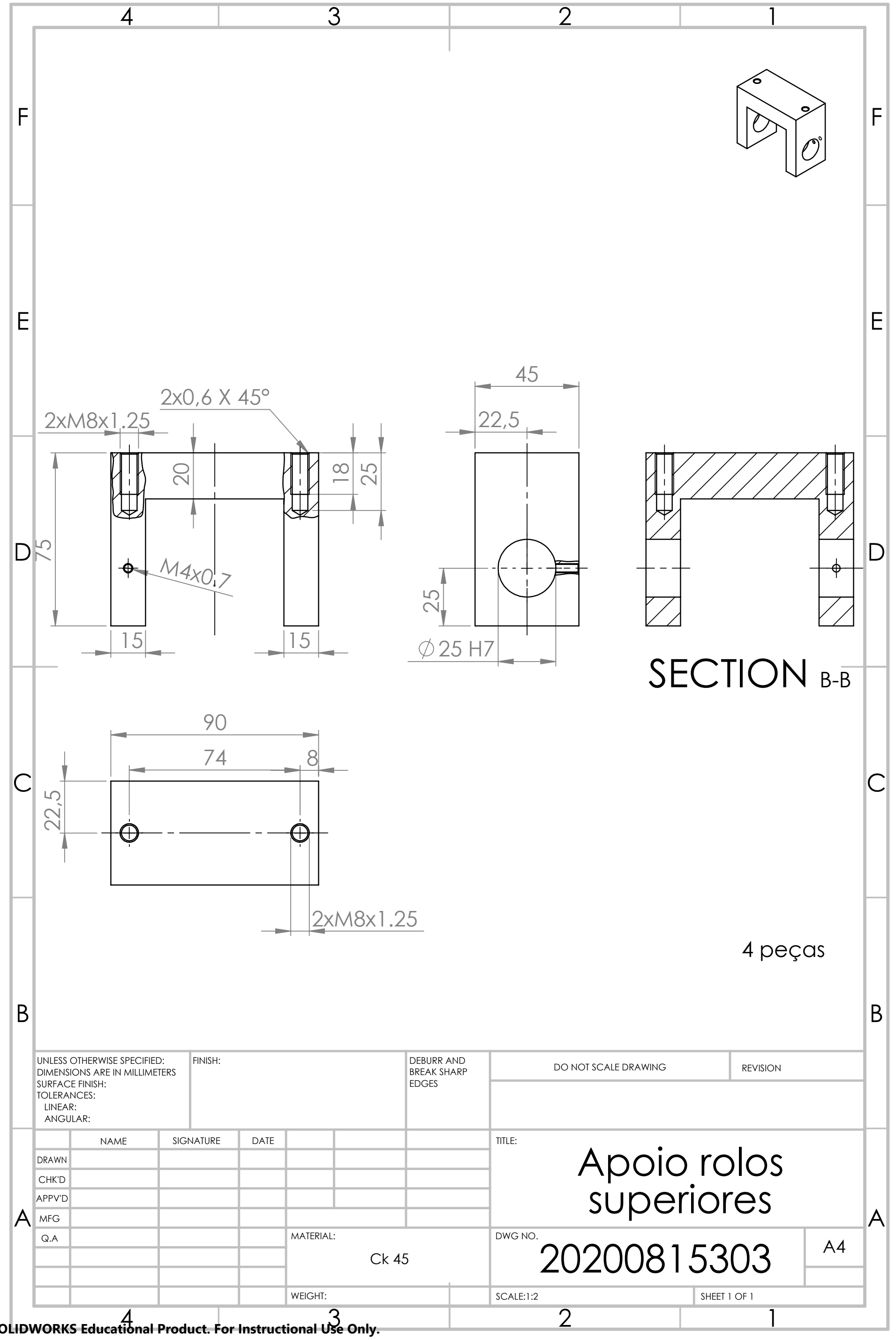




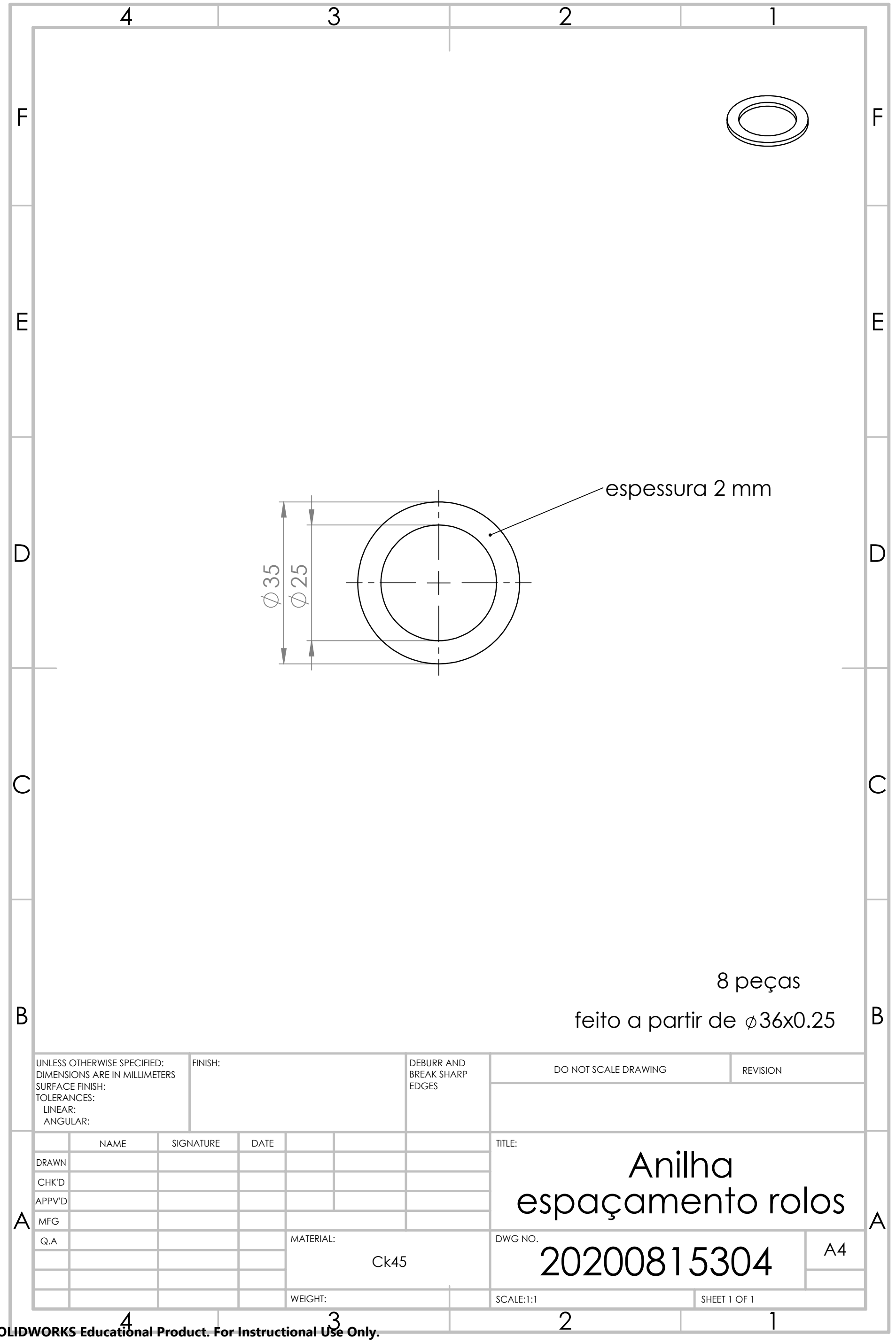




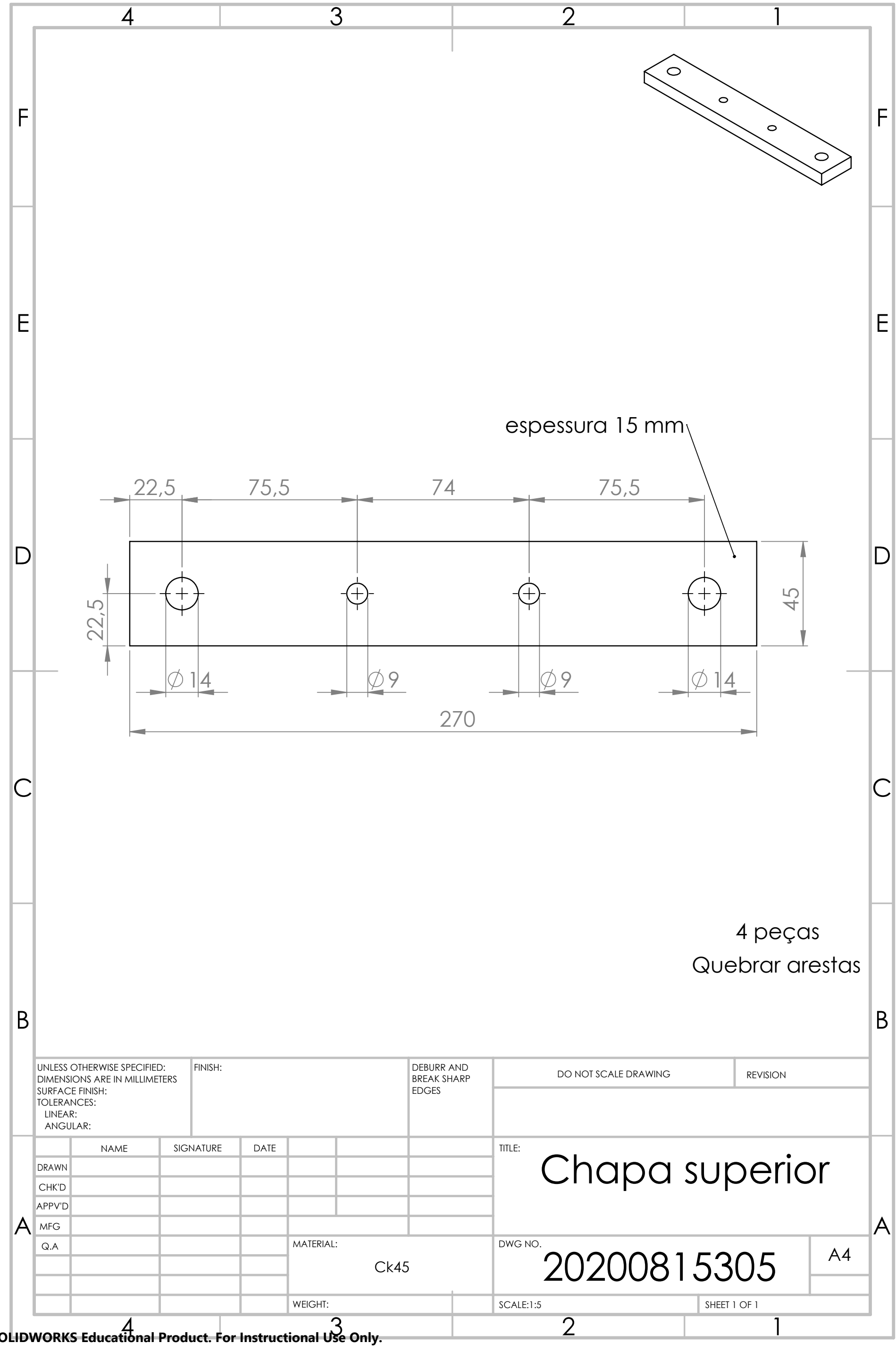




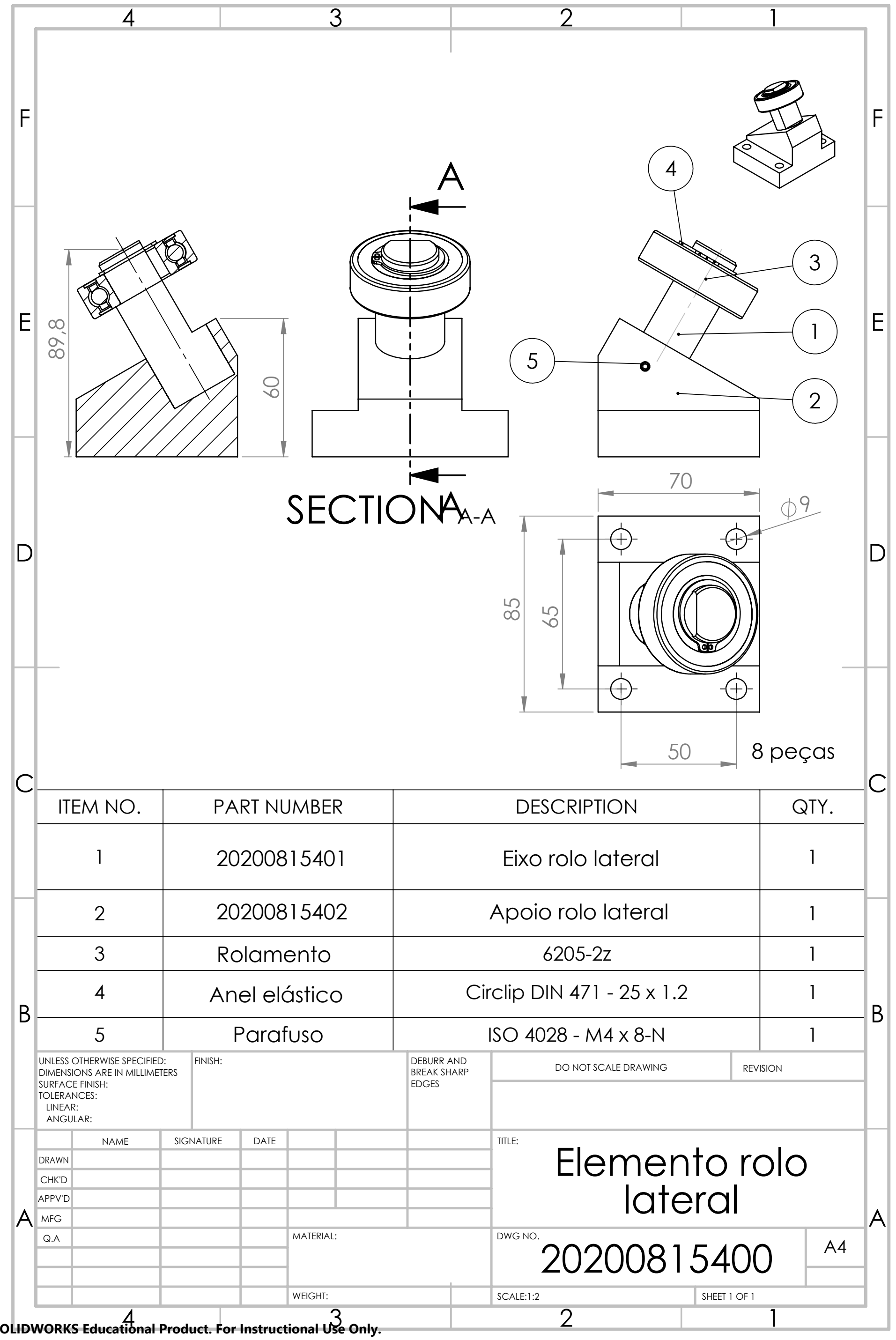




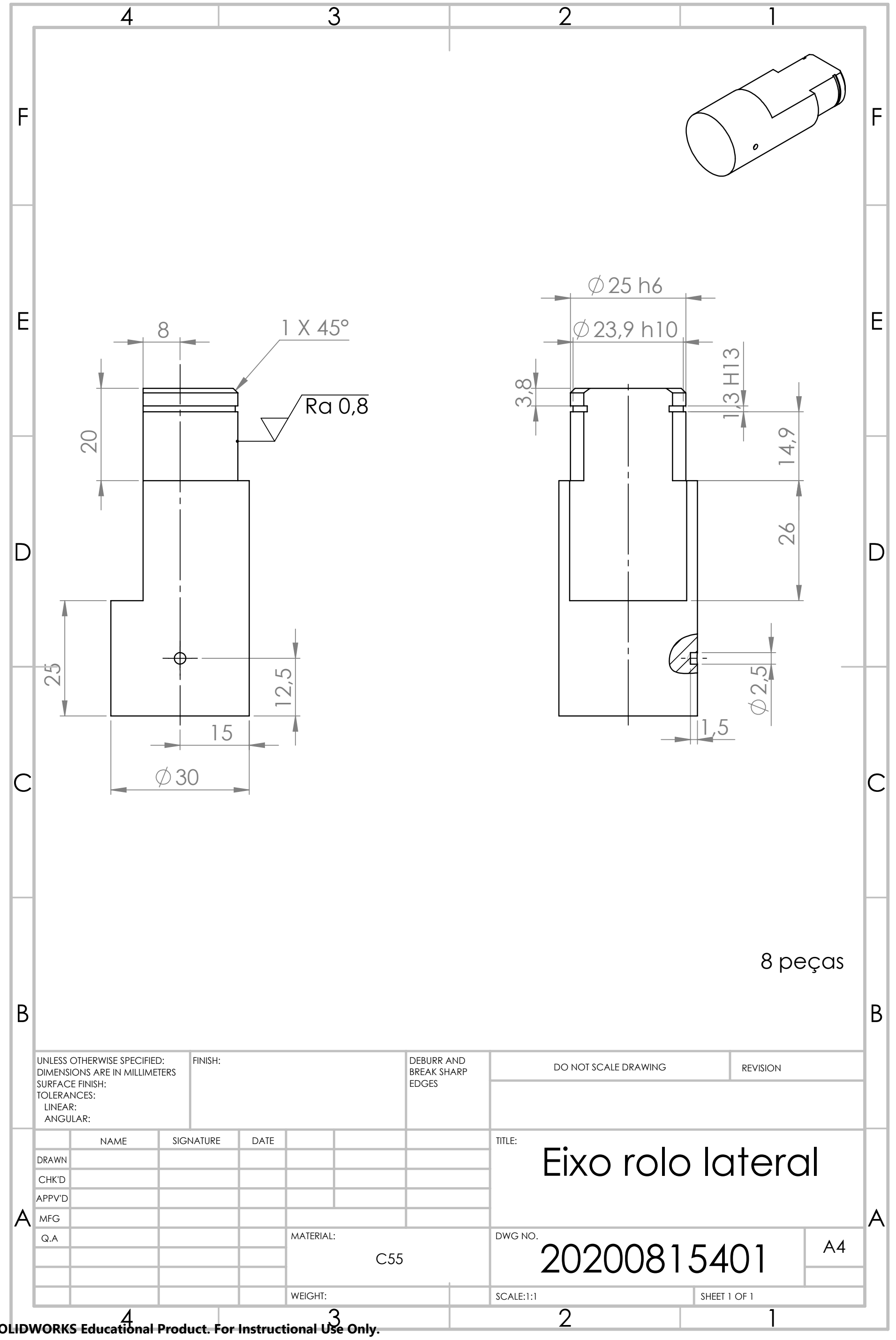




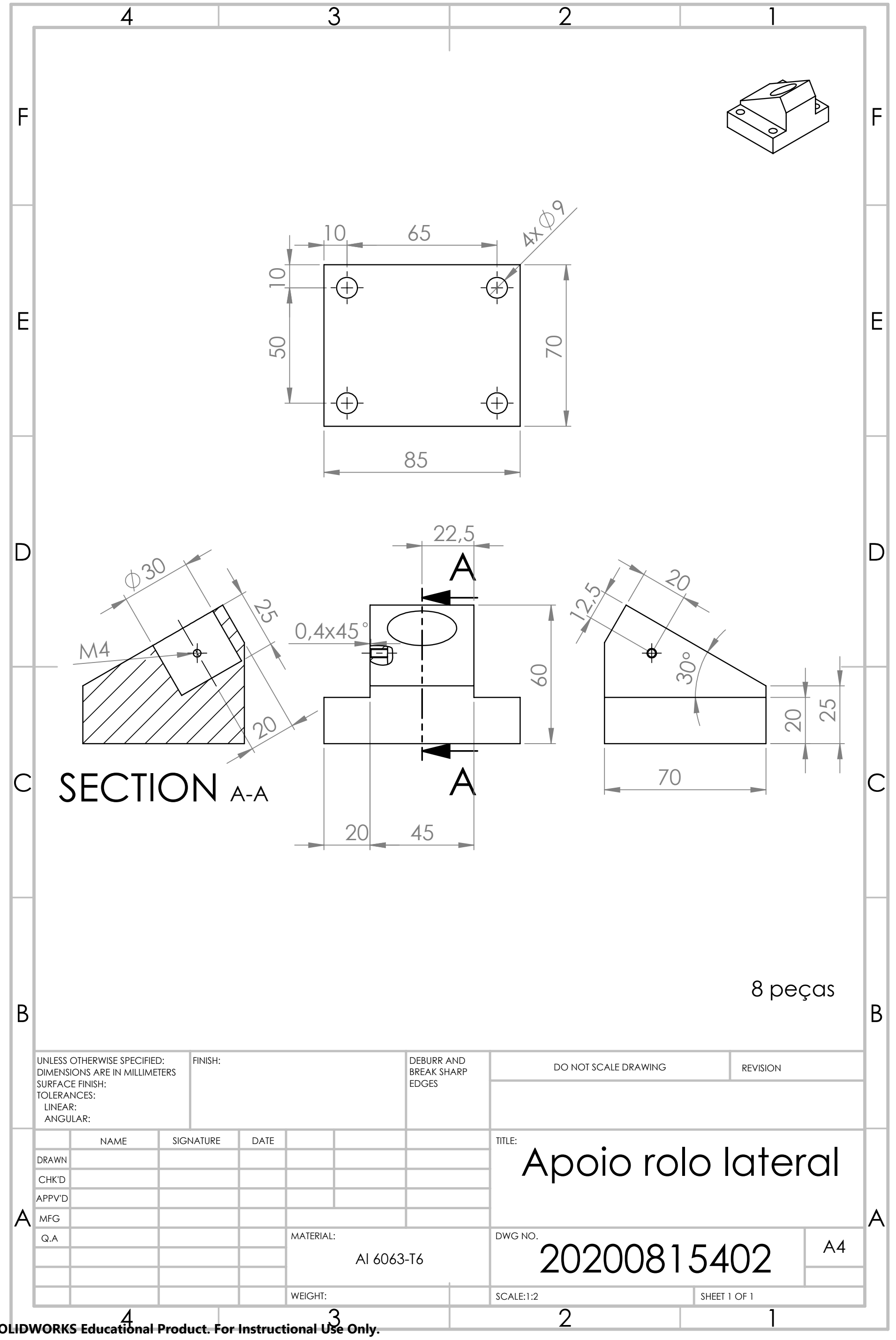




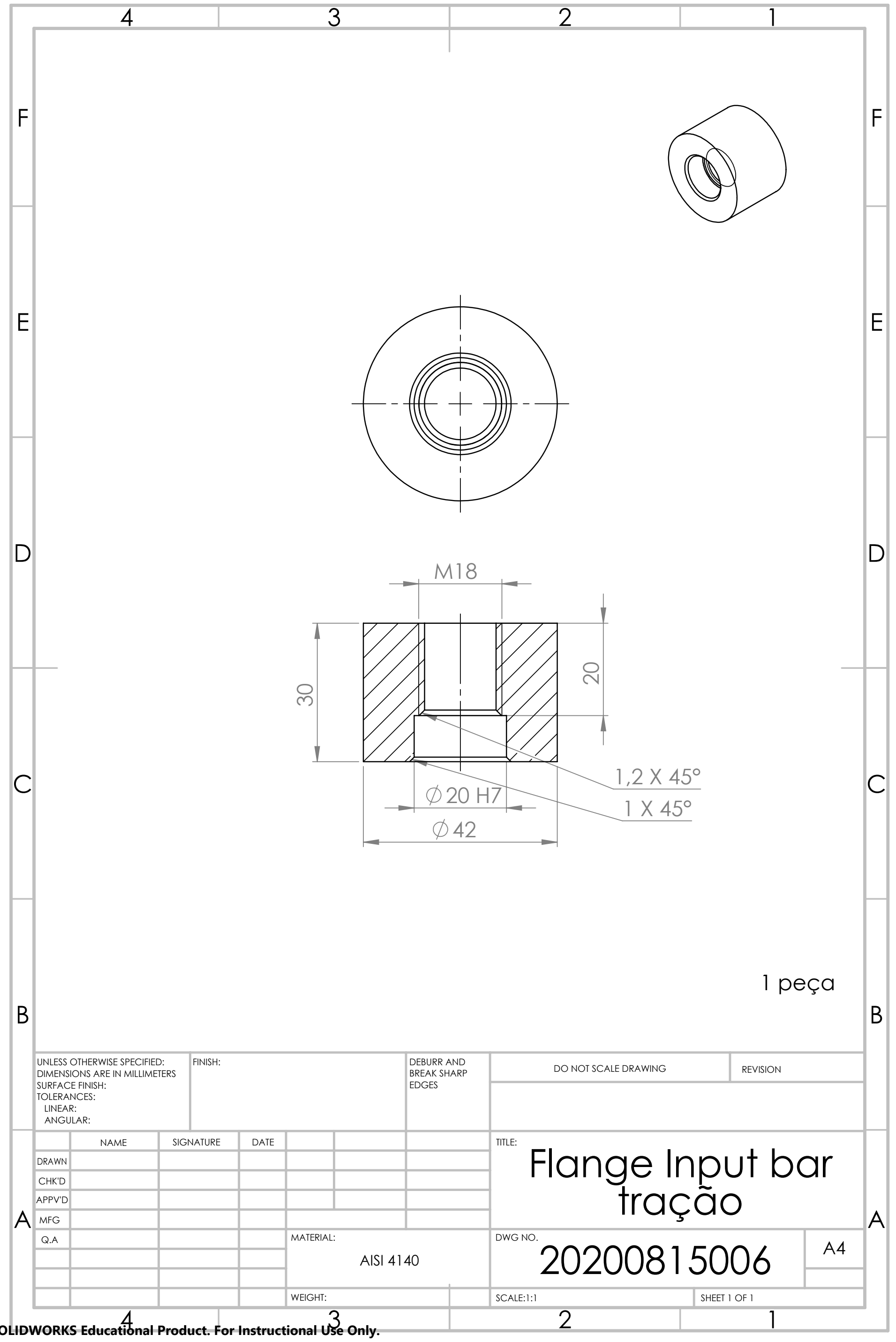




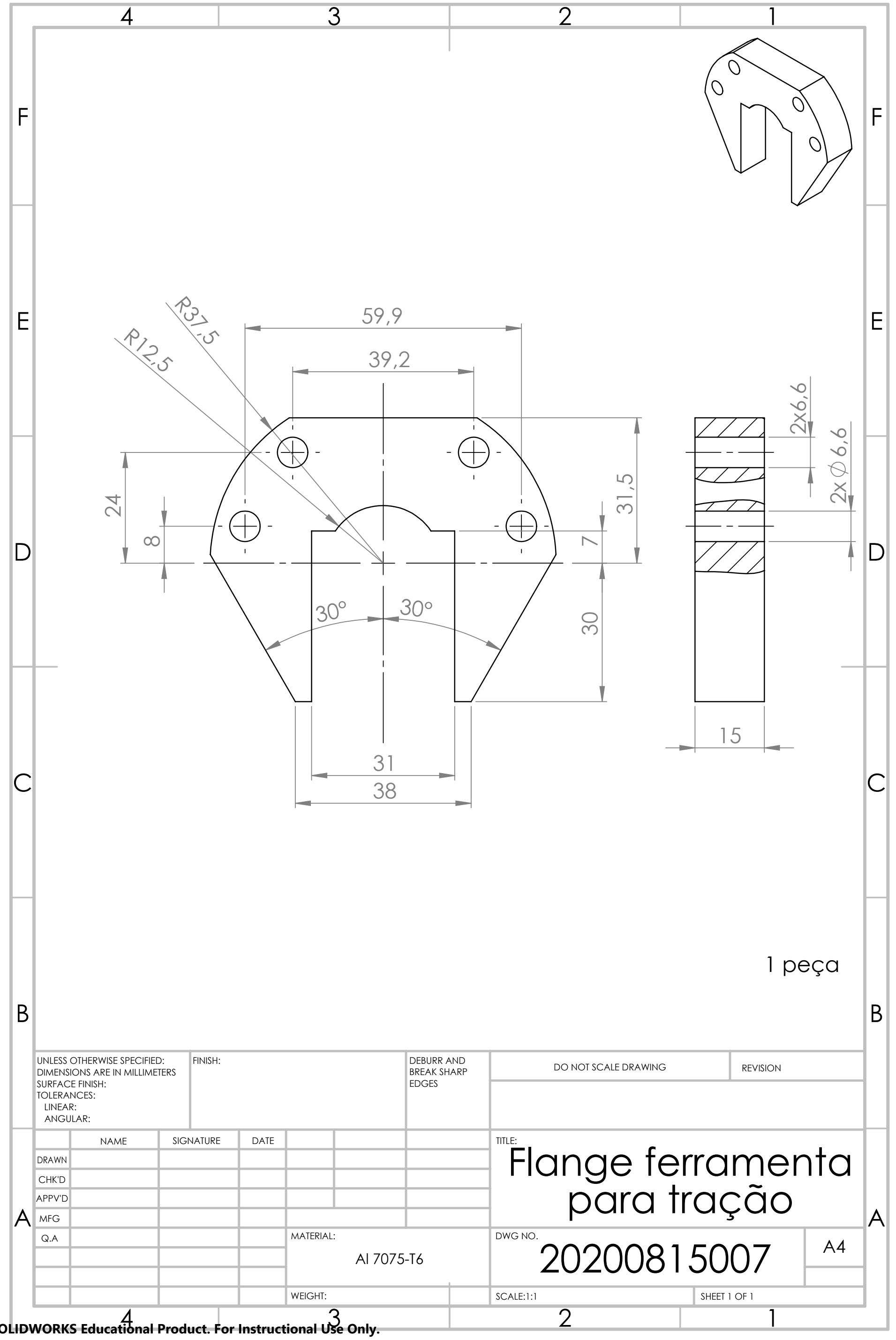




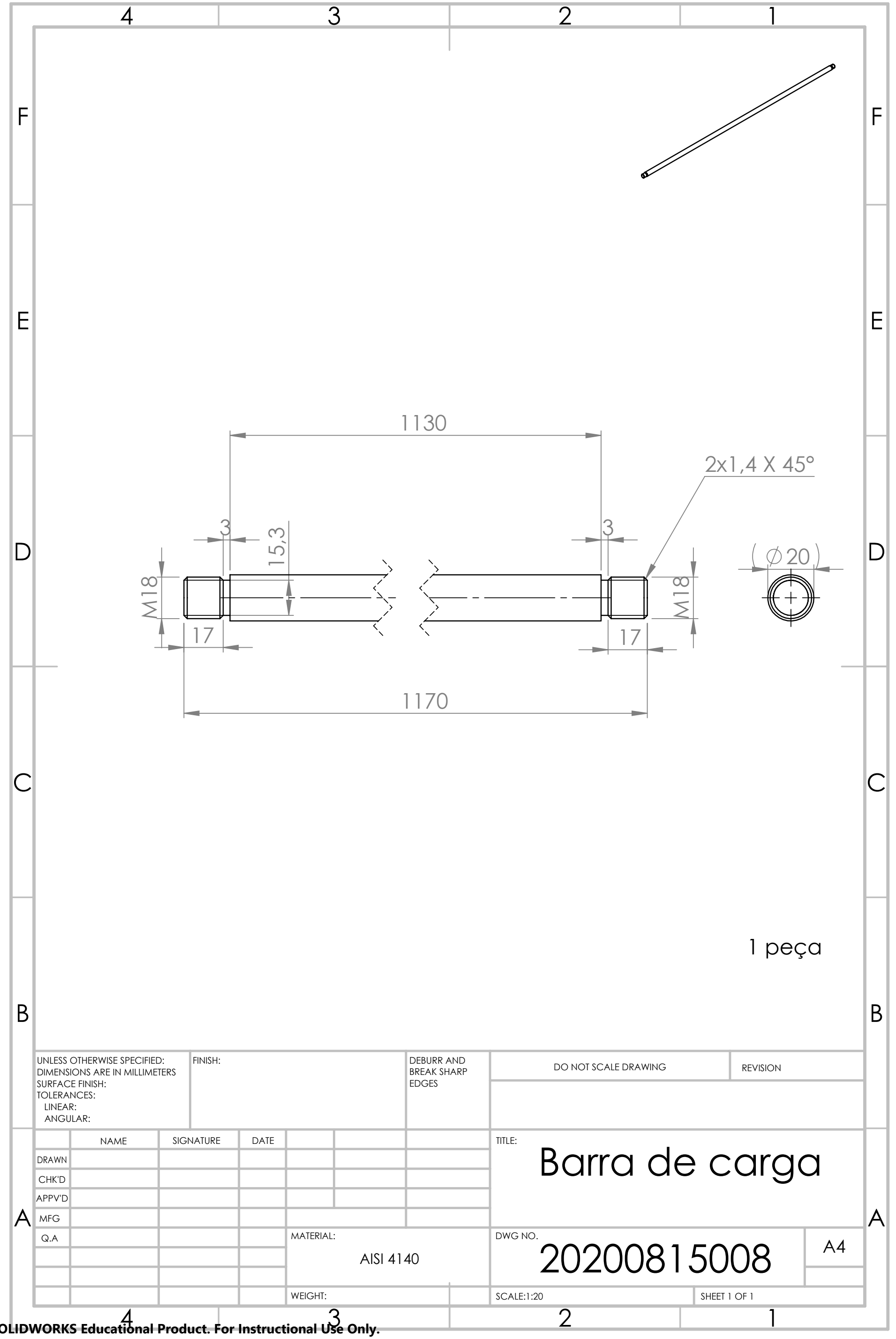




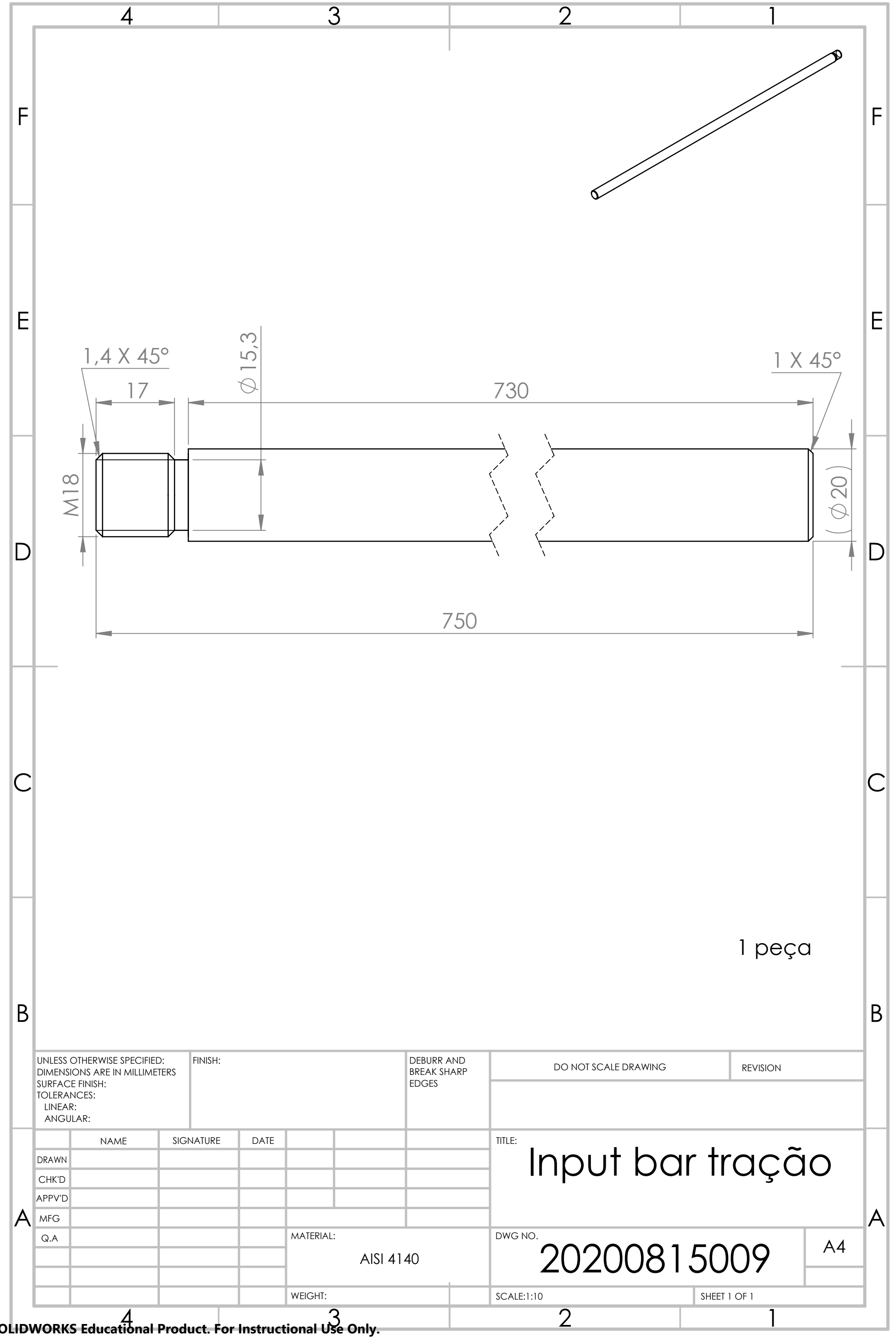




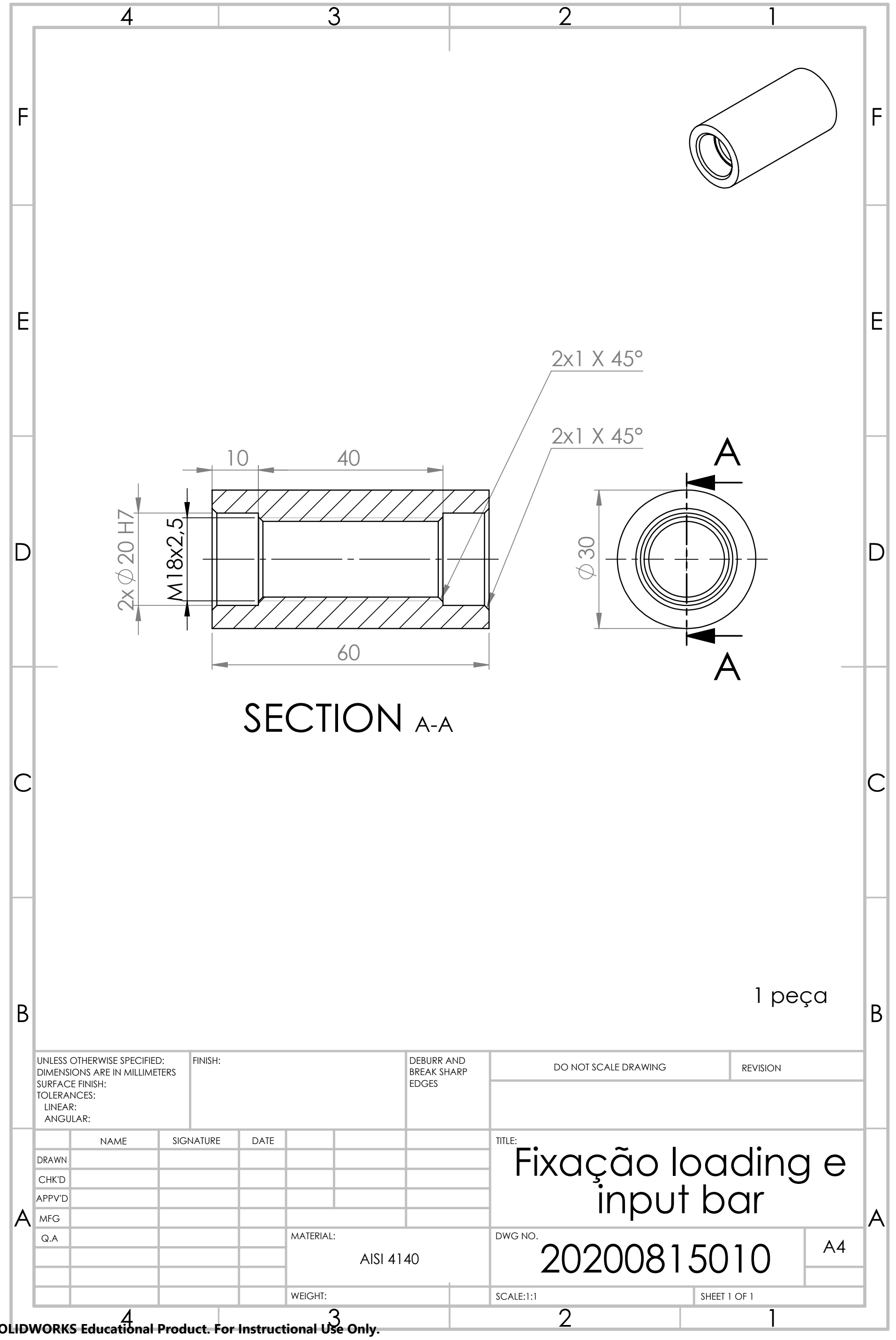




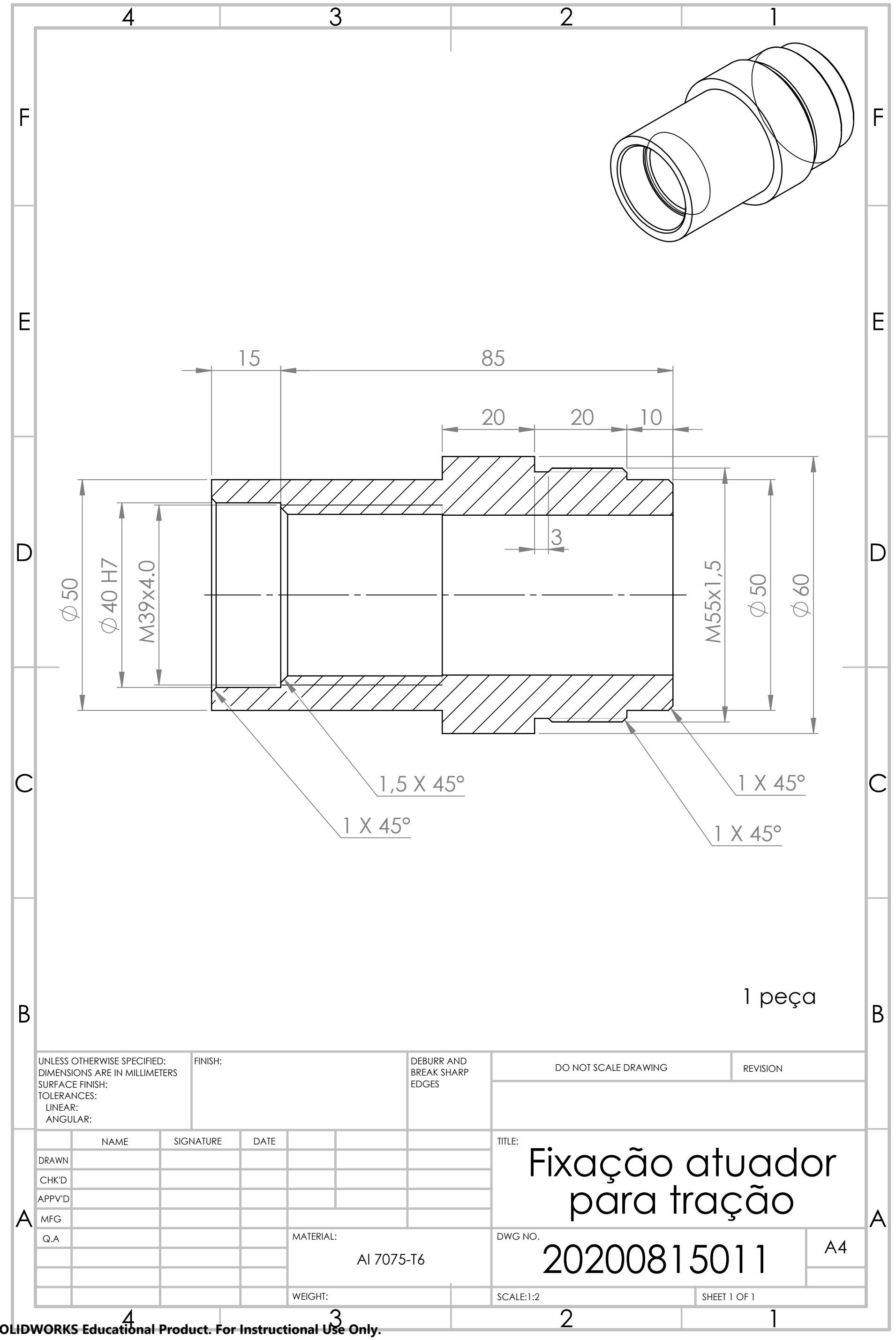




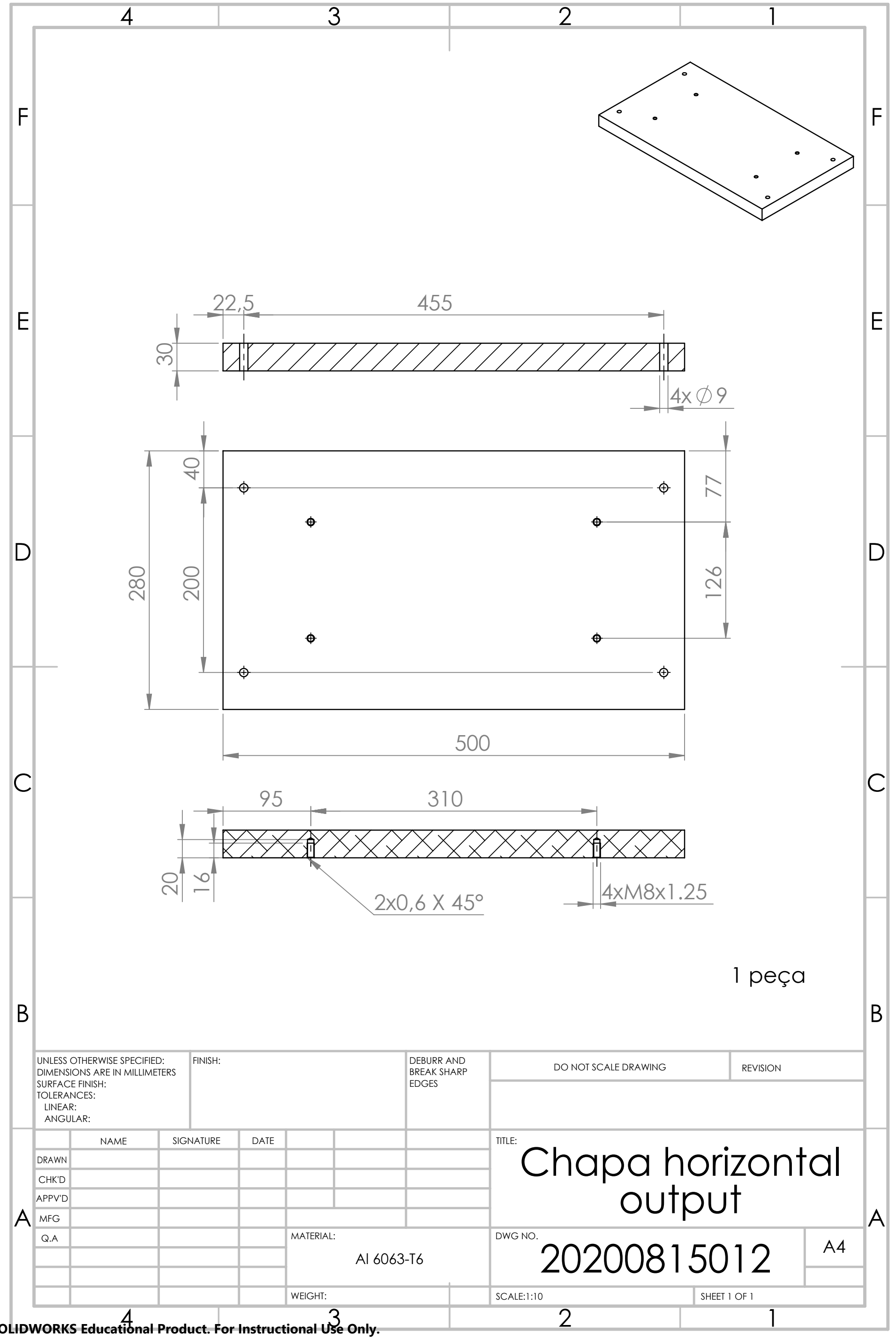




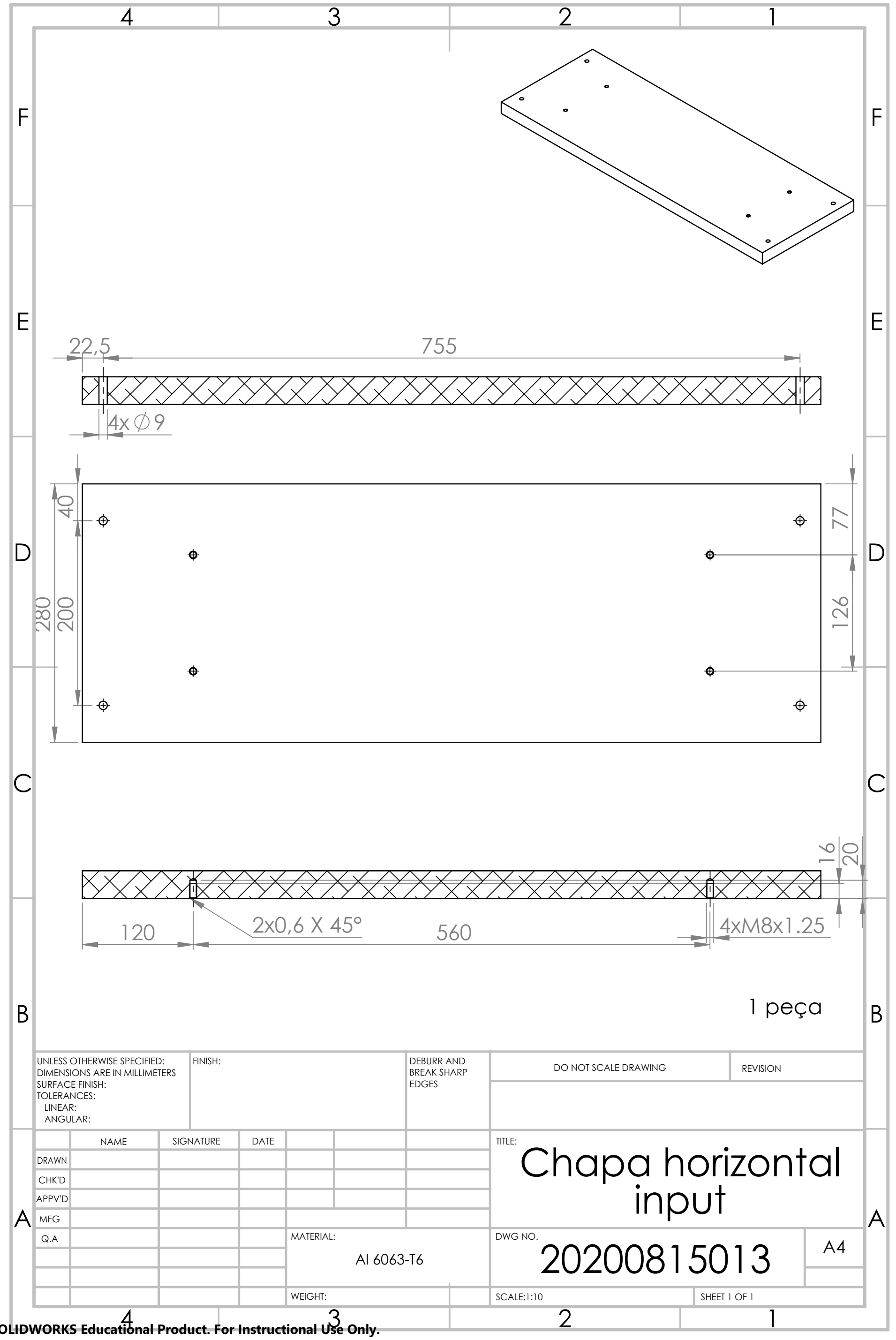




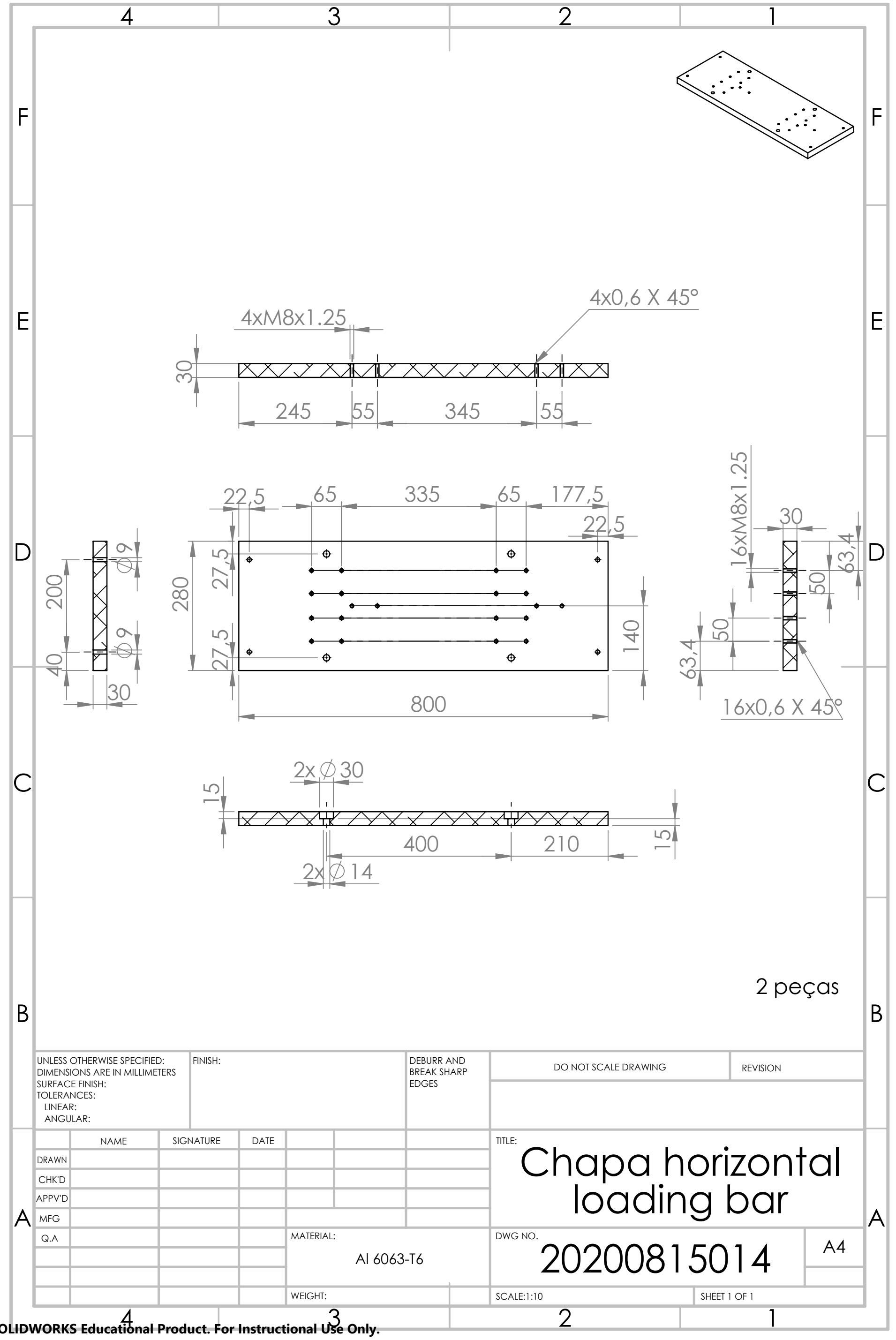





\section{Appendix G}

Mechanical Drawings

Compression Setup 


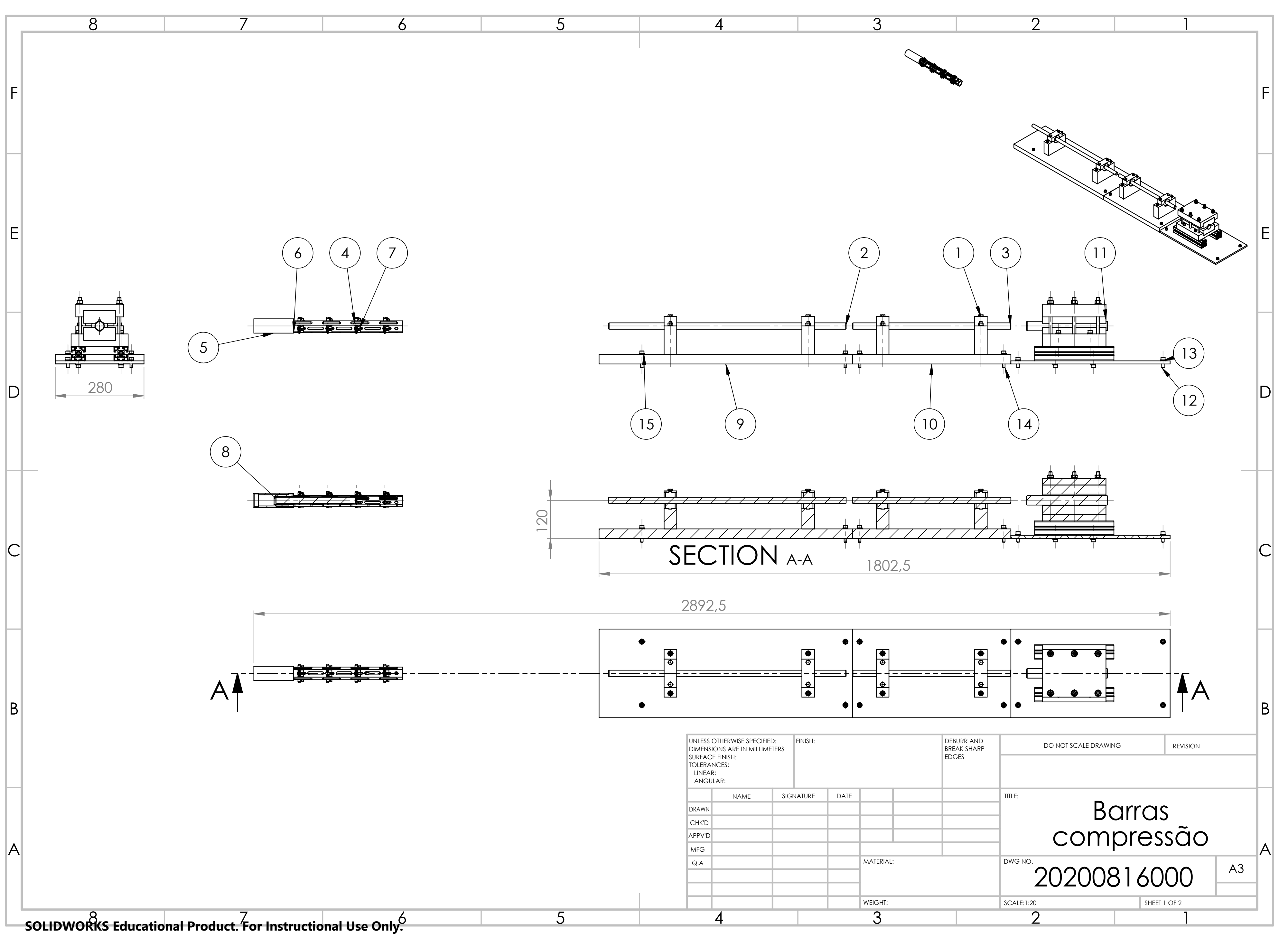




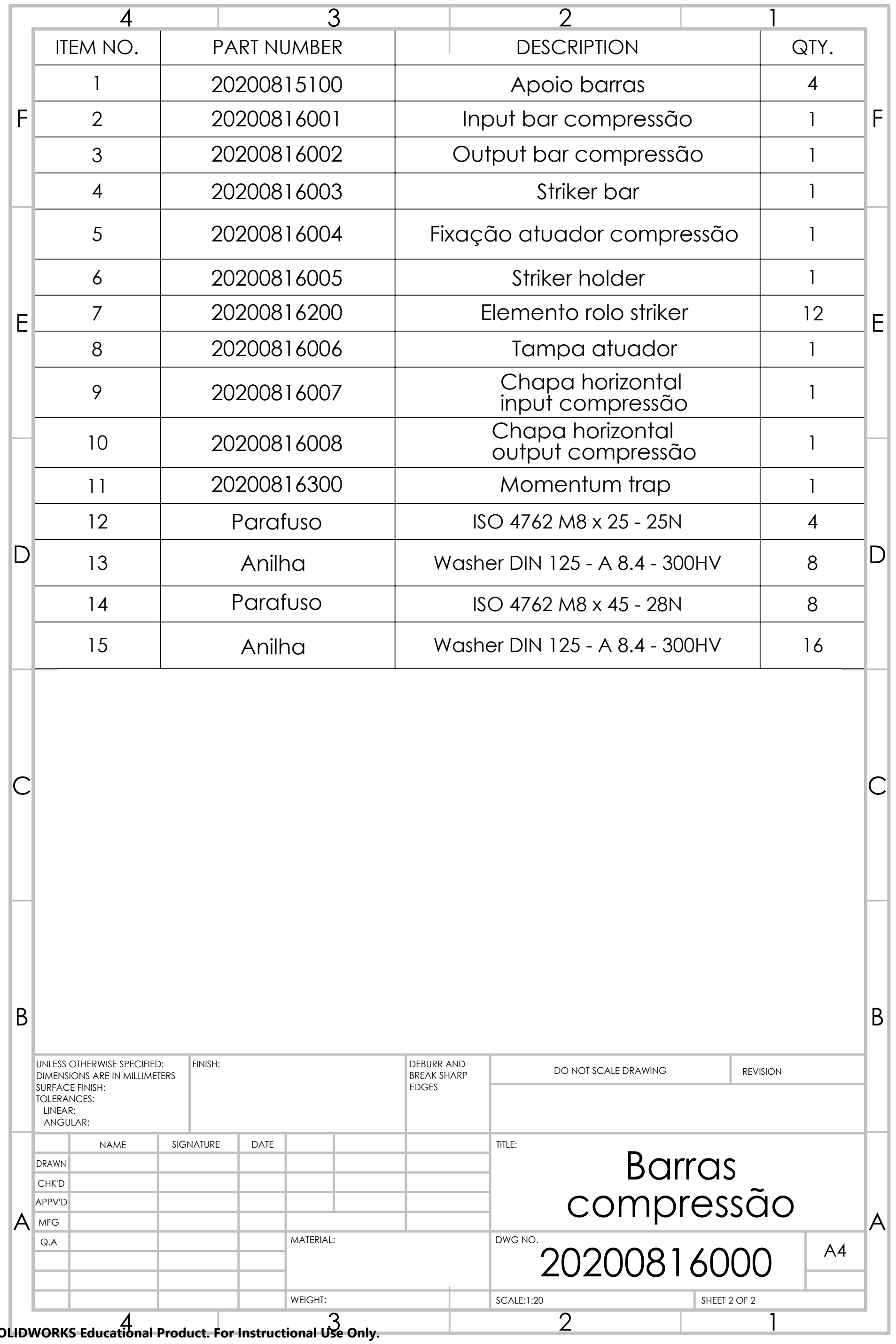




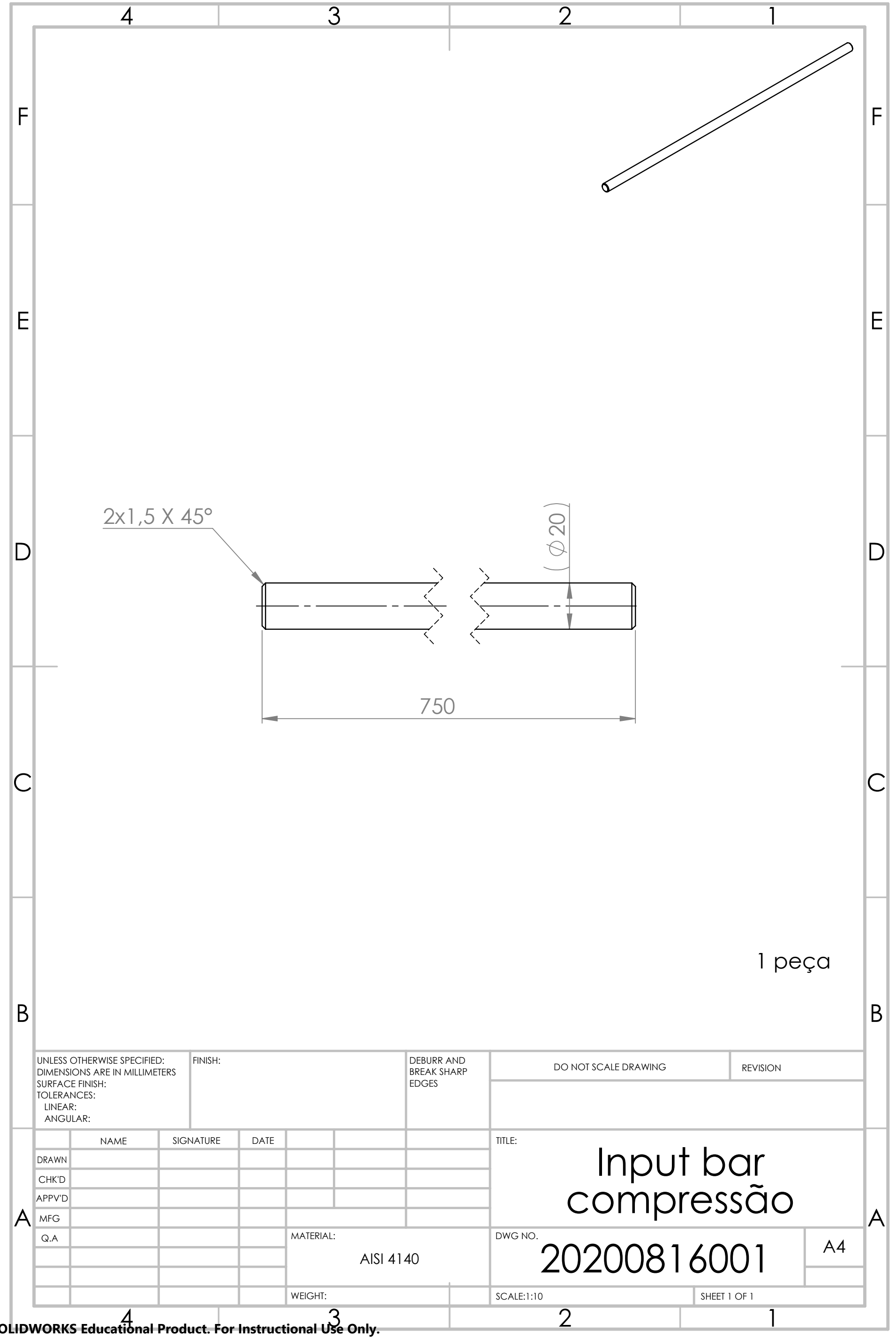




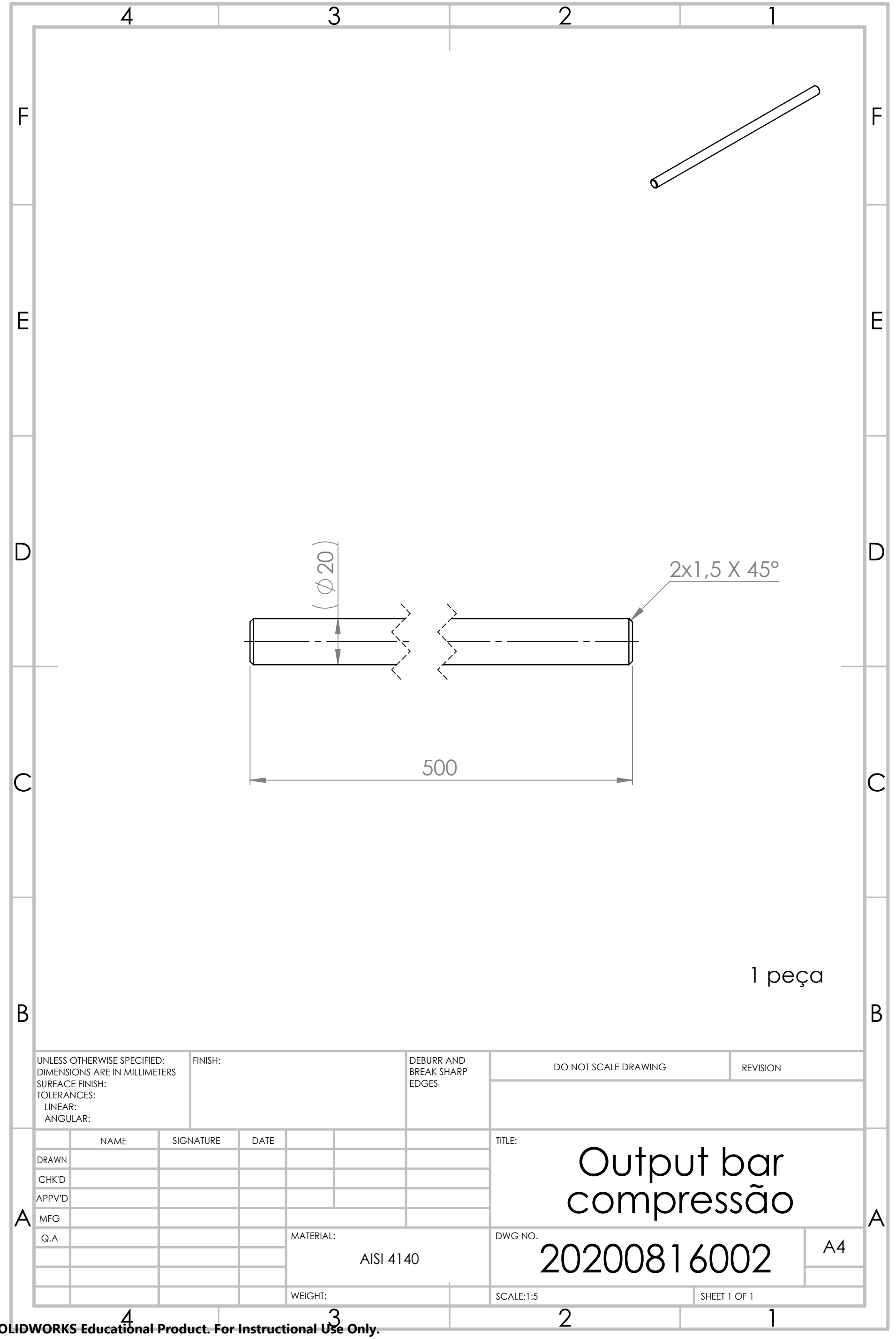



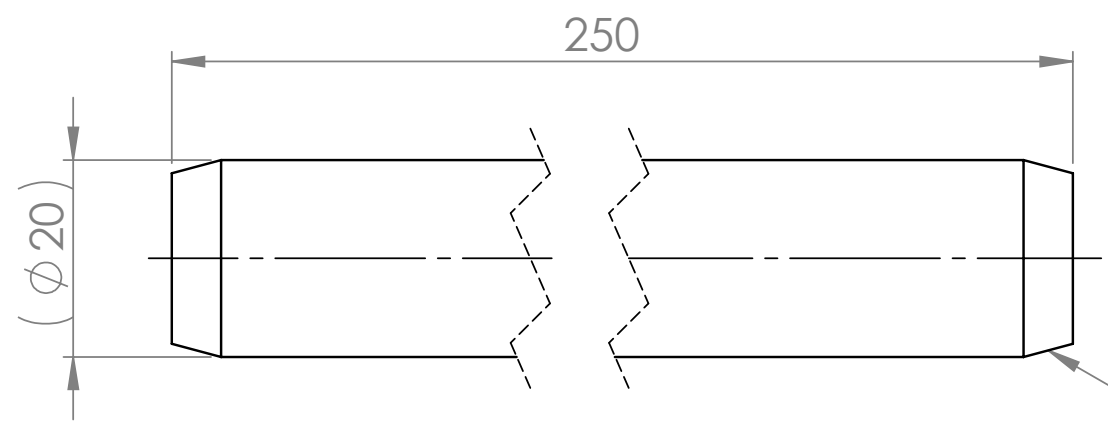

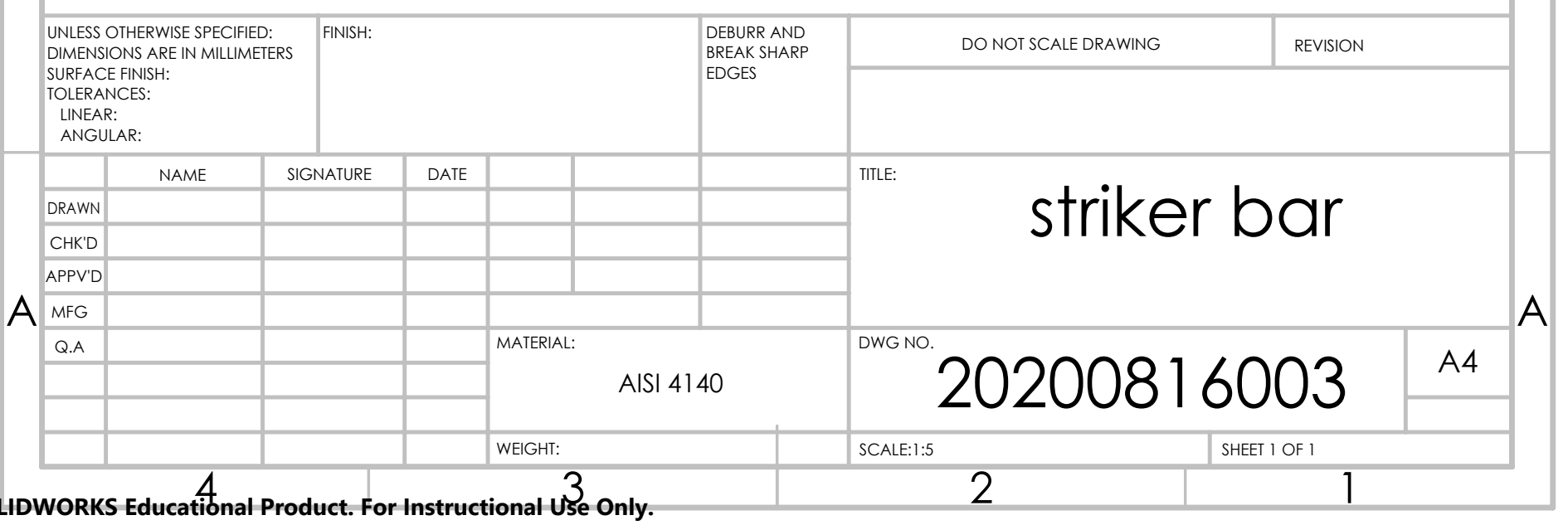




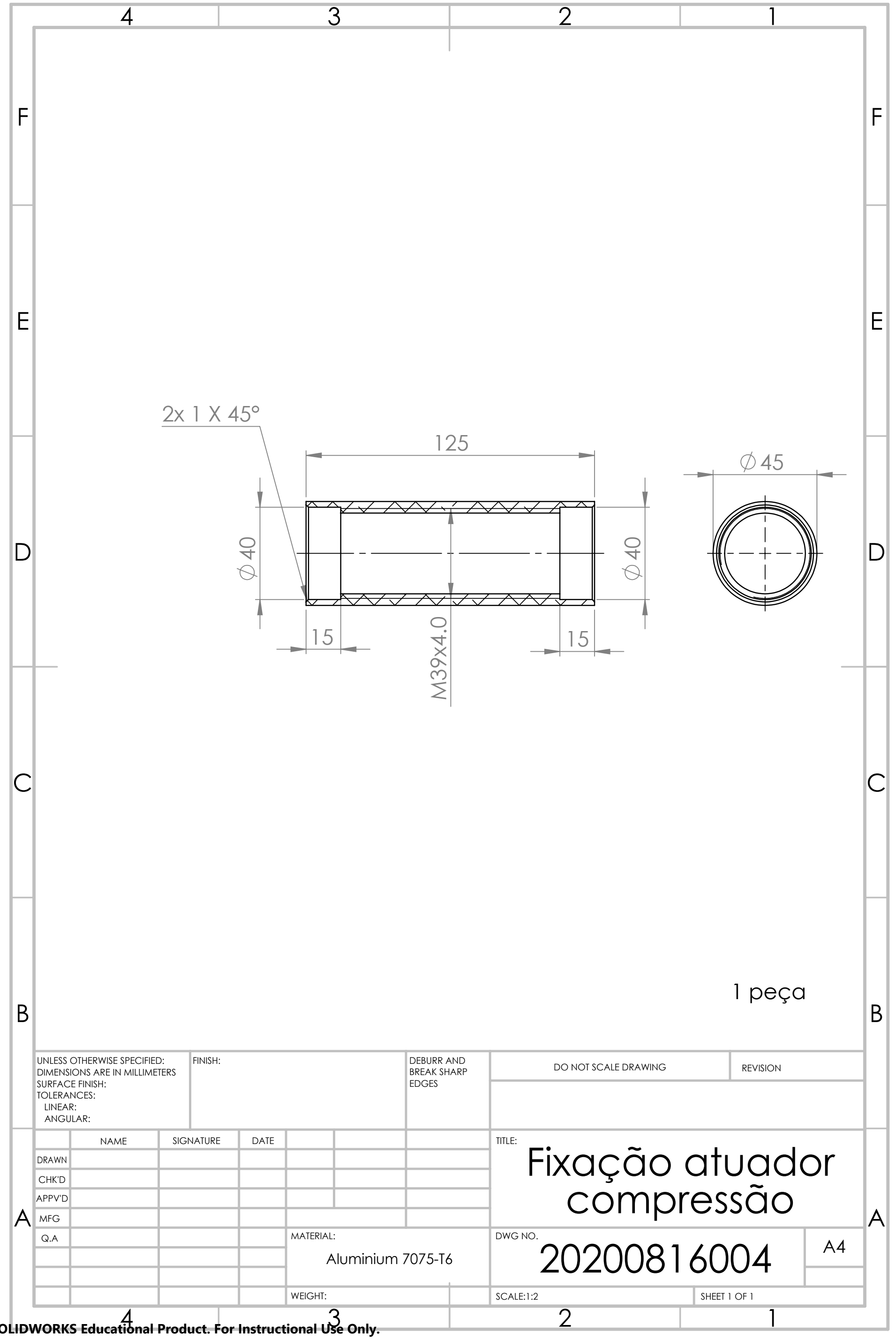




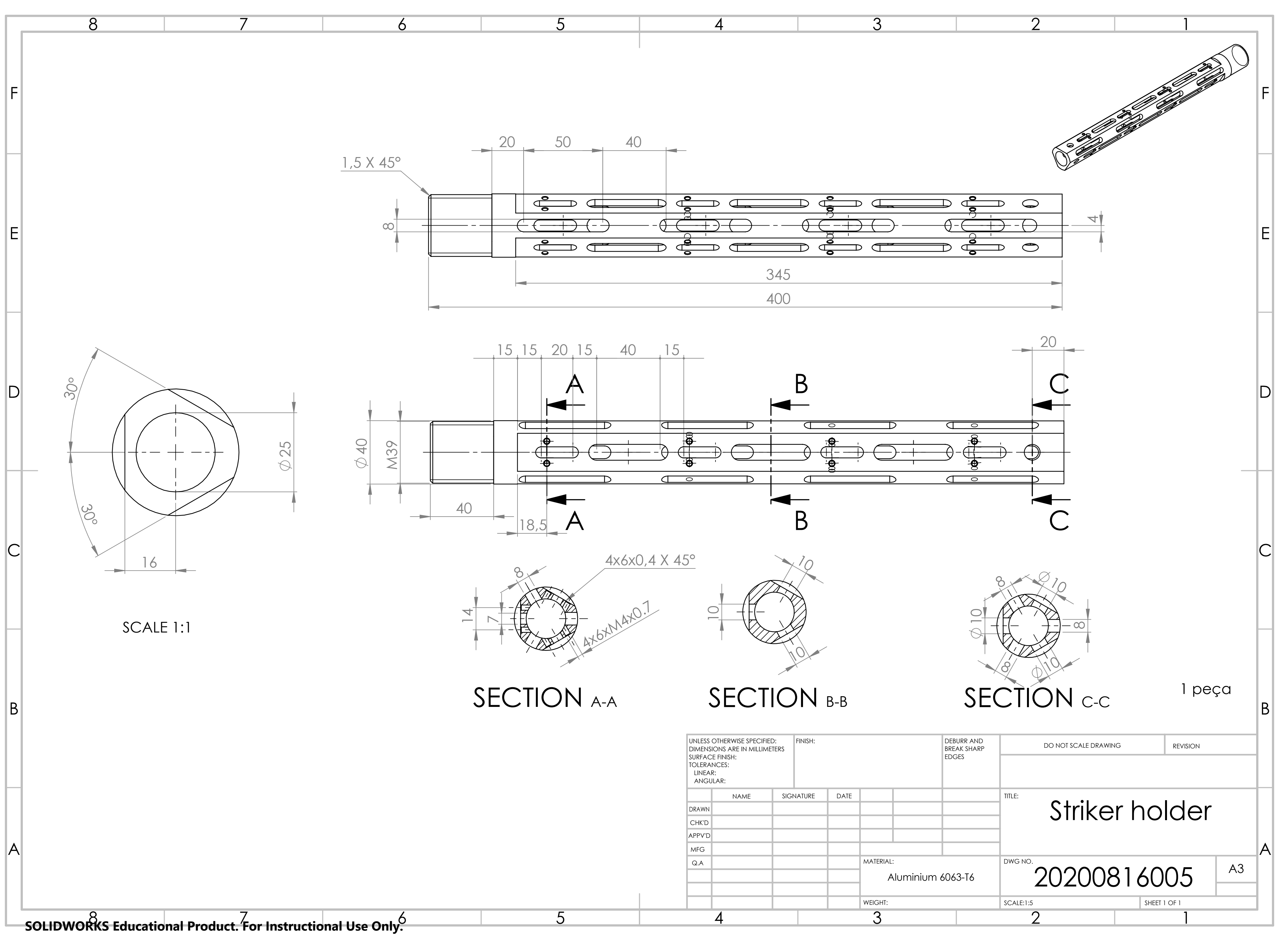




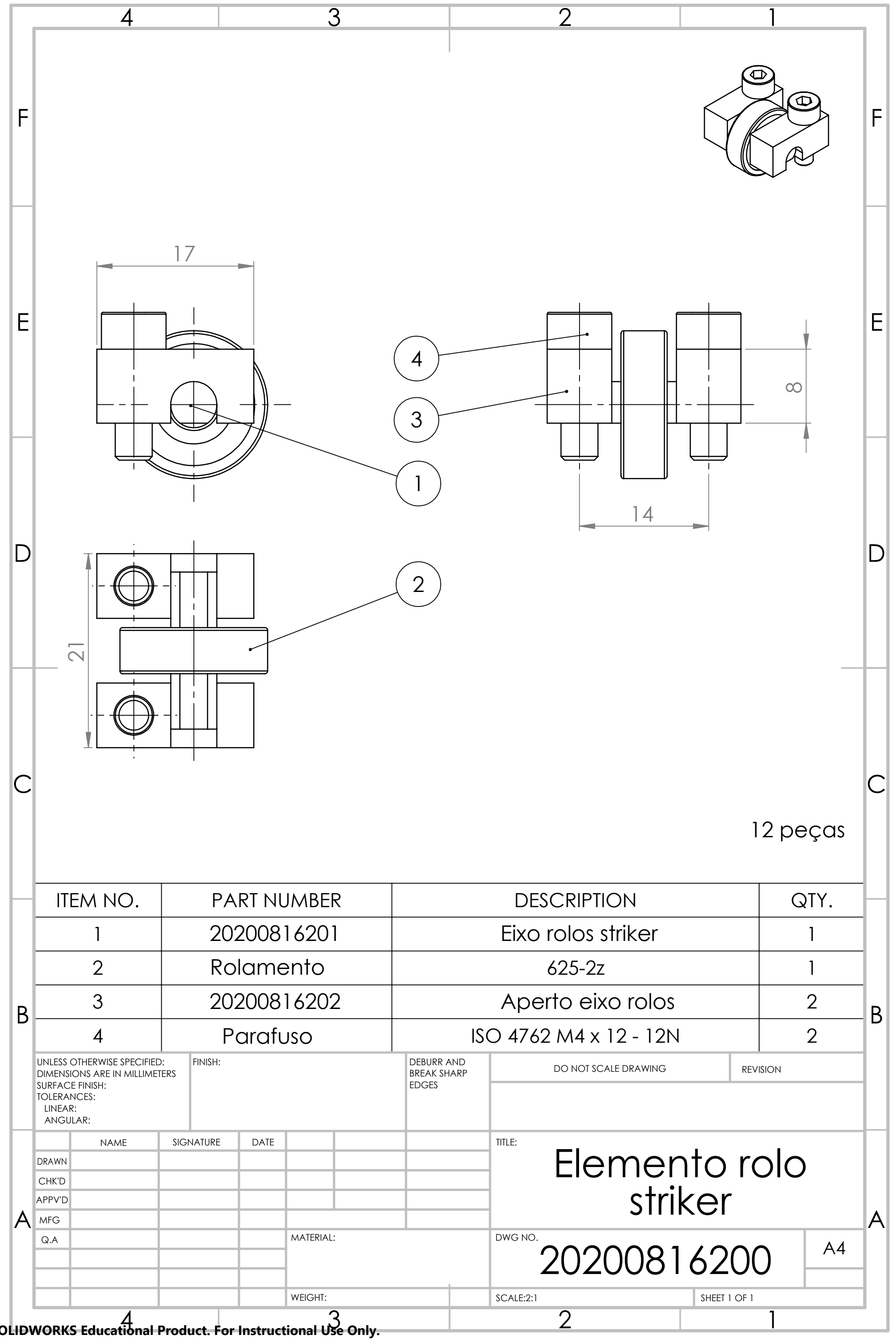




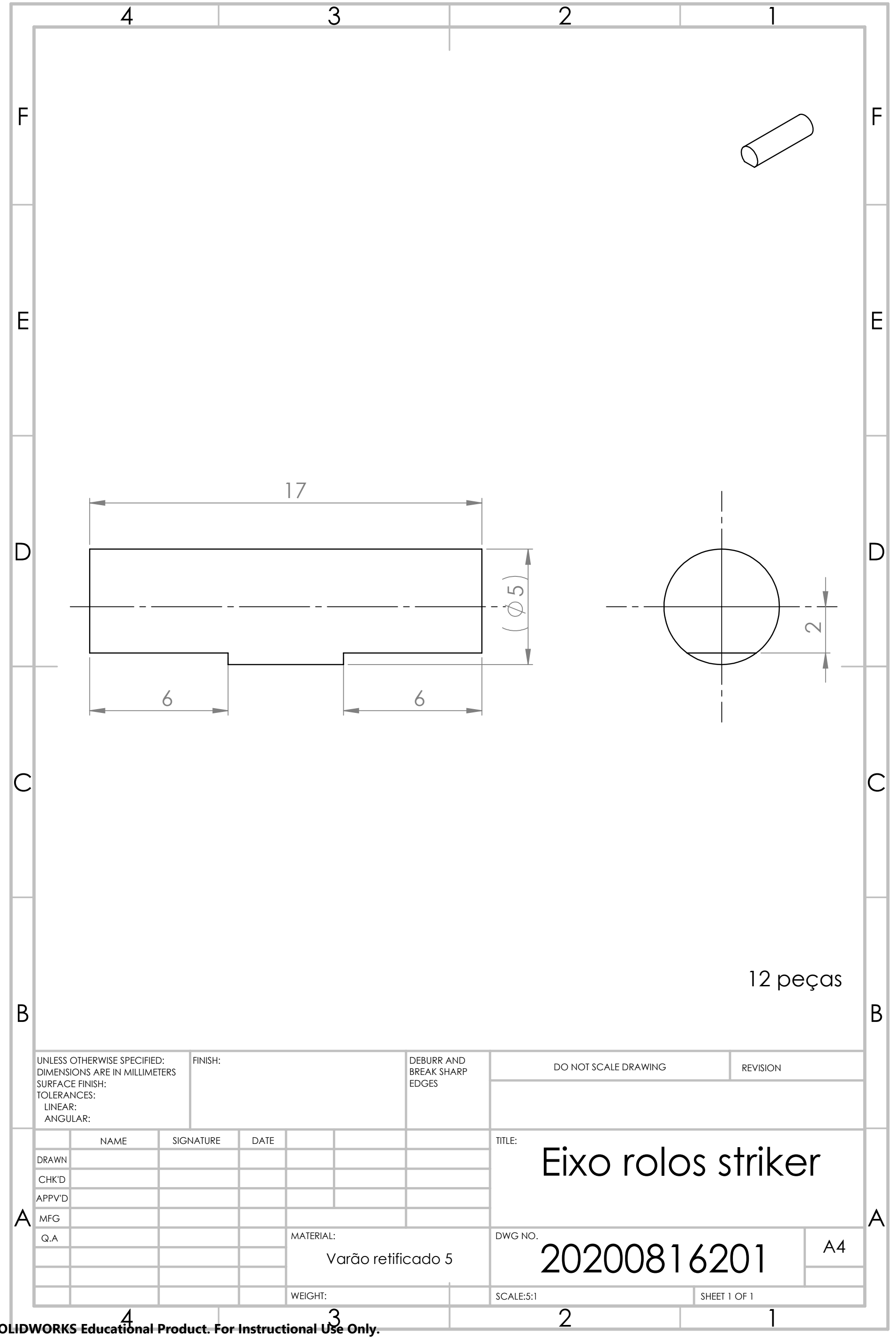




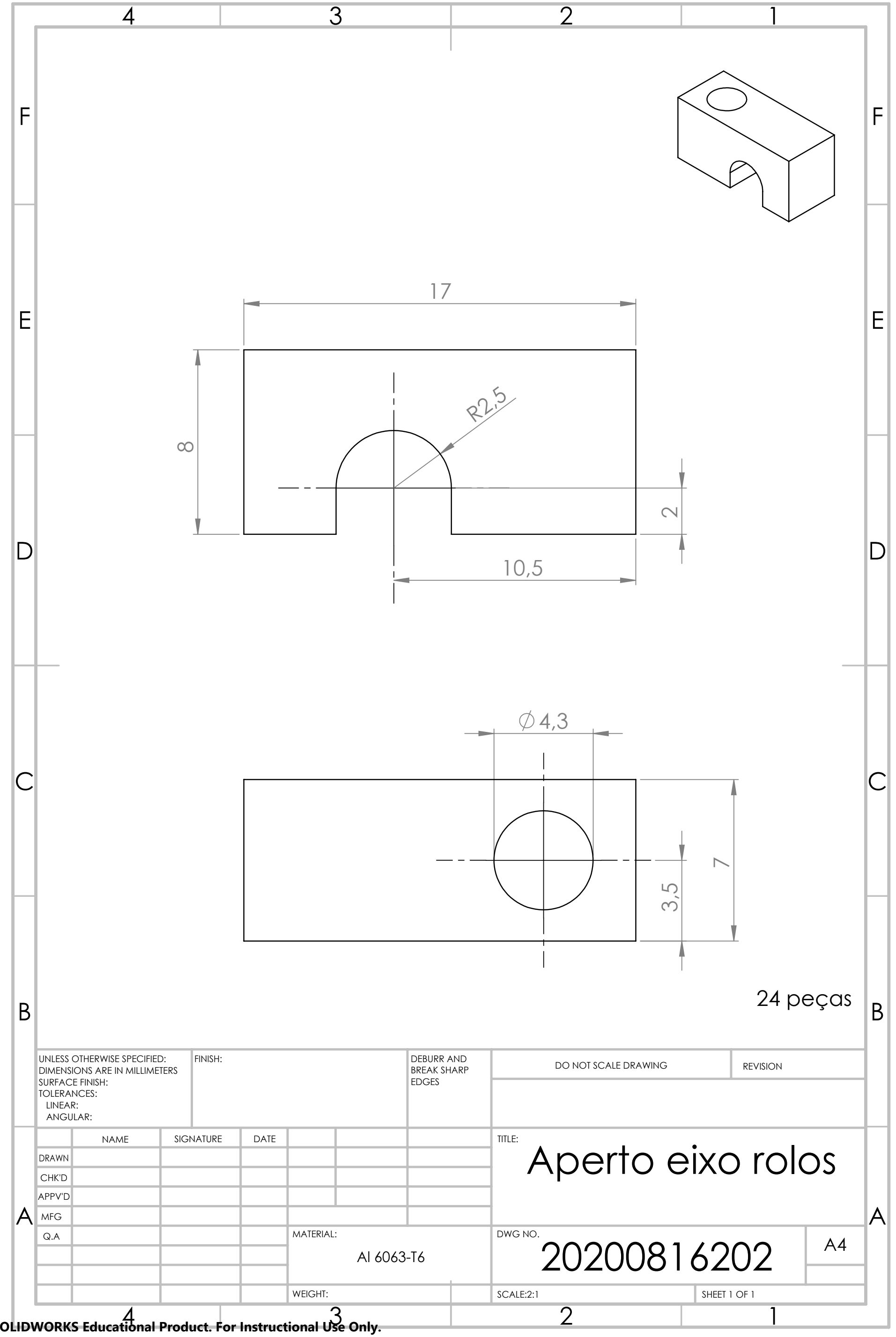




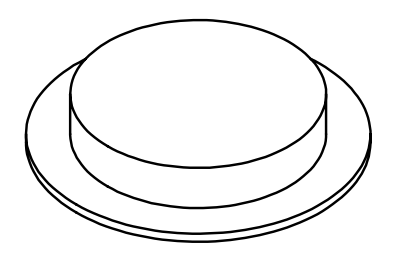

F

E

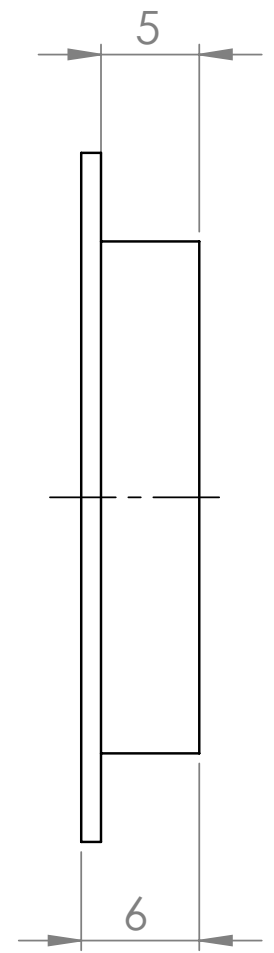

D

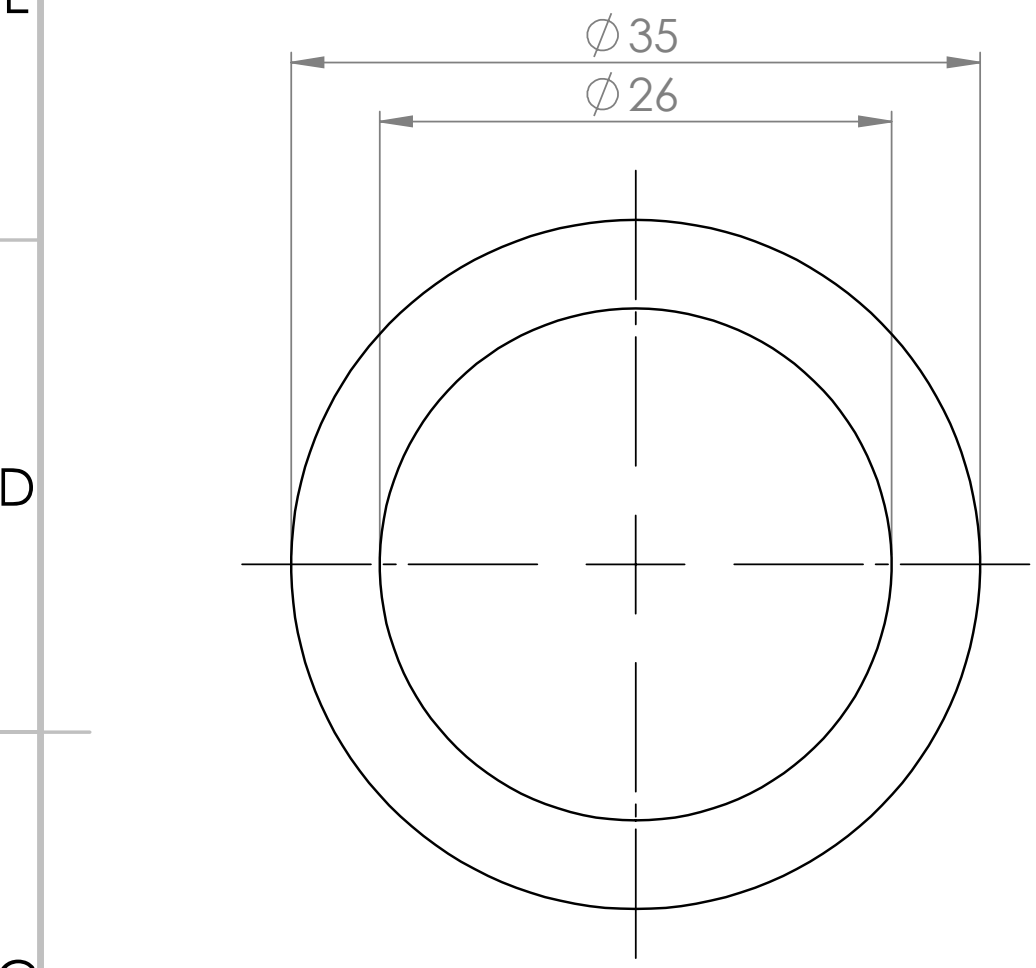

C

D

C

1 peça

B

\begin{tabular}{l|l|l}
\hline UNLESS OTHERWISE SPECIFIED: & FINISH: & DEBURR AND \\
\hline
\end{tabular}

DIMENSIONS ARE IN MILLIMETERS

SURFACE FINISH:

TOLERANCES:
LINEAR:

LINEAR:
ANGULAR:

\begin{tabular}{|l|l|l|l|l|l|l|}
\hline & NAME & SIGNATURE & DATE & & & TITL: \\
\hline DRAWN & & & & & & \\
\hline CHK'D & & & & & & \\
\hline APPV'D & & & & & & \\
\hline
\end{tabular}

Tampa atuador

A

\begin{tabular}{l}
$A P P V$ \\
\hline MFG
\end{tabular}

Q.A

\begin{tabular}{|l||l}
\hline MATERIAL: & M
\end{tabular}

Aluminium 6063-T6

DWGNO.

20200816006 


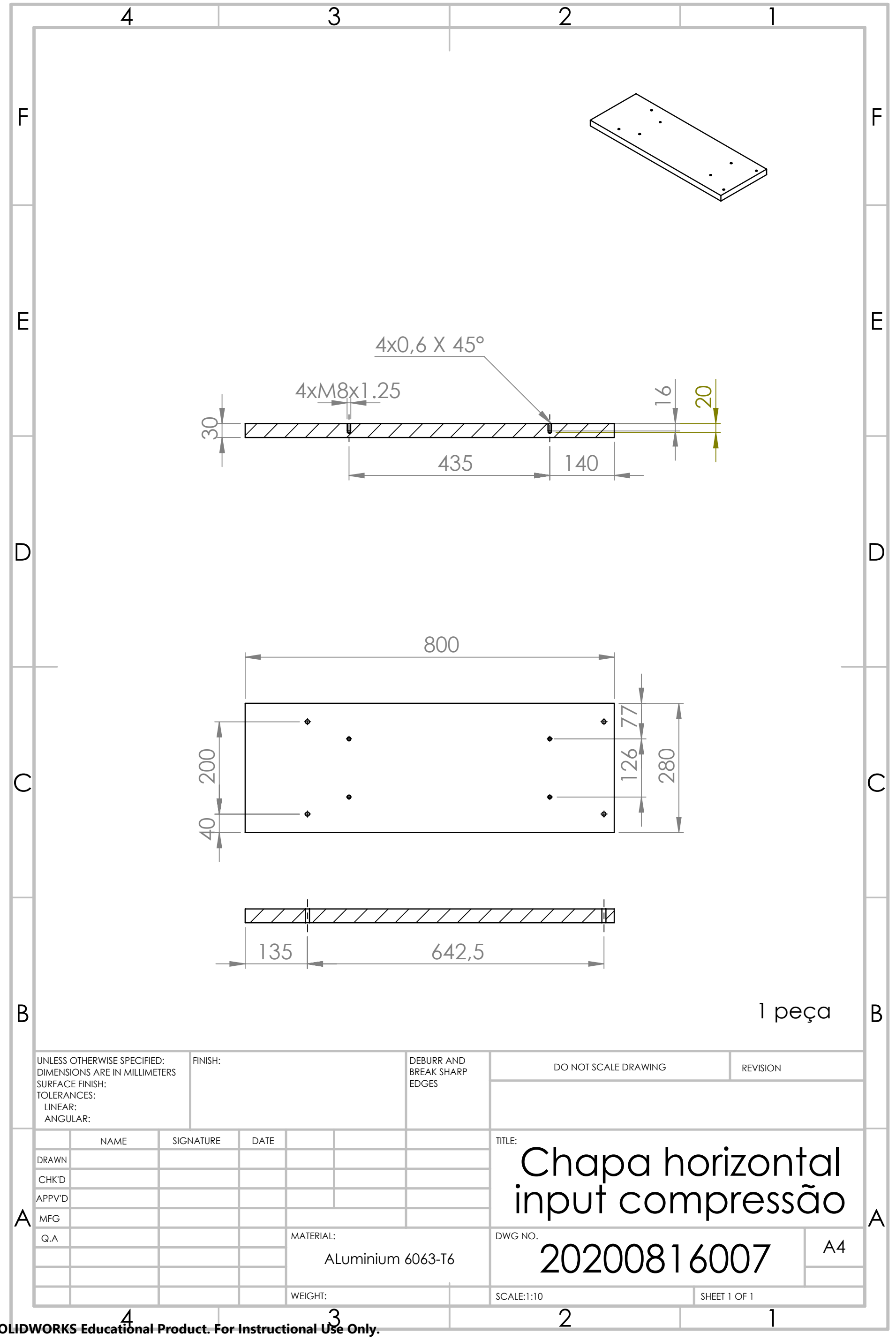




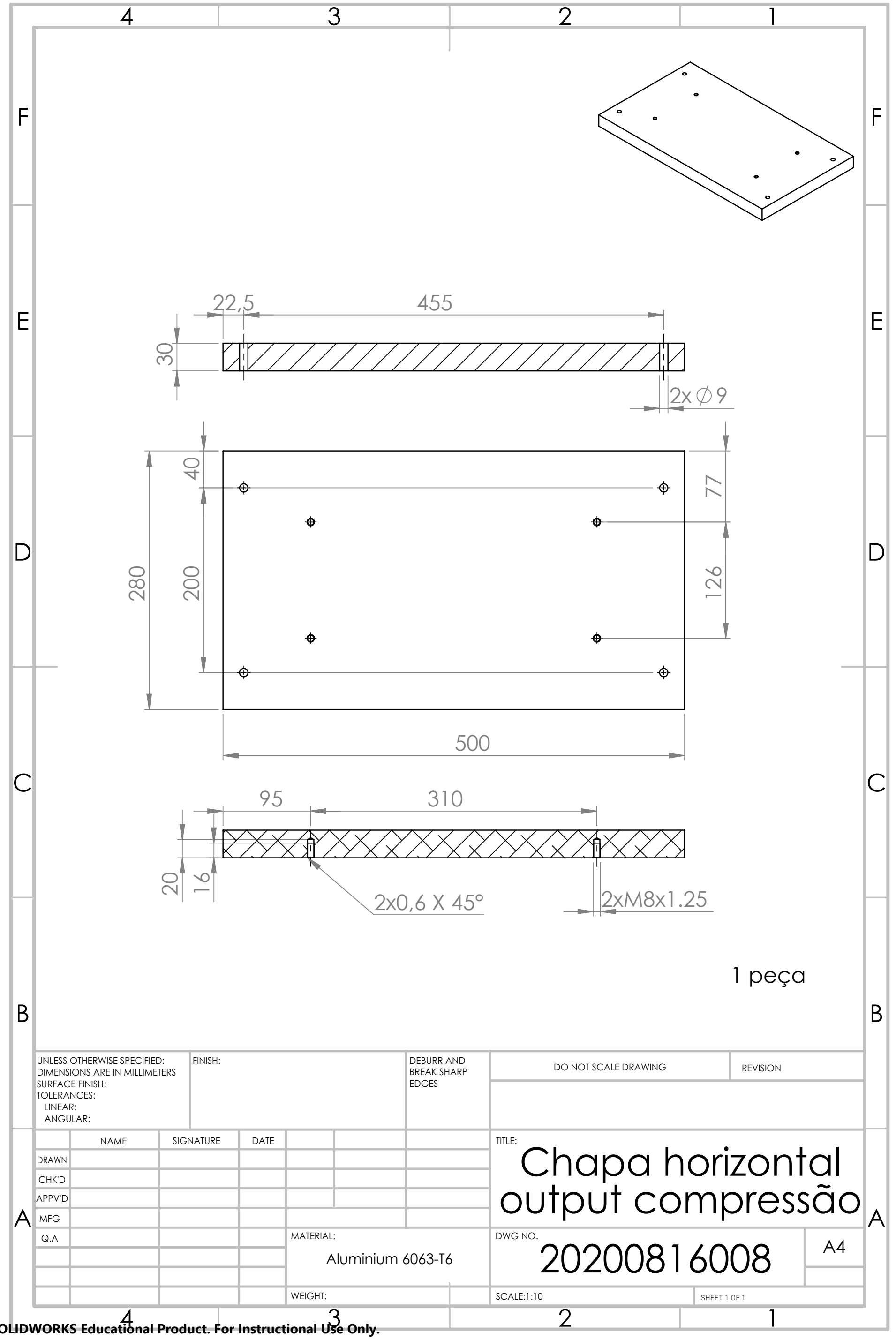




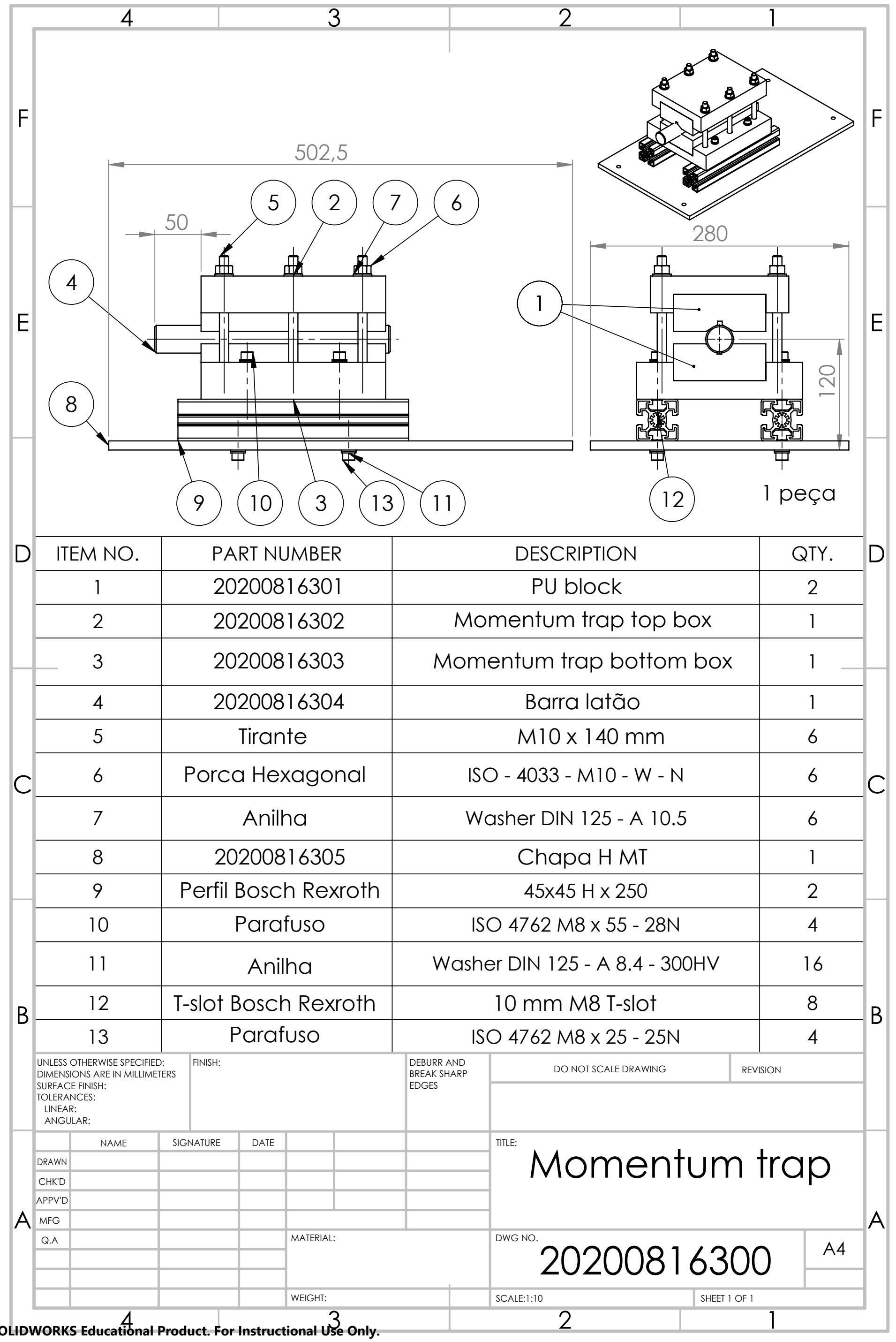




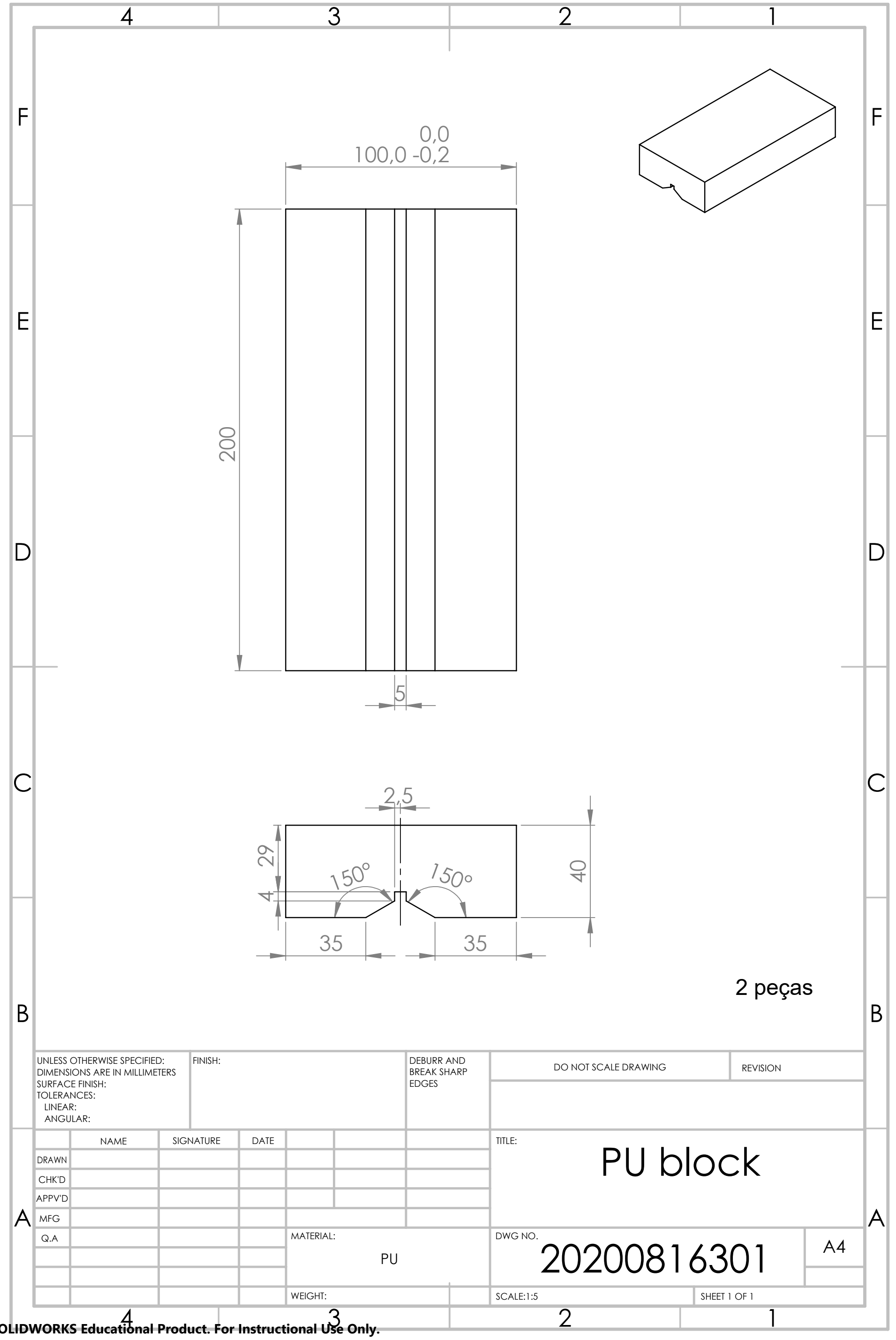




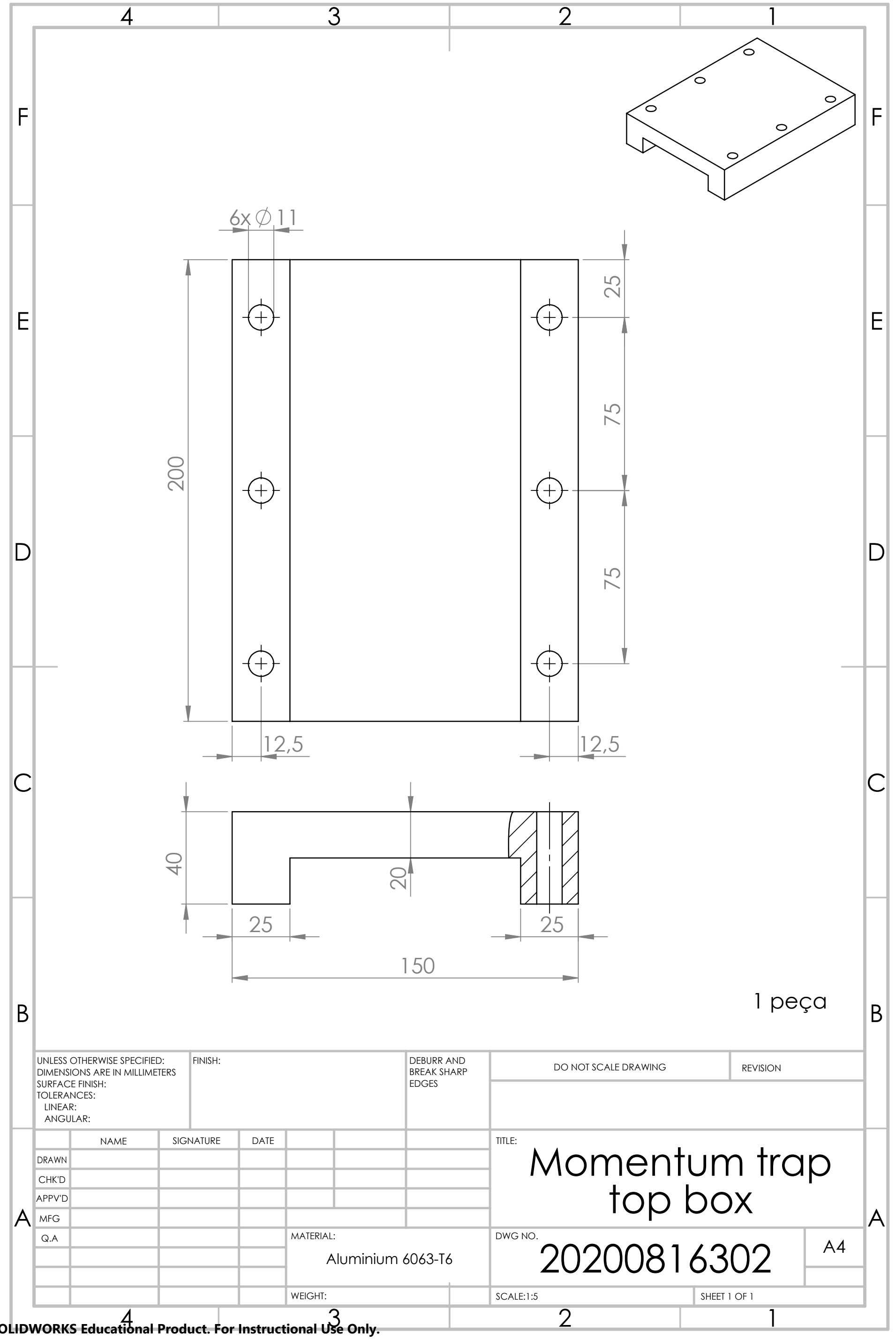




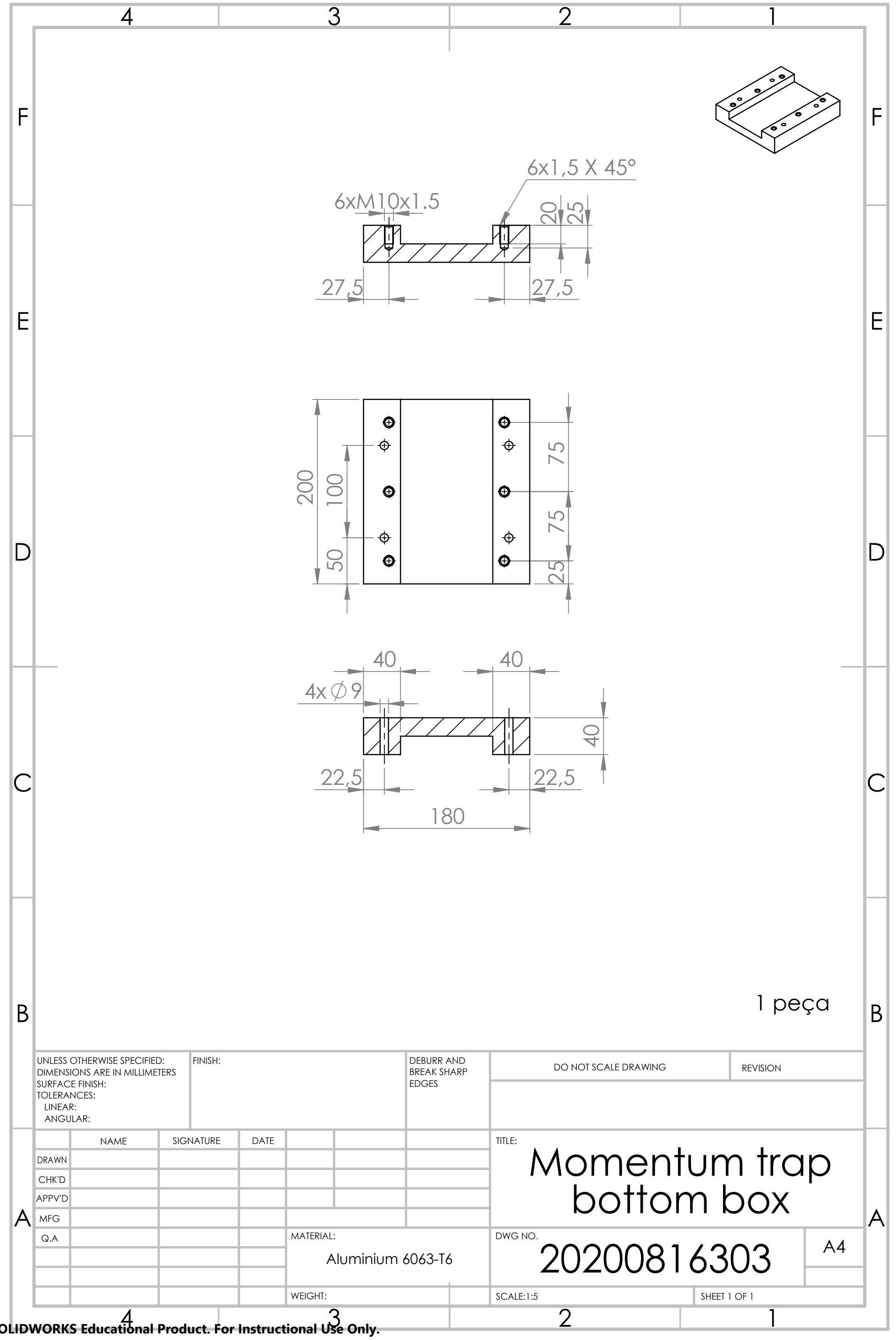




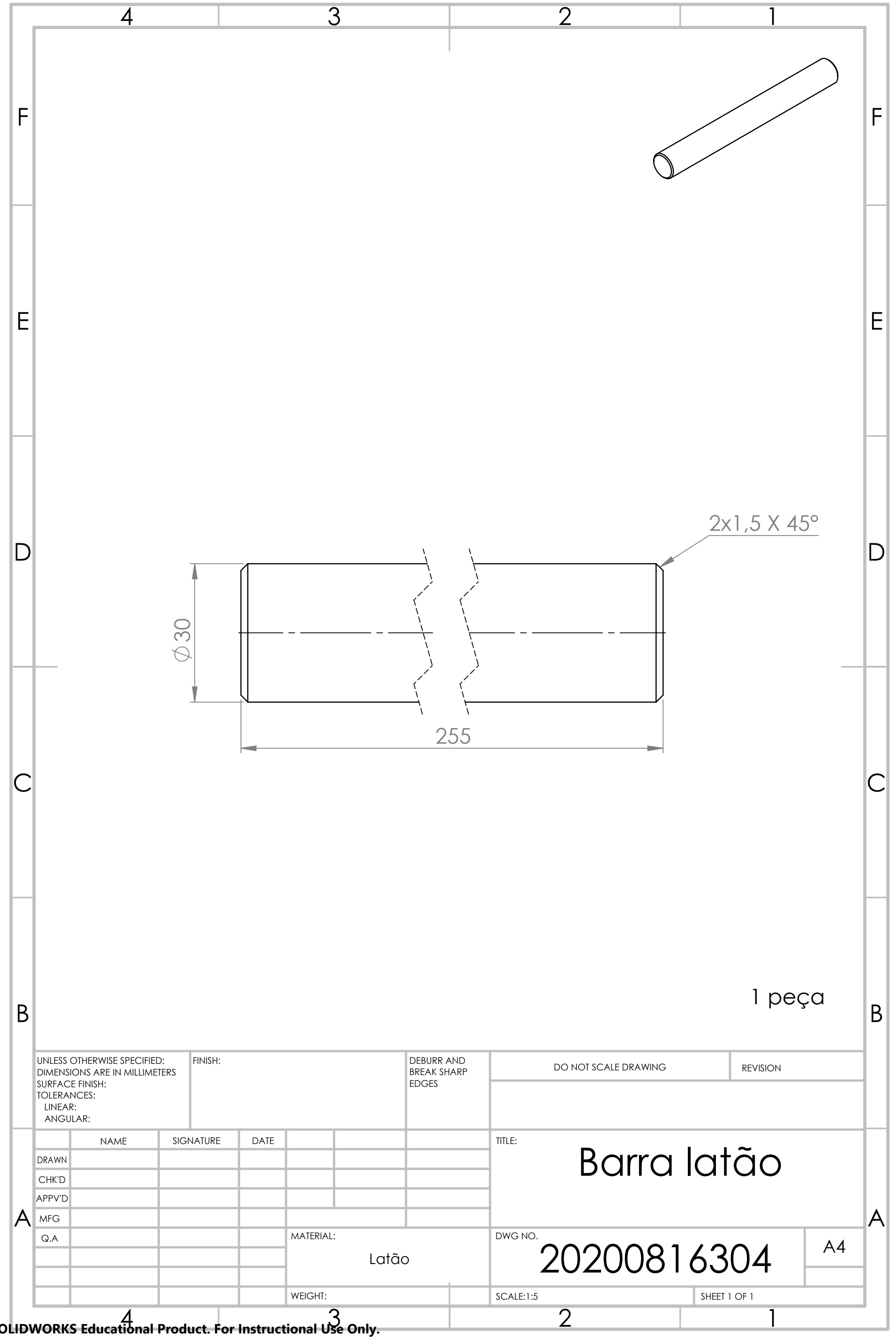




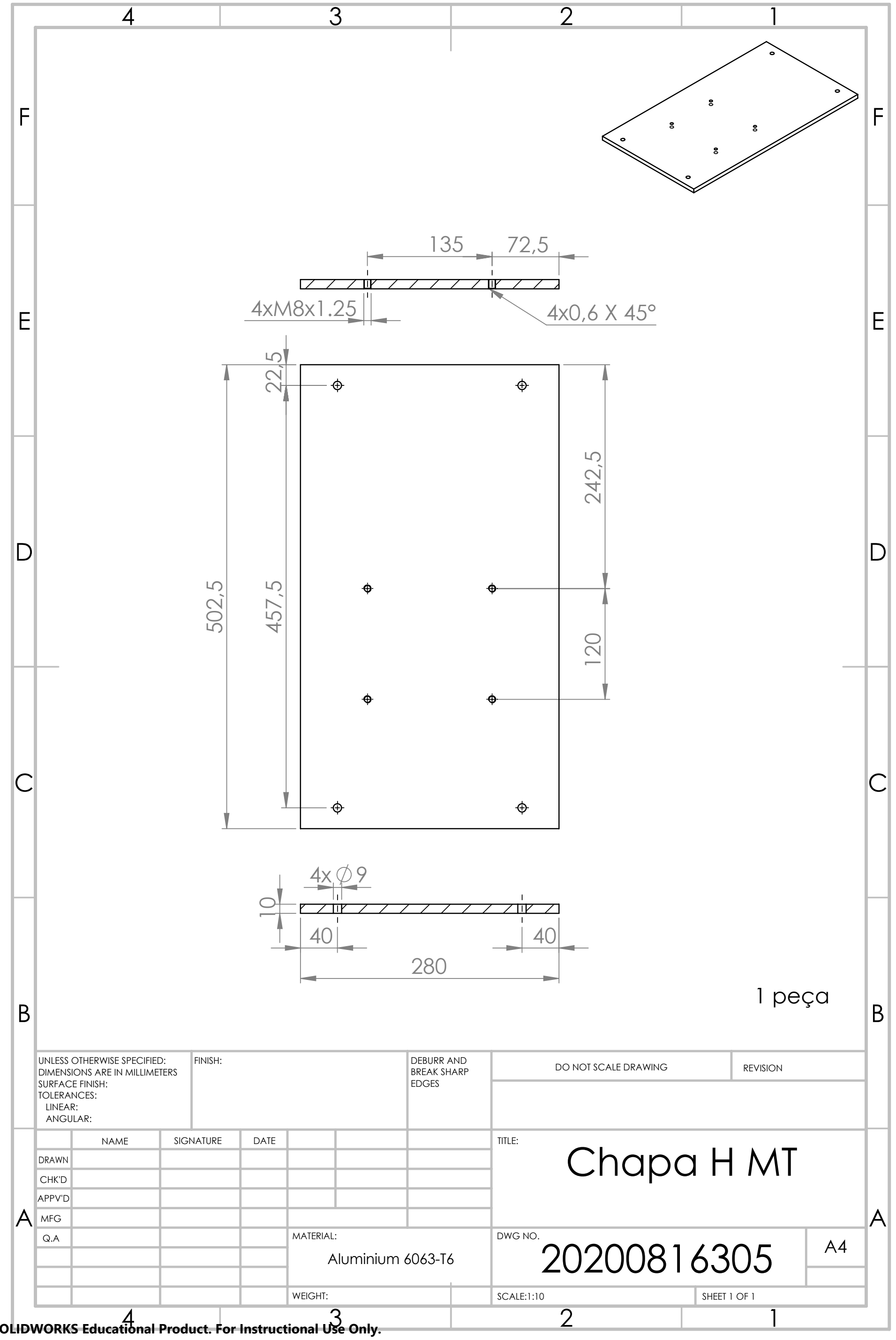





\section{Appendix H}

Mechanical Drawings

Support frame for tensile and compression setup 

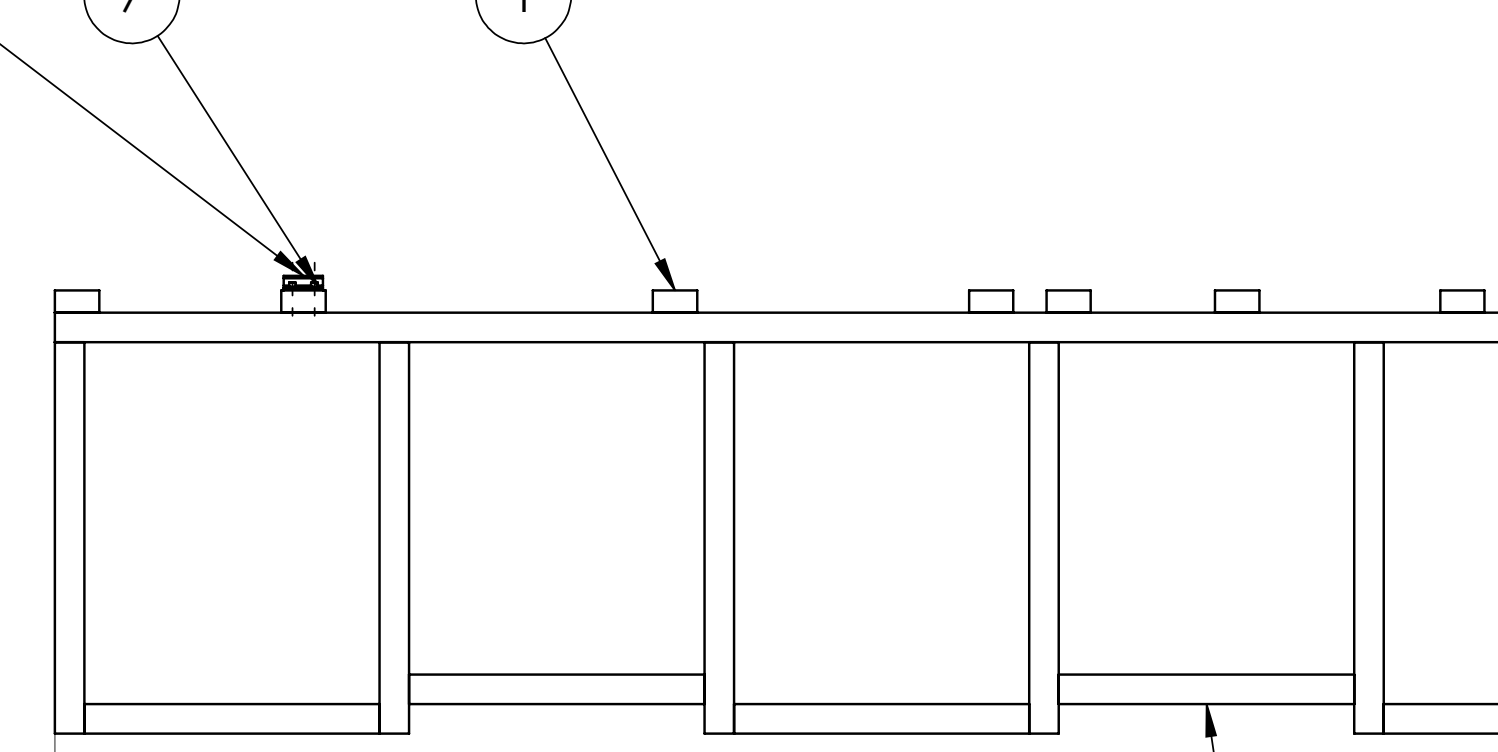

D

C

4

B

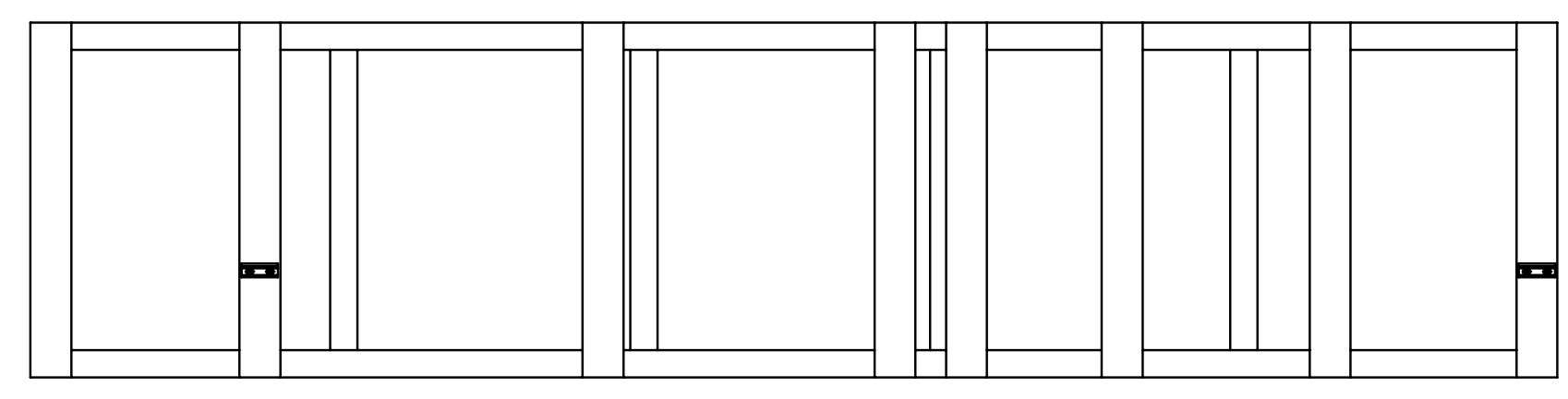

A

sOLIDWORిkS Educational Product. For Instructional Use Only.

3

2
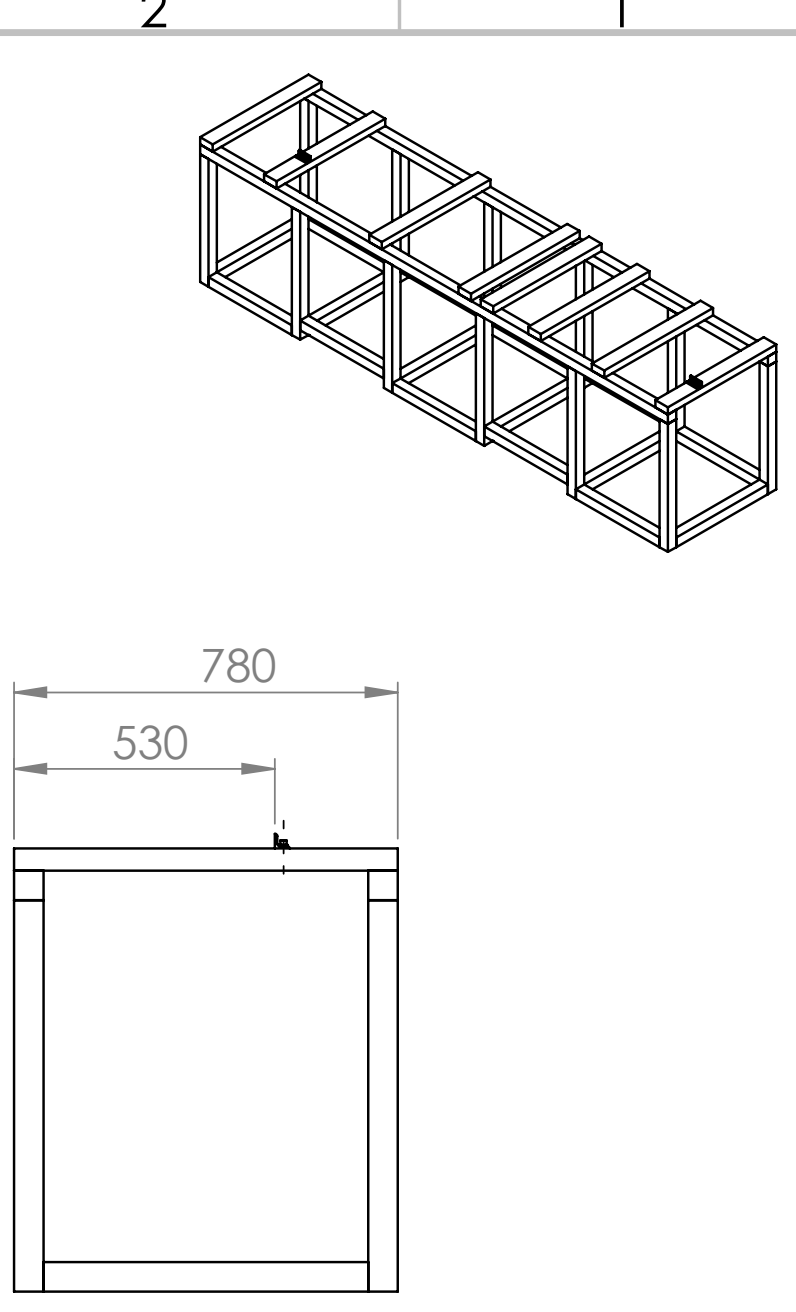

E

(8)

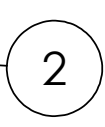

3

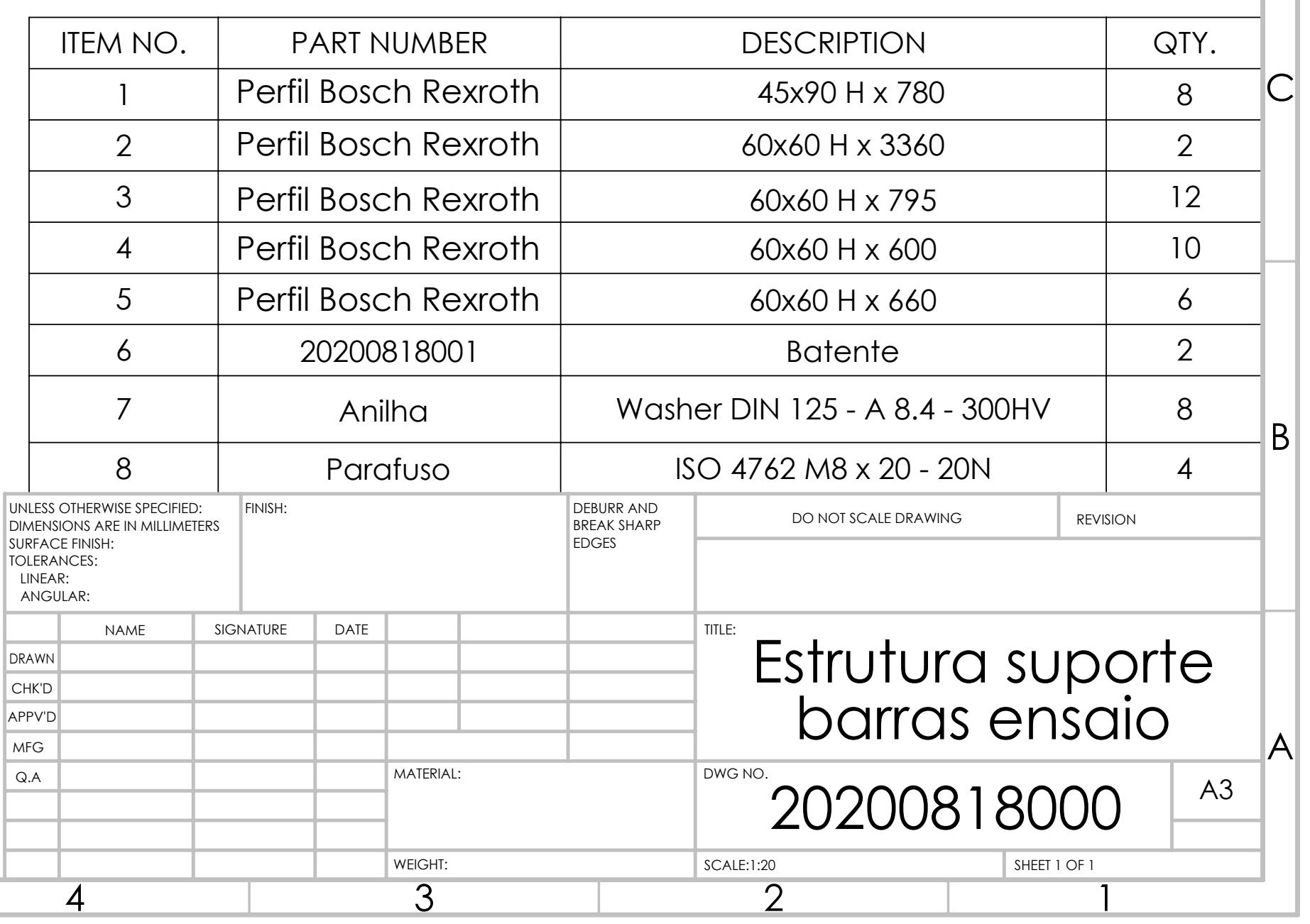




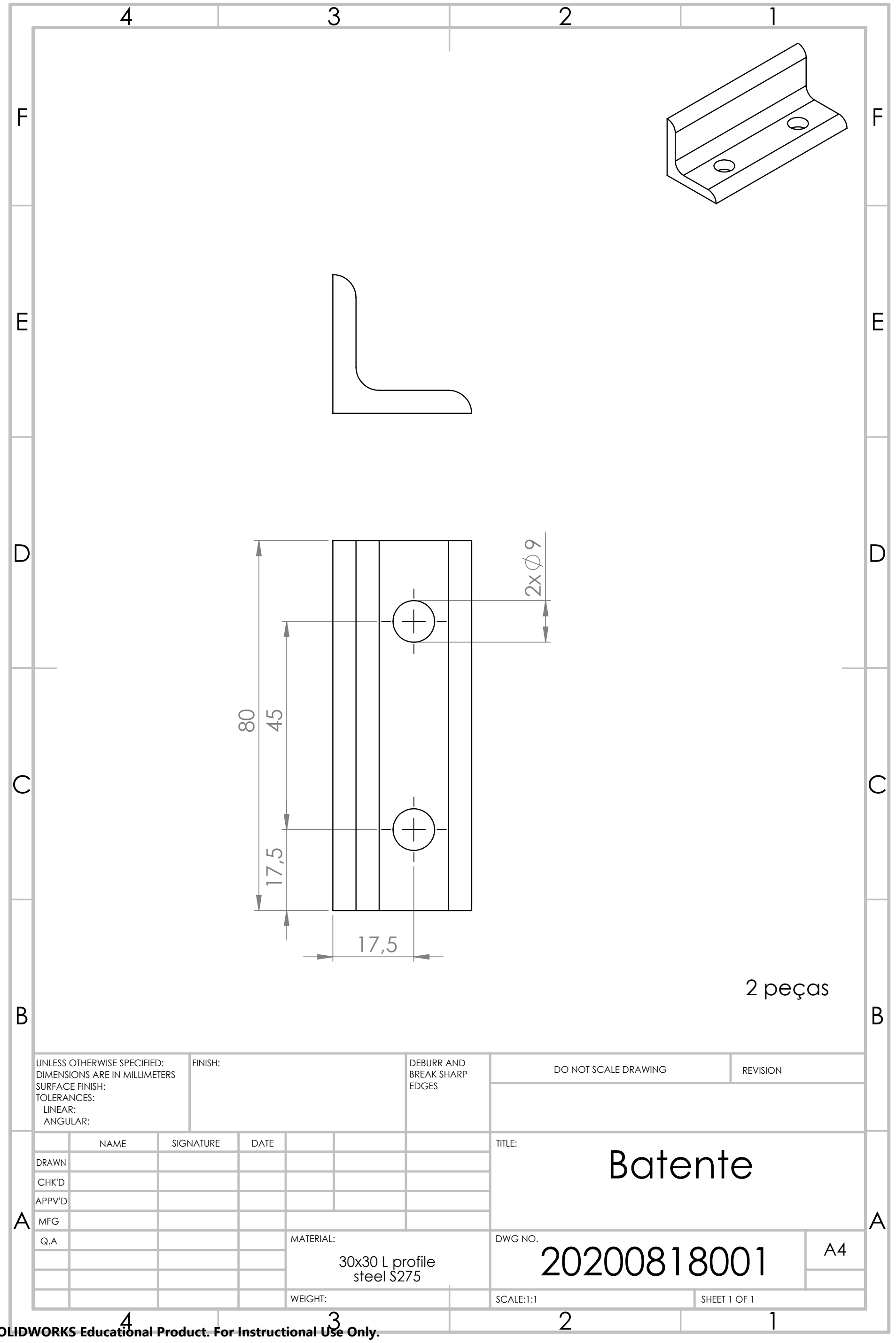

